


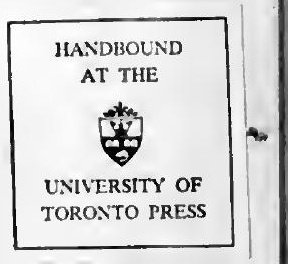


Digitized by the Internet Archive in 2007 with funding from Microsoft Corporation 




\section{PRICES AND WAGES}





\section{PRICES AND WAGES}

An Investigation of the DYNAMIC FORCES

in Social Economics

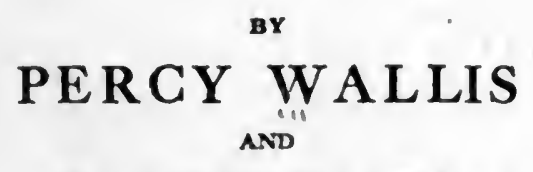

ALBERT WALLIS

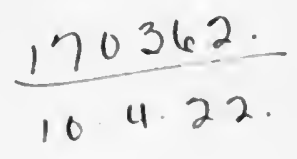

London:

P. S. KING \& SON, LTD. ORCHARD HOUSE, WESTMINSTER 1921 
$-38 x^{4}+40=0$

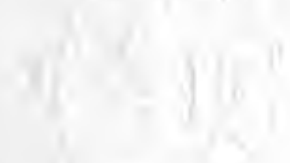

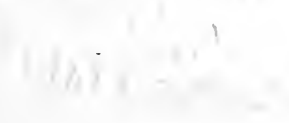

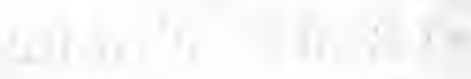




\section{PREFACE}

THE student in any branch of philosophy, if he cannot send forth his theories dignified by the habiliments of recognised authority, must always find it difficult to know when the evidence he has accumulated is sufficient to warrant his attempt to publish his investigations in the form of a book. Put his arguments into writing he must, if he is to know whether there is a logical theory to be extracted from his data, and if his conclusions seem to throw any fresh light upon the difficult problems of sociology or industrial development, it seems desirable that they should be published, even though their author has not the literary experience or skill that can claim public recognition for him as a writer.

It would seem that some of the most essential problems of sociology are shrouded in impenetrable darkness and doubt. For some unknown reason the sun of literary and academic knowledge has failed to penetrate to the tortuous mines of industrial thought and practice, where men grope to satisfy not only their material wants, but most of their spiritual and intellectual ambitions. Therefore we can scarcely afford to despise any fresh light, however homely or fecble it may seem. Some such new and unsuspected illumination will assuredly be found some day to be leading us out into the broader light.

And are we not groping in the dark ; or, at best, in a treacherous twilight? The only clear fact that results from any reflection upon the economic problem, is that we do not quite know-and no argument is ever quite convincing. From the learned Professor with his assured confidence in his superior knowledge and discretion, to the Shop Stcward with his loud assertions of certitude; one and all are in reality keenly conscious of uncertainty and contradiction of thought in respect to the details of their faith. True we all, with our unfailing instinct for self-justification, attribute the obstruction of the light to other people's want either of wisdom or virtue; but however satisfied we may be with our own luminosity, it remains a fact that we are none of us out of the wood. We have, at any rate, hopelessly failed to enlighten the rest.

It is the first directive desire in the following pages to combat the hideous obsession that our economic difficulties and all our social wrongs are due to someone else's greed, ignorance, or tyranny. The habit of basing theories of practical economics upon the assumption of moral shortcomings or unfair advantages in certain persons or 
classes of the community, can lead to nothing but an exaggerated estimate of the results from the petty human frailties common to us all, and end in a fatuous round of mutual recrimination. It exaggerates the power of evil-doers and greatly obscures the real nature of the natural forces which determine life's good or bad fortune for strong and weak, good or evil individuals alike. It is probable society never was really the victim of evil-doers or tyrants, but has always been the victim of want of understanding. Not want of general knowledge, but of the self-responsible research on the part of its members for the particular knowledge they are individually in want of.

Analysed to the bottom, we think it will be found that all our social grievances arise from the assumption that members of society are all paid too much or too little for the part they perform in the social labour of the community. It is the price of service that is the question at the bottom of all social troubles. The author of the researches and experiments in price estimating that form the subject of the following chapters, being engaged in ordinary commercial business, long ago became impressed with the fact that industrial reform must be considerably limited by prices, and that prices do not seem really alterable to meet any altruistic or other requirements. So that the true nature of this price of all our goods and services must be an essential consideration in social economics. As buyer for a business house, he was much impressed by the steady fall of all prices in the nineties, which made it possible to buy at better and better prices; and he was led to the conclusion that variations in the level of prices must depend on some natural law or definite cause. The common suggestions made by business people to account for the fluctuations of trade from good to bad, all seemed utterly inadequate, and the more elaborate ones by economists were either as inadequate, or based upon commercial circumstances so local, or themselves so greatly needing to be accounted for, that they quite failed to represent a prime cause or law. Therefore it seemed there was an opportunity for a commercial man to attempt a systematic study of price variations.

From that time statistical price data were systematically collected and studied in a scientific spirit of investigation, and the theory that the data suggested and which we attempt to explain in the following chapters, seems to show that prices are really a natural quality of commodities, dependent upon the amount of labour necessary to obtain them. The recognition of this fact seems to us very desirable. It is even probable that economists have unwittingly encouraged the popular belief in unjust prices and wages, outrageous profits, and monopolist oppression of the poor, by giving the impression that prices are an artificial result of capitalist ingenuity for speculation upon the consumer's necessities. It was felt that the 
failure of economists to satisfactorily account for price and trade fluctuations, was due to the overlooking of some phenomenon that was apparently of so small importance that it had not been adequately investigated by economic students. The locating of this "leaven" of price variation in the labour cost of gold is perhaps a new economic idea, and the attempt to substantiate the theory by experiment is probably unique in economic method.

The collecting of evidence and gradual development of the theory and experiments has been the work of many years, and has been found a study of absorbing interest and considerable profit. We have now made an attempt to gather up the scattered strands of data and observations into the form of a connected argument, which we believe should have some little interest for those who have any real concern for the public good. While the attempt leaves much to be desired, and much of the evidence is very incomplete, we feel that its completion might be stimulated by the publication of the present theory. 



\section{TABLE OF CONTENTS}

CHAP.

PAGE

I. INTRODUCTION • . . . . . . . . I I

II. The National Ixcome . . . . . . $\quad$ I5

III. Division of the National Income • • • • 47

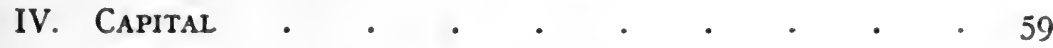

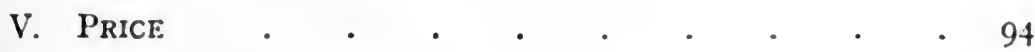

VI. Normal Prices of Crops, etc. • . . . $\quad$ I44

VII. GOLD . • . . . . . . . . 204

VIII. Prices in the United States • . . . $\quad$. 233

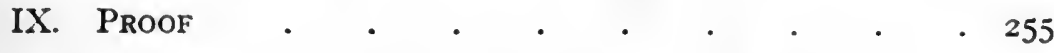

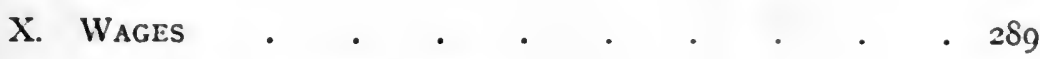

XI. Profit and Unemployment . . . . . 328

XII. RENT AND INTEREST • . . . . . . 367

XiII. Trade Fluctuations . . . . . . . . . 39 I

XIV. Conclusion . . . . . . . . $42 \mathrm{I}$ 



\section{LIST OF DIAGRAMS AND TABLES}

No.

I. The National Income-Figures for Persons and Production in Industries

2. Proportional Diagram of the National Production and Income

Division of the National Income

4. Salaries and Wages, United States Census ...$\quad$.

5. American Wages from Table 4 arranged as Percentages of the Average Production per Person, to compare with the English Wage Data

6. American Wages as Percentages of the Average Production per Person

7. Production in certain Available Trades from the Census of Production

8. Wages in Available Trades, from Labour Gazette.

9. Co-operative Wholesale Society Wages and Production (Distributive and Productive)

10. Wages of Coal Miners

11. Proportion of Wages and Salaries to the Total Production in the United States

12. National Income, Taxed and Untaxed

13. Gross Amount of Income brought under Review of the Inland Revenue Department for Purposes of Income Tax for 1907-08

15. Capital employed per Person in U.S.A.

16. Estimated Capital of United Kingdom

17. Wages paid from Current Production

18. Wages paid from Current Production

19. Professor Jevons' Index Number

20. Board of Trade Index Number

21. Mr. Sauerbeck's Index Number

22. Cotton and Maize Market Price Movement from 1894 to r 912

23. Cotton and Maize Normal Price Movement from 1894 to 1912

24. Rates of Yearly Cash Wages of Horsemen on certain Farms in Scotland.

25. Average Wages in United States from 1849 to $19{ }_{14}: \dot{ }_{4} \cdot$

26. Normal Value produced per Person in the Coal Mines of France .

27. Normal Value produced per Person in the Coal Mines of Germany

28. Normal Value produced per Person in the Coal Mines of the United Kingdom .

29. Normal Value produced per Person in the $\dot{C}$ Cal Mines of Belgium .

30. Normal Value produced per Person in the Coal Mines of Spain .

31. Normal Value produced per Person in the Coal Mines of Japan .

32. Normal Value produced per Person in the Coal Mines of Australia

33. Normal Value produced per Person in the Coal Mines of the United States

34. Oats Index (United Kingdom) :

35. Wheat Index (United Kingdom)

36. Beet Sugar Index (European) .

37. Cotton Index (Egyptian) Iron Index, Gross Value produced per Person at the Furnaces

39. Iron, Production and Price

40. Copper, Import Price (Regulus and Precipitate)

4I. Tea Index (India and Ceylon) .

42. Tea, Production and Prices

43. Gold Index 
so

Gold, Production per Unit of Labour

World Production of Gold

Gold Index (Transvaal only)

Wheat Index (Si. Louis) .

Cotton Index, U.S.A. (New York)

Maize Index, U.S.A. (St. Louis)

Osts Index, U.S.A. (Chicago)

Rye index, U.S.A. (Chicago)

Burley Index, U.S.A. (Chicago)

lotatoes Index, U.S.A. (Chicago)

Results of lixperiments in Price Forecasting

Transtaal Gold Mines, Wages and Production

Average Wages paid in certain Selected Trades

Wages (Irivate Company employing about 800 Persons)

Wages of Coal Miners in France

Wages, German İmpire (Krupp's)

Wages of Highway Labourers (Norway)

Wages of Navies (Railway Construction) (Norway)

Wiages of Seamen (German Empire) .

Cancelled.

4. Average Yearly Wage of Male Workpeople (other than Apprentices) in the Workshops of the State Railways in Wurtemburg,

65. Average Rates of Wages per Month, without Board, for Farm Libourers in the United States, 1866-19r4 . . . .

w. Average Wages, United States Census of Production -

67. Wages, and Production in Tons, per Person, in the Coal Mines (France)

68. Reduction of Wages through Unemployment (Wages Curve) facing

6. Percentage of Unemployment .

70. Wages returned to Labour Gasette. The Percentage Change of Actual Wages compared with Change shown by Unemployment Diagram 63

71. Effect of Competition on Wages for every 1 per cent. Increase of Unemployment shown on the Curve of Increasing Wages on Diagram 68

72. Return by Private Company. The Percentage Change of Actual Wages compared with Change shown by Unemployment

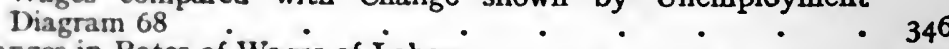

73. Changes in Rates of Wages of Labour $\quad: \quad: \quad \cdot \quad \cdot \quad \cdot 350$

74. Trading Accounts at varying States of Employment on Agricultural Production

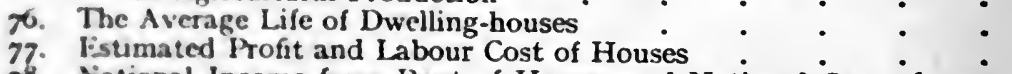

78. National Income from Rent of Houses and National Cost of providing them

79. Unemployment, showing Periods of Good and Bad Trade :

80. Avessment to Income Tax and Good and Bad Trade

81. Itoft and Loss, Cotton Spinning Companies, and Good and Bad

8z. Short Time, showing Periods of Good and Bad Trade

83. Bank lates of Discount, showing Periods of Good and Bad Trade 


\title{
PRICES AND WAGES
}

\author{
CHAPTER I \\ INTRODUCTION
}

Is introducing the subject and scope of our inquiry into economic principles, we wish to make it clear that we regard economics simply as the systematic study of the nature, growth, and distribution of wealth in human communities. It has sometimes been contended that economics should also include the study of man himself, physically, morally, and psychologically; but when we consider the magnitude of these branches of philosophy we think their inclusion would seem to give too wide a scope to economic inquiry. Therefore in the present state of our knowledge it is most profitable to confine our examination to the more obvious and concrete forms of wealth as required and used by average civilised men, regarding men as almost alike in nature, ability and desire. By this means we may better focus our investigations upon that part of wealth that can be exchanged or that has a price, and is therefore directly affected by organisation of labour and trade, by natural and social conditions of the community, and by that part of legislation and government which deals with these organisations and conditions. The advantage of this method is that we may more clearly see how the material conditions of people may be changed for the better or worse by altered methods in their organisation and work alone, without raising the still more difficult questions that arise from the modification of man himself, or from the varying character, prejudices, or ambitions of individuals or classes of the community.

We are aware many economists greatly elaborate the question of individual changes in men, with regard to their wants and activities, and especially of their " desires" in relation to demand and price. But as on the one hand they admit that if a large number of persons are under consideration the individual desire is merged in the more average aggregate desire of the group, and on the other hand, the variation between the desire of the groups depends upon their wealth or the individual "demand price" for what they desire, it would scem that we might as well leave out "desire" and its variations, and consider only man and the amount of his wealth: at any rate, we feel justified in restricting our economics to this simpler form of in. quiry, until it shall be found that more complicated questions of philosophy are needed to account for the phenomena of social existence. 
Nevertheless, it is evident that no philosophy of man's nature can be complete, or even well begun, without some sound knowledge of the nature and reason of the activities that occupy the greater part of his daily life and must have a profound effect on the forming of his character and destiny. For this reason, if no other, economics should receive the serious consideration and study of every intelligent citizen, and especially of those who in any way undertake the responsibility of teaching others. Yet there are probably very few people who make anything but the most perfunctory effort to understand the subject of economics, though nearly every one is loud in his complaints against man's nature and insistent in demands for his reform.

There are various reasons why the average person does not trouble much about political economy ; most people's lives are fairly busy, and leave little time and less inclination to pursue any form of study that is not directly connected with getting their living. But even those who do strive after some intellectual progress for themselves are content with a little superficial reading of economics, regarding decper study as too difficult for them, or too much like their business without being any practical use in business. Or probably the most common excuse is that the difficult problems of economics are best left to experts: that economists, financiers and politicians, being the only people who can really deal with such questions, may safely be left to look after the public interest involved in economic problems. This policy of leaving it to others to think for us is the most insidious of ethical errors ; and in spite of this fact being universally admitted, the habit persists to the working of endless mischief in human affairs. Thus, in the present case the great financier or politician is usually the most unlikely of men to go deeply into economics; he is much too practical and leaves the economic specialist to straighten out the deep problems of economic theory. The specialist again is the last of men to put his theories into practice, so the problem usually ends where it began. As a matter of fact these exalted experts make no claim to teach or lead, in either theoretical or practical economic questions; when they want to know what really ought to be done they appeal to the country. And we find ourselves in the absurd position of relying upon the insufficiently educated mass of the population to make up their minds correctly as to the best action to take in the most complicated matters, as for example, fixing the best form of taxation, guided only by the diametrically opposed views of rival political talkers.

When we remember that the economic problem of free trade versus protection has occupied the attention and a vast amount of the energy of the greatest statesmen and economists for nearly 100 years: moreover, that it has been the subject of a colossal experiment by the first commercial countries of the world, in the 
form of 70 years' practical experience, and that still the question is being argued with unabated vigour, without the slightest sign of being thrashed out or ended; it must surely come home to us that there is something wanting in our power of understanding either the theory or practice of economics. This is perhaps the most astounding example of our failure to comprehend the true nature of the efforts and purpose of our everyday life, but it is by no means the only one. There is the bitter struggle between capital and labour, with its wasteful strikes and endless legislation ; the care of the poor and the unemployed; to say nothing of foreign relations and the tragedy of war. These are questions of paramount importance that it is unquestionably our duty to understand and set in order; yet though these problems are old as the hills, hardly two people can agree as to what is the right or wrong about them; and there is not the slightest prospect of any settlement of the questions. We have to let them drift in the hope and belief that time will bring about what is right and needful.

To the younger and less experienced members of society it may seem that the great leaders of society have a definite aim, and knowledge enough to save us from simply drifting. But as we advance in age and experience it becomes more and more evident that the "Princes of Commerce and Finance," however well they may contrive to steer their own course, are profoundly ignorant of the economic nature of the stream on which they drift.

In course of conversation with us about the variation of prices, the manager of one of the largest cotton buying firms made the statement: "We do not attempt to understand the theory of price, we simply go on the prices day by day and make no estimate of the probable price." A statement like this simply means that these men who deal in millions are admittedly drifting, and astutely avoiding shoals and shipwreck for themselves by ceaseless watchfulness, which leaves them little time or desire to study the stream on which they and we are being carried onward. However confident we may be that the tide of human life and work will carry mankind to some good end at last, it is unquestionably true that many and great are the individual shipwrecks, often involving whole classes of mankind in permanent ruin of mind, body, or estate. And it appears that there is no means of avoiding these adversities. There is probably not a single political aim, a single cause, or philanthropic endeavour that is not held up or stultified by the voice of academic authority with its contemptuous explanation that such efforts are economically unsound and absurd ; an accusation often all too true. Yet philanthropist and politician alike leave economics to the expert, as something interesting but not practical. Surely it is not only interesting but of the most practical importance to know something that is true and certain about the science of our everyday life. It 
must be man's first moral duty to know the true nature of the social order in which he lives; and know it for himself, and by his own intelligence. We may be quite certain that however honest, strenuous, and far-reaching our political or philanthropic aims may be, they are destined to ultimate failure if we have left it to experts to shape for us our minds and conscience. How do we know they are experts if we have not the knowledge to judge ourselves?

We are afraid it must be admitted, however, that it is not only the layman who is to blame for our deficient knowledge of economics. For though man has been studying man and his societies continually from the dawn of history, economists can still tell us with great complacency that political economy is only yet in its infancy! Let us devoutly hope it is not in its second childhood, for it has certainly been an unconscionably long time growing up, and it is hardly to be expected that the public should take it to be of much practical use in this very grown-up world of politics and trade. It seems necessary here to inquire a little into the cause of this infant's backwardness before we attempt to help its development.

We have referred to economics as a science, but it is admittedly doubtful whether it as yet fulfils the scientific requirements. The first characteristic of a science is that it discovers facts and brings them together into groups of relationship or sequence. It is true that theory is absolutely necessary to the idea of order or sequence of facts, but scientific theory must start from known facts and depend absolutely upon facts for its evidence. The reasonableness of a scientific theory depends only upon the number of facts that support it, or the cxactness with which it fits the facts. The only approach to a proof of a theory's truth is by experiment; that is, by its theoretically predicting unknown facts that are afterwards discovered or brought about by application of the theory to practice. But in economic writing facts are most curiously wanting. Though a writer is treating expressly of the most ordinary and everyday activities and requirements of men, he hardly ever cites an actual fact from real life. The argument is chiefly based upon suppositionary examples of what would happen if a man acted in a certain way under given conditions. Such suppositions are at times useful to clearly illustrate an economic position or process that it may be wished to describe. But to base any conclusion or law upon such theoretical supposition seems to us most dangerous, for being suppositions only they cannot be brought to test by experiment. The supposition itself cannot be proved to be correct unless it can be found that actual facts and figures from commercial or other economic statistics do follow the supposed course. Although the reasoning from the supposition may be quite logical, there is always great danger that the resemblance to actual life is apparent rather than real. Because it is so very probable that both the economist 
and his reader are mistaken as to what is and is not fact in real business life. They are apt to take as axiomatic something that is in reality open to question or doubt ; for there is a very common notion that we all understand the general principles and common facts of economics-a notion that blooms perennial in the simple minds of men, however often it has been discredited by the real facts of hard experience. Even an economist may be unconsciously influenced in his judgment by some ill-founded axiom that is the common opinion of all men; unless he is continually bringing his deductions to test by actual facts and figures from commercial life.

May not this attempt to construct a pure theory of economics without the restraint of facts be the reason why economics has fallen behind the natural sciences and remained in infancy? It is surely a startling fact that while natural science has measured the distance of the stars and discovered new metals in the sun, built up great sciences with incredible exactness of detail and established its theories almost beyond the shadow of doubt, while it has, in spite of inconceivable difficulties, discovered some of the most profound secrets of the universe and pressed into man's service unseen material forces that a few short years ago were unknown and undreamed of, political economy has not been able to show us why trade should fluctuate from good to bad, or whether protective tariffs do a people good or harm, and has not even succeeded in constructing a theory that is lucid enough to guide men in the right method of treating the vast amount of data that must now exist in the records of the world's business.

Political economy has undoubtedly failed to grow up into a science because it has not based its theory upon facts. Professor W. Stanley Jevons says: "There is not a clerk or book-keeper in the country who is not recording numerical data ... Thousands of folio volumes of statistical, parliamentary, or other publications await the labour of the investigator."

And he had already said: "I answer, that my numerical data are more abundant and precise than those possessed by any other science, but that we have not yet known how to employ them."

This looks like rather severe self-condemnation, but it must in fairness be pointed out that though these data exist they may not be accessible to the economist. Probably it is just this inaccessible nature of economic data that has made the difference between economics and natural science. When the naturalist goes in search of facts, nature does not usually resent it, or if it does, has very little effective power of resistance. But it is not so when the economist wishes to pry into the ledgers, wages and costing records, or profit and loss accounts of some large commercial concern; there would be a good deal of resentment, in fact it is hardly to be thought of. It is well-known that Government must proceed cautiously 
in such matters and is met with suspicion and some resentment. And it is to be feared that the returns are often made in so perfunctory a manner as to be hardly trustworthy in many cases. This, of course, renders Parliamentary Blue Books and other published records of commerce that are accessible rather inadequate as cconomic data. And further, such data are very modern, so that most economic writers had not the opportunity to use them. Therefore, Professor Jevons was probably justified in saying: "I know not when we shall have a perfect system of statistics, but the want of it is the only insuperable obstacle in the way of making political economy an exact science-a correct theory is the first step towards improvement, by showing what we need and what we might accomplish."

But no step can be taken without some fact to step upon. A theory is only an arrangement of facts and must have data to arrange. A correct theory of economics without data is hopelessly impossible, for the assumptions from which it must start have not that simplicity of conception that constitute them axioms. However, the above quotations from Professor Jevons indicate that the "insuperable obstacle" is the want of data, and that seems at any rate to quite justify the attempt in the following chapters to found a theory of economics upon numerical data from business statistics, and state the problem so far as possible in the ordinary language of commerce. Not that we suppose there is any superior lucidity in commercial language beyond that of the carefully chosen words and terms of economic literature; but we feel there is no safeguard against logical inexactness, or from fear of misunderstanding to be found in special phraseology. Language can only be lucid so far as it is familiar-no word or combination of words can express an unfamiliar thought so that it cannot possibly be misunderstood or misapplied. We think that if any idea can be clearly conceived and isolated in thought, it can be expressed in practically unmistakable language if sufficient explanation is given; while no concise phrase however well chosen can be made so watertight as to avoid possible unisconception. Such specially exact phrases seem apt to simply hide the error they are designed to avoid, whereas all that is really necessiry is that the author should have a quite clear conception of what he wishes to make understood.

The difficulty of exact language does not seem to be so prolific of misunderstanding as the more subtle tendency to mistake a graplic description of economic phenomena for the explanation or reason of such phenomena. It is fatally easy in scientific writing to mistake a good description of a phenomenon for an explanation of it, and this is particularly the case when the subject under consideration can be given a familiar aspect, as is the case with many cconomic problems. As, for instance, the case of that very useful 
phrase "supply and demand." It is well known that some com. modities that are seasonal in their production are usually higher in price at the unproductive season when the supply is short. From this common experience it is apt to seem obvious that the high price is caused by short supply, and the low price by the increased supply, and that the ratio of supply to demand determines the price. But it will be found that in the season of least production there is still always enough of the commodity to supply all who will pay a high enough price for it. So why is not this forced supply made as large as when the commodity is cheap? We are answered that the supply is less because the demand is less at the high price. that the demand depends upon the price and the supply depends upon the demand to which it is adjusted and always made equal. So we arrive at the meaningless conclusion that the ratio of supply and demand, by which price is determined, is determined by the price. We are of course aware that this recognised paradox of two things each depending upon the other is supposed to have been explained by Say, Mill, and many subsequent writers. But we cannot see that the explanation they give is really satisfactory. J. S. Mill admits that it is not correct to speak of value as a ratio, but as an equation between supply and demand brought about by the adjustment of the price. If the supply is short the price will usually rise till the demand is thereby reduced to equal the supply. That may be a perfectly correct statement of what happens, but does not seem to explain what we really want to know. Why is it the price that goes up and not the supply that increases? The equation may be brought about by the adjustment of either of these factors. On what does it depend that the supply is not increased and the price therefore sent up ? This determining cause in the background seems always to be the cost of the supply, and the discussion of this cause of value will constitute a large portion of our inquiry in the following chapters, so we need not here further anticipate our arguments for the labour cost theory of value.

The glib phrase " supply and demand " may be a descriptive term that is very compact and convenient for skating over thin places in economic argument. But it affords no explanation whatever of the cause of price or its variations, and leaves us faced with the fact, that variation of prices is the source of the circumstance of supply and demand, and most other economic phenomena. It is, therefore, the chief object of the following chapters to break through this closed circuit of concise, and more or less elliptical, phrases that are sometimes dignified as economic laws, and if possible discover the underlying origin and cause of price. Which cause, so far as we can discover, has up to now eluded the grasp of economic investigation. But these well-considered economic truisims are by no means easy to escape, because they present more or less familiar economic cir- 
cumstances in a concise and suggestive form and with the appearance of logical conclusiveness. The result is that they crop up aptly at every turn of the economic argument, and in the following pages may corne in for discussion with rather wearisome frequency, but it is essential that the illusive nature of many of these established but rather scrappy and disconnected economic rules should be pointed out whenever they tend to obscure the connected thread of actual cause and effect that underlies them.

The chief purpose of this book is to demonstrate the real cause and nature of excliange value or price, and the bulk of the work is the investigation of the data relating to prices. Our reason for disputing some of the views of the later classical economists is that we feel that their elaborate mathematical statements of the laws of wants, desires, utility, etc., obscure rather than elucidate the true cause of value or price. These learned efforts seem to have failed to bring out any definite conclusion as to the forces that control our commercial and industrial system, or to afford any practical guide to economic reforms; which failure suggests that the line of investigation has wandered from the course that leads to any conclusive result.

We believe that the want of progress in political economy is very largely the result of an abortive theory of value, and that before it is possible to get a clear conception of the nature of price, it is necessary to revert to a considerable extent to the view of the older economists, who held that labour was the only source of value, and that the relative amount of labour determines the relative value of commodities. Apparently the reason why the earlier economists failed to found a theory of value that was convincing to their successors was that they did not quite grasp the fact that labour itself was the cost, and the only cost of production, and that nothing else entered into value. They seem rather to have argued that it was the cost of the labour entering into production that determined the value of what was produced; which view involved the contention in endless complications. The cost of labour being represented by wages, the amount paid as wages had to enter into the cost of production: and capital also with profits of stock. This complication led to the further intricate question of rent, and why some forms of profit and wages of ability that are in the nature of rent should not be considered to enter into cost. All of which complications have helped to obscure the underlying principle that the labour involved determines the value; and make it very difficult to discover what really is supposed to be the just economic relation of capitalist to wage earner or what is the share of the produced value that each should receive. These complicated laws, based upon conclusions from hypothetical cases, occupying so much space in the arguments of some writers and being necessarily based upon 
traditional commercial usage, it seems sometimes as if they were devised to justify such usage. And writers are sometimes criticised as partisans, or supporters of a particular social or industrial faction or school of thought. We believe such criticism would be quite unfair to any classical or really scientific economist : it is only that to each of us there appear some facts in the industrial expericnce that are axiomatic, and that any theory must be made to fit. liut, as evidence that the acceptance of such economic axioms, and the making complicated theories of value to fit them, is thought to be inevitable and necessary, it is interesting to follow the peculiar reasoning of Karl Marx. Marx certainly cannot be accused of reasoning his theory of value to support the individualist system of production, or the views of the prevailing school of economics. Yet he also complicates his theory of value with what seems a more curious sophistry than any of his predecessors, and culminating in the extraordinary theory that, while labour is paid the full use-value it produces, that value is only half-a-day's produce for a day's work.

Marx, of all economists, is perhaps the one whose views most resemble those of the present writers; starting, as he did, with the conviction that social labour time is the sole measure and cause of value and that profit can only be made by the exploitation of labour. But, while we regard it as absolutely necessary to correctly understand the nature of value before it is possible to appreciate the causes that determine its division between labour and capital, we do not, like Marx, attribute the division to any subtile and complicated peculiarity of value. On the contrary we regard the nature of value as a very obvious and everyday matter; but think that the measuring of value is the important thing to understand.

Like all other economists Marx seems to think it necessary to give a peculiar twofold nature to value ; and presumably the reason for this is to explain the difference between the cost of commodity in labour and its selling price. The axiomatic fact that the theory must here fit, is the supposed existence of a surplus value or margin of profit. It will be found in the following theory of wages and profits we do not require any surplus value or a double nature in our definition of value, so that our conception of value is quite a simple one. We do not recognise the various kinds of value that economists so elaborately distinguish. Use-value seems to us a tautological expression; surely it simply means usefulness. We might as well speak of use usefulness as use value, unless by value we mean the relative usefulness which determines how much of other useful things the useful thing will exchange for. In the latter case it means exchange-value, so that it is then only necessary to speak of it as value which expresses the relative form of usefulness. And when value is used in its proper relative sense, of money or market 
values, it is virtually synonymous with price. J. S. Mill objects to value being regarded as meaning the same as price, because the word price indicates value compared with money only, and value means a thing's power of purchasing other things in general. There might quite well be a general fall of prices, but there would not be a general fall of value - conmodities would exchange for each other in the same quantities as before. But while it is convenient to use the word price to express money-value, it is desirable not to fall into the error of thinking there is any difference in the nature of price and value. The two words may properly express value in rather different connections, but it is the same value that is expressed; and a commodities value cannot be greater or less than its price, even if prices generally have altered.

With regard to use-value, it may perhaps be thought that when, for instance, an artist gives $7 s$. $6 d$. for a tube of paint that would seem to a house painter worth about $2 d$., he finds a use-value in the paint that differs from the house painter's value of it. But the artist does not pay that price because he sets that value upon it, but because he cannot get it for less; it costs $7 s$. $6 d$. to produce and sell. The value the artist can produce with the paint is not a value in the paint ; the value that justifies him in buying it is the result of his skilful work with it. If it was a value in the paint other than its cost, that could be realised in use, the house painter could appreciate it as well as the artist.

The above mentioned curious argument which Marx constructs out of his theory of value, exchange-value, use-value, and price, is an effort to account for a hypothetical value which all things are supposed to possess in addition to their labour cost. That there is, or may be, a value in things in excess of their cost is a most common impression founded, in the first place, upon the common incapacity in appreciate what things do cost. And in the second place the vague impression that the work of organisation and finance is not any part of the cost of producing things. Marx is particularly unsatisfactory in this respect, and gives the impression. that he regards the capitalist as a person who sits and laughs while the misguided worker toils to produce surplus value for him. Even going to market to buy and sell is not regarded by Marx as part of the cost of supplying commodities.

A director of industry may in many cases be over paid for what he actually does, or may sublet his contract to a manager; but the work has to be done and is part of the cost. Quite overlooking this fact, Marx, like most other economists, thinks he must account for a surplus value; and does so by the astounding assumption that labour has an exchange value dependent upon its cost of subsistence, and a use-value which is different although it also depends upon cost ! For unless use-value of labour does depend upon cost, the 
value of its production will not depend upon cost either. And "subsistence" which is commodity produced by labour will not depend upon cost ; so neither will the exchange-value of the labour. All this bewildered circle of various kinds of values is invented to explain the imaginary surplus value, and rests upon the utterly fallacious assumption that there is such a thing as subsistence price of labour. The subsistence which labour gets depends solely upon how effectually it works-in fact upon how much it produces in a given time; almost independently of the money value for which the articles of subsistence may exchange. And in highly civilised communities the supply of labour can hardly be said to depend upon or be limited by the amount of subsistence produced. On the contrary, we contend that the value or price of labour, or what is much more correctly expressed as the wage of labour, is the one and only thing that depends upon supply and demand, and not cost ; because it is the only thing the supply of which cannot be altered to meet variations in price.

This contradictory case of the value of subsistence, at the very heart of Marx's theory, seems due to his quite unwarranted assumption that a day's subsistence of labour only costs half a day's labour to produce. Without any evidence or figures for his conclusion, he founds a hypothetical case upon this assumption and constructs his whole theory upon the working of this supposed case. It seems probable that much of the obscurity in which the theory of value is involved is due to the use of hypothetical methods in economic reasoning. A suppositionary example of some commercial process may be useful as an illustration of any economic effect that is being discussed, but it is highly dangerous to base laws or conclusions of any sort upon the hypothetical result of such suppositionary cases. Even though such conclusion seems to be inevitable, the supposed course of action that is taken to bring about the result may be nothing like a true representation of what actually takes place in ordinary or average commercial practice. Or the supposition may be assuming the very fact that it is supposed to prove, as in the above case, of the evidence for the supply and demand theory of price. It is hypothetically assumed that supply is short and concluded that price therefore must go up ; while the question is, if the price goes up, why should the supply be short ? Such hypothetical and isolated examples of cause and effect are always dangerous, and may be very misleading. Therefore we shall use such hypothetical examples solely as illustrations of the kind of commercial process we wish to explain, and strive as far as possible to draw no conclusions from them, basing our arguments solely upon the evidence of the available statistical records. And we hope thereby in the following chapters to construct a theory of value and its distribution between the co-operating classes of its producers, based upon the idea that 
labour alone enters into cost of production, and alone determines value: showing that the shares of rent, profit, interest and wages in which value is distributed are solely the outcome of that value created by the co-operating labour, and do not in any way enter into its cost of production or cause the value.

With the above aim in view, we shall start our investigations by an inquiry into the actual nature and extent of the wealth of the United Kingdom as shown by the official report of the Census of Iroduction. The object of the inquiry being to get a reasonable and sound idea of the nature and amount of the national wealth, and its proportion to the labour required to produce it. For it seems highly desirable, before entering upon a theory of the distribution of wealth, to get to know from Government records what wealth is actually produced. And also, so far as there are any records available, how that wealth is actually divided at the present time between the various classes who contribute to its production. This latter investigation we attempt in the third chapter; but in the second chapter in addition to discovering the average wealth per person, we further attempt to illustrate the form in which the wealth exists, and what becomes of it. Obviously things that are only in the making are not wealth. A man sinking a shaft to find gold might well die of extreme poverty, although untold wealth lay just below the bottom of his shaft. So we try to show how, and how much, the recorded annual production becomes wealth, and is consumed as such by its producers. And the result of the investigation is interesting in the fact that it leads to the conclusion that virtually the whole wealth produced is annually consumed.

As this conclusion leaves no margin for the production of capital wealth, it will be found necessary to reconsider our conception of capital: for, from all the evidence available, capital seems to be of rather a mythical nature. This being the case, it necessitates a ather long discussion of the definitions and theories of capital, which problems seem to have been an endless theme of controversy between economists. It is to be feared that in this section we indulge over much in hypothetical cases, the actual data being scarce. But if suppositionary illustrations can be excused anywhere, it is surely in the investigation of a form of wealth that seems to have no tangible existence, which apparently is rather the case with capital. Capital wealth seems to consist of estimates of future values to be produced by labour, as the result of their completing the production they have in hand and consuming it as income.

As the future value that labour will produce can only be estimated in moncy value, such estimates must imply a knowledge of the approximate price of the articles that labour will be obliged to prodisce before it is allowed to consume its present share of national income. That such estimates are always made is very strong 
evidence that prices, both present and future, are definitely determined within very defined limits, and can be predicted with tolerable exactness. But such estimates are made by purely empirical methods that might almost be described as " rule of thumb." And to persons who habitually make these estimates, the comparatively small deviations of prices from their estimated course are of so great financial importance, that such financiers become obsessed with the idea of the unstableness of prices; and they quite overlook the far more important, though to them quite unimportant, fact that the relative price or value of one commodity to another is remarkably stable. Potatoes never become as costly as pineapples or eggs as turtle soup. But on the contrary, the average price of such things as wheat, oats, maize, etc., keep their relatively distinct price levels with great persistency. But why? If the mean price depends upon supply, why should it not go up and down to any extent? Why should not the producers of potatoes take it casily and produce so few that they got pineapple price for them? And if competition of producers prevents this, why should not competition bring down pineapples to potato prices ? Obviously cost comes in to prevent such extreme variations; and all economists are obliged to recognise the limiting of price variations by cost of production.

But for some reason it has been thought necessary to keep cost of production in the background, as if it were only an imaginary point to which supply and demand allow prices to approximate as the result of more or less accidental circumstances. Though why they should tend to such a point is not at all clear, unless that point is itself in some way a determining factor. Economists seem to have caught from business men the habit of studying only the trifling variations of market prices, and look to them as the essential evidence of the nature and cause of value. While they seem to disregard the fact that cost must determine the relative price of different commodities, and thus be the prime cause of value. It is therefore the object of our long chapters on prices to bring cost of production to its proper place in the foreground of the inquiry, and show that the more or less accidental circumstances of local supply and demand are the result of price variation, not the cause.

The object of our contention is of course not simply to controvert previous theories of value, but to point out that labour cost of production is really the fixed point in economic practice and theory. And that the necessary adjustments of supply to alterations in that cost give rise to nearly all the phenomena that form the subject matter of economic inquiry. The more commercially obvious variation of market supply and demand have so long obscured the importance of cost in determining prices, that it requires all the evidence that can be obtained from price records to show how prices follow a common course, and presumably therefore a common cause 
of Buctuation. So that our examination of price data will be long and tedious; but we believe that it is necessary to studiously investigate this evidence from real price statistics, if we are to escape from the quagmire of hypothetical economic problems on to the firm though rough and difficult ground of commercial reality. The laborious nature of the investigation is increased by the fact that the methods of collecting statistical data are notoriously defective. With the result that there is so much data that is of no kind of use, and so little that is directly useful, that the finding of the evidence we rexjuire is rather like "looking for a needle in the bottle of straw."

But the detailed examination of various commodity prices is not only to show the common movement as evidence of a common cause of inovement, but to illustrate the constant adjustment of supply and demand, and point out the relation of these adjustments to the labour cost of the special commodity, gold. It is probably the impression that prices of commodities vary up or down while the labour time in the production of those commodities remains the same, that has been chiefly responsible for the idea that prices do not depend upon cost of production. To overcome this impression, it is necessary to appreciate how the value of gold, like other commodities, depends solely upon its cost, and as that cost varies, prices will vary, though the labour time in producing commodities is stationary. To understand the actual process by which this alteration of price is brought about, it is essential to grasp the relation of mean prices to labour time.

Another important reason for a conscientious study of prices is to get the proper understanding of the constant adjustment of supply and market prices to the real but unknown cost of production or normal price. Because such understanding will alone enable us to grasp the method by which our theory of value may be demonstrated by experiment. This test of the theory by the scientific method of experiment is explained in Chapter IX., with examples of actual experiments carried out. And this demonstration perhaps constitutes the really unique feature of our work. For these reasons we would ask the reader to tolerate the long, dry study of prices which occupies so much space in this volume.

The remaining chapters, which need not be summarised here, explain how these adjustments of supply and market price to the normal value determined by social labour time bring about the circumstances that determine the distribution of the value producerl between the co-operating capital and labour that produces it. And also how all the more important phenomena of the production and distribution of wealth are related and dependent upon this law. of value. Having indicated the general purpose of our inquiry, we will proced to examine an example' of wealth as it is represented by
the Blue Books. 


\section{CHAPTER II}

\section{THE NATIONAL I:COME}

THERE are various ways in which writers have approached the economic problem, such as the historical sketch of the development of commerce and civilisation; or the suppositionary primitive community and barter. These methods have their advantages, but also some disadvantages; such as the danger of reading into the illustrations of simple forms of barter and exchange the various misconceptions that the reader may have got from empirical acquaintance with business and political gossip. And of course there is always the possible objection that arguments based upon simple or primitive examples are not applicable to the vastly complex conditions of modern society.

All that is good in the above methods has been already made the best use of by other writers, so it now seems best to start directly with the problem as we find it in all its complexity at the present. time, and try to analyse out from it the simpler theory on which it depends. The most obvious fact that arrests the attention of any one who reflects for a moment on any economic problem is the evidence of accumulated wealth seen in all civilised communities, and which seems to be the necessary basis of civilisation and national progress. But, although it is such an obvious factor in our lives, when we come to state what wealth is, there is something very illusive in its nature, which renders it most essential that we should get the clearest possible notion what wealth really consists of. The typical and unsophisticated idea of wealth is a large bag of sovereigns ; but to-day a child would almost recognise the advantage of getting that bag of gold to a bank and exchanging it for a valueless cheque book. All adult persons nowadays think they understand that money only represents wealth, which really consists of the commodities produced by industry. But if any one became possessed of $£ 10,000$ worth of coal, they would certainly not find it more real wealth than the bag of gold. They, too, would be most anxious to convert it into a bank account. So, also, with all the stores of wealth in the factories and warehouses of the world ; the owners of which are most anxious and take much trouble to get rid of their goods. Even the bankers do not retain either the goods or the gold but pass them on like the rest.

It would seem that wealth was not something to be possessed but something to be exchanged for something else that was more 
real. What then is this real wealth that every one gives their wealth to get? It is really the same things as are exchanged for it. but in a form ready and so distributed and prepared that they can be consumed at once by their owner, or some one else who undertakes to supply the owner with their value in any form that is desired at a future date, either as goods or direct services rendered. What every one requires is as much as they can get of what they want, where and when they want it. So the produce of labour is not actual wealth at once, but the means to wealth; and only becomes wealth when it is actually on the point of being consumed.

Now we must try to examine the nature of the actual production and wealth of modern nations such as our own country; to see how far it conforms to this idea of a supply of things or services about to be used. To do this it is necessary to consult and make the best of such statistics and trade or crop reports as can be found; for unfort unately such data are far from complete. Taking a year's production of the United Kingdom as our example of wealth, the best evidence we have is from a Parliamentary Blue Book, published in 1912, and entitled "Final Report on the First Census of Production of the United Kingdom (I907)." This is an extensive survey of the people employed and the value produced in this country during that year, and gives us a very fair idea of the nature and extent of its wealth.

Liach year a nation produces certain goods and services which constitute its wealth, but, as the term " national wealth" is often supposed in some vague way to mean an accumulation or permanent store of capital, that may or may not be used, it will be better to describe this continuous result of wealth production as " national income." As stated, the amount of this income is based upon the Census of Production in this country for I907, which is the only one we have published as yet. Unfortunately, this census was taken for a limited number of trades only, which naturally were chiefly the larger industrial businesses. But as shopkeepers, railway companies, the smaller businesses and all the professions were left out, it leaves a good deal to be desired as a guide to the real size of the national production. In the introduction to the Census, however, Mr. A. W. Flux, director of the Census at the time of its publication, gives some estimates of this missing portion of the country's income, and the figures given below are substantially in agreement with his. This want of completeness, however, makes it necessary, in the case of a number of trades, to make estimates of production, specially for use in the following pages, such estimates being calculated from the census of occupations and population, averages taken from other trades, etc.

The result of these estimates from all sources is given on Table I, which gives in figures the number of persons employed in the various 
TABLE I

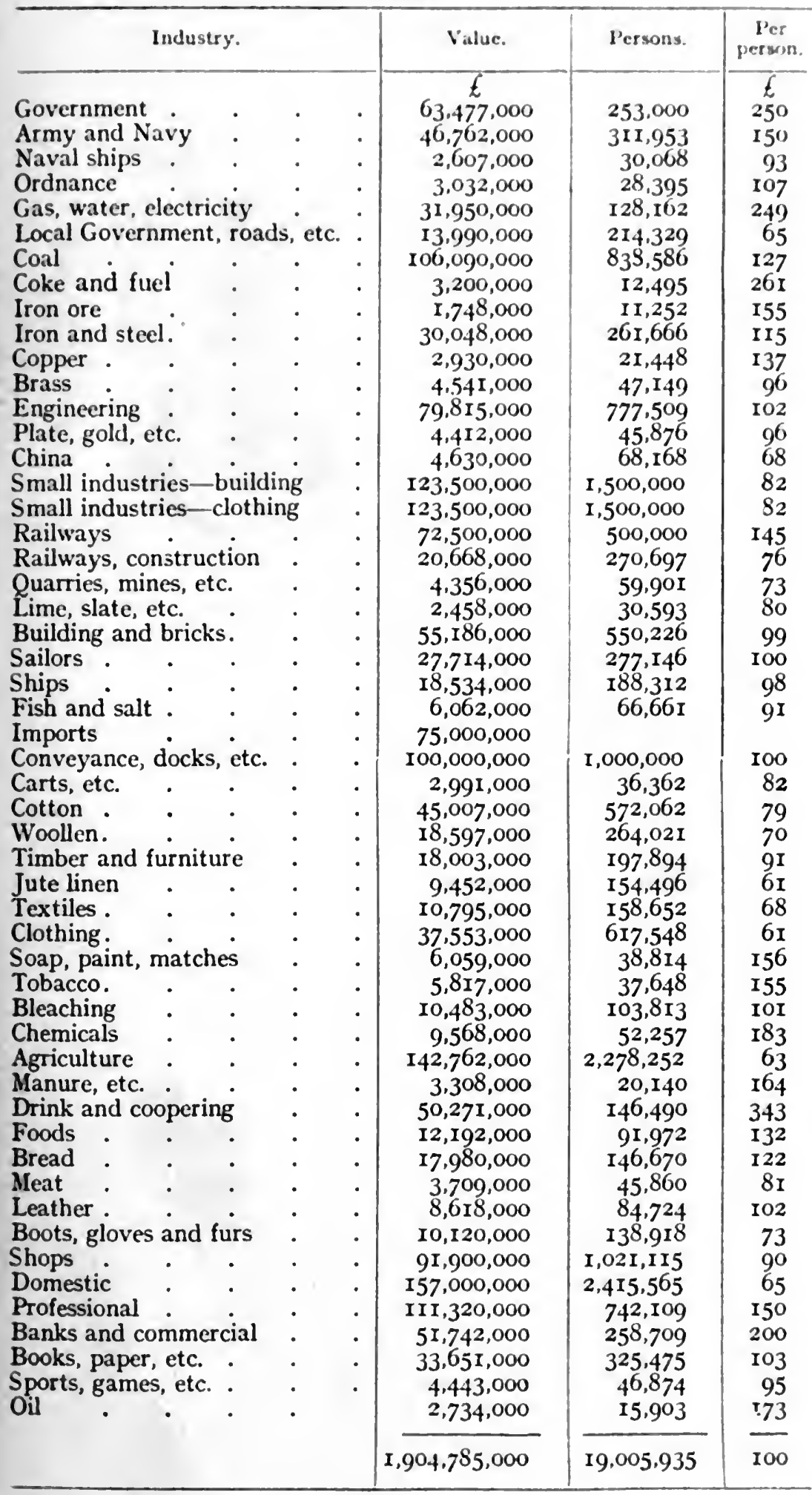


industries, the net value of what they produce, and the average portion of that value produced by each of those persons. This table is a key to Diagram 2, which represents the same industries, or groups of industries, as variously sized squares. These squares are drawn in proportion to the size of the value produced in the industries they represent, and the dots in each square indicate the number of persons employed in the group, each dot representing ro,000 persons. The thick outlined squares indicate that in those industries the figures for number of persons and value of their production are directly obtainable from the Census of Production or other official source, and the thin outlined squares represent those trades not returned to the Census and for which the value produced has had to be estimated from other sources. As our table includes the whole productive industry of the country, it would be very much larger than the tables given in the Census Report unless we had much condensed its form. To do this a good many of the separate industries returned to the Census are grouped together and represented as one square on the diagram. Some of the larger trades, however, are separate, and may be found in the tables of the Census Report, which official publication we recommend to any one who wishes to thoroughly study industrial production.

Great exactness of detail is not necessary to the present purpose, which is to give a graphic general view of the production of national income. The object of such view is to enable us to form a correct idea of the actual nature of income or wealth. There is commonly a vague inpression that income is money and that the products of industry are what we spend it in. But, as we have just seen, it does not appear that in practice any one wants to have actually in his possession any great amount of gold or goods, but always exchanges such wealth for a general claim upon future wealth to be taken in produce as it is wanted. If a person takes his weekly income in gold money, he does not keep it or consume it as such, but at once exchanges it for the goods which he does consume. So that these goods are his real income; the gold need not be real at all. It is well known that paper will do as well as gold, but paper will not do in place of income in goods. To provide this real income it is necessary that there should be a continuous supply of goods ready for consumption when and where they are wanted, and it is the nature and amount of this supply that is depicted in our diagram.

Income or real wealth must consist of products fit and ready for consumption: raw material or unfinished products are of no actual use to man and never would be if they remained unfinished. So the measure of our annual income or wealth is the amount or total gross value of the finished goods actually consumed. But if from the various market statistics and published records of prices we compile an estinate of the gross value of such goods consumed by the public, 
there would appear to be a great amount of other wealth that had been produced but not included in that estimate, all the vast quantity of iron, steel, machinery, corn and other farm produce, buildings, roads, railways, and endless unfinished things that were still unfit for man's consumption and not consumed. If, on the other hand, we included in our estimate the value produced by all these intermediate industries, we should be duplicating the value over and over again. The original value of iron ore would appear again in the value of the steel produced from it, again in the value of the machines made from the steel, again in the cloth made by the machines, again in the clothes made from the cloth, and yet again in the value distributed by factors and shops. Obviously the national income must not be reckoned both in the finished and unfinished state, or much of its value will be reckoned twice over. The object of Diagram 2 is to show how the net values produced by all the intermediate industries are only parts of the one total gross value consumed as income, and why that national income should be represented as a continuous stream of production.

In the upper portion of the diagram, the above-mentioned squares represent the production in all branches of industry and profession, whether the product is a complete or only an intermediate one. But to a void duplication of value, it is the net value that is represented after cost of materials purchased from other industries has been deducted. So that the squares on the diagram, or the corresponding values on Table $\mathrm{r}$, represent only the value added to the production by the labour of that particular trade, not the total value of the thing produced. This is very important to notice; the amounts given on this table are only the values added to the raw materials or intermediate products at each stage of their progress towards a completed article. The procuring and arranging of the data for finding the net production in industries was the chief work of the Census of Production, and we take their figures wherever possible. The Census also shows the number of persons employed in each industry, so that it estimates the production per person. This value per person is given on Table $I$ for each group of industries, and is one of the important facts brought to light by the Census.

It will be found that there is a rough similarity between these amounts per person, and this is rather a curious fact, for why should the people producing "Fish and Salt " produce just the same amount as those working in "Timber and Furniture," namely $£ 9 \mathrm{I}$ per person? There must be a vast difference between the amount and quality of labour required to produce different commodities, and it might be supposed that workers would produce 10 or roo times more value of one commodity than another. Yet we find that things so different from " Fish and Salt " as "Gold Plate, etc.," are produced nearly at the same rate per person, namely $£ 96$ for each person 
employed. "Sports," that is musical instruments, toys, billiard tables, etc., are produced at $£ 95$ per person. And the value produced in " Building " houses is $£ 99$. " Ships " $£ 98$, " Bleaching " $f$ ror and "Engineering" (mechanical) fIo2 per person. There are certainly some productions per person given in the chart that are a good deal higher than the averige, but there is reason to believe that this is largely due to error in the method of collecting and arranging the data witls regard to the production in these industries. The amount shown as produced for each industry is the net amount after certain expenses have been deducted, and, as will be explained presently, this deduction may not have always been correctly made in the Census returns, for, as it is shown by Mr. Flux in that publication, it is a very difficult matter to estimate the net output in many cases. In fact, it is a very complicated and difficult matter to get anywhere near exact amounts in these returns, as will be appreciated by any one who will study attentively the 900 pages of that ponderous Blue Book. It is only remarkable that the figures should in most cases come out so much alike as they do, for there was, of course, no intention on the part of the Census Office, or any purpose, in making the figures come alike at all. That they should come out so near to froo, which is the average per person for the national production, renders it very probable that there is some underlying principle which makes it necessary that the output per person should naturally approximate to the same money value. And the explaining of this principle is a large part of our endeavour in the following chapters.

We are also anxious that this diagram shall include really all the productive work of the community that can enter into the national income as value, or which has a price that is subject to the ordinary competitive forces of the industrial system. Therefore it includes a number of activities that are not recognised as productive by most economic writers. But it is probable that such inclusions will not be much disputed by modern critics, as it is fast becoming recognised that the performing of service may be an addition to wealth, as much as the making of some concrete commodity is. In fact, all work is service, and no one really makes anything. The farmer does not make the ox any more than the cook makes the beefsteak, or than the waiter who brings it to table does for that matter. Neither does the producer of the cooking stove make anything more than the waiter does: he only renders the service of fastening pieces of iron together in a certain useful way. All these persons perform services which together result in the economist getting a tough beefsteak for breakfast: but he could not show that any of them made the concrete thing. It seems desirable to definitely recognise that direct service is actually the production of desired results, and so contributes to the real income for which is exchanged nominal wealth or money. For some people seem to have the quite unwarrantable 
impression that all those people who are not engaged in actually manufacturing some concrete thing are to a greater or less extent parasitic upon those who do. This is an absurd notion that was only carried to its logical conclusion in the famous doctrines of the carly Physiocrats.

Thus, in the first column of Diagram 2 are given various departments of Government, which institutions, though regarded as quite necessary, are popularly looked on as anything but productive. But Government is necessary only because it manages the public business and arbitrates between the conflicting interests involved in the production of the national income. Without such an authority to direct collective interest and maintain law and order in the community, division of labour would be impossible, and production much less effective. In national and local Government, 253,000 persons are employed, and the estimated production per person is $£ 250$, which is about the annual cost. Just as the management staff in any business concern are part of the persons engaged in the production of that business, the Government staff are part of the persons engaged in the production of the community, and a portion of their labour enters into the cost of every item of the national income. A considerable number of these persons are employed in definite productive work, such as the Post Office, road-making, sewerage works, etc. And their numbers and the value of their work can be taken from the Census of Production.

The Army and Navy, although often classed as unproductive, must be included in our estimate so long as society considers them as necessary, our object being to determine what is, and not what ought to be, part of production. The value of this service is estimated from the cost shown in the Budget for I907; "Ordnance and Explosives" and "Naval Shipbuilding" are taken from the Census of Production; they are associated with national defence though a large part of the explosives included under "Ordnance" is used for blasting in mines and quarries and other industrial purposes.

In the seventh column will be found the production of "Professional " workers, such as authors, actors, architects, journalists, doctors, clericals and others who are employed in rendering services to the community which, although not usually included as productive, are adding to the pleasure of living. Many of the services are a very definite part of the regular productive work, such as architects' work in building, engineers' in works of construction, chemists' in dyeing, etc. The work of the teachers is also included in this section, and this is a very important part of production. Teachers produce direct services in developing the mind of the rising generation, and as it is now almost universally recognised that education is as necessary as food to young people, it follows that 
teaching is as much production as growing food is. As there is no actual data for the production in these professions, it is estimated at £150 per person on our diagram.

The next division, devoted to books, is rather interesting, because while it is recognised by the Census Office as productive, and while all wage earners and salaried persons, editors, canvassers, and the like, are recognised as the persons producing the books, the authors are not mentioned, and contributors are specifically excluded from the production, as they are expected to be doing something more useful elsewhere. We do not know why these persons should be supposed to have no part in this important industry, unless they luave the unfortunate habit of not working on the last Wednesday in the month, which seems in the Census Office estimation to prove productive non-existence. We have included authors under the heading " Professional," as they are certainly producers of part of the national income. And we wish to point out that the possibility of leaving this important source of production out of the Census shows the necessity for a revision of our ideas of what really constitutes national production and income. In the present section we have included the persons employed in paper-making as well as printing and bookbinding, making a total of 325,475 persons, as shown on the diagram and Table $\mathbf{I}$.

It is unusual to include domestic service as productive, but it is easy to see that there is no real difference between the work of the servant who cooks the food and that of the baker or butcher who prepares it. The same is true of the more direct services that minister to our wants. For ministering to our wants is all that any producer does, and domestic production of comfort must obviously be included in the national income. This large class of $2,415,565$ persons also includes the servants in hotels, gardeners, motor men, caretakers, etc., whose work has a definite cash value, and must be considered as productive in the most ordinary sense. The main difference between the production by this class of worker and that of most others is that their work is consumed directly it is produced, whereas the work of commodity producers is not consumed until some time has clapsed. But the duration of service is most elusory, and really does not constitute a difference. If a price is paid for it it must be regarded as a form of wealth; and whether the service is direct, or is indirectly serviceable through something produced, it is productive work, and must be included as national income.

In contrast to these direct forms of service, coal-mining is a case where most of the service is very indirect. Only quite a small part of the actual coal produced (Diagram 2, column 2) is used as coal in household fires, the value of that amount being about $f 26,000,000$. The balance is used in the making of iron, the production of steam, and many other processes. The greater portion of coal is therefore 
not part of the national income until it has been turned into some other kind of material that is ready for inmediate consumption. The total selling price of the coal at the pit is returned to the Census as $£ 122,637,000$, but this of course includes the cost of tools and materials of many sorts purchased and used in the mines; so to get the net output of the persons employed, these materials must be deducted. These, according to the Census Report, amount to $£ 16,547,000$, leaving a balance of $£$ 106,090,000 or $£ 127$ production per person. The report states that the materials used consist of " other materials and components worked up or used in producing the output, all tools, etc., used, but not depreciation." Which means that the wear and tear of machinery, that is, its depreciation by being partly used up, is still included in the cost of the coal, and therefore as part of the output of the miners. But as the machinery and plant used is the work of persons working in other trades, and included in their output, it should not be taken as the work of the coal miner also. Another important item of which no mention is made is rates and taxes. These constitute the sums paid for the work done by the persons employed in local and national service, and are included in their output, so should not appear again as the output of coal miners, any more than the raw materials and tools used. The Census Report, in not deducting these items from the annual output of coal, makes rather a serious duplication of output between coal and other trades. If a reduction were made for these items, the production per person figure on our diagram would come nearer to the average $t$ roo than it does, but as we have not the data, we must leave it at the Census figure.

In column I will be found the output of gas, water and electricity taken from the Census, and the amount produced per person, namely $£ 249$, seems very high, and quite away from the average. It is probable that there is here some error in the method of arriving at the real net output, and that, as in coal, there may be a duplication. The capital expense in these undertakings is very great, and the materials and services of which that outlay consists, such as dams, pipe lines, engines and surveying, etc., are the work of other trades, and have been included as part of the "professional," "building " or " engineering " production, and must not be again included in the light and water production. In fact, this group of undertakings that require a very great capital to supply the community with direct service in small instalments over a long period of years illustrates in a marked degree the extent to which duplication may be carried if the full deduction for work done by other industries is not made in the estimate of the net production. This error of duplication is liable to occur in all groups of industry, but especially in those where the capital is large relatively to the amount of work done by the persons using it. 
The capital of this group as estimated by A. W. Flux in a note on capital in the Census of Production is $£ 350,183,000$, and the whole of this represents work done by constructors, engineers, etc., and purchased by the lighting and water undertakings as their plant and tools. The cost of this plant has to be added to the price of the water supplied, and the way in which this is done illustrates how indirect service in the making of capital, that is plant, tools, etc., comes eventually to be consumed as national income. For this plant is actually consumed, the dams, pipes, engines, etc., do not last for ever, but are worn out by use and have to be replaced by continual additions and repairs. The community wants light and water, not only a certain quantity of these commodities, but a permanent and good supply, economically and conveniently delivered at the place and moment that the individual consumer wants it. This economical and very great convenience can only be obtained by using up a portion of the costly plant represented by the capital of this group of undertakings, and the consumer must pay for this portion with each foot of gas, gallon of water, or unit of electricity he uses. Then arises the question as to what is the price of this portion of $\{350,153,000$ worth of plant which the consumer gets with each gallon of water, or unit of electricity? Obviously, the whole cost of the plant and materials cannot be charged on the first year's supply of these commodities, or they would be so costly that nobody would have them. To distribute the charge over all the consumers that will in time benefit by the convenience, it must be divided equally between all the gallons of water, feet of gas, etc., that can ever be got from the works represented by this capital. As the actual length of life for the permanent plant of these undertakings is practically impossible to ascertain, it is usual to fix on a period of years as a reasonable length of time for the original work to last, and in which it should pay for itself. The time is fairly well represented by the number of years appointed by Act of Parliament in which the loans for such public works must be repaid. The time allowed varies for different parts of the work from ro to 50 years, but an average may be taken as about 40 years. It then becomes possible to estimate the amount that must be added to each portion of these commodities, that is to be supplied in that period, to replace the whole plant or fixed capital used up. This portion of capital cost is added to the price of the commodities, and the consumers use up and pay for the whole of the original work done by the constructors of light and water works along with the water or light they use in 40 years.

As above stated, the capital representing plant and original cost of these undertakings is $£ 350,183,000$. If we take it that the time in which this plant will pay for itself and have to be replaced is 40 years, the total capital must be divided by 40 to give the annual 
portion of this capital charge that must be added to the cost of the water and light supplied. This capital not being the produce of the persons working in this group of industries, its depreciation represented by this annual fortieth part, namely $£ 8,755,000$, should be deducted from the gross annual production, which on our diagram, taken from the Census, is $£ 31,95^{\circ}, 000$. Deducting $\{8,755,000$ from this would leave $£ 23,195,000$ as the net production of this group. This would reduce the production to about $\ell \mathrm{I} 8 \mathrm{o}$ per person, which would not be much too high for industries like these where competition is very limited.

In such undertakings the service of financial organisation and direction in the initial outlay is so large compared with the subsequent labour required to use the plant, that the remuneration for such capital services is large compared with the current labour employed, larger no doubt than it could be in any industry which was more open to competition. The original outlay is so great that it virtually gives a monopoly to the first persons to undertake it ; and if such undertaking is put into private hands, the considerable personal risk and responsibility taken by such persons entitles them to a somewhat high remuneration for the service of their experience and ability. Even in municipal undertakings of this kind, society seems to think it necessary to distribute the financial burden and risk by borrowing money at a stated interest. And this means asking the assistance of capable and successful business men, who expect to be highly paid for their services.

Without offering any justification whatever for the system, it should be pointed out that if society thinks it necessary to employ this expensive kind of labour to assist in managing the finance of such undertakings, they must expect it to increase the cost of the commodity produced. The somewhat large amount of interest paid for borrowed money is in fact the payment for the rather costly services rendered. But though the cost of this class of commodities is increased by the somewhat monopolistic nature of the undertaking, the common experience of municipal bodies is that there is no fabulous profit upon such work. Competition, though limited, still exists in the form of private water supplies, especially those of brewery or railway companies and other large consumers who can refuse to take water, gas, light or power from the common supply if it is too high in price. So that probably the high value produced per person employed in this group of industries is not so real as apparent from the data given. Which data, as in some other industries, are probably far from adequate.

Owing to the preponderance of the financial element in the above group of industries, they are rather intimately connected with local Government. So, as it was also convenient for the making of Diagram 2, they have been placed in the first column under Govern- 
ment, etc. But, as a matter of fact, these forms of our income are the completed products of coal and might well have been placed with other such direct coal products in the next column. To follow up the other forms into which the coal is changed by further manufacturing processes, the more important of these industries are indicated in the diagram, and are grouped as near as possible under the heading "Coal."

In the manufacture of coke, $£ 7,147,000$ worth of materials, mostly coal. were used, and the total production is $f(10,140,000$, the work of the $10,05 \mathrm{~S}$ persons employed in coke works. Thus the coal has been turned into a fresh set of commodities, the selling price of which is the sum of the work embodied in the coal and that of the coke workers, embodied in the coke and its by-products. The manufacture of fuel is included with coke in the diagram, and the average output per person is $£ 26 \mathrm{I}$. This figure appears to be very high when compared with coal, and is probably too high owing to unsatisfactory methods of returning the data to the Census. As in the last case, the capital expense is probably high, and it may be somewhat confused with that of the great coal and iron undertakings of which coke production is usually a part.

The quantity of coal and coke used by furnaces is returned at $64.994,000$, which again is added along with the iron ore to the value of the pigiron produced ; in fact, the materials used in the production of iron and stecl are three-quarters of the total value of the product, as against about one-eighth in the case of coal, showing this process to be later in the chain of production a step nearer to a finished constituent of income.

The industries designated " Iron and Steel," " Copper," " Brass," "Oil" and some other like industries supply products which become the raw materials of the "Mechanical Engineering " trades (column 2, Diagram 2), under which head we group a number of undertakings such as tin plate, sheet iron, chains, etc., which have an output per person varying a little above or below the average $f$ roo. The chief part of these products is again only, like the raw material, to be used up in the production of yarns, woven cloth, furniture, boots, and a host of other machine-made articles. Or along with other mineral products, these mechanical productions become a stream of building materials which go to build factories and workshops for the engineering trades, stations, bridges and rails for the railways, mills and weaving sheds for the textile trades, etc., and are all being added as part of the work and part of the price to the final products, the things used in the daily life of the people.

The connecting link between all these trades is the network of "Railways" (column 3. Diagram 2) carrying the coal and ore to the furnaces, the iron and steel to the engineering works, the machines to the mills, and so on. Unfortunately, this very important class of 
productive work has not been included in the Census of Production, so we are compelled to make an estimate of the probable net output of the 500,000 persons employed. According to the Statistical Abstracts for the United Kingdom, the net profits of the raikways for 1907 , not including steamboats, hotels, etc., were $£ 40,000,000$, to which must be added the probable wages, which, at $£^{65}$ per person, come to $£ 32,500,000$, making a total of $£ 72,500,000$ as the net production (see Table $\mathrm{I}$ ). To confirm this estimate by comparison with published figures we may add $£ 40,000,000$ for the cost of materials used, when it gives a total of $£$ 112,500,000, which is the gross output of railways shown by the Statistical Abstracts. In connection with this output we have to consider the output of the 270,697 persons employed in the construction of railway materials and repairs, who are returned as producing only $£ 76$ per person, because the profit on their work is included in the net receipts of the railway companies. If these two industries are added together, the output per person becomes $£^{1} 3 \mathrm{I}$, which makes it very similar to that of other large industries such as coal, and suggests that the estimate is probably about correct.

The next group, "Sailors" (column 4), is not included in the Census of Production; the number employed has been taken from the Census of Occupation. The estimated output of $£$ roo per person is probably not far from correct, as in the somewhat allied trade of shipbuilding, which is given in the Census, the I9,22I persons employed in the production of "Ships " make an output of $£ 98$ per person. This group, described as "Sailors," seems rather inadequate to represent our great shipping industry, but unfortunately the Census of Production does not undertake any investigation of this complicated branch of industry, and to make any estimates of its business and output as a whole would be much too difficult for any one but the Government authorities. For the purpose of our diagram, all the business part of this industry is included under "Commercial,": and the dock labour and porterage under "Conveyance." It would not be easy to say exactly what is to be included in such a vast undertaking as the shipping industry, as many allied trades are financially united with or dependent upon it, the whole forming a group of great complexity. They are all engaged in the production of indirect service, and united as the part of national capital devoted, like railways, to the transport and distribution of produce on its way to the consumer.

As in railways, a certain portion of the trade done by ships is the carrying of passengers, so part of the $£ 27,714,000$ produced is direct service, and not simply a value added to the price of other commodities. But by far the greater part of the value they produce is in the form of value added to the materials transported, and so to other products made from those materials. Thus the value created 
by the shipping service forms part of the continuous stream of intermediate goods that are to be used up along with many other services in the production of real wealth or income. It is the object of this chapter to illustrate how these goods and services that are used up and forgotten long before they get to the consumer as income are embodied as value in the price of each succeeding production in the chain of intermediate goods, till the finally resulting products or services are consumed as wealth, at a value that is the sum of all the labour embodied in each intermediate stage.

It is perhaps the fleeting and hidden character of these intermediate productive services that has led to the common but very erroneous conception of capital as a store of wealth that has been made by labour at some previous and more or less remote time. A correct view of this production in the great shipping industry may help us to realise that capital is not wealth, but unfinished work in land. It is unfinished labour and instruments of labour, tools that are not consumable as income and cannot be converted into consumable wealth by any alchemy whatever until the work upon them is finished and they have reached the final stage in the chain of productive processes. A large part of the capital of shipping companies ("Sailors") consists of ships. Ships are not wealth, except when they are pleasure-boats used as income. They are capital that cannot be converted into wealth by any conceivable means, except as they are worn out by use in adding value to the goods they carry. This wear and tear is not a store of wealth, it is simply a stream of work flowing through the hands of sailors and others whose labour is controlled by the shipping industry.

The whole capital of the shipping industry flows into it as the result of labour in other industries. The production of the shipbuilding industry ("Ships ") goes almost completely to be consumed as capital by this industry called "Sailors" on Diagram 2. Most of it is simply the replacing of the old, used-up, or obsolete ships ; and the price of all these renewals must be added to the gross value of the goods carried by the ships. Also a considerable part of the "lingineering " production is ships, ships' engines, or dock and harbour machinery of various sorts. A portion of the "Iron and Steel," "Coal," "Building," "Conveyance," " Government," and nearly every other production, also goes as indirect service or capital goods for the shipping trade. All this capital service flows into the inclustry, and for each $f \mathrm{I}$ worth that so comes in, a $f \mathrm{I}$ worth low's out as capital used up and value added to the various commodities handled by "Sailors." The capital is not saved, is not adranced to labour or any one, but is used up and replaced by value produced. But with every $f^{\mathrm{I}}$ worth that flows out there is also added to the value of the goods handled the value of the labour added by the sailors and others at work in the industry. This value 
is the result of the work, not the capital. The capital that represents a great line of $\mathrm{P}$. and $\mathrm{O}$. steamers does not add more to the price of a box of figs than the capital that represents one little old tramp ship does. If the great capital serves any useful purpose it adds less value to the figs. That is to say, they cost less labour to carry, so are cheaper.

It was mentioned above that the mercantile part of the shipping industry was largely included under "Banks" and "Commercial " in the seventh column of the diagram. Under this head "Banks" are included, also various commercial businesses, including brokers, etc., that employ 258,709 persons doing a variety of work connected with transactions in money values. Their work forms part of the cost of producing in nearly all other trades, and is embodied as value added to the things those trades produce. The total value of this "Commercial " work is estimated at $£ 51,742,000$, or $£ 200$ per person. This sum may seem rather small when the salaries of bank managers and such persons are included. But they form only a small part of the whole, which includes a large number of merchants with staffs of clerks, agents, and so forth, who reduce the average amount produced per person. We are apt to think the word production is not quite applicable to the result from the work of bankers, brokers, agents, merchants, insurance companies, and the like, but it certainly is so, absolutely. The letter written, account checked or ledger posted, is a necessary part of our business system and the division of labour. A balanced ledger also is as much a real production as a steam hammer. Neither of these is the least direct use to man, they will not feed, clothe, or please him; they are only stages in the production of what he wants. The men making the hammer and balancing the ledger are both equally contributing to the production of the national income, and, as we have seen above, neither of them produces anything but a service.

These services, such as "Banking," "Professional," "Government," etc., come as capital value flowing into other businesses, as was described above in the shipping industry, and they pass on from these businesses as increased price of the things they produce. On our diagram under "Sailors " and "Ships" will be found some of the industrial groups into which the shipping, "Railway" and "Conveyance" production flows as capital. It comes as increased value put into the raw materials of many trades, such as "Building" materials, woodwork and furniture (" Timber "), " Cotton," " Jute," etc. The capital goods and services that flow into these trades are added to and redistributed by the labour employed upon them, and are so passed on into yet another industry in the same way. The timber carried by the transport services becomes furniture for houses and factories, the cotton and wool become yarns, which in turn become cloth and finally clothing, and many other things which the 
community wants as real income. We can roughly picture this capital of goods and services flowing through one industry after another and changing in nature and value as each addition of labour is expended upon it. But it should be realised that in the last process, the retail shop for instance, as in the rest, this capital flows out as fast as it flows in, and is an absolutely continuous stream. But as it now flows out as income it must be consumed, and by the persons who have contributed to its making. So it appears that'the sailor on his ship, the steam-hammer maker, and the clerk at his ledger, are actually engaged in producing the things that they want, and are consuming them as fast as they make them. It does not follow that they consume them the same day as they make them, or in the same form as the services leave their hands to be finished by the division of labour method. But they consume as much each day as they produce, and at no time do they subsist upon capital or any such curious thing as some economists think it necessary to imagine.

It has been mentioned that part of the shipping industry was included under the heading "Conveyance" on the diagram. This industry was not included in the Census of Production, so it has been necessary to make an estimate of the probable number of persons employed from the "Census of Occupation of the People" for Igor, and to estimate their production also. It is possible that the estimated production of $£$ IOO per person is on the high side, but, this figure being the general average for all industry, it is not likely to materially alter the general view of industry as a whole. A slight over-estimate would make hardly any difference to the average production of the community or affect the deductions to be made from this gencral survey of national income. It is not only in the carrying of the original raw materials that these transport industries are concerned, they perform a very important function between nearly every stage in the productive process, and in distribution of the nearly finished goods. Under "Conveyance" and "Sailors" will be found a square representing "Imports." The finished goods carried by shipping are largely exports going as payment for the raw materials and other things imported. The value, shown in this square on the diagram as $£ 75,000,000$, represents the balance of our imports over exports in the year 1907-8. Although this is not part of the production carried on actually in this country, it shows an increase in the national income from investments abroad. The ramifications of industry are too wide to be strictly confined to the narrow geographical boundaries of a particular country. And these investments abroad mean that persons in this country are controlling, or to some extent directing, industry in other countries and getting a more or less justifiable income by doing so.

A very important group of the imports mentioned in the last paragraph as carried by sailors are the raw materials for the great 
textile trades, represented on the diagram as "Cotton," "Wool," "Jute," and other "Textile," which, with the complementary industries of "chemicals," which include dyeing and "bleaching." are all engaged in making the raw materials into cloth for the clothing and other trades producing things directly consumable as income. Also the leather and hides imported are the materials for the boot, glove and fur trades. The members of this group of industries are much alike in producing things nearly ready for direct use as national income, and there is an interesting similarity in the value produced per person, the average production being $£ 70$ for the whole of these trades, which vary but little from each other. This fact, and also that the amount is below the average of $£$ roo, is probably connected with the average quality of labour employed, and will be of interest when the theory of price comes to be examined.

Closely connected with shipping is the fishing industry, the capital of which is largely shipping of various sorts. This industry not being taken in the Census of Production, the number of men employed is taken from the Census Igor, and the value of the product taken from the returns of fish caught in 1907, valued at \{II,7 7 7,8I6. To complete the estimate, a deduction must be made from this sum for the cost of all goods purchased, such as coal, salt, nets, etc., and the wear and tear or depreciation of ships. This has to be estimated from returns in other trades, and as, estimated for the railways, this item amounted to 40 per cent. of the total, a similar deduction in this case would leave $£ 6,062,000$ as the net production of fisheries. The number of fishermen returned to the Census I90I was 66,661 , which gives the average production of $£ 9 I$ per person employed.

The Census of Production for Agriculture was taken for the year 1908, so does not exactly compare with the other returns, but is quite sufficiently near to complete the general idea of the production as a whole. This Census only applied to Great Britain, and the total value is estimated at $£ 150,800,000$. From this total, the goods purchased, such as fertilizers, offals, tools, etc., must be deducted ; the net total then is about $£$ ro2,762,000. The total number of persons employed in Great Britain are $1,673,000$, but in this total 300,000 occupiers are included, some of whom are also included in other trades. So a deduction of 200,000 has been made, leaving $1,473,000$ as the total number employed. If the net production is divided by this number, it gives about $£ 70$ as the production per person for Great Britain. The Irish product is estimated at $£ 50$ per person, which makes a total output of $£ 40,000,000$ for the 800,000 persons farming in that country, which, added to that of Great Britain, gives $£^{1} 42,762,000$, or $£ 63$ per person as the production for the United Kingdom.

Agriculture is another of the great industries producing raw 
materials or capital wealth. It is sometimes spoken of as if it represents the direct production of food, or even clothing, that is the direct need of the community ; but, as a matter of fact, hardly any direct real income is produced upon farms. One important branch of agriculture is a very indirect service. The breeding of horses is the production of capital, not only for farming, but all the transport trades, especially "Conveyance." And the value produced by breeding horses is distributed over the cost of producing a vast number of commodities. Under "Agriculture" on the diagram will be found some of the trades to which the farm produce flows as capital.

Under the very abbreviated title of "Manure" is included as well as fertilizers the seed-crushing and oil-cake industry. This group has rather a curious position in that it makes agricultural produce, mostly imported as cotton and flax seed, into the raw material used by farmers as cattle food. The other trades using agricultural produce as their capital are engaged in bringing this capital nearer to the final condition of income. The milling and "Bread," "Foods,"

" Meat," and " Drink" industries come nearly to direct production of income in its consumable form; but they do not include the hutchers' and bakers' shops which represent the final stage of that part of farm produce. But the meat industry hands on some raw materials to the leather industry, and although a large portion of the hides used to make leather are imported, a portion of the homegrown hides are so passed on to the boot trade. So boots are one of the final products of this branch of agriculture. But boots by no means account for all the leather; it goes to make many things. Some may become leather belting for machinery, and be used up in the production of a vast number of things; so that a bicycle is in part the production of agriculture also.

From the Census of Occupations we find a very large number of persons are not included in the Census of Production, although engaged in ordinary kinds of industry that may be carried on in small works or in the home. It is quite impossible to classify these industries, as they include persons carrying on very small productive undertakings such as dressmaking, tailoring, cobbling, carpentry, and a host of other small manufactures or repair jobs employing one or two persons, and too small to come under the classification of the Census of Production. It is probable that a considerable number of these persons are nominally in other employment, but lose part of their time, and are not therefore included in the returns of the trade to which they really belong. Others may be classed as outworkers, and the whole are estimated at 3,000,000 persons, roughly divided into $1,500,000$ in building and $1,500,000$ in clothing, in separate syuares on Diagram 2. Their work must be carried on under poor conditions without the help of machinery, so their production will be below the average, and may be estimated at about $£ 82$ per person. 
The last square on the diagram that need be mentioned represents retail "Shops," which, like domestic service, are not sufficiently recognised as productive. Shops perform the important and very difficult function of distributing the final products of industry; supplying them where and when they are wanted. It is not merely a matter of having so many finished goods at this place, and so many at that, according to the population to be supplied. It is not sufficient that a lady can go to a store and get a dress of good value, exactly like the last she had, and like those that 10,000 other ladies are getting. The real joy in life is choosing our own pleasures, and the opportunity to develop our own taste and discretion in what we enjoy. We would also remind those superior persons who look with scorn upon those whose pleasure is largely in their discriminative choice of dress, that there are also book-shops that offer us choice of reading. Surely life would be deprived of much intelligent pleasure if we all had to read the same books, and only those thought necessary by the majority elected to the administration of national production. A book that is printed but not so distributed that the persons who would choose to read it can get it, or know of its existence, is no more a finished product than an uncooked dinner on an uninhabited island. The shops perform the last service in the chain of services that convert the concrete materials of nature into income that can be consumed as pleasure.

Nearly all the concrete production of the national labour passes through shops before it becomes income. The rest of the product that is direct services passes through professional offices, theatres, picture shows, hotels and the like, which are virtually shops that distribute services. On our diagram, however, we only include the shops ordinarily so called. And as no separate or complete returns for this important industry were made to the Census of Production, we have to estimate the value produced. The number of persons is estimated from the Census of Occupations, and the value produced is probably about $£ 90$ per person. The leaving out of shops from the Census of Production is really a most serious omission ; not only does it leave out a portion of the supply cost or value of nearly every industry, but it virtually leaves out some industries altogether. The butchers' meat industry for instance might have no existence so far as the evidence of the Census goes. "Meat" on our diagram is really quite inadequate to represent this industry, as it only covers bacon-curing, preserved meats, pickles and patent medicines, etc. The real meat industry that also supplies raw material to the big leather trades is quite left out, and is only estimated by us along with many other industries under the title "Shops." Public-houses, which are the shops which supply drink, and are probably more than half the cost of producing it in accessible form, are also left out of the Census. And as the value of their production is probably in- 
cluded as brewers' profits, without any deduction for cost either of property or wages, it renders the Census figures for brewing quite useless and misleading.

This completes our sketch of the various groups of industry producing the national income. They together represent I9,005,935 persons, producing in goods and services a total value of $\{1,904,7 \delta 5,000$, or about $£$ I0o per person. It is somewhat instructive to notice that these figures represent absolutely the whole wealth produced in a year at the time of the Census, and that therefore the greatest possible average income per person working in the country would be $f 100$ per annum. This is, of course, for every man, woman, and young person who is employed, and at the pre-war value of currency.

It will be noticed from Table I that the value produced per person varies considerably in different industries. In some cases the difference is so great that it is difficult to see how it could come about ; in fact it throws some doubt on the reliability of the figures. Of course the average quality of the labour employed will account for a greater or less amount of work produced. But it is difficult to believe that the labour employed in brewing (Drink, etc.) is three times as efficient in producing as that employed in "Engineering." Nor is there the least reason to suppose that wages in the brewing trade are two or three times as much per person as in other industries. Rather the contrary; so that if the returns to the Census are correct, the profits on brewing must be vastly better than in engineering or any other trade. Brewers no doubt make good profits, but that the industry is three or four times as profitable as other trades is hard to believe. We sometimes read in financial papers of brewery companies paying no dividend on ordinary shares. Brewers have been known to fail or give up the business as unsatisfactory, which would not be likely to happen if brewers are, as their returns to the Census show, doing so much better than other trades. There is evidently some mistake, and the method of collecting the information for the Census is probably not applicable to an industry of this kind. As mentioned above, public-house and hotel property owned by brewery companies are not mentioned in the Census of Production. So it is evident that, as in the case of "Gas, Water, etc.," the depreciation on capital has not been properly allowed for. The depreciation represents the using up of such capital property; and such property is the work of others than those returned as employed in brewing, and should not be included in the value produced by brewing. Further, the persons working in these public-houses are engaged in producing drinks in the form required by the public, and undoubtedly add to the value which the public pay for it. These persons do not appear in the Census as engaged in the production, :hough probably a considerable part of the value they produce is 
included in the value shown in the Census as produced in the "Brewing " industries. Perhaps this is supposed to be covered by the difference between the wholesale and retail price of the article. But where the retail establishment is the property of the wholesale producer, such margin of difference in the price is only an arbitrary arrangement not subject to ordinary trade competition. It may virtually amount to the landlord and staff of the houses being the salaried employees of the brewery companies, in which case they should have been returned as persons contributing to the value produced by those companies. The vagueness of the Census report upon these important points renders its figures for production per person worse than useless. But as we have no data regarding "drink, etc." and tied houses, we have to accept the evidently incorrect Census figures.

"Coke" is another industry where there is evidently some mistake in the returns to the Census. It surely cannot be more than twice as profitable to make coke as it is to mine coal. The group of industries under "Foods" on the diagram also show a production that is obviously too high for the number of persons employed, for the group includes things like cocoa and jam where women are employed. A footnote to the Census states that the duties on sugar have not been deducted, and states the difference that such duties make to the value per person in the sugar industry. As taxes are paid for the work of Government that work is done by people not included in this group of industries, and so the production in this group shown as "Foods" should have been $£ 2,000,000$ less. This two millions might very well be transferred to "Shops " to represent the lost butchers' meat trade, and in that case the total income would not be altered. Also in this group it is found that the greatest production per person is in the ice trade, where the capital in plant is great, and the persons employed few. This seems to be the case generally throughout the Census; wherever the plant is large in proportion to the persons employed, the value produced is too high. This is no doubt due to the duplication caused by not deducting depreciation and taxes, which represent work purchased from people not included in the staff of the industry purchasing such work.

From these cases it appears that the evidence of the Census of Production in regard to production per person is very rough, and cannot be taken as conclusive in the case of any particular industry. It is probable that the greater part of the variation in these amounts per person is due to error. If we exclude the evidently incorrect figures for "Drink," " Gas, Water, etc." and "Coke," and make a liberal allowance for error in the minor irregularities, the figures on Table I suggest that if correct returns for production could be obtained, the production per person in the various trades would only vary above or below the average $£$ Ioo by a reasonable amount. 
That is, an amount that could fairly be accounted for by the average quality of the labour employed in the particular trade or professionsuch figures as, say, $£ \mathrm{I} 50$ and upwards for professional work, $£$ IIo for men in engineering, mining, etc., $£ 74$ for trades where many women and young persons are employed, and $£ 80$ for agriculture. But until we have more exact data as to net value per person it is impossible to make any actual averages that approximate to the facts sufficiently to be of any use.

The production per person for "Agriculture" given in Table I as $f_{63}$ is very low compared with the rest of industry. This is partly due to the very low production returned for agriculture in Ireland. But even the $£ 70$ for the United Kingdom alone is so low that it is difficult to understand why a large class of the community doing important productive work should only produce so little value per person. Farmers as a class do not keep any books, and are not considered able to make an independent return of their income to the Inland Revenue Department, so that it is very probable that their returns to the Agricultural Census considerably under estimate the actual value produced. The production of farm labour is, however, undoubtedly low, which is due mainly to a want of enterprise and energy in that class of labour. We are naturally apt to think that the low value produced in this industry is the result of the low wages paid to agricultural labourers. But it must be remembered that this $£_{63}$ value produced is the total average value per person. Out of it has to be paid not only wages and farmers' profits, but also all rents that have to be paid to landowners.

Notwithstanding the errors with regard to production in various industries and groups, the total $£$ I,904,785,000, or roughly two thousand millions, which is the figure given in the introduction to the Census of Production, is considered by most authorities to be about the correct estimate. It substantially agrees with Dr. Bowley's estimate, recently published, and may be regarded as approximately correct. This may be taken as the annual value produced by industry, and it is interesting and important if we are to get a sound conception of the real nature of national wealth, capital, or income, to discover what annually becomes of this production.

A great deal of the goods and services that make up the national production of $\ell_{1}, 900,000,000$ are absolutely used up and consumed in the production of this $f_{\mathrm{r}}, 900,000,000$. If we look down the list in Table I, we find many materials like coal, iron, brass, cotton, wool and machinery which are used up as fast as they are made, and converted into the food, clothing, etc., that are consumed as income. Also there are services such as "Conveyance," "Railway transport," shipping. law, and Government, the value of which is used up in the production of these goods that are capital used up in producing income. It is easy from Table I to count up $£ 700,000,000$ worth of 
goods and services that are not income, but are used up and forgotten in the production of income. It therefore appears that the national income would be less by this amount of production used up in producing the rest. But although these past products and services have been used up and forgotten-or never appreciated at all by the general public-they are not forgotten by those whose business it is to remember them. Their value remains as price, and the value of the nation's income is expressed in these prices. The value of the coal used up remains as the price of iron, and the iron used up remains as the price of the pocket-knife, etc., consumed as income. Thus the total income represents all the values that have been used up in its production.

In the bottom part of Diagram 2 an attempt has been made to illustrate the production of all the above industrial groups as it appears in its final stage as income. The consumable goods and services are represented by rectangular areas or columns, arranged in groups, each of which has a name descriptive of the kind of human want it satisfies as income. At the foot of each column is its money value in millions, with the six noughts omitted. These various commodities and services represent the same industries as the squares above, but they have changed very much in name, nature, quantity and value. "Engineering" and the "Iron and Steel "industries have vanished altogether as such; the "Mines and Quarries" are represented only by a little coal, and "Agriculture" by a few potatoes and a little fruit. They have now become boots, carpets, trains, medicine, etc., but for all that they are not new or additional production, but one and the same as that above arranged in fresh groups. It would be best if this income stage could be expressed in actual quantities or units of things used by the consumers, and as far as possible we should think of income as such things enjoyed by us. But there are no data for these goods units, and if there were it would probably be very cumbersome to tabulate or visualise; so we have to represent these items of income by their selling price or value.

To begin as before with Government and service, we have first the group "Law and Order." In it the $£ 90,000,000$ worth of "Government" and "Defence" is all the direct income that is left of the $£^{115,878,000}$ represented in the squares above as "Government," "Army and Navy," "Ships" and "Ordnance." This amount of law and order cannot be estimated very exactly, as it must represent only that portion of the service that is consumed by the individual for his own use and satisfaction, and paid for out of his private income-or more correctly, as we shall see, out of his share of capital. Any portion of these services used by any one in his business is not income but capital, and is added to the price of the goods his business produces. This capital only becomes income when these goods are consumed by some one, and such consumer then pays for the bit of 
Government service embodied in the price of those goods. Private individuals are always using Government services in the form of law and public management, or as direct Government service in the form of postal service, police force, highways and streets, sanitation, or peace and security of life and property; and it is this directly paid for portion that is represented by the above figures. In addition to this, these Government services are used by business firms. In many important ways law enters into most business transactions, and commercial security depends largely on law and order, as well as postal and other conveniences; but the cost of such service is added to the price of the firm's produce as stated above.

The next item will perhaps appear too small, but it must be remembered here again that by far the larger part of the cost of banking is added to the price of the goods produced by the clients of the banks. It is only the cost of private accounts, £r2,000,000, and the amount of brokerage on the exchange of shares and produce for private speculative accounts, and estimated by us at a brokerage of $\$ \$ \$, 000,000$, which have to be considered as final services or income.

The cost of "Money" is placed in this group because strictly it is part of the capital instruments used in production by "Banks" and "Commercial," and not income at all. Still it is partly consumed by persons who take pleasure in carrying or hoarding money, so has been left here as in some degree income. It is a small item, as actual money is only used in small personal transactions, the main business transactions being conducted without any money being used.

In the group "Pleasure," the only items that can be taken direct from the Census of Production are "Books," and "Sports" ; and in "Books" we have to estimate the amount to be deducted for printing, paper and books used in commercial undertakings. The total gross production of $£ 62,000,000$ given in the Census of Production is reduced to $£ 40,000,000$, the balance being estimated as used in, and added to, the price of producing the goods that make up the other groups. The items "Teaching," "Medicine," "Art," "Letters," and "Clerical" are taken as direct services. The number of persons given in the Census of Occupations as employed in these services multiplied by the average production per person given in Table I, is taken as the total value of the service. The item $\{7,000,000$ for "Legal" is only to cover directly personal legal expenses, which are estimated to be about half the estimated total of the returns to the legal profession. The balance must be put to the commercial consumption, and will be added to the cost of manufactured commodities. "Sports" (requisites, etc.) are taken at the Census gross value plus the shop expenses.

In the group "Service" the values are taken with but little alteration from the squares above. In "Small Industries" 
$£ 53,000,000$ is added as the cost of materials used in these industries to make the net production of $£ 247,000,000$ shown above into the gross value of the production or selling price. This $£ 53,000,000$ accounts for, among other things, the printing, account books, etc., that are used in these small industries and left out of the item "Books" in the group "Pleasure" mentioned above; also for part of the similar balance under "Legal" that has just been mentioned, and that from "Coal," "Light and Water," etc., that will be mentioned below; for part also of the "Iron and Steel," " Engineering " and other productions that were all indirect services, and do not appear in this bottom part of the diagram at all by name, but form part of the value in the materials used in these small industries. As a matter of fact, part of this $£ 300,000,000$ for small industries should be transferred to "Houses," "Furniture," and "Dress," if we had the data for making the division between them correctly.

The column "Shops" represents the service rendered by the persons employed in shops. These persons store and keep in condition till wanted the finished productions of industry, and display them for the convenience of the customers, who can thus have a considerable choice of things which they can take as income just when they may want them. The value of such services is taken as estimated for the square representing shops above, and is the net value of this service, and does not include the expenses of shops, such as taxes and appliances, nor the carriage on their goods. These expenses are added to the gross value of the items of income mentioned in the other groups. It would have been actually more correct to have added all the value produced by shops to the price of the goods sold, as that is how the production of shops actually enters into the national income. But there is no statistical records of the retail price at which the shop goods are sold. So that we are obliged to take the average value per person that such labour is likely to produce, and add it as an equal percentage to the wholesale value of commodities given by the Census, or retain it as the value of a separate service. As the former would be only a very rough approximation to the retail prices, and as the amount of shop service added to goods may be very different for different classes of commodities it seemed just as well to retain the value of this industry as a distinct service, becoming income as soon as it is performed, like the legal and domestic services.

In the group representing income in the form of "Houses," the $£ 70,000,000$ for building includes $£ 40,000,000$ for new dwelling houses, and $£ 30,000,000$ for repairs to such houses. This seems to be about the amount annually expended in houses, as will be pointed out in our subsequent chapter on "Rent." It is about two-thirds of the gross output of the building trades returned to the Census, but 
is very much less than that portion when the "Building" under small industries is included. But doubtless a very large proportion of the building done is in the erection and alteration of shops, factories, public works and buildings, etc., which as capital are used to produce, and are paid for in the value of, commodities. Further, the I23 millions odd as "Buildings" under "Small Industries" is actually for building and allied industries, and probably not more than half of it is strictly building. These small industries, as explained, are not returned in any statistics, and are only grouped by us roughly as trades more or less allied to building or clothing respectively, and no doubt including many other small trades.

Household coal, the value of which we have before estimated at $\{26,000,000$ at the pit, becomes about $£ 39,000,000$ by the time it is delivered at the place of use. This is because the value produced by "Railways," "Conveyance," etc., is embodied in it by the addition of 5 s. per ton average carriage. The other items in this group are estimated from the Census, light being taken as half the gross output of "Gas and Electricity," and "Water" also at half the gross value produced. The balance of these products is used in commercial undertakings and added to the price of other productions.

The items of income in the group "Furniture" are taken direct from the Census, and require very little explanation. Bedding includes sheets, blankets, and other materials used in the house, and not included in the group "Clothing."

The group "Dress" also includes items the values of which are taken from the Census, with the exceptions of "Machines" and "Materials." These represent the sewing machine, etc., from the engineering production, and the materials from the textile production used in the home to make articles of dress. Hosiery is valued at the amount returned to the Census under this head in the textile industries.

In the next group the large item "Food " is taken from the Census as the gross value produce by the industries connected with food production. In this $£ 280,000,000$ some portion of the grain production is probably included twice, but there are several items, such as garden produce, that are not included at all, which will tend to cancel the duplication. "Fruit" and "Potatoes" are taken at the value given in the Agricultural Returns, and "Fish" from those in the Statistical Abstracts.

The group "Travel" includes all kinds of conveyance of persons as distinct from goods. The $£ 30,000,000$ shown in the column "Railways" represents the probable amount of passenger traffic; the rest of the railway production shown in the squares above goes as added value to all the commodities in this and other groups that have been conveyed by rail. "Horses" represents the horses and 
vehicles, either public or private, carrying passengers. It also includes the keep for the horses and the services of the persons driving or tending the horses, which comes to a surprisingly large amount. Probably this branch of income is becoming relatively less, and that the income in the form of motor travel has greatly increased in the 12 years since the Census of Production was taken. It is also quite possible that we have somewhat over-estimated this form of income, and have included the value of some of the conveyance of goods that should have been distributed over the cost of other groups of commodities. Many of such groups of income may be under-valued owing to the want of information as to value produced in small industries and shops not included in the Census.

In each group of the goods that constitute the national income, some portion of the total is imported in the complete or nearly completed state, and sold with little additional manufacture through the retail shops. Such goods, indicated by the columns called "Imports," are seen in most of the groups and together amount to about $£ 230,000,000$. These imports are paid for by part of the production shown in the top part of the diagram; materials such as coal, cotton and woollen goods, ships, etc., and commercial and administrative service (called capital), are exported to the countries where the imports come from. These half-made goods and services would otherwise have been converted into income form in this country, or other things made instead of them. So that the imports consumed as income may be said to represent these goods produced as part of the national production, but which being exported do not come into the income shown at the foot of our diagram. The imports have replaced these productions, so that the man getting iron ore or coal for export is not producing iron or coal income for the country, but is really engaged in producing tea, dried fruit, or tobacco. These columns do not represent our whole imports, but only those that are consumed as income in nearly their imported form. The rest of the imports are used in producing other goods in this country.

These groups of finished or virtually finished production and service represented along the bottom of Diagram 2 as ready for immediate consumption as income constitute the real income on which the nation lives. It cannot live a single day on the intermediate products represented by the squares in the upper part of the diagram, so that these squares only represent groups of labour, not the wealth they are producing. The persons represented in the squares are really engaged in producing by the division of labour method the articles of wealth shown below, and the usefulness of what they make depends upon the number of articles or units of income that it results in. If the iron workers could start one day and double their output of iron, they would not be the least fraction better off unless more consumable things were made as the result of 
that increased iron production. An increase of consumable goods would no doubt result in due time from the increased production of iron, but till such time society would be no better off.

It will be seen that these groups of the various kinds of income amount to $£_{I}, S_{77}, 000,000$, or about $£ 23,000,000$ less than the total production shown in the upper part of the diagram. This is due to the social need of providing for the increasing population and future requirements. The controllers of industry having to make provision for these future needs of society, must arrange for the acquiring of capital instruments of production in advance. This means that part of the national labour during the Census year was engaged in producing some form of capital wealth such as buildings, machinery, etc., that could not all be converted into income during that year. Such capital or reserve is used up as increased production in the following years. And as in the Census year the production was probably increasing as the result of such increase of capital in previous ycars, the production of wealth is actually increasing progressively with the increasing capital. So that there should probably be very little difference indeed between the production and the income at any one time if the progressive increase could be correctly indicated on our diagrams.

The chief reason why this increase cannot show in the diagram of the year's production is that it takes the form of an increased number of goods units produced for the same labour or money value. These units of income are only represented by their total money value, either in our tables or on those of the Census or other statistics. So an increase in the number of units as the result of saving of cost, due to better capital instruments, would not alter the total money value, and would not increase the money value of the national income, though the real income in boots and things might have increased considerably. For this reason it would have been more interesting, as we have said, to have given the income part of the diagram in units of things actually used if it had been possible to do so. As this relatively small difference between production and income is only a maladjustment or lag between the increase of instruments of production and the increase of income resulting from the improved instruments, we may regard the top and bottom portions of Diagram 2 as virtually balancing.

This sketch of the national income and its production is admittedly very rough, but it is based on the best evidence that is available. There are no doubt many errors in the particular values attributed to certain industries and in the allotment of produce to the various groups of income, but the total amount of about $£ 2,000,000,000$ thus accounted for is about the same as that given by Professor Flux in the introduction to the Census of Production and accepted by other authorities. It should be clearly understood that this sum repre- 
sents absolutely the whole wealth of the country: it includes the income and virtually all the capital wealth also, so far as such wealth affects economic problems, for it is only the part of capital made use of and used up in production that enters into income, wages or profit . This point will be discussed further in the chapter on capital, but here we wish to point out that there is no evidence of any wealth existing beyond the yearly production, and the little margin of capital reserves in advance for future increase of production.

The imperfections of the sketch are largely due to the very limited scope of the Census of Production, which does not cover half the production of the country, and the want of any other complete data. This want of direct information as to net output is particularly felt in regard to small industries, transport, and shops that are all closely connected with the final or income stage of production. This renders the bottom part of our diagram very sketchy and incomplete. Nevertheless it should help us to realise that wealth consists solely in what a community can produce and consume in a given time. The concrete products of labour that are half-finished capital goods are not wealth, because they satisfy no human want, and those goods that are complete and ready to satisfy our wants as income are virtually used up the day they are finished, or at any rate start to be used and diminished in value from that time. So that the wealth can hardly be said to consist of concrete things, but is rather the potential productive capacity of the community, which capacity may be measured by the quantity of finished articles of income that flow over the counter to the consumer in a given time.

It is just this potential character of social wealth that gives it that mobile quality which enables the individual to realise his wealth just how and when he wants to, without his having to possess any concrete thing to constitute or represent his wealth. It is most desirable to try and visualise this mobile stream of potential wealth that alone renders possible the commercial system which insures that this fleeting income that vanishes as fast as it is made shall inevitably reproduce its like before it is consumed, and so perpetuate the ceaseless flow of service that supplies our wants.

Another thing that our diagram is intended to point out is that all the work of the community is equally part of the production of its income. The diagram has been made to include all work that has a price, and can therefore enter into the commercial or financial transactions of society, and become the subject of economic inquiry. The only branch of work that has been deliberately left out is that of the married woman in the home; although a vast amount of most useful work is done by them, it is work that is never exchanged, and has no price. The woman undertakes to work for her husband and family for such share of his income as they may privately agree to, and there is absolutely no competition either for her position or 
the market for her work. This class of production being altogether outside the competitive system, and never entering into exchange, it can in no way affect the economic position and may therefore be left out of our present inquiry. This in no way implies that the position of these workers is not a legitimate field of inquiry, but that it is a question of possible economic and social reform, rather than one affecting the economic principles that underlie our present commercial system. With this exception, our sketch of the national income includes the whole wealth of the nation, and it should be realised that from this fund alone must come capital, wages, profits, and all financial resources whatever.

Another important object of this sketch of national income is to express income in the form of value of actual goods and services, as they alone constitute the wealth which is measured by the money calculations in which wealth is usually expressed. For estimates, statistical, financial, and other business purposes, these calculations in money are used to represent wealth; and this leads to the common impression that money represents wealth : that there is a fund of money equal or at any rate proportionate to wealth, and that the capitalist holds either the goods or the money which represents them, and that one may be exchanged for the other. As a matter of fact, money no more represents wealth than a draper's yardstick represents his stock; the stick measures the cloth in his stock and the money measures its value. A calculation in yards may represent his stock and a calculated sum in money may represent his wealth, but one yardstick may measure all his stock and one piece of money measure all his wealth; they are standards of measurement only. Usually a draper has as many yard measures as he finds necessary to get all his measuring done as quickly and conveniently as he requires, and as many pieces of money as will conveniently measure his daily cash transactions. Of course the measurements made by a piece of money differ essentially from those made by a yard measure, and the exact nature of these money measurements, and what they really measure and represent, will be discussed fully under the subject "Prices." Money is also used rather differently from a yard measure in that it is used in small retail transactions as a token of the value that is exchanged. Like a token coin, money need not itself be valuable-paper properly stamped will answer the purpose. In any case it is only a measure and a record or account of that measure of the value exchanged. Here it is only wished to show that money is a recorded measure, but not an equivalent or duplicate form of wealth, or anything that can be converted into wealth, unless the wealth required happens to be silver or gold, and even in that case it is only metallic money that could be so converted.

It is highly important to realise that the national store of money does not represent or stand as the equivalent of wealth; but it is 
not at all easy to free the mind completely from this idea. If a workman has two sovereigns to measure his whole wealth, they not only seem to represent but actually to constitute his wealth. But as it is normally of no kind of use to him as gold, he at once spends it in food and clothing, which is real wealth to him. It might be supposed that this was a case of converting money into the wealth that it represented, yet this cannot be the case, for the people at the shops do not want gold any more than the workman did; it is not wealth to them either. They promptly take it to the bank, and the next week the workman's employer may go to that same bank for his wages cash; and it is possible that the next pay day that workman may again have those two identical sovereigns in his possession as wages. They have not been converted into wealth, could not be, they have simply been used to measure the workman's share of national income and the shopman's share and many other shares of wealth, and will go on measuring all sorts of people's wealth until they are worn out. Although this is well known to those who study economics, the ordinary convenient language that expresses wealth in terms of money is very seductive, continually allowing the notion of a secondary money wealth to creep into the argument and greatly confuse the issue. For example, in some of the above paragraphs relating to the forms in which the national income is consumed, we say the amount of the service representing income must only be the portion " that is consumed by the individual and paid for out of his private income." To pay for income out of income seems a curious confusion of ideas, yet what is wrong with the statement? In ordinary language what the individual spends is his income, and if the share of production he buys with it is not income, we must regard his money as income, and the goods he consumes as something his money represents. This seems to be the idea at the back of most economic thought, that income is a fund of money in some form that an individual possesses, which is just equal in value to the goods he will be able to purchase. As this must be true of all individuals, it follows there must be a national wealth in money that is always equal in amount to a second national wealth in goods which the money represents. This is obviously not the case, for hardly any one has his whole available income in the form of money, except in the case of wage earners who may have a week's income in their possession for an hour or so each week. And the rest part of the week that same money may be some one else's income, or more probably will lie at a bank because no one wants it. Nor does this money lie at the bank because it has been exchanged for goods which it represents. for obviously the bankers have not given goods for it. It is lying there because no one wants to measure or keep account of any value with it for the time being.

Obvious though this seems, the fact that while money is in our 
possession it does represent things that we can buy is very apt to lead the mind back to the feeling that money represents wealth, and that all wealth must be represented by a separate money value lying somewhere. To escape from this vague way of thinking of financial wealth it is essential that we think of wealth as goods and services only, and of income as these same commodities and services in the possession of the consumer and on the point of being consumed, and to regard money as a measure-token, sometimes used to indicate values of commodity produced or consumed. Then, if a man pays in gold for the share of Government and defence he desires, represented by his taxes, that gold is speedily returned to the banks again, and if in a day or two he wants a motor car, he goes to the bank for that same money again to pay for that. Or if, as is more probable, he pays in both cases by cheque, he uses and needs no money at all. What really happens is he takes out of his share of the national production so much Government service, and then a motor car of a certain value. And the amount that he has thus consumed out of his share of national production is measured by the money paid, or calculated as paid in and out of the bank. That is to say, the bank keeps an account of its client's claims upon or indebtedness to the potential productivity of the community, an account that the community can recognise as correct and reliable.

Thus we have seen that the national income or wealth of this country consists of a continuous supply of goods and services which in the year of the Census amounted to about $£ 2,000,000$, 000 value produced in that year. As the whole of this value never exists at one time either as finished goods or services, the wealth estimated at this value is really the potential productivity of the community for that year. 


\section{CHAPTER III}

\section{DIVISION OF THE NATIONAL INCOME}

HAvivg taken a fairly comprehensive view of the nature and mode of production of the national income, as it is represented by a typical year's production estimated by the Government Census, we may next proceed to an examination of how this income is divided between the various classes of consumers. This course is advisable because all economic inquiry is directed to the demonstration of the theory or laws which decided why and how this division shall be made, or the reasonableness or unreasonableness of the existing practice with regard to it. As the present inquiry has the same purpose in view, we wish to get the clearest possible knowledge of the actual methods now in practice as far as the available facts and figures will reveal them, before formulating any theory of the distribution of wealth or making any criticism of the existing method of division.

In the last chapter we found that $19,005,935$ persons were returned as taking part in producing the year's income, and it would seem that they are the only persons who have any direct claim to a share of the income they produce, as whoever else shares in the division must do so at the goodwill of those who produce it. As the above figures do not amount to half the population, there is a very large number of persons who share the country's income by the goodwill or, at any rate, the consent of those who produce it. It does not necessarily follow that all persons not returned as engaged in production have no claim to a share of income. As in the case of the married woman, they may rightly claim a share in return for actual domestic or other such work done, although that work owing to its not being exchanged has no price, and, therefore, does not enter into a commercial estimate of production or income. There are also children and aged people who have a moral claim in virtue of past or future services. But, however just their claim, it is obvious they can only get their share through and with the consent of some one who produces wealth. There is, however, still another class who, owning capital or land which they lend for productive purposes, are able to take a large share of national income without contributing to the work of production. As we have seen in the last chapter, the process of wealth production is so subdivided and complicated, and some of the services so remote, both in time and nature, from the final thing or service consumed as income, that it is by no means easy to say exactly how much any particular group of the producers have themselves made or what exact share they should own. 
Furthermore, it is open to question in some cases whether certain claimants to a share of the production have really helped in the work at all. The result of this complication and the element of doubt as to the result of commercial undertakings have led to the dividing of producers into certain financially different groups. These groups have grown up with the commercial system, and the shares of production they relatively claim are known as wages, salaries, profit, rent and interest ; and it is with the natural causes

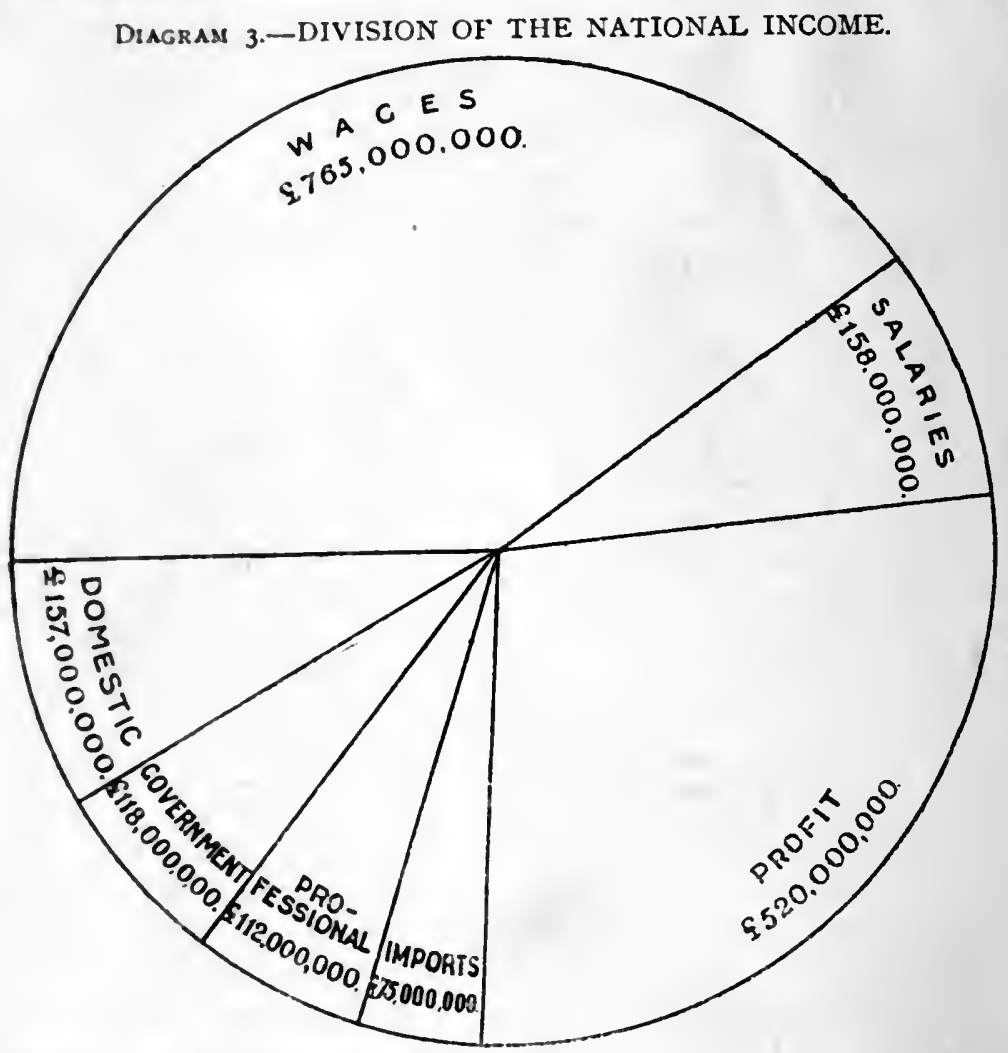

that give rise to these divisions, and the justice or otherwise of the apportionment of income to each of them, that economics is chiefly concerned. Without at present entering into any question of cause or reason of these divisions, or of their use or justice, it is our purpose here to see what proportion of the national income actually goes to each of them. Owing to the fact that many persons have to be partially included in more than one of these groups, and to the general complication of commercial relationship, it is not possible to state the actual number of individuals in each; but to facilitate an appreciation of the comparative allotment to each group; Diagram 3 has been worked out to illustrate the relative dimensions of these allotments as calculated from the following figures. 
From this diagram it will be seen that wages form the greater portion of the total income, and, therefore, merit our first attention. The $£ 765,000,000$ allotted to wages on the diagram is 53 per cent. of the total industrial production; and although at the moment we are not concerned as to why it is this particular proportion, leaving that for discussion at a later stage, we wish to point out reasonable grounds for this estimate. It is to be regretted that our Census of Production gives us no indication of the percentage of production going as wages, but for some unexplained reason no returns for wages were asked for. Fortunately, the United States has not been so reticent on the matter, and the wages have been returned

TABLE 4-SALARIES AND WAGES, UNITED STATES CENSUS.

Value of production less materials and expenses:

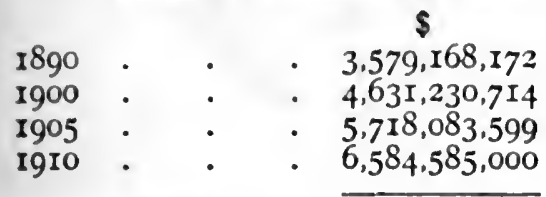

$\$$

Salaries:

$20,5 \times 3,067,485$

\begin{tabular}{|c|c|c|c|}
\hline$x 390$ & - & - & $391,988,208$ \\
\hline 1900 & . & . & $403.7 \mathrm{II,233}$ \\
\hline 905 & . & . & $609,200,25 \mathrm{I}$ \\
\hline דר & - & • & $938,575,000$ \\
\hline
\end{tabular}

Wages :

$$
2,343,474,692 \quad \text { II } \frac{1}{2} \text { per cent }
$$

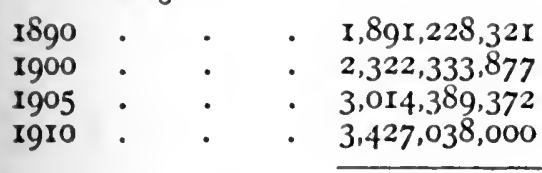

Wages and salaries

I0,654,989,570

52 per cent.

to each Census since I 850 . From these returns we are able to form an idea of the proportion of national income allotted to wages in that country, and may reasonably suppose a similar apportionment of our own production. The best American Censuses for our purpose are those from $I 890$ to $I 9 I 0$, as they give the wages paid to all the persons employed, both wage-earners and salaried persons, as well as the total value produced. And they also give the amount of miscellaneous expenses that along with the materials bought must be deducted from the gross output to get the net production. So the percentage that the wages and salaries are of the net production can be readily seen, as on Table 4 . That table forms the basis for the industrial part of Diagram 3, showing the proportion in which the total production or income is divided between the classes of workers who contribute to its production. 
But although these American figures are good evidence for the division made on Diagram 3, they cannot in that form be compared with any English wages data, because we have no official figures for the three necessary factors given in the United States Censuses; namely, the total production, the total wages, and total salaries, complete for any industry in this country. We can get the wages paid per person in some British industries (Table 7), and from another official source, the average production per person in the same industries. But as the total production includes that of certain salaried persons it cannot be taken as solely the production of the persons whose total wages we have the figures for. From the British data, therefore, we can only compare the average wage per person with the average production of all the persons employed; not as in the two previous diagrams, Nos. 3 and 4 , the total wages and total salaries with the total production. This being

TABLE 5.-AMERICAN WAGES FROM TABLE 4 ARRANGED AS PERCENTAGES OF THE AVERAGE PRODUCTION PER PERSON, TO COMPARE WITH THE ENGLISH WAGE DATA.

\begin{tabular}{|c|c|c|c|c|c|c|}
\hline $\begin{array}{l}\text { Census } \\
\text { for years }\end{array}$ & & $\begin{array}{c}\text { Wages. } \\
\$\end{array}$ & & $\begin{array}{c}\text { Production } \\
\text { per person. } \\
\$\end{array}$ & $\begin{array}{r}\text { Percentage } \\
\text { taken a }\end{array}$ & $\begin{array}{l}\text { of production } \\
\text { as wages. }\end{array}$ \\
\hline I 890 & - & 444 & $\ldots$ & 759 & $\left.5^{8}\right)$ & \\
\hline 1900 & - & 436 & ... & $8 \mathrm{I}_{3}$ & 54 & Average: \\
\hline I905 & - & 489 & ... & $85 I$ & ... & 56.7 per cent \\
\hline Íro & . & $5 \mathrm{I} 8$ & $\ldots$ & 889 & $58)$ & \\
\hline
\end{tabular}

so we want the United States figures in the same form for comparison. And for that purpose we get the American wage per person by dividing the total wages by those persons only who take wages; but to get the production per person the total production is divided by all the people employed, including the salaried persons. This arrangement shows the average wage is a larger percentage of the average production used in Table 5, and the English wage tables, than it is of the total production used on Table 4 and Diagram 3. The same data as for Table 4 is given on Table 5, showing wages as percentages of the average production.

The United States figures stated in this way show that wages at 56.7 per cent. of the average production per person is equal to wages at 52 per cent. of the total production, and in that form they can be compared with our English data.

This data forms the best basis for an estimate, but to show how similar the earlier American returns are, an attempt has been made to bring these returns into line. In them the number of salaried officials and the miscellaneous expenses are not returned, so it is necessary to estimate them. If the number of salaried officials is 
taken at one in 14 persons, and the expenses at ro per cent., the result is as the following table:-

TAMLE 6.-AMERICAN IVAGES, AS PERCENTAGES OF THE AVERAGE PRODUCTION PER PERSON.

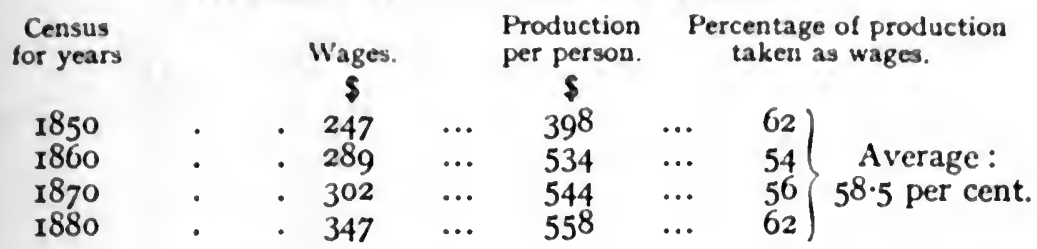

If these estimates for salaries, etc., are approximately correct it shows that 57 per cent. is a fairly safe figure to take in estimating the proportion of wages to the production per person. And forturately these estimates from American figures can to a certain extent be substantiated by figures from the United Kingdom statistics. The Board of Trade obtains a return of the wages paid in some trades, the production of which is given in the Census of Production, so that from these joint sources we can get the proportion of these wages to the production per person. As in other trades the necessary data is wanting, these are the only ones available. The average output per person for all the persons employed, is given in the following table :-

TABLR 7.-PRODUCTION IN CERTAIN AVAILABLE TRADES FROM THE CENSUS OF PRODUCTION.

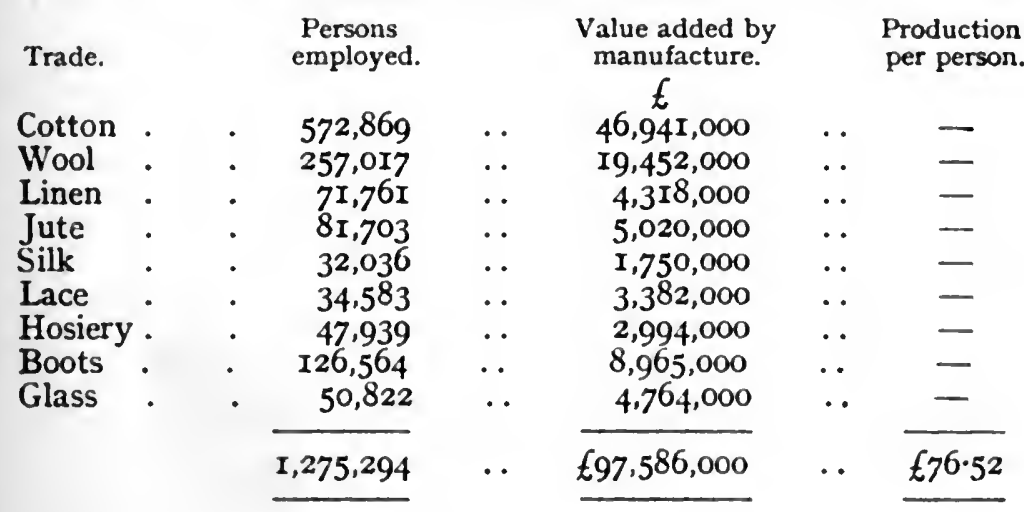

The wages returns to the Labour Gazette for these trades only cover a small part of the persons employed, but are fairly representative. They were taken for one week each month, and represent an average of 372,303 persons, or about 29 per cent. of the total number employed in the whole of these industries, and their average wage works out as on p. 52 :- 
TABle 8.-WAGES IN AVAILABLE TRADES, FROM LABOUR GAZETTE.

\begin{tabular}{|c|c|c|c|c|c|c|}
\hline $190 \%$. & Persons. & & $\begin{array}{c}\text { Wages. } \\
£\end{array}$ & & for the ye & ar. \\
\hline January & 377,127 & .. & 320,739 & $\cdots$ & $0.8_{50}^{\pi}$ & \\
\hline February & 368,673 & . & 318,287 & . & 0.863 & \\
\hline March. & 357.922 & .. & 308,918 & . : & 0.863 & \\
\hline April . & 382,643 & . & $335,32 I$ & . & 0.876 & \\
\hline May . & 379,242 & $\cdots$ & 335,682 & . & 0.885 & \\
\hline June & 371,857 & . & 322,924 & .. & 0.869 & Average \\
\hline July . & 363,509 & . & $3 \mathrm{I} 2,78 \mathrm{I}$ & . & 0.860 & $f^{0.868}$ \\
\hline August. & 371,857 & .. & 342,980 & . & 0.922 & \\
\hline September & 365,065 & . & 310,8 I 8 & . & $0.85 I$ & \\
\hline October & 378,718 & . & 326,853 & . & 0.863 & \\
\hline November & 379,878 & . & 324,359 & .. & 0.853 & \\
\hline December & 371,252 & .. & 320,340 & . & 0.863 & \\
\hline
\end{tabular}

TABLE 9.-CO-OPERATIVE WHOLESALE SOCIETY WAGES AND PRODUCTION (DISTRIBUTIVE AND PRODUCTIVE).

\begin{tabular}{|c|c|c|c|c|c|c|}
\hline Year. & Wages. & Profit. & Persons. & $\begin{array}{c}\text { Annual } \\
\text { Wage. }\end{array}$ & $\begin{array}{c}\text { Pro- } \\
\text { duction. }\end{array}$ & $\begin{array}{l}\text { Per } \\
\text { cent. }\end{array}$ \\
\hline I 898 Dis. & $\underset{I I 7,480}{£}$ & $\underset{219,659}{£}$ & 1,602 & $£$ & 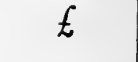 & \\
\hline Pro. & 266,493 & 49,469 & 5,955 & $50 \cdot 8$ & $86 \cdot 4$ & $60 \cdot 0$ \\
\hline I 899 & I 28,393 & 258,206 & $I, 724$ & & & \\
\hline & 356,447 & $68, I 53$ & 7,382 & $53 \cdot 2$ & $89 \cdot 0$ & $59 \cdot 7$ \\
\hline 1900 & $\begin{array}{l}143,390 \\
370,37 \mathrm{I}\end{array}$ & $\begin{array}{r}274,453 \\
57,635\end{array}$ & $\begin{array}{l}1,848 \\
7,462\end{array}$ & $55 \cdot I$ & $90 \cdot 8$ & $60 \cdot 6$ \\
\hline I9OI & $\begin{array}{l}\text { I } 57, \text { I93 } \\
399,594\end{array}$ & $\begin{array}{r}256, \text { I96 } \\
78,477\end{array}$ & $\begin{array}{l}2,033 \\
8, I 7 I\end{array}$ & $54 \cdot 5$ & $87 \cdot 3$ & $62 \cdot 4$ \\
\hline I9O2 & $\begin{array}{l}\text { I65, I96 } \\
446,371\end{array}$ & $\begin{array}{r}298,376 \\
87,571\end{array}$ & $\begin{array}{l}2,130 \\
9,139\end{array}$ & $54 \cdot 2$ & $88 \cdot 5$ & $6 r \cdot 3$ \\
\hline I903 & $\begin{array}{l}\text { I } 73, \text { I39 } \\
469,457 \\
185,486\end{array}$ & $\begin{array}{r}264,376 \\
85,384\end{array}$ & $\begin{array}{l}2, \text { II9 } \\
9,745\end{array}$ & $54 \cdot I$ & $83 \cdot 6$ & $64 \% 7$ \\
\hline I904 & $\begin{array}{l}I 85,486 \\
483,943 \\
\text { I } 93,530\end{array}$ & $\begin{array}{r}291,064 \\
97,936 \\
268,420\end{array}$ & $\begin{array}{l}2,196 \\
9,973 \\
2,246\end{array}$ & $55^{\circ} \mathrm{O}$ & $86 \cdot 9$ & $63 \cdot 2$ \\
\hline $\begin{array}{l}1905 \\
1906\end{array}$ & $\begin{array}{l}525,398 \\
206,531\end{array}$ & $\begin{array}{l}102,142 \\
369,012\end{array}$ & $\begin{array}{r}10,509 \\
2,300\end{array}$ & $56 \cdot 3$ & 85.4 & $65 \cdot 9$ \\
\hline 1907 & $\begin{array}{l}544,268 \\
228,647\end{array}$ & $\begin{array}{l}\text { II } 2,074 \\
440,361\end{array}$ & $\begin{array}{r}\text { II,I30 } \\
2,367\end{array}$ & $55^{\circ} 9$ & $9 I \cdot 7$ & $60 \cdot 9$ \\
\hline 1908 & $\begin{array}{l}674,037 \\
242,894\end{array}$ & $\begin{array}{l}120,255 \\
380,084\end{array}$ & $\begin{array}{r}12, \text { I I } 5 \\
2,438\end{array}$ & $58 \cdot 5$ & IOI.O & $58 \cdot 4$ \\
\hline Igog & $\begin{array}{l}723,015 \\
253,926\end{array}$ & $\begin{array}{r}67,562 \\
431,622\end{array}$ & $\begin{array}{r}\text { I } 2,953 \\
2,497\end{array}$ & $62 \cdot 7$ & $9 \mathrm{I} \cdot 8$ & $68 \cdot 2$ \\
\hline & 705,965 & 200,310 & I 2,938 & $62 \cdot 2$ & I03·I & $60 \cdot 2$ \\
\hline I9IO & $\begin{array}{l}265,745 \\
739,798\end{array}$ & $\begin{array}{l}404,981 \\
143,767\end{array}$ & $\begin{array}{r}2,635 \\
I 3,330\end{array}$ & $62 \cdot 9$ & & 646 \\
\hline IgII & $\begin{array}{l}739,798 \\
277,252\end{array}$ & $\begin{array}{l}143.767 \\
469,455\end{array}$ & 2,693 & $02 \cdot 9$ & $97 \cdot 3$ & 04.0 \\
\hline 1912 & $\begin{array}{l}764,393 \\
296,637\end{array}$ & $\begin{array}{l}203,102 \\
498,248\end{array}$ & $\begin{array}{r}14,073 \\
2,858\end{array}$ & $62 \cdot I$ & IO2:2 & $60 \cdot 7$ \\
\hline IgI3 & $\begin{array}{l}830,458 \\
308,278\end{array}$ & $\begin{array}{l}210,4 \text { I9 } \\
548,325\end{array}$ & $\begin{array}{r}14,915 \\
3,003\end{array}$ & $63 \cdot 4$ & I03.3 & $6 I \cdot 3$ \\
\hline & 885,395 & I 87,221 & I 5,787 & $\begin{array}{c}63.5 \\
\text { Average }\end{array}$ & ${ }^{102 \cdot 6}$. & $\begin{array}{l}6 \mathrm{I} \cdot 8 \\
62 \cdot I\end{array}$ \\
\hline
\end{tabular}


This average wage of $£ 0.868$ per week, for 50 weeks, that is, allowing two weeks' holiday, works out at $£ 43.40$ for the year, which is 56.7 per cent. of the $£ 76.52$ production shown in Table 7 for these trades, and very distinctly confirms the result obtained from the U.S.A. Census figures.

The only other information for this country that we have been able to trace is the wages and salaries of the Wholesale Co-operative Society, as published in the Seventeenth Abstract of Labour Statistics. The difficulty in these returns is to fix the actual amount of the production per person, as on the productive side the profits are very small and the wages high. If, however, the distributive side is examined, the reverse is the case ; the wages being very low and the profits very high. When the two sides are added together (Table 9) wages and salaries work out at 62 per cent. of the total production for the 16 years. This is very near the 63 per cent. shown on Table 4, and the 64 per cent. on Table II; and therefore it is probable that wages alone for this Society would be about 56.7 per cent. of the average production per person shown on Table 5 , or its equivalent 52 or 53 per cent. of the total production.

From the figures given it is quite reasonable to conclude that 57 per cent. is a safe figure to take as a basis for calculating the proportion of the production that goes to the workers. This figure is still further confirmed by the following table showing the wages of coal miners in France and Germany. The annual production is obtained from the White Paper Coal Tables, and reduced by $13 \frac{1}{2}$ per cent. to cover the cost of materials used, which is the same proportion as for coal mining in England. The average wage is obtained from the various Abstracts of Foreign Labour Statistics, but as these returns are made for various districts and for different classes of work the numbers have to be added together and the average taken for the whole to get the average per person used in Table Io.

The average wage for the miners in Prussia seems to be slightly higher than in other countries, which is probably accounted for by some little difference in the method of taking the returns rather than by any real difference in the proportion of wages. A slight variation in the cost of materials used might easily make I per cent. difference, and the inclusion of more officials as wage-earners may also be a factor in making the percentage of wages rather higher.

These figures are all too scanty, and the method of getting them returned to the various departments that collect them leaves room for improvement, both as to exactness and certainty as to just what they do or do not include. Nevertheless, such crrors usually tend to counterbalance each other, and, at any rate, the figures are all from recognised official sources, and as far as they go should be good evidence of the approximate proportion of wages to the production 
per person. And these figures are in substantial agreement with the estimate by Dr. Bowley in his "Division of the Product of Industry."

There is still less evidence obtainable with regard to the share

TABle 10.-WAGES OF COAL MINERS.

\begin{tabular}{|c|c|c|c|c|c|c|}
\hline \multicolumn{4}{|c|}{ FraNCE. } & \multicolumn{3}{|c|}{ Prussia. } \\
\hline lear. & $\begin{array}{c}\text { Production } \\
\text { less i } 3 \frac{1}{\text { p per }} \\
\text { cent. }\end{array}$ & Wages. & $\begin{array}{c}\text { Percentage } \\
\text { of } \\
\text { production. }\end{array}$ & $\begin{array}{l}\text { Production, } \\
\text { less r } 3 \frac{1}{2} \text { per } \\
\text { cent. }\end{array}$ & Wages. & $\begin{array}{l}\text { Percentage } \\
\text { of } \\
\text { production. }\end{array}$ \\
\hline $\begin{array}{r}1883 \\
4 \\
5 \\
6 \\
7 \\
8 \\
9 \\
1890 \\
1 \\
2 \\
3 \\
4 \\
5 \\
6 \\
7 \\
8 \\
9 \\
1900 \\
1 \\
2 \\
3 \\
4 \\
5 \\
6 \\
7 \\
8 \\
9 \\
1910\end{array}$ & $\begin{array}{r}£ \\
82 \\
78 \\
79 \\
75 \\
76 \\
77 \\
79 \\
89 \\
91 \\
85 \\
77 \\
79 \\
78 \\
79 \\
80 \\
85 \\
92 \\
107 \\
106 \\
91 \\
100 \\
90 \\
90 \\
91 \\
101\end{array}$ & $\begin{array}{c}f \\
45 \\
44 \\
39 \\
40 \\
43 \\
43 \\
45 \\
48 \\
48 \\
49 \\
46 \\
47 \\
46 \\
47 \\
48 \\
49 \\
50 \\
53 \\
56 \\
49 \\
54 \\
52 \\
54 \\
54 \\
56\end{array}$ & $\begin{array}{l}55 \\
56 \\
49 \\
53 \\
56 \\
56 \\
57 \\
54 \\
53 \\
58 \\
59 \\
59 \\
59 \\
59 \\
60 \\
58 \\
54 \\
50 \\
53 \\
54 \\
54 \\
58 \\
60 \\
59 \\
55\end{array}$ & $\begin{array}{r}E \\
E \\
- \\
- \\
- \\
- \\
- \\
- \\
- \\
- \\
- \\
- \\
- \\
- \\
88 \\
86 \\
90 \\
100 \\
94 \\
88 \\
90 \\
89 \\
82 \\
102 \\
108 \\
110 \\
107 \\
106\end{array}$ & $\begin{array}{l}E \\
Z \\
- \\
- \\
- \\
- \\
- \\
- \\
- \\
- \\
- \\
- \\
50 \\
50 \\
52 \\
55 \\
59 \\
55 \\
51 \\
54 \\
54 \\
53 \\
61 \\
68 \\
65 \\
60 \\
61\end{array}$ & $\begin{array}{l}- \\
- \\
- \\
- \\
- \\
- \\
- \\
- \\
- \\
- \\
- \\
- \\
- \\
57 \\
60 \\
61 \\
59 \\
60 \\
60 \\
64 \\
60 \\
64 \\
60 \\
63 \\
59 \\
56 \\
57\end{array}$ \\
\hline \multicolumn{4}{|c|}{ Average proportion of production : 56} & - & & 59 \\
\hline
\end{tabular}

of production going as salaries, the various Censuses taken in the United States, and cited above, are the only official sources of information on the subject. The division into salaries and wages, however, is a very vague and unsatisfactory one; and for most economic purposes it is more useful to include salaries under the 
title wages to distinguish the remuneration of all those persons who receive a prearranged sum of the total value produced from those who take the residual share distinguished as profit. So that perhaps the American Census data is sufficient evidence for the II $\frac{1}{2}$ per cent. of the total production shown on Diagram 3.

The following table gives the figures for the U.S. Censuses from I890 to 1910, showing that the proportion of production going to wages and salaries is 64 per cent. In this table the figures for production and wages are exactly the same as those on Table 5 . but the salaries are added, and the wages and salaries together are divided by the same number of persons as the total production. So the resulting 64 per cent. agrees with the total percentage of wages and salaries on Table 4. The fact that the American data when arranged as production per person agrees within $\frac{1}{2}$ per cent. with the same data stated in the total amounts of each proportion as on Table 4, shows that our English data that have to be arranged on the production per person method is correctly comparable with the American, and that this average production per person method is a sound means of comparing any such data.

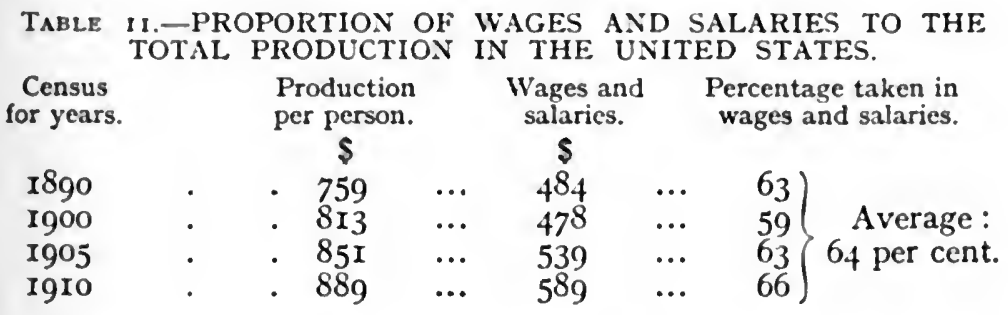

As such American and English wages and salaries figures as we can get seem to show that the share of wages and salaries together is approximately 64 per cent. of the total production, there is obviously 36 per cent. of the production left to cover profits, interest, and rent, which for the purpose of this chapter we are grouping together under the title "profits." As this division between the shares of production going as profits and wages is the chief question round which economic discussion centres, it is important to notice that such English data as we have and the good evidence of the United States Census show that the shares going as profits and wages have been very constantly about 36 and 64 per cent. respectively. And this division of production will become significant as our theory of profit and wages is developed in the following chapters.

As the above conclusion that profits average 36 per cent. of the production rests upon somewhat scanty evidence, we may attempt to support the conclusion by data from quite a different source; to show at any rate that there is not any very serious discrepancy between the two lines of investigation. Virtually all persons whose 
income is derived from salaries or profits make returns to the Income Tax Department so that incomes that come under review of that department will virtually represent the nation's income which is not actually wages. In the last chapter we saw that the whole national incorne was nearly $£ 2,000,000,000$. If the whole of this was subject to the industrial division into wages, salaries, and profits, 47 per cent. of it (that is 36 per cent. profit and II per cent. salaries) would represent the income of persons paying Income Tax; and the other 53 per cent. would represent income of wage-earners, whose incomes (pre-war) do not come under the review of the department. In that case 47 per cent. of the total national income should approximately equal the national income shown by the Income Tax returns. But as may be seen from Diagram 3, part of the national income is from professional work, etc., which cannot be said to be either wages or profits, or divisible into such denominations. The value produced, or income from these industries, can be seen on Diagram 2, and was obtained from the various official sources mentioned in the last chapter. But before they can be compared with the Inland Revenue estimates of income, those classes of incomes that are not likely to pay tax must as far as possible be separated from those that are taxable, in the way that is adopted on Table I2.

On Table 12, excess of imports over exports ("Imports" on Diagrams 2 and 3) is all profits subject to Income Tax. "Professional " is income of professional persons, and cannot properly be called either wages or profits; but is subject to tax and is called "Earnings" on the table. Government officials' income is also "Earnings " subject to tax. Both these " Earnings " are industries which include a few wage earners whose incomes are not taxed, and therefore contribute rather less taxable income than we estimate; and this is especially the case with "Government" servants. But as Government service is largely employed in improving property, locally or generally, there is probably a profit made on their work, which goes as increased rent of houses, etc. And thus it contributes to the landlord's or building industries taxable income rather more than we estimated; and such profit is not included in the output of "Government." So the two errors will about balance each other and the whole production from these industries may be taken as taxable income without sensibly disturbing the result on Table I2. "Domestic" service represents wages only, and income not subject to tax.

There remains the part of Diagram 3 that represents the industrial portion of the national income, which totals $£^{1}, 443,000,000$. This is divided on Table 12, into 53 per cent. for wages, that is, $£ 765,000,000$, not subject to Income Tax; and 47 per cent. for salarics and profits that are income subject to tax. The table then represents the whole national income, and if the II per cent. for 
salaries that is $£ 158,000,000$; and 36 per cent. $=£ 520,000,000$ for profits, are about the actual amount of production that goes to

TARLE 12.-NATIONAL INCOME.

\begin{tabular}{|c|c|c|c|c|c|}
\hline \multicolumn{2}{|c|}{ Not subject to income tax. } & \multicolumn{4}{|c|}{ Subject to income tax. } \\
\hline Income from & Wages. & Salaries. & Earnings. & Profits. & Total. \\
\hline $\begin{array}{l}\text { Imports } \\
\text { Professional: } \\
\text { Government : } \\
\text { Domestic } \\
\text { Industrial : } \\
53 \text { per cent. . } \\
\text { il . } \\
36 \quad \text { ". }\end{array}$ & $\begin{array}{c}\text { - } \\
\text { - } \\
757,000,000 \\
765,000,000 \\
=\end{array}$ & $\begin{array}{c}- \\
- \\
- \\
158,000,000\end{array}$ & $\begin{array}{c}- \\
112,000,000 \\
118,000,000 \\
- \\
- \\
-\end{array}$ & $\begin{array}{c}75,000,000 \\
= \\
- \\
= \\
520,000,000\end{array}$ & $\begin{array}{l}- \\
- \\
- \\
-\end{array}$ \\
\hline & - & $158,000,000$ & $230,000,000$ & $595,000,000$ & $983,000,000$ \\
\hline
\end{tabular}

these shares; the total "Salaries," "Earnings" and "Profits," which come to $£ 983,000,000$ on Table I2, should be about equal to the total income estimated from the Income Tax returns shown on Table I3.

TABLE 13.-GROSS AMOUNT OF INCOME BROUGHT UNDER REVIEW OF THE INLAND REVENUE DEPARTMENT FOR PURPOSES OF INCOME TAX FOR 1907-08.

SCHEdUle A :

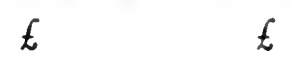

$$
\begin{aligned}
& \text { Land . . . . . 52,000,000 } \\
& \text { Houses . . . . . . } 214,000,000 \\
& \text { Property . . . . . . I,000,000 } \\
& \text { Farms . . . . . . } 17,000,000
\end{aligned}
$$

SCHEDUle C :

$284,000,000$

$$
\begin{aligned}
& \text { Government securities } \\
& \text { Business . . . . . . 393,000,000 } \\
& \text { Railways, mines, etc. . . . 84,000,000 } \\
& \text { Coupons, etc. . . . . . } 29,000,000 \\
& \begin{array}{l}
\text { Foreign securities: } \\
\text { Railways, etc. . . . . . } 38,000,000
\end{array} \\
& \text { Government . . . . . 24,000,000 }
\end{aligned}
$$$$
48,000,000
$$

SCHEDULE E :

Corporation and Government officials .

Table I3, shows the gross amount of income brought under review of the Inland Revenue Department, for purposes of Income Tax for $1907-8$, as represented in the Sixty-third Statistical Abstracts. 
It will be seen that the total income from profits, rent, etc., estimated from the Income $T a x$ is $£ 980,000,000$, which is only very little less than we estimated it to be on Table I2, by taking it at 47 per cent. of the industrial production plus " Imports," " Professional," etc. The popular impression no doubt will be that the income admitted to the revenue authorities should be a good deal less than the actual income from profits on the national production. And it probably is in practice, for it should be noticed that the above is the gross estimate of taxable income, and may include some property from which no actual income develops. Certainly the net value of income on which tax was actually paid in that year was remarkably less, only being $£ 671,000,000$. But probably the true income of the taxpayers from profits, etc., is much nearer the above gross figure, and cannot be far from our figures on Diagram 3. On the whole this seems to us good evidence that II per cent. for salaries and 36 per cent. for profits is about the actual amount of the industrial production that goes to these shares. The most important figures on this diagram of the division of the year's income (Diagram 3) are those of wages and profits, as the question of the apportionment of these shares of the production forms the greater part of economic discussion. And it is somewhat a departure from traditional usage to regard them as ascertainable amounts recorded by ordinary Government returns. While the figures are admittedly scanty there seems no reason why they should not be approximately correct, and they certainly show that the proportion of wages to profit might be cleared of all doubt if adequate returns with regard to wages were made by the Census or other Government investigations. It will be noticed that in these tables relating to profit, and also in Diagram 3 , profit includes interest and rent ; the subdivision into profit and rent will be discussed in a later chapter when the causes that govern these divisions have been considered. It remains only to reiterate what seems the important conclusion arrived at from this survey of the production and its division, namely, that these apportionments of wages, profits, rent, professional earnings, or any other income, are all simply divisions of the yearly national production, and must be integral parts of it. Being part of the produce, any share of it as rent, interest, or income, must consist of the goods produced; and any accurnulation or saving of income must be in the form of this produce, and be thought of as things, and not simply as money or funds. The necessity of a concrete conception of these shares of income will be obvious in connection with the discussion of capital in the next chapter. 


\section{CHAPTER IV}

\section{CAPITAL}

IT would seem that to complete our survey of the existing institutions for the production and distribution of wealth on the statistical method we have been pursuing, it is necessary to give some data in figures to indicate the amount of the national capital. But a study of the estimates of capital wealth reveal the fact that the figures in this case are both less reliable and less important than those related to production. That the total value of national capital is difficult to estimate is evidenced by the great difference in the results arrived at by different authorities. The capital of the ordinary business, joint stock, or other company seems such a very definite thing, and the capitalist wields such definite power, that it is difficult to imagine there can be any uncertainty as to the volume of the whole; yet the published figures vary from as low as $£ 9,000,000,000$ to as high as $£^{1} 4,000,000,000$. The usual method of calculating capital wealth is to fix upon a multiplier that represents the probable average rate of interest and profit, and multiply the yearly incomes of the nation as shown by the Income Tax returns by that multiplier, to get the amount of capital from which the yearly income is derived. The method used to obtain the following figures does not claim to be very much more correct, but is more in accordance with our general method of citing actual recorded amounts as far as possible; a method that should give correct results if such available data were adequate.

In our Census of Production no returns of capital employed were obtained, but in the U.S.A. Census the capital employed in industry is given. The figures in the various American Censuses from 1850 show a steady increase of capital per person from a sum just above the annual production per person employed to nearly three times the annual production. These returns do not appear to be very exact, as the Census authorities have at times changed the basis of their returns and modified their published results in the tables given for comparison in the Censuses of subsequent years, which makes it difficult to extract the most correct results. Nevertheless, these Government returns should be more reliable than elaborate general estimates and on p. 60 we give a somewhat abridged table of production and capital from those Censuses. 


\begin{tabular}{|c|c|c|c|c|c|c|}
\hline TABLE & 15. $-\mathrm{CA}$ & ITAL EMPI & OYED & PER PEF & SON & IN U.S.A. \\
\hline Year. & & $\begin{array}{c}\text { Production } \\
\text { per person. } \\
\$\end{array}$ & & $\begin{array}{c}\text { Capital } \\
\text { per person. } \\
\$\end{array}$ & & $\begin{array}{l}\text { rtion of capital } \\
\text { he production. }\end{array}$ \\
\hline I 850 & - & · 398 & - & 520 & $\cdots$ & $I \cdot 307$ \\
\hline ISgo & . & . 759 & . & 1,384 & .. & I. 823 \\
\hline 1900 & . & - $8 I_{3}$ & . & $I, 72 I$ & .. & $2 \cdot I I 6$ \\
\hline 1905 & . & $85 I$ & . & 2,064 & . & $2 \cdot 425$ \\
\hline 1910 & . & 889 & $\ldots$ & 2,488 & . & $2 \cdot 798$ \\
\hline 1915 & . & . 955 & . & 2,849 & $\cdots$ & $2 \cdot 983$ \\
\hline
\end{tabular}

It will be seen that according to the latest Census in America the capital employed per person was nearly three times the value of the production. So, failing other data, we may suppose the proportions about the same in this country. But before applying this estimate to the total $19,005,935$ persons engaged in our industry, we have to deduct those persons who use no capital, and also those whose proportion of capital is estimated from other data. These industries taken from our Table I are :-

Gas, water, and electricity, Employing $128, \mathbf{I} 62$ persons.

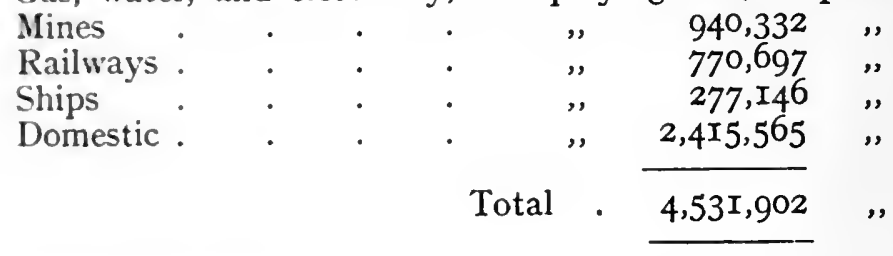

Deducting these persons from the I9,005,935 persons employed in the total annual production of this country, leaves $14,474,033$ persons whose share of capital not being separately recorded must be taken at the U.S.A. average. The United States Census only includes the industrial part of production, so that there are several groups from our national production diagram, such as "Professional," "Government," etc., which do not employ so much capital, but taking one with another, the estimate will be about correct if instead of three we take two and a half times the production per person as the capital employed per person. We may then estimate the national capital as on p. 61 .

This 10,500 millions represents roughly the capital wealth as it is generally supposed to exist, and this figure is similar to that of other writers who have estimated it wholly from the Income Tax returns. But to this total of capital there might be added a large amount for such unpriced capital as roads, streets, public buildings and parks, ctc., which it seems have to be left out of the estimates owing to the fact that they are not usually bought and sold, and therefore have no price in money by which they can be represented in an estimate of capital. Yet much work in alteration, construction and repairs is carried out upon them, and is part of the national production, 
and is included as part of the various groups of industry in our Diagram 2. For example, railways and roads run side by sicle all over the country, and the road is just as important to industry as the railway; yet while the latter is capital wealth the roads are left out simply because they have no exchange price. As roads are of such real value to agricultural, or in fact any other districts, it would seem as if they must be included as capital in any reasonable estimate. But if roads and streets are capital, why not public parks, forests and Crown and common lands? It is obviously very difficult to draw a line between capital and natural resources in some cases. For instance, we have in the following table taken land as representing

TABle 16.-ESTIMATED Capital.

At approximately the same rate as in U.S.A.

From U.S.A. Mining Report for 19 10 at 3.639 times the amount produced per person. Total for.

Published in the Statistical Abstracts

At the cost per ton given in the Census of Production

Income returned to the Inland Revenue at 20 years' purchase.

Income returned as inhabited house duty at 20 years' purchase .

Income returns from Inland Revenue at 20 years' purchase .

Gas, water and electric light from Introduction to Census of Production.

Sundries

$$
\text { Industries . }
$$

$3,575,000,000$

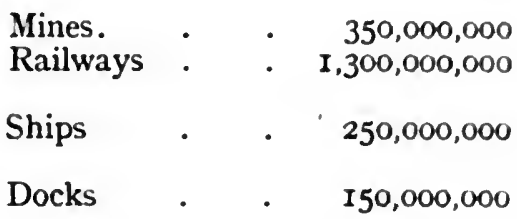

Houses . . 3,000,000,000

Land . . 1,000,000,000

Water and light. $350,000,000$ $525,000,000$

$£ 10,500,000,000$

capital. This, of course, means cultivated land, so that the question is whether it is the land, or the work done upon the land that is the capital ? Land that was drained, fenced, ploughed and then left to grow weeds would not be capital either as land or work done. From which it appears that the only work that is really capital when embodied in land, is work that results in some form of income produced from the land.

From the above considerations it appears that the total amount of possible capital is not of great importance, because the exact nature, source and limitation of what is to be called capital, in an economic sense, is a matter of some uncertainty. It is therefore of great importance to form some exact conception of the nature of capital before making estimates of its quantity or theories of its effect in social affairs. A want of definiteness as to the nature of capital seems to be the cause of much of the bewilderment that pervades modern economic writing, some of which is not intelligible 
at all to ordinary people. Therefore, it seems necessary to examine at some length the nature and place of this rather vague and fleeting element of production.

To follow up the above idea that capital is the portion of work used to produce income. Suppose capital, for instance, invested in a row of new houses: if, when they were just complete, the population of the neighbourhood fell off very much owing to closing of a mine or something of the sort, and the houses stood empty till they went to decay; they certainly would not be capital, the capital would be said to be lost. But if before they became dilapidated the mine re-opened and the houses were let for a time, then they would certainly be capital again. If again they stood empty, although they were then not capital, there would be the chance of them becoming so, and they might have some little value, might be sold. That is, some one would invest capital in them on the chance of the mine opening again, but they would not be capital till it did. They would be in the nature of a natural resource, like the original land; we might call them an "improved resource." The houses might be bought for very little and let at very low rent, thus becoming capital, but very much less capital than that which was lost. They might go on being capital and again not capital as many times as we may fancy, but would only be capital if they were used and producing income. But if this is true of houses alternately let and not let, is it not true of houses that are let practically all their existence ? They can only be used a certain amount and produce a certain amount of income in a month, or a year, whatever they may do or not do in the future. Neither future use or future income can be compressed into the present time, only the part that is used up to increase the present income is capital at the present time.

In the same way only the part of a machine that is used up in the production of income is capital. The turbine or engine at the mine that was sometimes standing idle was only capital when at work; and like the houses, even though at work all the time, can only do a certain amount in one year. It is the part of a machine used up, the wear and tear that has to be replaced by repair, that is the capital used in one year or other stated period, whatever may have been its first cost. If it cost $£ 500$ it may be said to represent $£ 500$ worth of capital, but in that case the question is how long or in what time is it capital to that value? If it is supposed to last 20 years, its capital value for any one year's estimate is $£ 25$. For a ro years' estimate, $£ 250$, or $£ 500$ for an estimate of 20 years' capital wealth. Again, $£ 500$ in gold, saved and hoarded up in a cupboard, is not capital, although it represents a definite amount of work. It is no more capital than is the same amount of gold lying in undiscovered gold mines, it only becomes capital when it goes into circulation and becomes part of the machinery of exchange employed in the 
production of wealth; and then only the part used up in a given time is capital, the rest, or the whole of it while hoarded up, is like the gold in the mine, only a resource. The mine is a natural resource, the gold coin an improved resource, though owing to its value and durability it is a much more valuable resource than empty houses or rusting engines. It is so much more valuable that it is not easy at first sight to see that it is not actually capital. But if we try to imagine starting to produce income with 500 sovereigns, it will be seen that whatever form of business or work you do with it, the first thing is that you must part with it-pay wages or buy food or machinery. That money has gone as far as its owner is concerned, and he is left with the machine or the work as his capital. The value of that capital will not depend on its cost, but upon how much income can be made by it ; that is, the amount of wages and profit it will produce.

The first point that we may realise from this conception of capital is the idea of its being something used up and not a permanent fund or stock. It is fully recognised, speaking in ordinary language, that money invested as wages in business is used up and must be reproduced by the business if the investor is to get his money back. When it is invested in machinery, it is in a more lasting and durable form, but most machinery wears out very fast, and must pay for itself before it becomes useless. Even the most durable forms of capital, such as buildings and railways, wear out and have to be kept up by continual repairs, and even then will become obsolete and useless from various causes. It is not very easy to ascertain the length of life of a dwelling-house, but a house roo years old will be looking very antiquated and unfit, unless it has had spent upon it sums for repair and alteration amounting to its original cost. A good many small country houses may last that time without having cost their original value for repairs, but a house kept up to the standard of our modern town requirements must have cost in less than roo years a sum for alterations and upkeep that amounts to virtually rebuilding it. It is probable the life of a house averages about 55 years (see Table 76 ), and that other works of construction have much the same durability. Against this durable capital we have to set those forms that are used up quickly and find the average duration, if we wish to find the length of time in which the whole wealth must be reproduced-a time that must obviously be considerably less than 55 years. Whatever time it may last, capital is nevertheless used up, and must be reproduced; and the only source of this reproduction is the annual work of production illustrated in our first diagram; from that production must come all capital. What then is the portion of the annual production that goes to make and keep up capital wealth ?

From Diagram 2 and the chapter on production we make rather an astonishing discovery, for we find the annual production to be 
roughly $£ 2,000,000,000$, and the annual consumption of income to be nearly the same; and as the comparatively small balance is destined to be consumed in the following year by the increased population, it would seem that there is nothing saved or left to replace the capital used up, much less to make an accumulation. But as we have seen that capital is something used up in production, the fact that it is used as fast as it is made does not diminish the stock as long as it is also made as fast as it is used. Economic writers have in some way given rise to the curious idea that capital is like a harvest, all gathered or saved up at one period and used at another season when otherwise there would be no capital, and then re-accumulated again at the next plentiful season. But as a matter of fact there is nothing saved or accumulated at all. The national production is absolutely continuous, capital being made as fast as it is used all the time throughout the years. From Diagram 2 it will be seen that only a small part of the coal is directly consumed as income in the year, and even that is capital ; first it is part of the capital of the coal and iron company who raise it, then it is the capital of the coal merchant, and lastly it is capital of the consumer as long as he has it in his cellar. Finally it is consumed, but some of the people who consume it are colliers, and while they have been consuming the coal they have been producing coal all the time, so that the capital in coal is always the same. The other consumers of coal are in like manner producing capital of many sorts, tools, buildings, clothing or food, for the miners, so that no capital diminishes. Then there is the rest and larger portion of the coal production that remains as capital rather longer, but is consumed nevertheless, as all capital must be. It is consumed in the production of capital of other sorts, in making iron, steam, gas, bricks and many other things, all of which are capital on its way to become income. In a previous chapter we have pointed out how this continuous stream of capital is passed on from one industry to another till it becomes the finished goods of the shops. The clothing and material of the shops is capital till the consumer gets it, and finally it is the consumer's capital till it is worn out. So it will be found that everything that is produced is capital, even the direct services should be so regarded; they are capital that is used up as soon as it is rendered. The domestic servant cooks a meal or makes a bed, the result being capital till the meal or bed is used. The teacher gives lessons to pupils who consume that service as it is rendered without any concrete thing to represent that service, and so it is also with many direct services. The capital used is the food, clothing, etc., of the teacher, the capital reproduced is the education given to the pupil, and the income is the education the pupil gets.

It will perhaps at first sight appear that as some of these services to not last in the capital stage for any appreciable time they cannot 
be regarded as capital, but as the production of income only that is at once consumed without giving rise to any reproduction of capital. But as we have pointed out in Chapter II. no one ever does produce a concrete thing: all labour is really service that is consumed at once. A smith who hammers a piece of hot iron into a horseshoe has produced no concrete thing-there is no more iron than he started with. The services of heating and hammering also are over and gone for ever when the iron is cold. No concrete thing has come into existence, but a value has been created in the iron that can last for a longer or shorter time, and be used up in producing, and be added to the price of things carried by the horse with the shoe. Such value will last as price till it has been used up as income by men who have reproduced a value in its place.

It is in no way necessary that all capital service should have a concrete form, a manager's ability may be part of his capital, the only essential point being that this ability has a price that shall represent it, and by which its cost can be embodied in any production that he manages. Any service that has a price is part of the cost of production, and therefore if not called capital in itself, must be taken as part of the capital employed in all other industries. It is obviously easier to regard it as direct capital service at its cost than to represent its cost as distributed over other groups. It will be seen that to regard the personal qualification of a manager, teacher or other such person as capital is to include man himself as something produced and used up as capital in producing income or national wealth. This is no new idea in economic writing, and it is, we think, quite a legitimate view, so long as the conception of capital as the part of production used as a means of producing income is kept strictly in view. Originally, man is a natural production like all his natural resources, and as such is not capital, and does not properly come under the review of economics. Only when some labour has been bestowed upon a natural resource does it become part of our wealth or have a price, and only such portion of a resource as has a price, and is used to produce income, is capital. It is the part of man's lifetime and ability used in production that is capital, the unused portion is a natural or "improved resource."

It is sometimes argued that these direct services are not capital because they do not help in the production of wealth, but simply produce income to be unproductively consumed. This view has led to the idea of productive and unproductive consumption, which seems to ascribe a productive virtue to some forms of consumption and not to others. It seems to the present writers a confusion of ideas to say that consumption is productive at all. It is true that capital is consumed in the production of goods, but it is always the process of reproduction not that of consumption that increases the value or the amount of these new goods. Still, it may be contended r.w. 
that there are direct services that are strictly devoted to giving pleasure and luxuriant refinements, as in fact there is also much production of concrete luxuries that do not contribute to or help production. We are not concerned here with any ethical question of the desirability of any particular luxuries; but we would emphatically contend that pleasure and luxuries, to say nothing of the refinement of living, of education and culture, are an important contribution to productive efficiency. The narrow idea that the only work that is productive is the production of enough food, clothing and house-room to keep man, or any class of men, in moderately good working condition till they have raised a moderately healthy family to take their place, is a notion that cannot be too strongly deprecated. Pleasure, variety and relaxation, both physical and mental, is necessary to vigorous health, and the desire and ambition to have all the comfort, self-respect, enjoyment and leisure that our civilisation affords is the great incentive to labour and energy in production. It is just the want of this stimulus of ambitious desire for new and varied forms of enjoyment that is characteristic of primitive and backward races, and just their desire for more comfort, enjoyment and interest in life that has raised the highly civilised races above them. The production of the luxuries of life is not only an aid to production, but largely the cause of productive energy and organisation, and the result of the labour in such industries is a valuable form of capital.

The object of this rather long digression is in the first place to demonstrate that capital is not an actual stock of something saved or possessed, but a continuous stream of work that consumes all it has made, and makes as much as it has consumed, and that any store that results from work but is not being consumed in the period that is being considered, is as far as that period is concerned, not capital, but an improved resource that may become capital some time or may not; in the second place to show that the whole of this stream of output or production is capital, and that income is only another phase of the same activities.

As this annual production of capital is about $£ 2,000,000$,000 worth, it will be seen that in about five and a half years the work of the country will have reproduced the whole of the $f^{10}, 500,000,000$ estimated as its capital wealth. But at the end of that time the capital and the income for the year will still be only about $\{2,000,000,000$, and all being well, a little more for the increased population. That is the real capital, the rest is only an estimate of the improved resources that will be used up as capital and reproduced as capital again in five and a half years. Some forms of improved resources will doubtless last longer than five or six years, but against this durable form of capital must be set those forms that last only a short time, or that are consumed as soon as produced. It should 
here be clearly understood that any estimate of wealth that includes the whole of the improved resources must be an estimate for the whole period of years that these resources are supposed to last, or in which they will be reproduced. That is to say, that $\ell_{1} 10,500,000,000$ represents the wealth of this country for five and a half years (see Table 16); but in any one year only part of the improved resources can be used as capital and reproduced. so $£ 2,000,000,000$ represents the material wealth for one year.

We have so far pictured capital as a continuous stream of reproductive work or a permanent organisation to produce what society wants rather than any kind of stock or fund of concrete wealth. Because to define capital as concrete goods and then write of it as "a fund" or "subsistence" or simply as "capital" without specifying what particular form of goods are meant, leads to great confusion of ideas and a vague feeling that capital is actually money in some form. An interesting evidence of the vague conceptions of capital is illustrated in a recent work on "Profit and Wages" by an American economist. Professor G. A. Kleene, after suggesting that the confusing term capital should be dropped altogether, goes on to support a form of the wages fund theory which represents capital as "subsistence maintaining labour" ("real wages"). In the argument in support of his contention he speaks of "paying capital out in wages" and "buying labour" as he buys a machine, which expressions lead the mind back to the idea of a fund of money, in spite of the repeated assurance that he intends real wages or consumers' goods. For while money wages are a familiar idea, that of an engineer having a fund or stock of ready-made clothing, bread and cheese, boots, beer and skittles, and all the rest of the things that wage-earners consume, is not familiar by any means ; nor is it very obvious that he can pay out these things. This theory seems to suppose that somewhere in the national resources there is a fund of such things that belong in various proportions to all the various capitalists and that do not belong to the wage-earners. And further that there is a mysterious period when there is no current production of such things by labour and that labour must " subsist" on the capitalists' fund till it can produce a new supply. As we have no knowledge of any such period or fund, it seems necessary to ask where and when they are. Where then is this fund of real wages? Doubtless there is a supply of such things continually produced for the national income, but is it at any time a reserve store and does it belong to the capitalist who pays wages? The wage-earners consume practically all they earn as fast as they get it, so that the ordinary goods they are paid in must be finished ready for consumption; they consist largely of food and clothing ready for use. Obviously the place to find such things is in the shops, virtually the whole stock of such things as are absolutely ready for use is found in 
the retail stores. No doubt a large proportion of the annual production passes through shops in a year, but this is not the same thing as a store to last over a period of waiting. The shopkeepers' stock is continually replenished by current production, and in the case of most of the food, the shops do not hold a week's stock in advance ; and as this is the chief thing which the capitalist is supposed to advance to the otherwise starving workers, there must be a very continuous current production of foodstuff. Economists seem to think that corn is the one thing that represents food, but wageearners do not buy corn or accept corn as wages. Corn is capital not ready for consumption, especially if it is on its way from Canada or Russia. It has to go through various processes of production and distribution before it is food, which is to say the current production of food by the workers is still going on, and in fact will go on till fresh supplies of raw foodstuff comes in. Certainly the crops being planted and the raw materials being made now will not be consumable goods for many months to come; but neither will the corn now grown or goods now partly manufactured be used or be wanted for consumption for many months.

But even if certain parts of the national productive system are supposed to serve the purpose of a store or stock, does this stock belong to the capitalists who pay wages? The assumption that all such stocks of consumable goods belong to capitalists seems to rest solely on common experience, and is regarded as self-evident. But it is quite as much a matter of experience that stocks belong strictly to certain individual capitalists and are not in any way the common property of a class. This being so, it seems that the real wages goods are the property or capital of the shopkeepers and a few warehousemen who hold stocks for the retail trade. The manufacturing capitalists, who have to pay far more in wages, have no claim upon the shopkeepers' stocks, and cannot " pay them out as wages." Yet the idea exists that in some way through the mysterious agency of money the capitalist does in practice hold these stocks. The economists in spite of their pious assurance to the contrary, always lead us back to the inevitable idea of capital as a fund of money that represents the stock in shops and warehouses. And that the store of consumable goods cannot be liberated till the shopkeeper gets some of this money from the capitalist in the form of wages and income spent in buying the shop goods. And this notion is certainly very difficult to escape from, because it seems as though when a person has produced and sold goods to some one else, and received actual money (gold) for them, it gives him a purchasing power with which he can buy back what he wants of those goods. He can buy back all those goods or part of them in a more finished state, or in fact anything else that is finished for sale. Whereas the person who has bought these goods seems to have his purchasing 
power reduced by doing so, and unless he can usefully consume the whole of them he must sell them before he can buy anything else. So the latter person holds his goods as a stock which only the person with the purchasing power can consume. But this person with the stock does not want his gold back, he cannot consume that any better than the goods. The fact is neither of them can consume either goods or gold and will not exchange them for each other. Neither can they pay real wages with them, the wage-earner cannot consume gold or capital goods; a firm cannot pay wages in its own production even if that production is bread. What all these people, including the wage-earners, want is an endless variety of products and services where and when they need them; and no stock or fund of such things exists except in the potential productivity of the community.

Gold being a commodity of great value, we are apt to suppose that its value makes every one anxious to possess it in unlimited quantities, and that it is essentially its concrete value that gives purchasing power. But as we saw in the first chapter, there is no such universal demand to possess gold, and the vast majority of goods are sold for paper acknowledgments of various kinds without the use of money or gold at all. When, as is commonly the case, goods are paid for by a cheque that is paid by the seller into his bank, it is not so obvious what is the concrete thing of value that gives the owner of the bank balance a purchasing power, or what he can in this case exchange for any goods he wants. If, for instance, a farmer sells corn to a miller who pays him a cheque for $£ 500$, and the farmer draws a cheque on his bank for $£ 500$ to pay for a motor car. What goods or concrete value does the motor car maker get in exchange for his car? He has a bank balance of $£ 500$ and the bank will give him gold to that amount, but what in that case has the bank got in exchange for their gold? They seem to part with gold freely in exchange for quite valueless paper; but it should be noticed that they will not do so unless the person drawing the cheque has a balance to his credit at their bank. So they obviously regard that balance as representing something real and equal to the gold in value.

A cheque paid into a bank is evidence of nothing but the fact that the person who draws the cheque has received goods that he is willing to pay for from the person the cheque is payable to. If again, for instance, a baker buys a froo worth of flour from a miller and pays by cheque, he gets a stock of real wealth in goods, but his wealth represented by his bank account is $£$ roo less. And the miller who is $£$ roo worse off in real wealth is credited with $£$ Ioo increase to his account, has $£ 100$ more purchasing power. If the miller then buys corn from a farmer his balance is reduced, and the farmer who has then less real wealth is credited with the $f$ roo purchasing power. 
So the bankers seem to consider that the man who has not got the real wealth has the purchasing power; but in accepting the purchaser's cheque as the origin of the purchasing power, they obviously regard the goods he holds as some sort of security for that power, and for any gold they may be called upon to provide their client with. Many large business firms do not pay any gold into the bank from one year's end to another, thougl they draw a great deal out for wages and personal use; it is true, as we have seen in a previous chapter, that this money very soon finds its way back to the bank, but is then credited to the account of the persons paying it in, and not to the bank. The cheques, bills, etc., that such a firm pays in must in the eyes of the banker represent some concrete wealth. And as all they can represent is the goods for which they were given in payment, these goods passed on as stock or capital to some one else must be the real wealth that gives the purchasing power represented by the firm's bank account. That is to say, the bank recognises that it is keeping account of an uncompleted bargain and that the goods sold have not actually been paid for in other goods or value; so that the seller has some claim upon them which he can use as purchasing power to buy part of those goods or any others. A claim that is security on which the bank can pay gold to its owner if he wants it.

This is certainly what the bank does in practice, yet it is equally certain that when a cheque has been paid for goods and accepted by the bank on which it is drawn, the bargain is complete. Neither the seller of the goods nor the bank have any imaginable claim upon those goods in any way, except that they may buy them if the owner is willing to sell. It seems that there are here two diametrically opposed facts, either of which is equally true, that the goods sold are the seller's real wealth, and that they are not his property in any sense. It seems to be this financial paradox that is the real source of all the vagueness and confusion in writers' views on capital, and that it is desirable at the risk of some mental effort to really grasp what is the true nature of this claim that gives purchasing power to an account kept simply as figures in the banker's books.

Such a claim must be upon the purchasing power of the goods or services that have been sold, because the cheques, etc., paid into the bank to make the deposit there were evidence only of payment for these goods or services, and that as they were only paid for by a cheque without value, they or other goods to that amount can be bought in return by another cheque without value. But as there is no legal or business agreement made to that effect, it remains to be seen what this claim on the purchasing power really is. A claim is not necessarily a legal one, it may be the inevitable result of the nature of things like a natural law, the outcome of circumstances that cause a claim to be binding simply because it is unavoidable. 
The claim on the purchasing power of goods sold that is retained by the seller is an inevitable one, the result of the exigencies of the commercial organisation. The first of these inevitable exigencies lies in the nature of capital which has been described above as that part of work or any result of work that is used to produce income. As it must always be of first importance to keep up an absolutely continuous supply of national income, it is obvious that the instruments of production must not be reduced by being consumed. So that it is the first essential idea of capital that it must be retained, that is replaced as fast as used; and it usually means ruin to a capitalist to consume his capital. Goods produced as capital are as a rule not of a consumable nature; but even in a case where they are in the form of consumable commodities, the person producing them makes far more than he could consume, and he cannot afford to use any great portion of them for his own consumption till he has passed enough of them on to some one else to acquire purchasing power to insure his getting the other necessities of life and business. When these goods are sold as material or tools to another producer, he makes them into another form of goods, and thus inevitably adds to their price his wages and profit. The result is that the purchasing power of the first producer will not be enough to buy the whole of what the second man has made, and the balance thus left represents the second man's purchasing power. A third man may again add his work to the cost of the goods in the finished condition and thereby get his purchasing claim upon them. The retail shopman will add to the price also, till the ultimate stock in its consumable form is worth much more than its first owner's price or purchasing claim. Each contributor to the work has added his costs to the price and can retain this amount as his claim on the purchasing power of the finished goods, simply because the owner of them must sell, and no one except those with a purchasing power can buy them. So it inevitably happens that the finished goods in the shop are of such a price that it will require the sum of all the purchasing powers of the various contributors of work to buy the whole of the finished produce.

From long experience of commercial procedure and results, bankers among other business men have come to realise that there is this inevitable law, and just because it is so inevitable, it is not made a matter of agreement, nor even thought much about or understood. But they realise that while a client has a deposit at their bank there must be goods, or, as it should be clearly understood, potential goods in some form that are not yet consumed and form part of the social capital of the community; and that these goods have a purchasing power which can buy, that is exchange for, any other goods from the current social production. In fact this claim on the social capital belongs to the bank while it is deposited with them, and they can 
buy securities with it ; that is, can give it to some one who wants a purchasing power in exchange for some security that he can give; security in the form of a potential purchasing power in fixed capital, or as we prefer to call it, an " improved resource." Money in gold is one of the various improved resources held by banks, and if a client wishes to draw his bank balance in gold he can do so. At first sight this looks as if the bank was giving away gold as well as the purchasing claims. But neither the gold nor the claim actually need belong to the bank, they have been deposited there by clients; they are in fact part of the social capital held by the bank at the discretion of the depositors. That being so, it looks as if the person drawing gold which was deposited at the bank by some one else has got his own purchasing claim and some one else's purchasing power in gold as well. But that is not really the case, for in drawing his balance from the bank he has relinquished his claim on the goods; he can no longer buy them with a valueless cheque; the " some one else" has now that power in place of his gold. This again looks as if two people had a purchasing claim in the goods, but the man with the gold will have to part with it if he buys the goods, he only exchanges one form of goods for the goods or services he wants. $\mathrm{He}$ has the power to purchase the goods; the " some one else" has the purchasing power of the goods, or any such goods as shall be produced in the place of the original goods, if they are consumed.

It appears then that when the capitalists or persons responsible for production pass goods on to others in the general productive system of the community they do retain an inevitable claim upon the purchasing power of these goods, to the amount they have contributed to their value. This current supply of capital goods and services is permanently owned by individual capitalists, because as fast as they pass it on to be consumed they, by the work they add to it, collectively reproduce it, and thus keep up the stock of goods on which they can claim their purchasing power. But to do this they must employ labour, and surrender part of their claim by doing so, for the goods so produced would inevitably belong to the labourers in part if they had not received money wages in place of their purchasing claim on the goods. So this supply of capital, which we follow other economists in calling " social capital," is in the nature of a common source of income, because every one engaged in producing it has a claim to a share of it ; but each must sell the part of his share that he does not want to get the part of the others' shares that he does want.

But while capitalists are recognised as owning all capital goods or claims thereon, it by no means follows that these goods are a fund or even a supply that can be paid out as wages. For, as we have just seen, the capitalists must actually buy part of their claim on the goods from the workers by paying wages before they can own all the 
purchasing power or capital. When the workers have spent those wages they will have practically consumed all the finished goods suitable for their consumption that are then current at the shops : so the stocks held by capital will be chiefly machinery, buildings, and luxuries out of which real wages could hardly be paid. In fact, it is a confusion of ideas to speak of real wages being paid at all, the term " real wages " refers to the real usefulness or value of the wages when they are used to buy goods and has nothing to do with what they are paid in or paid out of. And further, since the capitalists have virtually to buy part of their capital by paying wages, it seems that rather than capital maintaining the labourers during their work, it is labour that maintains the supply of capital from which real profits in goods are taken.

If capital were a fund or store used to maintain labour during the period it is at work on production that takes long to come to fruition, there should be some evidence of a diminishing of capital at such periods to be suddenly replaced when the marketing time comes. There seems to be no evidence of a periodical fluctuation in the stock of bread, meat, cheese, boots, clothing, or anything that labour need consume, nor does it seem that any person's capital wealth is reduced periodically by being used in any ordinary business; for the work done continually reproduces the capital that is used up. It may help to illustrate this process if we suppose a model colony of workers using and reproducing capital in goods in the way that is supposed to support labour. Let us suppose a number of farmers produce $£ 52,000$ worth of wheat, and at the close of the harvest have this stock as their capital, and that a miller and bakers are buying this wheat at the rate of $£ \mathrm{I}, 000$ worth a week and making it into bread, while a banker keeps account of their transactions.

When the miller buys $£ I, 000$ worth of corn from the various farmers, he employs 52 persons in his mill at about $£$ I Ios. $g d$. each per week, and their work and his profit will add to the price of the material he bought when it has become flour. The amount thus added by millers, as shown by the Census of Production, would be about $£$ I2O ; so at the end of the first week the miller's stock will be $£$ I,I20 worth of flour, new capital having been added to the original by the work that has been done. In the same way when the flour is passed on to the bakers, they will employ 208 persons making it into bread, paying about $£ I 7 s$. per person in wages, thus in wages and profit adding about $£ 420$ to the price. So the output of bread for the week will be $£ I, 540$ worth, which means that the week's work of these people has added $£ 540$ to the capital out of which sum wages can be paid without depending upon some fund advanced for that purpose. This addition to the price will be seen to be what covers each contributor's claim to the purchasing power of the goods, as discussed above. This model should further illustrate how, in spite 
of the fact that the goods produced are all consumed, actual goods still remain to cover all the claims of the various producers.

Now to complete the illustration by adding the payment of wages to our sketch of food production, it must be supposed that the process is continuous from the previous week, and it is best to start at the week-end. The farmers have their stock of wheat that they can sell to the miller at the rate of $£ \mathrm{r}, 000$ worth a week. The miller should be supposed to have $f I, 000$ worth of wheat in stock, and the bakers $£ 1.540$ worth of bread as their capital. It will be well, too, to suppose these producers have their last week's profits in hand in the form of cash; the farmers having $£ 360$ profits and rent, the miller $£ 40$ profit, and the bakers $£^{1} 40$, making the total income as cash in the hands of these persons $£ 540$. Also their workpeople will have wages in cash -5 I2 ploughmen with $£$ I $5^{s}$. each $=£ 540 ; 208$ bakers' men with $£$ I 7 s. each $=£ 280$; and 52 mill men with $£ I$ ros. $9 d$. each $=£ 80$; making together with the masters' incomes $£ I, 540$ in cash as shown in the Table 17 below.

TABLE 17.-WAGES PAID FROM CURRENT PRODUCTION. Distribution of National. Wealth on a Saturday at mid-day.

\begin{tabular}{|c|c|c|c|c|}
\hline Capital & $\begin{array}{l}\text { Farmers. } \\
\qquad \\
52,000 \\
\text { in corn }\end{array}$ & 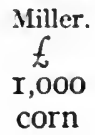 & $\begin{array}{c}\text { Bakers. } \\
£ \\
\text { r,540 } \\
\text { bread }\end{array}$ & $\begin{array}{c}\text { Workers. } \\
£\end{array}$ \\
\hline
\end{tabular}

Cash

\begin{tabular}{|c|c|c|c|c|c|}
\hline income & 360 & 40 & $\mathrm{I}_{40}$ & $I, 000$ & - \\
\hline & $£ 52,360$ & $£ x, 040$ & $£ I, 680$ & $£ I, 000$ & $=£ 56,080$ \\
\hline
\end{tabular}

This would fairly represent the ordinary condition of things at the close of the harvest, when the farmers' capital is in corn, and at midday on any Saturday when the common fund of metallic money is in the hands of the consumers as their individual capital. During that afternoon and the first day or two of the following week all that cash will have been spent at the shops, where alone "real wages" in commodities can be obtained, and by Monday night most of it will have been paid into the bank by the shopkeepers. In our illustration bread is the only consumable commodity and stands for all the things generally consumed by the public. So that by the Monday night the bakers will have taken at their shops and paid into the bank most of the cash, and by the end of the week the whole £. 540 cash will be in the bank, and the whole "real wages" in bread will have been consumed. This consuming of the previous week's produce means that $£ I, 540$ worth of bread has been converted into human energy and desire, that is, the individual's own capital which he can employ in the reproduction of another week's income. As pointed out in the last chapter, the regarding as capital the portion of human energy used up in production does not neces- 
sitate the conclusion that man himself must be regarded as capital, but only that the work and ability that he gives to the production of commercial or priced wealth should be so regarded. This is the capital with which the individual works, and constitutes what we have described as his potential productivity. Its value may be measured by what is paid for the service it produces, and it is actually the sole source of value. In our illustration this form of capital will be called "productivity."

While this consuming of bread or real wages is going on the "productivity" thereby produced is employed in the week's work. The miller and bakers will be using up their stock of wheat and flour, and will therefore require to buy more : but as they have at first no balance at the bank, they must wait till the bakers have paid in some of the cash, which they do early in the week, and soon have cash to their credit at the bank to the amount of $£ 1,120$. The miller, having made his $£ 1,000$ worth of corn and $£ 120$ worth of "productivity" (that is, the work of his men at $f 80$ value, and of himself at $£ 40$ ) into $\ell^{1,120}$ worth of four, he sells it to the bakers, who pay him a cheque, thus relinquishing their claim to the cash in the bank which now belongs to the miller. He then has to buy another week's supply of wheat from the farmers and pay a cheque for $£$ r,ooo, reducing his balance at the bank to $£ 120$. This $£ 120$ is new capital, or rather a new form of capital, and not part of or in place of the wheat used that has been replaced by the purchase of more and is in his store. The $£ 120$ is the new result of the work done by him and his workpeople at the mill during the week, and represents the "productivity" that has been consumed. It nominally belongs to the miller, but actually he has to purchase his workpeople's share of it, which he does by paying them their wages. Fifty-two persons at $\ell^{\mathrm{r}}$ ros. $9 d$. comes to about $£ 80$, so his bank balance is reduced to $£ 40$, which is his profit for the week's work. The bakers also will have produced new or changed capital to the amount of $£ 420$ over and above the original $£$ I, I2O worth of flour by adding to it $£ 420$ worth of " productivity "; this capital is in the form of bread to the gross value of $£ I, 540$. As this stock is not yet sold, the bakers could not pay wages or profits till the following week, unless they had cash from the week before. But this they have, as they have by this time paid in the rest of the $£ \mathrm{r}, 540$ and have only drawn cheques for $£$ I, I2O, leaving them a balance of $£ 420$. It is obvious in these cases that both profit and wages are paid out of the current production in the form of newly produced capital, and consumed as "real wages " and "real profits" or income in the form of current production of consumable goods from the bakers' shops. No fund of capital is used up, the miller still has his stock of wheat, the bakers their bread, and the workers the cash that will buy bread to renew their " productivity "-part of it 1 for as a matter of fact it is not quite all 
replaced, something has been used up, though it is not capital. Lifetime has been used, and the individual lifetime can never be replaced; it is the one really intrinsic thing used and gone, and it will be found that it is the thing by which alone real value, utility, or price can be measured.

When this round of work and wages is carried on to the farmers, it is not quite so obvious at first sight what work the wages are paid from. As the last year's wheat is consumed in the making of the "real wages," it seems as if they were maintained out of the last year's fund or stock of food. But the wheat is not the food, it is the current supply of bread they consume as real wages. The wheat is only capital on its way as a preliminary stage in the production of the final consumable commodity. If labour is said to be maintained or paid out of something stored as a preliminary stage in the production of " consumer's goods," we may argue that the seed from which the last year's crop of wheat was grown was the capital fund from which these wages and profits were paid, thus going back to the work of two years before. In this way we might go back to the beginning of agriculture looking for the original capital stock, a wild goose chase that simply leads us back to the natural resource to which their labour is applied and not to any concept of capital at all. The idea of wages must be confined to the actual thing handed over by the employer to his workpeople or to the things they can use as the result of what they receive, and not to the natural origin of such things.

The farmers do their work just as the miller and bakers did theirs. Only that we may limit the figures and simplify the illustration, we will suppose them to own their land and also to produce all they want for seed, manures, instruments, etc., that farmers usually buy. That is, we take their gross output instead of their net. They employ 5I2 ploughmen whose "productivity" is $f 640$; this, with their own value of $£ 360$ as managers, is capital in "productivity" worth $£ I, 000$ per week, which they employ in preparing their land for the next year's crop. As they have to produce $£ 52,000$ worth of wheat a year, they must average one fifty-second part of the work each week, so that the work of cultivation they do must result in cultivated land to the value of $£ \mathrm{I}, 000$ (see Table I8, First Friday). This $£ I, 000$ is the new form of capital made by the $£ I, 000$ worth of "productivity" used up, and this, with the cash at the bank which they received from the miller, makes the farmers' capital $£ 2,000$. But to make this capital, they have used up or allowed others to use up in the making of the "productivity," corn from their granaries to the value of $£ I, 000$. So they have to replace this by buying, as it were, or paying for a new stock in the form of cultivated land or potential wheat. They pay for this in wages, having $£ I, 000$ at the bank as the result of the current week's sale of corn, they draw $£ 640$ 
and pay their men, and have a balance of $£ 360$ as profits for the week. So here again no wages fund is used, no person's stock or capital is reduced; wages and profits have been paid, and the farmers still have their capital of $£ 52,000: 1,000$ in their land, and 51,000 still in their granaries. This production of the current wages and profits continues each week as illustrated by Table $\mathbf{r} 8$.

\section{TABle 18.-WAGES PAID FROM CURRENT PRODLCTION.}

Distribution of National Wealth on Saturday mid day.

Farmers. Miller. Bakers. Workers. Bank. Total.

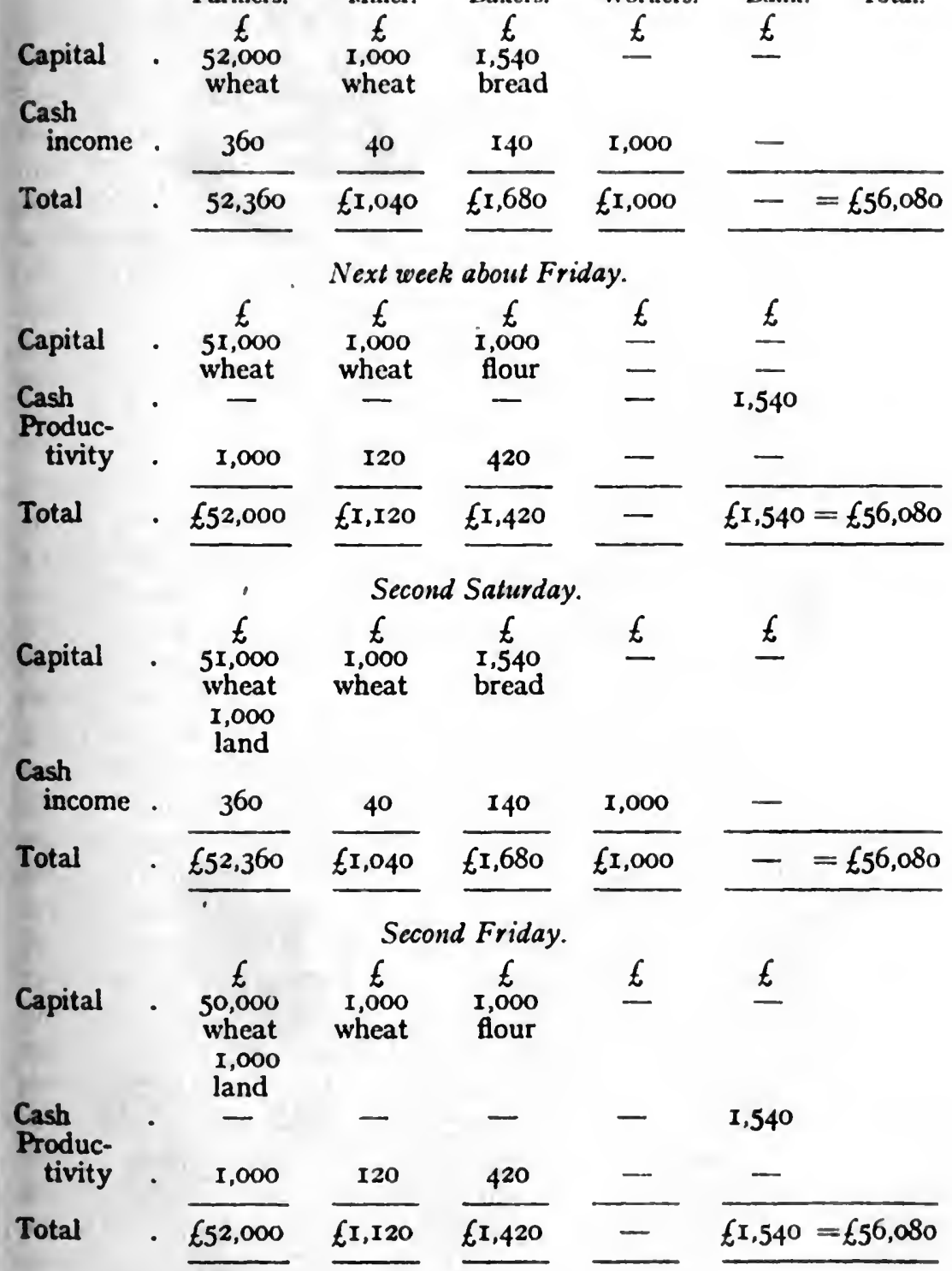




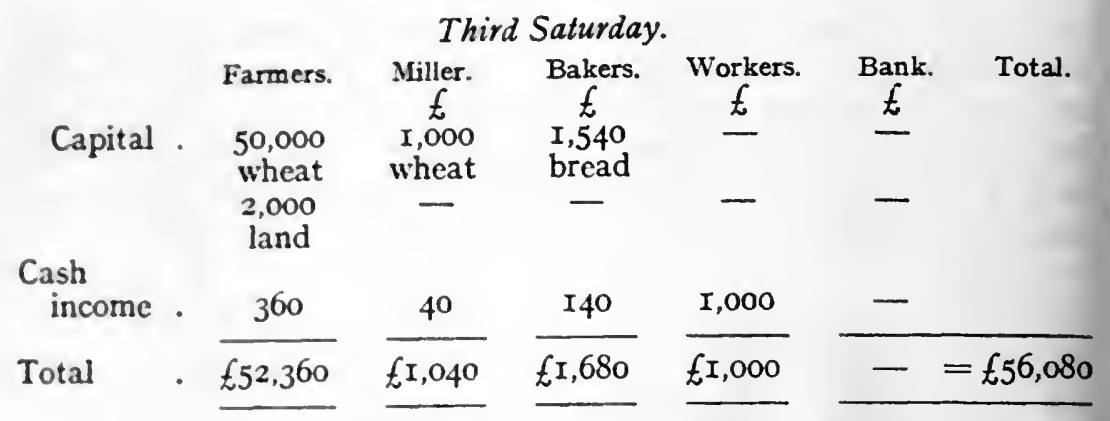

The above table shows the weekly round of production and consumption during two weeks, and it will be seen that all the capital stands at the same amount throughout ; the only change is that the wheat is changed into bread, consumed, and thus becomes human productivity, and is then reproduced as potential bread in the form of cultivated land. If the tables were continued for 52 weeks, the farmers' capital would consist less and less of wheat and more of growing wheat till it became all wheat again at the next harvest, but his capital would be $£ 52,000$ the whole time and consist of concrete value to that amount all the while also. It should be mentioned that the "Totals" in the above tables are simply the sum of the various amounts to show that they come to the same value throughout, and have no further significance.

From this illustration it seems that it is quite erroneous to suppose that capital is some fund advanced to or maintaining labour during the period that its work is coming to maturity. Workpeople engaged on making the means of production or capital usually make something that will never become food or clothing while it belongs to them, or is under their control. The farm labourer never makes anything to eat or to wear, the work he does next month or next year will be no nearer being food than this year's work. He is engaged in doing part of the current work of food production, and has just as inevitable a claim to a share of the current supply as the baker has; and neither of them can have it unless they can pay for it with their money wages that represent that claim. Moreover, the fund that maintains the workmen, whatever they may be engaged in doing, must always be a fund of consumable goods such as is only found in the current supply at shops. So much is this the case, and so obviously are consumers' goods the last form of current production, that some economists at any rate imply that such goods are not correctly capital at all. What they claim is that goods in the hands of the consumer are not capital, but if this is the case, it is hard to see why the same goods are capital while they are in the shops. If a pair of boots are not a means of production when on the feet of a workman they certainly are not so on the shelf of a shop. Or the stock of fruit in a greengrocer's shop; how is that an instrument or 
means of production? What does it produce any more than when it is in the consumer's larder? In fact, according to this claim, a ship load of fruit is not capital in the sense of a means of production or as something creating a demand for labour, unless it is to be made into jam or marmalade, and not even then if the jam is made by the consumer at home. To separate goods in the shops from goods in the hand of the consumer seems to be a defining of capital simply in deference to ordinary business language, and to imply that capital has no exact economic meaning or particular significance, which is perhaps true. But as most economists regard it as something on which the demand for labour depends, and essential to any system of production, it seems reasonable here to treat the subject at some little length and attempt to get some clear idea of why certain things should or should not be called capital.

For instance, it is usual to attach great importance to saving as the origin of capital, and the means of employing labour. But if consumers' goods are not capital, it is not quite easy to see how the consumer can save capital out of these goods which are his real income. Or if the act of saving simply consists in leaving the goods in the shops unconsumed, there seems no obvious increase of employment that could arise from that; the things would remain as capital but would not be an increase of any sort. It is the value of these goods as represented by a bank balance (money) that is usually supposed to be the capital fund that can support labour. But it seems very doubtful whether such a fund at a bank can arise simply by an act of saving, because, as we have seen, a balance at the bank seems to be associated only with goods having been passed on to the consumers and used up. If in our above illustration of food production (Table I8) we suppose the miller takes to saving, say $£$ Io a week out of his profits, thirty pounds worth of goods, represented by "bread," is what he considers absolutely necessary for his own consumption, and he proposes to save by taking $£$ Io worth less bread from the bakers. The result is that on the Saturday of our illustration he has only $£ 30$ cash income and a balance of $£$ ro left in the bank. Will this balance increase week by week as a fund available for capital? The result of this saving will be that the bakers will have $£$ Io worth of bread more than is wanted for that week and will carry it on as part of their next week's supply ; so that they will require about $£ 8$ worth less flour for that week. And further, as they have lost $£$ Io worth of custom, they must reduce their output per week, which means another $£ 8$ worth less flour on that account also, and the baker's income is reduced by this loss of trade by about $£ \mathrm{I}$ ros., and two of his men out of work, making another 5os. worth less flour wanted; so that altogether when the bakers come to pay the miller for flour the next week they will only pay him $£ I, 100$ instead of the usual $£ I, I 20$. But the saving miller will not 
expect to have to reduce his business because he is saving money, he will buy as much wheat and grind as much flour as usual, so that when he has paid $£$ r,o0o for wheat and $£ 80$ wages, his profit for the week will only be $£ 20$, and if he still considers $£ 30$ necessary for his week's income he will have to draw from the bank the $£$ Io balance he had saved, so he will not have saved money, but will have $£_{20}$ worth of flour as stock in his mill. Each week as long as he saves the bakers will only pay him $£$ I, IIo for flour, so his profits will only be $£ 30$ per week and $£$ ro worth more flour in his stock. Flour is all he will save, and at the end of the year he will have $£ 520$ worth of unused flour, and far from employing labour he will have thrown two bakers out of work who will have to emigrate from our very inelastic experimental colony.

Thus it appears that saving can only be made out of what a person makes or what he takes as income, as the miller might have saved bread in place of flour. But it cannot be made as a bank balance, as that only represents work passed on to the social capital of the community. And the stock of goods or flour cannot become capital so long as it is saved. If the miller wished to convert his useless store of flour into some form of income he must employ some one to work upon it ; and as these persons must first be fed, that would consume his flour or bread and occupy the full number of persons of our colony making bread as before. As bread in our illustration stands for all things that can be made by that number of persons, there is no possibility of other production of any sort unless it was a different kind of bread in place of what was consumed before. The miller might employ the two out-of-work bakers making bread for themselves and cake for him, but that would not be saving and there would be no more labour demanded or maintained. No more capital would be made and it should be noticed that no more is wanted so long as the population is the same and all are at work.

The only way more capital and income can be made is by an improvement in the means of production, and this must originate in more work done. If the miller by working longer hours in the organising of his business is able to run his mill with 50 men instead of 52, and he then employs the two men and part of his own time making a new kind of mechanical contrivance in his mill, he saves nothing, making and consuming just as much as before. But when he and his two men have completed their work he will have extra capital in the form of the new mechanical contrivance. If by this contrivance he can run his mill with only 47 men and grind more corn than he did before, he can increase his income by the saving in wages, and liberate five men who can work for the farmers to grow more wheat for the increased productivity of the mill. In that way the community can have more bread and the miller can eat cake as 
the result of capital in the form of extra wheat and machinery, capital created not by saving, but by work and organisation.

It is rather curious that while all economists represent the original formation of capital as work done in making instruments for hunting or tools for agriculture, indirect work to increase men's power of getting the necessities of primitive life, they seem, when arguing the economics of modern communities, to regard saving as the source of all capital. While, of course, no one would contend that anything could be saved unless it had first been made or come into existence, writers seem to attach very little importance to the work of making of capital, and great importance to the saving of it, as if the work done or goods made were not capital unless saved. From our above illustration of the production of capital in an imaginary colony it seems that it is not possible to create capital by an act of saving ; and if the same line of reasoning is applied to actual industrial processes it will be found that saving cannot produce, or make the goods produced become, capital. Tools, machines, buildings, intermediate goods or other capital cannot by their nature be consumable as income, cannot be consumed by the person who makes them; and on the other hand, consumable goods finished ready for use cannot be saved to any appreciable extent, they are highly perishable, and soon lose much by depreciation if held as stock. In common practice we do not find that the typical capitalist has great stocks of goods that are being saved; such stocks as do exist are largely in the hands of comparatively small business men who are most anxious to get rid of their goods. And if any such manufacturer has a very heavy stock of machinery and goods he will probably tell you, in the ordinary language of business, that his great difficulty is the want of capital; showing at once, both that capital is not simply a store saved, and that ordinary business language is not reliable as a means of defining capital or any other economic factor. Yet in spite of these obvious difficulties economists persist in thinking that in some mysterious way, through money and banks, capital is virtually the result of saving; and many and wonderful are the theories that are built upon this idea, some schools attributing every economic virtue to acts of saving and abstinence, while others regard saving and investment as the cause of all our woes, culminating in the vice of over-production and the still more insidious sin of underconsumption.

The impression that capital is the result of saving no doubt arises from the commonly observed fact that a person who does not consume the whole of his income does come to be possessed of capital. But to acquire the balance at a bank that represents this person's savings, he must have made, or caused to be made, goods which he has passed on to the social capital of production, his bank account showing the extent of his claim to a portion of that capital. These 
goods he has passed on are capital made by his work, and continue as such till they are consumed, but consumed by some one they must be or they are of no use to any one and not really capital. They are consumed directly or are used up gradually in the production of things which are directly consumed, but used they will be if he is to get any return from them in any way. They are not saved, but the persons using them up must first pay for them by producing capital of some kind in their place, and it is then on this new capital that the "saving person" with the bank balance has a claim. The repetition of this renewal may go on indefinitely so long as the saving person does not reduce his balance by consuming any of the social capital. As we have seen before, the bank can always find use for such unconsumed goods by lending the purchasing power they inevitably carry to some other capitalist who wants purchasing power in exchange for some security. This borrower recognises that the saving person is doing him a service by allowing him to own all the capital he makes as reproduction of the original goods without his having to refund the saving person's claim out of it. For this service he will pay him annually a percentual addition to his claim, as interest for the use of the purchasing power; this is not paid in recognition of any additional capital, but for the use of a share of the social capital transferred by one capitalist to another. There is no new social capital and no more labour employed or benefited than before, unless the second capitalist can improve the social production more than the saving person or other capitalists can do, in which case there would be a public benefit from his improved work, but not from the saving, as may be seen by the following example.

In this case we will suppose the person who has made or caused to be made goods which he has passed on to the social capital of the community, and thereby obtained a balance at the bank, proceeds to spend that balance, say, in a motor car. In what way does his case differ from the former? The goods are capital made by his work and continue as such till they are consumed, and the persons who have consumed them have produced capital of some kind in their place. But now, on this new capital, the "spending person" who has used his bank balance has no claim; he has handed over his claim on the purchasing power of the capital to the maker of the motor car. The latter will use part of it to replace the capital he used in producing the car, and the profit he may consume himself, and not save anything. There will be no more or less social capital or labour employed or benefited unless the motor car manufacturer is improving the means of producing cars, in which case there will be a public benefit as in the former case. The original goods produced are in either case the only capital involved, and they are consumed and paid for by other capital produced in their place. This process of capital reproduction goes on quite regardless of who may spend 
or save his income. The saving only determines who shall have the purchasing power existing in the ever-renewed production of social capital, and any interest paid is from one capitalist who has borrowed part of this social capital to another who has lent it, and is paid out of the borrower's profits in recognition of a convenience to him, not to the community in any way. Saving may benefit the public if it comes into the hands of an organiser who can improve the means of production ; but on the other hand, as it not unfrequently happens, if it gets invested in something that turns out a failure, it is a loss to society, not because it is consumed, but because work has been wasted in producing in its place something that is of no use.

In a case like the above, where a claim on the purchasing power of a share of the social production is passed on to some one else for goods bought, it may be at once passed on again, and that many times, without being saved by any one as his capital. But sooner or later it will inevitably fall into the hands of some one who wants to save; for as the individual's personal income depends upon the amount of goods he can produce and pass on, all producers will try to produce far more than they will actually wish to consume, and as the necessary passing on of these goods means in business language selling them, which is not always an easy matter for the producer to accomplish in a profitable manner, he must, while he is in the fortunate position of being able to do so, recognise the necessity of providing some reserve of capital against a possible time when sales might be unprofitable. In a competitive commercial system, also, an everincreasing capital is necessary in the form of machinery, organisation, etc., to enable the manufacturer to produce his goods at a saleable price; so that it very often happens that however much a tradesman may wish to spend his whole income or more, the exigencies of his business oblige him to save a large portion of income in the form of increased capital. So much is this the case, that it is not uncommon to find the owner of a thriving business that is making an ever-increasing return, obliged to use so much of that return in keeping the business up to the standard of efficiency necessitated by competition that he is short of ready money and does not save a penny out of the income he is actually able to draw from the business, though acquiring more capital every day. But this method of accumulating capital can hardly be called saving, seeing that the manufacturer spends all his income and all the returns from his business on improvements in machinery and organisation of the business, and all to the end that he may be able to get more to spend as soon as he possibly can. He waits no longer than he can help, spends all he can, and nothing is actually saved.

In other common cases persons may not find it any advantage to extend or increase the capital in their business, but although doing well may see the possibility of coming upon less prosperous times, 
and desire to save by not consuming the whole of their income. To do so we have before seen they may lend their bank balance, either through the bankers or by a direct loan to the manufacturer who is short of ready money, and the latter will consume this balance in things to increase the efficiency of his growing business and pay interest out of the returns of that business to the bank or to the man who has lent him his claim on the general stock of wealth. So again nothing is saved, but it appears that although capital is not the result of saving, the making of capital is really the means of saving, or more correctly, since nothing can be saved, a means of deferring the consumption of one's personal share; that is, by allowing others to consume your production that has been passed on to the social capital, you can retain a claim upon the general stock, to be satisfied to the amount of that claim at any future date. The possibilities of saving are limited by the fact that practically everything that man wants to save for future use is in the nature of things quite unsavable: food cannot possibly be saved for use in future years; clothing is practically unsavable for any long period; many worldly goods are so bulky that it would be very costly to store them up, and one and all deteriorate hopelessly with keeping. Houses and land are of course a recognised means of saving, but only so if they can be used when built or cultivated, as, if not, they, too, rapidly become wasted. It is not possible for any one to build houses just because they want to save for a future time; the houses must be wanted for use, must, like every other form of capital, be consumed. Therefore it is very necessary that society should provide some means of enabling persons to defer their consuming by increasing the general stock of capital and being able to draw upon it at a future time.

But as we have seen that the saving does not increase capital, it remains to be shown how the community not only comes to have a surplus of capital that the savers can draw upon, but is even willing to pay interest in addition to the original claim upon the general stock. Before a person can save or become possessed of a claim he may by his work have increased the social capital, and must at least have contributed to maintain it, or he would not have the necessary balance at the bank. We have seen above, in the suppositionary illustration of food production, how capital can be increased by any work that improves the means of production, so that the same amount of labour produces more national income. All persons who can borrow capital, that is, some one else's claim upon the national wealth, must be able or be supposed to be able to make some improvement in the means of production, by good work, invention, or organisation. A man who has found some way of greatly improving the production of steel, for instance, may not have previously produced enough capital to have a sufficiently large claim upon the 
general stock of coal, so he borrows from some one who has, and agrees to pay him interest for the use of his claim on the national production. Having got this capital, as it is called, he proceeds not to save, but to consume much more than his share of the current production of coal. If his operations are on a large enough scale he may even cause a temporary shortage of that commodity, causing the rest of the community to use less, but if by so doing he reduces the labour in making steel the community will ultimately benefit by the greater ease with which it will obtain tools and machinery. It does not follow, however, that more steel is wanted than before, and probably less coal is used in the new process of producing it ; therefore there is no extra store or production of these things arising from this new formation of capital. From what, then, does the increased income and interest come? The improvement in the production of steel means less work in making it, so that the saving in wages provides the profit and interest, but as this means a number of workmen thrown out of work there seems to be no advantage to the community, and certainly no maintenance of labour. In what, then, does the increased capital consist ?

The result of an improvement in production is always, in the first place, to cause some labour to be unemployed, and it is really this reserve of labour set at liberty for other work that is the new capital ; and there is no real advantage in the improved production unless this reserve is made use of to increase the national income. To a large extent, at any rate, this is always done, and these workers, liberated from the production of steel, are employed in making more luxuriant forms of wealth, things perhaps made as the result of the cheaper steel, bicycles and motors, for instance, and then there is an actual addition to the real wealth of the community. We are now able to see clearly that the claim which the individual gets by deferring his consumption of income is not a claim upon any store or accumulation of goods or wealth, but upon the future work of the persons whose power of production has been increased by the improvement in the method of their work. Therefore capital is actually the system or organisation of work, including all such goods, instruments and services (productivity) as are a necessary part of that organisation; and purchasing power is a claim upon the current production of that organisation.

It is significant that the first result of an improved method of production is the reduction of the persons employed in that particular trade, thus making a saving out of which profit and interest can be paid; because it thus appears that this making of extra profit is associated with unemployment, and that the concentration of capital on such improvement does not create a fund to employ labour, but enables the capitalist to reduce the employment open to labour, or at any rate to determine how much and in what direction 
labour shall be employed. Since the possibility of making this extra profit obviously depends on whether the price of the articles made by an improved process can be kept to the old rate that obtained before the improvement, it follows that the true relation of such profits to unemployment cannot be adequately discussed till we have investigated the question of price and competition. Still, it is pertinent at this stage to inquire a little further into the ordinary reason why the control of labour should come into the hands of those persons who have caused an improvement in the means of production, and through such persons into the hands of the person who has not consumed all his income; for let it be once more pointed out that the person who simply fails to consume cannot by that act obtain control of labour, unless he or some person who will use his credit can produce some improvement in the productive process.

It may seem rather incredible that every person who gets profit or interest for money has directly or indirectly caused an improvement in the means of production, distribution or exchange. But it should be understood that such improvement need not always be an invention of machinery or new process of organisation or discovery, but any form of greater efficiency in doing or organising some branch of business, greater ability, energy or foresight of any kind may constitute an improvement for the purposes of any particular branch of industry. In fact, anything that gives a particular firm a measure of business success above its competitors may be deemed an improvement and give more control of capital. It need not even be an improvement in any very exact logical or ethical sense, so long as it is deemed to be so by the public or a sufficiently large section of the public. But some such improvements there must always be, and when they are great or lasting, they distinctly increase the national income and the individual profit, giving the successful capitalist the directing control of labour and its results. Although such an improvement may reduce the number of persons engaged in an industry as a whole, it does ultimately increase the number employed in the particular business of the inventor of that improvement, and often to a very great extent when it is successful ; and it is this result that leads to the impression that such person's capital provides the means of employing much labour. But as we have seen that this organisation of labour is his capital, it is only true to say that his organised labour provides him with a large income.

In some cases the need of great capital outlay in the starting of a concern gives a very definite impression that a store of wealth is necessary to provide materials, tools and a living for those who do the work. The making of a water supply, for instance, that involves an outlay of a hundred or more thousands, gives the impression that some one possessing a great store of wealth must advance the means 
of living and working to the persons who make the dams, pipelines and engines, during the two or three years they may be at work, till the result of their labour can be brought to market, as some economists would put it. But as we have seen, in the chapter on national income, that the result of a waterworks cannot be fully brought to market under about 50 years, the maintaining of labour for that time would tax any store of wealth to extinction. But as a matter of fact, it is quite well understood that no one does provide any store of gold or goods; they provide a claim upon the national work which alone can provide the concrete goods as they are wanted. And there is no new or extra supply wanted. The men who make the dam or the engine have been consuming food and materials all their lives, maintaining themselves in the ordinary way, and no new supply of such foods is wanted just because they are starting on another job. They have not been withdrawn from the production of their own food and clothing for the purpose of making this waterworks, and thus left dependent upon some one's fund of capital ; they have never directly produced any food or clothing, nor have their fathers before them for generations back. Builders, engineers and navvies are a class of workmen who take a permanent part in the general division of labour, by which only modern production is possible. They are part of the workers who have been permanently liberated from the production of the direct necessities of life to produce the means of a more luxuriant form of production. From a study of the "Domesday Book" records, it seems probable that nearly the whole of the available labour was at that time occupied in the production of food and clothing, and only produced a very moderate supply at that; whereas, to-day, it only requires about half the supply of labour to produce these necessities. All through industrial history it is seen that a larger and larger portion of the country's labour has been set aside for the production of tools to increase productivity and for the production of more luxuriant forms of wealth. But they do not form a class that has to stand waiting for capital to employ them any more than the farmer or clothier ; they are quite as necessary to the complete system of production.

The constructors of a waterworks simply come from the part of the country where they were working last year to the place where water is wanted this year, and consume food and materials from the same source as they have always done. The only point is that the community now focuses a portion of its work of production and supply of goods at the point where these men are at work instead of at the place where they were working before. The consumers at the former place are now using and paying for water, and with their water they pay interest on the money they borrowed; that is, they relinquish their claim to some of their store of social capital and hand that claim to the capitalists from whom they borrowed. The 
capitalists in their turn use that claim by lending it to the people who now want a water supply, so the goods produced are now supplied to the same consumers at a changed address. It is the same capital, and possibly to some extent the same capitalists, but in a new combination; and it is this new combination of capital that gives the impression of a new fund of capital, subscribed to maintain the labour while doing the work, and to provide the land and materials. As we have before seen, these things already exist, or the organisation for regularly producing them is in permanent existence. But the community does not focus this regular supply of necessaries automatically at the spot and at the time when and where a supply of water happens to be wanted. Some person or persons must make themselves responsible for the distribution, use, and reproduction of the goods consumed from the social capital, and it is the organisation formed for this purpose that we wish here to examine.

To make a waterworks is to make an improvement in the means of production, and the persons making this improvement expect to obtain profit and interest from the result. Society is willing to pay such interest, on the assumption that these persons undertaking the responsibility and organisation have done work that is worth paying for. There is, as a matter of fact, much work of this kind done in connection with these large undertakings that is not commonly recognised as work belonging to them at all. In the first place, some one must make themselves responsible for the fact that the community wants and will pay for the water when produced, and for the date of the future time at which the persons whose production is improved by the advantage of such water supply will have reproduced goods to the value of those consumed in its construction. Then, in what is understood as the financing of the undertaking, there is much work which is done as a rule by the help of some large money-controlling person or firm, such as a Joint Stock Company, a Bank or Insurance Company, that has in trust innumerable claims on the social capital belonging to individual capitalists, great and small, throughout the community. These claims upon the work of the community are lent to the local organisers, and thus the supply of current goods wanted for the work is focussed at the place where the work is to be done. These financiers, who are far removed from the scene of the waterworks, are not usually thought of as taking part in that work, but are said to lend money. But what they really do in the ordinary course of their business is to collect and direct the unused claim upon production, organise the capital, and bring it to a focus where it may be consumed for the purpose of making a waterworks at this place instead of something else at another place. What they lend is their work, and it is to a great extent essential work, and interest is paid for that work. 
The financiers having done their part, the claims upon the social capital are entrusted to the local company or public authority, who contribute the local management and responsibility of employing the contractors, engineers, etc., and supplying them with funds in the form of the claims upon the current production of the community as they are wanted. And when the work is completed, this local authority or company continues to manage and direct the waterworks, and is responsible to the financiers for the interest on the borrowed claims upon social capital. This permanent responsibility carries with it the ownership of all the work when it is done, and it is this fact that gives the capitalist his peculiar position of owning all the durable instruments of production, and so becoming able to a considerable extent to determine the conditions upon which the wage-earners shall be employed and the price at which the resulting goods shall be sold when passed on to the social capital, thus fixing the amount of their claim upon the purchasing power of these goods. The precise method of carrying out this control must be left for discussion at a later stage of our inquiry; what is to be pointed out here is that their position is the result of the work of management and responsibility, and not of providing money or goods. The various workers who constructed the waterworks were part of the persons employed in the national production, and the capital in food, tools, materials and machinery was made and supplied by other workers employed in the national production. The constructors of the works use up the capital supplied by the other workers, and they in turn use up the water supplied by the constructors and staff of the waterworks; nothing whatever has been advanced to any one, each consumes only what he is deemed to have produced by his co-operation with the rest of the community.

The local authority or company has become the owners of capital, or as we prefer to call it, an improved resource in the form of a waterworks. It is not properly capital, because it has not been passed on at a price to the social capital and cannot be so passed on, except a little at a time in the form of wear and tear caused by use in supplying water. This portion used and passed on with the water is the portion of social capital on which the financiers have a claim as purchasing power or interest. This they can still continue to use as capital, organised to employ the navvies and engineers in making a waterworks or some other work of construction in some part of the country where it is now wanted.

The fact that interest is paid in recognition of work done is very much obscured by the fact that many persons receiving income from investments do not do any work in connection with the business from which the interest comes. This obscurity is due to the peculiar method by which business management is usually remunerated. In place of wages the person who takes the responsibility of organising 
a business takes as his remuneration the ownership of the business and of all the goods produced by it, making by their sale what profit he can. A man who has made a successful boot and shoe business may draw a large income from it long after he has handed over all practical working of the business to paid managers. But he is still obviously being remunerated as the owner, and for the work he is supposed to do in employing the workers and paying wages and salaries. If he should retire from the business and his successors buy him out by giving a sum of money, that is a cheque for his ownership of the business, he ceases to be remunerated as the owner of that particular business, but it will be found that he still draws remuneration as owner or part owner of some undertaking or other.

Before his successors can buy him out they must have some reserve of capital invested, or on deposit at a bank ; and as we have seen, such a deposit would be invested by the bank as a claim upon the social capital, being used in production somewhere on good security. Suppose it is being used by a seaside corporation in constructing a sea-wall and promenade, the owners of the bank deposit are in reality part owners of the works of improvement at the seaside town, and take a share of the corporation's income from those improvements. When they withdraw their balance from the bank and buy the ownership of the boot manufactory, they cease to be part employers of engineers and navvies in making sea-walls, and become employers of shoe-makers. The retiring boot manufacturer, on the contrary, when he receives the cheque from his successors and invests it in a new waterworks scheme, becomes.the employer of contractors and navvies, who having finished the sea-wall, come and construct the dam and works which, when finished, will be partly owned by him. He becomes a part owner of the waterworks and receives as such part of the profits from the supply of water; he is not a complete owner, and the share of profits he receives is a fixed sum distinguished as interest. He may leave this investment to his children or grandchildren after him, but the interest they receive will be in recognition of the work or responsibility of ownership, and not really of the loan of money, because no goods or coin was ever handed over in either case, but simply a cheque that represented a claim on the social organisation of industry.

A person holding a claim on the purchasing power of a portion of the social capital is always a part owner of the social production, a part employer of labour in that production, and can draw part of the profits of that labour as interest. If he invests his claim directly in some specific undertaking as a mine, railway, or waterworks company, he may know what particular industry he is part owner of. But if he invests through a bank or the Government he may never have the slightest idea what he owns or who he employs. Never- 
theless all income from capital comes from some form of ownership and is remuneration of an employer of labour.

These various examples of the nature, production, and use of capital are intended to help in forming a correct conception of the relation of capital to the national production, which is the source and also the substance of capital. The goods and services are all capital so long and in so far as they are used to produce income: but they all become income or are used up in causing other things to become income, and so become part of the cost of income. So the national income consists of the same goods and services as capital when those goods are on the point of being consumed; and the year's national income and the year's capital wealth are one and the same thing except that they do not exactly co-exist in time; the first part of the capital used in the current year is brought forward from the year before, and the same amount, or slightly more that is produced as capital in the current year, will be carried forward to the next, whereas the income is confined strictly to the consumption of the current year.

In addition to capital proper, there is produced each year a number of "improved resources" of very considerable value. They consist of such things as buildings, railways, mines, coin in gold and silver, machinery and innumerable other durable things which last for a number of years and can only be used in the production of a current year's income to the extent that they are used up or depreciated by being used. The fact of a manufacturer having the most up-to-date machinery in full work in his business will undoubtedly increase his year's income, but the fact that these machines will do the same amount of work again next year will not increase his income for this year; this he recognises when he only includes part of the cost of such machinery in the first year's expenses, and allows a certain number of years for the machines to pay for themselves. Most of the concrete forms of wealth that are commonly estimated as capital are of this nature, and are the things usually looked upon as security for investment and the means of deferred consumption. But we think it best to distinguish such things as "improved resources," because although they embody work done, and may have a price, they are of the nature of natural resources, in that they can only produce income as they are used.by labour in its work. They have a potential capacity of production greatly in excess of what can be utilised by the labour that can be applied to them at one time. Therefore an improved resource cannot be wholly converted into income until a considerable time has elapsed, whereas capital proper can be converted into income almost at once if enough labour is used upon it.

While this distinction is only one of degree, it is important when estimating the value or effect of capital in a certain period of time. 
For instance, the making of these improved resources is not an increase of the national income or wealth for the time being, and may, when done in excess, mean that the community has to some extent to forego or postpone part of its consumption, that it may be able to produce more income in the future as the result of the improved production due to this new resource. But as each year, while the community is producing such improved resources, it is benefiting from the improved resources of previous years, it is very doubtful whether there is ever any actual abstaining from consumption. More probably there is a steady increase in the national income, and certainly far more than if improved resources had never been made. On the other hand, some improved resources turn out to be no improvement in the means of production, and then the labour spent upon them is wasted, and there is an actual loss to the community. It is owing to failures of this sort that the claims of individual investors upon the social capital do not increase indefinitely.

There is another kind of national capital that is rather intermediate in character between an improved resource and capital proper which we have not so far included in our review of the subject because it has no price and so cannot be included in an estimate of capital value. Such work as that of persons on allotments, gardens and orchards is undoubtedly in the nature of capital, as is also the work of the married woman in the home, as we have before mentioned. This sort of work is capital in that it produces income and helps to produce human productivity; but as it has no price, it does not enter into social capital as part of the purchasing power. It is rather in the nature of an improved resource upon which its owner can work and produce income, independently of the general distribution and exchange of the community. It may, however, enter at times as a factor of competition into capitalistic production, so cannot be altogether left out of our review of capital.

Capital proper is the permanent organisation of the social production, and its produce that is used up in the production of income, including all goods and services that are a necessary part of that organisation and have a price. It includes all that part of improved resources, and all work and service (" productivity ") that is used up in the current production of income, and is the same thing as the national income, but in the intermediate stages before it becomes actually consumable. It therefore follows that the national capital is always equal to the national production, and the national income is again equal to and the same as the production, save for a little that goes as an increase of improved resources, which are a future reserve of capital in addition to income. And further, as capital of all sorts is only a condition of the national production, the increase of capital is only limited by the productivity of the communitythat is, its capacity for work and organisation. 
The national production is the really important thing upon which all social progress depends, so far at any rate as material things are concerned, and capital seems chiefly important for its negative properties which we have discussed in this chapter. It appears that capital is not the result of saving, abstinence, or waiting, and that it does not maintain labour during its work. Perhaps the chief importance of distinguishing between income and capital is that while production is in the capital stage it has the peculiar property described above, of being at once the purchasing power and the things to be purchased. For which reason its distinguishing characteristic of having a price is of so much importance, a point that will be further discussed in the following chapter. 


\section{CHAPTER V}

\section{PRICE}

THRoughout the foregoing pages we have found it necessary to represent our ideas of production and wealth by money values or price; in the last chapter especially we found that price was the most constant characteristic of the goods and services that constitute capital. So completely is the social wealth measured by its money value that capital has sometimes been regarded almost as if it consisted solely of an aggregate of prices. This aggregate of prices, that exists in the form of book accounts kept by commercial houses, banks, and Government offices, as lists of stocks and shares, and so forth, stands to capital very much as an engineer's drawing or plan stands to the work it represents; in which plan the persons engaged upon the work can more easily see the real nature and arrangement of what they are engaged upon than they can from the actual work itself. In the colossal work of the world's productive organisation it is impossible to follow very far, either by the actual or mental vision, any one simple product on its career of multifarious usefulness. It is soon lost in the maze of operations and the commercial and financial manipulations, by which man with incessant labour extracts from it the few material comforts and the vast complex of social impedimenta which he is pleased to call his wealth. The inconceivably varied divisions of the original material and its products, and the still more complex series of recombinations of products and services, that must attend the devious course of a barrow-load of iron ore, for instance, on its way to satisfy man's marginal demand for a penny almanack, is a scheme too intricate for the mind to grasp, except in the most vague and general way. The details and proportions of the manifold divisions and combinations of manufacture elude observation from the moment the changed production first merges its identity in the sea of the social capital. Each group of producers that receive and pass on that iron ore, or its products in the long chain of commercial evolution, receive it at a price, add their labour, and pass it on at an enhanced price; and that price seems often to be all they need know about its origin or its ultimate destination. And yet they must pass each fragment of the original substance on at just that price which represents its value as a fraction of the whole wealth of the community.

We are so used to think of everything as having a price that it seldom occurs to us that there is anything wonderful in the fact that 
they do usually have a definite value in money. Yet it is by no means easy to explain why every conceivable thing made by man should correspond in value to a particular quantity of metallic money, especially when the thing in question is a comparatively small commodity used in the production of other things, such, for instance, as nails in carpentry or building. And this difficulty is made still greater when we find economists tell us that the price does not depend upon the cost of production of the article, and even further, that the price is not fixed by the producer at all, but depends on what the consumer thinks it is worth compared with other things he wants to spend his money on, his marginal demand for it. How, for instance, can the iron ore producer know what price he must give for grease to be consumed in greasing his barrowwheels at a price that will be repaid by the ultimate consumer of penny toys or almanacks. To help realise the difficulty of thus fixing a price, let us try, even though it be in a hopelessly inadequate manner, to picture the career of that barrow-load of iron ore on its way to produce, among other things, an "Old Moore's Almanack."

When a barrow-load of iron ore is mined the cost involved by the labour and costly modern plant used in raising it must be included in the price at which it is passed on to the iron smelters ; and on its way to them its price is enhanced by the cost of transit. At the furnace its price is very greatly added to by the coal used to smelt it, and also by the great cost of plant and labour involved in the process. Then merged in a great aggregate of other barrow-loads of ore, additional material and labour, it becomes part of the raw material iron, that is passed on into the great circle of exchange, or social capital as we have called it. But it has not yet fulfilled any human purpose ; no one wants iron to consume, it must have further labour and its price added to it and be divided up into innumerable products. But in each product the included portion of the original barrow-load must bear a price that will cover its cost of production and all costs of labour and material that have been added to it in its present form, and must continue to carry its share of such costs till it is consumed as a finished article that ministers to man's desires. Some of this pig iron goes to the founders, who soon make it into castings for a vast number of mechanical purposes such as railway waggon wheels, lathe beds, etc., and stands and brackets that form the heavy part of most machines, such as presses, steam hammers, dynamos and wheels of many sorts. Another portion goes to be merged with still other iron and coal, becoming an unnoticed increment in a vast output of steel for use in engineering. Then on to the rolling mills to become rods, bars or sheets, or to the founders to become railway metals and chairs, or castings to be finished by the engineers as machinery for their own or other trades. Some of this, such as tinned plate, may soon become tin soldiers and fulfil its mission by 
giving joy to a child, having thus discharged its debt to human labour. But the rest must go on carrying its load of costs in the exchanging circle of the social capital ; and it seems as if much of it got caught in eddies of that great stream to circulate for ever without coming to the stage of satisfying any human want. For instance, the iron resulting from that whole barrow-load of ore may go back in the form of tramway rails to the very mine it originally came from, there to be worn out in producing more ore. But in that case it must be paid for as part of the cost of many barrow-loads of ore, and will thus in time have reproduced itself and its new self will carry on its load of price in the social capital. Sooner or later it continues its career, and from the engineers' shops emerges as engines, machines, tools, ships and buildings. The ships may carry machines and tools of which this iron is a part to the ends of the earth to do its work. Part of it may be at Rio Tinto as tools to mine copper, or be in a lead mine, coal mine, or perhaps a gold mine, getting gold to pay wages of the labour that is ever adding to the price of our wandering barrow-load. Or our iron may be in the wheels of a rag-and-bone man's truck, a knife tapping rubber trees out in the Indies, a pen with which Old Moore is writing his prophecies, or perhaps the plough that helps to produce food for the workers, who are adding their labour to the growing price. Each of these innumerable and scattered portions of iron in its many new forms has grown vastly in price, and diminished very greatly in bulk, but however many and small the portions, each is a fractional proportion of the original whole, and carries its share of all the added costs.

It is not necessarily the iron ore itself that must exist as capital in circulation till it is consumed as income, but the things it has been converted into must carry on the price of just so much of the iron tool or machine as has been used in their production. And it seems like a very nice point to discover how much of the price of a pickaxe used in a copper mine is embodied in the price of the brass work on an engine that drives the machinery of a linotype works. Yet the price of a linotype machine must include part of the cost of the engine used in its manufacture, and the price of the engine must include the brass work, and the brass work must include the copper in it, and the copper must include some of the price of the tools used in mining it. So as the things produced by our iron ore are recombined into other products they bring with them part of its price. From far scattered workshops in many branches of engineering portions of this iron may be brought together, directly as machinery or indirectly as worn-out tools that have made those machines, contributing some tiny portion to the complicated fabric of a paper mill. The humble rag-and-bone man's barrow wheels, as their iron is gradually returned to the earth from whence it came, as worn off fragments of iron rust, must reproduce their value by contributing 
rags to make into paper at the mills. The before-mentioned linotype machine comes to join the paper at the printing works, bringing with it also its contribution of price from many distant sources where our iron products have been used. For this barrow load of ore launched upon the sea of industry has travelled to every corner of the earth, and wherever a fraction of it or its products may wander on the countless eddies of the restless tide of commerce it carries with it the stern decree, that whomsoever of the world's toilers shall by use extract from it a decrement of utility shall replace the same by labour of his own and pass it on, or something in its place, of undiminished price. So that when the last fragment has fulfilled its usefulness there shall remain value in its place to pay the price of a new barrow load of ore. Thus, the steel tools that have helped the lead miner to win his daily bread must be paid for by contributing to the type-metal wanted at the printing works, and the knife that is out in the Indies sends its depreciation cost as rubber to make vulcanite for the switchboards and dynamo that drives the printing works. The rag-and-bone man's truck wheels again contribute bones to make bone black, which when mixed with oil and gum which comes with many other things in iron ships from distant shores will make the printer's ink. Thus, many of the scattered products of our load of iron with their true fraction of its price may reassemble as part of the fabric of a printing works. As each brings with $i t$, amongst all the other costs that make up its price, a fraction of the cost of that first barrow load of ore, any work that emanates from that printer's must embody in its price part of that cost. So when "Old Moore's Almanac" is published at this press, to be consumed as literary food by its faithful readers, each copy must represent a tiny fraction of the price of that original load of ore, which has at last fulfilled its purpose of ministering to man's wants. And it should be realised that while its price must cover an exact proportion of all the costs of every element as well as iron that has contributed to its production, the sum of all these fractions must come to something less than a penny, so that a margin of profit may be left, or the prophet will have prophesied in vain.

It is inconceivable that at every stage in the world-wide maze of commercial production each co-operator, however remote, should have a sense or knowledge of the ultimate form of utility in which his work will be consumed, and at his intermediate stage should justly proportion the utility he extracts, and work he adds, to some final price he knows nothing of, even if that final product and its price were fixed and knowable things, which they often are not. There must be some definite and accessible standard, common to and inseparable from all production, whereby every unit of work or utility must at every stage be inevitably measured, some intrinsic value in things by which they can be continually priced. So, Mr. 
Jevons' contempt for " such nonentity as intrinsic value" notwithstanding, we shall in the following pages seek to find this factor of intrinsic worth that gives price to all man's works.

Although it would hardly seem credible that the income derived from a great iron and coal company's gigantic plant depends to some fractional portion upon the sale of a $I d$. almanac, it is certainly true that it depends upon the sale of things of some kind that are directly useful to or desired by members of the community as part of what they want to consume. If a I $d$. almanac is one of those things it undoubtedly must subscribe its little factor to the capital of the ironmasters who have contributed to its production by their part in the great scheme of the world's division of labour. No doubt it is to the institution and growth of the division of labour that price may be attributed. While individual persons simply produced what they wanted and only exchanged with each other when and as occasion made it to their mutual advantage to do so, they could exchange just those things and quantities as they might wish to, without any regard to relative or standard value. But if under modern commercial conditions a boot manufacturer sells boots to a shopkeeper who has produced nothing that the manufacturer wants, the latter must accept in exchange for his boots either money or a cheque, that gives him purchasing claim upon the social capital or commodities in general. Therefore he must have some standard of value to measure the cost of the boots he is selling, relatively to the value of the commodities in general on which he is accepting a claim as payment for boots. So it is obvious that in a society where the individual producers never produce what they want, but only part of something that everybody else wants a part of, all these parts must have their cost represented by a price, to indicate the ratio in which they may exchange for one another. But when we come to inquire on what price is dependent or by what it is determined, it seems that economists are by no means agreed that it is fixed by cost of production and still less by any standard of intrinsic value. The older economists usually seem to have considered that price depended upon the cost of production, but as they use the word "value" in place of price, and do not always make it certain whether they mean value in use or in exchange, or whether they speak of money or "real price," they have in some cases left room for doubt as to what exactly was their view. However, Ricardo agrees with Adam Smith in saying " that the proportion between the quantities of labour necessary for acquiring different objects seems to be the only circumstance which can afford any rule for exchanging them for one another." Again, in a note replying to Malthus, Ricardo says " that cost and value of a thing should be the same"; it is, if he means by cost- " cost of production, including profits." But although these writers evidently thought that " real price " was 
labour cost of production, later economists do not seem to think the older definitions of cost and value sufficiently precise to determine what Ricardians actually regarded as the basis of price. And in their efforts to be more exact later writers have devised a remarkably complex theory of price or " exchange value," founded upon marginal or final degree of utility, or upon supply and demand arising out of utility, or vice vers $\hat{\boldsymbol{a}}$, for there would seem to be a difference of opinion as to which arose out of which.

So much attention has been given by modern economists to these theories of value that it is necessary for us to briefly examine them before going on to our own views upon the determinating factor in price. The theory of utility is based upon certain obvious facts of human nature that are sometimes made the subject of separate theories: theory of pleasure and pain, law of wants and so on. Writers have given much care and trouble to elaborate and detailed investigation of these theories as the basis of their economic principles, without, as it seems to us, being able in their subsequent treatment of the subject to clearly show how these fundamental laws apply to the more complex and practical questions of actual production and exchange, and especially to the question of price. The application of these laws seems rather to fade out and become lost in the discussion of special circumstances, and to be obscured by many desirable reservations.

As we have stated in our introductory chapter, however true it may be that all human efforts are the result of desires and of pains or pleasures, a full investigation of such questions is hardly the subject-matter of economics, but rather of psychology and ethics. While it may truly be said that man's desires and sentiments as also his energies, efforts and aspirations, must form the basis on which a study of social organisation inevitably rests, the same might be said of man's physical nature with just as much truth, and the investigation of all these subjects would lead us far beyond the proper scope of our subject. So we leave the full investigation of the springs of action to other branches of anthropology, and here accept man as we find him with his desires and activities taken for granted. There are, however, certain of these obvious facts of human desire and effort that must be recognised as the springs of economic action; and first we may take it that the things which man strives to provide himself with must necessarily have utility to him. And that utility of a commodity is the circumstance that it gives some satisfaction, real or imaginary, to the person who has it. Up to a certain point the theory of utility is quite understandable, and the law of utility upun which writers seem to lay great stress is: that as a person acquires a more and more plentiful supply of any useful thing, his desire for it grows less until its jutility seems to him to be less than that of other things he desires. 
Labour of some kind is necessary for the attainment of almost everything man desires, and speaking generally, continuous effort in the production of the things desired is distasteful to man, and if continued for long must ultimately become great hardship; and so by comparison leisure and rest come to have great utility to him. If he gives up the utility of leisure and works to obtain commodity, this commodity must in his opinion have more utility than the leisure that he sacrifices for it. But as the desired commodity becomes more plentiful as the result of his work, the utility of getting more of it becomes gradually less, while the utility of rest and leisure becomes gradually greater in his estimation, till at last a point is reached where the utility of rest and of commodity is equal and he will not continue to work for more commodity, or he would be giving what he desired more for what he desired less. The utility of the last bit of commodity he will work for and the first bit of leisure he will take are said to be the marginal utility of commodity and of rest respectively, and writers make a great point of the variation of these margins under changing circumstances. In illustrating such circumstances or applications of the law, writers generally assume that some relative value, market ratio of exchange, or actual money price enters as a factor determining marginal utility. But if the object of the inquiry is to discover the determining factor in price, it seems hopelessly to obscure any question of the claim of utility to be that causative factor of price, if price itself is admitted as a determining circumstance of utility. To avoid this elliptical kind of argument it seems necessary to illustrate the working of utility in exchange by a simple and primitive example free from any element or ratio of exchange, or price; to see whether under any circumstances such a ratio or price emerges from such circumstances of utility of exchange.

If we suppose a primitive man finding and grinding seeds into meal, or procuring other vegetable food which for convenience we will call meal, he would no doubt relax his grinding labours when he had as much stock as he was likely to want for his own use. But if he finds that by grinding more meal he can exchange it with a hunter for meat, the greater utility he sees in the meat would cause him to put forth an extra effort that he would not have done to make more meal for himself. Having worked harder to make meal for the sake of the meat, he will be willing also to give more meal for the meat than he would think necessary for his own supply for the same time; that is to say, more meal than he gets meat. But as the quantity of meat he gets becomes greater, its comparative utility gets less in his opinion. In the same way the hunter's idea of the utility of meal that was greater than that of the meat he had a stock of, gets less acute as his store of meal gets larger by exchange. So it seems that they will exchange until they have each got equal quantities of 
each, and the meal-grinder will not need to give more meal than he gets meat. Unless we suppose some inherent extra value in one of the commodities, the ratio of exchange is as one to one. But in common practice, things seldom exchange as one to one, there are different ratios in which things exchange. And these relative values, usually expressed as prices in accordance with which things exchange, are fairly constant, a fact that leads to the common idea that things have naturally inherent differences of value. If for the moment we suppose that both men desire meat twice as much as meal, it would appear that the exchange should be in the ratio of two of meal to one of meat. But although the meal-grinder might be willing to produce twice as much meal as he would have eaten himself, and given it in exchange for meat-if he cannot get ineat for less-why should he be obliged to do so? Why should the hunter demand twice the quantity of meal that he gives of meat ? Seeing his idea of the utility of meal is only half that of meat, there must be some other circumstance than the simple sense of utility to make him demand twice as much of it. If he also has unlimited meat, they can both ask, and both give, just the quantity that they both desire, and there will be a balance of utilities without any ratio of exchange being established. Utility prompts them to exchange for their mutal benefit, but determines no relative quantities or value; the ratio, if we so call it, would still be one convenience for another, or as one to one, whatever the actual quantities of the commodities exchanged.

In these supposed examples of exchange, there is evidently some element wanting that should give definiteness to the quantities of commodity involved, or reason why certain amounts should exchange. And we find the word utility as used by economists does not mean simply an appreciation of the different degree of usefulness arising from the properties of two contrasted articles, but the usefulness arising from the circumstance of greater or less supply or stock of such articles, or quantity available for exchange. As Gide puts it, "utility varies with quantity." But even if we take an illustration of exchange from definite quantities of stock, without any element of cost involved, it is doubtful whether any relative values are thus determined. If, for instance, the meal-grinder and hunter both had 12 handfuls of their commodity only, the hunter, who regarded the utility of meat to be twice that of meal, might offer four handfuls of meat for eight of meal, but there is no evident reason why he should want eight. And if he got it, he would then have eight handfuls of both meat and meal, or twice as much as the other man had, so that there would hardly be a balance of utility at that point.

If the hunter really wanted meal, he might be obliged to give six handfuls of meat for six of meal, if he could not get the meal elsewhere. And this proviso indicates that there is still some element 
of supply wanting to determine whether he can or cannot get meal elsewhere, or why he wanted more or less. If his luck was worse, and his day's hunting had resulted in one lark only, and that was not enough to satisfy his hunger, he might be glad to give the whole of that meat for five handfuls of meal, the ratio now being as five to one. But such ratios of exchange would vary with every promiscuous circumstance of supply or caprice of the moment, without giving rise to any notion of permanent relative value. Professor Gide tells us that utility in the ordinary sense of the word cannot explain why a diamond should have greater value than water; nor does the extraordinary meaning of the word used in economics seem to us to explain the point either. Gold might exchange for bread in any ratio that can be imagined, and there might be a great utility in such exchanges yet no establishing of any value peculiar to either commodity. All things would have equal value except for the circumstance of utility at the moment, the total utility or satisfaction that the thing will give at that moment. It hardly seems possible that there can arise any appreciation of degree or margin of utility unless there is in the mind some standard of the relative value of commodities in general.

As Professor Marshall tells us, " a person's demand for a thing is indeterminate so long as nothing is said as to price." It is this failure of the theory of utility to establish standard ratios of exchange peculiar to different commodities that has led to the variation of the theory known as "law of demand " or " final degree of utility," in which theory utility is indicated by the quantity of commodity a person will buy as the price of the article rises or falls from its mean rate ; that is, he will purchase more as the price falls and less as it rises. No doubt he will, but that does not appear to be because the utility or margin of utility is greater or less; apparently it depends upon the cost of the article. When a person is in doubt whether to purchase an article at a certain price, he may be choosing between the utility of that article and that of something else ; but neither his consideration nor his choice will alter the utility of either or their price. In all examples of demand price, demand schedules, and such illustrative contrivances, it is glaringly obvious that demand is determined by the price, but that does not explain the cause or determining factor of price. Professor Marshall tries vaguely to explain price by suggesting that it is an equation between the marginal utility of money and that of commodity. To explain that theory, he gives a curious illustration of a poor man and a rich man taking omnibus rides, and points out that as a man's wealth increases he is willing to pay more for any given pleasure, such as an omnibus ride, because the marginal utility of money to him is decreasing. The marginal utility of the $6 d$. and the omnibus ride is far greater to the mind of the poor man than to that of the rich one. But they both 
pay $6 d$. for the ride, so the price of that convenience evidently has nothing to do with these gentlemen's variously inflated margins of utility. The price of the ride no doubt depends upon the cost of running the omnibuses.

Not only does this theory fail to explain the origin of price, but even the price a person is willing to pay for a thing does not seem to be determined by a ratio of the supply price to the demand, or marginal utility of money, because it is shown by Professor Marshall's own illustrations that demand and utility of money depend upon the supply of that demand or the income of the purchaser. It is quite certain that every one's idea of the marginal utility of money would be infinitely small, and their incomes infinitely large, if it were not for the unfortunate labour cost of getting the income. Labour cost is found to be the determining factor both of supply and demand, and constitutes the quantities on both sides of the equation of price. So price is ultimately the equation of one man's labour time to another man's.

The reason for introducing money price into the theory of demand was evidently due to the feeling that price would introduce the necessary determining factor into the element of demand or desire. But this it fails to do, unless it is recognised that money income in some way represents an individual's power of production, and that it is his power of producing the things he wants, or their equivalent in things to exchange for them, that actually gives him his effective demand upon the things produced. His income being the return for his labour, it approximately represents what it has cost him in labour-its cost of production. In all the above examples of bargains of meat for meal, the indeterminate nature of the exchanges was due to the fact that we had lost sight of the element of cost in labour, or loss of leisure. Without this cost or sacrifice of leisure the theory of final utility is meaningless, there is no marginal utility in things that cost nothing. If we keep in mind that the mealgrinder and the hunter have had to spend more or less labour, that is, it has cost them more or less of their lifetime to get more or less of meat or meal, those two things will have a value measured in a common measure of utility, namely, "labour cost." And that cost would early become a standard of relative value that could be kept in sight through temporary exigencies of utility and supply. Doubtless one man's day's work would be roughly recognised as equal to another's by the industrious members of a primitive community, and the result of one day's work would exchange for the result of another's day's work or half of one for half of the other. This seems to be the only conceivable origin of value, and we emphatically agree with the older economists in contending that the basis of price is man's labour, and everything is worth more or less according as it has cost more or less labour time to make it.

Although recent economists are almost vehement in their efforts 
to assure us that price does not depend upon the cost of production, their arguments are by no means convincing. And some of their illustrations and the reservations they find necessary lead one to suppose that the question is not so definitely settled, even in their own mind, as they would wish it to be. For instance, Professor Gide remarks upon these rival views of cost and utility: "These then are the two main theories of value. Is it absolutely necessary to choose between them? No. Each represents one side of the truth." And again, "Final utility is in fact only the scientific name for scarce utility," it " not only implies scarcity, it implies also difficulty of acquisition... There is not one single product... that cannot be increased by taking the trouble. ... If chronometers are scarce, it is because the manufacture of a good chronometer takes time and special skill." "Even explaining value by final utility, then we cannot leave out of account the greater or lesser facility for multiplying wealth." It seems, then, from this statement that price (value) depends on utility; utility is scarcity and scarcity depends upon the labour cost of getting the supply.

W. S. Jevons, who is the first great English exponent of the utility theory, seems to have the same difficulty in explaining the circumstances that give utility its final degree. He says: "Cost of production determines supply; supply determines final degree of utility ; final degree of utility determines value." Surely this means that ultimately cost of production determines value or price. But though economists have completely failed to construct a theory of price free from the element of cost, or labour of production, they still maintain that cost can have nothing to do with price. Their opinion seems to rest solely upon the empirical impression that the labour cost theory is contrary to the actual facts of commercial experience, and their arguments consist of suppositionary examples of its impossibility. One such impression is that past labour on a commodity cannot determine its price, because once the production is finished its cost price in labour is for ever fixed and cannot be more or less. When that production comes to market, it may be found that it will not sell for that cost price, and any price it does sell for will not, therefore, depend upon that past cost of production. There may, of course, be mistaken or waste labour in an article that will never be paid for, but why will that article that has cost too much not sell for its cost price? If the market price is fixed by demand or utility, why should not the vendor of the commodity hold back, that is, keep up a short supply till the scarcity increases the demand and he can get his high price? There seems no reason why he should not get it, unless some one else who has produced the same commodity at a less cost keeps up the supply, so that there is no rise in price. In that case, it is the lower, or as we shall hope to show later, the average cost of production that fixes the price. And it should be noticed 
here that we do not regard one particular person's mismanagement of his costs as fixing the price of the commodity ; price is, of course, the mean price at any one time.

After giving such an example of miscalculation of cost resulting in too high price, Professor Gide remarks, "Still, is it not the case that, in reality, the selling price of nearly all objects tends to approach cost price, or at least to follow it in its variations, as if there were some link or necessary interdependence between them ?" This, he explains, is the result of competition; but why should it cause price to approach cost of production if price is dependent upon or " made " of utility ? Competition might bring prices to a common level at the point fixed by demand or desire, on which he claims all price depends; but why ever should they approach to cost of production. if variation of prices " are altogether independent of the labour of production "? Economists seem to feel that these theories of some subtle equation between things possessed and things desired have not quite given us a complete and conclusive account of the nature of prices and their determining causes. They all appear to have vaguely in their minds the idea of a cost of production that plays an essential part in the fixing of prices, though for some reason it must be kept in the background as some secondary circumstance. We hope our statement of the argument has shown that this circumstance of cost is really the prime factor that makes all value and determines all price. To us the theory of utility is quite meaningless if we leave out the cost in sacrifice of leisure that must be paid for the pleasure of commodity; the cost and the pleasure are the only things that can enter into the equation.

The cost of production theory of prices seems the simple and only solution of price and the economic questions arising out of it. But there are certainly a few exceptional cases of price that are not easily scen to depend upon the cost of production. And it seems to be because certain extravagant and impossible cases of scarcity price appear to constitute exceptions to the cost basis of value that some economists reject the cost of productions theory of prices. As Professor Marshall suggests, the price of quinine on a fever-stricken island might go up to any fancy figure, irrespective of its cost. In the first place we do not admit that the price of a quarter of an ounce of quinine on some South Sea island represents the price of quinine in an economic sense ; it is not subject to competition, and does not affect market prices. But even if that particular packet of quinine has acquired infinite utility by reason of fever, that utility does not fix the price. If there was no money or anything of value on that island, the quinine would realise no price, however desired it might be. In a case like this, the equation of price is all one-sided, and the price depends entirely on what can be given for the quinine. The value of what is given depends upon its labour cost, and the value 
of the quinine is measured by that cost, the other side of the equation being inoperative through the outside circumstance of isolation.

One side of the equation must have a quantity determined by labour cost, or no value or price will appear in the transaction. To continue Professor Marshall's simile, we might suppose that the only thing of value that could be given for the quinine was a picture by Raphael which had been found on the island. If the man who receives the picture for the quinine does not know that it has any special value, but thinks it is worth the quarter ounce of quinine, what was the price of quinine on that fever-stricken island?

When we contend that price is an equation between the labour cost of commodities, it does not follow that the equation cannot be disturbed by secondary influences such as supply and demand, even to the exclusion in some cases of labour cost on one side of the equation. But the labour cost must appear on one side, or there can be no price determined. From the above illustration it may be seen how futile it is to study cases of price that have gone to the extreme of a one-sided bargain. The only prices that concern the economist are those that affect the social production and distribution of wealth and are subject to industrial competition. Although such real prices are often disturbed by the secondary circumstances of supply and demand, it will be found that cost is the dominant factor that not only makes value but also determines supply and demand.

Some writers seem to have been greatly biased by the apparently exceptional cases of price. Thus, W. S. Jevons, immediately before he makes that remarkable statement quoted above, showing the relation of cost of production to price, had said : "Economists have not been wanting to put forward labour as the cause of value, asserting that all objects derive their value (price) from the fact that labour has been expended on them, and it is thus implied, if not stated, that value will be proportional to labour. This is a doctrine which cannot stand for a moment, being directly opposed to facts." This somewhat dogmatic statement suggests that there is some uncertainty as to the exact nature of price, or something wanting in the method of examining it. Since the time that the passage quoted above was written there has come into existence a good deal of valuable data with regard to price and labour, data that would have been a delight to $\mathrm{Mr}$. Jevons had he lived to see them. So we propose to make a thorough re-examination of the subject in the light of these data, to see whether a more convincing case cannot be made out for the cost of production theory of price.

Economists seem to recognise that price, or value as they usually call it, is of fundamental importance in economic inquiry, as is shown by their elaborate mathematical treatment of utility and demand. But when they come to apply this treatment to supply, production, distribution and exchange, this methodical line of 
investigation breaks down very much. After a very short and breezy sketch of what a supply schedule might be if we could make one, Professor Marshall remarks: "This instance will serve fairly well to indicate the general drift of inquiry before us; but it does not closely correspond to the actual conditions of life. . . As a matter of fact the supply of commodities is not so simply determined." The complex nature of the inquiry based on supply and demand seems to lead writers into many digressions descriptive of various methods and usages, with examples of commercial transactions between suppositionary employers and producers as they appear to the economic mind, a practice that we think is partly responsible for the tendency to represent price as a sum of money paid for a particular commodity, brought to market by a particular individual, as if each case of production, exchange and consumption was an isolated and self-contained transaction, in which a price appears as a transient ratio of the particular circumstances of the case. Professor Gide, speaking of value (price), says: "We must think of value as an illumination thrown on objects from the searchlight of our desires. As the ray turns this way or that it casues the objects of the outer world to start forth from the darkness, only to disappear again into the night as soon as it has passed over them. They had a value, they have one no longer." This is certainly a picturesque simile, but gives the impression of price as a curiously ephemeral phenomenon. It contrasts strangely with the impression we have striven to convey of the great stream of wealth production carrying its load of price, with its stern inevitable law that all who use a part of wealth must pay its price in reproductive labour of their own or that of some one else who has consented to labour for them. Most economists tend to fall into this rather detached and sketchy way of referring to both price and supply and demand, as if systematically following the effect of price upon industry was very difficult to those who follow the supply and demand theory. Jevons attempted to systematically carry out a mathematical inquiry into the effect of currency and finance upon prices, and was the first to introduce the systematic use of the index number of prices as a means of ascertaining fluctuations in the standard of value, a method that has been followed by subsequent investigators almost as if it were the only way to deal with the problem; and this not only applies to writers on economic questions, but index numbers are now being used by Government and public authorities in such matters as arbitration upon wage standards and in questions of practical political economy.

The object of the index number is to show the variation of the prices of commodities generally in relation to the money standard which is supposed to be stationary, or to have alone moved while general prices have remained unchanged. So the index number may be sai $d$ to indicate inversely the purchasing power of a sovereign. 
Although this hardly seems to us the most important thing to know about prices, it was nevertheless an advance in the method of investigation, as it recognised the necessity of systematically comparing changes of general price in a series of years. The difficulty of comparing general prices of one year with those of other years is not only in obtaining a great number of prices for a number of years, but in arranging them so that it is possible to make a comparison between them. When a large number of prices are obtained the mind cannot compare a list of all sorts of prices one year with another list of the next year ; it is found necessary to reduce them to some average or standard before one year's prices can be compared with another's. To get the average price of commodities it is necessary to bring them all to some common denominator, either of measure or price. As the object in index numbers is to indicate the change in price, the recorded amount of rise or fall in the price of each article is represented as its fraction of a hundred or percentage. Thus, if cotton has gone up from $6 d$. per pound to $7 \frac{1}{2} d$., it has risen 25 per cent. ; and if iron has gone from $£ 4$ per ton to $£ 48$ s., it has risen Io per cent.; the average of those percentages of increased price is $17 \frac{1}{2}$ per cent. Such an average percentage could be compared with a similar percentage for the next year; but as the number of years increased a list of percentages of many sorts cannot be usefully compared without again taking one as the standard to compare them with. This is done by making the prices of the first or the average year a standard or "base year." Whatever the prices of the selected articles may be in that year, that price is taken to represent roo per cent.; thus cotton at $6 d .=100$, iron at $£ 4=100$, and the average of those numbers $=100$ and is the index number for the "base year." If the following year the price of cotton is $7 \frac{1}{2} d$., that is a rise of 25 per cent., its index is 125 , and iron at $£ 48$ s. is Io per cent. up, and its index is IIo, the average of these two is $\mathrm{II}_{7}$, which is the index number of prices for the second year. Thus an index number can be obtained each year, or calculated for back years, making a list of numbers each of which is a percentage above or below the roo of the base year, and so the variation of average prices can be easily and directly compared.

If it was only a matter of two articles as in the above example an index number would hardly be required, but to get a good estimate of general price it is necessary to select a considerable number of typical commodities, and that with some discretion. In the Board of Trade index number there were 45 selected articles taken to represent the general production. They must be things the price of which is regularly quoted and such as have been quoted for a long time, so that the period brought under review may cover as large a number of years as possible; for this reason they are to a large extent prices of raw materials, often imports, because they are 
regularly quoted. The prices of retail goods as commonly consumed by the public would be a desirable addition to a representative list, but standard prices of such things are not very regularly quoted and are not available for many years. Another complication is caused by the fact that some of the quoted articles enter much more largely into the national expenditure than others. If such a thing as cocoa alters 50 per cent. in price while important things like iron and coal perhaps alter very little, the index of cocoa would affect the general index number out of all proportion to its bulk, compared with the great magnitude of the consumption represented by iron and coal. To compensate for these differences in bulk the nore important commodities are " weighted " or reckoned several times over. Thus in the above example of cotton and iron prices, if cotton is supposed to enter more largely into trade or expenditure than iron, it must, to give it its proper weight, be taken twice over. Its index number of $125+125=250$ for cotton, and that added to 110 for iron $=360$; dividing this by 3 gives the average 120 which is the "weighted index number "for the two commodities.

In the following pages we give examples of the more commonly quoted index numbers covering years from 1800 to 1902 . These Diagrams (19-20 and 2I), in addition to the numbers, give prices expressed in proportional lines to illustrate graphically the variation from year to year, so that the general trend of prices can be seen at a glance. The Board of Trade Index Number, Diagram 20, is one in which the percentages have been elaborately weighted, whereas the other two are practically unweighted. As these latter are the ones that have been most extensively used, it would seem that in spite of its mathematical appearance the index number does not lay claim to any very great exactness, and we are disposed to question whether as at present constructed they serve any great purpose. It would seem that the usual object of index numbers is simply to get the average money price of commodities generally at various times, for the purpose of comparison, without any provision for locating the factor changed or ascertaining any cause for such change. But if that is admittingly so, there does not seem to be any particular object attained; the comparison of a few quoted prices will usually show what change there has been in any class of produce in which the inquirer is interested, whereas few people have any reason to be interested in the exact rise or fall of the average price of everything, even if index numbers were exact averages of absolute prices, which they can hardly claim to be. The object of investigation by index numbers must be to discover some cause for price changes if the inquiry is not to be utterly barren. And it is impossible even to surmise a cause unless it is determined which factor in exchange is subject to such cause. No doubt most exponents of the system have in view some theory as to the factor that has changed. W. S. Jevons, 


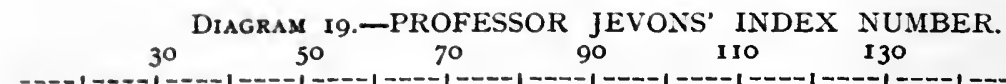

1410000000000000000000000000000000000000000000000000000000

1400000000000000000000000000000000000000000000000000000000 .

is 000000000000000000000000000000000000000000

125000000000000000000000000000000000000000000000000

119000000000000000000000000000000000000000000000

13200000000000000000000000000000000000000000000000000 0.-.--.--

130000000000000000000000000000000000000000000000000000

12900000000000000000000000000000000000000000000000000

145000000000000000000000000000000000000000000000000000000000

$157000000000 v 0000000000000000000000000000000000000000000000000000$

14200000000000000000000000000000000000000000000000000000000 -. - - - - I810

13600000000000000000000000000000000000000000000000000000

III 0000000000000000000000000000000000000000000000

II 50000000000000000000000000000000000000000000

II 110000000000000000000000000000000000000000000

10900000000000000000000000000000000000000000

91 000000000000000000000000000000000

11700000000000000000000000000000000000000000000

132000000000000000000000000000000000000000000000000000

112000000000000000000000000000000000000000000

10300000000000000000000000000000000000000

940000000000000000000000000000000000

SS 00000 000000000 0x0000000 000000000

8900000000000000000000000000000000

\$8 00000000000000000000000000000000

$10300000000000000000000000000000000000000-\ldots-0.001825$

90000000000000000000000000000000000

90000000000000000000000000000000000

81 0000000000000000000000000000

79000000000000000000000000000

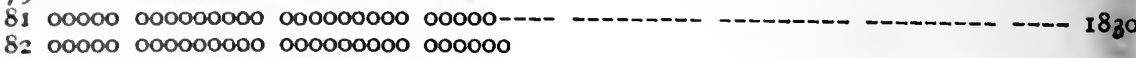

78000000000000000000000000000

750000000000000000000000000

78000000000000000000000000000

$800000000000000000000000000000---$

860000000000000000000000000000000

84000000000000000000000000000000

84000000000000000000000000000000

92000000000000000000000000000000000

870000000000000000000000000000000
85000000000000000000000000000000

750000000000000000000000000

il 000000000000000000300000

6900000000000000000000000

$740000000000000000000000000-1845$

7400000000000000000000000 00

78000000000000000000000000000

6800000000000000000000000

64000000000000000000000

64000000000000000000000

660000000000000000000000

65000000000000000000000

7400000000000000 000000000 00

8300000000000000000000000000000

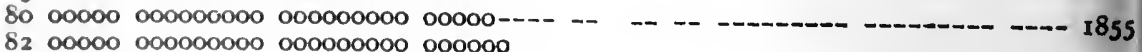

85000000000000000000000000000000

7600000000000000000000000000

7700000000000000000000000000

79000000000000000000000000000

78000000000000000000000000000

79000000000000000000000000000

78000000000000000000000000000

78000000000000000000000000000

78000000000000000000000000000

- - - - - - 1 - - - -

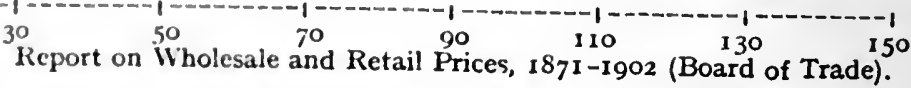


for instance, introduced the system to demonstrate a fall in the value of gold, and change in the value of money seems to be the usual object of the investigation. But whether the change or its cause is supposed to be actually in the money, or affecting the money only, as distinguished from, and independent of, the value of the goods, is not in most cases made at all clear. As the value of money is the reciprocal of the level prices, it is a mere truism to say that if one of them varies the other must vary inversely to the same extent. The sole object of the investigation, surely, is to discover which of these

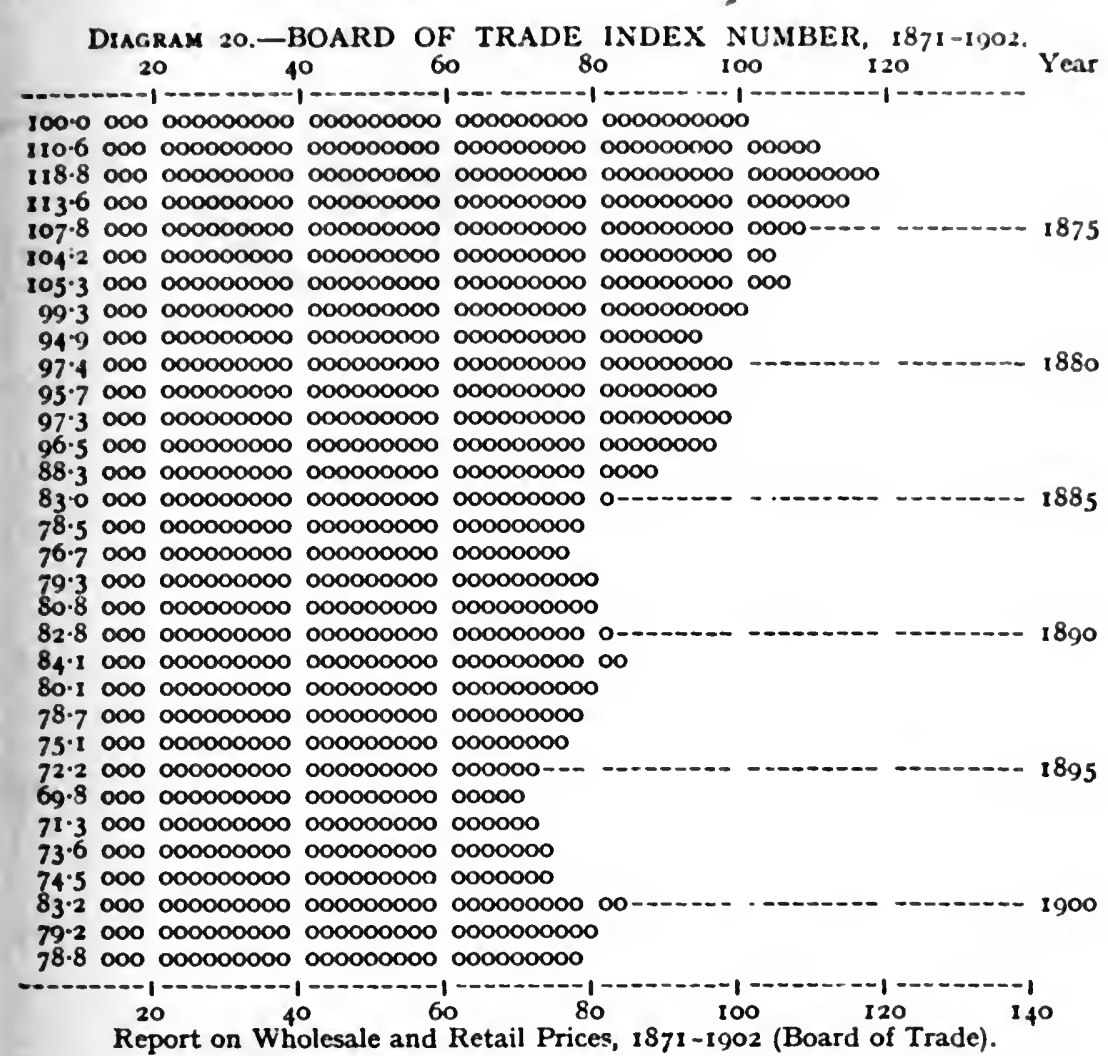

reciprocals has been the cause of or has been the subject of the change. Nor will it avoid the difficulty to contend that, as value of money and level of prices are only reciprocals of value, any cause affecting value necessarily affects both its reciprocal terms. Because value not being a concrete thing, but a ratio of two things, it cannot be the subject of change in itself, but only through causes acting on one or both of the commodities that are the subject of that ratio. In the present case the commodities that are compared in the ratio are gold and goods generally; and it does not appear that the index number as generally calculated has any power to determine which factor in the ratio has been the subject of change. The only evidence it could 
DIAGRAM 21.-MR. SAUERBECK'S INDEX NUMBER, I846-1902.

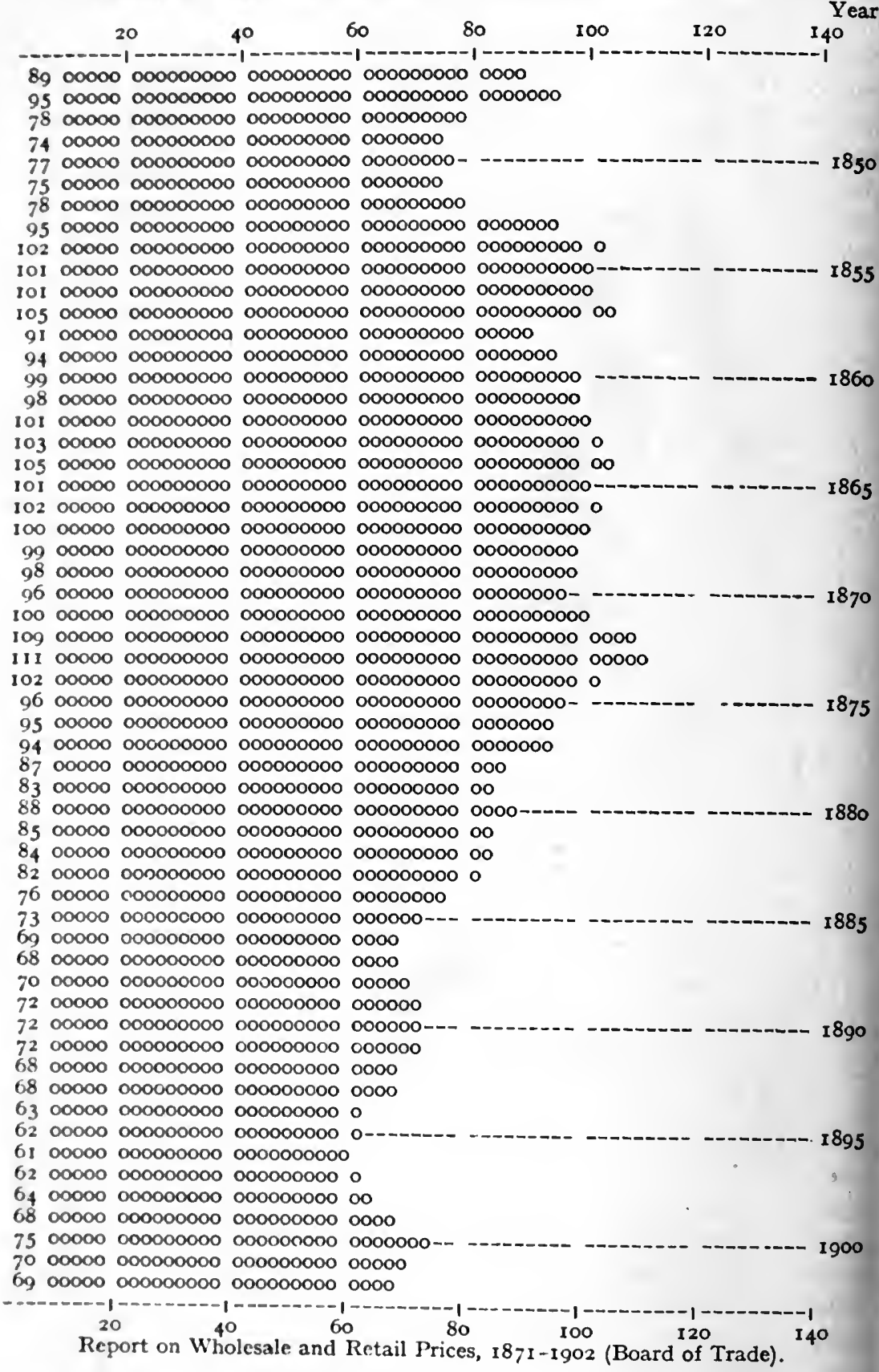

offer is the proof that the price of all commodities has moved in the same direction and to the same extent save for some ascertainable differences arising from specific causes; and the question is whether it can produce this evidence. 
As an example from real business figures, the declared average price of pig iron in 1873 was $£^{6} 45$. $3 d$.; in 1902 it had fallen to $£ 34$ s. $9 d$. Was this fall due to a change in the sovereign, or supply and demand of sovereigns? or to like changes in the iron? If the former, the price of all other goods should have fallen to the same extent. Turning to coal, we find that the average declared price in 1873 was 20.49 s., and in 1902 it was $12 \cdot 19$ s., or a fall of 4 I per cent. against the fall of 48 per cent. in iron, which is sufficiently near the same percentage to suggest a common cause for the fall of both prices; but if we next turn to the import price of jute, the 1873 price was 15.65 s. and the 1902 price 12.79 s., or a fall of only 18 per cent., which is a long way from the other percentages of fall. The index numbers for the two years are: $1873, \mathrm{I} 18 \cdot \mathrm{I}$, and $1902,78.8$, which is a difference of 39.3 per cent., or a fall of 33 per cent. only from II 8.1 ; and these differences in amount of fall would have to be explained before the general average fall could be shown to depend on a common cause.

The fact that the average of 39 per cent. can be taken between the extreme is no evidence of a common cause, that could be drawn in any case. The figures do not indicate in any way which of the factors has changed, or been the cause of change ; and any assumption that the sovereign or basis of price had changed would be most unsound and of no utility in practical questions of political economy. Such an assumption may be based on the very superficial observation that the prices have all fallen, and therefore the average fall of 39 per cent. indicates a probable appreciation in the value of the sovereign to that extent. But this is to leave out of account the very probable reduction in cost of production of the selected commodities. Their prices being the market price per unit, it may have fallen greatly as the result of improved production; whereas the value of the commodities must be supposed to be unchanged, if the alteration of value is solely in the sovereign. Cost of production is a factor that even the most erudite votary of the utility or supply and demand school has to admit is a circumstance limiting the fluctuations of price and forming a base to which, in the long run, all prices tend to approximate. And to the ordinary business manager this factor of cost is the dominating element in his calculations, and the standing cause of all trouble between him and his work-people, a very real and practical factor that we can by no means ignore. Whether we call it cost of production or supply and demand, which seems ultimately to mean the same thing, there must be such causes acting on one factor, or both, to bring about any relative change whatever between gold and commodity. An index number that fails to locate such cause fails to answer any good purpose, and if used, as it commonly is, to imply a change in the value of money, it seems to us a most uncertain and dangerous guide. 
As another example of actual price movements as compared with index number variations, we may take the variations in price of cotton and maize between the years I894 and IgI3. Giving the four years between which there was conspicuous alteration, the prices were: for I $894-5$, cotton, 6.44 cents per lb., maize, $42 \cdot 7$ cents per bushel ; for IS99-I90o, cotton, 8.69 , maize, 36.5 ; for I904-5, cotton, 9.Io, maize, $50 \cdot 0$; for IgI $2-I 3$, cotton, I $2 \cdot 29$, maize, 58.6. That is to say, from $\mathrm{I} 894$ to $I 899$ the price of cotton varied by rising 35 per cent., and that of maize by falling I4 per cent.; from I894 to 1904 the variation amounted to a rise in the price of cotton to $4 \mathrm{I}$ per cent., and only I7 per cent. for maize; then in IgI2 the variation had reached $9 \mathrm{r}$ per cent. for cotton, and only 37 per cent. for maize. These variations may be better seen in tabular form thus :-

Years from 1894 to I 899 .

Cotton A rise of 35 per cent. Maize
TABLE 22.

Years from 1894 to 1904 .
Years from

1894 to 1912 .

A rise of $4 \mathrm{I}$ per cent. A rise of $9 \mathrm{I}$ per cent. A rise of 17 " " A rise of 37 " ,

These percentages show a great variation in price and great contrast in variation between different commodities during the same period, and it seems questionable whether simply averaging these percentages of variation, regardless of their cause, can be a satisfactory method of forming an index number. The striking of a numerical average does not prove the variations to be more or less; they still exist. It simply ignores part of such variations on the assumption that a rise in one price is cancelled by a fall in another. But it is not quite obvious that a fall of I4 per cent. in maize does really lessen a rise of 35 per cent. in cotton, and make it ro.5 per cent., unless it is made clear that the two items actually enter equally into an account of some kind, such as cost of living for instance. There seems to be some feeling of this difficulty shown by the various theories of how the index percentages should be weighted. This process of weighting seems to be an artificial attempt to make the known variation of certain commodities represent a general movement that is presumed to have affected the price of all commodities to an average extent. But these attempts do not seem to give much satisfaction, as we find one authority weighting iron twice as much as wheat, and another weighting wheat more than twice as much as iron, while others do not weight them at all, and yet others have thought it would be better to leave such very variable prices out of index number calculations altogether.

The above variations in cotton and maize prices represent the figures upon which the U.S.A. Bureau of Labour Statistics calculates its general index numbers for the years 1894 and IgI2. After very elaborate weighting, averaging, etc., of these market prices, they take part in the index number, which, as published in the Bureau's 
Bulletin (Whole No. I8I), I915, was 70 for I894 and 102 for 1912. showing a difference of 32 per cent., which represents the average variation of all commodity prices in that period. But to assume that the averaging manipulations have produced a correct index of variations from such conflicting price movements as those of cotton and maize seems to us a rash conclusion, especially when we observe the difference made in those conflicting prices by a due allowance for the varying labour cost of producing the various commodities that enter into the price equations.

If through improved agricultural methods the cost of growing cotton fell by half, the fall of price should be registered by an index number as an appreciation in the purchasing power of the sovereign and a decrease in cost of living. But if at the same time, through improved production of gold, the sovereign has depreciated by half, the money price of cotton would be unchanged and the index number unchanged, showing no increased purchasing power and no decrease in the cost of living: whereas, really, society would have got double the amount for both cotton and gold for the same amount of labour, and have experienced all the business exigencies common to such trade movements. This error is due to the fact that ordinary index numbers, by accepting the reduced market price, recognise the altered cost of production in the commodity. But on the other hand, the index number does not recognise reduced cost in the gold, but supposes its price to be always the same.

As whenever variations in the cost of producing gold occur they alter the price of the commodity, and whenever the cost of producing the commodity alters, it also alters the price of the commodity, we cannot possibly tell by the level of price at different times which quantity in the equation of price has altered, whether it is the gold value or the goods value that has moved, or how much either of them has altered. To measure the movement of price, we must have some unit of value that does not vary with cost of production, or a unit that has a compensating element that adjusts itself inversely to the variations of cost. The thing that most readily adjusts itself inversely to the cost is the demand and its reciprocal supply or quantity, so that to get a compensated unit of price it must include quantity of commodity, number or weight, as one of the elements. But a quantity of one thing cannot be compared in a ratio with a quantity of another thing that has no quality in common with it. We cannot say how much gold a bushel of maize equals, unless they have some element of quality in common, such as the element of value. We cannot use value, however, in our compensated or fixed unit of value, because value varies with cost of production. The only other element common to commodity and gold that we know of, is labour time; time is a fixed measure common to all labour and things. If the element labour time is combined with the com- 
pensating element quantity, we get a unit of value that is fixed, the labour unit of value that does not vary with labour cost.

Such compensated commodity unit with a fixed value is found in our price index number, or, as we shall call it hereafter, the " normal price" of commodity. This normal price consists in the number of articles produced per person (labour unit) multiplied by the money price, and, as we hope to prove in the following chapters, competition insures that as the number of articles produced increases, the money value per article decreases, or vice vers $\hat{a}$, a compensating adjustment which insures that the value produced per person or "normal price" remains the same. As the normal price does not vary with cost of production of the commodity, but only with cost of gold, the movement of this price measures solely the change in the value of the sovereign. On the other hand, as the market price varies with the labour cost, both of gold and commodity, the difference in movement between the normal and market price measures solely the alteration in cost of commodity. The normal value being unaffected by increased productivity, we know that if normal prices increase, it is due solely to depreciation of the sovereign, that is less labour cost of gold, and that it does not increase the cost of living at all, though the market prices are higher. If normal prices being stationary or falling, the market price is going up (as in English coal, Diagram 28), we know that it is due to increased cost, and that it is to that extent an increase in the cost of living.

If we apply this compensated unit of labour to the above case of variations in cotton and maize prices, we find that the normal price of cotton between I894 and I9I 2 varied by a rise of 106 per cent. as against 56 per cent. shown by the market prices in Table 22 ; and that in the same period the normal price of maize also varied by a steady rise of 106 per cent. against the ups and downs shown by the market prices in the previous table. In Table 23 we give the normal price variations of these commodities, and in this form they can readily be compared with those of Table 22 .

\begin{tabular}{|c|c|c|c|}
\hline & $\begin{array}{l}\text { Years from } \\
1894 \text { to } 1899 .\end{array}$ & $\begin{array}{l}\text { TABLE } 23 . \\
\text { Years from } \\
1894 \text { to } 1904 .\end{array}$ & $\begin{array}{r}\text { Yea } \\
1894\end{array}$ \\
\hline & $\begin{array}{l}\text { A rise of } 3 \text { per cent. } \\
\text { A rise of } I\end{array}$ & A rise to 67 per cen & A rise to 106 per \\
\hline
\end{tabular}

From these figures it appears that the prices of these commodities have moved practically in unison, which fact in itself is evidence that their movement is due to the common cause of depreciation of gold, and also that the disturbing factor of cost of production has been eliminated by the use of the unit of labour. It will also be seen that such figures would require a very little simple averaging (none in this particular case) to give the general price movement. The average movement for the whole period is 106 per cent., and from Diagram 33 
it may be seen that the normal price of coal for this period in the United States varied by 97 per cent., so that the average variation of these three typical American prices is I03 per cent. 'To put this in the form of an index number percentage comparable with the U.S.A. index number quoted above, the percentages of variation must be divided by half; that is because the U.S.A. index number for 1912 is calculated upon the higher base year of $19 \mathrm{I} 4$, whereas our percentages are from the lower base of 1894 . If this 1894 base was taken in the usual index method as equalling roo, the average rise of the three commodities would from our figures be from 100 to 203, or reversed to compare with the U.S.A. index, from 203 to roo, which is 49 per cent. difference, against the 32 per cent. shown by the ordinary index number given above; so that if our normal price is the true measure of the depreciation of the sovereign, the ordinary U.S.A. index number is $I 7$ per cent. wrong, if used for that purpose. Moreover, as this 49 per cent. is all due to the depreciation of the sovereign, that is, increased production of gold per person, it does not indicate any increased cost of living. But on the contrary, the difference between the average rise of market prices in Table 22, and normal prices in Table 23, and the difference between normal and market coal prices for the same time, show that there has been a fall of about 54 per cent. in commodity prices due to greater production per person, and that means a fall in the cost of living.

But it is not only because the ordinary index number does not show the same variations as our normal prices that we think it is not a sound method of investigation. That conclusion depends, of course, on whether our compensated unit of value can be shown to actually adjust itself to varying cost of production. But that the price variations of separate commodities are more alike in the normal price form than in the ordinary market price units is itself evidence in favour of our labour unit method of examination. All normal prices of commodity will not give such striking uniformity of movement as in the above example, owing to the various causes that commonly disturb the course of prices, and which will be discussed fully in the following pages. But this case of cotton and maize prices may fairly be taken as an undisturbed example to illustrate the full effect of the labour unit method; and the result of that method in the case of cotton, maize and coal very obviously suggests that when the essential element of cost is properly recognised, a variation of the price level is found to be something that affects all prices similarly and to approximately the same degree; that is, an alteration of price level is an actually general movement, not simply an excessive movement of some prices that may be found to alter the average level. Such an average could be made of the most fortuitous and extravagant price happenings in which there was no general movement at all, in which the generality of prices did not participate. 
If an index number has any rational purpose whatever, the average price level it represents must be one in which prices of commodities generally are participating to a similar extent. The fact that coal, wheat and wool has gone up greatly in price would not argue that the cost of living has gone up, unless it was supposed that the extra cost of these things or some other general cause would produce a rise of price in things generally that are consumed as "living" by the community. If woollen cloth was dear, tailoring might be cheap, and more cotton might be used. If bread was dear, less might be eaten, and meat might be cheap. There is not necessarily any increase in the cost of living; and if men live on cheap meat, and wear cotton clothes, we have no justification whatever for taking the high price of wheat and wool and, in the form of an average, adding it to the price of meat and cotton, to prove that men's cost of living had gone up. The only thing that can justify averaging the price of one commodity with another in an index number is the assumption that there is some general cause why all prices should vary in the same direction and approximately to the same extent. This assumption is warranted by experience, and it alone can justify making averages of price movements.

If index numbers are justified by representing a really general change in level of price, it follows that any gross irregularity between the price movements of various commodities, as in the above case of cotton and maize in Table 22, is evidence of some error. Either the price movement indicated is not really general, and must not be assumed to add to the cost of consumers' goods anything beyond what the recorded price of such goods may testify to, or else the market prices of goods are not a reliable guide to changes of price level, and make a defective index; so that, when by our normal price indexes for each commodity we show that the price movement is general, and approximately equal for them all, it is evidence that this labour cost method is the more correct.

There is another case of contradictory results from index numbers which indicates that the method of calculating them leaves much to be desired if they are to be of any use in practical questions of price variations. If the much-quoted index numbers calculated by Jevons and Sauerbeck (Tables I9 and 2I), are examined, it will be found that there is a fall in price from an index of 157 in the year $I 809$ to 69 in 1902. As neither of the calculations alone covers the whole period, the two have to be taken together, although they are not directly comparable, not being based upon quite the same selection of articles, and having a different base year, which is in fact an average of prices for a Io years' period in place of a single year's prices to represent the 100 in these particular indexes. Nevertheless, during the short period for which the two tables overlap, that is, from 1846 to 1865 , it will be found that although Sauerbeck's figures are all 
higher and the variations more pronounced, they follow the same direction in most years, while in those where they do not, the divergence is only a few points, and that is probably somewhat magnified by Saucrbeck's tendency to greater fluctuations. The general trend of price is the same in both, showing the lowest point in 1849 and the highest in 1857 ; although Jevons does not show the high point in 1864 , he leaves off in 1865 at about the same relative position as the other. Since that year we only have Sauerbeck's figures, which show a further fall to the lowest point in I 896 , ending in 1902 at 69 . This great fall in prices can be clearly seen on looking down the shortening lines which indicate the proportional yearly rise or fall on the diagram.

It is very remarkable that when we turn to the various diagrams showing rates of wages for various people we find that from $185^{\circ}$ wages have been rising all the time that prices have been falling. In Diagram 24 the rate of wages paid to farmers' horsemen in Scotland shows at a glance the exactly opposite movement from that shown by the index number of prices; the wages have risen from $f_{19} 7 \mathrm{~s}$. to $£ 433$ s., and it may be seen by the table of wages paid to coal miners in France that this rise has been going on ever since 1847 , anyway; so that if we take the period from I847 to I9O2, we find that wages have gone up 104 per cent., and yet prices were 26 per cent. lower in 1902 (Diagram 21). If we take the whole period covered by the index numbers the contrast is still more remarkable. There is not much evidence of what wages were paid in the early part of the nineteenth century, but from the few records of agricultural labour and a few French figures for builders, carpenters, etc., they seem to have been much the same, but may have been a trifle higher than in 1847 . At any rate, they must have risen about 120 per cent. from 1809 to 1902 . As to the fall of prices in that time, Jevons' index number shows 157 for 1809 , and Saucrbeck's number for I902, reduced to compare with Jevons' figures, would be 57 , which shows prices to have been 175 per cent. higher in 1809 than in 1902. Yet, while they have been falling from that high point, wages have gone up at least 120 per cent.! When we remember it was shown in Chapter III., on the division of the national income, that wages were more than half the value of the production, it is hard to believe that wages can go up roo per cent. while the price of the product that they are half of is falling a like amount. As shown by the Census of Production for the United States and other evidence given in the above chapter, it seems certain that wages are always 57 per cent. of the product; so how that product can fall greatly in price while 57 per cent. of its cost has gone up to more than double is hard to see. And it certainly seems that if an index number gives such impossible results, it is hardly a useful means of research, and that wages movements should be a better guide to price variations. 

DIAGRAM 24. - RATES OF YEARLY CASH WAGES OF HORSEMEN ON

Married horsemen living in cottages. The average of five farms (John Smith, James Fleming, John Morrison, David Kirkpatric, and Thos. Biggar and Son). Report on the Wages of Agricultural Labourers in the United Kingdom.

$\& \quad 10 \quad 20 \quad 30 \quad 40 \quad 50 \quad 60^{\text {Year }}$

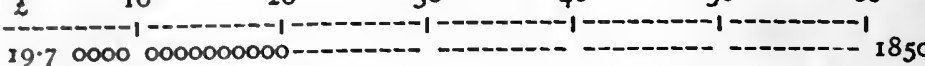

19.700000000000000

19.700000000000000

19.700000000000000

19.700000000000000

$20.100000000000000-10-155$

$22 \cdot 2000000000000000$

23.1 0000000000000000

$23 \cdot 700000000000000000$

23.700000000000000000

$24.5000000000000000000-1860$

24.9000000000000000000

25.60000000000000000000

$25 \cdot 70000000000000000000$

25.80000000000000000000

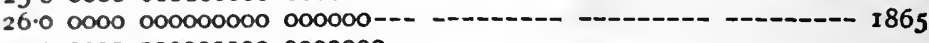

27.000000000000000000000

27.8000000000000000000000

$28 \cdot 70000$ 000000000 000000000

28.70000000000000000000000

29.40000000000000000000000

$30 \cdot 0,0000000000000000000000$

$30 \cdot 200000000000000000000000$

3I.I 00000000000000000000000

$32 \cdot 2000000000000000000000000$

33.50000000000000000000000 0000--

$34^{\cdot 2} 00000000000000000000000000$

35.50000000000000000000000000000

35.80000 000000000 000000000 000000

$35 \cdot 2000000000000000000000000000$

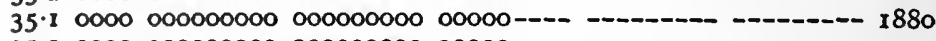

$35 \cdot 1000000000000000000000000000$

$35 \cdot 3000000000000000000000000000$

$34^{\cdot 6} 000000000000000000000000000$

$34 \cdot 7000000000000000000000000000$

34.70000000000000000000000 00000-

$37 \cdot 30000$ 000000000 000000000 0000000

37.5000000000000000000000000000000

$37 \cdot 200000000000000000000000000000$

$37 \cdot 300000000000000000000000000000$

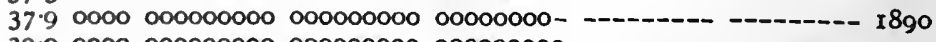

39.00000000000000000000000000000000

$39 \cdot 40000000000000000000000000000000$

39.40000000000000000000000000000000

39.40000 000000000 000000000 000000000

40.I $00000000000000000000000000000000-1895$

40.40000 0000000000000000000000000000

40.7 00000000000000000000000000000000

4I.1 00000000000000000000000000000000

4I.40000 000000000000000000000000000

42.40000 000000000000000000000000000 00--1-n- - -

$43 \cdot 20000000000000000000000000000000000$

43.2 0000 000000000 000000000 000000000 000

43.3 0000000000000000000000000000000000

43.3 0000000000000000000000000000000000

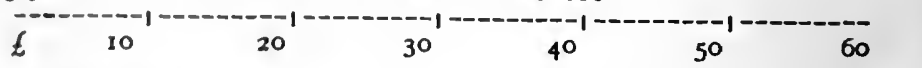

The above-mentioned rates of wages for horsemen (Diagram 24), is the only continuous record of wages in Great Britain that goes back for any length of time. But it is well supplemented by the 
record of coal miners' wages in France (Diagram 58), and perhaps still better by the remarkable table showing the wages paid in Krupp's steel works at Essen in Germany (Diagram 59) In this record we find the average daily wages in Germany have gone up from Is. $3 \frac{d}{d}$. in 1853 to $5 \mathrm{~s} .4 \mathrm{~d} d$. in Ig09. If we disregard the first two years which are probably rather too low to be quite a true record, the rise of wages in the period is 225 per cent. Such a rise is so remarkable that if unsupported by other data, it would hardly be possible to think it a true record of the facts, but all other European and American figures show the same considerable rise. Tables of wages are given (Diagrams 60 and 63) for agricultural workers in Sweden and highway workers in Norway, both showing the same upward movement which is just the reverse of that shown by the index number of prices. The most important record is perhaps that given by the United States Census of Production, because it covers the earnings of a large number of people and trades, and is therefore more likely to correctly represent the mean rate of wages. Unfortunately, the figures are taken for one year only in each decade, so that they will not make a chart of yearly variations as in the other examples; but as given below (Table 25), they show the great rise that took place during the century :-

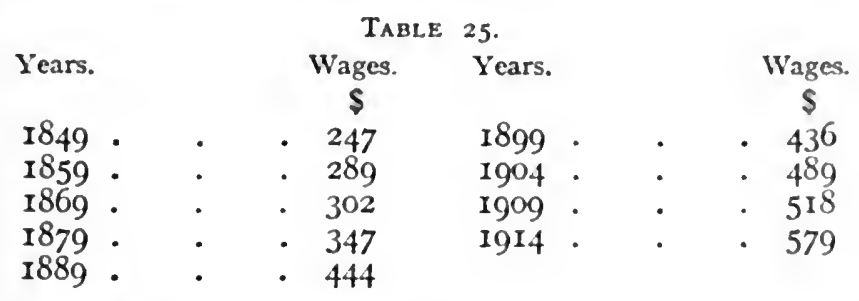

This increase which amounts to 134 per cent. is much less than the German figures given above, yet much too large to make it possible to believe there has been a fall in prices during the same period, while wages form 57 per cent. of the price that has fallen (Diagrams 61, 62, 64, 65).

In the above argument we hope it has been shown, in the first place, that the ordinary method of calculating a general index number by getting the average variation of prices does not in any way show that there has been any definite amount of rise or fall common to all articles or ascribable to a common cause. In the next place, that there is another method of calculating price index numbers for particular commodities, from their cost basis, giving results which make the usual index numbers look uselessly elaborate and of doubtful validity. And thirdly, there is this glaring contradiction between the fall in the index number of prices and the rise of wages at the same time, which throws considerable doubt upon the claims of the general index number to any great usefulness- 
in fact, seems to show such numbers to be actually wrong in that they show a fall of prices where no such fall can be. Yet if it is a matter of fact that certain commodities exchange for less gold than they did, the average amount by which they have fallen relatively to gold must surely be the average fall of price, and this the index number correctly shows. But is the amount of gold a thing exchanged for its price? We think it would be a negation of the common meaning of words to say it was not; yet some economists do not seem to think it is. Jevons clearly thinks not, as shown in the following quotations from his "Theory of Political Economy." He says: "It is scientifically incorrect to say the value of a ton of iron is the ounce of gold." "Nor is there value " (ratio of exchange or price) "in the iron nor in the gold." "Value in exchange" (price) "expresses nothing but a ratio." But if the price is not in the iron nor the gold how can there be a ratio of price between them ? As a matter of fact there cannot be ; as we have before shown, there would be no ratio of exchange or value between unlimited iron and unlimited gold, the circumstance that they exchange in any ratio depends on supply, cost, scarcity or something outside the things themselves, so any ratio of value must be a ratio between those outside circumstances. One of the most obvious of these circumstances that affect ratio of exchange, is that of quantity or amount of a thing. And as quantity is always expressed in numbers, which are ratios, it is natural to conclude that when the quantity or weight of commodities have been stated, that is all that is required to give a ratio in which they will exchange. But again, if there is no exchange value in the commodities there certainly is none in their weight ; things do not exchange for others because they are bigger or heavier, nor simply because there is more or less of them in existence. For iron is higher in price than coal, although there is probably far more iron in the world, and aluminium is more costly than either though its ore is probably the commonest mineral in existence.

As the number attached to commodity to represent its quantity does not constitute value it seems the ratio is one of abstract numbers only. Therefore, if there is any value concerned in the exchange, it appears still to reside in the particular commodity, or the gold given for it. The inherent value or, more correctly, the inherent usefulness of a thing cannot constitute its exchange value because there can be no ratio between specifically different usefulnesses. What is the ratio of bread to gold, for instance? would be a meaningless question. As we have seen we must in this case introduce some term of quantity to give meaning to the question. Mr. Jevons was obviously right in saying that the specific usefulness of the commodity did not constitute its value, and that the introduction of a measure into the equation did not make any ratio possible between an ounce 
of one usefulness and a ton of another. But it does not quite follow that the value which constitutes a ratio might not be inherent in a certain quantity of the articles exchanged. Is it not possible that the difficulty lies in the unit of quantity not being the right one?that it does not tell us what we require to know? What is it we actually want to know about a thing to enable us to contrast it in a ratio with other things? Perhaps the above example of aluminium is the most practical illustration we can take of the factor that makes a ratio of value possible. Its ore, alumina, is the most plentiful mineral in the world, so that the high price of the metal aluminium does not depend on scarcity; it is not nearly so useful to man as iron is, so its costliness does not depend on its utility or innate value ; and its weight as a basis of exchange value is about the most misleading standard that could be imagined. It must be most obvious to any one that the relatively high price of aluminium depends on the circumstance that it requires a great amount of labour to extract the metal from its common ore. In fact its cost of production is great, and any unit of quantity that is to form or determine its proportion in any ratio must be a unit of this labour or cost. It is not sufficient that we should simply attach a word expressing quantity or weight and say a pound of aluminium is worth $9 d$.; there is no possible ratio between a pound weight and $9 d$. In what ratio will $9 d$. exchange for a bushel ? is an unanswerable question. If we are to be able to answer it we must first have some idea of the nature and value of the thing measured by the bushel. Nine pence does vaguely represent to the mind some quantity of trouble or labour in getting or earning it, and a quantity such as a pound or a bushel does, though still more vaguely, represent cost of things in general because weights and measures are more or less familiar to every one as representing the things they buy or that they are paid for producing. If we were told that aluminium was worth 845 ., we should at once ask, how much aluminium for that price? Not because we wanted more or less of it or wanted it at all, but because we wish to attach some sort of meaning to the information given, and we know that it costs more to produce a large than a small quantity. We probably should not know whether the price was high or low when we did know the quantity, but we should get some dim idea that 84s. for a pound of the metal was a high price, or that the same price for a ton of it would not be an excessive price; but at the same time we should feel quite in the dark as to the true value of the commodity. If on the other hand we were credibly informed that it would take two men seven weeks each to make a furnace, another two men a like time to dig the clay, and yet another two men seven weeks each to melt out from the clay a ton of aluminium, we could roughly estinate that the six men would want an average wage of about $£ 2$ each per week for the seven weeks which would 
come to $f S_{4}$; and we should at once realise that $84 s$. was no price for a ton and that a ton of aluminium would cost from $£ 80$ to $£$ Ioo. The time required to produce a thing, or the number of persons required to make a certain amount in a given time, is the only information that can directly enlighten us as to real value or price of anything. Because with that information alone can we directly compare the result produced, with what from experience we find we can ourselves produce in a like time. The price per pound or ton is but a vague indication of any real value, while the price per person is much more instructive, as it represents very nearly the cost of production-would represent it absolutely if the record of the persons employed upon it was absolutely a true record of the actual numbers, and the time they worked upon the particular commodity.

This "quantity produced per person," is the only informative measure of quantity we can have in an equation of value, because it is the only quality common to all commodities. The only thing that enters as an essential and definite factor into all production, is labour; and labour when analysed is simply a portion of lifetime used up in producing some commodity or service. That portion of time is a factor of intrinsic value to each individual and never alters in value and is never affected by cost of production. Probably every economist has recognised this and would agree that labour was the best possible standard of value. But they seem to have despaired of making practical use of it, because as Gied puts it : " it is hopeless to look for a measure of value in trouble or effort, since they themselves would need to be measured, and we have no dynamometer which could do this." No, perhaps we cannot measure the effort, but we can measure the time it takes, and that is all that is necessary to constitute the average labour cost of a commodity. It does not matter whether an individual's " effort" in production is above or below the average effort of the community. What his production will be worth in exchange for a part of the general production of the community, will depend upon the average amount a person can produce of each commodity in an equal time.

Thus we can have a measure of labour or " effort " of production. And as this labour time is inevitably associated with the quantity of any useful thing that is produced in that time, it gives to that quantity of the thing a value which is always in a ratio to the portion of labour time in other things. So the labour in the ounce of gold is the value of the iron produced by a like amount of labour. But as the labour in the ounce of gold is not always the same, the ounce of gold is not the value of the ton of iron, nor does it correctly represent a ton. We have, however, previously seen how it is possible by taking the total value produced per person-that is, the number of articles produced, multiplied by the price; or the price per person instead of the price per weight or measure, to get a compensated unit 
of value which we call the labour unit. This unit of commodity value being composed of an element of labour common to the sovereign, combined with the element price, which is based on the nominal value of the sovereign, the unit so composed will vary directly with the sovereign. So that if the price of iron per person or "normal price" of iron is $\ell 4$, the ounce of gold literally is the value of the iron, or vice versa. Moreover, if the price of iron falls because a ton and a quarter is produced per person instead of a ton. competition will bring down the price per ton to $£ 345$. But as $\mathrm{r} t$ tons are produced per person the normal price will still be $f_{4}$, and the ounce of gold still the value of the iron. If at the time the market price of iron was falling the labour cost of gold was falling also, so that $£ \mathrm{I} 5$ s. was produced per person instead of $£ \mathrm{r}$, competition would bring the value of the sovereign down to $5 \mathrm{cwts}$. of iron again, instead of $6+$ cwts. ; so that $£ 5$ must be given for $1 \frac{1}{t}$ tons of iron. The iron is then $\ell t$ per ton again, but as $I_{4} \frac{1}{4}$ tons are produced per person the normal price is $£ 5$, the extra $€ \mathrm{I}$ showing the depreciation of the sovereign.

In this last case the market price has not varied, but the normal price has moved with the change in the standard value (gold). In the former case the market price did vary, but the normal price did not, because there was no change in the standard of value. It should be observed in passing that it is not necessary that gold should always be the standard of value, nor is that standard always actually conformed to in a gold standard community. We may at times speak of a low or special standard of prices, which exception will remain to be explained at a subsequent point. But as in a gold standard country value should always conform to that standard, we shall assume that normal price does so conform unless reasons are given for an exception.

From the above examples it may be seen that granting the necessary competition to make the gold standard valid, we have in the " normal price" of commodity a unit of value that while it always correctly represents the price at which the producer sells his produce, it never varies from any cause except change in the labour cost (value) of gold. The value of the amount of commodity produced is always the value of the amount of gold specified in the price. And as all variations of normal price represent change in the natural value of gold, such prices can be correctly used to discount the variations of market prices in regard to cost of living, and any practical questions regarding variations in cost of production, or sharing of national income. Nor is this normal price a new invention, for it is simply the cost price of the production per annum to the community - what the community pays the producer. It is the cost of production including profits as Ricardo puts it ; and seems to be the same as the older economists called " natural price." 
Probably the chief reason why writers never give any prominence to what they call natural price is because, not having the data for finding the labour unit or normal price, they only regard natural price as a sort of invisible mean or tendency of prices which never emerges as actual price, or even as a recognised mean price. Economists seem profoundly impressed with the conviction that prices have nothing practically to do with their cost of production, though, so far as we know, no one has ever given a comparative list of prices and costs of commodities or even of one commodity, to show that the price of an article does not conform to its cost of production. They seem to take it for granted that prices vary in all directions, while cost is virtually stationary. So the first point for us to try and establish is that there is an evident method and order of price variation which becomes apparent when prices are stated by their normal value, and not simply as market prices per unit of quantity.

The ultimate reason for the examination of prices is to discover whether the natural or " normal" price of commodity, which obviously is the cost price of the thing to the community, can be fairly regarded as the thing's cost in labour of the community. If prices are regarded as varying promiscuously and independently in any direction and extent that a capricious demand and supply may determine, it might be reasonable to suppose that there may be indefinite margin for exorbitant profits, rents and other charges, that have no relation to labour cost, yet which are all included in the natural price. But if that was the case, it would be impossible that they should show any common movement that could be traced to variation in value of gold or other common cause. So that our first object is to show that there is a movement common to all prices that would probably be found to be nearly uniform if actually correct data could be obtained regarding normal prices.

But it might be supposed that as our labour unit is compensated for changes in cost, increased cost, due to overpaid management or to profits, would not prevent normal prices varying uniformly with the gold movement, however excessive such profits or rents might be. But it must be remembered that prices including profits and rent cannot vary indefinitely above or below cost of production in independent cases, unless in such cases competition is inoperative or partly so. And if competition is inoperative it must also be remembered that the labour unit ceases to operate, as its compensating quality depends upon competition. So the normal price ceasing to be compensated, it would vary with cost, and not show the price movement in sympathy with cost of gold. If the use of normal price in the investigation of prices shows a movement of commodity prices in sympathy with gold, it proves that competition has operated in the cases under examination, and that their price must have been 
very near the mean cost, or they would not respond to the slight variation in the valee of the sovereign. So that there is a double purpose in discovering a common trend of price movements. It is evidence that there has been effective competition that has kept prices at a level that was sensitive to, and therefore presumably dependent upon, the labour cost of gold; and that such level could scarcely be anything but the ratio of value fixed by the relative cost of producing the goods and the gold. Then incidentally this common movement shows that the labour unit has the compensating quality we have claimed for it.

The complete nature of the connection between labour cost of gold and goods cannot be demonstrated at this stage of our inquiry. It is necessary to appreciate the true nature and extent of price fluctuations before we can completely see the industrial mechanism that determines the level of prices. And when we come to investigate fluctuations of prices generally, during any considerable period of years, we soon find as other economists have done, that the data are very insufficient, especially as normal prices have not commonly been quoted and therefore have to be calculated from that data. The excellent method adopted in the United States, and followed in our own Census of Production, of quoting normal price figures as output per person, does not help us very much in drawing up tables of yearly price movements, as these great general Censuses are only taken once in ten years. The normal price can be calculated by dividing the value of a commodity produced per year by the number of persons employed in its production. And this is easily done, provided we have a record over any considerable period of the net value produced, and the number of persons employed in any industry. But as these records are not very often complete, there are not a great many products the price of which can be thoroughly brought under review on the normal price or cost basis; and there are very few where the number of persons employed can be directly obtained from records covering any number of years. The best record of this labour unit in price that we have been able to find is the value produced per person employed in the coal mines of the world, and as was the case with wages in the same industry, the series going the farthest back are those published by the French and German Governments. They start from the year $186 \mathrm{r}$, and give the yearly record down to the present time, and as we have already cited the wages rates for the same period, they will form a suitable starting point for our review of prices.

The method of examining these prices as we have explained, is to get the normal price by finding the total value of the coal produced each year, estimated by its price at the pit head, and dividing it by the average number of persons employed in the mines that same year; and we give the results of these calculations in tabular form 
in Diagram 26. It will be seen that there are four columns of type in these diagrams; first the tons of coal raised per person per year; second, the market price or price per unit of weight, that is per ton; DIAGRAM 26.-NORMAL VALUE PRODUCED PER PERSON IN THE COAL MINES OF FRANCE.

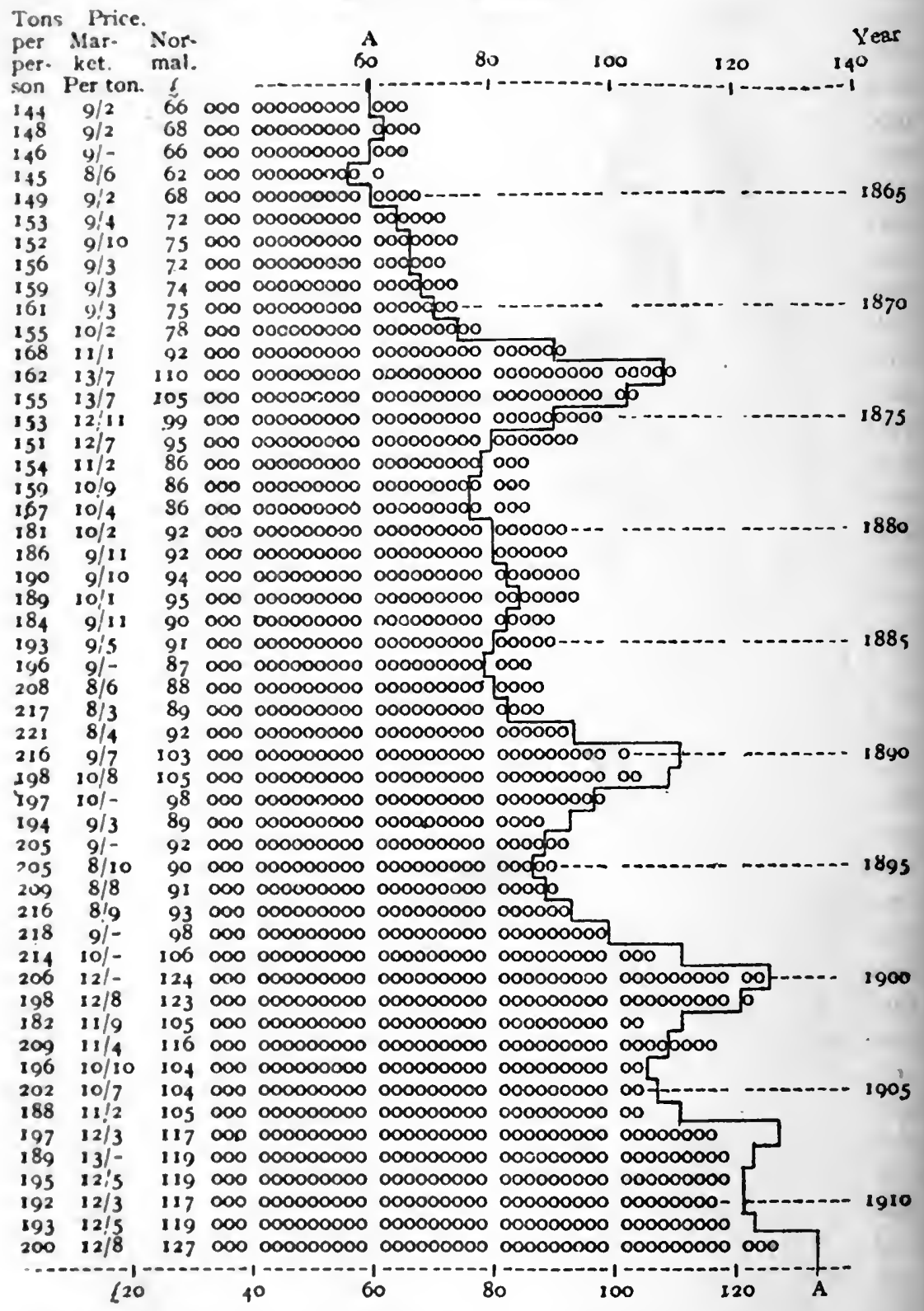

third, the normal price or price per unit of labour ; and fourth, the proportional lines showing graphically the ratio in which the normal prices vary year by year. It is this graphic portion that has been 
made the chief feature of the diagram, so that the yearly fluctuations of normal price can be readily seen and compared with other diagrams and with the curve AA, which is seen on this and other diagrams and represents the average normal price movement.

It will be seen by the first column of the diagram that the number of tons produced per person has increased from $\mathrm{I}_{44}$ in the year $\mathrm{r} 86 \mathrm{I}$ to 200 tons in 1912, and that there has been a fairly regular rise during the whole period. This rise indicates an improvement in the means of production: there is now less labour in a ton of coal, which looks as if the price should be less, whereas our second column shows that the price has risen. But we should remember that price is the ratio in which the result or product of labour will exchange for a like amount of labour in any other commodity or in the same commodity ; that is, a coal miner may spend his earnings in coal. So if he raised one ton of coal in $186 \mathrm{r}$, he could sell that ton for 9 s. $2 d$., and buy one ton of coal or a like value of anything else with it. If in 1912 he raised two tons at the same price, and sold them for $18 s .4 d$., he could buy two tons of coal or a like value of anything else. If the price had gone up in I912 to I2s. $8 d$. per ton and he raised two tons, he could sell them for $25 s$. $4 d$., and still only buy two tons of coal or anything else that had the same amount of labour in its productionsay a hundredweight of soap. The market price does not seem to matter, so the important question arises as to whether the prices in this second column really represent the price the coal producers get at all, because, if the price in I 912 had remained only $9 s .2 d$., the miner, having raised two tons, could buy two tons of coal for $18 s .4 d$. just the same. And whether he could still buy the one hundred weight of soap does not depend on the price of coal, but upon whether labour in producing soap had varied to the same amount as that in producing coal or whether it had varied differently. The amount his two tons of coal will purchase depends on how the normal price of the things he buys has varied, and one of these things that he can purchase is gold. Of that in I 912 he would get rather more than a quarter of an ounce, or $£^{\mathrm{I}} 5 s$. $4 d$. for his two tons, and that is what the second column represents-the amount of gold a ton of coal will exchange for, not what the producer gets for his labour-time. The price might have been I2s. $8 d$. in 1861 , when he could only raise one ton, and he would then only have been able to buy one ton of coal and probably only half a hundredweight of soap.

So that it is not at all obvious that the second column of figures represents the real price of coal ; it might just about as well claim to represent the price of gold. When we turn to our third column, showing the normal price, which we claim is the price the producers ;et, we find it differs considerably from the market price, and this lifference, as we shall hope to demonstrate later, is what shows the eal price changes. But at present we are chiefly concerned to show r.w. 
evidence for the existence of normal prices which exhibit wellmarked and constant fluctuations and constitute a definite law of price movement.

This normal price is represented in the third column and graphically in the body of the diagram, where it can be well seen by the lengthening lines that there has been a continuous general rise throughout the whole period. It is true there are several considerable rises and falls, the most conspicuous of which is the rise from 1870 to 1873 , which was probably due to the trade boom following the war of 1870 ; and it is possible that the South African War was responsible for part of the rise in Igoo also. But with these partial exceptions, the fluctuations are probably true normal price variations, and it is important to notice these rise and fall periods that stand out in the diagram like promontories on the general curve of the rising price line. The highest points are in I873, I883, I890, I900 and I9I2, and the lowest in $1864,1878,1886,1895$ and 1905 . These five well-marked periods of high prices will be found to occur in most countries at the same times and are important to remember, as they are significant in the study of real price movements. A smaller detail of fluctuation may be noticed in the production per person for I902, which had fallen from 198 tons in I9OI to 182 in I902, owing to a strike in that year. This small production accounts for the rather irregular drop in the normal price to $£$ I05, and probably means that the strike was late in the year and that the shortage had not time to raise the average price for that year, so that the higher price was carried on into I 903 , thus causing the normal price to go too high in that year, as it did in the case that will be pointed out in the diagram of English coal prices.

The most important thing to realise from the diagram is that the normal price shows certain distinct fluctuations upon a curve of rising prices throughout the whole period covered by the record. This rise is just the reverse of what is shown by ordinary index numbers, as may be seen from the Board of Trade Index given in Diagram 20. In coal, part of this rise coincides with a rise in the price per ton, which is by no means the case in all other commodities; but whereas the rise in the market price is from 9 s. $2 d$. to I2s. $8 d$., or nearly 35 per cent., the rise in normal price is 92 per cent., showing a great difference between the price per ton, on which alone the ordinary index number is based, and the changes of price shown by the normal price, which includes the unit of labour. That the rising curve of price shown by the normal is the more correct evidence of the actual movement is very much confirmed when we compare these coal diagrams with those of wages, which were cited above. For the gross contradiction between the movement of wages and price is quite removed by the normal price curve evidence.

In the diagram showing the fluctuations in the normal prices of 
coal raised by the miners of Germany (Diagram 27), the first noticeable feature is the low value produced per person in the earlier years, starting in $186 \mathrm{I}$ with only $£ 45$ value per person against $£ 66$ in France,

DIAGRAM 27.-NORMAL VALUE PRODUCFD PER PFISON IN THF: COAL MINES OF GEKMANY.

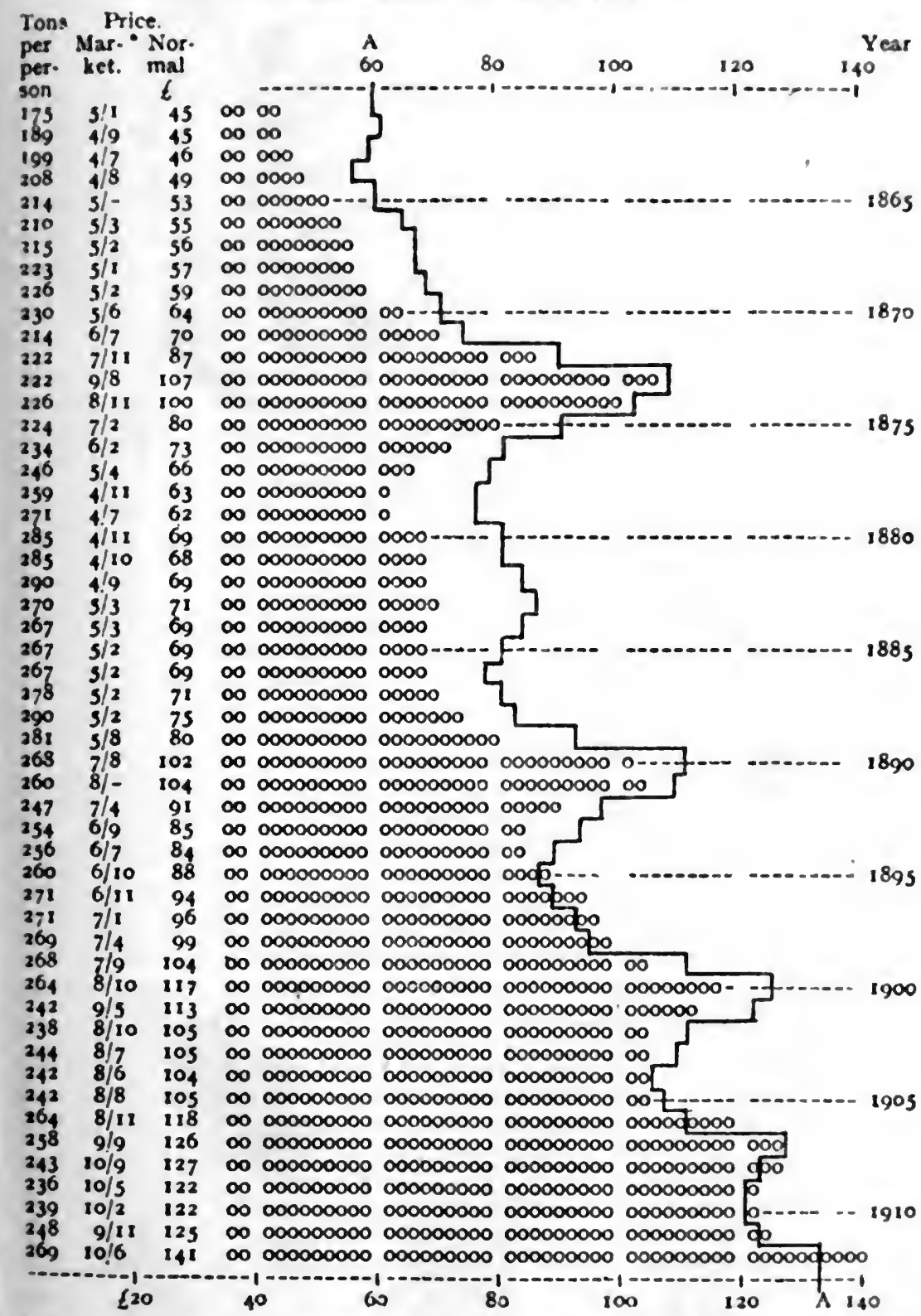

a fact that is the more remarkable because in the first column we find that the tons per person were greater in amount than the French production all through the period, starting with 175 tons in 1861 . 
rising to 290 in I 882 , and again in 1888 , and standing at 269 tons in I9I2 against 200 tons in France. Although it is not easy to see exactly why this should be the case, there are no doubt many contributing causes to these local differences in the standard of value produced in different industries and localities. The great difference in this case is probably due to the somewhat backward state of the industrial community in Germany in the years previous to I890. The high output in tons shows that the industrial methods of production could not have been far behind the standard of other European countries, though to some extent this tonnage may represent longer working days and more easily obtained coal. But although the output shows good productive organisation, it usually happens that in newly-commercialised countries the social status of the industrial classes is below the average standard of prosperity long after the productive ability of the community has become very efficient. Such countries can very effectively compete with others in all manufacture and trade while still remaining very poor themselves-at any rate, apparently so when their wealth is measured in money. An industrial community may submit to a low productive valuation of itself, which is a point that will be discussed more fully in the chapter on wages ; but here it is only necessary to point out the possibility of this explanation and direct our attention more particularly to the relative similarity of the price variations.

But this difference in the level of normal price makes it rather difficult to determine where the curve AA should be drawn on the various coal diagrams. As coal production affords the best evidence we have for the actual value produced by the persons employed in producing it, we take it as typical of the average production per person or " normal price" obtained in industry generally. Therefore we draw the curve AA that is to represent the average level of normal price year by year to fit as nearly as possible the three typical coal index diagrams of France, Germany and the United Kingdom. It will be seen that the curve is too low in the French and too high in the German diagrams in the years previous to 1890 , but is about correct for the production of the United Kingdom, so far as that record goes back. This curve, which is taken as typical of the average production per person for each year, will be represented on each of our normal price diagrams, so that the production in each commodity examined can be readily compared with the theoretical average for the year.

In the case of these first three diagrams the line AA helps very much in the comparison of the fluctuations of the normal prices in the three countries because it is the same curve in each, and although the German level of price is much lower, it may be seen to correspond to the movement indicated by the line. Whatever the cause of the low value produced in German coal mines may have been, we find 
that the normal price or value produced per person has risen to the same standard as other countries as German commerce has reached its modern high efficiency. It is rather interesting to see that under the stimulus of war prices and trade expansion in the years about I873 the value produced per person in German coal mines rises to much the same position as in France. This probably means that in this and other more advanced industries the social condition of the industrial classes rose to the level of that in France and England, but as the improvement probably did not include the whole of the industrial population of the German Empire, the better organised and better remunerated producers were swamped by cheaper production from the large areas of the Empire where custom still set a lower value on productive ability. So the normal price, which includes the total value both of profits and wages, fell again below the European average till about I890. However, from that time forward the normal price of coal produced in Germany has increased, overtaking France in I896, and being highest in Europe in I9I2.

Although it is not to be expected that the price movement should be the same in both countries, it is important to notice how they follow the same directions in their fluctuations, the highest points coming in $1873,1883,1890,1900$ and 1912 , the only difference being that the rise of 1883 is a little less and that of 1912 a little more marked. It is to these definite and undulating fluctuations common to nearly all countries that we wish to direct attention; and their systematic nature is made more evident if we glance at the columns of market prices on the various crop indexes in the following chapter. In those columns, the prices seem to follow no rule or continuous direction, but appear to jump one way or the other at random, a fact that should be kept in mind while noticing the undulating and similar movements in normal prices. These similarities point strongly to some underlying cause which affects prices generally, and it is the nature of this cause which we want ultimately to determine. For, as we have seen above, the value a producer gets for his produce does not depend upon the market price; and from the case of the German coal producer it does not appear either that it depends directly upon the quantity he produces. We are evidently not yet in a position to state exactly by what normal price is fixed. It is necessary first to discover some constant factor affecting all prices in common as distinguished from local disturbances of a particular price, and our first step is to demonstrate a common movement which may result from such common cause.

These general movements and their cause alike are often much obscured by disturbing factors in productive operations, such as strikes, wars, large speculative adventures, etc., and also by defective data and records; so that the systematic undulations of the price curves are not always easily made apparent in diagram form, espe- 
cially if the period covered is a short one, because any irregularity in the movements becomes proportionately larger as the number of fluctuations covered becomes smaller; and this is unfortunately the case with the English coal returns. Nevertheless, in the tables of coal prices for the United Kingdom (Diagram 28), the same general fluctuations are quite obvious, the periods of high prices coming at the same times, namely, I883, I890, I900, I907 and I9I3. The rise in $I 890$ was considerably greater than in the two previous countries,

\section{DIAGRAM 28.-NORMAL VALUE PRODUCED PER PERSON IN THE} COAL MINES OF THE UNITED KINGDOM.

Tons Price.

per Mar- Nor-

per- ket. mal.

son. Perton. $\leftleftarrows$

$\begin{array}{ll}333 & 5 / 7 \\ 322 & 5 / 5\end{array}$

$\begin{array}{ll}322 & 5 / 5 \\ 319 & 5 / 2\end{array}$

$315 \quad 4 / 10$

$318 \quad 4 / 10$

321

315

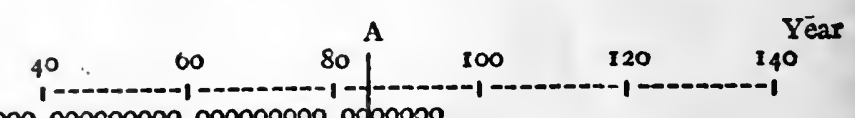

and on the other hand the fall of I895 was more marked, suggesting that prices had been boomed above their true position and had caused a reaction in the following years. In Igoo again the rise was much larger owing to the great quantity of coal required for the fleet during the South African War. Although the very marked rise in 1907 and its fall in I9Io is not mentioned as a high point in the other countries, it should be noticed that there was the same tendency in all the diagrams to a greater or lesser degree. During this period there was a steady fall in the number of tons raised, which is the converse of what happened in the other countries, probably indicating 
that coal is getting more difficult to obtain in England. The quantity, however, has not always been diminishing, as in 1873 only 250 tons were raised; but unfortunately there is no record available for the prices in these early years.

In addition to the similarity of these periods of high and low prices it is instructive to notice the undulating curve of the rise and fall. The prices tend to advance for a few years together and then fall back for another short period, not to start up and down alternately or regardless of any general direction. This is an important part of the evidence we wish to bring forward in support of our conception of a definite and systematic cause of price variation. But it will be noticed that there are one or two exceptions to this even movement observable in our diagrams. One such irregularity has been pointed out in the French coal tables, and in the English returns for the years $1893-4$ the proportional lines show irregular movement. They require to be reversed to complete the symmetry of the falling curve, and the undulating effect of the whole diagram is a good deal marred by the defect.

On the assumption that prices depend upon labour cost of production, such an irregularity as the above is inadmissible without some recognised disturbing circumstance, because the labour required to produce a thing that is not affected by the season can hardly be supposed to fall one year, rise the next, and fall again the third, as both increased facilities and difficulties of production are usually gradual and progressive.

So in this case, as in some others, some cause of irregularity had to be sought for, and it was a matter of no little interest to detect by the figures the existence of some disturbing social events, and to proceed to discover what the events might be that were forecast by the newly-made price diagram. In this case it was soon discovered that there was a big coal strike in I893. But theoretically a strike should not affect the normal price, as, while it raises the market price, it lowers the number of tons by which that price is multiplied, so that the value should remain the same. The problem was puzzling, and it required some thought to realise that the secret lay in the fact that the coal strike came at the very end of the year. The stoppage of the mines at the end of $\mathrm{I} 893$ very much reduced the number of tons raised, and as there was no further output in that year a rise of price could not be realised to compensate for the short number of tons raised in the season. Therefore the total value or normal price fell by the whole amount of coal not raised during the strike. But the following year there was inevitably a shortage, and coal prices went up before the re-opened mines could catch up with the demand. The high prices stimulated output, and the number of tons increased also, so that the value or normal price rose in 1894 to balance what it had fallen in 1893 . 
This is a good illustration of the transient and circumstantial influence of supply and demand, for its effect depended in this case solely on the fact of the financial year ending before the coal prices had got adjusted to the lessened productive power of the miners, which was $I 7$ tons less per man; whereas, if the financial year had been from July to July, instead of from December to December, the price would probably have agreed with the cost of production in both years, and the curve of normal price on the diagram would have been symmetrical. Also, the fact that our

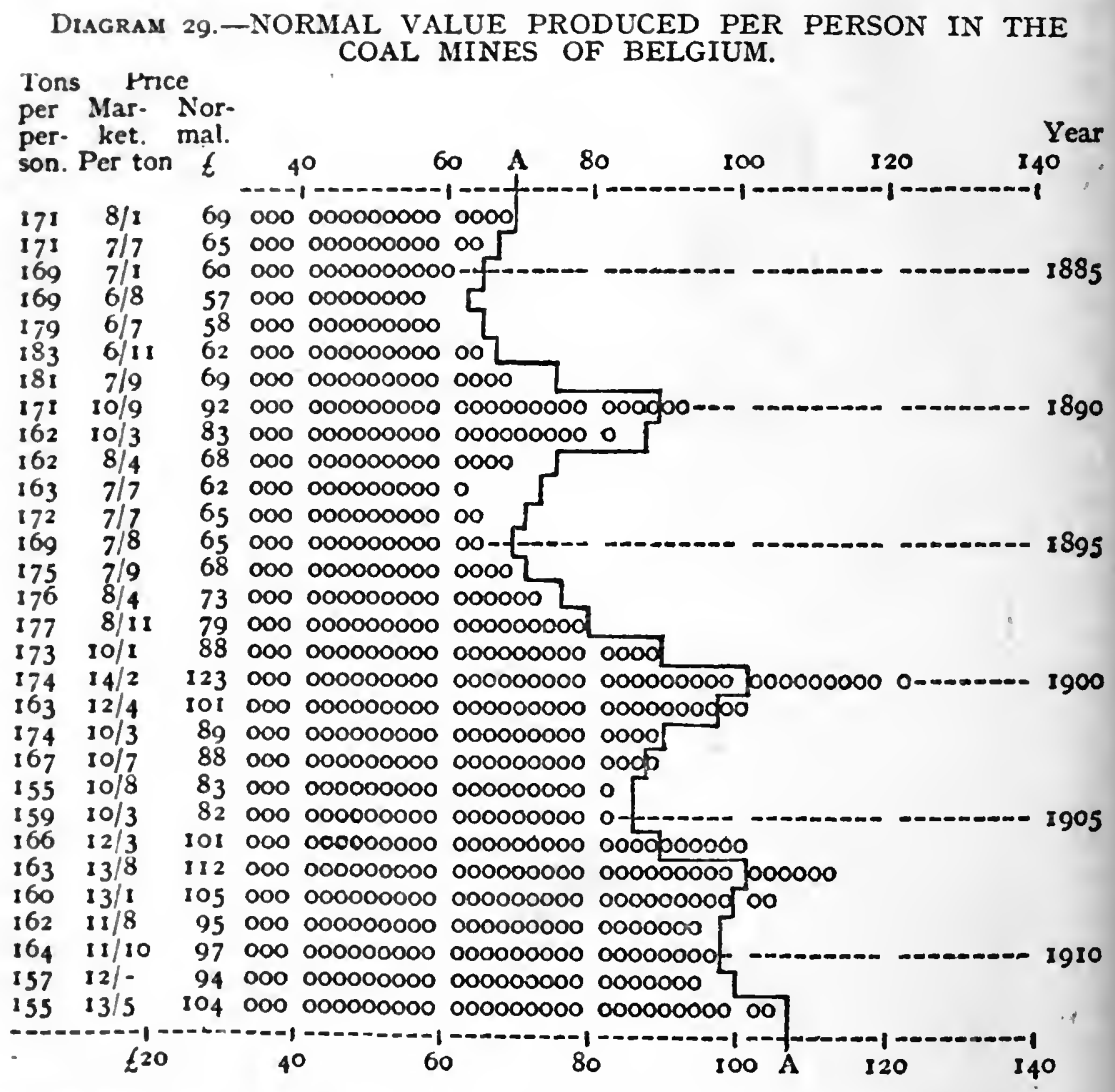

diagrams of normal prices can in this way indicate a small circumstance in the productive conditions of the country is evidence of their theoretical soundness and that normal price is definitely connected with the amount produced per person or its labour cost.

The remaining coal diagrams are introduced to point out the general similarity of movement in prices throughout Europe and even, to some extent, in other parts of the world. In Belgium (Diagram 29) the variations since 1883 are very much the same as in England, except that they show a rather lower level of normal prices. But this difference is not nearly so marked as that in the 
number of tons raised, which are very much lower than in this country; the greatest number being $\mathrm{r}_{3} 3$ tons in 1888 , and the smallest number being 155 tons in 1912 . This indicates that in Belgium, as to a less extent in England, coal is being obtained with increasing difficulty, which has not been met by sufficiently improved methods of working, and that the market price has gone up as the result of higher cost, as is shown by the very high prices in the second column. It further shows that there can be very little competition between the various countries, or prices could not remain so high in one of them throughout a long period.

In Spain there appears to be an opposite change in the conditions of coal production, the output having increased of late years. But the production per person is very low throughout, showing that there is an inferior productive organisation in Spanish mines; and that, as noticed in the early part of the German coal records, the social conditions of the industrial community were on a very low financial basis at the beginning of the period. The money valuation of the industrial productivity has, however, gone up in sympathy with that of more advanced commercial countries, so that the recognised value and also the actual production per person have gone up very fast in the last few years, making the rise of normal price since 1903 very much greater than in the other coal records that we have noticed.

These big alterations in the industrial status of a country very much alter the general appearance of the normal price fluctuations as represented on our diagrams. But it will be found that the fluctuations are really much the same in proportion to the general level of value produced, and that they change as that level does, so that the fluctuations of normal price are greater as the general level of value produced is greater towards the end of the period (Diagram 30). The rise in normal price up to 1890 is only feebly marked, but the fall in 1904 is distinct, and the rise from there comes as in other countries. The year I 900 itself falls short of the mark, owing probably to some labour trouble that we have not as yet been able to find any record of. The next year, however, it is up to the average line, and is followed again by the usual fall. The next rise in production per person that takes place up to the year I9ro is, as we have said, much more marked than in the other countries, owing to the improvement in the industrial conditions and the establishing of international conditions of competition.

The lower level of the value produced per person in the Spanish and Belgium coal industry makes it necessary to set the curve AA at a different level on the diagrams; for whereas in the United Kingdom index the curve runs from about $£ 80$ per person to $€ \mathrm{r} 30$, in this one it is only from $£ 40$ at the top to $£ 60$ at the bottom. Not only is the level of the curve lower to fit the average level of the normal price produced, but the fluctuations are made proportionate 
to the lower level also. As this will be still more obvious in other normal price indexes, the method of drawing the curve might be explained before going further. As of course to per cent. difference between two long lines shows as a greater actual difference than a Io per cent. difference between two short ones would, the curve that was made to fit the variations of the long normal price lines in English coal would not fit the same proportional variations in the much shorter lines of Belgian coal production. Obviously the fluctuations of a curve representing the proportional difference

Diagras 30.-NORMAL VALUE PRODUCED PER PERSON IN THE

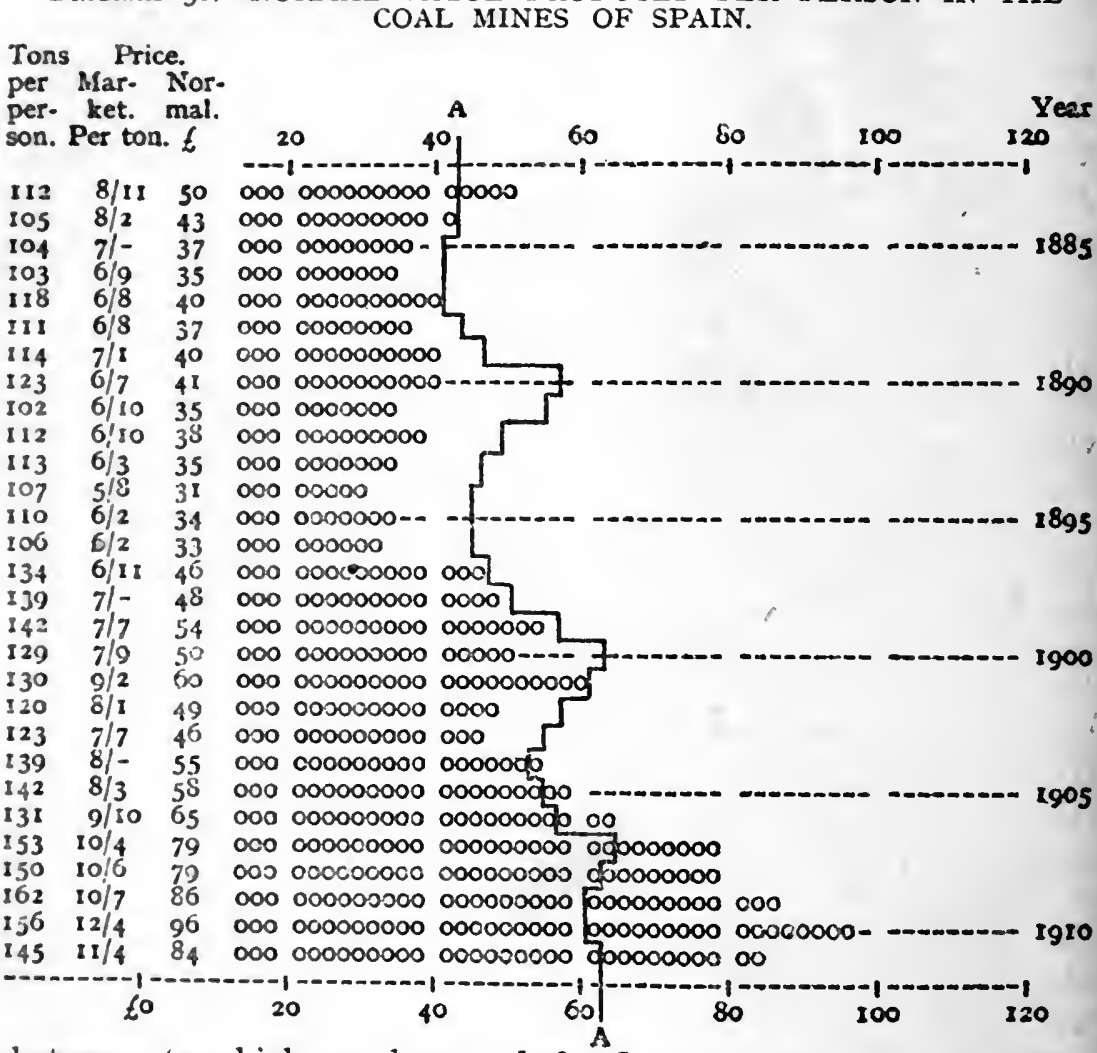

between two high numbers and the fluctuations in a curve representing the same proportional difference between two low ones must be different sized fluctuations, in the same proportion to each other as the integral numbers whose proportions they represent; so in comparing normal prices of two commodities in which the average production is different, the normal prices are totalled up and an average made for each commodity for the same series of years. Then the yearly variation in the one commodity should be to the other in the proportion that the average production of the one is to the average production of the other. The position of the curve AA each year on any diagram varies as much in proportion to its average 
normal price as the yearly normal price of coal in France, Germany and England varies from its average normal price; so that $A A$ is the same curve on all diagrams, but drawn in proportion to the average value produced per person, or average normal price for the whole period in each commodity.

If, as explained above, the high or low production per person in any particular industry necessitates a changed proportion of variation for the curve AA, it should also be changed in its proportions whenever the average production in any industry has changed during the period covered by the diagram. But as for general purposes of comparison it is simpler to have the same curve on every diagram, no alteration has been made for improved production during the period under

DiagraM 3t.-NORMal VALUE PRODUCED PER PFRSON IN THE COAL MINES OF JAPAN.

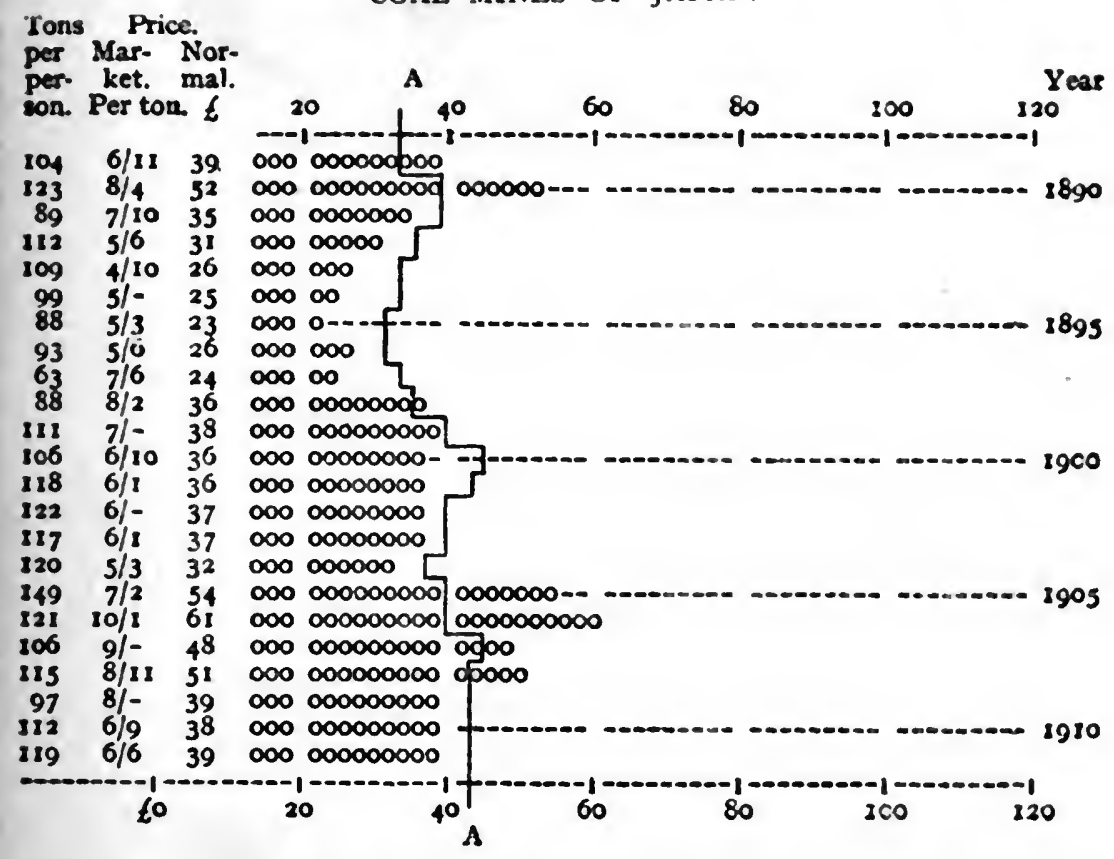

examination, so that when, as in the German or Spanish coal index, one end of the period is much below or above the average line, some allowance must be made for the changing industrial conditions; and it is the tendency of the normal price to rise and fall as the curve AA rises or falls, rather than the actual distance from the line, that is evidence of a common cause of movement. The whole period in the Spanish coal index is so much affected by the change from primitive to more efficient industrial conditions that the sensitiveness of the normal price to the common cause of price level is not so complete as in the more highly commercialised countries. Still, as pointed out 
above, the same fluctuations may be seen to occur in the price of coal even in this rather remote field of production.

The diagram of coal production in Japan (Diagram 3I) can hardly be expected to follow very closely the trend of European prices, but the same character of fluctuation can be seen, and there is some distinct resemblance to the same periodic high and low points. The chief exception is in the years about I905, where the great rise of value is due to the war with Russia. Although the agreement between this diagram and the others is not very complete, it is really remarkable that in a country so remote both geographically and

DIAGRAM 32.-NORMAL VALUE PRODUCED PER PERSON IN THE COAL MINES OF AUSTRALIA.

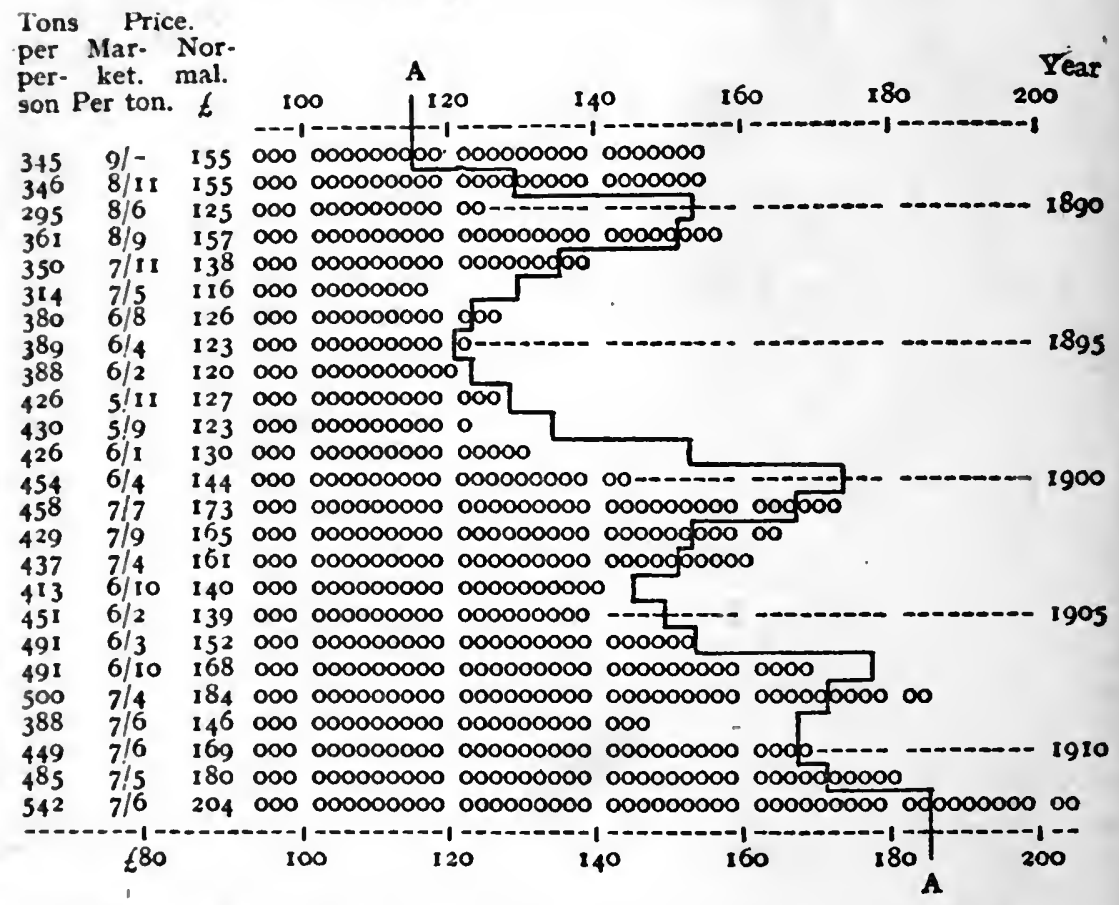

socially as Japan there should be any resemblance at all between price movements of its productions and those of European countries.

In the Australian coal prices (Diagram 32) we have an example of the variation of values in a gold-producing country whose gold supply influences the European gold basis. This probably accounts for the fact that, although in many respects the commercial conditions prevailing in a gold-producing country are of a somewhat special character, the price fluctuations are much the same in Australia as in England, though the normal prices are very much higher, and the rises and falls are more pronounced. The periods of highest prices come in the years I89I, I90I and I908, which is in each case a year 
later than in this country. The low points come at about the same places as in the other diagrams, though the very marked fall in I 909 is exceptional and probably was caused by undue inflation of prices in the previous year.

In the United States of America (Diagram 33) we have an example of prices in a gold-producing country whose gold does not influence the European gold supply; and in that country, consequently, prices are on a somewhat independent basis. As will be seen from the diagram, although the price movements start somewhat in the same way as in the other examples, after the year 1898 there is no real

DIAGRAM 33.-NORMAL VALUE PRODUCED PER PERSON IN THE COAL MINES OF THE UNITED STATES.

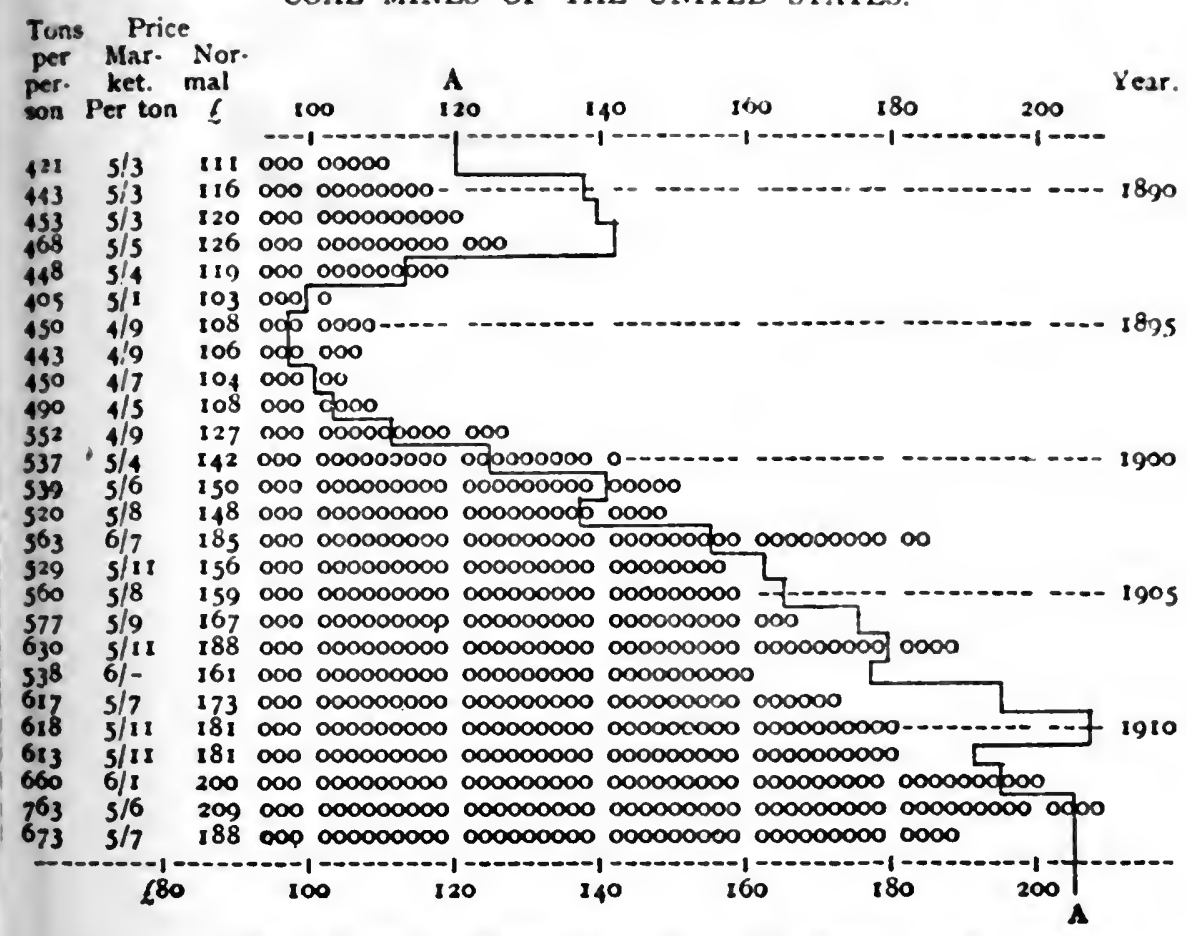

Note.-AA on this diagram is the curve of American prices.

resemblance whatever; from that year there is a great and continuous rise from $£ 108$ to $£ 209$ in 1913 . If the figures are noticed, it will be seen that there is no fall of prices in 1905, as was the case in European countries; and, further, the two projecting lines of high prices that break the continuity of the general upward curve are both irregular. That of 1903 was the result of a very big coal strike in I902, which did not end until October; and the price not having time to fully rise to the scarcity figure, the rise was carried on into the following year, as in the English strike of 1893 . The other rush up of prices in 1907 marks the great commercial boom year in America, which led to excessive speculation and inflated prices, 
resulting in a great slump and commercial crisis in I908. These irregularities break the symmetry of the curve, which would otherwise have shown an even rise of the normal prices quite unlike the fluctuations in Europe. These American prices are so different from our other examples that they will have to be discussed further when we come to American prices examined as a group by themselves; and the diagram is introduced at this point chiefly to illustrate a case of great increase in production without lowering the market price.

It will be noticed that the normal prices of coal shown in these diagrams have gone up enormously both in America and Australia, which is the more remarkable when we notice that the market price is nearly stationary, or has actually fallen in the latter country, a movement which, though not common in coal prices, would probably be found to obtain frequently in the prices of manufactured goods, especially in the earlier years, as shown by most index numbers. At first sight this case of Australian coal prices might suggest that it is the market price that best conforms to the quantity of labour theory of value, because this increase in the tons per person means, of course, less labour per ton, and in the Australian case the price has fallen with the less labour in production. In England and Belgium, on the contrary, the tons per man having decreased means more labour per ton, and the prices have gone up as the result. But this coincidence is quite superficial ; there is no proportion between the rise of market prices in Australian coal and the amount of labour or number of tons. And if the prices are examined in detail it will be found that they do not follow any rule with regard to the number of tons ; they sometimes rise with the less labour instead of falling, as in the years $1907=49 \mathrm{I}$ tons at $6 \mathrm{~s}$. Iod., and I $908=500$ tons, that is, less labour, at $7 s .4 \frac{1}{2} d$. per ton; and in the United States, where the labour has got much less per ton, the price per ton has not fallen at all, while in Germany, where the improvement in production and lessening in labour has been very great, the price has gone up greatly as well. There will often be found to be no regularity or order in the variations of market prices, such variations being the chance result of local supply and demand.

On the other hand, when we take the normal prices which are based upon the unit of labour, we find that this price, which is the price the producer gets, has gone up in every country during the last 30 years, whether the tons produced or the price per ton happen to be more or less ; and, also, we find that the variations of the normal price follow the same periodic fluctuations in most countries. This uniform result suggests that the unit of labour used as the measure of value brings prices to a common basis, which is subject to a common cause of variation; whereas the unit of quantity, such as a ton, introduces no common basis or consistent rule of variation. Although we are not yet in a position to fully explain the exact relation between 
the amount of labour and normal price, it may be seen that because the labour unit introduces order and consistency into price variations, it is probably the sound and essential factor in the determining of value. More than that we can hardly explain at present, because, although we have introduced into price the essential unit of labour, we still have not made any study of the industrial mechanism by which gold is made the effective standard of value. As this mechanism consists of the individual competition to obtain the maximum return for the labour performed, there are hardly !ikely to be any direct data to illustrate the precise industrial and commercial contrivances by which the equilibrium of value per person is continually secured. That such adjustments take place could be demonstrated by showing that normal prices did actually vary in common with the value of gold ; but, as was pointed out when speaking of the national income, the data for normal price per person are very imperfect and nonexistent for many industries. Therefore our normal price diagrams can at best only be approximately correct ; and it is necessary to examine all the possible examples of such price variations to see whether amongst the many irregularities there can be discovered any movement that can be recognised as common to all normal prices.

Theoretically, of course, all normal prices should vary alike and in common with the movement of the standard of value. But when it is remembered how very imperfect ordinary statistical data are, it must be obvious that no such theoretical exactness can for a moment be expected. The zigzag line AA on the diagrams represents the theoretical curve of the gold movement, but even that has been estimated, as will be explained later, on very inadequate data. But even if the data were good it would not follow that the price movement should be exactly alike in separate commodities, for although the average skill and opportunity tends to be alike for all, it may not always achieve that uniformity under special circumstances or over wide geographical areas. Therefore the object of our price diagrams is not so much to show that a great uniformity of price movement exists between all commodities, as to show that they are all sensitive and respond to fluctuations in the common standard of value; so that the explanation of irregularities, such as the strike years mentioned above, is sometimes better evidence of sensitiveness to the gold standard than absolute regularity would be, as it shows that a deviation from normal in one direction requires a counter-adjustment to restore equilibrium.

This sensitiveness of prices is evidence of the normal price being the labour cost price, because no such sensitive adjustments could be felt unless the price of commodities was sufficiently near to their average cost of production to render cost an essential consideration whenever there is any change in the standard of value. 


\section{CHAPTER VI}

NORMAL PRICES OF CROPS, ETC.

Is continuing the investigation of normal prices in other commodities the first difficulty is the absence of data with respect to the unit of labour; industrial returns being either altogether wanting, or when they are made, the net output, the number of persons employed, or something is wanting that is necessary to ascertain the output per person ; or the returns are only for short periods, or made singly at intervals of time, as in the various Censuses of Production; the one British Census giving the only data of the kind for most industries in this country. That being the case, we are obliged to trust rather more to estimates than is desirable, and are still limited in our choice of commodities to those for which a return of some sort has been made.

The best data we can find for our purpose are those from various agricultural products, with regard to which the Board of Agriculture has for some time past published returns of prices and acreage. As the average amount of labour required to cultivate an acre will be the same whether the crop is good or bad the labour cost of the crop can be represented by the number of acres used in its production almost as well as by the number of persons employed, except that in a long period of years there would be some lessening of the labour required per acre owing to improved implements, modes of transport, etc. This error will probably account for a large part of the overhigh normal prices in the first few years on our crop indexes, as great improvements in reaping and ploughing machinery were coming into general use very fast in this country about the year 1885 . We have no data for getting the normal price before the season I884-5, as, although the acreage and price have been recorded, there are no returns for the crop per acre, so that we do not know what the returr. per acre or per person was.

The above statement with regard to the acre correctly indicating the amount of labour only applies to the same or similar kinds of crop, there would be a very considerable difference in the amount of labour per acre required to grow a crop of oats or a crop of garden produce of some kinds. Although in a general sort of way it is recognised that the difference in price between a gallon of corn and a gallon of strawberries has something to do with the cost of growing them, it is by no means always recognised that the difference in price between all different kinds of produce very closely represents the 
difference in cost, their prices being simply the real labour-cost, including of course the labour of the entrepreneur or owner of the business, whose share is usually called profit. It is usually vaguely supposed that these differences in price depend on many things other than labour, such as speculators and middlemen's profits, obtained, as it is assumed, without their having contributed to the labour of production-a most unwarranted assumption-and on various like extortions by financial rings and combines. All these ideas amount to nothing more than a belief that there is room for indefinitely large profits between the cost and the selling price; the cost being wrongly supposed to consist of wages and expenses only, as if the entrepreneur's labour was a free gift of nature. This is a belief and standing cause of complaint, persisted in by the public generally, in spite of the fact that every one finds in his own business that it requires much labour to get a reasonable profit at all.

This popular fallacy is much encouraged by the hopeless failure of economists to explain the phenomena of prices, and the inextricable confusion of their vague theories, or rather their vague generalisations, expressed by terms like utility and demand, which, as we have seen, may describe the phenomena in appropriate language, but can explain nothing whatever. In contrast to this indefinite conception of price as simply the chance result of a combination of circumstances and its corresponding to cost by accident only, as Professor Marshall tells us, we contend that price always closely approximates to cost, and the average price over any considerable period is actually the cost of the commodity to the community. It should be repeated that we mean by cost the cost of production including profit. And it may be contended perhaps that if we mean that any amount of profit, rent, interest, and extortionate charges of any sort, that may come to be included in the price of a thing, is to be called part of its cost, then of course it becomes a truism that its price coincides with its cost. Truism or not, it has been much contested by many economists; and it remains a fact that whatever work, real or imaginary, is charged for in the price of a thing, is part of that thing's cost to the community. If production is badly managed, and an extravagant price is paid for part of the work that is not work of any use or value, that unnecessary expense is part of the cost, and is included in the price. It should be clearly understood that the purpose of this investigation of normal prices is not to prove the truism that price is cost including profits, but to show reason for believing that in a competitive community profits, including rent and interest, are controlled by a definite law, which, under normal conditions, restricts them to a proportion of the price which fairly well represents the recognised value of the services of the entrepreneur or owner of the undertaking.

In attempting to demonstrate the truth of this contention, we are 8.r. 
taking this questionable market price that is supposed to be the result of accidental circumstances, and multiplying it by the amount of coal produced in a year, or the crop of corn produced in a year, thereby getting the total value of the coal or crop. This is the total cost of that crop or output of the commodity to the community: but this cost cannot be compared with the cost of other things, or with the expenditure of labour generally, unless the unit of quantity in that cost or price is one that is a common measure of quantity in prices of all other commodities or services. A ton, pound, or bushel, is not a measure of quantity common to all forms of production; the only such common standard of measure is the labour time expended. To get the total value expressed in this common measure of quantity, we divide the total value produced by the number of persons producing, or by the acre which represents the persons, and thus get the value per person or acre; and this value per person can be directly compared with the value per person in the production of any goods or services whatsoever, and with values in general.

This price or value per person is the cost price in the sense that it costs the community that much, and is the average value it pays to each person who is employed to produce the commodity in question. And it is the actual cost of producing in any sense, on the assumption that the persons employed on its production get on the average only the same value as they would get in any other form of productive work. It is the object of our investigation of prices by the labour unit method to show that competition does ensure that the producers do get only the average price per person common to industry in general ; and that the total value of a commodity or its normal price is its cost price, and that there is no surplus value beyond that cost price.

It may be contended that we are using the term " cost price" in a new and unauthorised sense which perverts the common meaning of words. But our reason for giving this meaning to cost of production is that we cannot see that, as it is used in economic writing, the term has any exact meaning whatever. To the individual business man his costs are a very definite pecuniary liability that needs to be clearly distinguished from the total value he produces, and to leave an equally distinct surplus of profit. But it is equally well known that each producer's costs are a different percentage of his total production, and he may include quite different items in his estimate of it. One producer's costs for a given commodity may be as great as another producer's total value, including his profit. But in that case, if the producer getting the profit gets it because he manages his business best, can the former producer's high costs due to bad management be in the economic sense actual costs? Are they not partly profits which he has let slip from his possessions, as too high 
rent, interest, or other form of profit going to some one else, or as -extra profit to merchants from whom he purchases his materials? On the other hand, if the profits of the well-managed concern are due to the fact that they can buy on a larger scale and drive hard bargains with the producers who supply them with materials, etc., do their costs quite represent the cost to the community? Are not the producers of their raw materials paying part of the costs as loss of their profit on the materials they supply at a price below the true cost, whatever true cost may be, for it seems distinctly difficult to say just what is cost and what profit?

Even the most exact estimates of cost include the gross price of materials purchased, about one-third of which is not cost, but some one else's profits. So that in the economic theory that regards profit, interest, or rent, as a surplus value beyond labour cost, it would seem that the ox sold by the farmer includes in its price a surplus value, but the ox to the butcher is all costs; the value of the hide that leaves the butcher includes in its price a surplus value, but in the tan pit its value is its cost price only; the value of the leather sold by the tanner includes a surplus, but the value of the leather in the leather-merchant's warehouse is its cost price only. And so the bootmaker purchases the leather at a price that includes a surplus value, but in estimating the price of boots he considers the whole price of the leather as strictly a cost of production. It is to be devoutly hoped that the consumer who finally purchases the boots may discover all these lost surpluses in the wearing of the boots, for it is very doubtful if they will ever be discovered by any one else. It should perhaps be here noticed that most economists do not actually use the phrase surplus value to express the margin of value going as extra profits or rent, but under the name of "surplus produce" or "quasi-rent" the same idea of an excess value arising without extra labour cost seems to be implied. Otherwise why should not the average cost of production of commodity coincide with and in fact constitute its average value or price? By their anxiety to prove that value is independent of cost of production writers clearly postulate the existence of these surplus values existing at each transfer of commodity from one producer to the next in the chain of industrial processes.

The existence of such surplus or excess value above the labour cost rests entirely upon the assumption that the persons receiving this surplus value have done no useful work for it, nothing that was a necessary cost of producing the value represented by the commodity, or that the value of their labour or service is not equal to the surplus value they receive as payment for it. We by no means wish to contend that many recipients of profits, interest, and rent, are not greatly overpaid for their services; but what we wish to point out is that if we claim to know that such services are overpaid, we 
inevitably imply that we know what their services are actually worth. Or, what comes to the same thing, we assume that we know what the cost of producing a commodity would be without the services of those who receive the various forms of profit in payment for their services. The assumption of any such knowledge is, we consider, absolutely without any kind of warrant. The least we can expect is that writers assuming such knowledge should give some actual figures as evidence of cost value or for the actual value of the services of persons whose remuneration takes the form of profit. But, so far as we know, no economist has even attenipted to discover what the true labour cost of any commodity or service may be, or given us any statistical evidence as to the source of such knowledge of cost value. We submit that no such evidence exists for the cost value of so much as one single commodity or service ; and we regard a cost value distinguishable from the price of a thing as a purely mythical conception, or, more correctly, as no conception at all, but simply an economic phrase.

As the supposed meaning of cost of production as distinguished from price seems quite undefinable, and the surplus value quite unmeasurable, while the existence of either of them depends on quite unwarrantable assumption of knowledge, we take it as much more reasonable to assume that the average price of a commodity is its cost price. It is obviously the cost of the commodity to the consumer; it is an actual price that can be obtained from official figures; and it does not depend upon any assumption or premature conclusion that society pays something for nothing, or mysteriously produces a value that it has not made. The question as to whether any of the labour or organisation of industry is greatly overvalued remains to be answered by the evidence afforded by the comparison of prices and price variation, and by the examination of the social arrangement by which the value produced is divided between its producers. If society pays one man to do the work, and two men to watch him do it, because none of them will do it without such arrangement, the labour of those three men is the necessary labour cost of the work. But it does not produce any surplus profit or a price in excess of cost, so that to assume the existence of such surplus to account for overvalued labour before discovering the evidence for any such unnecessary labour seems premature.

We propose to examine normal prices to see whether there is any evidence for the existence of a surplus or other excess value or price; but it is somewhat difficult to understand what surplus value may really mean. It surely must mean a rise of value above labour cost, but, value being a comparative term meaning the ratio in which a thing exchanges for other things, there cannot be a general rise of value above values generally. Therefore we take it to mean that some particular industry at times gets a higher value than others 
in the form of higher profits owing to some circumstance which gives it a monopoly of some kind. If in the commodity prices we are examining there is any case of considerable surplus valuc, or "surplus produce" making the market price and total value high in comparison with the labour, so that it is far above its labour costthat is, has few persons employed to produce the value-when we come to divide its high price by the few people, the resulting value per person will be very high. Whereas if the total value of a crop or output is near to or below its cost-that is, has many persons employed in proportion to the value-the normal price or value resulting from the division by the persons will be very low. Or if the crop of a commodity like wheat, sometimes sold at or below its cost, and at other times far above it, when we reduced these two prices to their normals, one would be above the other to the full extent that the price was above cost, as we shall point out that it was in the case of the Leiter corner in wheat; and a series of such prices, arranged as in our diagrams, would have no order or direction, but simply follow the zigzag of market price movements. Therefore, if it can be shown that these normal prices, arranged as a diagram, do not only follow a general method of undulatory fluctuations, but that this continuity of direction in their ups and downs is more obvious in them than it is in simple market prices, it must be because the total output values on which they are calculated do maintain a fairly constant ratio to the number of persons or labour cost of producing the things.

It does not follow from this that we suppose profits to bear a fixed proportion to wages and other business costs, or that profits do not fluctuate considerably, but that, as it will be fully shown in the chapter on that subject, they are governed by a definite law of competition, which keeps them a fairly constant proportion of the normal cost, and that it is great laxity of reasoning to regard them as indefinitely enlargeable and controlled only by accidental circumstances. At the present point we are attempting to show that the normal prices of crops year by year follow a similar undulating course of fluctuations to those of coal, and not an indiscriminate zigzag without direction, as they must certainly do if the market price on which they are based had no relation to cost. Unfortunately it is not always easy at once to see the suggestive similarity of undulations in the diagrams or indexes of normal price, owing to the many irregularities due to special circumstances, for it is notorious that the exceptions in such illustrations are always more conspicuous than the rule from which they stand out by contrast, but it should always be remembered that if the rule did not exist, the exceptions could not be conspicuous by contrast with it. Further, it will be explained that many of these exceptions are the result of fluctuations of profit, and in cases where such variation was considerable 
the resulting irregularity in the curve of normal price is very marked. It is the first object of these diagrams to show how variations in profit or other returns from industry are made distinguishable by this method of investigating prices; and by explaining how these rising or falling normal prices affect the supply, and how the supply reacts on the market price and profits, we hope to ultimately explain the law that controls them both.

This process of examining by diagrams the movement of normal prices is confessedly a laborious method of research, but we believe it is the only one founded on the examination of actual price figures from commercial statistics, and we adopt it because there seem to be no more direct data available. If figures were obtainable to show directly the sums expended on wages and costs of material in industries generally, it would not be necessary to adopt this roundabout method of finding the real costs and profits of commercial undertakings; in fact, there would be no problem to solve. But such information is for obvious reasons not readily obtainable, though it is much to be desired as an elucidation of economic problems; and we are glad to seize upon one scrap of such direct evidence that has come under our notice, and make use of it in giving some modicum of support to our contention that normal price very closely represents the cost of commodity.

In examining wheat and oats prices we find that while the area sown with oats each year has remained practically the same during the first 29 years covered by our diagrams ( 34 and 35), the area under wheat has fallen from $2,749,470$ acres in 1885 to only $1,970,542$ in I9r4, which seems unquestionable evidence that oats are on the average a more profitable crop than wheat. Yet if we look at the wheat diagram we shall see that the price of wheat has been rising all the time, and if that increased price is not increased cost it must be increased profit. It is very hard to see how those who hold that cost has little or nothing to do with price, and that increased prices simply mean increased profits, can account for farmers reducing the area of wheat when they were getting ever higher profits, while yet keeping on growing the same area of oats. On the face of it these facts support our view that the increased price is increased cost, including profits, and not greater profits compared with the paid labour cost, that has remained stationary. That they retain oats in cultivation shows they are the more profitable, yet the price of oats is considerably lower than that of wheat, and if price is nothing to do with cost, why should oats sell for less than wheat? If the demand price for wheat is 25 per cent. higher than for oats, why should the supply of wheat be diminished? What law of supply and demand will account for that?

Our contention is that the cost of growing wheat must be greater than that of growing oats, that there must be rather more persons 
employed to the acre of wheat than to the acre of oats, not that there is more profit to the acre of wheat. If we take an average of the normal prices of wheat and oats for the 29 years covered by ou1 diagrams, it will be found that wheat sells at about 261 per cent. more than oats; but the persistent reduction in the acreage argues that the extra cost of growing wheat must be rather more than 261 per cent. So that, as the selling price is not more than 261 per cent. higher, it does not leave the farmer quite so good a margin of profit as he gets from oats; he evidently thinks so, or he would not give up growing wheat in favour of oats. We claim that the examination of these normal prices by the wheat index method is able to show that cost of growing wheat is rather more than $26 \frac{1}{2}$ per cent. greater than that of growing oats. This obviously depends upon the assumption that there is a very close connection between the cost and the price, which assumption, we think, is demonstrated to be correct by the fact of a I or 2 per cent. difference in cost reacting upon the amount cultivated, for if it is not the cost which thus reacts, what is it? If it were simply that less wheat was wanted, the demand could be increased by lowering the price ro per cent., which price would still be higher than for oats.

We believe that our assumption that the price always nearly, and usually very nearly, corresponds to the reasonable cost of producing the thing, is quite borne out by the sensitive manner in which prices respond to the varying conditions of production, and of supply and demand; yet, as we have said above, we are very glad to come across a piece of corroborative evidence from direct cost figures. This information is contained in an interesting modern book on "The Determination of Farming Costs," by Mr. C. S. Orwin, who writes in the form of a report of the proceedings of the "University of Oxford Institute for Research in Agricultural Economics." In this book we find direct evidence of the cost of growing wheat and oats from statistical records contributed by agriculturists, and, therefore, of a direct and simple character such as, unfortunately, can all too rarely be met with. It is probably the want of accessible information regarding the very intimate details of producers' costs and profits that has led to the widespread notion that cost has little or nothing to do with prices; therefore, if our contention that wheat costs rather more than $26 \frac{1}{2}$ per cent. more than oats to grow is supported by these direct cost figures, it is a corroboration of no little interest and importance. From the investigations of this Institute as tabulated by $\mathrm{Mr}$. Orwin from records of farmers' costs it appears that the average cost of growing wheat in $1914-15$ was $£ 6 \circ 13$ per acre, and that of growing oats was $£ 4.676$; that is to say, the cost of growing wheat is 28 per cent. more than growing oats, or $\mathrm{It}$ per cent. more than the selling price of wheat over that of oats as shown by 29 years of market prices. 
This I $\frac{1}{2}$ per cent. then represents the "little more" than $26 \frac{1}{2}$ per cent. shown by our wheat index figures. Of course, these figures are not strictly comparable with ours from normal prices, as they are for quite different periods of time; therefore the exact $I_{2}^{\frac{1}{2}}$ per cent. is no doubt a coincidence for that particular year. But the fact that there can be such a coincidence puts it beyond all question that the $26 \frac{1}{2}$ per cent. is approximately the extra cost of growing wheat, and that the evidence given by the Oxford Institute supports the view that normal price represents the labour and profit in production and the total price of a commodity to the community.

As there is so very little of such direct evidence as the above to be obtained, we will continue our investigation of normal prices by examining their effect upon acreage in various agricultural crops. The first crop prices we propose to examine are those for oats (Diagram 34), because for certain interesting irregularities, that will be explained later, wheat price variations are more complicated to follow than those of oats, the supply of which comes very largely from the British Isles. The diagrams illustrating the movement of normal crop prices are drawn up on the same plan as those of coal prices, except for an additional column to be explained below and the fact that the normal price is estimated from the acre instead of the persons engaged. This, as we have previously explained, simply means multiplying the published crop per acre by the average market price, and the resulting "price per acre" is our normal price, given in the third column of the diagram, in pounds sterling and three point decimal fractions of a pound. Although this change in the unit of labour that we are obliged to make may lose something in precision, it introduces a somewhat new and interesting evidence of the practical reality of the normal price in that, as we hope to show, it is this price per acre that ultimately fixes the number of acres that will be planted each year. It is the means by which the farmers regulate the supply and bring the price up or down to the mean or "normal," which is the price, or total cost, at which they find they can profitably produce their crops. As we have just seen, such alterations in the area which the farmers will cultivate sometimes afford good evidence that prices closely corrcspond with cost. What we wish to show is that there is this normal price agreeing with cost, and that if any farmer's costs are above or below that normal, he will be found to increase or reduce his acreage of that crop accordingly, thus adjusting his supply to what he thinks will be demanded at his full normal price. He may go on, as we have seen, for years without succeeding in getting the right acreage to give him the desired full return. For when we remember that differences in profits of agriculture are probably very small, and that farmers' profits are notably subject to fluctuation through vagaries of crop and stock results, it is very doubtful whether they can know 
to 2 or 3 per cent. what returns they are getting from their crops. They may pay well some years, and be a clear loss in others; how are they to know whether a little sinaller profit is the result of too low normal prices or the bad luck of the crops? The fact is, farmers are not actually conscious that normal prices are 2 or 3 per cent. toolow; it is far too fine a point to determine in ordinary agricultural results. Yet by their watchful efforts to get the best they can from their labour, and by the controlling laws of competition and cost of production, they are as a whole led sub-consciously to adjust their acreage to the actual demand for their produce at the normal price.

It is to help in pointing out these changes in the acreage that we have introduced the column of + and - signs which indicate that the acreage was added to or diminished in that season. It would have been an advantage if we could have reproduced our detailed diagrams of monthly price movements, to show how the price at planting time affects the acreage, how the acreage planted affects the price, and so on; but the present cost of publication prohibits it. Such tables are necessary for an exact study of the effect of price upon acreage and price fluctuations, but the text will, we hope, be made comprehensible by the index diagrams alone. Diagram 34 we call the Oats Index, a title which is only used to denote a table or list of prices indicating their relation to labour and to each other, and not in the special sense of an index number, which, as we have explained above, is usually an average price of various things. To rightly understand these diagrams of prices it should be appreciated that each year is a seasonal one, starting in September of one year and ending in August the next year, that is from harvest to harvest, because it is always very difficult to keep clearly in mind what year is intended when speaking of any kind of crop that begins in one year and ends in another.

The purpose in these crop indexes is, as before, to see how far the price variations agree with each other, and especially how those of crops agree with those of coal and wages, also to some extent to show the method by which these variations are adjusted to fix the mean price of the commodity, and to agree with the variation of general prices. But it should be recognised that there is not likely to be any absolute agreement between these variations, owing to the great difference in the commercial exigencies peculiar to such very different classes of commodity as coal and corn. Crops being greatly affected by the season, the supply is continually being altered by circumstances over which the producer has no control, and, on the other hand, the ease with which one crop can be partially substituted for another makes the supply readily controllable by the farmers without general loss of output, both of which conditions are just the reverse of coal. Therefore, that the price fluctuations 
should often deviate from those of coal is in no way remarkable, the only remarkable thing is that they should in any way agree.

A general survey of the oats index, and especially of the monthly fluctuations, will give some idea of the natural and also artificial vagaries of supply and market price. The crop per acre, that is the result of the same amount of labour, has varied as much as $29^{\circ} 8$ per cent.-from 34.25 bushels in $1887-8$ to $44^{.49}$ bushels in I909. The market price, too, has varied as much as 140 per cent.from I3s. $5 d$. in October, 1895 , to $32 s .3 d$. in May, I9I5, and as may be pointed out for the benefit of the believers in supply and demand, when the crop was $29^{\circ} 8$ per cent. greater the price was Is. $5 d$. a bushel more. All these extreme circumstances must make the equilibrium of supply and demand most difficult to find, and it renders it really most extraordinary that in spite of these complications there can be any kind of resemblance between price variations in crops and those of a stable production like coal.

We are comparing oats prices with those of coal because up to this point in our inquiry the normal price of coal is the only standard of price we have got on a labour cost basis; and we wish to broaden that basis by showing that other commodity prices conform to the coal standard and establish it as an indicator of general price level. That the variations in the normal price of oats may be readily compared with those of coal, the same average production line AA will be found on the Oats Index, Diagram 34. It should be understood that this line does not represent an actual amount of money or value earned, because in this case it is the value obtained per acre and therefore not the same amount at all as that obtained per person in coal. But whatever the value produced per person in oats might be when it was stated as so much per acre and set out in lines on a diagram, as the average length of line in the oats diagram is to the average length on the coal diagram so is the proportion of variation shown by AA on this diagram to the same proportion of variation on the coal diagram. And as the average return per acre seems to be sufficiently near to the same result per person in coal to satisfy the producer of oats that they pay him as well as getting coal would do, or as any other trade would be likely to, the position of this proportional curve at any time represents the average return to industry at that time. Also, it should be noticed that the various yearly positions on AA come half a season earlier on this diagram than in coal. This is because each season in crops is part of two years, and the largest part of the season, eight months of it, is in the second year; so that the first season on the diagram includes four months of $\mathrm{r} 884$ and eight months of $\mathrm{r} 885$, and is taken to coincide with 1885 on the coal or other diagrams of annual production.

The Oats Index, Diagram 34, starts from I884-5, and that and the two following seasons show a normal price a good deal above the 
curve AA. This high return per acre is no doubt somewhat misleading, and due to the fact, mentioned above, that the acre at that time represented more labour, that is, more persons employed on it, than it does in the later years. At about that time agricultural instruments for quick ploughing, reaping, hay-making, etc., were coming into general use very quickly, and the number of persons employed per acre was no doubt decreasing considerably, while the total area cultivated remained practically the same. We have no

\section{DIAGRAM 34-OATS INDEX (UNITED KINGDOM).}

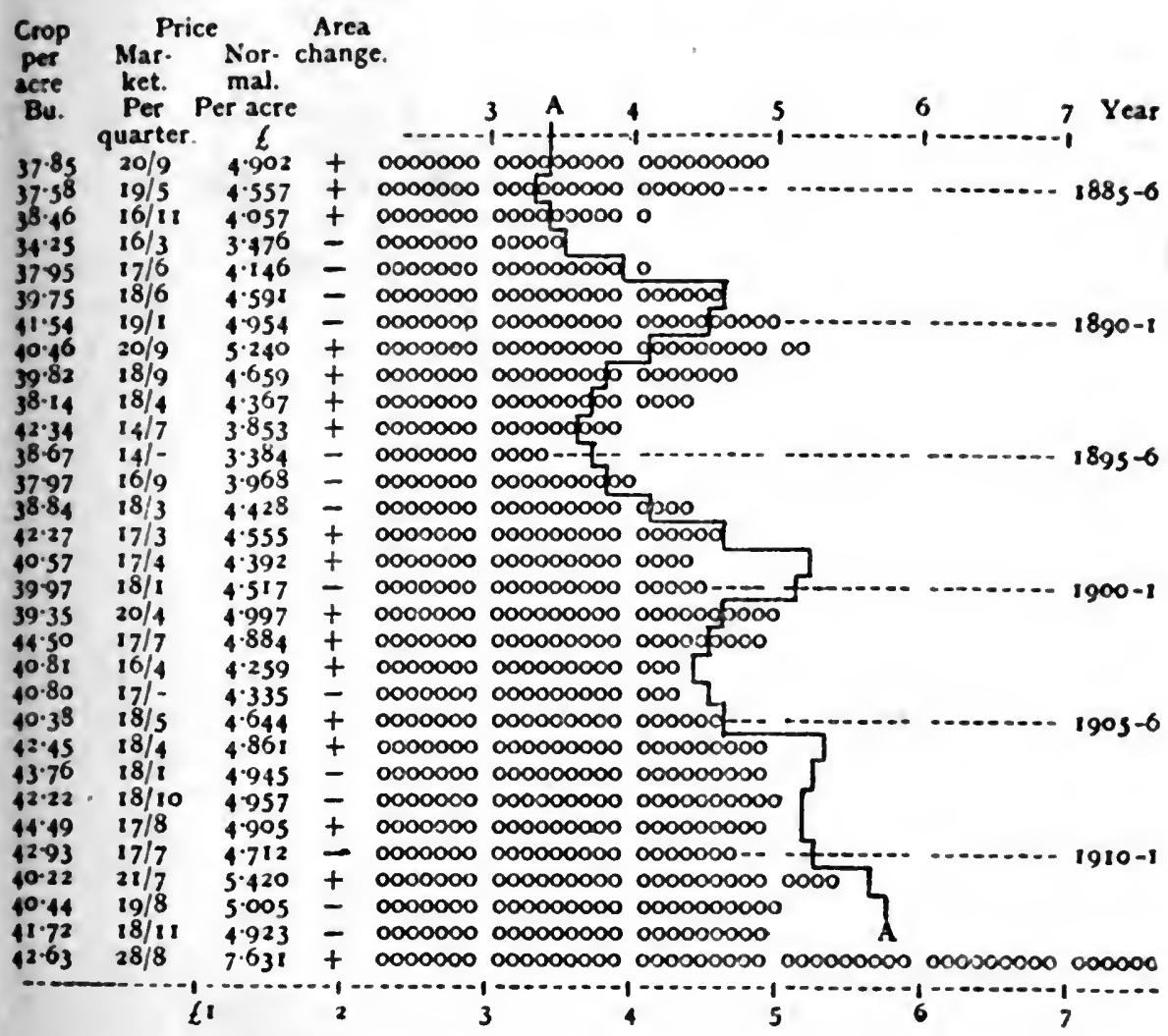

data for the labour actually employed on arable land, but while from I88I to I90I the total area cultivated in Great Britain was the same, the Censuses of Occupations of the people show that the number of labourers had decreased so much that whereas each person in I88I cultivated 23.3 acres, they cultivated $29^{\circ}$ I each in Igor. This means that our normal value per acre on the diagram should be compensated for this difference of nearly 20 per cent. in the labour per acre if the value per acre is to correctly represent the value per person. We have not enough data regarding the number of persons employed in agriculture to make this allowance year by 
year in its correct proportion; but the approximate error may be calculated for ISS6, where it is greatest, and a similar allowance may be made for the neighbouring years.

We can only estimate the number of persons to the acre of land under cultivation by the figures published in the Censuses of $188 \mathrm{I}$, IS9I and IgOI; and as we have to start from the year I886, we take it the number of acres cultivated per person in that year would be half way between the numbers for I88I and I89I. It appears that the acres cultivated per person were :-

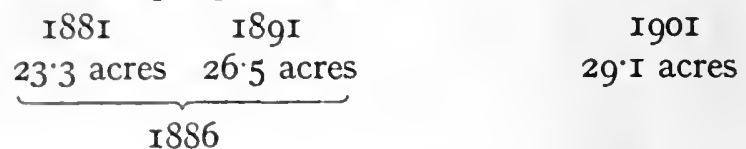

25 acres per person-against $29^{\circ} \mathrm{I}$ acres per person.

So that in I 886 one person cultivated 25 acres, and in I 901 he cultivated 29'I acres. That is to say, in rgor the value produced by one acre goes to provide the twenty-ninth part of one person's income, while in 1886 it had to provide the twenty-fifth part. As the production had to provide more of a person's income in I886, it was relatively less per person than the same amount would be in Igor, when it had only to provide the twenty-ninth part of a person with his income. So that to compare the production per acre of 4.557 , say $£ 4^{\circ} 6$, in $I 885^{-6}$, with the production per acre in I900-I, which, according to the curve $\mathrm{AA}$, should have been $£ 5$ 'IOo and does correctly represent the value per person, the former year's price of $£ 4.6$ must be reduced by the proportion in which the twenty-ninth of a person is to the twenty-fifth part. As 29 is to 25 , so is $£ 4^{\cdot} \cdot 6$ to $£ 3^{\circ} 96$, so that when this allowance is made for the division between more persons in I886, the normal price for that year is only equal to about $£ 4$ per acre ; and the same allowance must be made for the preceding and the following years, and in a diminishing amount each year down to I90o. After that date it probably wants a little compensation in the other direction, that is, a little added to the normal prices.

After the above allowance has been made it will be seen that the return per person from growing oats in the first three years on the diagram was still above the average return for other industries as typified by coal, and indicated on the diagram by the curve AA. This being the case, it is natural that the area under this crop was increased in those years, though in $I 886-7$, as the normal was very little above the curve, the increase was quite small.

In $1887-8$, when the allowance for the more persons per acre is made, the normal price of $£ 3.476$ was probably quite below the curve, and would seem a very bad return after the previous good years, and we find that the area under oats was reduced by the large amount of $24 \mathrm{I}, 000$ acres.

The next two seasons, I888-9 and I889-90, were probably both a 
little below the returns from other industries, for prices were then quite at the top, so that the decrease of area still continued, though it was only small in the latter year.

In I890-I the price went very low at the beginning of the season, just when it was sowing time. Probably this was the result of the unusually large crop of $4 \mathrm{r}^{\circ} 54$ bushels to the acre, which made purchasers think that the supply was still too large for the clemand and that prices would come still lower. If that price had continued the return per acre would probably have been below the average, and farmers would certainly think at this time that it was not paying them; and so they again reduced the area by some 9,000 acres. It was probably rumours of a big reduction of area that affected the market and sent prices up at the end of the season, in spite of the big crop, and made the normal price for the season $£ 4^{\circ} 954$ per acre, which was well above AA.

The result of this reduction of area was emphasised by a smaller crop of 40.46 bushels per acre in I $89 \mathrm{I}-2$, causing the normal price to reach $£ 5 \cdot 240$, thus making it a very good season and much above the average $\mathrm{AA}$, with the certain result that there was a very big increase of area of over 100,000 acres.

In $1892-3$, although the return per acre was brought down by the increased area, it was still much above the average of trade generally. The normal price of oats being so far above AA in these years suggests that the price of oats was not controlled by the common cause that was depressing prices; but it should be noticed that the price was falling with the others, although it was high. Although, through the want of exact knowledge on the part of both producers and buyers, the area under oats had got unduly reduced and the price sent too high, the inevitable result swiftly followed: oats growing was too good, every one wanted to be in it, and the area was increased nearly 200,000 acres-over 300,000 in the two years, which was an unheard-of increase.

This brought prices down in $1893-4$ and the normal fell to $£ 4.367$, yet that was still as much as ever above $\mathbf{A A}$, and the area under oats was again increased and the price fell still further in 1894-5. when prices generally were quite at the bottom. Both the market price and the normal price were lower than in any other year in the period, yet as they were still above AA the area was again increased. This shows that the curve AA represents the actual level of general prices and the cost basis of production, for farmers could not have thought oats growing comparatively good business when the money return was so low unless costs had gone down. A little allowance must, however, still be made for the greater number of persons employed per acre, so even then these normals were a little too high.

But the increase of area had been overdone, for in $1895-6$ oats prices went still lower in spite of the poor crop, and the normal price 
fell below AA when general prices had begun to rise. This bad result led to a very prompt and drastic reduction of the area under oats by 223,395 acres, which made the returns for the next season very much better.

In $1896-7$, although the harvest was small, the price was much better, and the normal price a little above AA, so that it might have been expected that the acreage would be increased again. The reason why this was not done was no doubt the fact that wheat prices were going up beyond all expectation, owing to the speculative holding up of American wheat by Leiter in his famous cornering attempt. This rise caused farmers to greatly increase their area under wheat at the expense of oats, and to repeat the same thing in the season $1897-8$, when wheat prices were still higher. This reduction of area in favour of wheat must have caused some shortage of oats, which accounts for the higher price, and these two years having a normal price above the average curve AA. Whereas, if it had not been for these special conditions caused by the Leiter corner, it is probable the area would have been considerably larger and the normal price of oats below the line to compensate for the over-good years from I89I to I 894 .

In I 898-9 the crop turned out a large one with $42 \cdot 27$ bushels to the acre, and as the result of the much reduced area, the normal price might have been expected to go above the line again; but the great fall in wheat prices, due to the breakdown of the Leiter corner, had started a depression of corn prices generally that lasted for several years. However, the normal was just up to the average of the rising price level, and as wheat was no longer an attractive crop, the acreage of oats was increased.

This increase of area made I899-1900 a very bad year for oats growers, the normal price being very much below general prices, which were then about at the top. But, owing probably to the hopelessly low wheat prices at the time, the oats area was again increased, with the rather contradictory result that the normal price improved a little. This contradiction suggests that the depression of oats prices in this year and the following season Ig00-I cannot be altogether accounted for by the growers' mistakes in adjusting the area. Or perhaps it would be more correct to say that their diffculties in that adjustment were very greatly increased by the great depression of prices on the corn markets, due to the tremendous oversupply arising from the Leiter corner and its failure. The area under oats at this time was not larger than was required, as proved by the little rise of price in I900- $\mathrm{r}$; but the very low price of wheat, and the small income to farmers from that source, made them obliged to sell oats at such price as they could get. And that price was not likely to rise to its proper level or oats would have been so much nearer the price of wheat than usual that to some extent wheat 
would be substituted for oats and less oats required. It is a curious fact also that, while the English farmers were getting this very low price for oats, the imports of oats, as shown by the Statistical Abstracts, went up from five to seven million hundredweights, and that at a much better price than the home growers were getting. These imports from Russia were probably for war purposes, so that it looked as if some patriotic merchants were doing their bit for their country in Igoo. But it should be noticed that, while the vagaries of supply produced by war conditions and great speculation quite prevented the proper rise of oats prices to their normal cost-position in I900, growers recognised that the cost of growing them was not repaid at the price ruling that year, and though the area was not really too large, they reduced it by 30,000 acres.

In Igor -2 , although the reduction had only made the total area the same as in $1889-1900$, the normal price rose considerably above AA, showing that the area was actually rather below the requirements when the prices of corn generally were better, owing to the restoration of more normal conditions of supply both at home and from abroad. This good normal price of $£ 4.997$ encouraged another increase of area by 42,000 acres.

In spite of this increase, the I902-3 normal was still as much above the average price level, so that the acreage was still not too great. But no doubt this very good result was partly due to the record harvest after two poor ones; for it is very commonly the case that when there is a great change in the relative cost of grain, due to difference in natural crop results, the market price does not rise or, as in this case, fall quickly enough at the beginning of the season to compensate for the increase in the crop per acre. For these reasons the normal price for this season was above AA and the area again was very largely increased. We can here see that the great overproduction and low price of wheat, that reacted on oats and depressed their price after the great corner, making them unprofitable in the two years I 900 and Igor that should have been a high-price point, actually so kept down the area under oats that the two years, I902 and I903, were so much above the average as to nearly compensate for the loss in the two former years. The high point of prices that occurs in nearly all commodities in the year I900 was only displaced two seasons in oats prices, as a result of the Leiter corner and war speculations. So the rise of prices in this period may be considered to have taken place in oats as in other things, though it was somewhat displaced by circumstances of supply.

The increase of area in the first of these seasons was so successful that it was carried too far in the second, with the result that in 1903-4 the normal price was a little below the mark. This low return may have been attributed to the comparatively poor crop ; anyway, farmers made the mistake of again largely increasing the area. 
The season I904-5 was distinctly bad as the result of the too large acreage, and resulted in the big reduction of over 200,000 acres. This allowed the next season I905- 6 to be just normal, and as the area was then very little increased, the season I906-7 shows a rise of normal, though not as much as shown by the average curve AA. The fact that oats remained thus rather below the average of prices, and that wheat was at this time well above that level, will account for the strong tendency to reduce the area for the rest of the period. The increase in 1909-Io was probably due to the fact that high wheat prices and other prices being good made farming good upon the whole, and rather more land being worked, oats got a share of it. But the increase was a mistake, making Igro-II distinctly worse, causing a big reduction of acreage again.

The season I9II-I2 shows a rise of normal price in accordance with the movement of the average AA, resulting in an increase of area which was a mistake on the part of the growers, for the normal, although higher, was not up to the mark, and the result in the following seasons was very bad. It will be seen that, on the whole, oats prices from 1904 follow the general curve AA but are continually a little below, and the result of that is that oats went out of cultivation to the extent of 400,000 acres in that period.

In view of the very many complications introduced by crop variations in oats, and in the other crops which affect the farmers' opinion of oats growing, and also the further complications from the rather uncertain methods of collecting agricultural data, it must not be supposed that there can possibly be any exact point by point agreement in the price fluctuations of two commodities so different as coal and oats. That there should be any easily traceable relation of high and low periods coming at the same times is sufficiently remarkable. But it should be further noticed that when the times do not exactly agree, and the variation of oats is above or below the average coal fluctuation, the increase or decrease in the area under oats shows that in practice the position of oats prices is regarded as good or bad as it keeps pace or falls behind the price movement of coal-that is, the general level of prices. This means that it is generally supposed that the same cause that makes the price of coal vary should do the same for oats and for commodities in general ; but we must examine a few others of these commodities before we attempt to finally discover this underlying cause of price fluctuation.

\section{United Kingdom Wheat Prices.}

In the Wheat Index, Diagram 35, we can see the same periodic fluctuations of normal price and irregularities similar to those of oats prices, resulting from the farmers' efforts to make the best use they can of the incessant variations in the prolificacy of the crops 
they have to cultivate. The period covered by the diagram is the same as for oats and, as in their case, the normal price of the first few years is very much above the curve of average prices. But it must be noticed that, as we have explained in discussing oats prices, the acre no doubt represented more labour in these earlier years than in the subsequent ones. As before, the acre in 1886 represents the twenty-fifth part of the year's work of one person and in $190 \mathrm{r}$ a twenty-ninth part, so that to compare the normal

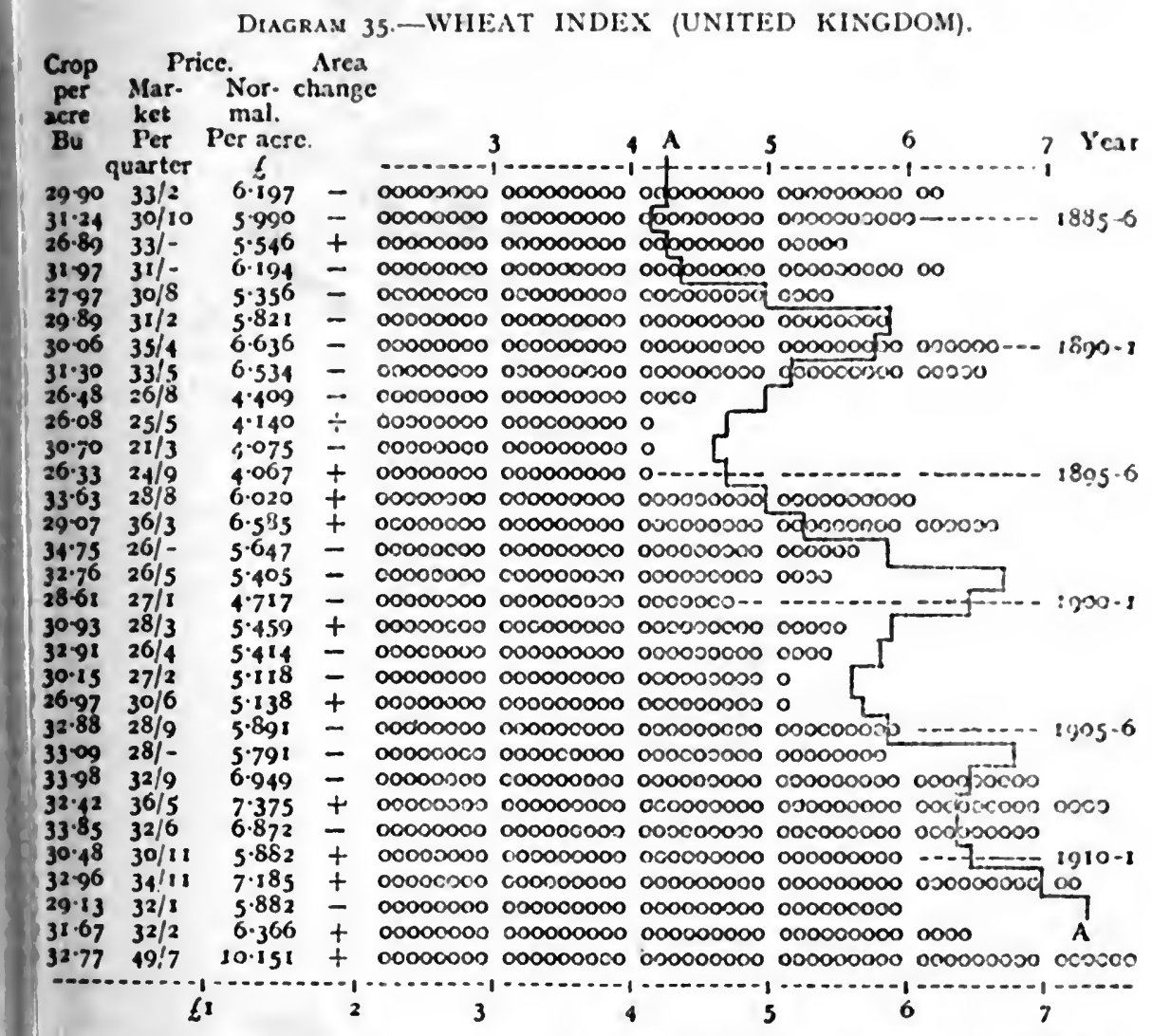

price in $1885-6$ with the curve AA, which is correct for the persons per acre in 1900 , the former year's normal price must be reduced by the same proportion as in oats. The normal price per acre for I885-6 is $£ 6$, so as $29^{\circ} I$ is to 25 , so is $\ell^{6}$ to $£ 5^{\cdot} \mathrm{I}$, which would be about the correct normal price when the allowance is made for the greater number of persons.

Even with this allowance the price is much above the average return, so that it might have been expected that the area would be increased instead of reduced. This persistent reduction of the area does not seem to support the view that the area will always be increased when the value produced per acre is above the average r.w. 
level of normal prices. But it must be clearly understood that, in addition to the various disturbing influences above mentioned as distorting normal prices of crops, there is the fact that a crop of any kind is only a part of the business of farming, especially in this country where it is nearly all mixed farming. A farmer who farms both crops and live stock may not always be certain which branch of his agriculture has contributed most to his profits, and he may be led by a general prejudice in favour of one branch to overlook for a time a temporary improvement in another. In this country prices of wheat had been falling from 56s. per quarter in 1877 to 30 . in 1886 , which would doubtless prejudice farmers against wheat growing. There was evidently a strong feeling in favour of grazing; permanent pasture was increased a million acres between I888 and I892, showing that agricultural opinion was then strongly in favour of grass land. In all consideration of the probable adjustment of acreage to prices, the prevalent opinion of the farmers must be allowed for. In this case they were not likely to break up newlymade pasture because of two years' high wheat prices if they were convinced that the rise was only temporary and due chiefly to their previous reductions of area. It would seem, too, that the farmers' views in this case were not ill-founded, for, from the persistent reduction of wheat area throughout the period covered by our diagrams, it is evident that this crop does not pay so well as some other branches of their business-oats, for instance, the area under which was being increased in these years.

So it comes about that the reduction of area was continued in these two seasons in spite of the fact that the normal price was $£^{I}$ above the average return per acre. But in the season I886-7 this good return began to be appreciated, the average market price being very high owing to the small crop ; so the area began to be increased again.

I887-8. In this season trade generally was improving, and the previous reductions in wheat area still kept the price up in spite of the big crop. So it was a very good season for wheat growers and the acreage under that crop was increased by the large amount of 279,000 acres.

This large increase brought the price down in I888-9, and, when we make the allowance for the more persons per acre at that time, it is probable that the normal price was quite down to, or a little below, the curve $\mathrm{AA}$, so that farmers started reducing the area again by a large amount.

In I $889-90$ it will be seen by the Diagram No. 35 that the normal price is only just up to the curve, and no doubt was actually below it if allowance is made for the more persons per acre. As trade was then at its highest point, this result from wheat would not be as good as in other branches of agriculture, and the area was again reduced. 
This reduction sent the price up at the end of the season and saved it from being a very bad one: but it should be appreciated that it must have been distinctly below $\mathrm{A} A$.

In $1890-1$ a fall of prices had started, and wheat fell over 5s. a quarter in October. This low price in the autumn, when preparations were being made and the crop sown for the season, led to another reduction of area by 90,000 acres. The effect of this reduction was to send the market price very high at the end of the season and to make the year turn out a good one, the normal price being above $A A$ and much better than the season before.

It may strike the reader that it is not very obvious how the circum. stance of farmers planting less wheat for next year should cause a rise in the value of the wheat they have by them, which is, of course, the crop planted the year before. Yet current stocks of agricultural produce are, in ordinary market language, said to rise in price as the result of reduction of area; and as they commonly do rise at the same time, and partly as the result of such reduction of future crops, some explanation of the phenomenon may be useful. It will illustrate the sub-conscious process by which producers inevitably bring about the adjustment of supply to demand, so that the true normal price is soon realised as the average price of the crops.

Obviously the amount sown for next year makes no difference to the supply of wheat to be sold this year, and, seeing that the area sown in the winter will not be estimated and published for twelve months or so, the buyers this year cannot know that there is actually going to be any reduction next year. The fact that acreage is being reduced makes no difference either to supply or demand; why, then, does the price go up? According to our theory it simply finds its true cost of production price, which is illustrated by this year I890-I. The crop was a good one after two poor years, and the farmers whose crops were extra good would think to themselves: "There is a tremendous lot of wheat about; prices will be low, but with the crops I've got the price will pay me all right. I will make a profit while I can see one." And such farmers would sell wheat at the same price as they got the year before and not know that it was below the normal price for the present year, that price not being known to any one at the time. But there are other farmers whose crops have not done well who think there is not very much wheat about, and they know that with their poor crop there is no profit for them at the prices ruling in October and November, and they say to each other: "I'm not selling at that price. I would rather burn the stuff! Wheat growing's played out in this country, and I won't grow an acre of it next year "- which rather dramatic assertion may result in some of them planting rather less. Other farmers may be led to do the same, and the report of reduced crops spreads abroad and encourages farmers with poor crops to 
hold their wheat for a better price. So it comes about, most unfortunately for the great Ricardian theory of rent, that those farmers who grew bad crops at the margin of cultivation did not sell at the then market price, and the price went up in the latter part of the season. If the farmers with small crops had sold too early the price would not have gone up; but if the farmers with good crops had not sold too early it would never have been low, and they then would have all sold at the same price, that is, $35 s$. $4 d$., which was the normal market price and the average price that they did sell at. That was the inevitable normal arrived at simply as the result of each producer selling, or refusing to sell, in accordance with what he knew his crop had cost him, without any knowledge of the actual supply or demand.

But this tendency to largely reduce the area under wheat, as we have above pointed out in its relation to the area under oats, seems to be a general tendency; for even in $189 \mathrm{I}-2$, when the price was very high at sowing time, the area was reduced by 92,901 acres. This persistent decrease in the wheat acreage seems to prove that this crop is not really a successful one in this country, the demand for English wheat being kept down by the supply of dry and superior flour-making wheats imported from other countries. Although the imported wheat is usually a little higher in price owing to freightage, its superior quality prevents home-grown wheat from rising to the same price by limiting the demand for the home production.

It was probably owing to this competition that prices continued to fall so very much in the later part of this season $I 89 \mathrm{I}-2$ in spite of the reduced area. But it must also be noticed that the crop was a very large one, which to a considerable extent cancelled the effect of the lessened area.

The prices continued to fall in $1892-3$, and although they recovered a little in June as the result of bad crop prospects, they did not by any means compensate for the crop failure; and it was a very bad season, with the normal price at $£ 4409$, which was below the return for oats, and caused a great reduction of area by 342,000 acres.

In I893-4 the price went up a little in October and November, which may account for the increase of area, which, although only nominal compared with the great decrease, was a mistake, for prices continued to fall hopelessly.

And in I894-5 the lowest point of prices was reached at I7s. $8 d$. per quarter, which corresponds with the lowest point on the curve AA. But the normal price of wheat was much below the average of prices generally, with the result that there was a sweeping reduction of wheat area by 423,000 acres. It seems obvious, in looking back over the period, that the good years for wheat growers previous to 1892 had retarded the necessary reduction of area, with the result that the 
over-good period had to be compensated for by the extra depression from 1892 to 1896 .

The next season, $1895-6$, the price went up a little in November, owing probably to the previous great reduction of area. This slight improvement at sowing time probably accounts for the increase of area, which was evidently a mistake, as it sent prices down again at the end of the season and made the normal price per acre the worst in the whole period.

This departure from the sound normal price guide might have been rather disastrous if things had been normal in the following year; but they were not so, and, both crop per acre and price improving, the increased acreage was no doubt an advantage to the farmers. This sudden rise in 1896 is quite abnormal, both with regard to agricultural circumstances and the position of other prices, as may be seen by the curve AA and the various coal indexes given above. This being continued in the next year as a high price period resulted in a fall to a low point in I9oo, when coal was high, thus forming rather a startling exception to the periodic undulations of the price curve of the other diagrams, as the most characteristic high point of 1900 is quite missing. When in compiling these indexes this marked departure from the regular price fluctuations was discovered, it threatened a serious flaw in the contention for a common law of price undulations controlled by cost in relation to the standard of value. The standard of value for us, up to the present point of our investigations, is the average movement of coal and oats prices, and from that standard there is a serious departure. Therefore, the resulting hunt for the disturbing circumstances was the source of no little interest to the inquisitive mind of the enthusiastic student of economic science. The irregular circumstance was discovered to be the Leiter " corner " in wheat that held up the American supply for the two years 1896 and 1897 , and the light which the result of that colossal effort throws on the subject makes this exceptional disturbance of the price undulations strong evidence of the general law of price movements.

It is a very commonly accepted idea that a corner in wheat or other commodity can actually alter the price to the permanent detriment of the consumer. But the result of this attempt, as of others, shows very clearly, even as it is reflected merely by English wheat prices, how difficult it is to make any real difference to the normal price by means of any artificial curtailment of the supply, and how promptly competition brings prices back to a point low enough to compensate for the artificial rise and establish the normal value for the period. In the years $1896-7$ and $1897-8$, Leiter tried to make his famous corner in wheat, with the result that the price was suddenly raised above the normal by nearly $5^{\circ}$ per cent. The corner had the same effect on the market as a bad harvest, for as 
long as the wheat was held up it did not exist for any practical purpose, and the prices rose exactly in proportion to the amount so held. And further, it had the same effect on acreage as a bad harvest, the area planted in 1897 being nearly 25 per cent. larger than in 1895 , the increase being 423,528 acres; so that instead of a crop of only $38,000,000$ bushels, we had $58,000,000$ and $56,000,000$ for the two years respectively. The result of these big crops was to break the "corner," and by overstocking the market to keep the price below the normal for the following years until the increased value made in $1896-7$ had been compensated by the loss of value in the years $\mathrm{I} 897$ to $I 900$, showing how very promptly the price determines the supply and the supply brings down the price to its cost of production value. If these years could be rearranged so as to read I 895-6, I 900-1, I899-1900, I898-9, I896-7, I 897-8, their proportional lines of normal price would produce on the diagram a curve of undulation almost exactly corresponding with that of coal or the curve AA, and show how the great "corner" only altered the year in which the rise of price took place, without making any real difference in the average or the whole price over the period. It is important to notice how quickly and how fully the production of the wheat increases in response to a rise of price, showing that nothing prevents an increase of supply but the fact that the margin of profit is not enough to make the extra production worth while. The price represents nothing more than the reward that will induce the necessary labour to be put forth. Further, it shows that if by financial strategy a higher margin of profit is temporarily obtained, the induced over-production promptly brings about a reduced profit in the lean years that swiftly follow any commercial boom of prices.

For the above reason the high price point of I899-I900 was displaced in the case of British wheat, but the average amount of rise was there and was followed by the depression indicated by the curve. The partial recovery from the very low point of I900-I led to a small increase of area without much justification, but it was nothing compared with the reductions on either side of it. The normal prices for these years approximately follow the movement of $\mathrm{AA}$, but at a lower level; and this low level of normal wheat prices caused very large reductions of area in I902-3 and 1903-4.

In I904-5 the normal price was still more below the average, owing to the very bad crop; but as this was not known at sowing time, and as the market price had then gone up considerably, there was a bold increase of area by 429,000 acres. The crop was so bad that even this increase did not bring the price down much during the season; but it made it low at sowing time in I905-6, so that there was a small reduction of area, which seems to have kept the price up in spite of the good crop and big acreage. But the reduction 
was evidently not enough, for the price fell badly in $1906-7$, when it should have been higher, and made a considerable reduction of the area again.

1907-8, owing to the reduced area, was a good season, and the very big crop made the normal well above the average, and as the area was for some reason not increased, being virtually unchanged, the good conditions for wheat growing continued to the next season.

1908-9. This season was again very good, owing probably to the high price of American wheat ; the normal price was much above the line and the area greatly increased. The high American prices continued into the season $1909-10$, but there was a considerable drop in market prices, due probably to the increased area and big crop in this country, with the result that the area was a little reduced. As at the end of the season the wheat crop had done very well, this reduction of acreage was perhaps felt to be a mistake and growers decided to increase the area again for the next season.

1910-r. The increase which was made at the beginning of this season turned out to be a mistake, for American prices were lower and the season turned out badly, showing again the reaction from the over-good years that preceded it. The following season of IgII-2 was again good, owing to higher American prices and a good crop, but the increase of area was not desirable, as the next two seasons again show the reaction due to the still too large wheat area.

Although none of the fluctuations of wheat prices agree exactly with the average position of prices as represented by the curve AA, having been more or less displaced by crop irregularities or commercial speculations, the principal fluctuations still occur relatively to each other and within the same periods as those of the average curve. The two chief depressions occur at the usual date, and their excess is to a large extent balanced by the opposite excess in the high points. Our contention for a common price movement does not demand that commercial speculation upon industrial or crop exigencies shall never be able to temporarily divert prices from their normal course, but that any such divergency must inevitably be balanced by a counter-divergency. So that the average of the fluctuations will be very nearly alike for all commodities over any given period. Irregular circumstances like strikes, speculative trade booms, and especially wars, can locally interrupt the action of natural competition and divert prices from their normal course; and such deviations do certainly obscure the similarity of the price movement on many of our diagrams. But it should be remembered that such disturbances of the normal relation of cause and effect are found in all departments of science to greatly obscure the working of natural laws and render their elucidation difficult.

The difficulties of investigation that arise from the complicated details of commercial practice must be overcome by the examination of 
many prices to discover and distinguish those variations that remain constant in time and are common to all commodities, from those that may be attributed to local disturbances. And further, by the analysis of the irregularities, it may be found in most cases that they consist of oscillations about a mean price, and that the mean actually corresponds very closely to the curve of average price fluctuations. For this latter purpose we have examined the producer's position in relation to price each season, and the result of that position, in some little detail, not by any means to show that his estimate or decision upon the position was the correct one or in accordance with sound theory, but to point out how his errors only counteract each other and how the inevitable mean position soon asserts itself. It must not for a moment be supposed that the producers have any knowledge of this mean position or average curve ; it is only that we find that the farmer's efforts to cultivate as much as he can at a profit, and as little as he can at a loss, result in a series of fluctuations about a mean result, and that this mean is found itself to fluctuate periodically, and that these periodic movements are common to all commodity prices. The fact that without any knowledge of its existence such a fluctuating mean is discoverable from the movement of yearly normal prices of commodities is strong evidence of a common cause that deternines price fluctuations. For the purpose of investigating the evidence for such common movements of prices, we propose to illustrate by Index Diagrams the movement in yearly prices of all the commodities for which labour cost data can be obtained. And we shall endeavour to point out that the fluctuations in supply or " area" are regulated and determined by the price, which they would not be unless that price was sufficiently near to cost of production to make it an essential consideration in deciding whether more or less of a commodity shall be produced.

\section{Beet Sugar Prices}

Although sugar prices are not specially useful for our purpose, we introduce them at this point in conformity with our plan in this section of our work of bringing together all the evidence we can obtain relating to the movement of actual prices, including every commodity for which we can get the necessary data to calculate the price per acre or normal price. The European sugar industry is distributed over a great part of the Continent, and our figures are based upon returns from Russia, the Netherlands, Belgium, France, Germany, Austria and Hungary; so the price variations in this commodity should be typical of the general movement over a wide area, though the returns only cover a short period from I898 to I9I2. Unfortunately these returns do not lend themselves very well to our method of examination, as they are not truly returns for one industry, but for two-the growing of beetroots and the manafacture of beet 
sugar. So that the value per acre or normal price cannot be arrived at in quite so direct and simple manner as in other examples of crop prices.

Though we are taking sugar as if it were simply a crop, because we have no data respecting the number of persons engaged in sugarmaking throughout the Continent, we are still obliged to calculate the value of the crop from the market prices of manufactured sugar, because again we have not the necessary record of beetroot prices. So we are in fact including all the labour of manufacture as part of bringing the crop of beetroots to market, which is, of course, not quite so satisfactory, as it means regarding this part of the cost of production as a fixed amount not varying throughout the whole period; still, that probably would not greatly affect the relative price fluctuations, so in default of better data we are regarding sugar simply as a crop. This method is to some extent justified by the fact that the value not only depends on the weight of roots grown, but on the percentage of sugar in the roots. But although the sugar produced best represents the value of the crop on our sugar index diagram, the normal price of the manufactured article can hardly be expected to react quite so promptly on the acreage as the price of roots would do.

In addition to the above complications, it is well known that during the early part of the period covered by our diagrams the sugar industry was a sort of financial battlc-ground, upon which the nations of Europe entrenched themselves with bounties and tariff walls of quite extraordinary dimensions, making the sugar market an operating theatre where tariff reformers demonstrated their theories by cutting up the sugar refiners. So that it is hardly to be expected that the price fluctuations should correspond very exactly with those of less protected industries.

Although as seen by the beet sugar index (Diagram 36), the normal price of sugar cannot be claimed to follow the fluctuations of the curve of average prices AA, beyond the suggestion of a similar depression between I90o and I906, and the subsequent rise to I9II, it will be found on close inspection that most of the conspicuous irregularities are accountable for as the result of the growers' efforts and mistakes in adjusting the acreage to secure a paying return. The most serious cause of irregularity is no doubt the fact that there are two distinct interests involved in the production of sugar-that of the grower, who wants a heavy crop, and the manufacturer, who wants a high percentage of sugar, which may mean small roots and a light crop per acre. The number of trade and Government organisations to insure the manufacturers a sufficient supply of good sugaryielding beetroots has given the trade a somewhat artificial or experimental character, and a level of prices that is rather subject to big changes as the methods of that particular trade may vary or as 
the organisation between its different sections may be more or less complete. The above mentioned Government aids and tariffs are part of this organisation of the beet sugar industry, and though they do not appear to have made much difference to the average price of sugar as a whole, they would no doubt make some difference to the price of what was imported into a free trade country. So as the market prices quoted on our diagram are the import prices of sugar in this country, no doubt the bounty-fed sugars were at a price that was artificially low during the first part of the period. We find that the first four seasons on Diagram 36 work out at too low normal prices, which is probably due to the sugar bounties which were discontinued after 1902, from which date the normal prices work out about the average price curve. This seems to support the view that

Diagram 36.-BEET SUGAR INDEX (EUROPEAN).

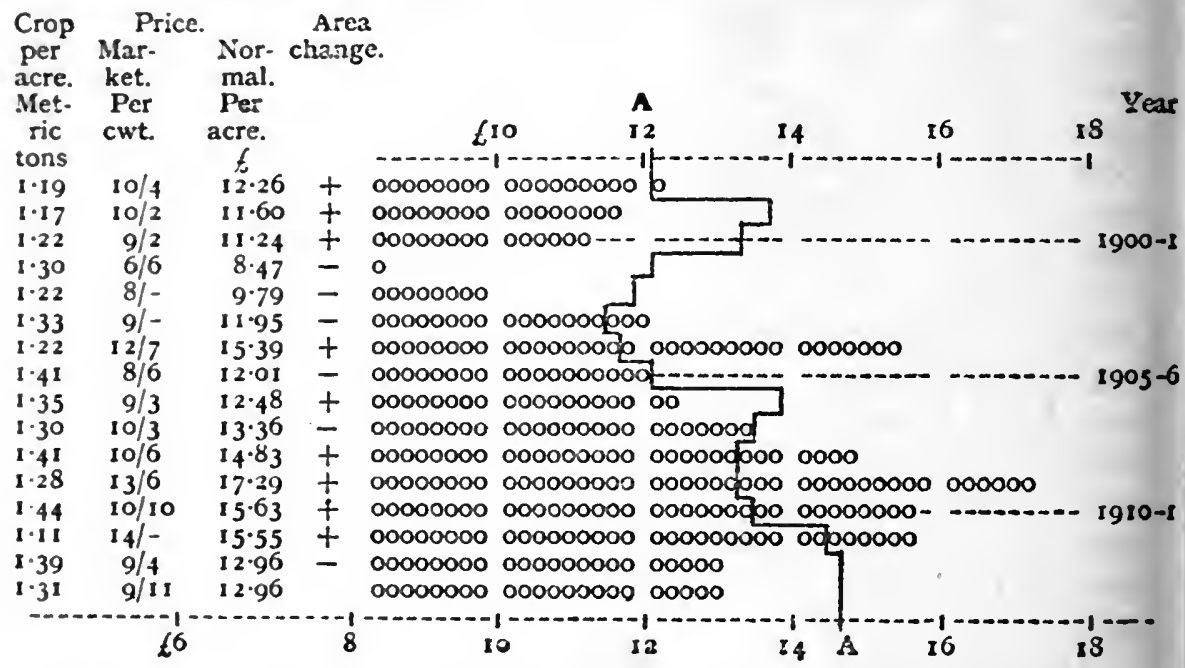

the bounties did somewhat reduce the price in this country, and that price rose a little when the bounties were discontinued.

In comparing the variation of sugar prices with the line $\mathbf{A A}$, showing the level of general prices, it should always be kept in mind that, as we have mentioned above, the acreage planted is beetroots, and the price is for sugar, so that between these productions there is a very elaborate manufacturing process which requires considerable time to complete and affords opportunity for accumulating stocks of intermediate products, and the holding over of production into another season, so that the crop returns of adjacent seasons may overlap, and somewhat disguise the real value of the season's production per person.

The season $1898-9$ starts the period for which we have data, and the normal price will be seen by Diagram 36 to be a little above the price level line AA. This rather high normal price led in 1899 , when 
planting for the following season, to an increase of the area by 104, 165 hectares, or about a quarter of a million acres, an increase so large that it made prices begin to fall that season and to continue falling considerably in the next.

1899-1900. This over-large increase brings the normal price a good deal below the average point in the present season. But if the sugar bounties actually did bring down English prices by ro per cent. or so, the normal price where bounties were received would be that much higher than we have represented them on the English price basis; and in that case the normal value for this season would be very little below the line $\mathrm{AA}$. However that might be, the price rose steadily during the season owing probably to the fact that the sugar crop turned out rather badly. And it is important to notice in regard to this, that although the crop of roots was 9.6 tons per acre, the crop in sugar was only $I \cdot I 7$ tons against $I \cdot I 9$ tons in the previous season when the root crop was only $8 \cdot 8$ tons per acre. This looks as if the percentage of sugar in the roots had turned out badly for the manufacturers, making the normal price per acre seem low. But it does not follow that it was a bad return from the growers' point of view; they may have got a good price for their big crop, without regard in many cases to the percentage of sugar in the roots, which would account for their increasing their acreage under beets in 1900 by the large amount of 139,328 hectares, although the normal price of sugar was a little below the general price level.

The relatively low normal price at which in these years the grower seemed satisfied is probably due to the low productive valuation of agricultural and some other labour, still customary in Central Europe at that date. The low return to the growers was a standing com. plaint, and that low return would not vary so much or so quickly as the profit of the manufacturers and factors. So that the grower would often be as much as a year behindhand with his adjustment of area. This may explain why in the season 1900-1, although the normal price was $£$ II $\cdot 24$ instead of $£ 13 \cdot 2$, as it should have been, there was still a small increase of area. Though perhaps the apparent error is somewhat lessened by the fact that bounties were still making their returns a little better than they look from the English prices.

Igor-2. These persistent increases, which together amount to 302,548 hectares or three-quarters of a million acres, culminated in a beetroot crop nearly 50 per cent. larger than that of season $I S 9 S-9$. This great crop coming when prices were falling, it is not surprising that the present season turned out disastrously for the grower with a normal price of $£ 8.47$ against $£_{12} \cdot 0$ as it should have been for 1902 . It should be noticed that, as may be seen by the line $A \mathrm{~A}$, trade throughout the world had begun to decline from the high water mark of 1900 , so that the large production of sugar, which reached $5,820,410$ tons or $1,378,685$ tons more than in $1898-9$, was very much 
too large for the decreasing requirements of the world in a period of depression. It is therefore quite in accordance with the rule that the area is reduced by $I 80,240$ hectares.

I902-3. This season starts with a sudden rise of price from $6 s$. to $7 s$. $3 d$., reaching $8 s .4 d$. when the planting time came round. This rise was evidently accepted as an omen that the bad conditions were over, to some extent; and the result was that only a small reduction of the area by 34,956 hectares was made. This optimistic view was hardly justified, for the price stopped rising and the normal price remained below the average at $£ 9 \cdot 79$ instead of $£ I I \cdot 8$.

1903-4. The result of this too small reduction was made obvious hy the decided fall in price to $7 s$. Iod. in the present season, and made for a large reduction in area by 107,460 hectares, and when this reduction began to be appreciated, the price ran up to Ios. Iod., making the normal price $£_{\mathrm{II}} \cdot 95$ instead of $£$ I0.40, or I2s. above the standard of prices. The stopping of the bounties during this period seems to be a contributing influence in making prices in England higher than the standard, so that it is doubtful whether the beet sugar producers obtained all the benefits of this apparently satisfactory result. The rise in price at the end of this season was helped by the failure of the new crop, the beetroot produced being only $8 \cdot 0$ tons to the acre, and the sugar production reduced to $I \cdot 22$ tons.

I904-5. This season starts with high prices, and the smallness of the crop quickly ran them up to ${ }_{5} 5$. $8 d$. per cwt. ; naturally this price was somewhat better than expected, and the area was increased by the enormous amount of $362,88 \mathrm{I}$ hectares, or nearly a million acres, which brought about the big fall in price to $8 s .7 d$., in spite of which, however, the season turned out a most remarkably good one, the normal price being $£ 4^{\circ} \mathrm{O}$ above the general level of prices. Although a little improvement in trade was due this season, as shown by the rising curve $\mathrm{AA}$, this normal at $£ \mathrm{I} 5.39$ was a most unusual return to the acre; it was no doubt brought about by the combined circumstances of a large previous reduction of area and the failure of the current crop, illustrating the often recurring experience that a crop failure results in a better money return than a bumper yield does.

rgo5-6. The crop this scason was a good one, the largest up to the present date, with a high yield per acre, and shows the reaction caused by the bumper crop, the average price being $4 s$. Id. per cwt. less. At first sight this should have caused a large reduction of area, but it should be noticed that although the normal price is much lower, it is still up to the line representing the level of prices generally, so the reduction of area was only 47,063 hectares.

Igo6-7. This season the normal price was still considerably below the general standard of prices, but as prices were improving on the last seasons, there was a small increase of acreage which kept prices 
from rising, and left it a very bad season compared with trade generally, which, as shown by some of our diagrams, was booming.

1907-8. The belated discovery of this poor result may account for the growers' behaviour this season, for though the return per acre was up to the average price in trades generally, the area was reduced by 82,895 hectares. An added reason of this may be conditions just the reverse of those in the season I899-1900, when the growers did better than the manufacturers. In the present season it may have been that the manufacturers were doing well at the expense of the growers, a possibility that is supported by an incident to be mentioned in the next season.

1908-9. This seems to have been another very good season in the beet sugar industry, with a normal price of $£_{4} \cdot 83$ against $f_{1} \mathrm{I}_{3} \cdot 2$, shown by curve AA. This return would not have been so much above average prices but for the rise in market price at the end of the season due to the then evident failure of the new crop just grown. But in Germany, at any rate, the good return was largely due to high sugar percentage in the roots. Figures from a German sugar factory report, made famous in sugar controversy by Mr. Martineau's reproduction of them, show that in this season the yield of sugar was very good, and that the firm, after paying a dividend of 22 per cent., paid $£ 8,669$ to growers " on account of the good year, and the short weight, but good quality, of the roots." Which incident seems to suggest that the growers needed some encouragement to keep up the beetroot area, and a want of some such practical stimulus to beet growing on the Continent generally may have accounted for the decrease of area in the last season. Perhaps even then this policy was not sufficiently general, for, considering the goodness of the season, the increase of area was not very large.

1909-10. Although this increase was not large it would probably have resulted in a fall of price save for the fact that the beetroot harvest was a failure, and the considerable shortage amounting to 400,000 tons less European sugar produced sent the market price very high, which made a very good return for the year, especially as trade generally was improving and price going up. This combination resulted similarly to $1904-5$ with a high return to the acre, the normal price being $£^{1} 7 \cdot 29$, instead of $£^{1} 3 \cdot 2$, which would have been the figure if sugar had conformed to the average AA.

Thus we get the rising price curve between 1905 and I9ro coming in beet sugar somewhat in advance of the rise in other commodities, which possibly is accounted for by the considerable strides made at this time in cultivating beetroots with a higher percentage of sugar in them; an advance that was not always an advantage to the growers as high percentage beets are usually small and make light crops, tending to decrease areas. However, this season was so good that, as could only be expected, there was a great increase of area by $1 \$ 9,530$ hectares. 
IgIO-II. This somewhat inflated prosperity of the sugar industry would probably have broken down a good deal in this season if the coming crop had not again saved the manufacturers. The season starts with a sensational drop in price from I3s. $4 d$. to $9 s$. $9 d$., as shown by records of monthly prices; and would certainly have taken the normal price much lower if the great increase in area of I54, 784 hectares had produced anything like a fair crop. But the obvious failure of the new crop again sent the price up at the end of the season, so that the normal price still remained above the average of general price.

I9II-I2. Owing to the failure of the crop planted in the last season the production of sugar for the present one was over a million tons less than the previous year, causing the price to rise to I7s. $7 d$. per cwt., and a value per acre of $£ 15.55$ or $£ I \cdot 2$ above the general avergage of prices in spite of the great crop failure. This satisfactory result with very high prices at the beginning of the season led, of course, to an increase of area of 80,644 hectares, with the inevitable result that in

I9I2-I3 there was a lig drop in price which the reduction in area of 80,644 hectares was quite too little to prevent. In consideration of the previous great increases in acreage and the present good crop of $\mathrm{I} \cdot 39$ tons of sugar per acre, this reduction was quite inadequate to prevent high normal prices of the last several seasons from reacting on this and the following one.

I9I3-I4. In this season the price was still 'much below the average of prices shown by the curve AA, which means that prices having been above the cost of production standard during the above boom in beet sugar, had led to too great an area coming into cultivation, with the result that in the present seasons normal price has fallen rather below cost of production level. This must result in a reduction of area under sugar; but owing to the War, we may never know what the reduction of area in IgI4 actually was, though it would probably have been very large.

This extra complication caused by the two rather opposite qualities of weight and sugar percentage, both being essential virtues of a good crop, yet ministering in different degrees to the somewhat conflicting interests of the manufacturer and the grower, renders miscalculation as to what is the best paying acreage to keep in cultivation even more inevitable than is the case in more direct crop harvests. Still, it is evident that there is a distinct limit to the distance that price can diverge from the cost of production level, and the greater fluctuations in price level in this State protected industry evidently follow the general periodic undulations common to all industries, in spite of the minor irregularities caused by the complicated circumstances of the trade. The high price period of Igoo may not have been so pronounced in Central Europe as in England and France, 
as is indicated by the normal price of German coal. This was perhaps due to the lower customary estimate of productivity, abovementioned; and the depression in sugat prices was emphasised by the unorganised methods of the growers, who were at this time largely peasants, and the constant efforts of the manufacturers to persuade them to increase the area under beets. But allowance must also be made for the sugar bounties in force at the time, which probably made up to the producers some of the deficit in normal price in the first four years.

However, it is evident the growers thought they had kept the area too high, as may be seen by the great reductions in the following three years, which reduction in connection with a poor crop sent the normal above the mark in 1904-5. If the area had been correctly adjusted this over-high normal would have been divided between rg00-I and I90I-2, when the depression between I900 and I906 would, in beet sugar, have had nearly its normal proportions. Again, from I908-9 to I9II-I2, a combination of good and bad crops with changes in acreage led to very high normal prices, and a finally much too large area. This resulted in very low prices, and a normal much below the line in the following years; so that though beet sugar prices do not keep at all well to the average AA, they are all the time endeavouring to find that level, and ultimately following it by a series of compensating irregularities. And this is really all we can expect to show from prices in an industry the data for which is so complicated and unsatisfactory.

\section{Egyptian Cotron Prices.}

The price movements in cotton from Egypt do not conform very closely to the general European fluctuations, but follow a somewhat erratic course that does not well illustrate the undulating continuity of direction that we think indicative of a common determining cause of prices. But this crop has a special interset in that, although it has an intrinsic value that is greater than that of most other cotton crops, and therefore a special demand value of its own, neither the special value nor the demand seems to determine its price, which price on the contrary seems in a marked degree to depend upon cost of production. This rather independent position is due to the fact that Egyptian cotton is of a superior quality from the great bulk of American cotton, both in length of staple and lustre, qualities that render it indispensable for certain manufacturing purposes. Nevertheless, it is only a cotton of superior grade, so that its marginal utility does vary sympathetically with American prices under certain relative crop conditions in the two countries. This fact, in certain years at any rate, makes it difficult to determine exactly how much of its high price depends upon cost, and how much upon sympathy with the higher American price, which price: is due to the higher 
basis of cost in that country, and is very noticeable from Igoo to the end of the period; a basis, by the way, which we have not yet attempted to explain, but which will be discussed at a subsequent stage. Another and more important difficulty in drawing a comparison between these prices and those of other commodities is the fact that while the cost of producing most things has been falling throughout the period, that of Egyptian cotton has gone up, and that in rather a sudden manner owing to cost of irrigation connected with the Assuan dam. This and the above disturbing factor together would cause a distortion in the index diagram from about the year 1904, when compared with other normal prices, which, although the amount assignable to each cause is not separately distinguishable, would together amount to about ro per cent. So, as will be seen below, we have to make a compensating allowance to that amount to bring the diagram into line with those for other commodities, in which probably there should be compensation in the opposite direction if it could be satisfactorily calculated.

Although these special circumstances and the disturbed course of the Egyptian agricultural development have given these cotton prices a rather jerky and irregular movement, it will still be found that the general movement is very much in the same direction as in other things. Though the high and low points of prices certainly do come somewhat off the exact marks, that is an effect not infrequently brought about by the growers' efforts to keep them on the mark. The information with regard to this crop is fairly complete, but, unfortunately, no record of the actual price obtained by the growers is given, so the following charts are worked out on the Liverpool spot price for " fairly good fair brown." This price will probably show the same variations as the growers' price; and, as it is the variations that we are concerned with, the result will be practically the same for our purpose. The Egyptian cotton index diagram is drawn up in the same way as the previous ones, the normal price being obtained by multiplying the crop per feddan ( $I .038$ acre) by the spot price; and the proportional lines give the price variations in money value, each o representing 4 s., or $£^{\cdot} 2$ as in the last diagram.

The first season for which exact data is obtainable is $1894-5$, which was about the date when the Delta Irrigation Barrage was completed. In that season the crop was 4,619,000 kantars, a kantar being 99 lbs. of cotton, or about one-fifth of an American bale. The crop per feddan (acre) was 4.78 kantars, or, for the purpose of our calculations, sufficiently near $478 \mathrm{lbs}$., per acre, which is more than double the crop obtained per acre in the United States; a fact that indicates that the cost of growing cotton by the irrigation method must be very great, for, even with double the yield per acre, Egyptian cotton cannot compete in price with the American. This 
must mean that the cost per acre is much greater, or with their great advantage in the quality the Egyptian producers could, by producing and selling at the same or nearly the same cost and profit as the Americans, capture virtually the whole market to the exclusion of nearly all American cottons. That they do not do so, and that the American acreage is growing faster than the ligyptian, seems certain evidence that the high demand price does not raise the market price above the normal cost price enough to allow for any extraordinary profit, but simply pays for the cost of production, including ordinary profit.

1894-5. This crop of 478 lbs. to the feddan multiplied by the

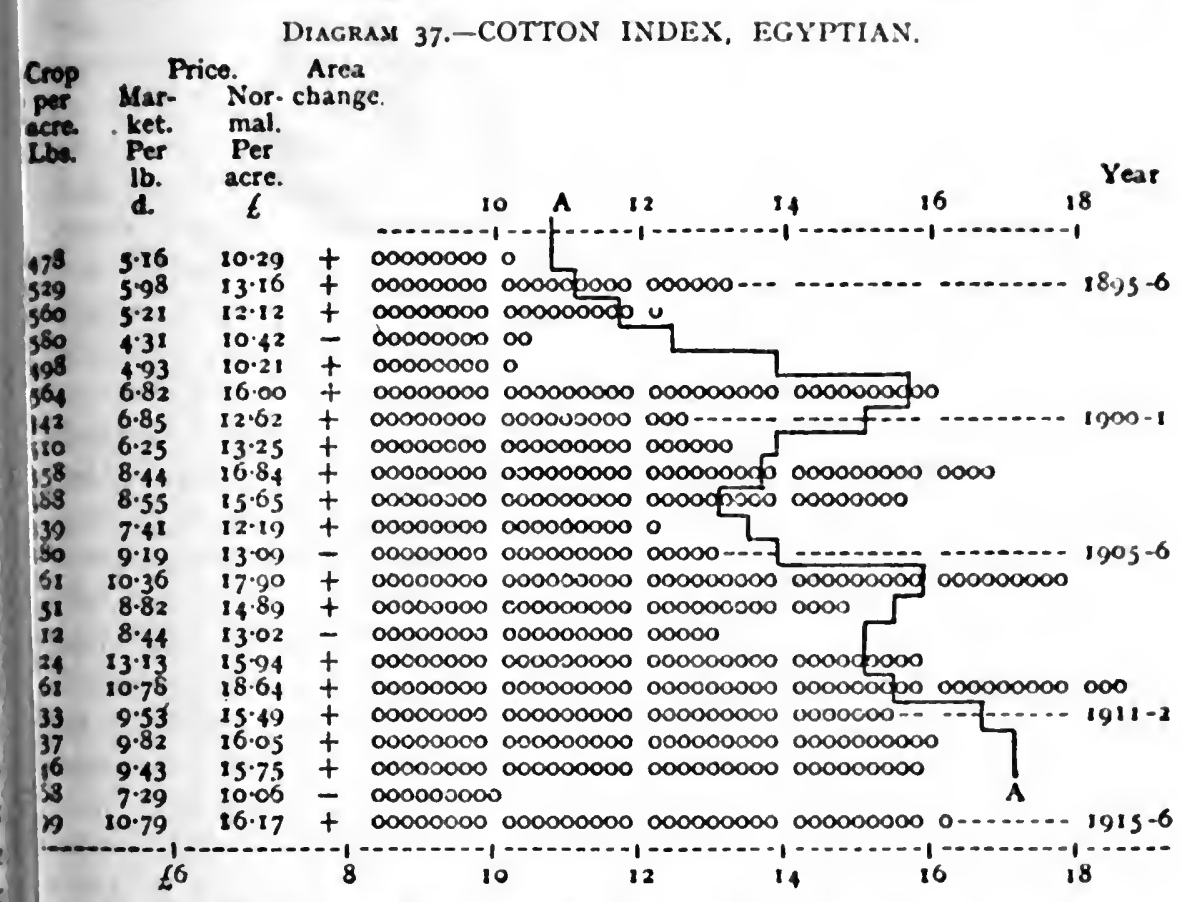

spot price, which was $5 \cdot 16 d$., comes to $2,466 d$., or about $£$ Io per feddan, which is the normal price for the season. This was below the line of the average price level, so that the increase in the area planted for the following year was contrary to the sound rule. But it should be noticed that the price was going up in March, and about the average in April, while the planting was being done; and this, with perhaps an optimistic spirit, engendered by the completion of the barrage, led planters to a view that was more hopeful than the actual price warranted.

1895-6. The result in this season justified the increase of area in the last one as it happened, but if it had not been for the very small crop in the United States, that sent the price of American cotton up $0.5 d$. higher than in the last season, the result of the increased r.m. 
acreage might have been decidedly bad for growers. There was a slight improvement in trade generally also, so that there was a distinct advance of cotton prices. The normal price was $44 \mathrm{~s}$. above the curve of average prices in spite of the fact that the crop was a good one of 5.29 kantars per feddan, which would have made an over-supply if it had not been for the American shortage. As it was the area was substantially increased without bringing about the fall of price that usually follows such increases.

I896-7. As American prices did not continue to rise but fell a little this season, they no longer justified the increase of area in Egypt and the normal price fell considerably. It was, however, still above AA, so that the area was still increased, which undoubtedly made the total area somewhat too large for the normal level of prices.

I $\$ 97-8$. The result of the last season's increase was to bring prices down much too low in this one, when American prices were also low owing to a big crop there. The normal price fell very much, being $f_{\mathrm{I}} \cdot 8$ below the average line; which resulted in a decrease of area by 6.589 feddan. When this decrease became known the price recovered a little, but the crop of $580 \mathrm{lbs}$. per acre was too large for any material rise to take place.

I898-9. This season is difficult to understand, as the increase in the area is not justified by the conditions of the market, for, although the price was slightly better, it did not nearly compensate for the very much worse crop; so that the normal price was very far below the general average of prices shown by AA. The only reason for the increase seems to have been that the rise of about a penny a pound tempted the growers with hopes of a continued rise. Such a rise might have been expected with such a poor crop, because trade generally was good and prices going up, as shown by other price indexes and the line AA. But it is always difficult to force up the price to compensate for a bad crop when that crop falls between two good ones. The big crop that is selling keeps prices low at the beginning of the season, and when they should go up at the end of the season the largeness of the growing crop, that is obvious by July, makes buyers hold back for lower prices. This no doubt is what happened in this very bad year for Egyptian cotton growers. But, even allowing for such unforeseen circumstances, it is difficult to see how there could be any increase of area sown with cotton when prices were nearly 40 per cent. below the normal price of commodities generally. We very much doubt whether there actually was such an increase of area that season. It should be understood that the Government figures for area under cultivation are only estimates of acreage by local tax collectors or agents and may not always be correct. It could not, we think, occur in any highlyindustrialised community; but commercial agriculture in Egypt 
was in a very primitive stage in 1899 , a great part of the planters being simply workers upon their own small holdings, who probably never made any profit properly so-called, and were willing to work for very little when times were not good. Such growers would probably not always be well advised in the increases of their acreage nor very correct in their statements of area sown. There is evidence that the area was not very unduly increased and also that buyers were holding out at a risk for lower prices in the fact that next season, in spite of the big crop, prices went rather too high : thus to some extent justifying the increases of area. The alternate combination of good crops in Egypt with bad ones in America and vice sersa has displaced the position of the years of higher normal prices ; but, save for these circumstances of crop variation, the average prices for the four years would have approximately followed the curve AA. And it is obvious how the over-good years, by inducing increased area, react by insuring a too low value for the next years.

1899-1900. The reversal of conditions in this season suggests that the position in the last one was not altogether the result of over acreages, but to some extent due to speculation on the crop variations. The normal price reached the average line AA, and went somewhat above it : but this rise was helped by the bad crop in the United States. The price at planting time being well above what was a good paying figure, there was a large increase of area causing a rapid fall of price; and this increase would probably have made the next season even worse than it was if the crop had turned out well. This effect that the season's planting of an increased or decreased area has upon current market prices, has been explained above while discussing wheat prices. In that instance it was a rise of price due to reduction of area, and in this case it is the reverse process of an increase of cotton planted causing a fall of prices. As the amount planted does not actually alter the real current supply or demand, a change of price can only be due to the grower's view as to whether it will best pay him to sell or hold back. In the previous case it was the man with the good crop whose costs were light compared with the crop he had obtained who would be most likely to sell early, and the man with the bad crop who would hold back for better prices. But in a season like $1899-1900$, when prices were rising rapidly, both men would obtain their price by planting time, and the difference would be that the men with the good crops would have done so well that they would be sure to increase their area for the next season; whereas the men who had not done so well might not see their way to decrease their area in so wholesale a manner that it would compensate for the other men's rash increase. So that the area gets increased in spite of the unfortunate men's wishes. In this case the less fortunate planters are not necessarily those with a bad crop, but possibly individuals who have speculatively held back for top prices; 
and when the lucky men who have sold out and increased their acreage begin talking about great crops next year, buyers also hold back for lower prices. The speculating planters then become anxious to clear out, and prices come down with a run. Thus, the increase of area may be said to result in a fall of price, although it is only indirectly true.

This fact that in the same season one planter's result may be very much better than another's should be clearly kept in mind. If this is not appreciated it may seem, in reading these seasonal price and acreage variations, that the planters are always doing the wrong thing; and that the result only comes right with the theory from outside causes. There are the underlying fluctuations in the basis of price indicated by the curve AA which are the cause of trade booms and depressions to be hereafter explained; but the minor seasonal variations are due to crop irregularities. These irregularities represent actual loss or gain of profits due to crop variations and failure to correctly adjust the acreage to them ; a failure largely due to the varying fortune of the individual growers. But, although the conflicting interests of planters may often result in increasing the area to their detrinient, a point is soon reached as in I897-8, when the market price was $4 \cdot 3 \mathrm{I} d$., when the normal price gets down below the no profit level and the acreage has to be promptly reduced. Nor must it be supposed that this is a lowest point limiting falling prices in the long run, for such a limit is found in $1905-6$, when the average market price was $9 \cdot I g d$. , or again at 8.44d. in I908-9; showing that the cost limit rises and falls with the general average of normal prices indicated by the curve AA, and is never far from it. It is no way possible that planters or farmers should succeed in closely adapting their acreage to the correct normal price position ; for while it is easy for us, looking back upon the recorded figures, and speaking as if planters were one man, to say he should have done this or that for his best interest, it is a very different thing in practice for agriculturists to know or to act collectively, with perfect judgment; in fact, it is obviously impossible, and there must always be a strong element of chance in their calculations. Still we contend there is a general standard of normal price such as is illustrated by the curve AA ; and if the normal price of a commodity like cotton falls below that standard, an increase of acreage is to the planters' detriment, and very much so if persisted in ; although the loss may be deferred, or to a considerable extent redeemed, by a general rise in the standard of prices as in the season I899-I90o.

I900-I. Owing to the poor crop in this season the price jumped up over $I d$. per pound, and kept high until planting time, when the increase in area made a rapid fall; the result $£ 2 \cdot 40$ below the standard shows the increase to have been a mistake that was not redeemed by other conditions, as trade generally had taken the turn to the falling side. 
Igor-2. In this season again the increase of area is difficult to understand, as it must have had a disastrous effect if the crop in the United States had not turned out a poor one; the price which was low at the beginning of the season would have fallen still lower if it had not been helped by the rise in American. As it was, the normal price was a little below the standard AA.

1902-3. The increase of area in the last season was prevented from having the usual effect as the crop for that season turned out a poor one with only 4.58 kantars per feddan. So that there was a big rise in price this season in spite of the large increase of area, and the normal price was $£ 3.20$ above the standard, when trade generally was bad. But the chief reason for this rise was, in addition to the poor crop, the fact that there was beginning to be felt the effect of a big speculation in America. This was the Sully corner in cotton, which reached its height in the early part of 1904 , when came the failure of Sully and the collapse of the corner.

I903-4 saw the final stages of this disastrous attempt to corner cotton. The area was increased by nearly 8 per cent. owing to the inflated price, and this increase in conjunction with a similar one in the United States made it quite impossible to keep the price up; Sully failed, and the price quickly fell $2.50 d$. per pound. This extravagant speculation makes these two seasons stand out disproportionately on our cotton index at a point where prices should have been falling. This boom of normal price above the general level probably shows there was some little excess of profit and advantage generally to the Egyptian cotton growers, at the expense of Sully and other speculators. But it does not follow that there was any great departure in cotton prices from the normal cost basis. The extension of the area under cultivation, both previously to and during the boom, probably meant increased cost per acre; and the boom prices made it possible for the Egyptian growers to well cover this high cost. It only prevented their undue increase of area from being a loss to them, as it almost certainly would have been in I903-4 if the corner had not taken place.

So greatly do the costly new irrigation methods seem to have increased the cost of producing cotton that, as mentioned above, we have in this and the following years deducted so per cent. from the normal price to compensate for the increased cost per acre of growing the crop, combined with the rather higher price due to the influence of the American price level. This means that the labour per acre has been added to by the extra labour required to work the new irrigation plant and by the interest that has to be paid on the past labour in constructing the plant. This extra labour which shows mostly in the form of rates and taxes, so much increases the planter's costs; and as our production figures are unfortunately the gross figures, they include, as we have before pointed out, part 
of the labour cost (as taxes, etc.), of the work done by Government servants, contractors and others, in producing the irrigation. That is the work of persons not recognised as working upon the feddan of cotton, but actually doing part of the work. The number of these irrigation workers was increased, and the feddan now represents about ro per cent. more labour than it did in the earlier years on the diagram. It should be remembered that in all these crop prices we are only using the acre of feddan, to represent the labour, because we have no direct record of the number of persons employed or cost in labour. If the cost in labour suddenly goes up Io per cent. the price will too; so to bring the normal prices of this second half of the diagram into proportion with the earlier ones, we have had to deduct Io per cent. from them. When this is done the result of the above season I903-4 is still very high above the standard of prices shown by $\mathrm{AA}$, as the boom of the corner had prevented the large acreage from bringing down Egyptian prices.

I904-5. The previous season having been so good, we get a further increase in area in this season. Enterprise was no doubt encouraged by the completion of the Assuan Dam; and the market prices were still higher than at any time before the boom years. But with the higher cost, this price was hardly good enough; and the increase of area sown would probably have made the price very low at the end of the season if the new crop upon it had not turned out a complete failure, owing partly, no doubt, to the faulty irrigation by the new supply of water. As it was, the normal price was below the point indicated by $\mathrm{AA}$ as the correct one.

r $905-6$. When the miserable crop of only $380 \mathrm{lbs}$. to the feddan is taken into consideration, the prices with which the season starts were very low ; and that brought about a decrease in area of 4 per cent., and as the result a big run up in price at the end of the season. Even with the price up to $10.54 d$. in June, which was much higher than anything recorded before, the actual result was still below the standard of normal prices.

So it is again seen that the increased area resulting from the high profits of the "corner" years reacts upon the returns in these two following seasons, making them below the average level of profitableness. The Assuan Dam, in addition to increasing the expenses, seems to have reduced the crop per feddan, as from the completion of the Dam up to the present time no crop has reached 4.70 kantars, which is IIo lbs. less than I897-8. The average crop from 1894 to I903 was 5.Io kantars per feddan, and from I904 to I9I5 it was $4 \cdot I 7$ kantars. It is possible that the published returns for the earlier years are on the high side, and the later ones more correct, but there can be no doubt that the result of the increased water supply has not been a success, as is shown by the large drainage schemes now being undertaken. 
1906-7. The conjunction of the crop failure in 1905 and the big reduction of area for $1906 \mathrm{kept}$ the price for this season so high that the normal is raised to $£_{1} 8$ instead of the standard of $£_{15} .8$ for 1907 . The year 1907, however, was a record one in the cotton trade, the boom which took place in most industries being exceptionally big in cotton-spinning. This boom accounts for the continued rise in price up to the end of the season, although the area was increased by 61 per cent., or 96,933 feddan. This high price in conjunction with one of the best crops grown since the construction of the Dam made a very good result from the grower's point of view.

1907-8. The season started with the high prices created by the boom, but with the depression that came in 1908 the increase of area, although only $2 \frac{1}{2}$ per cent., caused a rapid fall in price to the end of the season. The normal price is much reduced, coming again below the average. But the boom prices at the beginning of the season put the chief effect of the depression off until the next season.

1908-9. So we get the normal price for that year below the average with a decided reduction in area of 43,360 feddan, and a recovery in price at the end of the season. Thus the depression came as in other industries, but was slightly delayed and accentuated by local conditions.

1909-10. In I909, owing to the early flood of the Nile, the crop was a greater failure than in 1905 , with the result of a very rapid run up in price to the record figure of $15.87 d$. in March, 1910. This price indicates very clearly that the normal price of Egyptian cotton is regulated by its cost rather than by its superior quality; for while that quality is always the same relatively to American cotton, its price is not. In this same month, while Egyptian cotton was $15 \cdot 87 d$. per pound, American cotton was only 8.ogd.; whereas in the following year, when American was at the same price, Egyptian was selling at $10.60 d$. only. If the trade is prepared to pay $15.87 d$. for the particular kind of cotton when it has happened to cost more, it is evidently only the increased production stimulated by high prices that prevents the price remaining at that figure. And as it is obviously the case that growers ordinarily do increase production and take a lower price for this cotton than its quality can secure, what is to prevent them increasing the production and lowering the price till it is as low, or lower, than that for American cotton, if there is no element of cost that prevented them doing so? At first sight the increase in area by 45.555 feddan seems a rather small response to such very high prices, but it will be noticed that the normal price is not very greatly above the line $\mathrm{AA}$. So that the return from growing cotton at these high prices was not much more than in industries generally, which means that the cost of cotton had gone up as well as its price, owing to the poor crop.

Igro-r. This season the crop was decidedly better, being $4.6 \mathrm{I}$ 
per feddan, making this season better than the next, for the moderate increase of area in the last season was not enough to bring the normal price down to the general standard. But so good a return led to another large increase in area planted for next season.

IgII-2. The good normal price of the last season encouraged another small increase in this season, though it was not justified by prices at the time, and brought the normal price for the season below the standard, with the result that this season, which should have been the better one according to the estimated curve AA, was worse than the previous one. The over prosperity of I9IO-I, and increased area therefrom, reacts on the following seasons, making IgI2-3 and Igr $3-4$ below the line.

I9I4-5. The war starting caused a panic in the cotton trade as in many other industries, and cotton prices fell very rapidly. The effect of this big fall makes it very clear that the cost basis is the paramount factor in production; for the low price immediately resulted in a record reduction of the area by 33 per cent. This would not have happened if the usual normal price was inflated by quality considerations. If the comparatively high prices of previous years represented large profits resulting from the limited supply and special demand for Egyptian cotton, the general fall of cotton prices in this season would still leave Egyptian growers with a better profit than those which other countries could get. Planters would argue: " Cotton prices being so low we must increase our area and output, or we shall not make a living." That they do not act upon this argument shows that they think it would be working at a loss, that is, below what they consider to be the actual cost to them.

Egyptian cotton prices, although much disturbed by local conditions of production, and very much overruled by the price of the great American supply, are very good evidence that the normal price of commodities depends very closely upon their real cost of production. That is upon cost including a normal profit-profit bcing the cost of the organisation and management which is found necessary for the production. With the exception of the special deviation caused by the Sully corner, the fluctuations of cotton prices since rgoo follow much the same course as those noticed on other diagrams.

It is also important to notice in this and other diagrams of normal prices how, as we have before mentioned, the point at which reduction of acreage takes place is not a fixed minimum market price. At planting time in $\mathrm{x} 9 \mathrm{r} 5$, prices were rising and at $8 \cdot 20 \mathrm{~d}$., yet were recognised as hopelessly bad, and led to an unprecedented reduction of area. Yet the market price was higher than that of many earlier years, when incrcases of area were made; showing that it is the normal or cost price that really matters. And further, it may be seen that the low normal price has more effect when the average line AA 
is very high than when it is low; it is the distance of the normal price from that average line that makes for big reductions of area. This shows that this theoretical line represents the movement of the cost basis of price and not merely what market prices happen to average. It represents, in fact, what we believe to be the course that normal cost prices should follow if the adjustment of acreage to prices was carried out perfectly.

Adjustment of production to price is not perfect, or likely to be, so that only the average tendency of price fluctuations as a whole can afford reliable evidence of a common line of movement. There are a great many other important commodities the prices of which should be brought under review as evidence, before it can be positively demonstrated that prices as a whole conform to a general law, and that their well-recognised fluctuations depend upon the fluctuations in cost of producing the commodities. But we might mention, in passing, that this remark applies with equal force to the opposite contention that price is not dependent and does not follow variations in cost, for many economists make very dogmatic statements in support of this contention without investigating any actual price figures at all. In fact, as we may have remarked before, figures from commercial returns of any sort seem to be studiously avoided by nearly all economic writers; possibly because they wisely recognise that such figures make very uninteresting reading. Still they surely are the only real evidence and should be borne with, rather than accept dogmatic conclusions based on plausibly readable examples of supposed and glaringly exceptional cases.

\section{Pig Iron Prices}

The iron smelting industry is so large and important a portion of the national production that in great commercial countries the state of the iron trade is often regarded as indicating the general condition of commerce, and as the measure of general prosperity in the community; so that it is very unfortunate that the data as to labour cost in producing iron is so far from complete, that we can only estimate its normal price in very rough figures. Although iron prices, the number of furnaces in blast, and other records have been kept since the year 1873 , there has been no proper record of the number of persons employed, except such figures as are given in the Census of the Occupations of the People, for the various census years. Therefore the persons employed in the years between these censuses have to be filled in and the variations in their numbers is estimated from the number of furnaces in use; figures of which are published by the Home Office in the General Report of Mines and Quarries. The data from this Blue Book is given in our table of iron production and price (Table 39), in column 3 of which will also be found the number of persons employed per furnace. When the number of 
persons published in the four census years as working in blast furnaces was divided by the number of furnaces in work, the number to each furnace was found to give an increasing progression as they come down to later years. As this progression seems to be constant in direction, we conclude that the number of persons per furnace for the years between the censuses can be safely filled in by numbers conforming to this progression, and the total number of persons found for these same years, by multiplying the number of furnaces by these persons per furnace for each year. This estimate probably gives very fairly correct figures for the persons employed in smelting iron each year. In addition to the incompleteness of our data for the labour unit, we find in the iron industry an extreme case of the difficulty arising from not being able to get the net output figures. It will be seen by our diagrams that the production per person has sometimes gone as high as $£ \mathrm{I}, 200$ or $£ \mathrm{I}, 300$; and when it is remembered that the average net production per person for the community, as shown by our only Census of Production, is about $£$ Ioo, it will be seen that these gross production figures leave room for considerable error. As these gross figures include all the cost of producing the iron ore and the coal used in smelting, to say nothing of the very costly plant used up in each of these industries, we are practically in the same difficulty that we found in beet sugar, in that we are including a great part of two or three other trades and all their price and cost variations, under our normal price of pig iron. This source of difficulty is to some extent counterbalanced by the fact that one of the included trades is coal, upon which the line AA is based, and which must of necessity therefore correspond to the line; but even then the gross figures would be so much above the net production, which alone can be expected to conform to the rules of price variation, that it is remarkable how nearly these gross output figures for normal price follow the fluctuations of the curve AA.

The first year for which we have the figures is 1873 , when prices were very high, owing, no doubt, chiefly to the boom in trade after the Franco-German War, and partly also to greater cost at that time, as the result of smelting methods and furnaces that have since become obsolete. This higher cost of production in the first few years on the iron index (Diagram 38), probably makes their normal prices show rather high, though the distortion on that account does not amount to much, except in the first year. If our normal prices (in the first column of the index and column 6 of Table 39) were net figures, they should not be affected at all by this extra cost, as the extra number of persons should reduce the normal as much as the extra money price of their produce puts it up. But as the extra labour is engaged in getting the larger required quantity of coal, or in increasing war supplies for the Government, it is not included under the head of persons working in iron works. The cost of such 
labour, which is represented by rates and taxes and cost of materials purchased by the iron furnace companies should, if we had the data. be all deducted from the gross value produced to get the actual net production or true normal price. However, with the exception of the first year or two, as we have said, the relative fluctuations of the normal price of iron are not greatly disturbed by this error, and it

Diagram 38. - IRON INDF.X.

Gross Value produced rer person at the furnaces.

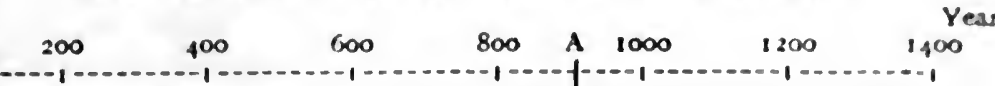

13900000000000000000000000000000000000000000000000000000000000

950,0000000000000000000000000000000 od 00000

75000000000000000000000000000009 -

69000000000000000000000000005

6600000000000000000000000 og 5

61000000000000000000000000

5300000000000000000000

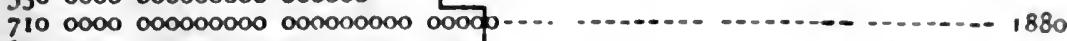

69000000000000000000000000000

8000000000000000000000000000000000

$73000000000000000000000000000 \mathrm{gp}$

68000000000000000000000000000

$62000000000000000000000000--F$

560000000000000000000000

62000000000000000000000000

60000000000000000000000000

69000000000000000000000000000

$8600000000000000000000000000000000000-7 \ldots \ldots \ldots$

74000000000000000000000000000000

650000000000000000000000000

6600000000000000000000000000

7200000000000000000000000000000

69000000000000000000000000000 .

7600000000000000000000000000000 po

300 000000000000000000000000000000

7900000000000000000000000000000000

10100000000000000 00000000 000000000 000000000

I260 0000000000000000000000000000000000000000 ob000000 000 -..... 1900

910000000000000000000000000000000000000

9400000000000000 000000000 000000000 000000

9300000 10000noon 000000000 000000000 00000 5

80000000000000000000000000000000000

91000000000000000000000000000000000000 b-..

970000000000000000000000000000000000000 bo

10600000,000000000000000000000000000000000000 og

900000000000000000000000000000000000000

1010 00000000000000000000000000000000000000000

9300000000000000000000000000000000000000000
101000000000000000000000000000000000000000000

960000000000000000000000000000000000000000

$\$ 2000000000000000000000000000000000000000000000000$ p000

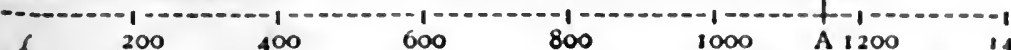

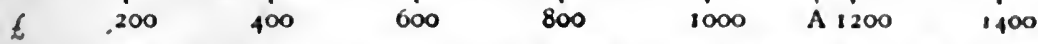

will be seen that the fluctuations follow very fairly well the movement of the curve AA all down the period.

There are of course various years that stand out above or below the line $\mathrm{AA}$ on the iron index, and in some cases the reaction after a year of over high normal price may be seen by the depression in the next, as in the case of 1900 and rgor, and also in 1907 and 1908 as usual. The chief failure of the normal to follow the line is between I885 and 1895 , when it was all the time below the mark, falling as 
much as 20 per cent. below in $\mathrm{r} 892$. This was evidently a very depressed time in the iron trade, but it will be seen that, although on a lower level which probably represents reduced profits, the fluctuations still follow the same direction as those of the curve AA, rising to within 6.6 per cent. of the average in I89o. A depression like this should theoretically result in a reduction of production (area)

Diagram 39.-IRON. PRODUCTION AND PRICE.

\begin{tabular}{|c|c|c|c|c|c|c|c|}
\hline & $\begin{array}{l}\text { Persons } \\
\text { employed. }\end{array}$ & $\begin{array}{c}\text { Furnaces } \\
\text { in } \\
\text { blast. }\end{array}$ & $\begin{array}{l}\text { Persons } \\
\text { per } \\
\text { furnace. }\end{array}$ & $\begin{array}{l}\text { Tons } \\
\text { per } \\
\text { person. }\end{array}$ & $\begin{array}{l}\text { Price. } \\
\quad £\end{array}$ & $\begin{array}{c}\text { Index. } \\
£\end{array}$ & $\begin{array}{c}\text { Pig iron } \\
\text { made. } \\
\text { Tons. }\end{array}$ \\
\hline I 873 & 23,222 & $68_{3}$ & 34 & 283 & $4 \cdot 920$ & I 390 & $6,566,45 \mathrm{I}$ \\
\hline 4 & 22,065 & 649 & 34 & 271 & 3.504 & 950 & $5,991,408$ \\
\hline 5 & 22,130 & 629 & 36 & $28 \mathrm{I}$ & $2 \cdot 666$ & 750 & $6,365,462$ \\
\hline 6 & 22,230 & $5^{85}$ & $3^{8}$ & 295 & $2 \cdot 328$ & 690 & $6,555,997$ \\
\hline 7 & 21,100 & 54 I & 39 & 310 & $2 \cdot 106$ & 660 & $6,608,664$ \\
\hline 8 & 19,920 & 498 & 40 & 320 & $I \cdot 900$ & 610 & $6,381,051$ \\
\hline 9 & I 9,880 & 497 & 40 & 302 & $I \cdot 744$ & 530 & $5,995,337$ \\
\hline \multicolumn{8}{|c|}{$1880--22,680-\cdots--567-\cdots--40----342-\cdots--2.078-\cdots-n 10--7,749,233$} \\
\hline I & $22,600 \mathrm{C}$ & 565 & 40 & 360 & $I \cdot 916$ & 690 & $8,144,449$ \\
\hline 2 & 23,330 & 570 & 40 & 377 & $2 \cdot 218$ & 800 & $8,586,680$ \\
\hline 3 & 23,180 & $55^{2}$ & $4^{2}$ & 368 & I $\cdot 990$ & 730 & $8,529,300$ \\
\hline 4 & $20,95^{\circ}$ & 476 & 44 & 373 & $I \cdot 8 \mathrm{I} 6$ & 680 & $7,811,727$ \\
\hline 5 & 19,9 & 434 & 46 & 371 & $I \cdot 680$ & 620 & $7,415,469$ \\
\hline 6 & 19,150 & 399 & 48 & 366 & I. 532 & 560 & $7,009,754$ \\
\hline 7 & 20,300 & 406 & 50 & 373 & $I \cdot 650$ & 620 & $7,559,518$ \\
\hline 8 & 21,573 & 423 & $5 I$ & 369 & $I \cdot 620$ & 600 & $7,998,969$ \\
\hline 9 & $23, \mathrm{I} 44$ & 445 & 52 & 360 & I.908 & 690 & $8,322,824$ \\
\hline \multicolumn{8}{|c|}{ 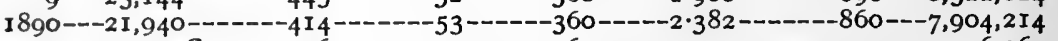 } \\
\hline I & $20,300 \mathrm{C}$ & 376 & 54 & 365 & $2 \cdot 020$ & 740 & $7,406,064$ \\
\hline 2 & 19,910 & 362 & 55 & 337 & $\mathbf{I} \cdot 920$ & 650 & $6,709,255$ \\
\hline 3 & I 8,200 & 327 & 56 & 381 & $I \cdot 724$ & 660 & $6,976,990$ \\
\hline 4 & I9,6I0 & 325 & 56 & 408 & $I=762$ & $7^{20}$ & $7,427,342$ \\
\hline 5 & $2 I, 260$ & 344 & 57 & 393 & $I \cdot 75^{8}$ & 690 & $7,703,459$ \\
\hline 6 & 21,755 & 373 & 57 & 407 & $I \cdot 874$ & 760 & $8,659,68 \mathrm{I}$ \\
\hline 7 & 22,040 & 380 & 58 & 399 & $2 \cdot 000$ & 800 & $8,796,465$ \\
\hline 8 & 22,300 & 378 & 59 & 386 & $2 \cdot 0.40$ & 790 & $8,609,7$ I9 \\
\hline 9 & 24,660 & 4 I I & 60 & 382 & 2.650 & Ioro & $9,42 \mathrm{I}, 435$ \\
\hline \multicolumn{8}{|c|}{$1900--24,180 \cdots \cdots--403---60----379-\cdots-3.404-\cdots 1260--8,959,691$} \\
\hline I & $20,523 \mathrm{C}$ & 336 & $6 \mathrm{I}$ & 386 & $2 \cdot 35^{8}$ & 910 & $7,928,647$ \\
\hline 2 & 21,575 & $34^{8}$ & 62 & 402 & $2 \cdot 340$ & 940 & $8,679,535$ \\
\hline 3 & 22,340 & 349 & 64 & 400 & $2 \cdot 324$ & 930 & $8,935,063$ \\
\hline 4 & 23.220 & 327 & $7 \mathrm{I}$ & 374 & $2 \cdot 140$ & 800 & $8,693,650$ \\
\hline 5 & 24,500 & 345 & 71 & 392 & $2 \cdot 324$ & 910 & $9,608,086$ \\
\hline 6 & 26,495 & 368 & 72 & 384 & $2 \cdot 562$ & 970 & I0, I 83,860 \\
\hline 7 & $26,57^{\circ}$ & 369 & 72 & $38 i$ & $2 \cdot 790$ & 1060 & IO, I I $4,28 \mathrm{I}$ \\
\hline 8 & 24,470 & $32 \mathrm{I}$ & 76 & 370 & $2 \cdot 504$ & 900 & $9,056,851$ \\
\hline 9 & 23,850 & 318 & 75 & 400 & $2 \cdot 424$ & IOIO & $9,531,987$ \\
\hline \multirow{2}{*}{\multicolumn{8}{|c|}{ 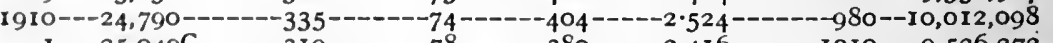 }} \\
\hline I & $25,049 \mathrm{C}$ & $3 I 9$ & 78 & 380 & $2 \cdot 416$ & & \\
\hline 2 & 24,335 & 3 II & 78 & 359 & $2 \cdot 662$ & 960 & $8,751,464$ \\
\hline 3 & 25,690 & 337 & 78 & 399 & $3 \cdot 000$ & I 200 & $10,260,315$ \\
\hline
\end{tabular}

to raise the market price and bring the normal price to the level that is general in other industries and represented by AA. In crops we saw that a period of low normal should cause a counter period of high normal through the reduction of area; and to a certain extent we can see the same tendency in the iron index by the higher normal prices following the depression, and showing a little above the line in r896-7 and I899. But in an industry like iron, with its ponderous capital fixed in a great plant and organisation, the production cannot 
be greatly reduced at a year's notice without much loss. It is not possible to switch off producing iron and produce copper instead, like a farmer can to some extent change his crops when prices favour one more than the other. So that iron companies will struggle on for a year or two making little or 10 profit rather than scrap the costly plant representing their capital; and therefore a depression will have to last some few years before enough producers are forced out of the trade, to bring prices above the average again. Nevertheless, we find that during the depression from 1883 to 1894 furnaces to the number of 227 went out of blast, showing that a process equivalent to reducing the area was going on very effectively; and doubtless would have been more drastic still if it had not been for the partial recovery in iron prices in 1890 and $189 \mathrm{I}$.

It is instructive also to notice that there is some evidence that it is the inferior and less productive furnaces that go out of working as prices fall and trade becomes bad. During the great fall of prices in the first few years covered by our index, it may be seen from the second column of Table 39, which gives the number of furnaces at work each year, that in 1873 there were 683 and their average production per furnace, found by dividing the total output given in column 7 by 683 , was $9,6 \mathrm{r}_{3}$ tons against 12,065 tons produced by the 497 furnaces that were at work in 1879 . This shows that it was the least efficient furnaces that had gone out of work, and that the reduced price was largely the result of the more economical working and reduced cost by the more efficient plant that remained at work. This is also borne out by the returns for the consumption of coal per ton of iron. They show in 1873 that 2.546 tons were used against 2.188 in 1897 , which is direct evidence of reduced cost of production in these years. It was probably these improved methods and the consequent fall of price in this and other European countries that led to the depression of the iron trade being particularly acute in England at this time.

But not only do these second-class furnaces go out of blast at times of depression, it appears also that some of them come in again as prices improve. It may be seen from Table 39 that from 1886 to r889, 46 furnaces came into blast again, and that the tons per person fell by 13 in the last three years. And if, as is probable at such time of increase, the persons per furnace were rather more than our even progression in column 2 shows, the fall per person would be more. As the number of furnaces again becomes less with falling prices till I894, the number of tons per person rises from 360 to 408 , showing that some of the furnaces were still relatively inefficient, and went out of working first. Although the figures are not exact enough to demonstrate the second-rate quality of the incoming furnaces in every case down the table, there is an indication of the tendency all through, as may be seen in 1895 and 1896 , when prices were improving, 
and the reverse in Igo8 and Igog. That these furnaces which represent the marginal production of iron go in and out again so quickly as prices rise or fall, shows that the margin of profit over cost was never very great, or they would still be able to keep on working at a small profit though prices were low.

This coming into work of second-rate furnaces when profits are good is a phenomenon of some importance in this inquiry, as the possibility of inferior furnaces or inferior firms coming into competition in this or any other industry means that such firms may improve, or new efficient ones come in under the easier conditions made by high prices. As these increased producers will make competition very acute when prices begin to fall, it behoves the efficient firms previously existing to keep prices reasonably near to cost at all times, or they may find that serious competitors have sprung up under the encouragement given by an easy margin of profits, and in the price cutting that must then take place they might not find themselves the most successful. We shall hope hereafter to show that in this way marginal production really competes to keep down profits and rent to a level that has some reasonable relation to the service performed by the recipients of such profits. Altogether the normal prices of iron very fairly well support our view of a common cause of price variations that may be indicated by the curve AA, and also that such prices are determined by cost of production including a reasonable profit as cost of management and direction.

\section{Copper Prices.}

In examining price fluctuations of all the foregoing commodities we have been able to calculate a normal price, but in the case of copper it is impossible to obtain any information regarding the output per person except the very limited data given by the U.S.A. Censuses. From them it appears that the production per person has slightly decreased, the figures for the last three censuses being:
I 889 .
I902.
Igro.
II 78
- Ir'74
- $9.86 \mathrm{r}$ short-tons per person.

But as the production per person in other countries may have increased by as much or rather more than it has decreased in the United States, we can hardly base any opinion as to increased or decreased cost upon these scanty returns. From the market prices given in our Copper diagram it would seem that the cost of producing copper has altered very little in the last thirty years.

As we are not able to give a normal price on the basis of the labour cost of copper, we are obliged to content ourselves with an examination of the fluctuations of market prices alone, and it should be understood that they only feebly represent the real movement. Still, they may be seen to follow a somewhat similar course when taken over a fairly long period, and as they afford another example 
of a commercial corner and its inevitable breakdown, they are of some interest as showing the effect of price upon production and its relation to cost.

It will be seen in the first part of the copper price diagram that the prices are a good deal above the curve AA. This is due to

DiAgRaM 40.-COPPliR. IMPORT PRICl:. (REGULUS AND PRI:CIPITATL:)

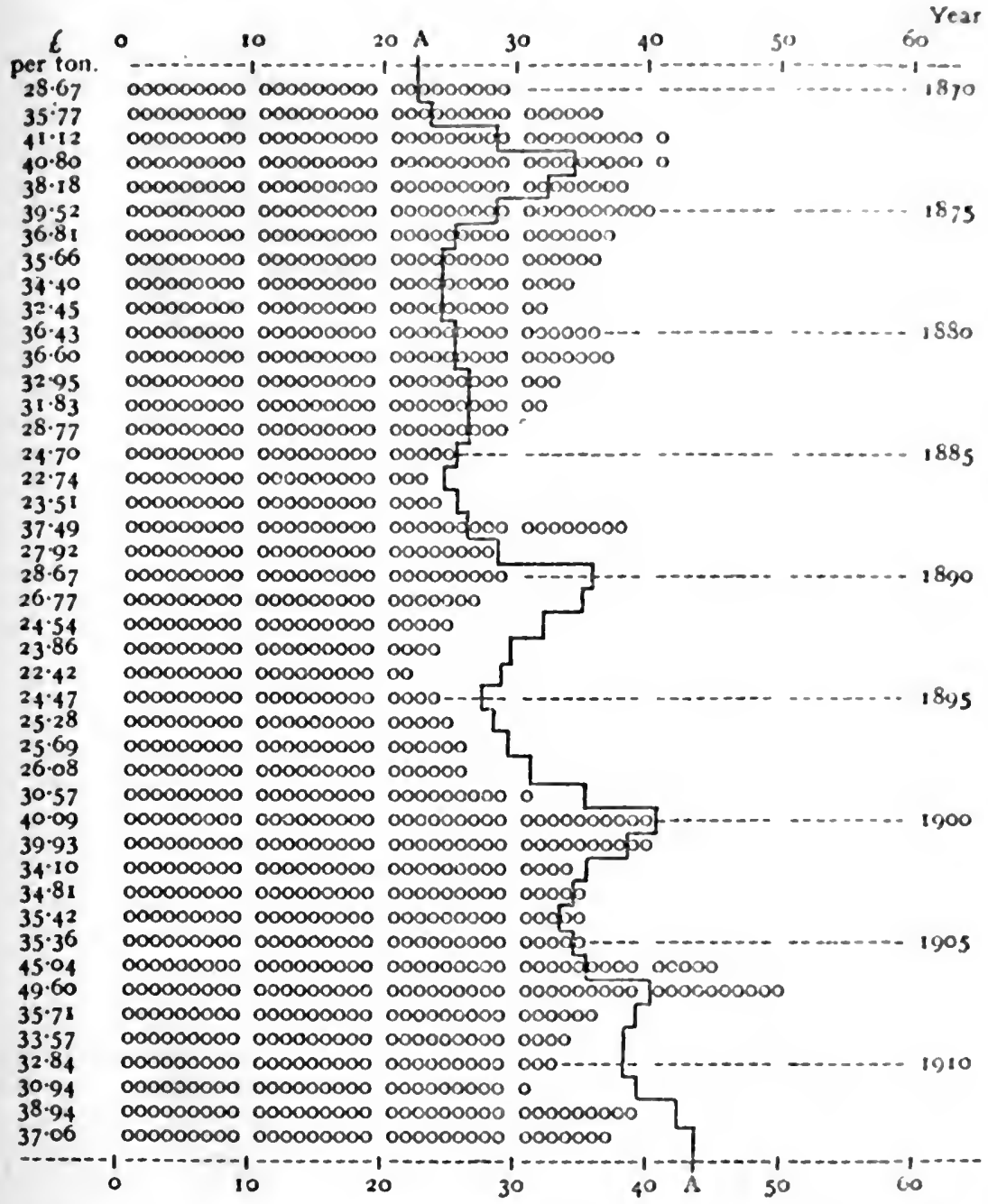

the higher cost of getting copper at that time which made the price high. These are not " normal prices," but simply market price, and not compensated for changes in cost, so that the actual distance from AA does not affect the question. It is simply a question of agreement in time between the price fluctuations and those of $\mathbf{A} \mathbf{A}$. The price of copper starts low in 1870 , rises to $f_{4} \mathrm{I} \cdot \mathrm{I} 2$ in $\mathrm{IS}_{72}$ and 
keeps high till 1875 , when it starts to fall and gets lower until 1879 , following the same course of fluctuations that were seen in coal prices in France and Germany after the War. Also, as seen in coal, there is a little rise in these copper prices in 1880 and then a falling off until $£ 22 \cdot 74$ is reached in $r 886$, which agrees with the lowest point on the curve of normal price movements. A rise of prices then sets in until the year 1890 , which was quite in accordance with the regular movement of prices generally except for the unaccountable jump up in $I 888$, when the price rose to $£ 37^{\circ} 49$. It is evident that an erratic movement like that which is quite contrary to the general price movement for those years needs accounting for by the discovery of some speculative activity or other disturbing factor of a decidedly special nature. This cause is undoubtedly found in the operations of the Frencl Copper Syndicate or "La Société Industrielle Commerciale des Métaux," a graphic account of which is given by C. W. Baker, C.E., in his "Monopolies and the People," from which we quote the following sentences:-

"This syndicate of French capitalists began operations in I887 with the intention of cornering the tin supply.... But before completing their scheme they relinquished it for a grander enterprise, which would embrace the copper production of the world. They made contracts with the copper-mining companies in every country of the globe, by which they agreed to purchase all the copper which should be produced by the mines for three years to come, at the fixed price of 13 cents per pound. . . . If the Société, which is backed by the heaviest capital and managed by the shrewdest business skill of France, does what it intends to do, and its tributary producers are faithful to their contracts, for ten years to come, yes, for all years to come-for it is not likely that an enterprise of such golden returns will ever be abandoned if it can once profitably be carried out-the world must pay for its copper whatever these monopolists demand." In holding over us this grim threat, Mr. Baker seems, from his various provisoes, to have recognised the possible difficulty of the " contributory producers," and in a footnote he adds-." Since the above was written the collapse of the syndicate has taken place." Mr. Baker's explanation of the cause of the collapse hardly seems to us to get to the bottom of the matter; the actual fact being that with the price of copper so inflated no conceivable system of contracts or anything else could prevent the supply being greatly increased somewhere, and the fall of the combine was inevitable. The effect of this uncontrollably great supply is clearly seen in the following two or three years, for while according to the curve AA the price of copper should have been about $£ 35^{\circ} 00$ in I890, it only reached $£ 28.67$. The great speculation so inflated the production and price previously that the full rise was prevented from appearing at the natural time. But if the years I 888 and I890 are transposed and 
placed after I 889 , so as to read I $889-90-88$ it would be seen that the actual price had been altered very little from the normal average. the only real difference being in the date of the high point. From 1890 the usual fall starts as in other commodities with the lowest point in 1894 and followed by the regular rise till 1900 , from which year the price is quite up to the curve AA. It is probable that copper prices would not be quite up to this point in these years if it were not for the fact that more than half the world's supply comes from the United States, and the average price being therefore influenced by the higher level of American prices, which level will be further discussed in the chapter on American prices.

The boom of copper prices in 1906 and 1907 was very marked, as it was seen to be in cotton, iron, and various other things. This was a commercial boom due rather to speculation upon the then rising prices than the position actually attained by the natural rise, so that we find that all commodities did not participate equally in this boom or the slump that followed it. Copper did go up greatly, and the over production produced by this high price in these years caused a reaction that made prices low in the remaining years of the period. On the whole copper prices quite suggest a common movement of prices dependent on some common cause.

In addition to the general evidence for the cost of production basis of price afforded by the evident tendency of all prices to vary in the same direction at the same time, the consistent failure of all these attempts to monopolise industries by corners and financial boosting of prices witnesses to the potency of competition to keep prices to that cost basis. It does not seem possible to raise the price of any commodity above its normal cost without inducing an increased marginal supply, which supply, as we have seen above, will speedily lose its marginal character and become a competing force to send prices below their normal cost, below which average cost they must remain until some producers are forced out of the business, or the gold production improves the level of price and increases demand. Any commodity that is to be cornered or artificially sent up in price without inducing a greatly increased supply must be one the natural supply of which is strictly limited, and such commodities seem very rare for copper itself is not usually considered an over plentiful mineral, yet the supply seems to know no limit when the price is high enough.

\section{TeA Prices.}

Although in the case of tea from India and Ceylon we have returns for the acreage under cultivation, we have unfortunately not been able to obtain the monthly prices, so that we cannot exactly identify the price with the particular crop to which it actually belongs as we have been able to do in previous crop indexes. The index 
Diagram 4I, representing normal tea prices cannot, therefore, be taken as absolutely correct for the particular year, but will, nevertheless, quite well indicate the fluctuations over a period of more than a year or two. The price quoted each year is, moreover, the price for which the previous year's crop is sold and, as the gathering of the leaves goes on during the greater part of the season, there is a good deal of overlap between the seasons, and between one year's price and the next. Another defect in the data is that prices used are the average quoted import prices, and include China and other

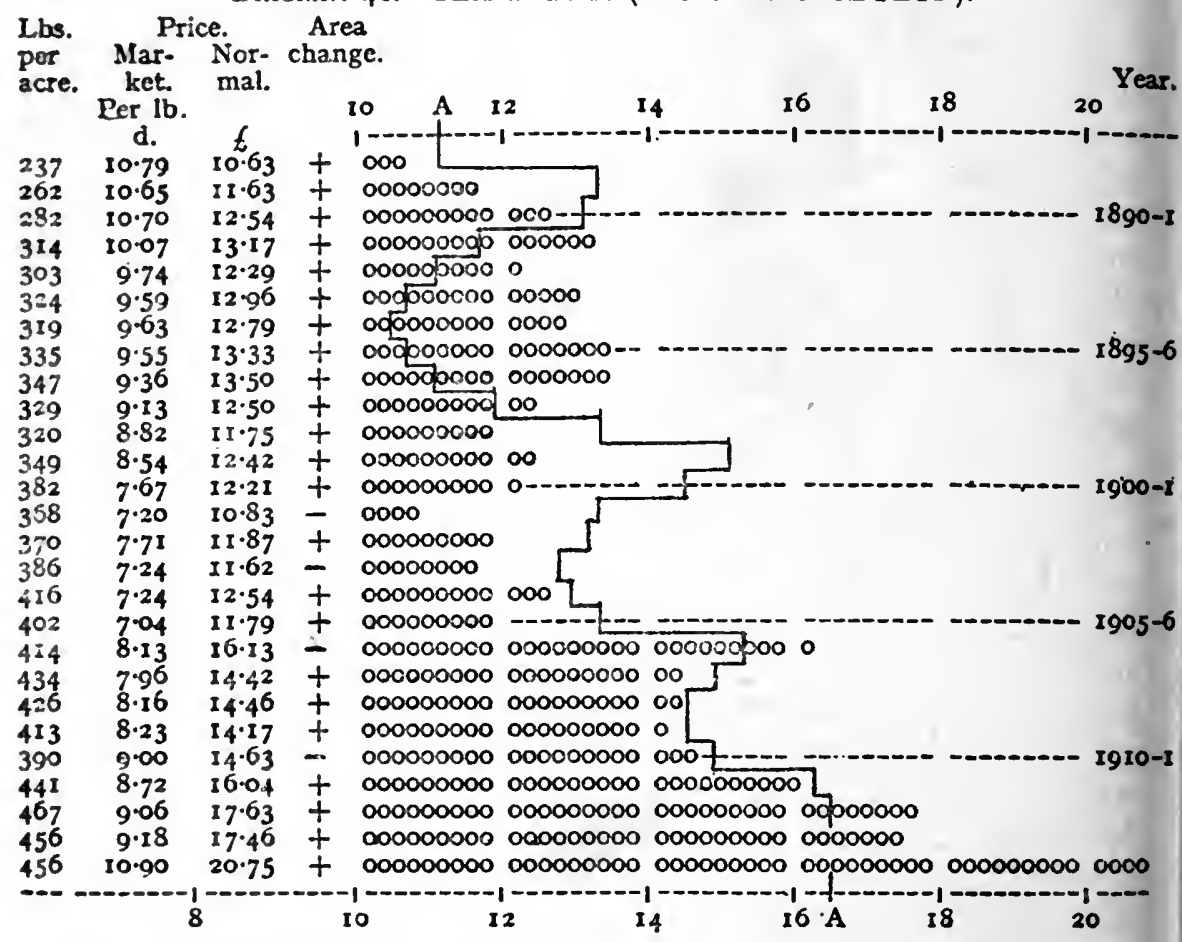

teas, but as the Indian teas are much the largest part of the supply, the others will probably not very greatly alter the average price. These difficulties impair the exactness of the evidence with regard to yearly fluctuations, but the general resemblance between this index and the others is visible especially in the latter part, and there is some interest in the examination of tea prices, owing to the fact that some eminent economists have regarded tea as specially suitable to illustrate demand price in the theory of supply and demand.

The normal prices of tea do not fluctuate very exactly with the curve of general prices, or on the face of it, very greatly support our contention for a similar movement of all prices as the result of a common cause of variation. The irregularity in the movement of tea prices is no doubt due to the comparatively new and experi- 
mental character of modern tea planting in British India. The undiscovered possibilities of tea planting are testified to by the most extraordinary increase in the crop per acre all throughout the period (see Tea Index, column I), and by the equally remarkable increase in the demand for tea as shown by the supply going up by 400 per cent. without reducing the price to any extent at the end of the period (see Table 42, columns 2 and 4). But although these peculiar circumstances of the industry give an appearance to the

TABLE 42.-TEA.

\begin{tabular}{|c|c|c|c|c|c|c|}
\hline & Acres. & Crop. & $\begin{array}{c}\text { Crop } \\
\text { per } \\
\text { acre. }\end{array}$ & $\begin{array}{l}\text { Price } \\
\text { per } \\
\text { lb. }\end{array}$ & $\begin{array}{l}\text { Value } \\
\text { per } \\
\text { acre. }\end{array}$ & $\begin{array}{c}\text { Area. } \\
\text { Increase + } \\
\text { Decrease - }\end{array}$ \\
\hline I888-9 & 524,327 & Lbs. & Lbs. & $d$. & $\underset{f}{f}$ & 1 \\
\hline 90 & 538,701 & I $4 I, 090,900$ & 263 & 10.65 & $I I \cdot 63$ & + \\
\hline $1890-1$ & 564,827 & I $58,937,900$ & 282 & $10 \cdot 70$ & $12 \cdot 54$ & + \\
\hline$I-2$ & 612,437 & $I 92, I 42,300$ & 314 & $10 \cdot 07$ & $13 \cdot 17$ & + \\
\hline $2-3$ & 636,869 & $193,147,900$ & 303 & $9 \cdot 74$ & I $2 \cdot 29$ & + \\
\hline $3-4$ & 668,839 & $216,653,900$ & 324 & 9.59 & $12 \cdot 96$ & + \\
\hline $4-5$ & 688,527 & $219,304,700$ & 319 & $9 \cdot 63$ & $12 \cdot 79$ & + \\
\hline $5-6$ & 720,7 I 7 & $241,247,600$ & 335 & 9.55 & $13 \cdot 33$ & + \\
\hline $6-7$ & 763,280 & $264,567,400$ & 347 & $9 \cdot 36^{\prime}$ & 13.50 & + \\
\hline $7-8$ & 820,119 & $269,836,700$ & 329 & $9 \cdot 13$ & $12 \cdot 50$ & + \\
\hline $8-9$ & 865,680 & $277,244,400$ & 320 & $8 \cdot 82$ & $\mathrm{II} \cdot 75$ & + \\
\hline 90 & 893,658 & $3 I I, 691,600$ & 349 & $8 \cdot 54$ & $12 \cdot 42$ & $t$ \\
\hline $1900-1$ & 906,487 & $345,892,300$ & 382 & $7 \cdot 67$ & $12 \cdot 2 I$ & + \\
\hline$I-2$ & 911,767 & $336,60 \mathrm{r}, 700$ & 369 & $7 \cdot 20$ & $10 \cdot 83$ & - \\
\hline $2-3$ & 911,252 & $337,5^{80}, 500$ & 370 & $7 \cdot 71$ & II 87 & + \\
\hline $3-4$ & 932,835 & $359,960,100$ & 386 & $7 \cdot 24$ & $I I \cdot 62$ & - \\
\hline $4-5$ & 913,225 & $380,339,900$ & 416 & $7 \cdot 24$ & I $2 \cdot 54$ & + \\
\hline $5-6$ & 986,049 & $396,400,100$ & 402 & $7 \cdot 04$ & II.79 & + \\
\hline $6-7$ & 993,468 & $4 I I, 604,500$ & 414 & $8 \cdot 13$ & $16 \cdot 13$ & - \\
\hline $7-8$ & 976,092 & $424,136,000$ & 434 & 7.96 & $14 \cdot 42$ & + \\
\hline $8-9$ & $1,001,475$ & $426,422,800$ & 426 & $8 \cdot 16$ & $14 \cdot 46$ & + \\
\hline 9-0 & $1,090,996$ & $451,022,900$ & 413 & $8 \cdot 23$ & $14 \cdot 17$ & + \\
\hline Ioro-r & $r, r 44,399$ & $445,339,400$ & 390 & $9 \cdot 00$ & 14.63 & - \\
\hline$I-2$ & $1,031,852$ & 455 , I 96,700 & $44 I$ & $8 \cdot 72$ & 16.04 & + \\
\hline $2-3$ & $1,049,458$ & $489,897,600$ & 467 & $9 \cdot 06$ & I7.63 & + \\
\hline $3-4$ & $1,092,847$ & $498,758,000$ & 456 & $9 \cdot 18$ & $17 \cdot 46$ & + \\
\hline $4-5$ & $I, 109,164$ & $506,559,800$ & 456 & I0.90 & $20 \cdot 75$ & \\
\hline
\end{tabular}

tea index which does not seem to directly support our contention, neither does it seem greatly to support the demand theory of price. For when greater quantity of tea is produced for sale, it by no means always follows that prices fall, as may be scen from Table 42 , if the price and crop columns are compared. During the first half of the period the demand certainly increases enormously with the falling price, but it increases quite as much in the second half period with 
the rising price. In I906, when the price went up a penny a pound the demand as shown by the total crop consumed went up also by over $15,000,000 \mathrm{lbs}$. of tea, nor was this a case of over-production above the demand, for though the price fell slightly the next year when the supply was further increased, it recovered in 1908 while the supply was still greater, and for the succeeding years both price and demand increased. In the one case of I9OI-02 the production was less, but the price instead of going up when less tea was offered for sale, went down nearly a halfpenny, so that the dependence of price on supply and demand must not be taken as a quite self-evident fact.

When we come to examine the tea index more in detail we find the irregularity lies chiefly in the fact that normal prices of tea were high in the period I 890 to I898, when they should have been low, and low in the following five years when they should have been high. This, as in the case of some other crops that we have examined, may be partly an error due to the fact that the acre at that time represented more persons than it did in the later years. However that might be the returns from tea planting about 1895 were no doubt a good deal above the average production per person, as shown by the continuous increase of area. Market prices had been very high in previous years, and their continuous fall had allowed the demand for tea to increase greatly with this falling cost of production, even in this period of bad trade and low prices generally. Then it must be remembered that the area under tea cannot be so quickly increased as that under such crops as wheat or oats. It takes three years for the trees to mature before tea can be picked from them, and no doubt they are only small trees then and do not yield quite the full crop. For that and many other reasons it is, no doubt a costly and somewhat speculative business to start tea planting or greatly increase the area. It was no doubt owing to this cost and risk that the area under tea did not increase fast enough at the beginning of this period to bring tea prices down sufficiently to compensate for the increased return per acre. It will be noticed that in the very good season I89I-92 the area was only increased by about 24,000 acres, and in the still better year of $1893-94$ by only 20,000 acres, while in the comparatively poor season of $1897-98$, at the end of the good period, the.area was increased by 45,000 acres. The result of this slow increase of area was that the established planters got the full advantage of their increasing crops with but little competition to reduce the price. The result of their very good profits was that speculators got to fancy there was no end to the demand for tea, and ultimately increased the area so quickly that it got considerably too large for the requirements at the time, and the price came down too low in I898-99.

Then we see the opposite difficulty of reducing the area. The world's supply of tea had been nearly doubled by this great increase 
of 100 million pounds per year of Indian tea, and the supply from the ever-increasing crops had got quite too great for the dernand. But if you have got 45,000 acres of young tea plants doing well at a great cost you cannot root them up and plant something else in their place because they do not pay for a season or two, and when after three years they are producing tea you will be less likely to destroy them, even if you have some other better crop to put in their place, which probably tea planters had not at that time. If a prosperous firm of planters see that their competitors have thousands of acres of young trees coming on, they may feel obliged to extend their nursery planting, although their old plantations are not paying a profit; the difficulty of leaving off was great, and the hope of increased demand was great. So no doubt it comes about that the optimistic increase of area continued for a time, and we find the area was still increased by 28,000 acres in $1898-99$, by only 12,000 in 1899-1900, and 5,000 in 1900-1.

In I90I-2 the area was actually decreased by a few acres, and tea planting was at its worst, with a normal price of $£$ ro 83 , when it should have been $£^{1} 3^{*} 2$, as shown by the curve AA. So here again we see a case of displacement of the high point period of prices on an unusually large scale, a scale that probably could hardly occur in anything but a somewhat new industry which had never before had any such extended area, and in which there was but little experience of turning to alternative crops. In such case new land that had been cultivated at great cost, could not be given up without great loss, with the result that the high normal prices when prices should have been low so increased the area that normal prices were very low at the time they should have been high in Ig00 and Igor.

In 1903-4 the full effect of the over-supply, and also the depression of prices generally, was realised, and 19,000 acres went out of cultivation at the correct point indicated by the curve AA. This seems to have made things a little better in 1904-5, but the consequent increase of the area was a great mistake, and made $1905^{-6}$ a very bad season. Even then there was a slight increase of area which probably accounts for the decrease of 17,000 acres in the following season when prices were booming.

The season Igo6 -7 turned out a very good year with the normal price well above the curve of average normal price, so that it is rather remarkable that there should have been a reduction of area. But the high market price that season was chiefly due to the boom of commercial prices, which we have before noticed in many commodities in 1907, and without which the reduction in area would have been necessary. The chief reason, however, why the longdelayed reduction took place in this most unlikely year was that planters had found a good alternative crop in rubber which was 
booming at that time and seems to have grown well upon tea plantations.

The decrease of area prevented the slump of prices in I907-8 from being very great in tea, and from this point the normal prices closely follow the curve AA till the beginning of the War. We think it will be found that although the special circumstances of the industry have allowed for a big displacement of the relative price positions during one period of rise and fall, the general evidence of tea prices confirms the view that there is a common cause of price movement that cannot be long escaped from, and that even a temporary deviation from this determining cost of production basis must be balanced by a counter deviation before the normal course can be continued. The appearance of this diagram really supports our contention that there is a common movement of price variations dependent upon the fluctuations in the gold standard of value, which movement is indicated by the curve $\mathrm{AA}$, and although the prices of certain commodities may at times depart widely from that average line, their oscillations on either side of that curve tend to balance each other and bring their average movement into coincidence with it.

From the examination of the recorded variation in price of commodities during a considerable period of years we may sum up one or two provisional conclusions. In the first place, we found that all through the period covered by our diagrams, which have all been carried as far back as the available data will allow, there has been a general rise of prices consistent with the rise in wages which has been going on during the same years. This consistency was best illustrated by comparing wages with the normal prices of coal in France and Germany, where the records cover a longer time than in other countries or in other commodities that we have examined. Further, it was seen that this agreement between the movement of prices and the movement of wages was much better brought out when the labour unit was introduced into prices as the unit of quantity, in place of the fixed measure (or bulk unit) alone. The normal prices were then found to follow a more consistent course of fluctuation than the market prices alone do, for the latter in some cases have gone up and in others down during the period, with but little regard to the periodic rise and fall. It has already been explained that the reason why normal price movements agree with each other and with wages movements more closely than market prices do is because the normal price only varies with changes in the gold standard of value. The purpose in examining price variations is to show that there is an effective competition that insures that the labour time unit of quantity shall have a compensating value when used as the unit of quantity in price. By using this unit of the "amount per person" as the unit of quantity, and the money or gold price as the unit of value, we get a compensated price that auto- 
matically adjusts itself to changes in the quantity of commodity produced by the same unit of labour at different times. As we have seen repeatedly, when the harvest resulting from a given amount of labour (the acre) is a good crop and the producer has much (1) sell, the money part of the price falls, and the normal price is about the same as if it had been a bad crop. In which latter case, the money price would have arisen to compensate for the small quantity to be sold, and, therefore, the return to the acre would be the same for a bad crop as a good one. The result of this is that in our comparison of price movements by this unit of labour or normal price, we eliminate the fluctuations due to variations in the productivity of labour, and, therefore, if our numerical data were perfect, any change in the normal price of the commodity must be due to a change in the value of the money standard, and that standard being common to all normal prices, must cause the same change in the normal price of all commodities at the same time and in the same direction.

Theoretically, then, normal prices should all fluctuate alike, except for special disturbing causes, and in such cases any deviation of a price from the common course should be compensated for by an equal deviation in the opposite direction beforc the normal course is re-established. In commercial practice the methods of price adjustment take time ; the knowledge of market requirements and industrial prospects is not sufficiently perfect to attain such exact working of the theoretical law that there shall be no margin of error, but we believe a correct result would be very nearly attained if really adequate returns for any industry could be examined and they covered a reasonable period of time. But if commercial methods are not perfect, very much less perfect still is the recorded data from which we have to discover the evidence of the normal price adjustments throughout past years. So that if from the fragmentary evidence it can be shown that there is such a common tendency of prices to follow the same direction in their movements, it is good evidence that the unit of labour or labour cost is a naturally determined or innate value.

We think this value determines price, save only for fluctuations in the standard of money value, which would not occur if gold, which represents that standard, was actually the fixed value that it is taken to be. As gold is a produced commodity like other things, it is reasonable to suppose that its cost of production varies, but as its market price can never vary, we cannot give it a compensated normal price and eliminate variations in the productivity of labour in mines. So this standard varies in accordance with the labour employed in its production, and it therefore appears that not only is price fixed by cost of production, but variations in price are caused by cost too. 
So far as we have gone in the examination of prices then, it seems reasonable to conclude that price depends upon labour cost of production. The fact that normal prices, which exclude variations in productivity of labour, seem obliged to follow similar and equal fluctuations shows that there cannot be any great margin between the cost and the price. And it has been pointed out, in many special cases that have been noticed in our review of prices, that there cannot, under ordinary circumstances, be room between the labour cost, that includes the entrepreneurs' remuneration, and the price of the production, for anything of the nature of unlimited profit. The profits obtained are, in most cases, a fair payment by results for the labour of management, and in any case are part of the cost to the producer and to the community. The whole evidence seems to point to the fact that it is the labour or life-time used up in production that gives things exchange value or price, but there remain certain problems that very much obscure a really convincing view of this fact that has so long hung in the economic balance.

In the first place, if price depends on the labour-time involved, how can prices periodically vary from high to low as we have seen they do? One hour's labour-time is always the same amount, yet the price of its resulting production has been seen to vary periodically from changes in the gold standard, the value of which is itself fixed by labour-time. And as throughout the whole period under our review the production per person has been increasing, and everything is produced with less labour than it used to be, how does it come about that the price of everything, which price we claim is determined by this labour, has gone up ?

We believe the answer to these questions is in reality simple, though its very simplicity makes it elusive and hard to keep clearly in mind. We have to remember that the price of everything must be measured by something else that can be taken as a standard of value. And if that something else that is used as the measure of value has itself been produced in less time than it used to be, more of it is produced by the same amount of labour than was done by that labour, say, 25 years ago. So the amount of that standara' commodity given as the price of things will be more than used to be given, and the price of the thing is more-has gone up. That is so, of course, provided that it is the commodity used as the standard, gold for instance, in which the greatest saving of labour has taken place. For if there is an equal saving of labour in the things that are to be purchased by the gold no change of price will appear, both having been produced with equally less labour than they were. From this it can be seen that if the standard of value, gold, is at one time produced with less labour, the price of commodities will rise; and if at another time commodities are produced in less labour- 
time than gold, prices will fall. But although the price of commodity may thus rise and fall the value resulting from equal periods of labour-time is the same. If one season more commodity is produced than formerly, the standard of value being unchanged, the market price of that commodity will fall; but as the quantity is more the result to the producer is the same, the normal price for the labour-time is unchanged.

But although this answer to the above questions shows that it is quite possible to have a change of price while that price still depends upon the labour-time involved, it does not explain why it is that the producers of the standard of value, gold, should be induced to give a greater amount of it for other things and thus raise prices. For instance, if a gold miner can give $£ 2$ for a 20s. pair of boots because he gets two sovereigns' worth of gold in the time it took to get one previously, and a shoemaker can give two pairs of 20s. boots for $£ 1$ because he makes them in half the time he used to do, why should the miner give $£^{2}$ for a pair of boots? It looks very much as if boots had fallen to Ios. per pair instead of rising in price or even remaining stationary, and that the gold miner would simply be able to buy four pairs of boots for his two sovereigns. But, from common experience, we know that it is contrary to all facts to suppose that gold miners are the only persons benefited by improved production. And in this case it is obvious that if the gold miner wants four pairs of boots it will require another shoemaker to produce them, the first shoemaker being only able to make two pairs by his improved method. It is quite improbable that any one would start in that industry and be content to get $£$ I for two pairs of boots when in the same time they could get $\ell^{2}$ by mining gold. But if we suppose, as is generally recognised by economists, that labour and capital will flow into the most paying industry, which in this case is gold mining, it may be supposed to do so until there are so many more miners that four sovereigns are produced to every two pairs of boots. And then the result of the improved method of production would be that boots had gone up to $£^{2}$ per pair. But this, of course, means that the shoemaker would be able to get $£ 4$ in the time the gold miners get $£ 2$, because he can make two pairs of boots in that time. So the labour will flow back into the shoe trade, and obviously a point will be reached where boots will be $£ \mathrm{I}$ per pair and both the gold miner and shoemaker will earn $£^{2}$ in the same time; the price of boots will be unchanged at 20s. a pair as at first. But, seeing that the normal price or value per person has gone up 50 per cent., both these persons being twice as well off, a record of price, or index number, that simply records no change in the purchasing power of the sovereign does not seem to throw much light on the economic or sociological meaning of the changes that have occurred. Such figures would not even show the important fact that the price or 
value of labour had gone up 50 per cent., that much more gold having to be given for it because it could produce that much more if it was employed in gold mining.

Again, the above explanation of how the price of boots may be adjusted goes on the assumption that just as much as the labourtime of making a pair of boots has gone down the labour cost has gone up. That is, the value of the labour is more measured in gold, and that the price is determined by that amount of labour at its new value. But if, as is often claimed, the price does not depend upon the cost of production measured in gold, or the index numbers or other methods of price investigation do not make this rise in the value evident, only recognising the relative change in value between goods and gold, the above explanation does not necessarily hold good, and it seems quite open to question what the value of the boots really is. It would appear that they might vary from Ios. to $£^{2}$, and if they are selling, say, for I5s., should they be regarded as 20 . boots fallen in price to I5s. or as IOs. boots risen to I5s. ? There seems no possible means of determining such a point by any theory of supply and demand or without admitting a cost basis of value; and we should be driven to the conclusion that value begins and ends with the sale price of the moment. No doubt we are commonly content to regard things as being of the value that is asked for them, but it is quite a practical question in business ethics whether the price obtained for a commodity is a fair and just one. And we hear a good deal about extortionate prices, cutting prices, fixing prices, under selling, dumping, etc., but there seems very little hope of satisfactorily discussing such questions while price investigations simply tell us that the level of price as represented by boots at I5s. has fallen 25 per cent., but does not inform us that at the same time the community is getting half as much again of gold and twice as much commodity, facts that might be thought to make some difference to the importance of the 25 per cent. fall of prices.

In the above imaginary case we were supposed to know just what the gold miner gets, what the shoemaker could produce, and so on, but in actual business there is no such complete knowledge, and if, while such changes in the production of boots are going on, the price happens to be I5s. per pair, all the average shoe manufacturer would know would be : that in spite of all the improvements he has made in getting to produce two pairs in place of one, the price of boots has fallen from $£$ I to I5s., and wages have gone up 50 per cent., so that he thinks he gets less profit per pair and will get none if wages go up any more. It might be a practical question for such producer whether he should invest more money and work in further improvements in boot making, or invest a little in gold mine shares. $\mathrm{He}$ wants to know whether the fall in price of boots is really due to the fact that they cost, or should cost him that much less, or whether 
it is due to something beyond his control, such as a shortage of gold. in which case there should be better opportunities in the mining business. He wants to know a little more than the market price of shares. He desires some indication of future prospects: are wages going up or down, are boot prices going to be better or worse, in fact, is it gold or boots that is going to be a little above the average of general prices; and any index number or other economic hypothesis that can only indicate all the above changes in production as a rise of 25 per cent. in the purchasing power of a sovereign does not seem of much practical use to this gentleman.

And it seems more hopelessly inadequate still, to help settle questions of rates of wages, taxes, or more ethical points arising out of business transactions. If ten years ago boots were 20s. per pair, and five years ago had gone down to ros., and were now up to $15 s$., and we wanted to know whether that was a fair price, it would not help us much to be told that the level of price was 25 per cent. lower than it was ten years ago, and 25 per cent. higher than it was five years ago. We should not know whether a benevolent trade was providing us with 20s. boots for 15 s., or whether an unscrupulous combine was making us pay I5s. for Ios. boots. Our candid opinion would depend, of course, on whether we wanted to buy or sell the boots, but in either case we should be quite certain that the other man was the rogue; and beyond this pious conclusion the intelligence of man, with all its index numbers, does not seem able to get.

We cannot help thinking it is an important point in favour of our method of examining prices that our indexes do show a change of normal price when both gold and commodity have moved together. The indexes are for independent productions, so they indicate in which commodity a change of price has occurred, and whether it corresponds with the gold movement or not. And we hope ultimately to show that these price indexes can be of practical utility in business forecasts. But the theory is difficult, for it is always difficult to keep clearly in the mind a simple theory when its working results are vastly complicated. The data, too, in support of this theory are so scanty and imperfect that it is only by the examination of a large mass of evidence that its probability can be substantiated; and the next step in search of this evidence must be the examination by our labour unit method of the production of gold, which is in most countries the commodity by which all values are measured. 


\section{CHAPTER VII}

\section{GOLD}

THE use of gold as the monetary standard of value is so general throughout the world that we are apt to regard it as the natural and final measure of wealth and all values. Its suitability as a means of transfer of values in small business transactions is so obvious, and in conjunction with other less costly metals it answers all the purposes of money so well, that there seems no reason to apologise for its use. As it is again obviously necessary to have one common standard of money value for all business manipulations, whatever their magnitude or method of transaction, it follows that gold appears to be about as good a monetary standard of value as we could have. But we speak of "monetary standard" advisedly, for while it is quite necessary to have money of some kind, and therefore a standard of money, it does not follow that money is the only standard of value. As we have before hinted, and hope further to point out, it is doubtful whether gold is really the final measure of value at all, even under present commercial and economic conditions. This, as we have pointed out, is due to the fact that gold, like other things, has to be produced by labour, and therefore its cost in labour-time will certainly vary as the mineral happens to be obtained with more or less difficulty. As its marginal utility or relative value depends upon how much sacrifice of lifetime has to be made to get it, the measure of its value is obviously the labour it costs, and its value must always vary exactly with the labour of producing it. This fact that the value of gold varies considerably must very much detract from its usefulness as a standard of value ; and it becomes absolutely necessary either to adopt another standard or be able, as with our normal prices, at all times to measure and allow for the variation of the gold standard in all economic calculations. For this reason we propose first to examine the changes in the value of gold by our unit of labour method, and then try and see how this revised gold standard affects prices; and in subsequent chapters, see how normal prices affect profits and wages, and the economic position generally.

As we mentioned at the close of the last chapter, the data regarding this very important point are very far from complete, and this is much to be regretted, as we believe that if we were in possession of complete data as to the labour cost of gold throughout the whole period over which some of our crop and coal indexes extend, it would be comparatively easy to substantiate our view of the effect 
of gold production upon values. But as the evidence is much too incomplete to afford anything like a direct proof that the labour cost of gold determines prices, it remains simply to point out how far the variations in the cost of producing gold follow the same lines as in other productions. Then to give some reason for the apparent differences in its cost movements, as compared with other things: state the theory we propose to base upon the slender evidence afforded, and leave the probability of that theory to be substantiated by the indirect evidence of its capacity to explain the commercial phenomena that experience has made so well known to the business world. This is the course that is commonly found necessary in scientific investigations, owing to the difficulty of obtaining the direct data required, a difficulty which is in reality the cause and reason for the investigation: for if the data were actually complete, there is no reason to suppose there would be any scientific problem remaining to be investigated. It is only our want of complete knowledge of the facts that prevents the true conclusions being self evident.

The first difficulty is the very short period over which the figures respecting the production of gold per person extend, the earliest record going back only as far as I895, and therefore covering very few price fluctuations. Also war conditions greatly disturb this short period and much obscure the resemblance which actually exists between the value of gold produced and the price novement shown by the curve AA. Further, it will be noticed that the production of the United States gold mines is not included, which. though to be much regretted, is quite unavoidable, as the number of persons employed in these mines is not collected except for the Census years, and even then the returns are rather confused by the fact that the mines are worked for other metals such as silver and copper along with the gold, and therefore the output per man of gold alone is somewhat uncertain. The returns for the Census years suggest that the production per person in that country is considerably higher than that represented in our indexes, and it is unfortunate that we have no data for the yearly variations in its cost of production. As, however, America seems to supply little or no gold to other countries, its output probably has little direct effect on European prices. Another point which renders our diagrams less perfect than they should be is the same error that vitiates nearly all our indexes, namely, the fact that the production which we divided by the number of persons is the gross production, and not the net output as it should be. The cost of materials, etc., bought, depreciation of plant, and sinking fund and such other expenses incurred by commercial undertakings should be deducted if data for them were returned to the Government records. Such data are very incomplete, and the want of them no doubt accounts for much of 
the difference in production per person in different trades. In the case of gold it appears that the cost of stores purchased is 28.5 per cent. of the output against only 13.5 per cent. in coal mining, so that the production per person in our gold index is probably I $_{5}$ per cent. too high compared with coal. These and many other defects in the data render it very improbable that there can be any point by point resemblance between the minor fluctuations of the gold index and the price indexes of commodities. Even if the data were more perfect, many local business exigencies must intervene between the work of the remote gold field and trade prices in the great commercial centres of Europe and America. So that, although fluctuations in

DiAgRAM 43.-GOLD INDEX.

(World Production PER Unit of Labour, U.S.A. NOT INCLUded.)

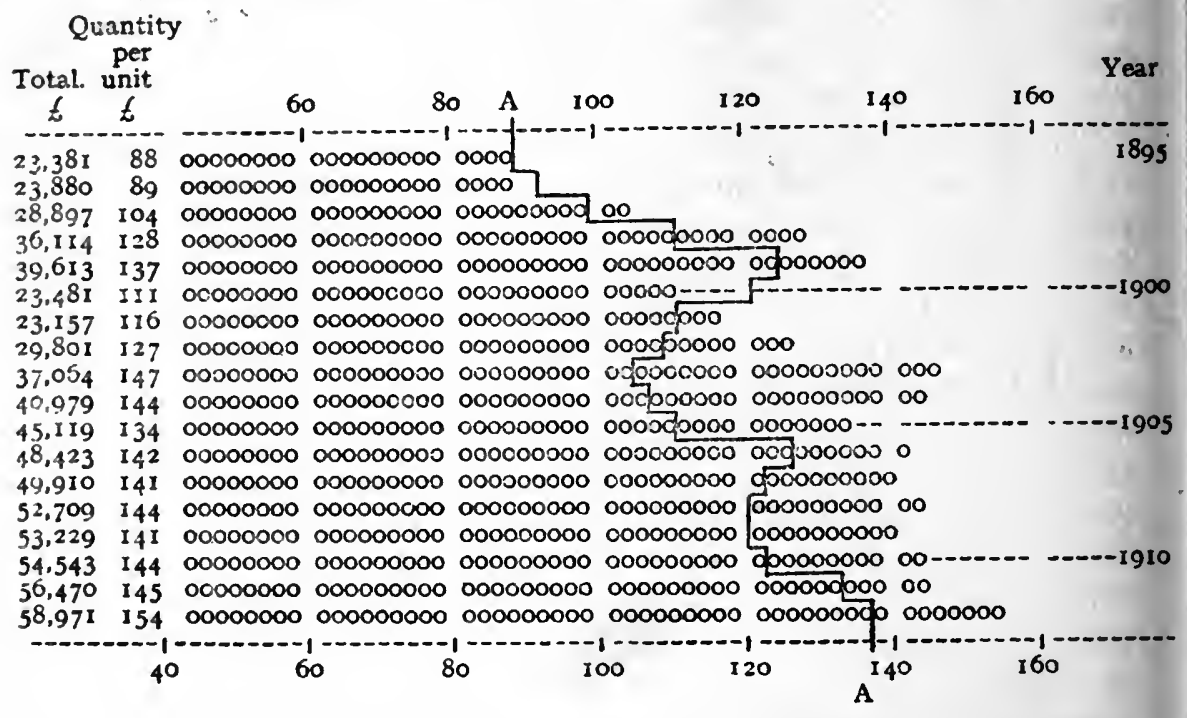

cost of production in gold mines may determine the fluctuations of prices, the relation of the cause to the effect may be much the same as the relation of the great lunar-tide-wave to the local tide movement at various geographical points, where the rise and fall may be great or small, late or early, or even non-existent, yet all obviously dependent upon the same great tide wave.

The Gold Index, Diagram No. 43, represents the whole of the gold supply that affects European prices to any great extent, and is made to show the production of gold per person or normal value of gold, in the same way as the normal price of other commodities has been illustrated. But it should be remembered that there is no market price for gold that can vary inversely with the cost, and so send the normal price up when the output per person is low. The normal price of gold is always the same at about $£ 4$ per ounce, that 
being the weight of four sovereigns, and no one would give more than one ounce of gold for an ounce of gold, however scarce gold might be. Yet it is equally obvious that if gold is so difficult to get that it does not pay so well to mine it as to work at other forms of industry, gold will not be produced unless in some way a virtually. higher price is paid for it. Naturally a gold miner never wants gold in exchange for his gold; what he must have is goods of some sort, and of these he must have more per ounce of gold if that gold gets harder to obtain. So what really happens is that when gold is scarce more commodity is given for it ; which is to say, more goods at the same price, which means that the goods are lower in price. To express this operation in the form that has become familiar to us in the investigation of crop-prices, we might say that when the crop of gold is bad its value virtually goes up by bringing the price of other things down. The commercial operations by which this is accomplished will be discussed further in the chapter on trade fluctuations, but here it is only necessary to point out that such a process is inevitable.

The value produced per person given in this gold index is based upon figures from the Mines and Quarries Report, published by the Home Office; and some of the details of these figures are given on Table 44, which shows where the gold supply of the old world comes from. The total production figures for the supply of gold are given in the first column of the index (43), because they will be found useful in explaining the price movements that we think arise from alterations in the value of gold per person. These total supply figures take the place of the crop per acre or tons per person of the other indexes, because in the case of gold the crop or tons per person is always identical with the value, never altering with any difference in market price. The average variations of commodity prices which are supposed to follow the variations in productivity of gold are indicated by the curve AA as on other diagrams; and the first thing to notice about it is, that the points on the curve come one year earlier on the gold index than on other diagrams that synchronise with the calendar year. The reason for that alteration of position is the obvious fact that if the level of price depends upon the production per person of gold the productivity of one year cannot be expected to react on prices till the next ; the year's production might not have reached its maximum level till late on in the year; and even if it had, it must take time before the industrial and commercial reactions can visibly affect the level of price. In the crop indexes, where each season is part of two years, the date of the annual price level agrees with the latter part of one season and the beginning of the next, which is as near an agreement in time as the two differently timed seasons will allow.

In addition to the old world gold index (43), we give a special 
index of the Transvaal supply, because it goes a year or two further back (Diagram 46). Also Diagram 45 of the world's production of gold, including that of America. On this diagram we have drawn the curve AA, copied from the coal diagrams, so that the curve may be easily referred to for years earlier than those given on Index 43 . But the curve must not be expected to agree in any way with the total production of gold, in fact, it is useful to show how little con-

TABLE 44-GOLD.

Production per Unit of Labour.

\begin{tabular}{|c|c|c|c|c|c|c|}
\hline & Persons. & Value. & $\begin{array}{l}\text { Per } \\
\text { unit. }\end{array}$ & Persons. & Value. & $\begin{array}{c}\text { Per } \\
\text { unit. }\end{array}$ \\
\hline $\begin{array}{l}\text { Transvaal } \\
\text { Australia } \\
\text { India } \\
\text { New Zealand } \\
\text { Russia }\end{array}$ & $\begin{array}{l}1895 \\
61,648 \\
85,000 \\
22,368 ? \\
15,000 \\
82,325\end{array}$ & $\begin{array}{c}£ \\
8,569,555 \\
7,708,029 \\
968,260 \\
1,162,164 \\
4,973,126\end{array}$ & $\begin{array}{r}£ \\
139 \\
91 \\
43 \\
77 \\
60\end{array}$ & $\begin{array}{l}1896 . \\
73,387 \\
84,730 \\
22,746 ? \\
14,889 \\
72,508\end{array}$ & $\begin{array}{c}\quad £ \\
8,603,821 \\
7,456,287 \\
1,173,658 \\
I, 041,428 \\
5,605,364\end{array}$ & $\begin{array}{c}£ \\
\text { II } \\
88 \\
52 \\
70 \\
77\end{array}$ \\
\hline & $266,34 I$ & $23,38 I, 134$ & 88 & 268,260 & $23,880,558$ & 89 \\
\hline $\begin{array}{l}\text { Transvaal } \\
\text { Australia } \\
\text { India } \\
\text { New Zealand } \\
\text { Russia }\end{array}$ & $\begin{array}{l}\text { I897. } \\
78,657 \\
84,844 \\
23,658 ? \\
\text { I4,198 } \\
75,2 \text { I2 }\end{array}$ & $\begin{array}{r}\text { II,653,725 } \\
9,291,408 \\
1,232,582 \\
980,204 \\
5,740,000\end{array}$ & $\begin{array}{r}\text { I48 } \\
\text { IO9 } \\
52 \\
69 \\
76\end{array}$ & $\begin{array}{c} \\
\text { I898. } \\
92,806 \\
75,06 \text { I } \\
23,658 \\
13,672 \\
77,518\end{array}$ & $\begin{array}{r}\text { I6,240,630 } \\
\text { II,334,405 } \\
\text { I,608,504 } \\
\text { I,080,69I } \\
5,850,000\end{array}$ & $\begin{array}{r}\text { I75 } \\
\text { I5I } \\
68 \\
79 \\
75\end{array}$ \\
\hline & 276,569 & $28,897,9$ I9 & IO4 & 282,715 & $36, I I 4,230$ & I 28 \\
\hline $\begin{array}{l}\text { Transvaal } \\
\text { Australia } \\
\text { India } \\
\text { New Zealand } \\
\text { Russia }\end{array}$ & $\begin{array}{l}1899 . \\
93,000 \\
75,300 \\
24,046 \\
13,291 \\
83,742\end{array}$ & $\begin{array}{r}16,272,857 \\
\mathrm{I} 4,254,666 \\
\mathrm{I}, 723,082 \\
\mathrm{I}, 5 \mathrm{I} 3, \mathrm{I} 73 \\
5,850,000\end{array}$ & $\begin{array}{r}\text { I75 } \\
189 \\
72 \\
\text { II4 } \\
70\end{array}$ & $\begin{array}{c}1900 . \\
7,000 \\
74,733 \\
25,026 \\
13,502 \\
90,988\end{array}$ & $\begin{array}{r}I, 000,100 \\
\text { I3,303,468 } \\
1,891,804 \\
1,439,602 \\
5,847,000\end{array}$ & $\begin{array}{r}143 \\
\text { I78 } \\
72 \\
\text { I07 } \\
64\end{array}$ \\
\hline & 289,379 & 39,6 I 3,778 & I37 & 211,249 & $23,48 I, 974$ & III \\
\hline $\begin{array}{l}\text { Transvaal } \\
\text { Australia } \\
\text { India } \\
\text { New Zealand } \\
\text { Russia }\end{array}$ & $\begin{array}{c}\text { I90I. } \\
7,8 \mathrm{I} 7 \\
66,034 \\
25,506 \\
12,732 \\
86,720\end{array}$ & $\begin{array}{r}980,381 \\
\text { I3,801,580 } \\
1,970,230 \\
1,753,783 \\
4,651,682\end{array}$ & $\begin{array}{r}125 \\
209 \\
77 \\
\text { I39 } \\
54\end{array}$ & $\begin{array}{l}\text { I902. } \\
42,816 \\
66,234 \\
27,8 \text { I0 } \\
\text { II,398 } \\
86,770\end{array}$ & $\begin{array}{r}7,301,50 I \\
\text { I4,4I5,299 } \\
1,970,230 \\
1,951,433 \\
4, I 63,278\end{array}$ & $\begin{array}{r}\text { I70 } \\
2 I 9 \\
7 I \\
\text { I7I } \\
48\end{array}$ \\
\hline & I98,809 & $23,157,656$ & II6 & 235,028 & $29,80 I, 74 I$ & 127 \\
\hline
\end{tabular}


TABLE 44-GOLD (combinued).

Production per Unit of Labour.

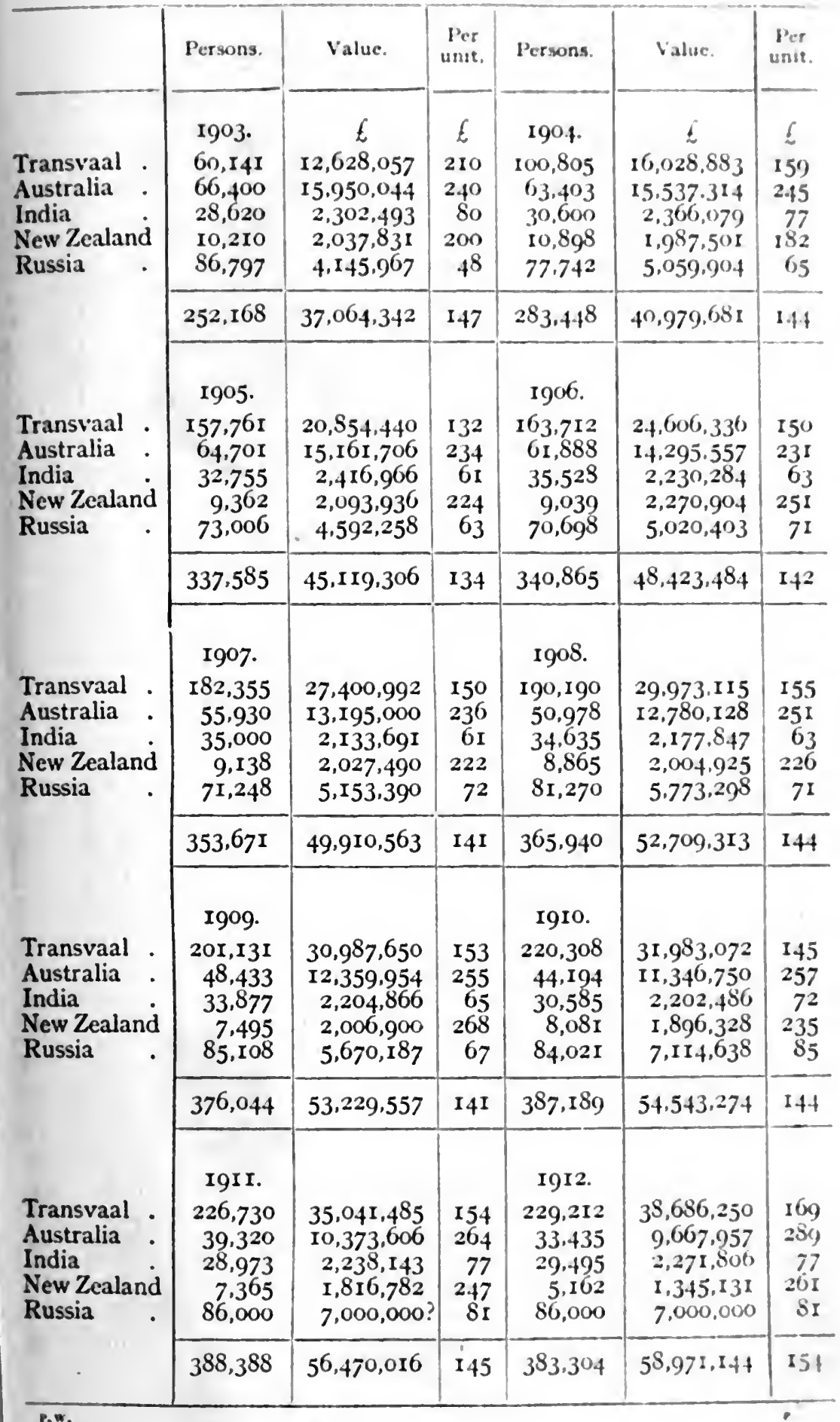


TABLE 44-GOLD (continued).

Transvaal Production.

\begin{tabular}{|c|c|c|c|c|c|c|c|}
\hline & Persons. & Value. & Unit. & & Persons. & Value. & Uñit. \\
\hline I8g & & $5,5^{\check{\tau}} 8,642$ & $\underset{I \sigma 2}{t}$ & I904 & IO0,805 & $\underset{I 6,028,883}{£}$ & $\underset{159}{t}$ \\
\hline I89 & 48,156 & $7,651,336$ & I59 & I905 & $I 57,761$ & $20,854,440$ & I32 \\
\hline I 895 & 61,648 & $8,569,555$ & I39 & Igo6 & 163,712 & $24,606,336$ & I50 \\
\hline 1896 & 73,387 & $8,603,821$ & II 7 & I907 & I82,355 & $27,400,992$ & I50 \\
\hline I897 & 78,657 & $I 1,653,725$ & 148 & rgo8 & Igo, I9o & 29,473, I I5 & I55 \\
\hline I898 & 92,806 & $16,240,630$ & I75 & I909 & $20 I, I 3 I$ & $30,787,650$ & I53 \\
\hline I899 & 93,000 & I6,272,857 & I75 & Igro & 220,308 & $3 x, 973$, I23 & I45 \\
\hline I900 & 7,000 & $\mathrm{I}, \mathrm{000}, \mathrm{IOO}$ & I43 & IgII & 226,730 & $35,04 I, 485$ & I54 \\
\hline I9OI & 7,817 & $980,38 I$ & I25 & IgI2 & $229,2 \mathrm{I} 2$ & $38,7 \mathrm{II}, 58 \mathrm{I}$ & I68 \\
\hline I902 & 42,816 & $7,301,501$ & I70 & I9I3 & 219,629 & $37,35^{8}, 040$ & I70 \\
\hline I903 & $60, I 4 I$ & I $2,628,057$ & 210 & IgI4 & 201,162 & $35,588,075$ & I77 \\
\hline
\end{tabular}

nection there is between the level of prices and the actual quantity of gold, and it will be seen that the price curve is much nearer to the production of gold per person shown on Index 43 .

Our general survey of the fluctuations of commodity prices since I882, or during as much of that period as we could get the required data for, may be taken as summed up by the curve AA, which represents our estimate of what the average price movements have been, and to which we have tried to show they have approximated as nearly as we can expect them to when the incompleteness of the data is allowed for. It will have been gathered from what we have said of prices varying with changes in the standard of value, and following a common course of variations, that the variations of price level should theoretically follow the variations in the labour cost of producing gold, or its value per person. It is the evidence for such agreement of price movements with cost of gold that we are now attempting to investigate. But when we come to make such investigation we are faced with the before-mentioned difficulty that the requisite data only go back for a very few years, data for the value per person of the Old World supply only going back to I895. That portion of the supply produced by the Transvaal mines alone gives us the labour unit back to 1893 , but beyond that we have no cost data, so can only draw a few rough conclusions from the world's supply, or actual quantity alone, which is not of much use as evidence from our point of view. But we may use the three gold Diagrams 43, 45, and 46 together as some little evidence that commodity prices have varied in accordance with the production of gold per person.

By the curve AA, seen on Diagram 45, it is shown that commodity prices were very low in $I 885$ and rose very considerably up to the year 1890 , although the diagram shows that the total quantity of gold did not increase very much. But the labour cost of getting the 
in the production of gold per person due to the higher productivity of the Transvaal mines.

Again, from I8go we find prices falling till I895, although the total quantity of gold produced each year was increasing from $24 \frac{1}{2}$ millions in 1890 to $40 \frac{3}{4}$ millions in 1895 (Diagram 45), which makes the price movement of this period very difficult to explain by the "quantity theory of money," which contends that, other factors being unaltered, prices must rise if money in circulation is increased. But on the assumption that more gold was found necessary for currency or the bank reserves that were greatly on the increase at that time, or for other purposes, it would be necessary to get more gold even at an increased cost, which would lower prices. It will be seen by the Transvaal gold index that from I893-I896 there was a very rapid fall in the production per person, which means an increased labour cost, and we see by AA, Diagram 45, that prices fell with the lower productivity of the gold mines. The data on Diagram 46 for the Transvaal supply do not cover all this period from $x 890$, but so far as they do, $1893-5$, they support the view that the production per person was falling, showing increased cost to get the required supply and a corresponding fall in commodity prices.

Coming now to the period covered by Diagram 43, for which we have the labour unit data, we find that the general level of prices indicated by the curve AA corresponds with the gold production of the previous year at $£ 88$ for I895. From that point commodity prices rise rapidly with the increased output of gold per person until I9oo, when, notwithstanding that the production of gold was still higher per person, the average of prices stopped rising, although certain commodities, such as English coal, continued to go up owing to War demand and prices. This stopping of the advance of prices may have been due to the demand for gold, which is increased by high prices, having outstripped the supply, because in the following years, when the supply was obviously short, prices fell rapidly. But recognising the roughness of the data, too much must not be made of this disagreement between the point reached by prices and that of gold production. The position of prices depends upon the net values produced in gold and commodities respectively, and as our figures are for the gross production in both cases there is considerable margin for error. Considering this fact, the rise in prices from 1895 really corresponds very well with the rise in gold production to the high value per person in I899.

The South African War, coming in r9oo, resulted in the complete stoppage of the Transvaal mines, and the Old World's supply of gold which alone has any obvious result on European prices, may be seen by Table 44 to have fallen over $£ 15,000,000$, remaining at that low point for the two years I900 and rgor. The supply did not get back 
to its old 1899 position till 1904, when no doubt a considerably larger quantity of gold was wanted, so that probably the shortage was felt until I9II, when again prices came within an approximately correct relation to gold production. This sudden stoppage of the gold supply, coming when prices were high and trade good, may be compared, as we have said, to a bad harvest, and would undoubtedly cause a great rise in the relative value of gold. As that commodity cannot rise in market price, there must follow a fall in prices of commodities generally, if anything like an adequate supply is to be obtained by extending the inferior mines left in work. Unfortunately this sudden closing of the Transvaal mines does not afford a

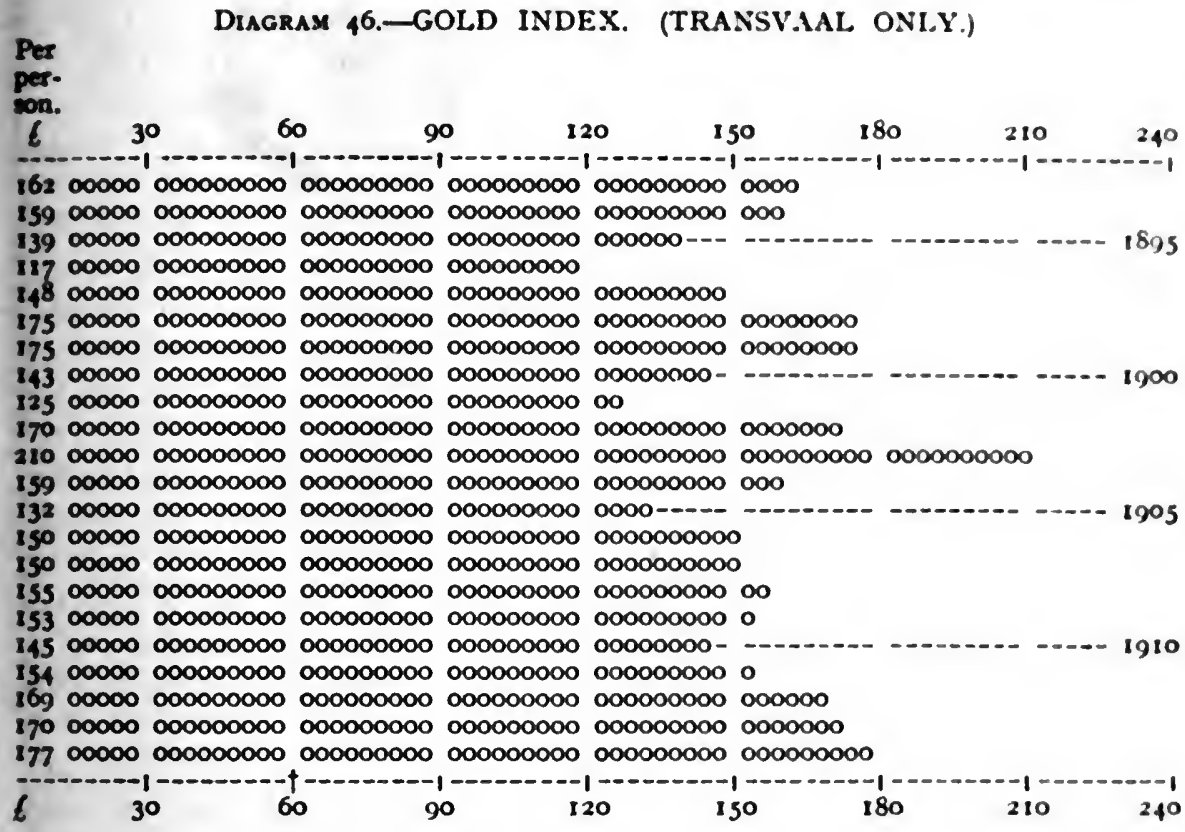

real example of falling production per person, such as would occur if natural gold supplies were failing faster than man's ingenuity in mining and extracting gold from poorer ones was increasing. In a natural and gradual falling off of gold mines the consequent lowering of commodity prices would stimulate production from mines on the margin of production that would have become a wider margin as the good mines became less productive. But a few dominantly prolific and well-worked mining districts, supplying the greater part of the world's requirements for gold, would have the effect of reducing the possibilities of marginal gold production; so that when the greater part of the dominant mines temporarily suspended work in rgoo, there was but little marginal production outside the Transvaal that could be stimulated into producing gold by the 
fall of commodity prices. As the Rand mines were expected to be in work again in a few months, there would, of course, be no temptation for capitalists to open up new mining districts or start working expensive mines, so a competing margin of production virtually did not exist.

In this way any large productive concern or district that by reason of size or other advantageous circumstance can adequately and cheaply provide the greater part of the required supply of a certain commodity, gets a more or less effective monopoly of that industry simply by reducing the possibility of a marginal supply to very narrow limits. In this case the greater part of the effective marginal gold production was no doubt in the Transvaal itself, and was cut off by the War like the rest, so that there was actually no possibility of any effectual increase of supply in the short time the Rand mines were stopped, however low commodity prices might fall. So it came about that there was a very great shortage of gold for the next four years, and prices fell considerably until I904.

But in this period prices did not fall strictly in accordance with the reduced production of gold per person, for although in the first two years the fall in prices was about the same as the increased cost of gold, they continued to fall and remained low till Igra, although the production of gold per person had very much increased. This high production of gold in 1903 and 1904 would be powerless to put up commodity prices unless there was marginal competition in gold production to insure that the total production was increased up to the quantity demanded by the reduction in commodity prices offered by the community. As we have shown above, such marginal competition was probably wanting and took some years to develop; so while this marginal competition was in abeyance the normal value of gold could go up without raising prices.

It will be seen at the foot of Table 44 that in 1903 the production per person in the Transvaal mines had gone up to such a high figure that it affected the average output for the whole gold supply, making it $£$ r 47 (Diagram 43) per person. But this only means that the most productive and easily worked mines on the Rand had got to work and were making a big output per person but a short total output, for when the next year they employed two-thirds more workers they only produced one-third more gold, and the value fell from $£ 2$ ro to £I59 per person (Diagram 46). The cause of this delay in getting to work was no doubt the difficulty of getting the labour back into the mines, and as it came back it would naturally be put into the better mines and not into marginal ones or into marginal work on the better mines. But this less productive work would have to be done eventually if the good mines were going to keep ahead of the secondclass ones, so as the labour came back the less productive work was proceeded with and the value produced per person fell. This fall 
was continued in the Transvaal till 1907 , showing that the marginal production was being re-established so that prices would become more sensitive to alterations in production of gold per person. But it does not follow that the returning labour and competition had been able to make good the shortage that had occurred between 1900 and 1903 , which, as may be seen by Table 44, amounted to about 45 millions.

The annual production for the Old World supply had, however, got up to above its 1899 level by 1904 , and prices began to rise. As the actual shortage could not possibly have been reduced by the slightly increased annual output at that time, this rise of prices seems to have been the effect of the rising production per person. The drop in the gold per person in 1905 was all due to increased labour in working the Transvaal mines. As may be seen by Table 55, the persons working were increased by 50 per cent., and the production per person fell considerably, showing that normal conditions and normal competition were being quickly restored in the gold mining industry.

As the result of these more normal conditions the big rise in the production per person in 1906 sent commodity prices up with a run in 1907 (see Diagram 43, keeping in mind that AA shows the price movement one year too soon on all these gold diagrams, as previously explained). If things had been quite normal it might have been expected that the price rise in 1907 would have gone five points higher than that of Igoo. But the shortage was still effective in keeping prices below their gold production level, and the big trade boom of 1907 was evidently ill founded ; gold production had only gone up $f \delta$, and prices went up $£ \mathrm{I} 6$, which was too much, and the boom ended in a crisis, and prices fell again badly in 1908 , as has been pointed out in the examination of various commodity prices. From this point the level of prices shown by the curve AA roughly follows the fluctuations in gold production, but at some ro per cent. or so below the proper level, owing to the depressing effect of the gold shortage, which could not possibly have been made up before Igro, and probably not wholly even then.

During this period of gold shortage prices were kept down by industrial competition of individual consumers, financial corporations and banks, to get possession of the gold they required, as is indicated by the changes in rates of foreign exchange and bank holdings of gold. It is very difficult to follow in any detail the complicated financial operations of reducing prices to get gold, but it seems obvious that such reductions must take place if miners are to be induced to go to greater labour and expense to get it. We propose to discuss the matter further in a subsequent chapter, but it may help us to realise the possibility of this process if we for a moment here consider the effect of these changes in the gold holdings of various national banks, and the requirements of foreign exchange. 
If prices are high it is always found that trade is good and that more gold is wanted, not only to pay the increasing wages of the larger number of persons in employment and as bank reserves against the greater liabilities due to increasing business, but also as reserves against an unfavourable foreign exchange. No country that does not produce gold can import more than it exports (in the strict theoretical sense) and pay the difference in gold for any length of time, but that they frequently do so for limited periods is seen by the extraordinary quantity of gold that is continually being shipped from one country to another, largely for the purpose of balancing the exchanges (see Bullion and Specie in Statistical Abstracts). If such shipments of bullion are made by a country when prices are above the cost of gold level, it means that the country or some one in it who is responsible for these commercial conditions is in a financially unsound position in so far as they are exporting gold at the nominal value of $£ 4$ per ounce, whereas a new supply cannot be obtained for $£ 4$ worth of goods while prices remain at the high level. The banks being the people concerned in insuring that there shall be enough gold to make any such shipments and enough left to meet all demands, will regard an adequate supply of goid as the first necessity of commercial stability, and they will take steps to insure either an increased supply or a diminished drain on their reserves. By raising the bank rate or perhaps by selling securities at reduced prices, they will give a check to commercial over-confidence which will at once cause speculative prices to fall, and producers who are at all holding for advanced prices will start to sell. This will start a general fall of prices which will find out any unsound business concerns; stoppages will occur and output will be reduced; unemployment and lower wages will result and prices continue to fall till gold production becomes profitable and the quantity of gold reserves restores commercial confidence.

If the above financial exigencies are duly appreciated it will be seen that in a period of gold shortage like that from Ig00-rgro the competition of the various national banks to get their required portion of the limited stock of gold would inevitably lead to a general fall of prices, that would be kept below their proper level until the required quantity of gold was again fully provided. As the ordinary marginal competition in gold mining was completely dislocated by the war conditions in the gold-producing country, the rise in the production per person would not necessitate an increased total output and rise of prices to countcract the depression of I900-I904. But after 1905 as normal conditions in the Transvaal were restored prices began to fluctuate to some extent in accordance with gold output per person, although on a lower level due to the still existing competition of national banks to obtain a fuller portion of the short supply of gold. 
Making allowance for the combined effect of competition to get possession of the short supply of gold and the dislocation of competition in gold mining countries due to the War, counteracting to some extent the effect of increased production per person, we think it may be seen that the movement of prices shown by the curve $\mathrm{AA}$ does show a very distinct tendency to fluctuate with the increased production per person. Between 1900 and 1905 the War, of course, completely prevents the normal action of competition. But the rise and fall from $1895^{-1901}$ and the movement from 1905-1913 shows a distinct relation to the gold production. This relation is quite as close as the rough gross production data can be expected to give us, and seems to support the conclusion that the supply of gold varies inversely with the level of commodity prices and that the level of commodity prices depends upon the production of gold per person or its labour cost. If gold is produced with less labour than its equivalent market value in goods, capital and labour will flow from commodity production into the marginal gold production and increase the supply of gold at a somewhat advanced average cost, while the flow of capital and labour out of marginal commodity production will cause less to be produced, but that at a somewhat less labour cost, till the value produced per person is equal in gold and commodity. But if in spite of the flow of labour into gold production the labour cost did not advance, that is the value per person remained greater than in commodities, consumption and employment would be increased by the greater value of gold produced per person, commodity prices would rise and more persons be employed in the production of both goods and gold, constituting a period of rising prices and good trade.

This seems a simple and direct reason for the fluctuations of normal prices shown by our price indexes as occurring in commodity prices generally, and for their following the variations in the production of gold. But there are various reasons why previous economic theorists, who base their opinions upon marginal utility or on the quantity of money, have not recognised the possibilities of this theory. In the first place, most economists hardly seem to recognise the requirement for a current supply of gold, or that its falling off would cause a shortage that would affect prices; or, at any rate, that no definite amount of new gold is required. Owing to the fact that gold is a very durable metal and of such value that no great quantity is intentionally wasted, the quantity of the standard metal in existence tends steadily to increase, and, although there are no very exact data as to the world's stores of gold, there is no doubt a great accumulation. This fact seems to have led to an impression that there is always more gold in the possession of the community than is actually wanted; and that, therefore, a greater or less cost in producing the annual addition to the stock cannot cause more or 
less of that stock to be used in circulation and so affect prices. It is thought that if the desirable portion of that stock does not come into circulation and a fall of prices results, the reason for the fall must be sought in the cause that prevents the existing stock of gold or other money from being used and not in the cost of the unnecessary additions to the stagnant accumulation. But any one holding such views should, we think, reflect for a moment on the amazing assumptions that are implied by their contention. If the annual production of gold makes no real difference to the money in use, but is simply a fatuous addition to an indefinite quantity of precious metal, we are, in effect, asked to believe-in so far, at any rate, as the 60 per cent. used in currency is concerned-that all the labour, capital and business ability employed in getting that gold is virtually without aim or purpose; that it does not matter whether they get that gold or not, and that the rest of the world pays for and keeps up this supply of what is not wanted regardless of its cost.

If, on the other hand, gold is wanted, it must be wanted by some persons who require to use it in some way, and, however mistaken or curious that use may be, they still want more or less of it, and will accordingly go to more or less expense to get it, and the demand for it will increase with its scarcity, as it would with any other commodity. But as its demand price cannot alter, an increased supply can only be induced by lowering other prices, and it is just for that reason that a small alteration in its price or quantity has a great effect on general prices.

It is usually estimated that 60 per cent. of the annual production of gold is used in additions to the currency, and if that is not wanted why do Governments go to the expense of obtaining it ? No doubt a great deal of it goes to swell Bank reserves, and in the present state of financial theory and practice it would seem rather rash to say that these reserves are not necessary. There may be some gold reserves that are a mistake, but so long as they are deemed to be wanted they must be regarded as necessary, and the ordinary bank reserve must certainly be so, as long as it is entrusted to these institutions to supply gold on demand for use in the businesses of those whose commercial transactions are wholly carried on by means of bark accounts. It would seem that banks exist chiefly for the purpose of supplying gold on demand in exchange for contributions of goods to the social capital, the existence of which is vouched for by a cheque signed by the person who is the receiver or holder of the commodity, and the banks make themselves responsible for a correct account of such contributions to, and extractions from, the social wealth. Gold, like any other production, is handed on to the social capital, and the banks, being large users of gold, sign cheques or other instruments as receivers or holders of a portion of this gold. But as they, like other holders of any portion of the social capital, 
are losing interest on the value of all they hold, they will not hold more than is necessary for their business. The object of the banks is to supply the required gold while neither they nor the community hold any more gold than is absolutely necessary: in fact to keep the proportion of gold to goods exactly at the required point. This required amount in normal times is that which will just be enough for each citizen to have in his possession, just that amount that his financial position warrants him in carrying for the purpose of defray. ing his current expenses, and all such money obligations as he is in the custom of discharging in cash. Each week a vast sum in gold is drawn from the banks to pay salaries and wages, which represents the bulk of this amount that is required, and although most of it finds its way back to the banks during the following week, it will be required again the next week-end; and its amount will increase with the increased prosperity of the community.

This gold is absolutely necessary and must be forthcoming when wanted, and if the annual supply should fall short of this demand the banks must find the balance from their reserves. These reserves also must be large enough to meet any possible demands made by clients with deposit or current accounts, as well as provision against the above-mentioned possibility of having to make shipments of gold abroad. So that the reserves must be kept in a fairly definite proportion to the deposit business done. The banker is burning his candle at both ends when in prosperous times he is increasing his weekly supply of cash and increasing his deposit accounts without obtaining more gold for reserve. The keeping of the right gold reserve is a nice point, as is testified to by the extent to which gold is transferred from one country to another to keep the reserves in the required place. Millions of pounds' worth are imported by this country from the United States one year and millions exported to the States another; so that of late years the imports, though they run to many millions, practically balance the exports. Countries would hardly go to the trouble and expense of shipping all this treasure backwards and forwards if the exact amount of gold in a country did not matter; and the fact that they do so transfer it shows that the demand for gold is a very real one.

But it may be thought that the annual supply of gold is so small, in proportion to the quantity already in reserve, that a little extra cost in obtaining this small increase cannot appreciably affect the cost of the whole or greatly affect prices. The point, however, is that, if owing to increased cost of production the necessary supply is falling off by but a little, that little cannot be made good by paying more for it, as is done in other commodities. The price of gold cannot be raised, so that the shortage cannot be prevented in that way, and must tend to increase until it is of serious importance unless some means of inducing an increased supply can be found. 
As the price of gold cannot go up, it seems inevitable that the price of goods must come down if gold is to be kept in use at all ; and we find that during the period from Igoo to I 905 prices did fall, recovering again as the gold supply was restored to its required level.

From this examination of the gold production by the unit of labour method, and from our remarks upon price variation at the close of the last chapter, it will have been seen that we not only regard price variations as coincident with variations in the production of gold per person, but regard the production per person in gold as in some way the actual cause of price variations. These periods of high and low price have been recognised by all economists as periods of trade depression and expansion, but most writers have been content to sum up the evidence in averages of the general price level, which simply substantiate the truism that the purchasing power of the sovereign is the reciprocal of the level of prices. This process of investigation fails to find the cause of the alteration in the equation of exchange, or even to explain in which factor the change has taken place. Even in the quantity theory of money, in which it is sought to show that the change is in money, the issue is obscured by including goods in the form of bank deposits on the money side of the equation, so that a so-called change in the quantity of money may be actually in the quantity of goods. So far as we know, very few writers have thought it necessary to tabulate the prices of separate commodities, to show either how far their individual price variations correspond to the general movement or conform to the supposed law of supply and demand. Still less have they made any attempt to connect the price with its labour cost to see how far that cost varies from, or follows, the general level of prices or how it reacts upon and determines the supply, which reaction quite prevents the greater or less supply having any permanent effect on price, as such rise or fall of that price will at once increase or diminish the supply. This reaction of price upon supply leaves the cost alone the permanent determining factor in price. But it must be clearly understood what we mean by cost, for cost of production has been used in various rather vague senses by many writers, which fact may lead to misunderstanding on this important point:

As we have frequently stated, by cost of production we mean the sacrifice of life-time necessary to produce a commodity, the price of the resulting commodity being determined by the social labourtime used up in its production. But economists have always felt a difficulty in seeing how things that take the same labour-time to produce can at different times have various prices. As we have stated, this variation is the result of varying labour-time in the standard commodity, by which the unvarying labour-time is measured, and we must now examine more exactly how this unit of labour-time becomes the standard of price. 
The unit of life-time used up in labour is a factor of intrinsic value to every individual worker ; an hour, a day, or a year, is an unalterable measure of something intrinsically valuable to every one personally and to society as a whole. As such it is a measure of value entering into every production, and is the only thing that is common to them all. So in all forms of produce there is this common value in various proportions, as they take a longer or shorter time to produce; and they have a relative value in accordance with that proportion. So that their price might be quoted in hours of labour and all business exchanges made with hours as the basis of price, a paper currency could be made in notes of various time values, and a " one-day note " could be paid for a day's work and exchanged as a legal tender for any kind of goods that took an average day's work to produce, in fact perform all the functions of money quite as well as, if not better than, our present currency. It would have the great advantage that the standard was really a fixed one and not subject to variations that could affect prices. It may possibly be thought that, as the work done in an hour by different persons varies greatly in quantity and quality, a one-day note might be too much or too little to pay for the work done by a certain individual and thus distort the supposed value of the paper money. But that is just the same under any monetary standard, the quality of the work must be considered in fixing a remuneration. It would be quite possible to pay a labourer a "one-day note" for working ten hours and to pay a manager a "one-day note" for every hour he worked. When these came to be given in payment for goods they would have the same value and would buy things that had a day's labour used in their production - for example, as much coal as was produced by half a day's labour and half an hour's management would be given for a onc-day note. Whether the goods so purchased had really cost the correct time at which they were valued could only be settled as it is now, by experience and competition. When you give Ios. $6 d$. for a pair of boots you do not know that it is the true cost either in time or money, but experience shows that competition between producers insures that it shall be very nearly so ; and that would obtain quite as much with a "one-day " note or a note of any other time denomination.

But, although the varying result from a day's work is no diffculty in the way of a labour time basis of price, it may have been one of the factors that in the past have prevented such a basis of currency from being evolved in business practice. In a primitive state of society the value produced in a day by different individuals would vary so greatly, and the moral obligation to do any work would be so uncertain, that it would not be likely to occur to any one that the value of the things produced really depended upon the time expended upon them; in fact, it is only very slowly that men 
are coming to recognise that it is so. Moreover, any currency based on labour-time would require high commercial organisation to carry it out, and a satisfactory currency of any sort took long to evolve. Without an advanced state of civilisation it would be impossible to get anything that had no value of its own to circulate freely in exchange for goods of visible value; and for that reason it is natural that things of high value and durability, like gold or silver, should have been among the first things to form a basis of currency and valuc. There are curious and interesting exceptions to this method found in some primitive communities; but it is doubtful whether anything used as primitive currency could lead to any great progress in commercial development unless it was a thing of some real value and use. It is very natural that when security for fulfilment of contracts and business stability generally was little developed, any one parting with goods of perishable value, that he did not want to use at the time, in exchange for something he could keep for future use or exchange for useful things when he wanted them, would only accept something tangible and of enduring value that he could keep stored up indefinitely. The precious metals naturally fulfil this requirement; and, having therefore come into use as the means of storing wealth, would inevitably come to be regarded as the measure of wealth. So, no doubt, it came about that gold became the visible standard of value, not because it was the best standard at all, but because it could be easily stored or saved. This again was dependent upon its value, and its value depends upon its scarcity ; for if it was common as dirt it would undoubtedly be dirtcheap. It is because it is scarce, and takes much labour-time to find or obtain, that it has any value; and it is that labour-time in it that makes it possible as money or as a standard of price. It is this labour-time, represented by a piece of gold, that alone can be a measure of value. A sovereign and a pair of boots have nothing in common but the labour in both of them; nothing else in them can be compared in any conceivable way. So it appears that gold used as a standard of value is only a concrete commodity used to represent the abstract labour unit that is embodied in it, and has the rather unfortunate effect that the stable standard of labourtime is, in practice, represented by an unstable concrete commodity.

From our examination of the variations in the cost of producing gold, it has been seen that, so far as the scanty evidence goes, it has varied in a similar way to commodity prices. And most economists have supposed that some change in the value of gold causes variations of price, though there seems to be great difficulty in arriving at any satisfactory explanation of just what the effect is, and how it comes about. The most generally quoted theory is that known as the " quantity theory" of money ; but that can hardly be said to have 
been universally accepted, or quite to agree with the record of gold production, as we pointed out in the case between the years $1890-5$. And in the form of this theory, which includes bank deposits as currency, we entirely dissent from the contention that the quantity of money must be equal to the value of the goods, or anything like it. The velocity of money is not quantity, and has nothing to do with it, while exchanges of commodity can be made without money being used. And the so-called equation of exchange is hopelessly vitiated by the inclusion of bank deposits or cheques on the money side; these deposits are goods, and of course if we call goods goods, and their value money, then the money will always equal the goods. But then a change in the money side of the equation need not be a change in money at all, but a change in the value of the goods, and have nothing whatever to do with the quantity of money-value is not quantity of money. It seems that the way in which real money affects prices has yet to be definitely explained.

It is a matter of common experience that when commodities become more costly to produce, they rise in value or price, and fall in price when they are produced more easily. So when gold costs less to obtain, it is often spoken of as having fallen in value, and it is therefore taken as evident that goods will be relatively high in price. But although in generally descriptive language this may be a fair statement of the observed facts, it is not strictly a correct description, because gold does not vary in exchange value, its price is only low in effect and not in fact. Its less cost would not have lowered its value if commodities had not gone up in price. But the observed fact is that things do rise in price, and the problem is Why ?

In the little illustration given in the last chapter of how increased production of gold affected the price of boots, there seemed no reason why the gold miner should give more for his boots simply because he got gold more quickly than he used to do; a man does not give $2 d$. to go into a $I d$. show just because his salary is raised. But we pointed out that he might want more boots, and that as labour would have left the shoemaking and gone into the more profitable gold-mining or allied industries, there would be a shortage of shoemakers, and the reason for offering more for the required boots would be quite obvious. This belief in the flow of capital and labour into the best paying trades is essential to all economic theories, yet no one seems to have been bold enough to suggest that it is the flow of these factors of production into and out of gold mining which causes alterations in the level of prices.

No one will question that a gold mine pays or does not pay in accordance with the circumstance that the yield of metal is more or less than a certain quantity per person employed in getting it. But in other industries the amount that must be produced to make the difference between paying and not paying varies with the price of 
the article produced, which price will probably rise as the production falls off, as in the case of bad crops. But in gold, the price does not vary, so that it would seem that the supply must fall off very promptly and definitely whenever natural circumstances make gold less easily obtained. Though no doubt the larger and more profitable mines carry on over unprofitable periods with the methodical precision common to all big businesses, there must be a margin of smaller or less fortunate mining concerns that increase or diminish very rapidly with changing fortune. This means that there will be a flow of skilled and rather independent labour in or out of gold mining as it is more or less profitable. And it is important to remember that profitable is after all a comparative term expressing the relative utility of working at one production or another that gives a greater return to the labour expended. Even though a low return in gold mining is not improved if the price of commodities comes down, the cost of living and stores of materials being less, mining gold may become more profitable than the othe1 industries and labour will flow into it. Or it may flow out of it if the price of commodities goes up, as illustrated by the following extract from the Manchester Guardian of September 28th, I9I8, showing the effect of war prices on gold production :-

"At a meeting of the Chamber of Mines to-day, the President (Mr. Wallers) referred to the serious position regarding the Transvaal gold output. He pointed out that the decrease in the first eight months of IgI 8 amounted to $£$ I, 3I5,694, while in the same period the working costs increased by $£ 468,698$. Of contributing companies, six were making an actual loss, while $I_{5}$ showed a small profit, but standing charges turned the profit into loss. Under existing conditions the end was growing very near. It would be a pity if the actual closing of some mines was required to bring home the real position."

Whether Mr. Wallers and his friends did actually realise exactly what the "real position" was, and what was necessary to alter it, has not yet been recorded ; but it seems to us that nothing but a fall in the price of the commodities that compose the "working costs" can possibly save those unfortunate gold mines from closing. Some further idea of the nature of this shifting of labour and capital in the mining industries may be gathered from the following two or three extracts from the U.S.A. Geological Survey, relative to the production of gold and silver in the following years.

Gold and Silver, I906, pp. 20 and 21 :-

"A strong advance (in tonnage of ore) was shown by Arizona, 900,000 tons; Montana, 478,000 tons; Utah, I68,000 tons; Tennessee, I39,000 tons; Colorado, I44,000 tons; and Idaho, II,800 tons. In the first four States, this was wholly due to the activity in copper mining continued from I905, and stimulated by the high 
prices of this metal. . . The copper ores are much poorer in gold and silver, the average extraction value being only $\$ 1.55$ per ton."

This extract shows that copper (commodity) prices were so high that gold mining was not paying, except where the metal was found along with much copper. Prices generally were then going up, and copper advanced during the year from 13.21 cents per $\mathrm{lb}$. to 19.30 cents.

Gold, Silver, Copper, Lead and Zinc, r907, p. 103 :-

"The year 1907 opened with the mining industry in Colorado in a flourishing condition, and with every indication that a record mineral production would be made by the different districts, while the conditions were so favourable, with high metal prices and freedom from labour trouble, much development work was in progress, and there was a shortage of experienced miners at some of the gold camps. But with the falling off in metal prices which began in July, the production from the silver-lead-zinc mines not only decreased rapidly, but many producing mines temporarily ceased operations. . . . These changed conditions caused many miners to turn their attention to gold mining, and many leases were taken up which would not have been acceptable in the earlier months of the year."

Gold, Silver, etc., I907, p. I42 :-

"During the early months of 1907 , the operations were handicapped by a shortage of gold miners, but after the decline in the values of silver and the base metals, many miners returned to Cripple Creek from the different silver-lead camps of the State, and labour was plentiful at the end of $1907 . "$

In the early part of 1907 prices went very high, as may be seen on several of our price indexes. The natural rise owing to the increased production of gold per person has been going on for some years, and led to rash speculation and trade boom in this year which ended in a financial crisis in America, and a great fall of prices. Copper, which had reached 25.0 cents per $\mathrm{lb}$. in March, had fallen to 13.06 cents in December, and as seen by the above quotation, labour was flowing back into gold mining.

Gold, Silver, etc., I908, p. 130 :-

"At no time in the history of the district have treatment and transport charges been so advantageous as in I908. . . . There was an abundance of skilled labour and a great demand for gold leases. Not only were these taken on well-developed properties, but in the early months of I908 over 100 leases were taken on old dumps."

In 1908 prices of commodities were low and gold mining was relatively profitable, and as the world's production had by this time nearly caught up with the requirements, the increased production per person could have its natural effect of raising prices, and as our various price indexes show, prices continued to rise till 1913 , when the top was reached. 
These quotations from the prosaic records of the Geological Survey give us quite a vivid picture of the ebb and flow of industry in gold mining, as the average find of gold varies relatively to the average value produced in commodities. But while probably no one will be surprised at this prompt movement of capital and labour between different kinds of mines as their relative remunerativeness varies, few perhaps would be prepared to admit that this oscillation extends to industry of all kinds, and that as the flow into gold mining increases it reduces the flow of labour and capital into other industries just enough to lessen the supply of these factors and cause prices of commodities in general to rise. It must be admitted that it is difficult to realise how an insignificant alteration in the number of the always small portion of the community that is engaged in getting the annual supply of gold can affect the world's supply of labour enough to have a definite effect on commodity prices in general. Yet we cannot conceive of any alternative to the conclusion that the level of price is altered in this way; for if the production of goods and gold is to go on side by side, there must be some means of keeping them about equally profitable. If they are not, no new enterprise will go into the one that is least so; and as the price of gold cannot alter, it must be the commodity prices that are adjusted one way or the other to maintain the required equilibrium of supply and demand.

The first reason why it is difficult to realise the truth of this theory of price fluctuation is that we are apt to think of this movement of enterprise into or out of gold production as quite local and confined to a certain class of mining industry, and to suppose that the phenomena simply mean that less copper and more gold is wanted at one time than at another, and that the mines are worked accordingly. But while this is superficially true, it does not cover the whole of the question; more gold may be wanted, but it is not strictly true that less copper is wanted. It is not probable that the supply of copper will ever be more or quite as much as mankind desires; we shall always want more copper unless some miraculous discovery of the metal is made. It is only relatively to our other wants that copper is less desired ; it is simply because we are more than usually short of gold that we are only willing to pay a low price for copper. And that is an important difference, for it means that if the required supply of gold can be got more easily - that is more gold per personwe shall actually want more copper and its price will probably go up ; and the same would be the case with all other commodities. It is important to realise that as we get more gold without a greater proportion of labour to do it we, as a consequence, want more of other things. Wants are unlimited, save by supply, and if more gold is produced without increased labour costs, the community is better off, and its wants for all commodities increase. 
The result of this is that as labour fows into gold mines and produces more gold at an increased return per person, more copper and all other commodities are wanted, and more labour will flow into their production in consequence. If in any such commodities the means of production are not improved enough to cause the return per person to be increased as much as it is in gold, the price of those commodities must rise to make the value per person enough to induce labour and capital to come into their production. So the flow of labour out of copper or other mines must be made good by a flow in from other kinds of industry, and they again must get an inflow from somewhere else until the last ones to have their labour depleted are filled up from the ranks of the unemployed. Or the unemployed come in earlier on in the movement, which, as we shall see more fully when we discuss wages, has the same effect on prices, as the socalled unemployed are in reality partly employed in some form of industry. In this way the wave of ebb and flow, with its resulting rise or fall of price, must pass through the whole field of commodity production. Though the flow out of each industry may be small, it must be made good by a like inflow ; for as rather more of everything is wanted owing to greater prosperity in gold mining, every industry will want to do a little more work rather than a little less. The increased prices giving a better margin of profit will stimulate business effort, with the result that there will be increased employment, and probably improved production in other things beside gold, which means greater real prosperity as well as improved trade and high prices. The engendered optimism may for the moment raise prices still more in the form of a trade boom, even going beyond the true gold position. So that the small wave of higher prices started by gold mining prosperity does not tend to get less or fade away as it spreads out over commerce, but passes as a vibration undiminished throughout the whole.

The analogy of a vibration or wave may help us to realise that the small bulk of the original flow of persons into or out of gold mining. compared with the vast bulk of the world's commerce, does not in any way prevent the possibility of that small disturbance affecting the whole field of prices. A pebble dropped into a pool of water will start a series of waves that will travel from the centre of disturbance out over the surface of the water to almost any distance, theoretically to infinity if there was no friction, the size of the pebble making no difference to the area affected by the movement. The height of the wave above or below the plane of the disturbed surface depends on the size of the pebble or other cause of the disturbance, but the distance the wave will travel depends on the elasticity of the water or other medium in which the wave is moving. So in this wave of ebb and flow of capital and labour into various industries, the height of the price wave or the number of persons going from one particular 
industry into another, depends upon the extent of the original increase or decrease in the difficulty of producing gold relatively to that of producing goods, but the commercial area over which the movement of labour and rise or fall of prices will extend depends almost entirely upon the elasticity of the commercial medium in which the movement is taking place, or the comparative freedom at the time from a retarding friction.

There are no doubt various sources of friction in the commercial organisation, but they are chiefly local in their retardation, diverting or nullifying the price movements at certain points, but not preventing their general transmission. So that the spreading of the wave of price variation may be practically unlimited in respect of area affected; and the height of the wave represented by prices is unlimited so long as the initial cause of disturbance keeps growing greater relatively to improved means of production in commodities other than gold. It is not necessary to labour the analogy further; the point is that a variation in the level of price is somewhat like a wave or vibration, in that it is a disturbance of equilibrium, and therefore it is not necessary for us to suppose that the original disturbing cause must be great in degree or amount simply because its effect is far reaching and of great importance.

It is just this idea that a general rise of price is something of great magnitude compared with the gold production that is another cause of difficulty in accepting this simple explanation of the rise and fall of prices. But is it not a mistake to suppose that even a big variation of price involves anything of great magnitude? Certainly, if we multiply all the goods in existence by a figure representing their increased money value we shall get a colossal figure as the sum result, but that figure could be written on a small sheet of paper; it does not constitute any great magnitude or represent any. It simply represents other similar figures in ledgers and bank books, and it takes no more time or space to write $£ 2$ in these accounts than it does to write $\ell_{\mathrm{I}} \mathrm{I} 5 \mathrm{~s}$. od. There are no more goods, no more labour, wealth or money save a little addition to the gold currency. Apparently the only necessary result of a rise of prices is that as retail prices are more each citizen will require to have in his possession a little more gold to defray his current expenses. More gold will be required to carry out the usual cash transactions, and this little more gold is just what we are claiming has come into the possession of the community, because it is got more easily than it was, and if this is the only actual difference caused by the increased production of gold, surely that increased production may be regarded as a cause adequate to produce that difference. The tangible result of an increased production of gold per person is not greater than or out of proportion with the cause, and the normal rise of prices is simply the means by which the advantage, derived from 
the extra quantity of gold obtained by the same social labour is distributed through the whole community.

The mention of this tangible factor in a rise of prices brings us back to the fact that a certain amount of gold is required by society, and if that supply is always to be kept up, society will at times have to take steps to see that the gold production does not fall short of those requirements, so that it is possible to look at the phenomena of price variation from the requirement point of view. If prices are high and trade generally stimulated thereby, more gold will be wanted both as money and as a commodity in art and commerce. If increased supply is to be obtained it is probable that rather poorer and more expensive mines will have to be worked, so that getting this increase will make gold mining on the whole less profitable. And if at the same time some good mines became partly worked out, as often happens, gold mining would become so distinctly less profitable that less of it would be done instead of more, and there would be a shortage of gold, society would not have so much as it wanted. It is probable that society, outside of banks, which have been mentioned above as the organ sensitive to gold, is never conscious of being short of gold, yet it must sometimes be so, and undoubtedly was so between I900 and I905. That we do not recognise that we are short of gold must be due to the fact that we simply do not recognise what it really is that we need, and mistake the symptoms for something else, such as over-production, or the like. But that this does not continue till all the gold mines are closed proves that the community in some way recognises the necessity for more gold and does reduce prices to get it.

It seems never to have been clearly stated by what means this encouraging of gold production is accomplished; the ordinary language of supply and demand does not explain it, because the demand price of gold cannot rise or fall. There is no reason whatever why the community should want less of other things because it wants more gold. As it does not have to give a higher price for the gold it wants, there is no reason why it should give less for other things or why prices should fall. It is certainly not easy to see why persons in business should reduce their prices to obtain gold when they are not even conscious of being short of that commodity. But it has been pointed out that the banks are conscious, and that their efforts to keep the necessary reserves of gold start a fall of prices. Then though society may not be conscious that it wants gold, it finds that it cannot sell commodities at the price it has been getting for them. and trade will become depressed. The lower profits due to the fall of prices will cause a reduction in commodity production and an increase of unemployment. The unemployed labour will not be able to find employment unless prices are reduced enough to increase the sales and output. But competition for work will reduce the 
wages till profits are about normal at the reduced commodity prices, and both wages and prices will thus fall till gold mining pays and the bank rate falls as gold becomes plentiful. The flow of labour out of the depressed commodity production will have flowed into the reviving gold industry till the result in each is an equal reward for the labour-time worked, from which point employment will rise to its average position and trade to its average prosperity.

This, then, is what we believe to be the simple explanation of the variation in the level of prices. The mean price of a commodity to the community being determined by its cost in labour-time, its price measured by a time standard could not vary unless the time required to produce it varied. But if the price is measured in gold, commodity in which the labour-time has not varied may rise or fall in price as the required quantity of gold is produced in more or less labour-time, because as more or less is produced, more or less will have to be given as the price of commodities, or there will be a flow of labour and capital into or out of gold, and too much or too little commodity will be produced in proportion to the gold, and the requirements for each will not be satisfied.

When these requirements are satisfied and equilibrium established, the value produced per person in gold should be equal to the average value produced per person in other commodities. But there are many reasons, some of which have yet to be explained, why the production per person of any certain commodity may vary from the theoretical average. Therefore, our various indexes of commodity prices are not expected to show the same actual value produced per person, but are intended to show a similar movement in the variations. The defects in these diagrams and in the data for them are discussed elsewhere, but their theoretical average, expressed by the curve AA on our gold index, has been shown to fairly approximate to the variations in gold production. The fact that gold production per person has gone up as man's knowledge and experience has developed with the scientific discoveries of recent years is no more than might be expected. But that the prices of all things should follow the same direction and approximately to the same extent is by no means so easily explained. The reverse migit reasonably be expected, for progress in the arts should have made production cheaper and prices to fall, so that the evidence of any agreement between prices and gold production is significant evidence that price is determined by the labour cost of gold relatively to the labour cost of commodity.

We think the simplicity and completeness of the above theory of variations in the level of prices render it a plausible explanation of the recognised phenomena, and we hope and feel personally convinced that it is a sound view of the problem. But at the same time we recognise that this conclusion must rest upon actual evidence 
existing in authorised figures from commercial statistics. For this reason we have given a number of diagrams of the variations in normal prices, and shall proceed to give others, not only for this purpose of showing that there is a rough, though quite cvident, resemblance in the periodic fluctuations, but also to show how many of the irregularities are quite explainable as minor fluctuations above and below a mean, fluctuations due to want of knowledge on the part of individual producers as to what that actual mean is, and their often mistaken efforts to get the most advantageous result for themselves. The mean price is what we regard as the true price of the commodity, and contend that this mean, in which all the speculative variations of price result, is a definite cost price determined by the value of gold produced per person employed in getting it. The difficulty in actually demonstrating a convincing resemblance between the price movements of commodities and production of gold has been the incompleteness of the record of gold production per person and the very short time over which the record extends. Because the result of examining collateral evidence over a short period is always to bring out too prominently the minor irregularities to the obscuring of the general resemblance, which would be much more evident in a longer period where a broader view of the whole could be taken, yet the short and defective evidence notwithstanding, there appears to be a distinct connection between the variations in gold production and prices over the short period illustrated by our diagrams.

If it is admitted that there is this appreciable amount of connection between the variations in gold production and commodity prices during the period covered by the data, it should be further observed that during the earlier years where there is no record of the number of persons who produced the gold, the prices of commodities have varied in a similar manner; and as shown by our longer price indexes, such as those for coal, oats, wheat, etc., these earlier price variations have been much in the same direction and to the same extent in each of the commodities, which uniformity suggests just such a common cause of variation as the gold production theory affords.

The data at our disposal are certainly inadequate and often incomplete even as far as they go, but the theory it suggests seems so capable of explaining the industrial phenomena that the desirability of acquiring more evidence upon the suggested lines is very obvious, and the theory itself is well worth further consideration. It should be recognised that though a theory must be based on the evidence of facts, it is not necessary to the vitality of a theory that the evidence should be complete. But if its significance is appreciable, it has a claim to be thoroughly investigated and understood. and the production of further data insisted upon. 
So far our investigations lead to the conclusion that the labourtime embodied in commodity is the only source of its value, and that the proportion in which one commodity will exchange for another is as the ratio of labour-time in the one is to the labour-time in the other. That price is this ratio of labour-time measured in gold, but as this standard of measure is a fixed weight of gold which does not vary in bulk or value with its labour cost, its nominal price may not correctly represent the ratio of its labour cost. So that while all commodities exchange for each other correctly as the ratio of their labour cost is to the theoretical labour cost of an ounce of gold, they would not at any time be exchanging for gold in the correct ratio of its actual labour cost unless the weight of the ounce of gold could be altered in accordance with its varying labour cost, or some other adjustment be made in the ratios of the equation of price. As the weight of the ounce cannot be altered although an ounce of gold is no longer produced in the same time as $£ 4$ worth of goods, it must be altered in effect ; that is to say, that more than $£ 4$ worth of goods must be given for it if their price is to be in correct ratio to the gold's labour cost. That is, goods must fall in price if the labourtime in the ounce of gold increases, or miners will not continue to produce gold when they can get more money (gold) by producing goods; or in the opposite case, producers will not make goods to get gold (money) if they can get that gold with less labour by mining it.

What we wish to make clear is that the alterations in the natural facilities for obtaining gold make it necessary that prices should fluctuate, and that there must be a flow of labour in or out of each industry as its normal return per person is rising or falling relatively to others. Our examination of normal prices is to show that production in any industry does increase or diminish as the price rises or falls, and that the normal prices do apparently follow the production of gold per person. The variation of price and the flow of labour in industry are part of the social mechanism by which the price equation is adjusted, but the labour cost of gold is the prime cause and controlling factor in the level of prices.

In the light of these conclusions we shall next examine a few more commodity prices to see how far they afford evidence of this controlling factor in prices before we go on to consider the important bearing of this cost theory of prices upon economic problems generally. 


\section{CHAPTER VIII}

\section{PRICES IN THE UNITED STATES}

IN the last chapter we endeavoured to show that fluctuations in price were due to alterations in the value of gold, arising from alterations in the amount of labour-time necessary for its production, and that the effect of this variation in its cost was transmitted as a wave of rising or falling prices throughout all other forms of productivity. We also pointed out that such a wave, however small, might be expected to extend as an undiminished rise or fall almost to the whole area of the commercial field, if the commercial organisation which represents the medium in which such a wave must travel, is sufficiently elastic. But it does not follow that the commercial organisation is a perfectly elastic medium, or that price waves will travel in it to infinity, or with any great velocity. There are, in fact, many sources of inelasticity or friction which do modify the final result of this transmitted wave of price variation, at certain times and parts of the commercial field or the world's market. The world's price movement may be well compared to the rise and fall of the tide at various parts of the world's coast line, and at various parts of the commercial world price waves may tend to neutralise each other at some points, or to pile up at others, to produce a more or less permanent high or low level of prices at such places. Some of the principal causes of varying price level in different parts of the world are geographical position, natural resources, quality of commercial organisation and temperament of the people; and when the probable variations in these important conditions are taken into consideration, it is not surprising that there should be found considerable differences in price levels between great commercial centres and more remote or uncivilised parts of the world. But it may cause some surprise to find that a different price level obtains in America from that we have been examining in Europe.

The chief reason for this is no doubt to be found in the fact that the United States produce their own supply of gold, and also have such unlimited natural resources that they are not actually obliged to export gold to obtain any of the necessities of life. Therefore they can keep up the required supply of gold without undue expenditure of labour-time upon working poor mines. That is to say, the return per person in producing gold is higher than in the Old World, and this return, being the standard return by which value is measured, means that the standard of all other productions per person are 
higher when measured in gold. More gold must be given for other productions, so prices are higher than in a country whose supply of gold costs more labour.

From our examination of gold production per unit of labour we have come to the conclusion that this relatively cheaper supply of gold in the United States is the cause of the high level of prices obtaining there, and that as its cost fluctuations are to a great extent independent of the Old World supply it will account for the differences between the fluctuations of price in America and Europe. Unfortunately, as we have explained in the last chapter, we have no very satisfactory figures for the United States gold production per person, but as far as it goes it seems to show that the production is higher than that of the average European supply, and that it is increasing. The only production figures we have been able to get are from the U.S.A. Censuses of I889, I902, and I909, and they are for silver and gold together. The data is also somewhat rough and uncertain as to output per person, especially for I889; but from the figures given we estimate the value of gold produced per person to be $£$ I34 for I889, £I86 for I902, and $£ 2$ IO for I909. This amount is somewhat higher than the value produced in the coal mines, a difference due in great measure, probably, to the inexact gross data. But although it is higher than coal and the curve AA on the following U.S.A. price diagram, it distinctly suggests a proportion of rise similar to that of the curve.

We find that the normal prices of various commodities produced in the United States all fluctuate so consistently in a similar direction and degree as to give considerable support to the supposition of a common cause of variation. As this was found also to be the case in European countries, the conclusion that American prices are governed by a similar controlling law seems inevitable. And as our price level appears to depend upon the value of gold produced per person, the higher level of prices in America almost certainly depends upon their greater output of gold per person as indicated by the above Census figures. Seeing that the normal prices in America are undoubtedly higher, and that on our supposition they depend upon a practically independent basis, determined by that country's gold supply, it is obvious that American price variations cannot be closely compared with our foregoing diagrams of European commodity prices. They must be compared one with the other to see how far the price variations in the United States show evidence of a common determining cause for that level.

As in other countries, it seems that coal is the only American production in which there has been any official record of the actual number of persons engaged in obtaining it year by year, and it is this data alone that can give us the true labour unit for calculating the normal price. So that it is unfortunate that the coal data only goes 
back for a short time compared with that for other commodity prices which we propose to quote, and therefore cannot be used as typifying price movement over the whole period. So far as it goes it constitutes the best example of the variations of price level in the United States, and may be taken as showing about the normal movenent. The diagram of normal coal prices in U.S.A. has been discussed in a previous chapter (Diagram 33), and we need only be reminded here that the depression of prices between the years 1890 and 1900 roughly corresponds with the depression of European prices at this period, but that the subsequent steady rise of American prices down to the present time is quite unlike the European movement in showing no depression after 1900 . That depression, which was due to the shortage of gold owing to the stoppage of the Transvaal mines, did not extend to the United States, which seems to indicate that the Old World supply of gold has very little effect on American prices. The two irregular price years that stand out from the general curve of rising coal prices have been explained as due to a big coal strike in the case of 1903 , and to the big trade boom in 1907 , followed by the consequent slum of prices in 1908 .

\section{U.S.A. Wheat Prices.}

It is the price of various agricultural productions that give us the longest record of normal price variations in the United States, taking us back to 1866 in some cases. As before stated the advantage of crop reports is that we can use the published figures that give the value produced per acre, in place of the missing value per person, for which there are no published figures giving the number of persons into which the value must be divided. The acre can be used to represent these persons on the assumption that it represents a practically unvarying amount of labour or persons, a quantity that does not vary with the size of the crop, and not very much from year to year. But as we have had occasion to mention before the use of the number of acres in place of the number of persons may lead to error when the period under consideration is a long one, and there has been much time for the means of production to improve. During the fifty years represented on our U.S.A. Wheat Index (Diagram 4i) there has been a great advance in the methods of producing most crops. An advance due not only to the many improvements in agricultural instruments such as harvesting and ploughing machines, and the increase in up-to-date crop growing, by the extensive timesaving methods, but also to the many labour-saving arrangements for storing, lifting and carrying to market, that have been rapidly growing in efficiency of late years. So that no doubt there are distinctly less agricultural persons employed to the acre to-day than there were in 1867 . 
This means that in 1867 and all the early years on our diagram, the returns per acre must have actually been divided between more persons-that is less each-than in the later years. So that if we had the figures for the actual number of persons employed the value per

Diagram 47.-WHEAT INDEX. (ST. LOUIS.)

Price.

Per Mar- Nor- Area

acre. ket. mal. change.

Bu. Per bu.

\begin{tabular}{|c|c|c|c|}
\hline $\begin{array}{r}9.9 \\
11.6\end{array}$ & $\begin{array}{c}\$ \\
2.81 \\
2.56\end{array}$ & $\begin{array}{c}\$ \\
27 \cdot 72 \\
29 \cdot 70\end{array}$ & + \\
\hline $12 \cdot 1$ & 1.94 & 23.47 & + \\
\hline 13.6 & 1.28 & 16.61 & - \\
\hline is.oC & & $19 \cdot 20$ & \\
\hline $\begin{array}{l}12.4 \\
11.6\end{array}$ & $\begin{array}{l}1.32 \\
1.61\end{array}$ & $\begin{array}{l}16.37 \\
18.68\end{array}$ & $\begin{array}{l}+ \\
+\end{array}$ \\
\hline 12.0 & $1 \cdot 76$ & $21 \cdot 12$ & + \\
\hline $12 \cdot 7$ & $1 \cdot 51$ & $19 \cdot 18$ & + \\
\hline $12 \cdot 3$ & $1 \cdot 16$ & 14.27 & + \\
\hline$I I \cdot I$ & 1.49 & 16.54 & + \\
\hline 10.5 & 1.45 & 15.22 & - \\
\hline 13.9 & $1 \cdot 22$ & 16.96 & + \\
\hline 13.1 & .94 & $12 \cdot 31$ & + \\
\hline $\begin{array}{l}13.8 \\
13.9 \mathrm{C}\end{array}$ & 114 & $\begin{array}{l}15.73 \\
15.85\end{array}$ & $\stackrel{+}{+}$ \\
\hline 131 & 1.02 & $13 \cdot 36$ & - \\
\hline 10.2 & $1 \cdot 33$ & 13.57 & - \\
\hline 13.6 & .95 & 12.92 & - \\
\hline $11 \cdot 6$ & 1.05 & $12 \cdot 18$ & + \\
\hline 130 & .87 & $11 \cdot 31$ & - \\
\hline 10.4 & 90 & $9 \cdot 36$ & + \\
\hline 12.4 & 79 & $9 \cdot 80$ & + \\
\hline $12 \cdot 1$ & $\cdot 78$ & $9 \cdot 44$ & - \\
\hline $11 \cdot 1$ & 92 & 10.21 & + \\
\hline 12.9 & .80 & $\begin{array}{l}10.32 \\
11.12\end{array}$ & $\bar{t}$ \\
\hline $\begin{array}{l}13.9 C \\
11.1\end{array}$ & & $\begin{array}{l}11 \cdot 12 \\
10.27\end{array}$ & + \\
\hline $\begin{array}{l}11.1 \\
15.3\end{array}$ & $\begin{array}{l}97 \\
.90\end{array}$ & $\begin{array}{l}10.77 \\
13.77\end{array}$ & \pm \\
\hline $\begin{array}{l}3.3 \\
13.4\end{array}$ & $\begin{array}{l}90 \\
.68\end{array}$ & $\begin{array}{r}3.77 \\
9.11\end{array}$ & -- \\
\hline $11 \cdot 4$ & .57 & $6 \cdot 50$ & +- \\
\hline $13 \cdot 2$ & .56 & $7 \cdot 39$ & -+ \\
\hline 13.7 & .65 & 8.91 & ++ \\
\hline $12 \cdot 4$ & $\cdot 79$ & $9 \cdot 80$ & $t+$ \\
\hline 13.4 & .96 & 12.86 & $+t$ \\
\hline 15.3 & $\cdot 72$ & $11 \cdot 02$ & -+ \\
\hline 12.3 & $\cdot 71$ & $\begin{array}{l}8.73 \\
8.87\end{array}$ & +- \\
\hline $\begin{array}{l}12.5 \mathrm{C} \\
12.3\end{array}$ & 73 & $\begin{array}{l}8.87 \\
8.98\end{array}$ & $\overline{+} \bar{t}$ \\
\hline $15 \circ$ & $\cdot 78$ & $11 \cdot 70$ & -1 \\
\hline 14.9 & .72 & 10.44 & +- \\
\hline $12 \cdot 9$ & -94 & $12 \cdot 13$ & -+ \\
\hline 12.5 & 110 & 1375 & ++ \\
\hline 14.5 & $\cdot 91$ & 13.20 & -- \\
\hline 15.5 & $\cdot 78$ & 12.09 & -- \\
\hline $14^{\circ} 0$ & $.98^{\circ}$ & 13.72 & $t+$ \\
\hline 14.0 & 118 & $16 \cdot 52$ & + \\
\hline $15.4 \mathrm{C}$ & $1 \cdot 19$ & $18 \cdot 33$ & ++ \\
\hline $13-9$ & 97 & $13.4^{8}$ & ++ \\
\hline $12 \cdot 5$ & 1.09 & 13.63 & \\
\hline 15.9 & 1.05 & 16.70 & \\
\hline 15.2 & .92 & 13.98 & \\
\hline $\begin{array}{l}16.6 \\
16.9\end{array}$ & $\begin{array}{l}1.24 \\
1.18\end{array}$ & 20.58 & t \\
\hline & & 19.94 & \\
\hline
\end{tabular}

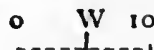

000000000 o. 0000000000000000

000000000000000000 000

0000000000000000

000000000 000000000

000000000000000

00000000000000000

000000000000000000 Franco-Prussian

0000000000000000 p $^{2}$

0000000000000 -...

0000000000000000

00000000000050

000000000 0000000

00000000 od

00000000000000

o00000000 00000 -

000000000000

0000000000000

000000000000

000000000 of

000000000 of

000000000

0000000000

000000000

000000 opoo

000000000

0000000 o of

000000000 o

000000000 0000

000000000

0000000

0000000

000000000

00000000 oo

000000000000

o0000000 o

000000000

000000000

000000000

000000000 of

0000000000

000000000 00

000000000000

000000000000

000000000 oo

0000000000000

000000000 o00000

000000000 0000000

000000000000

0000000000000

000000000 0000000

000000000 pooo

000000000 b0000000 0.................... $1914-5$

0000000000000000000

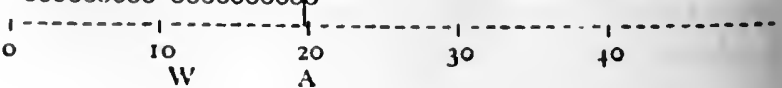


person or " normal price " would be less than it is for the later years. and not more as it appears to be on Diagram 47, as the result of the acre being taken to represent the same number of persons all through, which in fact it does not. This change in the number of persons represented by the acre is no doubt very much greater than that before noticed in English crops, the data for which did not cover such a long period, and in this longer period it no doubt constitutes a serious error in the earlier years on the diagram. It so much distorts the normal price curve from I $866-1885$ that it cannot possibly represent the true level of prices on the gold basis of value.

But although for the first twenty years on our longer American crop indexes the normal price curve $A A$ is on quite a fictitious level, the fact that the various commodity prices follow the approximately similar fluctuations shown by the curve indicates that they are controlled by a common cause of variation. And from what we have seen in our examination of European prices and gold the cause of this common variation of prices is doubtless the variation in the labour cost of the gold. As in our previous diagrams, the curve $A A$ is a composite average of the American prices of coal, cotton, wheat and maize. It should also represent the value of gold produced per person, but as just explained, it fails greatly in that respect owing to the imperfect data for the number of persons or labour cost per person. This being so it is much to be regretted that there is no record of the value of gold produced in these years, by which we could correct this error in the normal value of crops. As we have mentioned elsewhere, the next best evidence to the direct gold output figures would be a complete record of the wages paid each year. A record of American wages does go back to these years, but unfortunately it is only taken for the Census years, so misses most of the more interesting price fluctuations, and cannot be used in any detail. But the level of wages at each Census, which we indicate on our diagrams by the broken curve WW opposite the years marked " $C$ " in the first column, is useful as evidence of the extent of the error in the number of persons in the earlier years. This curve is drawn on the assumption that wages in $19{ }^{4} 4$ were the usual 52 per cent. of the product and therefore equal to ro\$ per acre; then if the curve of wages fluctuations taken from the U.S.A. wages Diagram 66 is reduced to the same scale as the wheat index, it will show what the relative level of wages must have been in the earlier Census years back to $\mathrm{r} 86 \mathrm{~g}$.

It will be seen by this broken curve that in r 869 wages were only $5 \$$ per acre, so that if all the rest of the I $\$$ normal price for that year was profit, farmers must have been doing remarkably well, their profit being nearly three-quarters of the whole price of wheat. It is hardly necessary to say that no such thing can have happened for any length of time, and not even for a single season without inducing 
an over production and fall of prices in the following years. There is, however, not the slightest reason to suppose that wages were to any extent higher fifty years ago. All the evidence points to the supposition that they were somewhat lower, and they certainly were in I869 if the official Census is any evidence. Admitting wages to have been no higher, the only alternative to account for the high normal prices at the beginning of this period would be to suppose that profits were at this outrageously high rate of more than double what they usually are. Profits may have been good in $1867-8$ as the result of the after-war quasi-prosperity, but there is no evidence that the general level of profits can go up to such an extent as threequarters of the production. Such phenomenal profits would inevitably bring about a vast increase of area, compared with which the increase caused by the famous Leiter corner would simply be as nothing. Such profits and the spirit of rash speculation which such good opportunity always engenders would certainly have led to a collapse of the inflation that would carry prices far below the average, and result in anything but a period of high normal prices. Instead of this boom of trade we find the area under wheat was

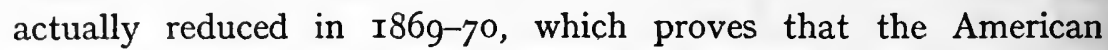
farmers did not find themselves getting fabulous profits. It is a much more probable assumption that the means of production being at that time in a relatively low state of efficiency a larger number of persons were at work upon the acre, and that therefore the return per acre in those years is not a true " normal price" that can be compared with that of later years. It is the true return to the acre, but not to the "labour-time." The labour-time to the acre was at least double what it is now and therefore the total wages paid per acre would be double what the curve $\mathrm{W}$ shows, that is Io\$ per acre, and the profit therefore would only be normal.

Although the normal prices before I885 cannot for the above reason be compared with those of recent years, they represent with approximate correctness the fluctuations of those prices and can quite properly compare with the adjacent years from I 866 to $\mathrm{I} 884-5$. The curve AA, although distorted by the number of persons error, can like a bent foot rule be virtually correct for measurements by its̀ sub-divisions, the error in a few contiguous inches would be quite negligible, while the rule was quite useless for measuring a whole foot ; so AA will quite well serve our purpose for comparing the price fluctuations of American crop produce, though it should be kept in mind that the average trend of the fluctuations prior to I 885 should be a curve parallel to the curve of wages.

Notwithstanding that as shown above normal prices of wheat in the United States were nothing like so high as our diagram represents them, and also that much of the high price was due to extra cost resulting from the recent civil war, still the high market prices 
no doubt made profits good, and they are well up to and a little above the curve in $1867-8$. This was probably the close of a period of rather over-high prices and was followed in the next two years by a slight depression as witnessed by the reduction of area in 1869-70.

The increase of area in $1870-1$, when the normal was below the line, was probably due to the poor crop and the rise of price when winter wheat was being sown. But allowance must also be made for a general tendency to increase area at that time when wheat growing in the States was as a rule so evidently profitable.

In $1871-2$ prices were rising again owing to the high European price and the demand for wheat during the Franco-German warand all through this period normal wheat prices tend to be a little above the average AA, so that there was a continuous and considerable increase of the area under cultivation.

In $1876-7$ the area was a little decreased, no doubt owing to the very low price at the beginning of the season when the sowing was taking place. But the very poor crop sent the price up in the later months and made the normal price for the season above AA.

The above reduction of area was probably the cause of the price going very high at the beginning of $1877-8$, which resulted in the great increase of area by nearly six million acres. This brought about the usual reaction in $1878-9$, when the market price of wheat fell for the first time below the dollar, bringing the normal price down to the average curve and making for a very small increase in acreage. It was shown by the general Census taken the next year that this increase was a very large one by three million acres, but that is no evidence that the increase took place in that particular year, but that it was an error in the yearly estimates distributed over the whole time since the last Census.

The next five years are good evidence that our curve of normal prices is still somewhat distorted by the greater number of persons per acre, for although the normal price was never below AA there was a persistent reduction of area. This indicates that although the curve makes wheat growing seem up to the agricultural average of profitableness, that average was low compared with other industries. If the curve AA was drawn to show a less return per person employed it obviously would come nearer to the curve of wages, and that probably illustrates what actually happened. Wages probably went up in the good year r897-8 and did not fall again so fast as the normal price did, so that the profit was smaller at the time than our diagram would imply, and consequently the area was reduced.

This reduction helped by a rather small crop sent the price up a little in $1883-4$ which led to an unfortunately large increase of area in that season. This brought market prices lower than had ever been known in the next season of $1884-5$ and caused a reduction of area by five 
million acres, showing that this was a period of bad trade in wheat growing and that the true return per person was nearer to our wages curve than to the return per acre curve AA.

I885-6. The crop this season was a very bad one and that with the decreased area sent prices up a little at the beginning of the season, which probably accounts for the increase of area although the normal price for the season was below the line. But the reported increase of two million acres was probably much exaggerated as shown by the returns at the next Census.

The next season the normal price was up to the curve and the area a little increased. In $1887-8$ it was below the line and the area decreased. And again the area was increased in $1888-9$ when the normal was up to the line.

In I889-90 the annual estimate of area showed it to be $38,124,000$ acres, but when the Census figures for that year came out the area was found to be only $33,580,000$ acres, an error of 4,544,000 acres; so that in the above period, as we have mentioned, the increases of area must have been over-estimated. But as this error should be spread out over the decade, the estimated two million acres reduction in I889-90 may have been about correct for that season, and accounts for the rather better market prices in I890-I and the great increase of area, which would have been rather disastrous if the crop had not turned out badly and sent the price above the dollar again at the end of the season.

I89I-2. This season seems peculiar, as there was a reduction of area in spite of a high normal price, but it will be noticed that the price had fallen below the dollar again, which probably seemed like the limit of bad prices to wheat growers in those days, so the area under winter wheat was reduced before it was recognised that it would be a well paying season, owing to the very big crop. The very high normal price was evidently due to the crop, which was larger than any known in America up to that time, and the failure of the market price to come down quickly enough to compensate for the big supply. But the reduction of area was actually justified, for the price did fall badly in the next season and led to a further big reduction.

The next two seasons see wheat prices to the bottom, and still a little further reduction of area in I894-5.

1896-7. As we have mentioned, in English wheat prices there was a great rise of price this season, which was found to be due to the Leiter corner, which commenced about this time. Wheat prices were at their lowest point in I894-5; but might possibly have gone lower if the corner had not started to send them up, as the lowest point of prices indicated by coal (Diagram 33) was not until this season of $1896-7$. Wheat prices being so low it was undoubtedly the time for a speculator to buy, and Mr. Leiter may 
have thought that speculation had cut the price of wheat down to a suicidal figure and that it only required a strong financial stand to restore the price to its normal position of about \$I per bushel. He probably was not aware that the cost of growing wheat was so much less now that less persons were required per acre, that at the present gold standard position its natural price was only a little more than half a dollar; and, therefore, that a small advance upon that low price would call forth an inexhaustible production of wheat. When in this season he had, by holding up wheat, raised the price to about $\$ \cdot 85$, the area was increased four million acres in America alone.

In 1897-8 Leiter got the price up to the dollar again, but not before the area had again been increased by another four million acres, resulting in 100 million extra bushels of wheat from America, and, as we have seen, a great increase in England and probably all over the wheat-growing world. The supply was quite inexhaustible, and Leiter could not buy and hold it all up, so the corner broke down as all such corners must, and the wheat market was overstocked for some years after.

In I898-9 prices fell to what was probably below their natural level, but the remarkably fine crop per acre made the normal return per acre above the average curve ; the next two seasons, however, were much below it, and the census returns show that the area had been reduced by Io million acres. But these extravagant and contradictory alterations of area seem to us of doubtful authenticity, and can only be taken as very rough evidence at the best. For the very next year, in the season I900-I, the area is again reported to be increased by seven million acres without any apparent reason, for the normal price was very low. It looks as if this increase was a good deal in the nature of a correction of the over-estimated census returns, or the calculation of the alteration from a different basis. However that might be, the increase must have been a mistake, for the next season I90I-2 there was another reduction by three and a half million acres, which kept the price up in spite of the big crop, and made a very good normal price for the season.

This normal price above the average led to an increase of winter wheat area in 1902-3, which reacted on the price and sent the normal much below the line, again resulting in a reduction of the spring wheat area and a big reduction in the next season. This sent the normal price up to the line again in 1904-5 with the usual increase of area, which resulted in the next two seasons being below the curve and with big reductions of acreage.

1907-8 was not quite up to the average curve, but the curve was then getting high, and the market price touching the dollar in October, there was a considerable increase of area. And in spite of this increase prices went up and there was something in the nature :0\%. 
of a boom in wheat prices during 1908-9 and r909-10, helped no doubt by the decrease of area in the first of these seasons and the very moderate increase in the second.

The success of the last two seasons, and the keeping up of the price into the early part of this one, led to a considerable increase of the area which depressed the price, which had not time to recover after the failure of the spring wheat crop became known. The failure of this part of the crop made the season a very bad one and led to a big reduction of area in the next season; and it seems that only by restricting the area can the normal price be kept up to the line for the rest of the period.

United States wheat prices do not show the many well-marked fluctuations of European prices, but they fairly well follow certain fluctuations of their own, which variations are indicated on our diagrams by the curve AA. There are the distinct depressions from $I 868$ to $I 872$; from $I 873$ to $I 878$; from 1879 to $I 891$; and the fall from $I 892$ to 1895 , from which point there is an almost continuous rise till I9I4. Roughly, there are two great periods noticeable on the diagrams as a fall of market prices from I867 to I894-5, which is quite explainable by the obvious fact that the vast improvements in agricultural instruments, methods, and means of transit, have greatly lowered the labour cost of producing the wheat; and a rise of market prices up to I9I4, which is not at all explainable by any obvious increase in cost. We cannot for a moment think that it costs man any more labour-time or anything else to get wheat in I9I2 than in I894; every conceivable instrument, material or service is made in less time than it was, so in what can its extra cost consist? The common inexactness of business language has led to a common impression that it is the increasing wages that make everything higher in price; a misimpression that is much encouraged by the present fictitious prices, that are due to the suspension of the gold limit for the political purposes of the War. But if prices went up because wages were high, while gold was the only legal tender and actual measure of value, there would be a prompt stoppage of the gold supply, as we have explained in the last chapter. Gold miners' wages would have to go up like the rest or they would soon leave the mines; but no matter how high their wages went up, the price of gold could not rise. So its production would soon stop and prices, as we have seen, would have to come down.

Another common excuse for the price of a particular commodity such as wheat going up is to say that the price of all the materials and requisites of the business cost more. But, although that may be quite true, it is only stating the fact that prices generally have gone up and does not explain in the least why they have done so. And yet another very favourite suggestion to account for high prices is that commercial contrivances are arranged to include high 
profits or rents in the price of the goods produced, and in controversion of this impression the rise of wheat prices from 1894 is instructive. For, although the normal price of wheat has gone up all the time from 1894 till it is three times what it was then, we see that there has been continual reductions of the area every time the normal price gets below the curve AA. Such reductions prove that the higher price is not all profit, or no grower would give up an acre of such profitable crop. That they do reduce the area proves that a little fall of price below AA renders wheat growing unprofit. able at the high prices of $1911-12$, just as much as at the low price of 1893-4-the percentage of profit evidently inust be much the same. Producers evidently cannot determine the level of price for their productions, but are always groping to find out the true price and adjust their acreage so that their selling price may be a little above it ; in which laudable attempt they fail as often as not. This true mean price is undoubtedly determined by some cause beyond their control, and which, as we have seen in the last chapter, can be quite simply accounted for by the variation in the value produced per person in the gold mines.

Note.-The acreage and crop per acre of wheat and other farm crops are taken from "Statistics of Principal Crops (1913)." The price figures are specially supplied from the same department, the Bureau of Statistics, Department of Agriculture, Washington.

\section{Cotton Prices.}

It will be seen by the Cotton Index (Diagram ${ }_{4} 8$ ) that prices in this typical industry follow very closely the same line of fuctuations as wheat, except perhaps that they keep a little closer to the line of theoretical commodity prices indicated by the curve AA, a fact which tells rather heavily against the common notion that cotton prices are the artificial creation of vast financial speculations. Like those of wheat, prices of cotton were very high from 1870 to 1875 . owing chiefly to war conditions; but in this case it was probably the after-effects of the Civil War still making somewhat artificial conditions in the cotton industry, which of course had been practically suspended during the conflict between North and South. It is also most probable that, as the cotton trade was then comparatively young as one of the great industries of the world, great improvements in the method of cotton production were going on, as was the case in wheat, which would mean that in the earlier years more persons were employed per acre, so that the curve AA is distorted, as was explained under wheat prices, and that it should more closely follow the broken curve of wages (WW). This is more probable, as after the employment of slaves was abolished more attention would doubtless be paid to improving agricultural methods; but, 
DiAgRAM 48.-COTTON INDEX, U.S.A. (NEW YORK).

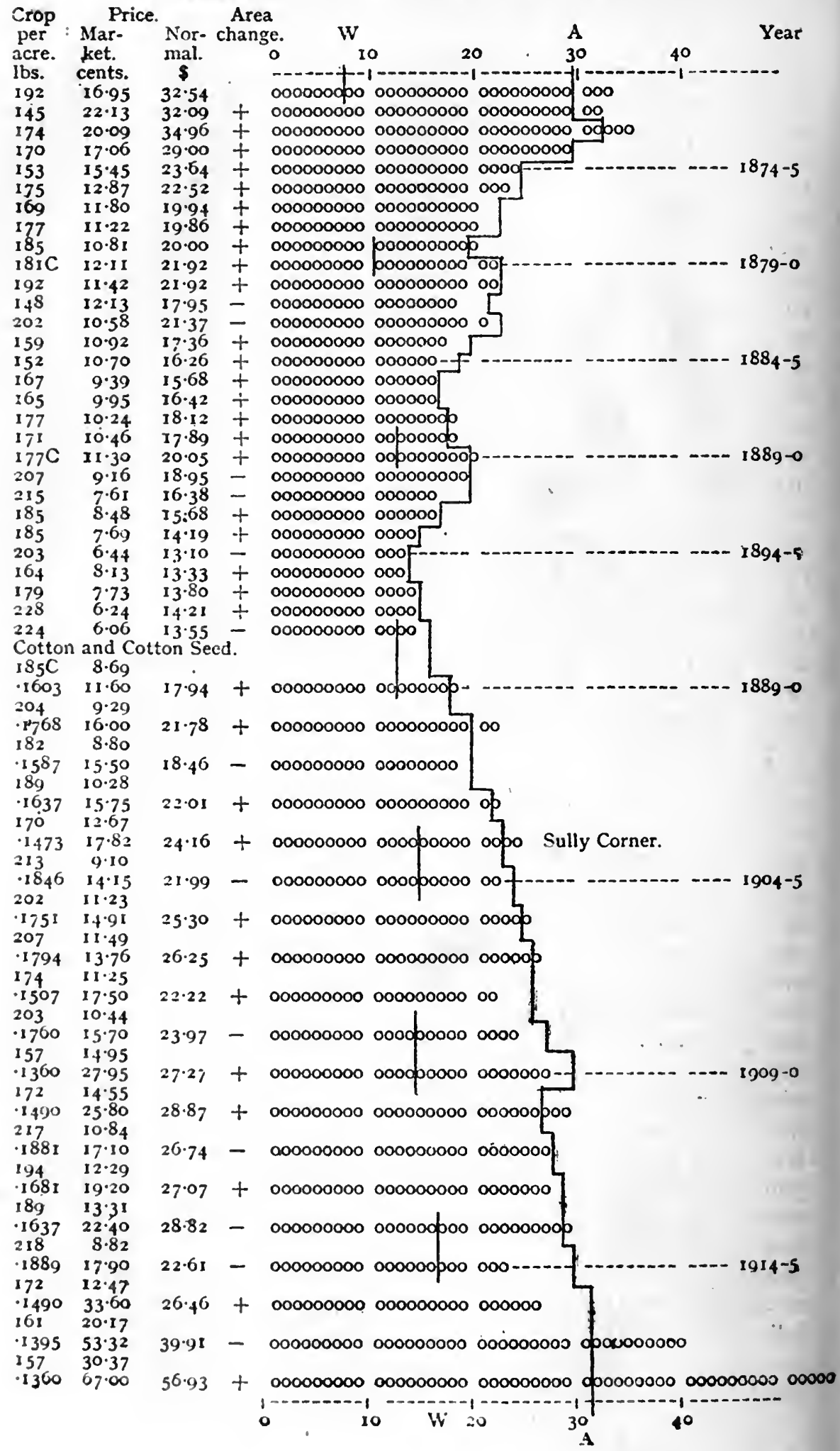


as we have no data for the extent of such improvements, we can attempt no exact estimate of the actual number of extra persons working to the acre of cotton at that time. But, as before explained, the curve AA correctly showe the relative fluctuations, though on a fictitious level, due to the use of the production per acre instead of per person. The fact that the apparently high normal prices down to 1890 were due to higher cost rather than high profit is shown by the smaller increases, or even reductions, of area whenever the normal was below AA. The exception to this rule in $1876-7$ was due to the rush up of prices in January and February, just as it was time to begin planting the new crop. The same depressions of price as seen in wheat will be noticed here, between I 880 and I 890 , and the fall, down to the year $189.4-5$, followed by the continuous rise till I9I5.

Following cotton prices down the index diagram we find the high point in 1890 well marked in this commodity, as also the falling prices from that year till $\mathbf{1 8 9 5}$, and it is interesting to notice that in the first two years of this fall the large crops caused a big drop in the market price which resulted in a big decrease in the area planted. If farmers are getting excessive profits a fall of price should not discourage them if it is caused by their having big crops : but as in this case the return per acre had fallen $\$_{f}$ we find three and a half million acres of cotton land going out of cultivation. Yet, again, in the next two years, though the normal price was still lower, a like amount of land came into cultivation, because the price was up to the curve AA, which indicates the true cost at the time including average profit. The result of these adjustments of area seems to have been that growers have managed to get just above the average return or normal price during the period covered by our diagram.

After the season $I 898-9$ there is a complication in the cotton index, the production of the cotton crop being divided into two portions owing to the growth of the cotton-seed oil industry. The seed having become an important marketable portion of the crop. we have to make two lines each year on the diagram, in the first of which the cotton or lint is given in pounds weight per acre in our first column and its price per pound in the second. The seed is given in the second line, in decimal parts of a ton per acre in the first column, and its price per ton in dollars in the second column. the normal price, or index of value per person, including both products, is given in dollars in the third column. This division of the crop into two items makes the monthly price and average data more complicated to follow because the total cotton crop that affects the quantity upon the market consists of two parts, the cotton = "lint " and the "linters"; which latter is the short cotton that hangs to the seed after the bulk of the cotton has been removed. Now that the seed is sold to the crushing mills, there is still a little linters that goes with it, and the oil millers have found it possible to get this 
short cotton off the seed and sell it as cotton, so that it still counts as part of the year's crop of cotton. But its value does not enter into the cotton crop per acre on our index, as it is included in the value of the seed per acre. It is necessary to explain this peculiarity of the cotton crop product, as it complicates the figures on the cotton diagrams, but it does not otherwise make any practical difference to the significance of the normal price figures.

After this alteration in the allocation of the cotton crop, it may be seen that the normal prices still follow the line of general prices so nearly that it cannot be supposed that these prices are based to any extent upon speculative demand or supply. They were rushed up a little at the beginning of I900-I in sympathy with European prices, but the figure was evidently above the American standard of value, for they promptly fell below the standard in the following year. Another famous attempt to make artificially high prices occurred in $1903-4$, in fact in I902-3 Sully began to make a great corner by holding up cotton, with the effect that the price went up greatly in spite of a good sized crop. The details of this rise are well seen in the monthly price and acreage reports, which show that there was a prompt increase in the area planted with cotton of a million acres. The crop from that acreage not being a specially big one, Sully kept the prices up until March, I904, when it became known that there would be a big increase of area again. It turned out to be an increase of over two and a half million acres and the prospects of a great crop broke the corner, and prices began to fall very rapidly. The great crop of $\mathrm{I} 3$ million bales sent market prices to the bottom, and would, no doubt, have still further depressed normal prices had there not been a steady natural rise of prices in progress at the time.

The trade boom of I906-7 sent cotton prices up with those of other commodities, and, after the commercial crisis in which that boom ended, we get a set-back in 1908 , as shown by the index of normal price on our diagrams. On the whole, the movement of cotton prices in the United States well supports the view that prices are definitely determined by labour cost, the value of which labour is determined by its value in producing gold.

Note.-The acreage and crop figures are taken from "Cotton Facts," Shepperson Publishing Co., New York (edition of rgr6). The prices for the earlier years are from an old edition of the same work, kindly supplied by the publishers, but the later prices are from the author's own record of current prices published in the daily market reports.

\section{Maize Prices.}

Maize is another American crop the price movements of which follow a very similar course to those of wheat, the most obvious 
difference being that they do not show such high war rates in 1867 and the first few years till 1873 . This is probably due to the fact that the error in respect to the number of persons per acre is not so great as in wheat. The crop per acre shown in our first column (Diagram 49) does not show any improvement during the periol

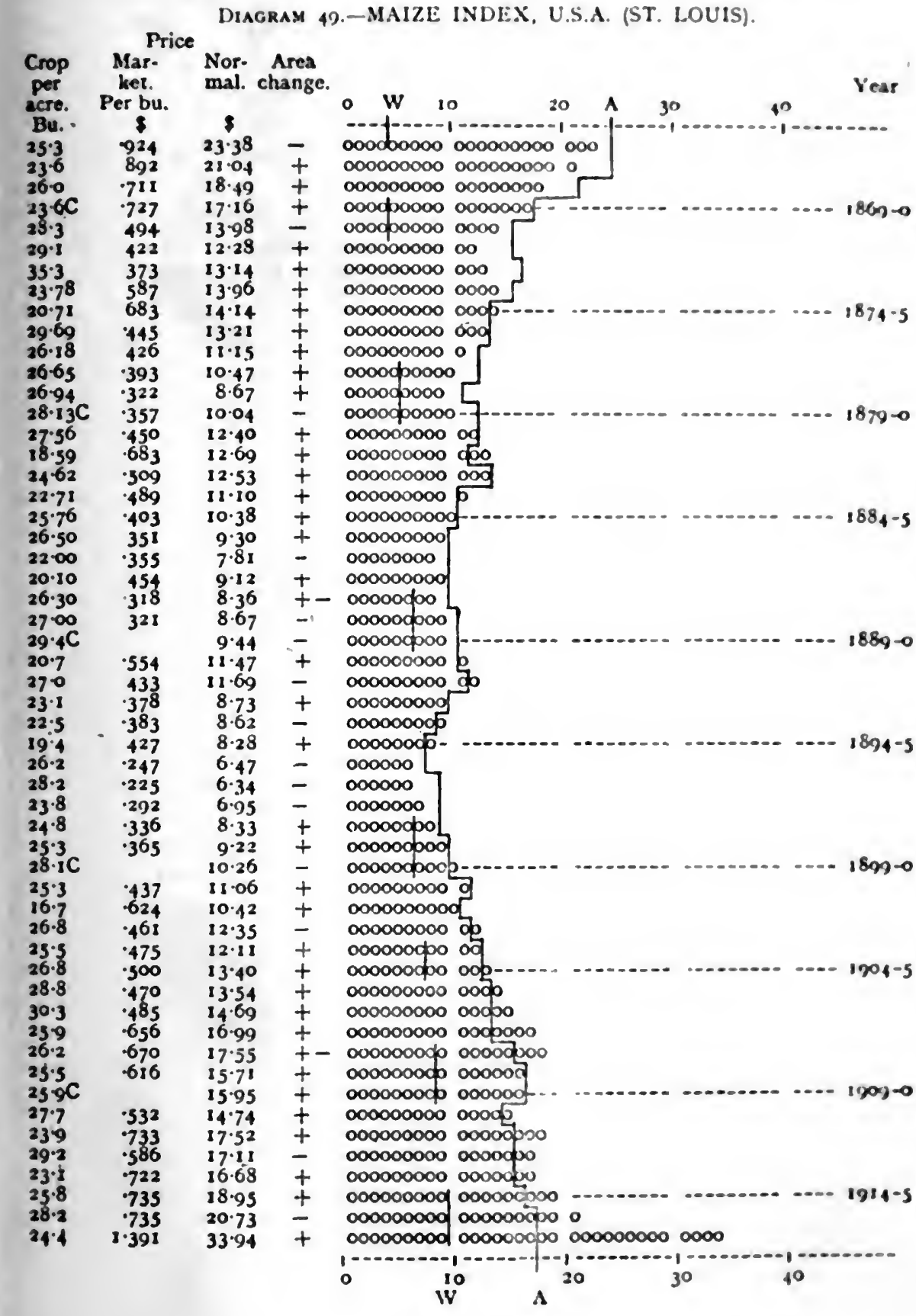


covered by our diagrams; so that it is quite possible that in maize there has not been so much improvement in the agricultural methods of its production as in some other crops, and that therefore there has not been so great a change in the number of persons per acre during the period covered by our index. But the curve AA will still indicate the relative fluctuations from high to low prices that should theoretically occur, although the distance of normal price below the curve is not evidence of an actually bad return in those years farther back than 1879 .

The very big drop in price in I870-I naturally made a decrease in area, but it may have been found to be still a paying price in the following years as general prices came down.

In the season $1878-9$ and $1879-80$ normal prices fell below the line of average prices, probably owing to a rather too large area having come into cultivation, a result perhaps of the same business laxity that caused the extraordinary incorrect estimates of acreage, one of which appears in the latter of these years. In the first season, I878-9, the annual report gave an increase of area by a million and a half acres; but when the Census for the following year was taken, the increase turned out to be Io $\frac{1}{2}$ million acres, which is rather a considerable error and one that might reasonably be thought to render any price calculations upon such data too doubtful to be of value. It appears, however, that the crop also was underestimated by some 200 million bushels, so that the return per acre was not much affected; still it shows that too much must not be expected from crop reports as data, especially in these earlier years when the statistical methods were probably less efficient than in later years. The fact that prices were at this time below the line led to a reduction of area in $1879-80$, but that was on too small a scale to have produced a rise of normal prices had there not been several rather poor harvests in succession in the following years, especially in $188 \mathrm{I}-2$, which sent normal prices a little above the line that season.

During these good years the acreage was again increased by some I2 million acres, which was probably too much, and accounts for the low prices that came after I885-6, and continuing till I890, kept the normal prices a little below the line at that time. As this became realised there was a big reduction of area in I886-7, and again in I888-9, when, though the annual reports gave a large increase, the Census showed a reduction of three million acres, an error of five million. This unconscious reduction, with the help of a poor crop in I890-I, raised normal prices to about the right point, and kept them a little above the general level of price all through the depression till $1894-5$, when general prices got to the bottom. So that it seems the efforts of the growers simply threw the high point in maize prices a little behind that of the curve without much affecting the extent of the fluctuations. 
The result of this belated rise, however, seems to have been rather disastrous, for maize growing, having seemed to be rather more profitable than other things all down the period of falling prices, led growers to increase the area planted by the extraordinary amount of 19 million acres in $1894-5$, when all other prices were at the bottom. The result of this rash speculation was that maize prices fell lower than they have ever done before or since, and normal prices also fell below the average level for the next three years. The next years are up to the curve of average prices, and the acreage is increased. The Census claims the extravagant increase of 17 million acres for I898-9, and a decrease of II millions for I899-1900; so it is more probable that the annual estimate which shows an increase of six millions for the two years is the more correct.

From that time normal prices of maize have gone up with the general rise of prices in the United States. The boom of 1907 does not show greatly in this commodity, as the normal price or return per acre in maize was distinctly high all through the years between 1905 and I910, due, perhaps, to the growers having learned moderation in their increases of area, which were not extravagant for a time of high prices. If that is recognised, it will be seen that this period of prices above the average may be regarded as reciprocal to the depression from over-acreage between 1895 and 1900 . In the rest of the seasons the price very fairly well follows the curve AA, although from some cause the return per acre seems to be greater than in other crops. This apparently high return is no doubt due to some special circumstance of the industry, of which we have no knowledge, but it probably means increased cost, or more labour per acre in some way. and the error would disappear if we had any good returns for the actual persons employed and the net output. The increasing area, however, is quite in accordance with the good normal price; and the exceptional case of a decrease of area in 1912-13 shows that the profits in maize growing are not actually above the average or growers would not give up such a paying crop just because the market price was a little low at sowing time. In that season, I9I2-I3, the market price fell at the beginning of the season, and the acreage for the next year got reduced before it was found that the good crop would more than compensate for the lower price and make the normal for the season good. On the whole, however, maize prices very distinctly follow the general rule of American price movements, and support the contention that price variations are determined by variations in the standard of value dependent on its cost of production.

\section{U.S.A. OATS Index (Chicago)}

There are a few other American crops for which the return to the acre is published, and for which therefore a normal price can be calculated, and although they perhaps do not add anything to our 
argument, we include them in accordance with our general plan of collecting all the available data. The record of oats prices does not go back so far as those of wheat and cotton, but so far as it goes the normal price follows the same general direction. Starting from the lowest point in American prices in $1894-5$, the normal price of oats (Diagram 50) was a little below the average of general price for four or five years ; and growers seem to have increased the area under this crop a good deal while the return was below the average normal, which would account for the price continuing low. But there is considerable reason for suspecting that growers did not make this

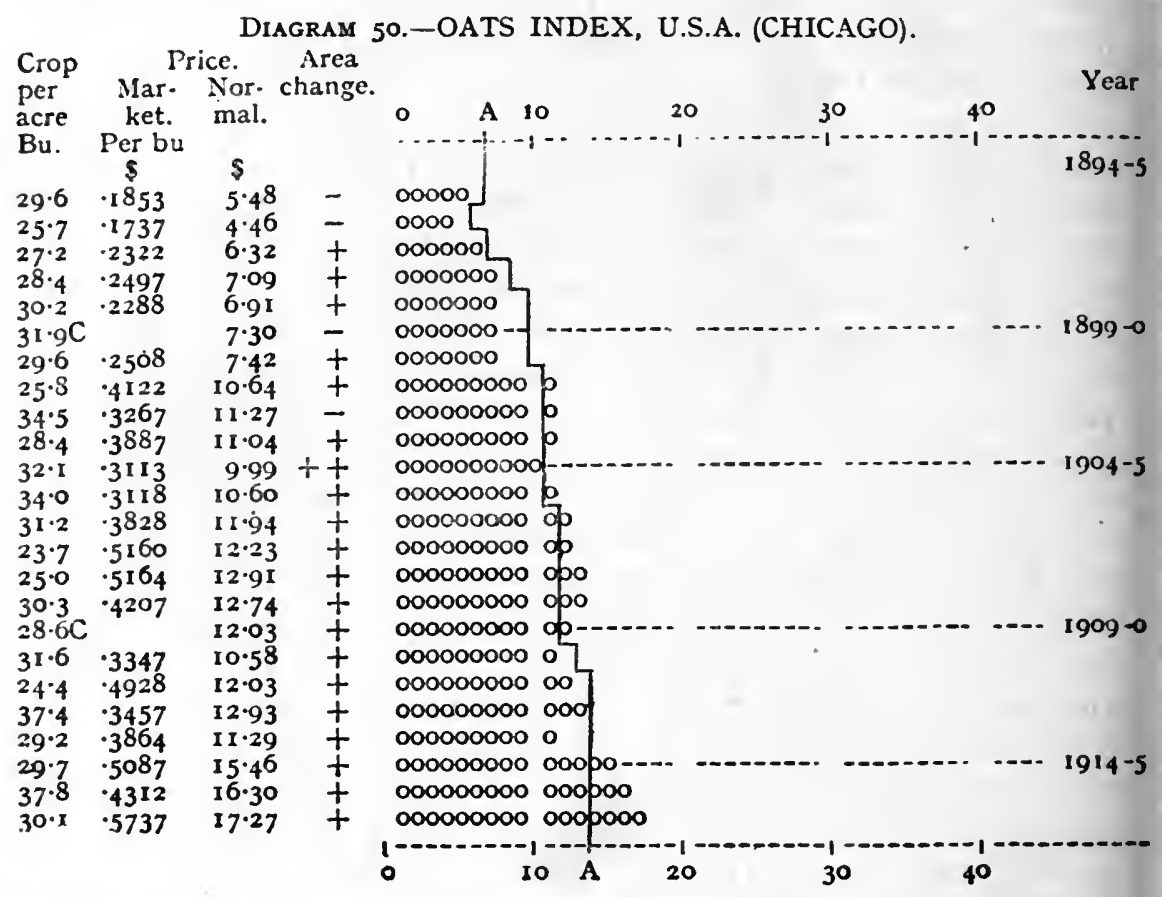

mistake, but were really decreasing their acreage of oats; for the Census report, by its return of the acreage in I889-90, shows that the increases could not have taken place unless the decreases were much under-estimated, for at some time there had been a decrease of over three million acres. The increase of a million acres shown by the Bureau figures for I899-I900 is contradicted by the Census, which records a decrease by two million acres. As we have pointed out, these contradictory returns show that the yearly reports of acreage cannot be taken as quite exact, and the growers may have kept nearer to the sound rule of procedure than our + and - signs would suggest.

From this point the normal returns per acre of oats has continued to rise steadily in common with, and to about the same extent as, all other United States prices. They steadily keep a little above the 
curve of average prices, indicated by $\mathrm{AA}$, especially between 1904 and rgro, and it will be seen that the area also steadily increases as the result of such good returns. The exception to this in 1902-3 was, as we have noticed in other instances, due to a considerable fall of price at the beginning of the season and a reduction of the area planted before it became realised that the big crop would make it a good normal price for the season. This gond period probably brought about the usual too big area, for we find the normal prices go below the curve in the next four years, and would probably have continued so if the War had not sent market prices up or the area had not been reduced.

The further increases of area with the rising War prices is quite in accordance with our theory; and it will be seen that the normal price of oats quite well supports our contention for a common movement of prices in conformity with variations in the standard of value. The curve AA, it must be remembered, is the same on all the U.S.A. diagrams, and the movement of all prices conformably with it is good evidence that it represents approximately the variations in the value of gold produced per person in the United States.

\section{Prices of Barley, Rye and Potatofs}

The rest of the United States crops, the production details of which have been collected, need not be discussed at any length, as they do not throw any fresh light on the determining factor of prices, though their price movements follow the general course of American prices.

Rye prices (Diagram $5 \mathrm{I}$ ) follow much the same general fluctuations as wheat throughout the short period covered by the record. The prices on the whole tend to be below the curve AA, and, as will be seen, the result is many reductions of acreage under the crop. The exceptional increase in I900-I seems rather incomprehensible, as the market price was so low ; and probably it is somewhat overestimated, as it is seen by the "crop statistics" that the various estimates of the area in existence were very conflicting. It will also be noticed that in the few years when the normal was above the line, increases of area were nearly always made, or transferred to the following season, as in $1898-9$ and $1912-3$, which simply means that farmers did not discover that the season was a paying one till after they had planted their crops for the next season ; in which case they very commonly try to do better the next season when, as a matter of fact, it is too late.

Normal prices of barley will be seen (Diagram 52) to have frequently gone above the curve, when the good result from the high normal has been followed by a reaction caused by the too large increase of area. But the records of area and alteration in acreage seem much confused; especially about the year I900, when, as seen 
from " statistics of crops," it is very difficult to say exactly what the area was. The little reductions of area also in rgro-I and I9II-2 are quite unaccountable. But the general movement of barley prices during the period conform very well to the common movement of American prices.

The record of potato prices (Diagram 53) goes a few years further back than the rest of these minor crops, and shows part of the higher price period before 1894 . The normal price in this commodity follows a very erratic course, and does not follow the general price movement so well as most other things do. This irregularity is

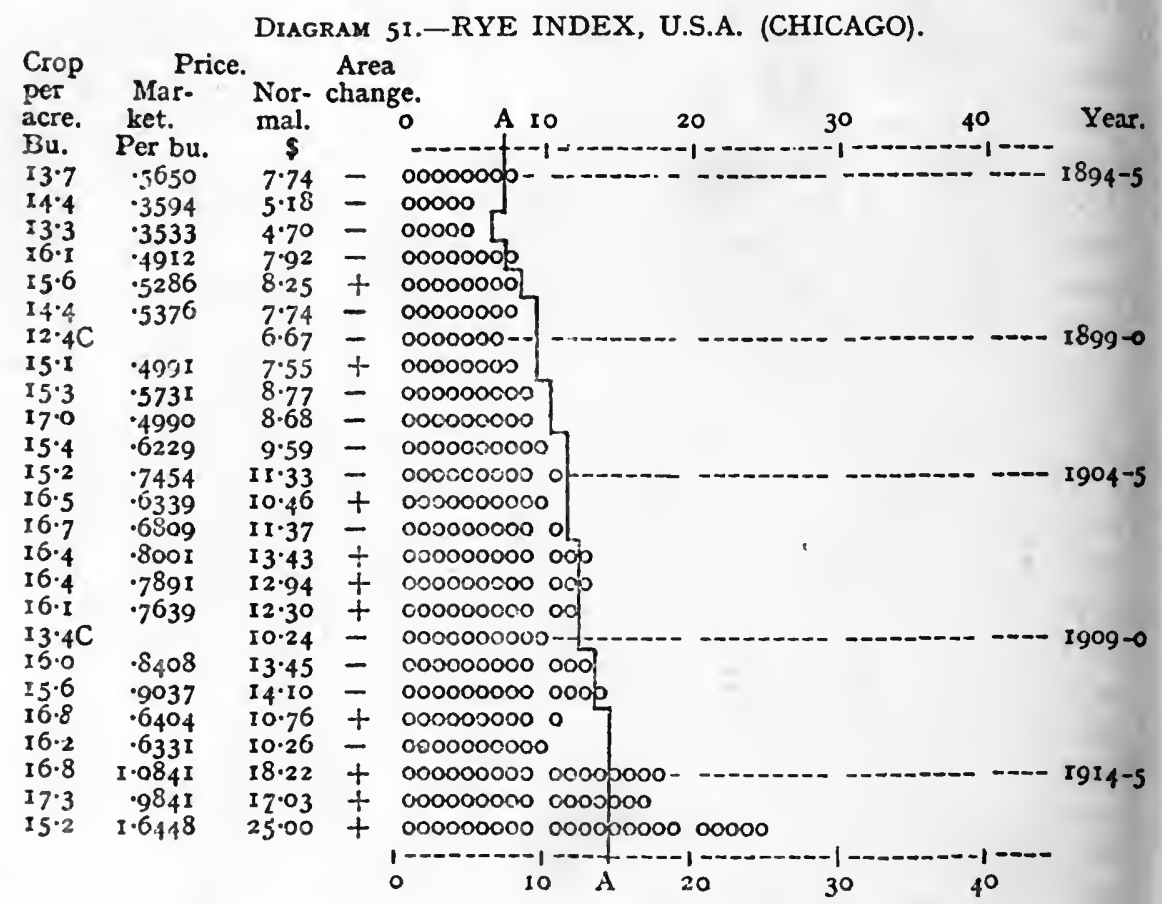

probably due chiefly to the very great variations in the crop to the acre, which defeat the growers' efforts to adjust the acreage to the demand; so that the price does not react with so much exactness upon the area or supply. Further, potatoes, like barley, are a small crop compared with wheat, and this again makes a difference in the completeness with which prices are brought up or down to the average level. It should always be understood that farmers are virtually without any exact knowledge of variations in the standard of value or of the real extent to which acreage is being altered by the growers throughout the country. So that there is a strong element of chance in their calculations, which will detract from the perfect adjustment of area to prices unless the number of personal decisions are practically infinite. The less the number of individual decisions going to 
make up the total determination of the area to be planted, the greater will be the error from the element of chance, and the prices will show a greater tendency to speculative variations.

This defect in the prompt adjustment of normal price to the cost of production basis notwithstanding, potato prices, like the rest, very clearly follow a general curve of variation common to all United States prices for the period: and American prices as a whole very definitely support the contention that prices are dependent upon the labour cost of producing the commodity, and vary in money value from a common cause, which cause was in the last chapter shown

Diagram 52.-BARLEl INDEX, U.S.A. (CHICAGO).

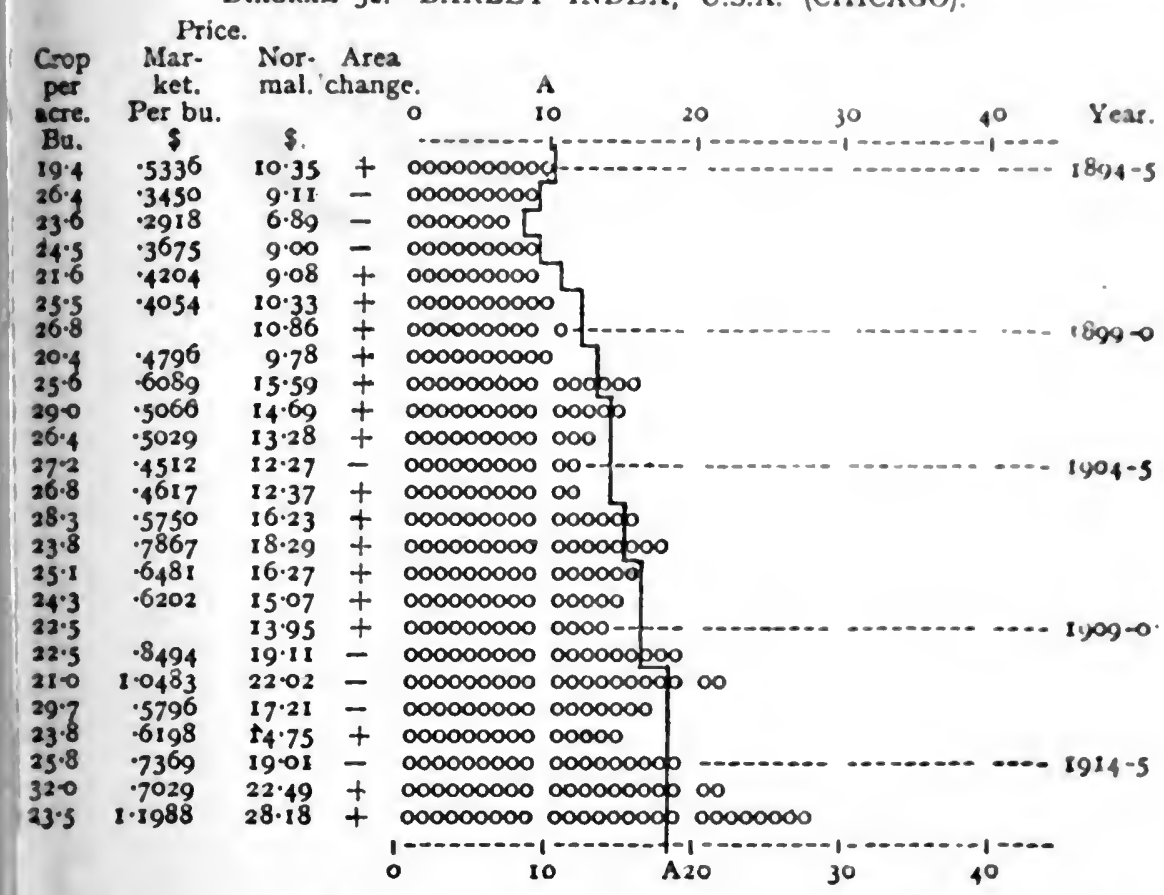

to be the variation in the labour cost of money or the commodity in which price is measured.

In this long review of price variations, a considerable amount of discussion has been bestowed on the producers' efforts to adjust supply (acreage) to the current price, representing demand or requirement, and we wish to make it clear that these adjustments have not been discussed simply for the purpose of excusing the many deviations of normal price from its proper movement. Although error in adjustment does often cause such irregularities, it is really this adjustment of the supply that makes any connection at all between labour cost and market prices. The whole theory of price depending on the labour cost of gold depends upon the fact that sooner or later, according to the nature of the production, such adjustment of supply 
must inevitably be correctly made. The promptness with which such correct adjustment is attained may depend upon the size of the industry; when it is large, the great number of individual determinations reduce the margin of error by counteraction of the extreme

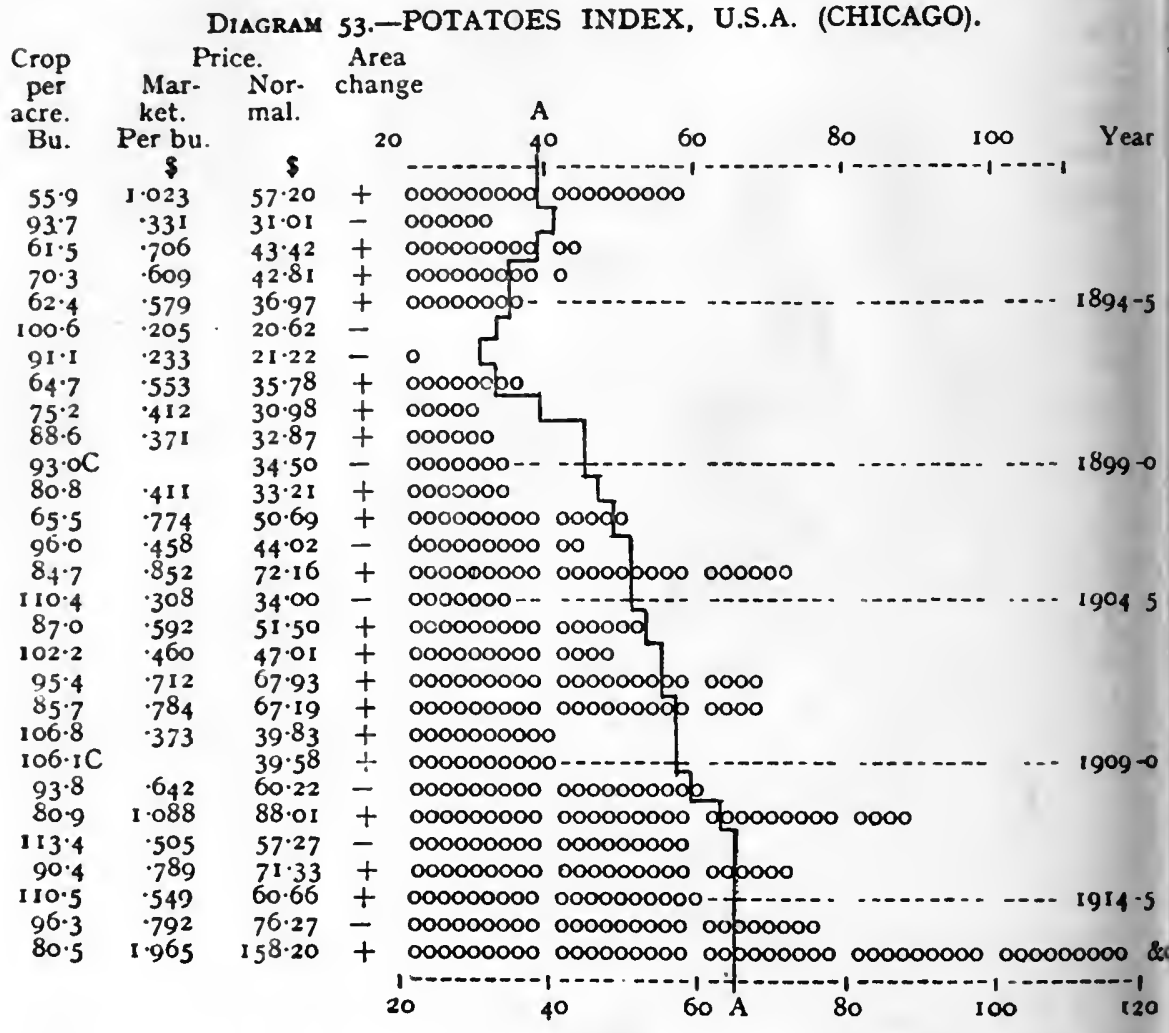

error on each side of the mean ; or such promptness may depend on trade organisation and efficient distribution of market information and statistical data, when the average judgment will be improved. And it is our purpose in the following chapter to show that at any rate in a highly organised industry this adjustment may be relied upon from season to season, and its effect on prices estimated to some nicety. 


\section{CHAPTER IX}

PROOF

TuE title of this chapter may perhaps sound a little presumptuous, but it must not be supposed that because we speak of the proof of the argument we mean to imply that our contention is proven; but we do wish to emphasise our opinion that it could be proven if society were sufficiently impressed with the desirability of doing so, and would make the necessary effort to complete the required data. The purpose of this chapter is to point out the method by which a proof could be obtained and show that, so far as it has been attempted, the result does support our views. No doubt all economists very reasonably think that there is some definite utility in expounding and understanding economic theory, and that the work of economists should be of some practical use to commercial and political leaders in their efforts to organise a better social order in the state. It must be admitted, however, that not only do their practical sugges. tions for procedure seem somewhat vague and contradictory, but their theoretical conclusions are so guarded and surrounded with reservations that they amount to little more than tentative suggestions or statements of personal conclusions of a provisional nature. It hardly seems to have entered their minds that if any such conclusions are really important to society it should be possible to put them to the proof by experiment.

It seems to be almost universally concluded that actual experiments are impossible in economic science, and we find Professor Gide rather despairing of the fruitfulness of the inductive method, because it is deprived of its most powerful means of observation, in this science where experiment is not possible. But surely it is a great mistake to suppose there is any essential difference between natural and economic science that renders experiment impossible or even especially difficult in the latter. Man is absolutely as natural and as much a part of nature as a bird, and has probably been experimented upon as regards his physiological structure more than the bird has. The only practical difference is that average business men are apt to resent any economic experiment upon themselves, or any observation of a special nature by the public or Governinent: although all men are unconsciously trying economic experiments upon themselves and each other in the most blind and unscientific way possible, and usually much to their detriment.

The economist's difficulty in adopting the experimental method 
seems partly to be in the fact that they have not yet quite realised the essential nature and requirements of an experiment. The socalled national experiments in taxation and trade encouragement are much too general and comprehensive in character, as Professor Gide points out, and are quite wanting in the artificial isolating conditions essential to a true experiment. But they are by no means the only kind of experiment possible in the study of economics, a fact that Professor Gide seems quite to recognise, for he evidently thinks some form of experiment should be possible when he proposes three stages of procedure in economic method, which methods seem so sound and scientific that we quote them in his own words :-

“ (I) By observing facts, without any preconceived idea, particularly those facts which appear at first sight the most insignificant.

"(2) By imagining a general explanation which will enable us to connect groups of facts in the relation of cause to effect; in other words, by formulating a hypothesis.

" (3) By verifying the soundness of this hypothesis, ascertaining either by experiment in the strict sense, or, if not, by observation of a special nature, whether it fits the facts."

It would seem that economists have failed to attain the true scientific method by not really acting upon these excellent rules. They seem to have accepted certain business traditions, and a few general facts, without very much observation of them, and have thereon based certain hypotheses which they rightly recognise as the first step in the procedure. But they have failed to bring their hypotheses to the test by experiment, or " by observation of a special nature." It is just this last of Professor Gide's three stages that seems to us so very scientific and essential. All scientific observation began by accepting traditions and doubtful facts, and it has been the bringing of the thereon founded hypotheses to the test of special observation or experiment that has taught which were the facts and which the traditions, and how it would be possible to make further experiments. Without the provisional hypotheses no special observation or experiment is possible. But the danger has always been that the hypothesis, simply by virtue of its plausibility, has been taken as the ultimate explanation of the phenomena without having been brought to test by experiment upon real facts and figures.

In the hope of escaping this danger we have attempted to follow strictly the three stages of economic reasoning recommended by Professor Gide. In our early chapters we examined, with as few preconceptions as may be, facts from published records of the nature and extent of the national wealth which forms the subject-matter of economics. Then we considered certain hypotheses, notably that of utility and supply and demand, and, not finding them supported by observations of a special nature, we discarded them for 
the older hypothesis of cost of production as the ultimate cause of value. Having adopted this hypothesis, we have subjected it to test by the examination of values in the form of actual prices, by a method of observation of a special nature. That is, by using the labour unit we reduced them all to their common labour cost and compared their variations with the labour cost of the standard of value. This special method of observing price facts was for the purpose of bringing out the relation between the labour crost of gold and that of commodities. And this special method of observation, which Professor Gide seems to regard as akin to experiment, has, we think, demonstrated that there is a very real connection between labour cost and price, and has gone far to prove the reasonableness of our theory of value. Nevertheless, such special observation must fall far short of actual proof unless the data is much more complete than we have found it to be in records of normal prices, one obvious difficulty being that where data must be supplemented by estimates of the probabilities it is not very easy even with the most just intentions to avoid giving too much weight to those alternatives which best fit the observer's hypothesis. Therefore, ever since the inception of this theory of prices, it has been the desire of its author to bring his hypothesis to test by experiment. If, as we have tried to show by a review of past price variations, the price of a commodity is determined by the labour cost of gold, the labour cost or the production per person in gold being known, and the production per person or labour cost of a commodity being known, it should be possible to experiment in forecasting the market price of that commodity to see whether the theoretical price will be confirmed by what turns out afterwards to be the actual price of the commodity. Our great objection to the supply and demand theory is that it has not, with all its mathematical pretensions, led up to any experiment in foreseeing the price of commodities. Professor Gide in discussing the law of supply and demand remarks rather pathetically :

"But what does all this lead to? Sceptics will perhaps say, -Will all these curves enable us to foresee when coffee or bread will go up in price ?' Alas, no! And yet it is something to be able to put into precise and elegant formula notions which formerly were mere approximations."

As this famous economic law appears to lead to nothing but precise and elegant formulæ, we are contending for the cost of production theory, which we believe does enable us to see when coffee or bread will go up in price. Having founded this hypothesis upon the special observation of the pertinent facts, we propose now to show how it has to some extent been tested by experiment, to do which we give below some examples in forecasting prices.

To forecast prices on a cost basis the first necessity is to know r.m. 
how much of the commodity has been produced per person employed in its production, or in default of the number of persons, the amount produced per acre. As we have explained, this gives the labour cost of the commodity, but to find its money or market price it is further necessary to know the production of gold per person for the year before if possible, as it takes about one year for an alteration in the production of gold to fully affect prices. When the following experiments were first attempted the returns of gold production were not obtainable in time to make the forecast calculations quite certain at date of publication, a difficulty among others that has not yet been quite overcome, and one that may be a very serious hindrance to estimating prices, especially in war time, when such returns get far behind or are not made at all. The fact that to make a forecast these two groups of data must be obtained before the trade conditions they represent have had time to fully act upon prices very much limits the choice of commodities to experiment upon. Even if the gold returns are fairly well up-to-date it is very difficult to get production returns for most commodities. The article that has proved to be the best in this respect is American cotton, the returns being published earlier than those for any other commodity. The returns for jute can be got fairly well in time, and many others could be got if the importance of having the information was recognised. Coal could probably be estimated also, but in its case there are so many different kinds used for various purposes that it is almost impossible to get returns of production for any particular sort that has a quoted market price that could be forecast; the average price of coal for which returns are given in "The Mines and Quarries Report" has no corresponding market price quotation. At the commencement of these experiments an attempt was made to deal with these articles, but owing to the difficulties mentioned it had to be given up, as it was found to be more than one investigator could do to collect the necessary information on which to make a correct estimate for a number of commodities.

The cotton price forecasts results obtained in these experiments are set out in detail below, and although the number of trials is small, they constitute a really remarkable record when it is remembered that all experienced cotton merchants are agreed that it is quite impossible to forecast the price of cotton. The very practical approximations to the actual price that was subsequently realised shows that in cotton, at any rate, there is a very real connection between its price and the labour cost of cotton and gold. These examples of cotton prices forecasts are taken from the cotton circular published by the writer, copies of which can be seen in the library of the Statistical Society, so that there can be no doubt that the actual estimates were made in advance of the market and are 
of the nature of experiments in that the estimated figures could not be prejudiced by knowledge of the ultimate facts.

To appreciate the practical correctness of these forecasts sorne of the difficulties of their actual compilation should be understond. In addition to the difficulty of the belated gold returns it must be remembered that it is essential to know how big the crop is going to be, and that almost before the harvest is completed, if a forecast for the season is to be published in October, for the cotton-picking is not finished till November. Even then, of course, the quantity that the growers have got is not actually known; the only information, therefore, is the various estimates which may or may not be approximately correct. The cotton trade journals publish many estimates by various authorities, but we notice that in the season Ig12-13, which is one for which a forecast is given below, out of the 33 estimates quoted in Cotton for December, 1912, only four were published as early as September. One of these gives the estimated crop as $12 \frac{3}{4}$ million bales, two others give $13 \frac{1}{2}$ millions, and the fourth gives it as $14 \frac{3}{4}$ millions; a difference that would probably have made a halfpenny per pound difference in the price of cotton that year. The other estimates quoted were published at various dates in October, November and December, and came a little nearer alike, but still varied from $13 \frac{1}{4}$ to $14 \frac{3}{4}$ million bales. The actual crop only gradually becomes known, comes into sight, as it is termed, when it is registered by the authorities at the various ports and cotton trade centres where it first comes upon the market.

So before the price can be predicted the crop must be estimated; or at any rate the various trade crop estimates must be judged between for the most probable mean opinion. Therefore, the following price estimates are largely estimates of the size of the crops, and one factor in that estimate is the position of current price, which is likely to be lower than the normal if the growers think the new crop is going to turn out a large one, or above normal if the crop seems to be turning out a short one, so that the variations of market prices current for the old crop may be an indication of the new crop prospects. But again, as we have frequently pointed out, the current prices may be diverted from their normal position by prospects of increase or decrease of area planted for the next season, so that an early estimate of what the area will be is also necessary to appreciate the exact significance of the current price position, and still more necessary as the first evidence of what the ensuing crop will be. For, obviously, the size of the new crop depends a good deal on whether the area is greater or smaller, and if the total crop is unduly large or small it will affect the price through supply. It is one of the chief advantages of the cost theory of price that it makes it obvious that if the average current price is above the 
normal at planting time the area will be increased, and that it will be decreased if average prices are below normal at planting.

So it will be found that the following price forecasts consist very largely of estimates of crop and acreage, which are very important factors in finding the necessary normal price of cotton before the market price can be estimated, and it will be seen that these forecasts involve somewhat complicated calculations and considerations, especially in the more complicated form they take in the later years of these experiments. In the earlier experiments the forecast is not quite so early or so ambitious as in the later ones, and these early ones were the result of many previous attempts to discover some practical theory of the cause of prices and their variations.

\section{FirST EXPERIMENT, I904.}

In the spring of I904 the theory of prices on which this book has been based first became sufficiently developed to make it possible to found an estimate of future prices upon it. That possibility being realised, an attempt was made to indicate the probable price of cotton, although in this case the estimate was not published. At that time cotton was selling at $7 \frac{1}{4} d$. per lb. in Liverpool; the forecast estimate then made showed the average price for the year should be $6 \cdot 47 d$., and, therefore, the existing market price was above normal, and would certainly lead to an increase of acreage, but no attempt was then made to estimate the percentage of the increase. The actual result for the year was an increase of area by 2,823,000 acres and an average price of $6.60 \mathrm{~d}$. The result of this first experiment was so good that its author decided to publish a circular the following year in the hope of interesting the cotton trade in his method.

\section{SECOND EXPERIMENT, I905.}

In March, I905, the first circular was issued, the market price at the end of February being $4 \frac{1}{4} d$. , the forecast of the acreage was stated thus :-

"The present price of cotton being still below the cost of production, it is certain to reduce the acreage under cotton this year and help the planters to hold for higher prices."

The lowest possible average price for the year was estimated at $4 \cdot 06 d$. In May it was found necessary to modify the estimate for the price as the crop returns showed that the total crop would be $I 3 \frac{1}{2}$ million bales instead of I3 million, and in June the final estimate of the acreage was made thus:-

"The Bureau report on the acreage will be issued early in June. We still expect our estimate (April, Circular No. 2), of a certain Io per cent., and probably 15 per cent. reduction in the acreage to be confirmed." 
In July more complete information was obtained from the United States as to the general movement of prices (representing the belated gold returns), and from this information it was possible to estimate that the price should work out at 5.10k., but owing to the very large crop we thought the price would hardly reach that point, so the estimate was still put at $f \cdot 6 r k t$. as the lowest possible. In July the bureau's second acreage estimate was published, showing the area planted to represent a reduction of $1 .+.9$ per cent. instead of their first estimate of II 4 per cent., so that the forecast estimate of a probable 15 per cent. reduction made four months earlier was quite as near as theirs after they had spent four months collecting reports from the cotton belt. The October Circular gave an estimate of the probable crop on the reduced acreage:-

"We still think the most probable crop will be rol millions, although II and I2 millions are suggested in many quarters."

At the end of the year it was shown that the actual price obtained for cotton was $5.09 d$., which was the exact price estimated on a cost basis with the corrected gold supply evidence mentioned above but not adhered to as the supply was thought to be too large. It probably was too large and would have brought the price down if the coming crop had not threatened to be a failure.

In these first years it was attempted to make the forecast estimates of price for the calendar year, and not for the crop year (September to August), as it was thought by including part of two crops in each year's estimate the over- or under-supply from one crop would be virtually corrected by the next, and at that time no better way of estimating the effect of an over-supply on the price had been discovered. Owing, however, to the adoption of this method the failure of the Igo6 crop could not be taken into account, so that no allowance was made for this failure putting the price high at the end of this year. This error made the forecast one halfpenny too low, but it should be noticed that practical buyers in the trade varied in what they actually gave for cotton by more than a penny per pound above the average to a penny below, so that this estimate of the average though too low was still a very. useful approximation. The actual variations of price in the English market were from $6 \cdot 42 d$. to $4 \cdot 07 d$, a variation of $2 \cdot 35 d$.

\section{THIRD EXPERIMENT, I906.}

The estimate for 1906 was calculated as before for the calendar year, and the forecast published in January was $5.90 \%$. as the average price for the year. From this price an improved estimate of the probable size of the crop was made, taking the "into sight " movement of the crop as an indication of the growers' view of how their crops would pay them at the then ruling price, which at the 
end of December was $6 \cdot 40$. That price being above the forecast average, it should induce a large " into sight " movement if the crops were larger than had been expected, whereas if the crops were small the growers would not consider the price would pay them well enough and the "into sight" movement would be slow. The movement does not seem to have been particularly brisk, for the estimate made in February reads :-

"From an examination of the 'into sight' movement Io $\frac{3}{4}$ (million bales) seems to be quite the highest possible; if this is the case higher prices are almost certain."

In April an estimate of the area to be planted was made on the basis that as the price at that time was above the estimated average an increase of area would be made.

"We therefore estimate that the acreage to be planted this year (1906) will be 283 to 29 millions."

This represented an increase of $7 \frac{1}{2}$ per cent. on the 1905 area. In June the bureau estimate was published giving the area as $28,686,000$ acres, so that at this early stage of the experiments the above estimate was a very fair approximation though the final result showed that both estimates were far too low. In the July circular an estimate of the probable fall in price was given.

"We expect the price to gradually fall, and it may reach as low as $5.25 d$. before the end of the year if the crop prospects continue good."

The lowest price touched in August, I906, was 5.29d.

The crop grown in 1905 turned out to be II, I6r,ooo bales, so that the above estimate of $1 \mathrm{O}_{4}^{\frac{3}{4}}$ was rather low.

The actual price for the year was $5.95 d$. per pound; the actual variations in the market were from $6 \cdot 59 d$. to $5 \cdot 29 d$.

\section{Fourth Experiment, I907.}

This experiment turned out very badly, chiefly on account of the very faulty data available, and of an under-estimate of the rise in prices brought about by a great trade boom in the first eight months of this year. The above-mentioned under-estimate of the acreage was confirmed rather than corrected by the bureau report, which estimated the area at $28,686,000$ and it turned out to be $32,049,000$, and the total crop $13,630,000$ bales instead of about 12 to $12 \frac{1}{2}$ as was gencrally expected. In November, I906, a note in the circular shows that this possibility was considered :-

"If, however, both the crop and the acreage are larger than our estimate it will make but little difference to the price except that it will be a little lower early in the year and a little higher after the acreage for 1907 is known."

The estimated price for 1907 was put at $5.75 d$., which was altered 
to $6.40 d$. in June and again altered to $6.70 d$. in September, the actual price being $6 \cdot 38 d$. If the original estimate had been adhered to with more confidence, and the position examined on that basis, it should have been possible to have seen the financial crisis was likely to come. Unfortunately, it was too early in the experiments for their author to be sufficiently certain of the price inovement and to know that the prices were actually so much above the gold basis of value. At this time the information with regard to gold production only made it possible to know that prices were likely to go up as the South African mines were just getting back to full output and reducing the shortage of gold which had put the prices down from 1900 to 1904. Unfortunately, there had been no previous record or experience of the effect produced upon prices by a cheaply-produced but short supply of gold, so no exact calculation could be made of the time required for prices to recover their normal course. To a certain extent the probable movement was seen in February, 1907, when the circular observes :-

" The gold output for the United States is now to hand and shows an increase of nearly $£ 2,000,000$, so that it is probable prices will keep well up to last year and, if anything, a shade higher. We therefore expect the very good state of trade in the States to continue for another year, although, owing to the certainty of advances in wages, there will be a gradual slackening towards the end."

In May the impression that the acreage had been very much under-estimated began to be a factor in estimating; and, seeing the error was $2 \frac{1}{2}$ million acres, it is hardly surprising that it was difficult to make an exact estimate of the price. The difference made by this change of view is shown in the following extract :-

"If $5.85 d$., or a shade higher is the average (price) it means that the price obtained up to this month (May) instead of being well over the average has been only a shade above, so that the acreage being planted this year will not be much larger than last."

The actual increase was only $\mathrm{II}, 000$ acres.

The rest of the year's calculations were quite upset by the rapid run up of prices and the sudden fall in September owing to the financial crisis in America. This under-estimate of the financial position made the estimates for the next season very far from satisfactory. Having failed to understand that the price had gone so much above the real basis of price it was erroneously expected the recovery would be much quicker than it was, whereas actually the amount that the year 1907 was above the normal had to be compensated by 1908 being below. Although the estimate for this year was so very bad, the error of $63 d$. was not so great as the variation in actual prices paid by the trade. which varied from $7 \cdot 57 d$. to $5 \cdot 75^{1}$. 


\section{Fifth Experiment, I908.}

The error in the interpretation of the last year's price movements made this experiment a failure also and the worst one of the whole series. The estimate on a $12,000,000$ bale crop was a price of $6.90 \mathrm{~d}$., and the actual only turned out to be 5.67 for a II,500,000 bale crop. To a certain extent the position began to be appreciated in March, Igo8, but not to the full extent:-

"It is now very evident that prices generally have outrun the improvement in gold supply, and we are feeling the effect of the inflated prices of $1906-7 . "$

In April the usual acreage estimate was made, but owing to the uncertain condition of the market no exact percentage was attempted.

"We expect a decided reduction in acreage and a big upward movement of prices for new crop cotton."

This reduction in area was not made, the acreage planted being increased by I,3I0,000 acres. A similar reverse of the usual order of procedure occurred in wheat acreage just after the Leiter corner. It seems to come about as the result of the growers who have done so well in the previous year being too slow in finding out that prices are going to be too low, so that they plant a larger area than is justified by current prices with the result that they lose all the advantage gained in the good years. This was certainly the case in this instance, the increase of area had a disastrous result, bringing the price down to $4.80 \mathrm{~d}$. in December, 1908, which made our forecast quite out of it.

These two years' experiments were very disappointing to their author, not simply from the fact that the forecast price was so much wrong, but because he had failed to appreciate the logical conclusion of his own theory in not foreseeing that in 1907 prices had gone above the gold basis and that a crisis must be the result of increase of acreage and other enterprise on the basis of current high prices. The chief cause of this failure was the unsatisfactory evidence as to gold per person at that time which left a margin of uncertainty as to the standard of value at that period. The result of the experiments so far had not given any very definite support to the theory of value depending upon cost, as two out of the four published forecasts had turned out badly; although this was not a very promising start it was not quite a failure, and as it was a line of investigation never even tried before, being thought quite impossible, the result was sufficiently good to give hope of better results in the future when the system had been perfected.

The variation between actual price paid for cotton that year was I.9od.; the error in the forecast was $\mathbf{I} \cdot 23 d$. 


\section{Sixth EXPERIMENT, I909.}

The estimate for this year, published in February, was 5.704 . for the year's average price, and this turned out ton low, the actual average being $6.36 d$. The year, however, started with the price at only $5 \cdot 00 d$., and the crop was $13.925,000$ bales, the largest ever grown before, so that the price could hardly have gone so high above the estimate as it did had not weather conditions at the end of the year made the coming crops a failure and sent market prices up. In the March, 1909, circular, after an examination of the " into sight " movement, an idea of the probable acreage change could be given ; and it must be remembered that this is before the sced is in the ground, as the planting is done in March and April. The first estimate of the position was stated thus :-

"These facts do not give any very certain indication as to the size of the present crop, but they do point to the fact that unless there is a very considerable rise in price during March the acreage planted this year will be reduced."

In April the idea of a reduction in area was reiterated.

"We think the continued low price is very unfortunate as it must mean big fluctuations when the reduction in acreage is an actual fact."

"We still think our estimate of $5 \cdot 70 d$. for the year is quite moderate. Seeing the average to date is only 5.12d. prices must be considerably higher during the next nine months."

It did go higher, and so much as to bring the average considerably above the forecast estimate; but as the price was at this part of the year so much below the estimate, it is evident that the final error, though large, did not prevent the forecast being a very useful guide to the general movement of the price. In May, 1909, the acreage reduction was confirmed and the percentage indicated :-

' Miss Giles' estimate of a 3 per cent. reduction in the acreage appears to us to be a very fair estimate, but, if anything, we should be inclined to expect a larger reduction."

This estimate of the position was confirmed, as the bureau indicated a 3.9 per cent. reduction of area.

This was the last forecast made for the calendar year, as a method of estimating the variation from normal price, due to a too large or too small supply, was arrived at partly from experience gained and largely from the use of the published figures showing the cotton used each season, or what has gone off the market, which gives a very fair idea of the quantity required per year. In this year (rg09) it was made very evident that it is almost impossible to estimate the average price for the 12 months' cotton supply, which includes part of two crops, the second portion being part of the new crop, the cost basis of which cannot be estimated in January 
when the old crop forecast is calculated, as at that time the new crop is not planted. In these earlier estimates the intentional increase or decrease in the new crop was supposed to counterbalance over- or under-supply in the old crop cotton, but it was found that this compensation might be much overdone and the average price of the new crop cotton be on quite a different basis from the old. At the end of this particular year the price rose far more than the reduction in acreage justified, due to the fact which could not have been foreseen in January that the weather was so bad that the new crop that was coming in at the end of the year was a failure, and the cost per pound therefore very high. The acreage was only reduced 4 per cent., but the crop was 25 per cent. less, so that the price at the end of the year went up much faster than was expected or likely when the forecast was made. The error in the forecast price was $66 \mathrm{~d}$.; but, as the actual prices paid varied from 8.50 to $4.93 d$., this forecast would have been very useful information both to buyers and sellers of cotton.

\section{Seventh Experiment, Season Igo9-Io.}

With the change of period covered by the estimate so that the forecast price should be for one crop only, an attempt was made to also forecast the movement of the price during the season, and to

EXPERIMENT 7.

Igo9-10.

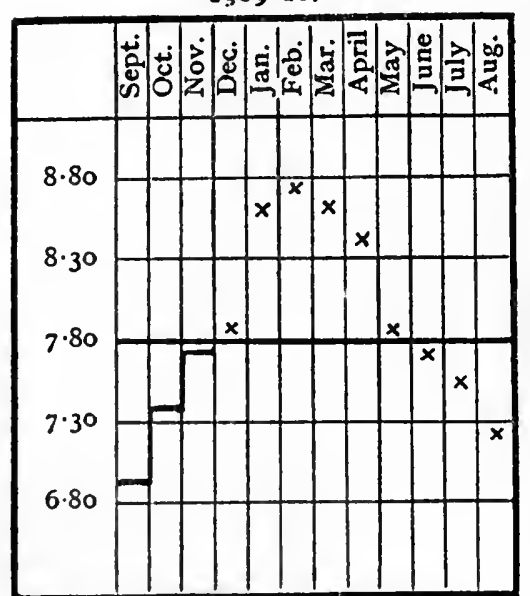

Thick Curve-Average price for season to date.

Thick Line-Estimated average.

Stars-Estimated course of prices for season illustrate this addition to the forecast a diagram was included in the circular.

In January, I9Io, an attempt was made to estimate the crop from the ginning reports, in place of the into-sight movement, of which it is practically only another form. The object of this, as explained before, is to judge whether the crop is coming to market quickly in indication of a good crop, or slowly as a poor one. To know what proportion of the crop is represented by the amount ginned up to date, it is necessary to compare it with some previous season the result of which is known, and it must be one when the market price was in a similar proportion to normal price as the market price is to the normal when the estimate is being undertaken. The season taken in this case as the most similar was I903-4, but the comparison was not altogether a good one, as in that season prices had not been rising so fast as in the 
present one (1909-10). The estimate on this basis made the crop II,000,000 bales, which turned out to be too large, as the actual growth was only ro,389,000 bales. Although this estimated crop taken for calculating the season's price was too large, making the calculated price of the present crop too low, the final estimate came out quite correctly at $7 \cdot 80 d$. This was owing to the rather fortunate fact that the allowance to compensate for the short supply was over estimated, and would have made the final estimate too high if the estimated crop had been quite correct.

At the beginning of rgro the spinners decided on a policy of short time to prevent the price going up as the result of speculation, and in the March circular it was pointed out that there was danger in this policy.

"The short time movement has had the desired effect of making the price steady, and looks like preventing the upward movement to $9 \cdot 00 d$. Whether this result will prove satisfactory is still open to question, as it is certain to react on the acreage to be planted this year."

In May, I9I0, the estimate of the acreage was put thus:-

"Taking the acreage last year as 32 million acres, we expect the area this year, I910, to be about 33 million; that is, slightly less than the area planted in $1908 . "$

The final bureau estimate made the area $33,418,000$ acres, or slightly larger than we expected, still, it is quite certain the short time worked by spinners had prevented the large increase that would have followed if prices had been allowed to go up, as was further confirmed in the following season. This small increase of area is very important to notice, when it is remembered that the short time policy was undertaken because the Manchester cotton spinners thought the ruling price of $8.00 \mathrm{~d}$. was very much too high owing to speculation, and took this step to counteract it. If this price had really been so much above cost the profit must have been so large that all growers would have increased their area to get more of it. The difficulty caused by the short time movement was furthet pointed out in the August, I9ro, circular :-

"The price this season works out at $7 \cdot 55^{d}$. on a cost basis, and with normal competition should have reached $8.00 d$. except for the organised short time of spinners. This means a very considerable gain to the spinners this year, but unless the weather conditions improve and a good crop results, all the gain will be lost next."

A glance at the Cotton Index Diagram (No. 48) will show that the season I909-10 was above the average level of prices, but that Igro-II was still higher instead of the usual reaction taking place; cotton prices were not reduced by the short time movement. In September the circular suggested that time would show " the effort to have been a failure." And seeing it has not been tried again, 
it looks as if this had been found to be the true estimate of the position.

The variation of prices paid for cotton this season were from 8.50 to $6 \cdot 77 d$., which could have been completely avoided if the trade had known the correct forecast was $7 \cdot 80 d$.

\section{Eightu Experiment, Season igio-II.}

The average price for the first three months of this season worked out at $7.90 d$. , and the final forecast estimate of $7 \cdot 40 d$. was published in the beginning of November, I9Io, in the diagram of price movement given below.

This diagram shows a continuous fall from January, I9II, to August,

EXPERIMENT 8A.

1910-11.

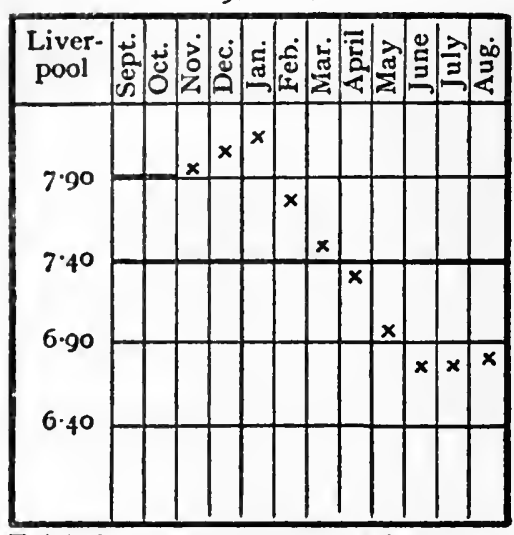

Thick Curve-Average price for season to date.

Thick Line-Estimated average.

Stars-Estimated course of prices for season. whereas the actual movement was a big rise in April, May and June. This rise was the direct result of the holding back policy of the previous season, and should have been foreseen in our estimates if we had experienced a similar case before; as it was our forecast of $7 \cdot 40 d$. was too low owing to this run up which made the actual average $7 \cdot 9 \mathrm{I} d$., the difference of $\cdot 5 \mathrm{I} d$. representing the loss to the spinning trade. The final price in August of only $6.8 \mathrm{od}$. shows how very far the market had miscalculated the real position, as the spinners who bought in these months of high prices must have lost very heavily on their purchases.

In the December, I9ro, circular the fear that this result might be expected was expressed :-

"Taking all these factors into consideration, we are forced to the conclusion that the crop is small and $7 \cdot 40 d$. is quite on the low side for the season's average."

Even at this early date it was possible to see there would be an increase in the area planted :-

". . . the tendency is still for lower prices in the new year when the acreage increase begins to tell."

In the May circular the following notes give a very accurate idea of the real position :-

"The spinners this season are paying very heavily for the attempt to regulate prices by organised short time. Our estimate for April has proved to be much below the actual, the continued buying by spinners having made it possible for the 'bull raid ' to be successful. 
Although the price has been rushed up to the really absurd figure of 8.3rd., we think a very big reaction is certain." " Sev'eral acreage estimates have been made, all showing large increases, but we think they are rather on the low side as the present price will tempt every effort to be made to increase at least ro per cent."

The first estimate of the acreage made by the bureau gave the increase as only 4.8 per cent., but the final estimate made it 9.8 per cent., which shows that the calculation from the price basis is much more correct than the most careful estimates based on the reports of a number of observers, which is the ordinary method.

In June the conviction that there would be a fall was reiterated:-

"The market is certainly very strong at present, which makes it very difficult to forecast a big fall, still we stick to our original idea that the position is very critical and buying at these prices a great mistake."

This was certainly true as shown by the final result indicated in Diagram $8 \mathrm{~B}$, and although the forecast failed in not showing the run up in prices for May, the original estimate and the reiterated assurance that the price was too

EXPERIMENT 8a. $1910-11$.

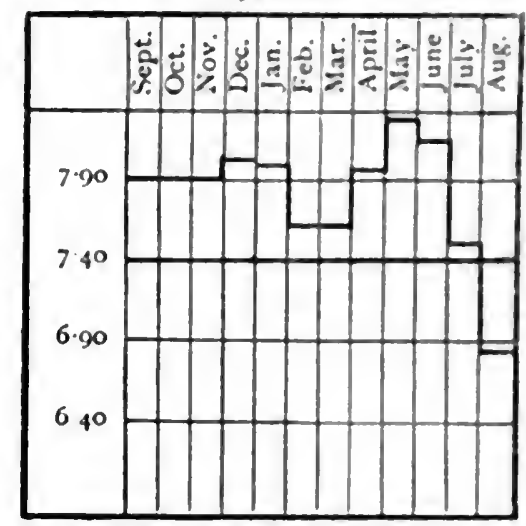

Thick Curve-Average price for season to date.

Thick Line-Estimated average. high was much nearer the facts than the prices were that were paid by the trade, as they varied from $8 \cdot 42 d$. to $6 \cdot 57 d$.

\section{Ninth Experiment, Season igit-i2.}

At the end of October, IgII, the average price for the season was estimated at $5.60 d$. and the following diagram published giving the general movement. This estimate proved to be very near the final result, although it was based on an under-estimate of the crop, which we then thought to be $15,000,000$ bales, but which turned out ultimately to be $16,501,000$ bales; but at the same time the acreage had been under-estimated by the bureau so that the crop to the acre was not so much more as the total crop figure would suggest. Then by this season "linters" had begun to be an important part of the total cotton crop, as they amounted to 556,000 bales, but as this part of the crop is obtained after the seed is sold to the oil mills, although it adds to the quantity of cotton on the market it does not directly affect the growers' normal price like the actual "lint " cotton obtained in the original delinting. As up to this point seed or linters 
had not been definitely taken as a factor in these estimates, the estimate for this season was based on $205 \mathrm{lbs}$. to the acre, and the actual "lint" was $2 x 7$ lbs., so that the estimated crop that affects the grower's normal price was not far out, and with these two modifying circumstances the error in estimation of the crop did not very greatly affect the forecast price.

In February, I9I2, it began to be seen that the estimate of $5 \cdot 60 d$. would be too low :-

"In gauging the probable movement of prices for this season it must always be borne in mind that the real price of cotton this season on a purely cost basis is at least $6 \cdot 0 d$., and our estimate of $5.60 d$. is based on the probable effect of the large over-supply."

EXPERIMENT 9A.

I9I I-I 2.

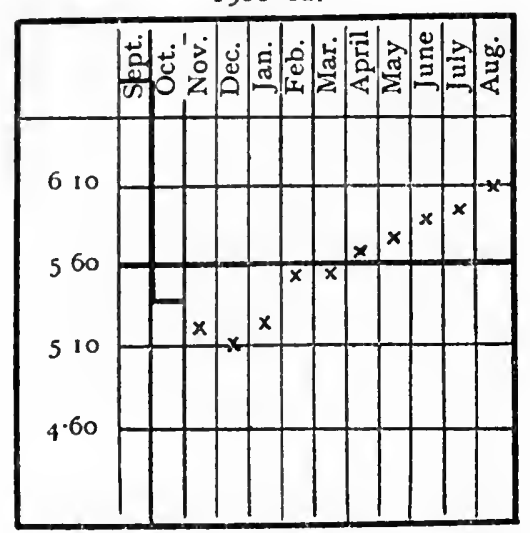

Thick Curve-Average price for season to date.

Thick Line-Estimated average.

Stars-Estimated course of prices for season.

In April the acreage reduction was estimated at 3 per cent., and in May this was thought to be on the low side :-

"In estimating the acreage reduction at 3 per cent. last month we have taken a very moderate view of the position, so it is more likely to be a larger rather than smaller reduction, and if so the large surplus this season will have little or no effect on prices."

The first bureau estimate put the reduction at 7 per cent. and altered it in the final estimate to 5.2 per cent., so the forecast estimate of more than 3 per cent., although too low, was quite as near as the first bureau estimate and at least a month earlier.

The error in this estimate was caused by the difficulty of getting an exact idea of the movement of the standard of general prices, owing to the late publication of the gold and coal returns; these returns might be made much earlier if they were thought to be of any immediate use, and it is to be regretted that their use is not recognised, for the lateness of their publication adds very greatly to the difficulty of an early forecast.

In August, after the first report was issued by the bureau showing 7 per cent. reduction of area, the comment on it was :-

"On the other hand the bureau is apt to over-estimate the reduction, but taking into consideration the very rapid advance in prices this month it is highly probable the reduction is over 5 per cent."

The actual average price obtained for the crop was $5.9 \mathrm{I} d$. or $3 \mathrm{I} d$. more than the forecast, but seeing the variation in prices paid by 
the trade was nearly $3 d$. -from $7 \cdot 53 d$. to $4.92 d$ - - the forecast was comparatively correct; the price movement during the season was fairly correctly forecasted, as may be seen by comparing the Diagram 9 B with 9A, which was published in November, rgrr.

When all these continual variations of the crop, the area and the productivity of gold mines are remembered, it seems remarkable that the price can be estimated at all, and the fact that such grood approximations to the future price can be calculated in spite of these difficulties suggests that the method of these estimates must be a very sound one. It should be recognised, too, that the whole of the necessary data for such estimates might be obtained correctly for

EXPERIMENT 9B.

$1911-12$.

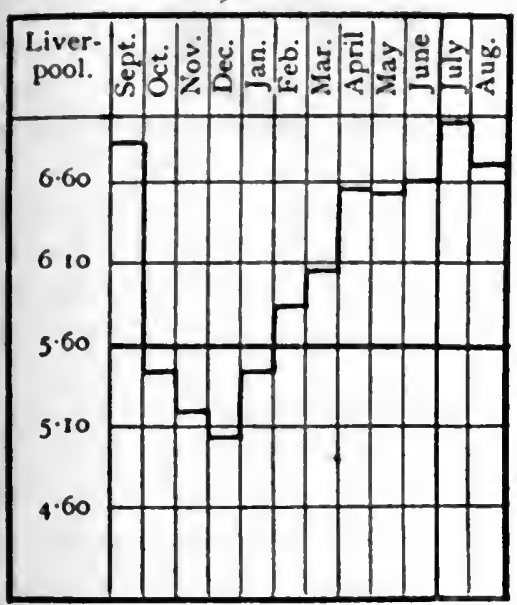

Thick Curve-Average price for season to date.

Thick Linc-Estimated average.
ExprRiment IOA.

$1912-13$

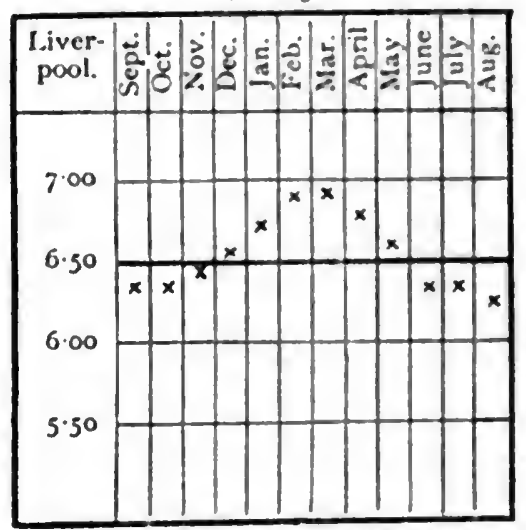

Thick Curve-Average price for season to date.

Thick Line-Estimated average

Stars-Estimated course of prices for scason.

every detail, in which case it seems probable that the price could be forecast to a certainty, and within a very small fraction of error.

\section{Tenth Experiment, Season rgiz-I3.}

This season the estimate issued in September, I912, indicating an average price of $6.50 \mathrm{~d}$. per pound, although just $\cdot 28 \%$. too low, was so very nearly correct that no correction of it was necessary during the year's forecasts. The price movement month by month for the season also was forecast very fairly correctly for so long in advance. The total crop was also estimated from the condition report :-

"If the estimate of the condition this year can be taken as any" indication of the final yield, it indicates a crop of $\mathrm{rg}_{9} \mathrm{lbs}$. to the acre. The total crop on the estimated acreage, if this yield is correct, will be about $13 \frac{1}{2}$ million bales." 
The actual crop turned out to be I 4 million bales, but the acreage also turned out to be 700,000 acres more than the first estimate, making a larger total crop without much altering the crop per acre.

The following example of a forecast calculation is the one for this season, and is interesting as showing how the actual calculated figure sometimes comes even nearer to the actual price realised than the figure its author ventured to predict. To compare the ginning report with that of a previous season in which the conditions were similar, it is taken that as the ginning report of 1905 is to the ginning report of I9I2, so is the total crop of I905-6 to the total crop of $\mathrm{rgI}_{2}-\mathrm{r} 3$, which is the present season to be estimated.

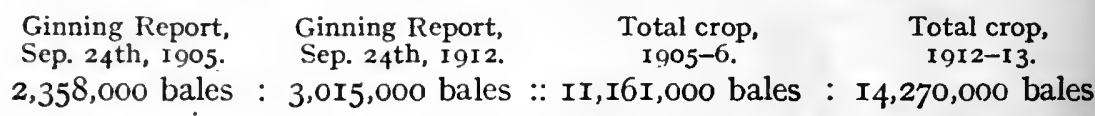
This $14,270,000$ bales $=209 \mathrm{lbs}$. to the acre, and the price last season (I9II-I2) was $5.9 \mathrm{I} d$., giving at a yield of $22 \mathrm{I}$ lbs. a return of $\mathrm{I}, 306 d$. per acre, so that the smaller yield of $209 \mathrm{lbs}$. to the acre will have to realise $6 \cdot 25 d$. per pound to be as good. Then it must be taken into account that last season the acreage was reduced (see Index 48), which means the price $(5.9 I d$.$) then obtained was considered unsatisfactory, and$ the reduction was made to make the price proportionately higher this season. So that an addition must be made to $6 \cdot 25 d$. as the advance to be obtained from that reduction, and a precedent is required to show how much must be added to make the difference between a paying and non-paying season. The season 1905-6 was a paying one, and the previous season I904-5 was not, as shown by the reduction in the area that year. The difference between the paying crop and the non-paying, as seen by the difference between the normal prices for the two seasons (shown on Index 48), was $\$ 3 \cdot 3 \mathrm{I}$ or $165 d$. ; but this additional price led to a greater increase by 300,000 more acres than the decrease in $1904-5$, so it indicates that it made the price a little above the average cost. Therefore, it was in this case estimated that if about I2od. were added to the last season's return it would make it a paying price, so for this season that we are estimating (rgI2-I3), we add this amount to the $\mathrm{r}, 306 d$. making the required paying price $1,426 d$. to the acre; and in that case our estimated crop of $209 \mathrm{lbs}$. to the acre, would have to realise $6 \cdot 82 d$. per pound to come to that amount. So it was found by the actual calculation that $6.82 d$. was the average price for the season.

If the acreage estimated by bureau had been correct, that is, rather larger than it was, its use in the above calculation would have resulted in the forecast figures for the crop per acre and the average price, as well as the total crop, being almost exactly the same as the actual result turned out to be. As it was, the actual figures were: Crop, 14,039,000 bales; crop per acre, $202 \mathrm{lbs}$; and the price, $6 \cdot 78 d$. 
In March, 1913, an estimate of the area to be planted was made :-

"These figures clearly point to an increase in acreage this year. sufficient to bring the area planted equal to 191\%, and possibly larger. We consider that an increase in acreage of 7 per cent. or more will put the danger of a squeeze out of the question. This estimate of the acreage is based on exact definite data, and is therefore much more likely to be correct than a collection of mere guesses from any number of correspondents in the actual cotton growing area."

This was rather a bold statement, and it should be remembered that the estimate of 7 per cent. increase was made four months before the bureau estimate is published and without any direct information from the cotton growing district, whereas the bureau has a host of correspondents all over the cotton belt whose work consists in trying to make an estimate of the actual area in their particular district. The only data for our estimate is the price in relation to the crop, and the result of this method compared with the attempts of the bureau is very strong evidence of the soundness of the theory on which our calculations are based. The first bureau estimate gave the increase of area as only $2 \frac{1}{2}$ per cent., this was later altered to $3 \frac{1}{2}$ per cent., and the final estimate published 16 months later made it 7.7 per cent. increase, and the total acreage

EXPBRSMENT 108. $1912-13$.

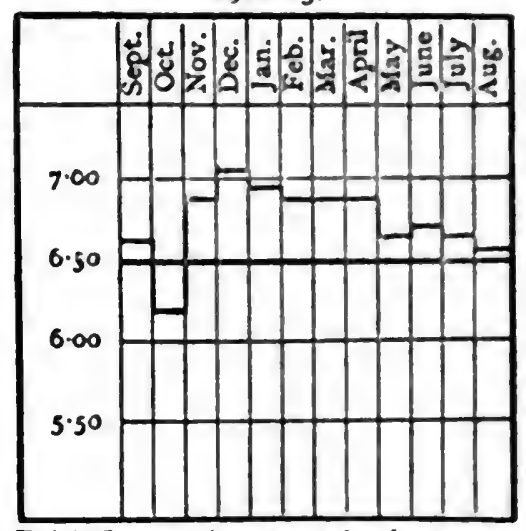

Thick Curve-Average price for season to date.

Thick Line-Estimated average. 37,458 ,000 acres, against $36,68 \mathrm{I}, 000$ acres in $19 \mathrm{Ir}$, which figures show that our estimate from the price basis was for all practical purposes quite correct and months beforehand.

The total result of this season's estimates is probably one of the best made, as the area, crop and price were correctly forecast. The price movement during the season (estimated stars $10 \mathrm{~A}$, and actual zigzag line $\mathrm{IOB}$ ) is given in the above diagrams.

\section{Eleventh Experiment, I9I3-I4.}

The actual price movement this season made the forecast seem a very poor one after the good one last season. The chief cause of error was a miscalculation of the probable movement of the general price basis. Seeing there had been a considerable falling off in the production of gold it was thought the trade boom of the last few years was coming to an end, whereas it carried on to the middle of s.w. 
$\mathrm{I}_{\mathrm{I}} \mathrm{I}_{4}$ and then the war upset the price position so that it will never be known whether this expected depression would have started. It should be remembered that at the best the production returns for gold are very poor, for reasons that we have mentioned in the chapter on gold, and they have to be supplemented by evidence from coal and other productions. So that it is by no means easy to know exactly how soon the wave of falling prices will attain its full effect, and the high prices may carry on for a time especially for a commodity of American origin where the basis of price is somewhat independent of the gold supply for which we have full production returns.

The estimate published in October, I9I3, was put at $7 \cdot 00 d$. for the season's average price, based on a crop of $I_{4}$ million bales, and

EXPERIMENT IIA.

I9I3-I 4 .

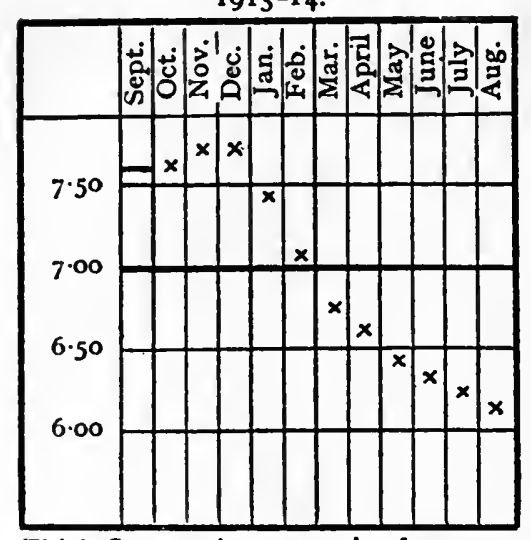

Thick Curve-Average price for season to date.

Thick Line-Estimated average.

Stars-Estimated course of prices for season.

difficult to arrive at any very season."

The trade position was indicated thus:-

"We expect the present high prices will check business, and seeing the great boom in trade has certainly reached the top, this check to business will be felt more keenly as the season advances and bring about the rapid fall in I9I4 shown on the diagram."

In the early part of the season the price fell more quickly than we expected, so that in January, I9I4, the average price for the month came down to $7 \cdot 09 d$., or nearly to the average for the season. At this time the information coming through showed that the crop would be considerably larger than I4 million bales; certainly the acreage figure was also increased, but it still left the crop to the acre a little more than the basis of our original estimate. Owing to these facts the price falling gave us the impression that the return to the 
acre was better than expected and led to our over-estimating the probable increase in the area planted. To some extent this error was foreseen in February, $19 \mathrm{I}_{4}$ :-

"The average price for the season to date is a little lower than we expected, so the question of acreage to be planted this year is more difficult to decide. The farther fall in price indicated in the diagram to start in March was based on the assumption that the acreage would be increased, but the temptation to make this increase is not quite so great now the price obtained is lower."

In March the area was estimated :-

"We expect an increase of at least 3 per cent., and probably 4 per cent."

In May, the price began to rise rapidly, chiefly owing to the low condition reports and very cold weather in Texas. In July, the acreage estimates came through showing a slight reduction instead of an increase of 4 per cent. It is probable this tendency to plant a small area accounted for the run up in price, especially in conjunction with the low condition reports. The final report issued in 1915 showed the area under cotton was still the same as in I9r3, so that our estimate of area for this season was wrong, although not any worse than many of the bureau estimates.

The rush up of price in June proved to be a miscalculation on

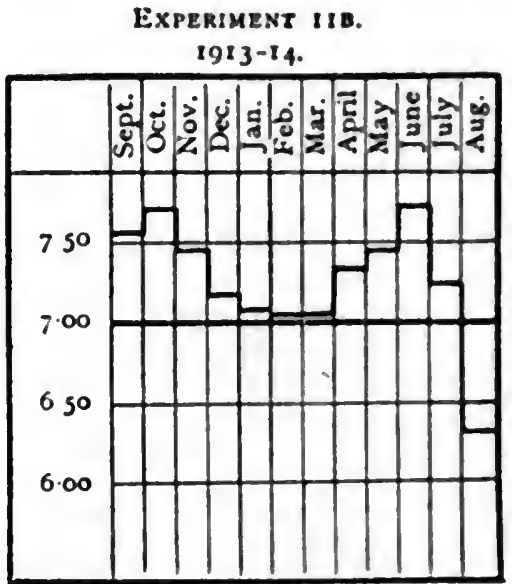

Thick Curve-Average price for season to date.

Thick Line-Estimated average. the part of cotton buyers as it fell again very rapidly in July to $7 \cdot 13 d$. before the question of war became the important factor. We can now never know what the August figure would have been in normal times, but it is certain it would have been low as the crop turned out to be a record one, and all the time the condition reports continued to be very low, showing them to be a very poor guide.

The final result was very similar to that of the season I9IO-II, when the price was run up near the end of the season, only to fall back to the lowest point of the year when the new crop came forward. These rapid changes caused by sudden bursts of speculation have always failed to realise the speculator's hopes when the real price movement is in the opposite direction. No doubt the misleading condition reports helped to bring about this miscalculation by the trade which is clearly indicated in Diagram IIB, and the curve of stars on Diagram IIA, indicates that the forecast would have been 
nearer a reasonable course of prices. Although our forecast average price was $30 \mathrm{~d}$. too low, the actual price paid by the trade went $\cdot 66 d$. too high, the variations being from $7 \cdot 96 d$. to $6 \cdot 20 d$.

\section{Twelfth Experiment, Season I9I4-I5.}

The unusual developments created by the war made it impossible to carry on the experiments on the same lines as the previous ones, but it was still possible to indicate within rather wide limits the gencral course of prices. Owing to these difficulties the first definite estimate could only be made at the end of November, I9r4, instead of September. As most of the markets were either closed or controlled, very little data could be obtained. The monthly estimates

EXPERIMENT 12A. $19 I_{4}-r_{5}$.

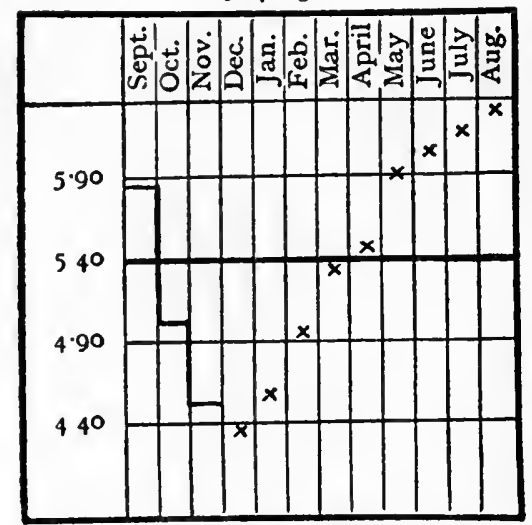

Thick Curve-Average price for season to date.

Thick Line-Estimated average.

Stars-Estimated course of prices for season. were, however, kept up as far as the data would admit, and the following extract is interesting, as it illustrates how even under war conditions the cotton harvest indicated by the ginning reports, taken in conjunction with the current price, gives the exact size of the crop grown.

"Our method of calculating the size of the crop from ginning reports is to compare the figures with some season when the price movement is similar, as unless the price is taken into consideration the estimate is certain to be wrong. The season IgII-I2 was almost identical with the present one, and

a reference to our circular of December, I9II, will show we then estimated the crop to be at least $\mathrm{I}_{5}, 800,000$ bales, and that the acreage must have been much larger than the bureau estimated. The final result showed both these estimates to be practically correct. The crop turned out to be $16 \frac{1}{2}$ million bales, and the acreage figures were corrected by $I_{\frac{1}{2}}$ million acres. We therefore think it is probably fairly safe to estimate this season's (I9I4-I5) crop as the ginning figures show :-

$$
\text { Ginned. I9I4 IgII Crops. }
$$

As II,300,000: II,624,000: : I6,500,000: I7,000,000 bales.

This estimate turned out to be exactly correct, as the actual crop was $17,090,000$ bales.

The average price for the season was estimated at $5 \cdot 40 d$., and a steady rise in price for the remainder of the season :- 
From the beginning of 1915 the reduction of area was estimated at 20 per cent., which turned out to be rather too high, as the final result was only a reduction of $14 \cdot 2$ per cent.; but as will be shown by the final price movement for the season the actual reduction was not enough to keep the price up at the end, which means the growers had under-estimated the position. If the reduction had been as much as we estimated it should be the growers would have got a better price, and the average would have come up to our esti. mate.

The effect of war on prices was indicated by this extract :-

"Since writing the circular for March, we have made a very careful study of the price movement between 1870 and 1873 to sec what effect the (Franco-German) War had on prices. We find a very considerable rise directly traceable to the war, and the rise continued for quite two years after the war ended ... so any idea of lower prices for some time is quite out of the question."

In June and July the price instead of going up fell considerably, probably owing to the acreage being reduced 15 per cent. only, which was not enough to keep prices up; the error of this policy was pointed out in July:-

EXPERTMENT 123.

19145 .

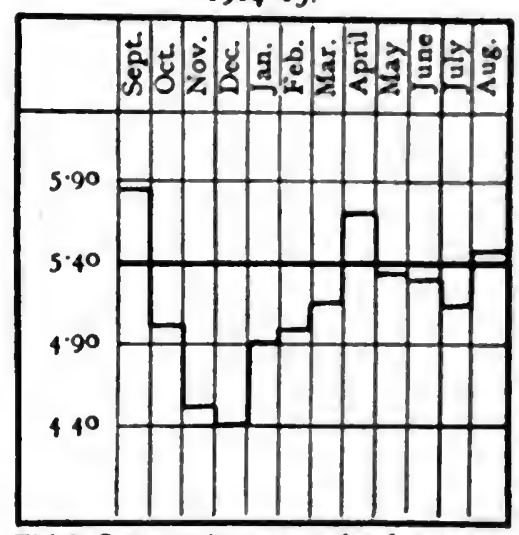

Thick Curve-Average price for season to date.

Thick Line-Estimated average. those growers who are selling at to-day's prices will wish they had held on, and all spinners who do not buy as far ahead as possible will make a great mistake . . . there must be a reaction from the present price as it is really far too low."

In the August circular higher prices were again predicted, although in July they had kept very low :-

"The growers are selling their cotton at a sacrifice which is quite unnecessary, but this sort of thing cannot go on indefinitely, and when the reaction does start it is likely to go just as much the other way, with cotton absurdly dear."

The final result given below shows the inevitable rise of price commenced in August and that the average for the season was $5 \cdot 17 d$. against our estimate of $5 \% 40 d$. For war conditions this is a very good approximation, as there was hardly any previous record on which to base calculations of war price deviation from the normal : actual prices varied from $5 \cdot 81 d$. to $4 \cdot 25 d$. 


\section{Thirteenth Experiment, Season igi5-I6.}

In September, an estimate of the size of the crop was made from the condition reports :-

"The condition report just issued gives the average in the cotton belt as 69.2 per cent. ; this may mean either $200 \mathrm{lbs}$. or only I $80 \mathrm{lbs}$. to the acre as it is compared with the year I9I2 or I9Io. Up to the present we think the latter figure the more likely, which will mean a crop of about II,800,000 bales."

The actual crop turned out to be II, 949,000 bales on a slightly larger area, making the above estimate almost exact. In October, I9I5, the size of the crop was re-calculated by the ginning report

ExPERIUENT 13A.

r915-16.

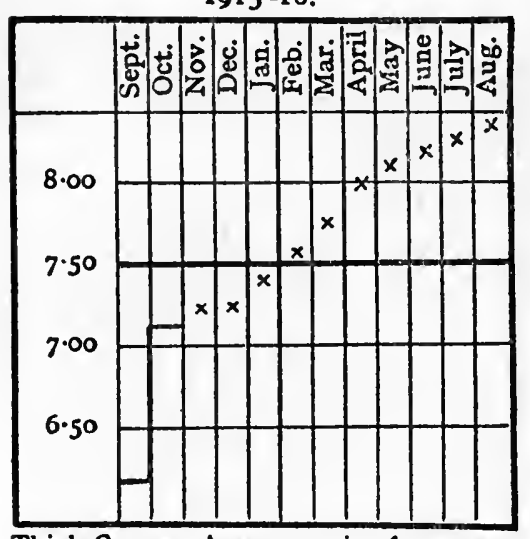

Thick Curve-Average price for season to date.

Thick Line-Estimated average.

Stars-Estimated course of prices for season. and worked out at much the same figure. An estimate of the price could only be indicated approximately at this time :-

"... it is quite possible to calculate the average price at $7 \cdot 60 d$. on the basis of the season before the war."

In November, the first estimate was made at $7.50 \mathrm{~d}$.

This estimate, although it looked so very high at the time, turned out to be rather on the low side, as the actual price was $7 \cdot 78 d$., but it must be considered to be a very successful estimate for such difficult times.

Calculating from the later ginning reports the crop looked like being smaller than the estimate made at the beginning of the season. This turned out to be a mistake, the low ginning figures being the result of a holding back by the growers, which was more pronounced than in the previous season when the crop was so much larger. In December it was pointed out that the estimate of average price was more likely to be on the low side rather than the high :-

"What with high freights and increased costs owing to war conditions it must be remembered that cotton even at $7 \cdot 50 d$. is not at all a high price, so that any deviation from our estimate is far more likely to be on the high side than the other."

This season several new factors began to be felt, the freight charges which up to now had been so nearly regular began to rise so much that the difference between New York and Liverpool widened very rapidly. Then, owing to food problems, the cotton seed price ran up very much, from an average of $\$ 18 \cdot 00$ to $\$ 33 \cdot 60$ per ton, making 
the return to the acre very different from the growers' point of view. Linters or cotton reclaimed from the seed by the oil millers also made a much larger addition to the total crop, this item alone accounting for $\$ 90,000$ bales. These factors made it necessary to revise the basis of calculation, so from this time the price had in be taken from the New York prices and the extra for freight added to get the Liverpool price.

Calculating from the New York price, which at the end of January was below the pre-war level, we estimated a small reduction in the acreage, but the rapid rise in price of seed made the situation rather better than we expected. The extra obtained for seed did not quite bring the price up to the old basis, but brought it sufficiently near to cause part of the land that had gone out of cotton growing the year before to come back into cultivation; so instead of a small reduction an increase of 12 per cent. was made to area. In the light of later events this increase has been shown to have been a mistake from the growers' point of view as the price would have been much higher, and the reduction in area in I9I7 unnecessary.

In April, 1916, the question of the increase in the quantity of linters began to show:-

"Since the issue of the (March) report we have attempted to get some satis-

Experiment 138.

1915-16.

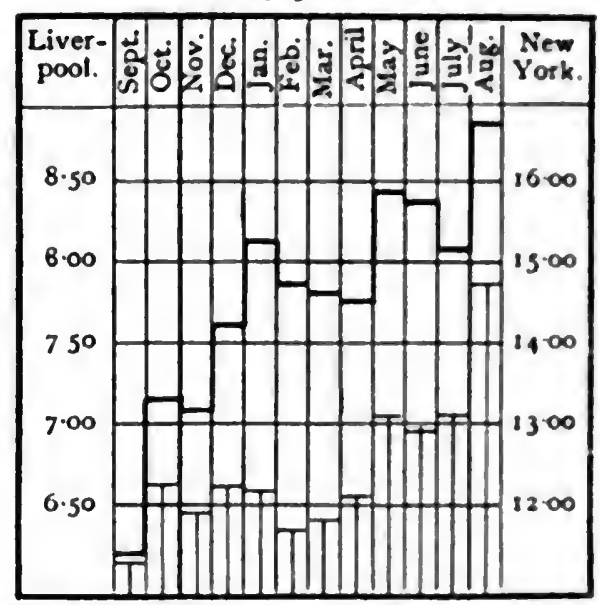

Thick Curve-Average price for season to date.

Thick Line -Fstimated average.

Liverpool

T Curve-Average price for season to date. New York.

factory reason for the great increase in linters, the total being 123,000 bales more than last season, while the total (cotton) crop is about one-third less. If linters this season had been the same percentage as last crop the total production (of cotton) would be very little more than the II $\frac{1}{2}$ million that we expected."

The reason for this increase was found to be the great demand for cotton seed oil, which caused a much larger proportion of the seed to be treated in the oil crushing mills instead of going as manure, with the result that more cotton was reclaimed from this seed by the millers. Under these circumstances it may be claimed that our estimate of the actual growth of lint was correct although the total crop turned out half a million bales larger.

In February and March a slight fall in price took place, but it 
was pointed out that this was only temporary and a further rise would take place.

In May it began to be evident that the estimate of the area would be too low, but we still expected the price to be maintained as other commodities, such as wheat and maize, were so much above the old basis and cotton still below, and in this month the price did take another big jump up to above the estimate in the original forecast chart. The acreage report published in July of a I2 per cent. increase failed to bring the price down in August, as the cotton of the new crop turned out to be much poorer than the early condition reports indicated, the condition report issued on September Ist being only $6 \mathrm{r} \cdot 2$ per cent., against about 80 per cent. in the previous ones. The final result shows the estimate for the season's price to have been very near the actual, but the comparatively low price in New York makes it difficult to understand what the inducement to increase the area was.

The forecast was only $28 d$. out, while actual prices paid varied by $4 \cdot 06 d$. from $5 \cdot 78 d$. to $9 \cdot 84 d$.

\section{Fourteenth Experiment, Season igi6-i7.}

The estimate for this season owing to the increase in area was only put at I0.50d., but in December, I9I6, it was seen that the price would probably be very much higher :-

" This year the ordinary price calculated gives a very poor idea of the actual highest point that may be reached as the extra for war conditions is so uncertain and irregular. The influence of the war will probably be between 30 and 50 per cent. ; if the former, the average price will be II.50d., and if the latter, $13.00 d$. for the season ... At the beginning of the season it was very doubtful as to whether cotton would reach a sufficiently strong position to make war prices, owing to the estimated increase in area planted and the large carry-over.'

The January circular had to register a very big drop in price, but the final bigger rise was still expected :-

"The rapid rise in November put the market in such an unsettled state that a "bear raid " had every chance of appearing to be successful, although it is probable the high prices were really justified by the actual position."

In March, although there had been a most sensational fall in price during February, it was possible to foresee that the highest price would be in August :-

"This low price just before the planting time will be almost certain to prevent any decided increase in acreage, so instead of a fall in price at the end of the season, we shall get the highest price in August." 
In April the acreage was estimated :-

"The chief reason for this high price will be the small acreage planted. Although the price has risen a good deal it is still too low to make for any decided increase, so we have fixed on $35,000,000$ acres as the probable area to be planted, the same as we estimated last month."

This turned out to be correct, as the bureau put the area at $34,600,000$ acres, and our estimate was again confirmed in June. The final result shown in the diagram was an average price of $13.22 d$., which was very much higher than our estimate, but as indicated by the quotations given above it was foreseen that this original estimate must be modified as early as February, when the price was absurdly low. The variation of prices paid that season was from $9 \cdot 25 d$. to $20 \cdot 15 d$., a difference of 10.9od.

In judging of the value of these experiments as evidence of the cost of production basis of prices, it should be remembered that it has always been held to be quite impossible to really estimate beforehand what market prices are going to be, so that any practical approximation to an early forecast is an advance both in economic and commercial practice, and should therefore claim the attentive consideration of any one really interested

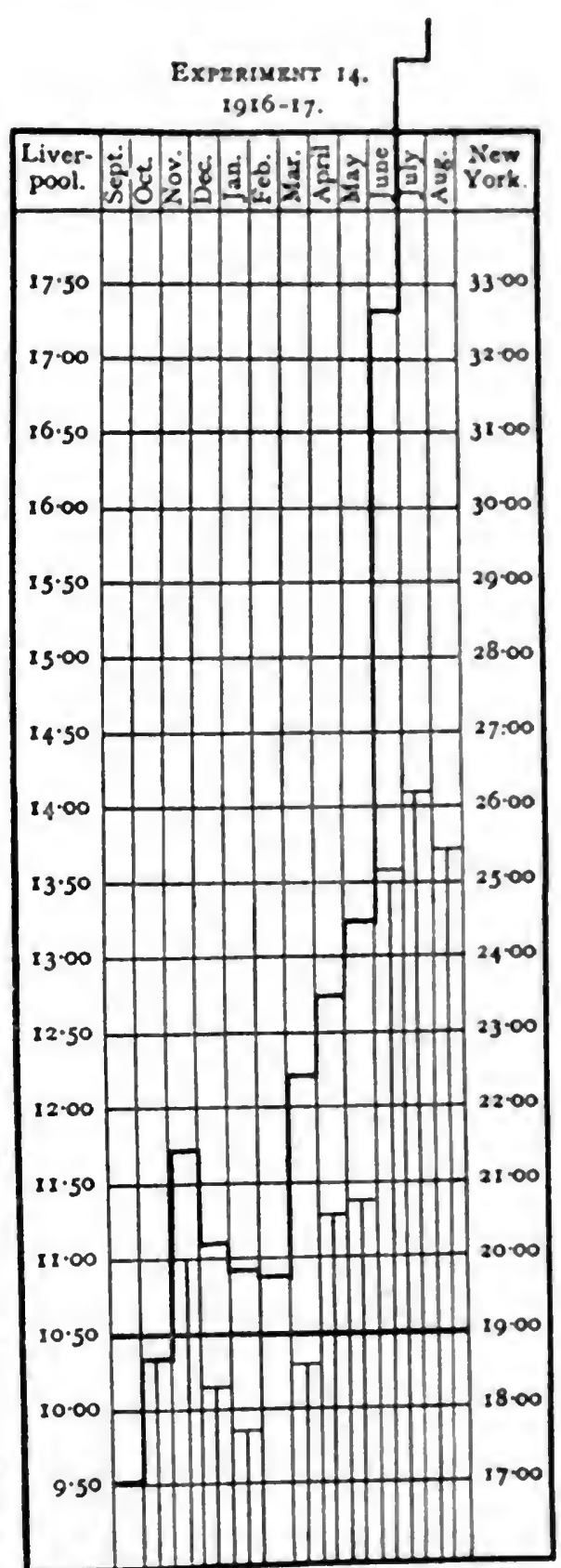

Thick Curve-Average price for
season to date. Thick Line-Estimated average. T Curve-Average price for soavan to date, New York. 
to know the truth about economic theory. Before forming a conclusion as to the value of their evidence there are one or two points about these experiments that should be clearly understood. In the first place, as this method of forming a forecast is new to commerce, there is no data provided by trade or other statistical organisations that is specially suitable for the making of these calculations, and the ordinary trade returns on which they had to be based were often very inadequate. Therefore a critical examination of the results should be undertaken from the point of view that most of them are wonderfully correct, rather than that of magnifying the fact that in a few of them errors were made. It may no doubt be argued that if the experiments are based on a sound economic principle they should give the true result every time, and that, therefore, the failures are the real test of the law. But, though this may be true of an exact experiment, it has not the same force when the data or materials for the experiment are admittedly defective, in which case the failures must be examined in the light of the successful results and the cause of error thoroughly ascertained.

It is important also to notice the dates at which these forecast estimates were made, relatively to the events predicted, as it may reasonably be argued that the forecasts were biased by, and probably unconsciously based upon, the ordinary cotton trade rumours and predictions, and that the series of correct approximations made were simply a run of fortunate guesses such as sometimes does occur in such prognostications. But if it is appreciated that most of these estimates were made months before the ordinary trade information was available, it must be obvious that the estimates could not have been affected by this ordinary information, and must have been made solely upon the data mentioned in each experiment. The virtue of these experiments lies in the fact that they are calculations based upon the few simple known facts about the previous acreage, current cotton prices, and the level of general prices as determined by the production of gold, and were not influenced by any form of commercial opinion. As a matter of fact, at the time these forecasts were being made the trade was taking just the opposite view to that held by the writer of the circular.

Another point that may not be quite appreciated by those who are not practically interested in price fluctuations is that it is the average price for the season that it is important to know in advance. As in the above forecast charts an attempt is made to indicate the varying prices during the season, it may perhaps be supposed that these variations from month to month, or day to day, are the important thing to know, but while these varying prices are very useful to know they are after all only erroneous prices due to the trade's want of knowledge of what the true price should be, and if all buyers and sellers knew what was the correct mean price no one 
would buy at more or sell at less than that mean. It is very commonly supposed by the trade that the average price is not what they want to know, as it is quite certain that the price will not be or remain at that level when they want to buy and sell. But a little thought must convince any one that as the average price is really what a given crop sells for, any one who buys for more or sells for

TABLE 54-RESULTS OF EXPERIMENTS.

\begin{tabular}{|c|c|c|c|c|c|c|}
\hline & & $\begin{array}{r}\text { Pri } \\
\text { Estimate. }\end{array}$ & Actual. & $\begin{array}{l}\text { Acre } \\
\text { Estimate. }\end{array}$ & eaze. Aclust. & Memurki. \\
\hline Exp. I & 1904 & $6 \cdot 47$ & $6 \cdot 60$ & Inc. & Inc. & \\
\hline Exp. 2 & 1905 & $5 \cdot 10$ & 5.09 & $\begin{array}{l}\text { Dec., } \\
15 \text { per cent. }\end{array}$ & $\begin{array}{c}\text { Dec., } \\
\text { 1.9 per cent }\end{array}$ & $\begin{array}{l}\text { Hureau tst. } 11 .+ \text { per } \\
\text { cent. }\end{array}$ \\
\hline ExP. 3 & 1906 & 5.90 & 5.95 & $\begin{array}{l}\text { Inc.. } \\
7 \frac{1}{2} \text { per cent. }\end{array}$ & $\begin{array}{l}\text { Inc., } \\
20 \text { per cent. }\end{array}$ & $\begin{array}{l}\text { Bureau ist, il per } \\
\text { cent. }\end{array}$ \\
\hline ExP. 4 & 1907 & $\left\{\begin{array}{l}5 \cdot 75 \\
6 \cdot 40 \\
6 \cdot 70\end{array}\right.$ & $6 \cdot 3^{8}$ & No change & No change & $\begin{array}{l}\text { Bureau estimate of } \\
\text { area } 29 \text { millions, } \\
\text { actual } 32 \text { millions. }\end{array}$ \\
\hline ExP. 5 & 1908 & $6 \cdot 90$ & $5 \cdot 67$ & Dec. & Inc. & \\
\hline ExP. 6 & 1909 & $\begin{array}{r}5.70 \\
5 \cdot 00 \\
\text { lowest }\end{array}$ & $6 \cdot 36$ & $\begin{array}{l}\text { Inc., } \\
3 \text { per cent. }\end{array}$ & $\begin{array}{l}\text { Inc.. } \\
\text { 39 per cent. }\end{array}$ & \\
\hline ExP. 7 & $1909-10$ & $7 \cdot 80$ & $7 \cdot 85$ & Inc. & Inc. & Short time. \\
\hline ExP. 8 & $1910-11$ & $7 \cdot 40$ & $7 \cdot 91$ & $\begin{array}{l}\text { Inc., } \\
\text { so per cent. }\end{array}$ & $\begin{array}{l}\text { Inc.. } \\
9.8 \text { per cent. }\end{array}$ & $\begin{array}{l}\text { Bureas ist, } 4 \cdot 8 \text { per } \\
\text { cent. }\end{array}$ \\
\hline ExP. 9 & $1911-12$ & 5.60 & 5.91 & $\begin{array}{l}\text { Dec.e } \\
3 \text { per cent. }\end{array}$ & $\begin{array}{l}\text { Dec. } \\
5.2 \text { per cent. }\end{array}$ & $\begin{array}{l}\text { Bureau sst. } 7 \text { per } \\
\text { cent. }\end{array}$ \\
\hline ExP. 10 & $1912-13$ & $6 \cdot 50$ & $6 \cdot 78$ & $\begin{array}{c}\text { Inc., } \\
7 \text { per cent. }\end{array}$ & $\begin{array}{l}\text { Inc., } \\
7.7 \text { per cent. }\end{array}$ & $\begin{array}{l}\text { Bureau ist, } 21 \text { per } \\
\text { cent. }\end{array}$ \\
\hline ExP. II & $1913^{-14}$ & $7 \cdot 00$ & $7 \cdot 30$ & $\begin{array}{l}\text { Inc. } \\
3 \text { per cent. }\end{array}$ & & \\
\hline ExP. 12 & $1914-15$ & $\begin{array}{r}5 \cdot 40 \\
4 \cdot 40 \\
\text { lowest }\end{array}$ & $5 \cdot 17$ & $\begin{array}{l}\text { Dec., } \\
20 \text { per cent. }\end{array}$ & $\begin{array}{l}\text { Dec. } \\
\text { is per cent. }\end{array}$ & $\begin{array}{l}\text { Bureall Ist. so per } \\
\text { cent. Difference in } \\
\text { area made estimate } \\
\text { too high. }\end{array}$ \\
\hline Exp. 13 & $1915-16$ & $\begin{array}{r}7 \cdot 50 \\
5 \cdot 60 \\
\text { lowest }\end{array}$ & $7 \cdot 78$ & No change & $\begin{array}{c}\text { Inc., } \\
12 \text { per cent. }\end{array}$ & \\
\hline ExP. 14 & $1916-17$ & 10.50 & $13 \cdot 22$ & Dec. & Dec. & \\
\hline
\end{tabular}

less than that price is a loser by doing so, and if dealers knew for certain what that price was they would not buy and sell at any other. But even in the present state of commercial doubt as to the true price it is most important to know the average price, because if current prices are above mean price they must inevitably soon come down, and if they are below they are certain to go up; whereas with its 
present knowledge the trade is by no means certain whether prices are going up or down.

If these few points are kept in mind we think it must be seen that the above experiments go far towards demonstrating that the mean price of commodity is determined by cost of production, and can therefore be estimated independently of the variations that may occur on either side of that mean, and they certainly show that if the statistical data were made more complete it could be definitely proved whether this was so or not. We claim it to be a great advance in economic theory to be able to make a practical estimate of prices in advance of the market, and to do so in opposition to all trade and market traditions, for it has always been held to be quite impossible to know the price in advance. The prevalent idea amongst the Liverpool cotton traders at the time of the earlier experiments was that cotton could be grown to sell at $3 d$. per pound because that low price had been reached in $1898-9$, and that the higher prices paid were the result of gambling in New York, so that a forecast based on the idea of the cost of growing cotton having gone up enough to make $6 d$. a cheap price was to them quite an outrageous misunderstanding of the facts. Yet the forecasts were made, and that in spite of the many difficulties of defective data and war disturbances of commerce, under which circumstances it is significant that in fourteen experiments, the results of which are given on Table 54, we find, with perhaps one exception, that the resulting forecasts were so good that any business transactions based upon them would have been attended with far more than average success; in fact, they were used to the distinct advantage of the few persons who used them.

It is necessary to thoroughly appreciate the fact that these forecasts are based solely on the assumption that the average price of cotton is exactly its average cost, its cost including the average cost of management and directive ability; and further that there is no excessive or irregular profit that can affect the average.

This assumption enters into every detail of the calculation. When the ginning report indicates that the crop per acre is small the conclusion that the price will go up would be quite unwarranted if demand had anything to do with the average price. We have no data or knowledge with respect to demand; it does not enter into the calculation.

It could not be safe to estimate that the acreage will be reduced because the current price is low, unless that low price meant selling cotton below cost. No man living would cultivate less acres because the profit was small, unless he thought he could employ his time and land to better advantage ; and if he could do so he would certainly be working at a loss if he went on growing cotton-he would not be getting what his land and service were worth.

It may perhaps at first sight be thought that this fact does not 
prevent the cotton planter from having a very exaggerated idea of what his service is worth, but it does, most effectually. If planters get a big profit by over-estimating their own value, any one of them who had wit enough to take a little less profit per acre might undersell the lot of them, increase his acreage without limit, and make great wealth by coming down to his real cost price. That this increasing of area to bring prices to cost level does really take place very promptly is proved by the case of the Sully corner in cotton mentioned in the last chapter, when the rather larger profit sent the acreage up by three and a half million acres in about a year.

These forecast calculations are based solely on this assumption that the mean price of cotton is its cost, and the figures would be quite useless if that assumption was not the fact. Therefore that these price forecasts have proved so approximately correct is strong evidence that the assumption that the price is determined by cost is also correct.

We regard it then that our inquiry into prices has given us substantial reasons to believe that the price of commodity is dependent upon labour cost measured by the labour cost of gold, and that therefore it follows that the mean price to the community of any and every commodity or service whatever has naturally a predetermined price that the community must pay if it wants that commodity or service. The purpose of this long inquiry has been to substantiate this idea of everything man desires having its value or price actually determined by the ease or difficulty with which he can wrest it from the grudging hand of nature-a price determined by nature. The absolute price of a thing is the labour-time men must expend to get that thing, and that price can only alter by change in the natural conditions or change in man's power to overcome those natural conditions. The money price of the thing is simply its absolute price measured in the absolute price of gold, and so in addition to changing with a change in its own absolute price it can vary through a change in the absolute or labour-time price of gold. The price for instance of a fruit is as much one of its natural qualities as its colour, its smell or its taste; even though that price may never be translated into a money value, the labour-time must be given to obtain it.

It is only this fact of the cost or price of commodity being a definitely fixed thing that makes our commercial system possible: the very important business method of extending currency by the use of banking accounts, as we tried to point out in the chapters on capital and the introduction to prices, could not be carried out unless the price of the commodities represented by bank accounts was something inevitably fixed within very reasonable limits. When a banker gives gold in exchange for a signed cheque he must have very good reason to believe that there is some natural law why the goods represented by that cheque have some absolutely determined 
value. As he probably has no idea what or where these goods are save that they are represented by something existing in the social capital, he must have a very practical belief that they cannot be used or consumed by any one without such user has paid for them their absolute price in labour that has inevitably replaced them by goods to the same value.

The economic significance of this conception of price as a fixed quality of things will become apparent in the following chapters; it here remains only to point out one or two qualities of this natural price. It should in the first place be understood that by price we mean the mean price to the community, and it does not in any way detract from the realness of that price that locally, both in time and place, the actual prices paid should vary on either side of that mean. It may perhaps be contended that any promiscuous collection of prices might be added together and divided by the number of separate price items, thus giving a mean price, though that mean need not be the price of any particular thing or its cost to any one whatever, and in fact be a meaningless calculation to find the obvious. But if the foregoing examples of commodity price variations and forecasts have been understood it will be seen that mean price as used by us does mean not only the price of a definite quantity of a commodity, but also of a definite quantity of labour, and is therefore not an average of prices but an actual price for a given quantity, and one that can be estimated before the occurrence of the various price transactions of which it is the mean.

As should also have been apparent from the foregoing examination of prices, it does not follow that because a mean price exists that every individual buyer or seller should know just what that price is, nor that every producer should know what the cost should be. So that it is quite consistent with our contention that price variations should take place, although we hope it has been shown that these variations tend very quickly to return to the mean level. But these variations are not solely due to ignorance, and it should be understood that under present commercial conditions there is some use and purpose in these local variations of price; it is part of our productive method. As the world's production of wealth is carried out by individual industrial concerns there is no central organisation that can decide what should be produced, and how much of it. Nor should it ever be supposed that it would be easy to establish any such control of industry; in fact there is good reason to believe that it would be impossible for any such central organisation to really know and provide what mankind requires. But wanting such central direction of industry it is obvious there must be some method of securing the production of what society wants in the quantity that it is desired, and this adjustment is accomplished by this local variation of price. If more of a certain commodity is wanted, more 
is purchased from stocks at the shops until the dealers find there is a slight shortage of that commodity; then, regardless of its real value, they offer a higher price for an increased supply and raise the price to their customers. So the price of that article is sent up above the normal price, and, as we have seen in many examples, the result is an increase of production (area in crops), and this production increases till the supply overtakes the demand, when the price will drop and probably go below normal and the production will then soon decrease.

This we have seen it to do in very many cases, but why? If society was willing to pay more to get what it wanted and is still wanting it, why does the price drop? Obviously because the producers can produce the increased supply at the old price, and as the lower the price the greater the demand, they come down to that old price to secure the greater demand and largest sale they can. But why then do they not set the price lower still and secure a still greater demand and sale? Evidently because they have reached the cost of production limit and cannot go lower. So these variations of prices from the cost basis only prove the very substantial existence of that cost of production mean price, a price that cannot be ignored or overridden by financial artifice. If retailers to increase their sale were able to lower their prices for a commodity by buying largely of some firms who had exceptional natural advantages in production, the demand might increase to any extent, but not the supply, for as natural advantage cannot be extended at will, and all producers not having such advantage would reduce their acreage or production at that low price, there would soon be a shortage. That would cause those retailers or some others to promptly offer a price that would probably be more above the normal than the other was below. From this well recognised result of price controlling it will be seen how very difficult it would be for any central controlling body to organise national production and price by legislative methods of deciding what should be produced and at what price. Unless they were able absolutely to know the marginal supply price of every commodity, they would be continually causing shortages of those things which are most necessary to the community. War experience has shown that the central control of prices very effectually reduced the supply of everything and entailed upon that controlling body the necessity of also directing production at its own risk and expense. And although the result of that state production may have been justified by the country's emergency it will hardly recommend itself as the most desirable or most economical method of conducting the production of wealth. It seems to us that no such control of industry could hope to attain any measure of success until the true nature and cause of price have been recognised and demonstrated beyond any possibility of question. 
Towards such a complete demonstration we venture to contribute our conviction that the above inquiry shows that prices are not artificial usages, or the result of accidental circumstances, but a naturally fixed and determined quality of things constituting as it were a fixed point from which economic theory must start. 


\section{CHAPTER $\times$}

\section{WAGES}

IN the last chapter we came to the conclusion that the price of a commodity was a naturally predetermined quality of the thing due to the cosmic causes which determine how much lifetime man must expend in getting that commodity. But if this is true, we are in this chapter confronted with what may seem to some readers the rather startling deduction that wages do not enter into the cost of a commodity, or affect its price. Wages paid for the same amount of labour-time are notoriousty variable, and if the price went up when higher wages were paid for the same labour-time, such price could not be said to depend on the labour-time alone. It would partly depend upon the wages, or the cause that raised the wages; and in that case the price would not be naturally predetermined, unless it could be shown that the cause of the rise of wages was also naturally determined, which in many cases it is not possible to do. As this implies a contradiction of the conclusions reached in the last chapter, it is necessary to carefully examine the question of whether it is correct to say that wages enter into cost of production or the price of commodity.

In the first place it is important to understand what is really meant by wages; they are often spoken of as the price of labour, because they have a certain resemblance to the price paid for commodities. But we think that is a misleading definition of wages, chiefly for the reason, as it seems to us, that labour is not a commodity, and has not properly any cost of production. Some economists have regarded labour as a commodity that has to be produced at a very considerable cost, and that its price must tend to conform to or depend upon its cost. But they do not seem to have established any definite connection between the cost of raising a family of workers and the wage they will be able to obtain, or that a particular individual's labour has a value dependent upon his cost of production. Labour is not the man or the quality of what he lives upon, but it is human lifetime expended in work; and what labour gets as the reward for lifetime given is the means of living or the power to live ; in fact lifetime is the reward of lifetime given. It is a cycle in which nothing is exchanged for anything else, so cannot be regarded as the sale of a commodity, but may perhaps be regarded. as we have regarded it in a previous chapter, as the use of capital and the reproduction of that capital continually.

r.พ. 
Labour to us is a form of capital, and is the capital of the individual labourer that cannot be sold except partially in the case of slavery; so that in a free country it has no price, and is not paid for in wages. Wages are more correctly described as the price paid by the employer for the wage-earner's share of what he and his employer mutually produce; in which case it is the price of a part of the commodity. The reason why that price is not fixed by the cost of production of that part of the commodity is simply that it is so difficult to determine exactly how much of the mutual production has resulted from the labour of the employer and how much from that of the employee. So a speculative and competitive bargain has to be struck between them as to their respective shares; and it is the nature of this bargain that forms a great part of all economic problems.

If, then, wages may be defined as the money value of an undetermined portion of the labour cost of a commodity, the apportionment of a greater or less part of its value to the share of wages would not alter the value or magnitude of the whole. From a yard of cloth we may measure off I2 or I 8 inches, as the case may be, but the yard of cloth will not be more than a yard because we measure off the half of it instead of the third. If the wage-earner expends more labour on a commodity, the price naturally tends to rise; but in the case of his being able to demand higher wages while his labour-time in producing a thing is unchanged, it does not appear that the price of the commodity can be put up to compensate for that rise of wages. To think that prices can be put up in this way is to suppose that the employers can put up prices of commodities just as it suits them to do, regardless of the demand for the goods, or the competition of other producers, which supposition, as we have seen in our review of prices, would be very contrary to the observed conditions of trade. It may, however, be thought that if the demand for higher wages was general, and employers had to pay them, they would then compete less with each other till they had all raised their prices to compensate for the high wages they were paying; in which case wages would enter into cost of production and affect the price. But though we experience many cases where prices seem to have been put up in this way, it is necessary before accepting them as evidence to make quite sure what it was that made the worker's demand for an advance an effective one. If it was made effective by a general rise of prices due to increased productivity in gold mines, the rise in wages might be naturally due and a further rise of prices due also from the same cause. Wanting such natural cause, to suppose all employers paying high wages and suspending competition between themselves is a very big and very vague supposition. If they can do this, why have they not done so long ago and sent both wages and prices sky-high?

War experience has shown us what, as a matter of fact, was quite 
obvious before, that when everything goes up in price there is no advantage to anybody, and if gold went up too, there would really be no change of price or relative values. But as we have seen in a previous chapter, although gold cannot go up in price, it can go up in scarcity; and the result of a universal rise of commodity prices would be that gold would go out of production altogether, and stay out till prices came down. If, under such conditions, gold was insisted on for use in the arts, it would have to be paid for at more than $\$ 3$ I7s. 6d. per ounce; and then gold currency could not be maintained at its present standard of value, which consideration makes the supposition of an unlimited rise of prices rather a bold and difficult one. There is really no evidence that prices ever have, or could have, risen in this way while there is a gold standard or any other fixed standard of value. The extraordinary rise of both wages and prices during the War which seems to be evidence of the possibility of an unlimited rise of wages and prices is due to the fact that the gold standard is practically suspended and normal prices have become fictitious. A pair of boots valued in 1919 at $£ 2$ treasury notes would certainly not make $£ 2$ in gold if a desire to obtain gold for goods became at all general; a fact that is disguised by the circumstance that the Government took precautions to prevent any great quantity of gold being demanded by the public during the War. The normal price becomes fictitious only because it is based upon gross production figures; if net figures that represent the correct number of persons were used, it would be found that the value per person had greatly fallen owing to the War. And further, if that could be done, the nominal or market price, which varies with cost of production would more nearly show the true cost under a no gold standard of value, because the great war-time rise of prices is due to the great rise in the cost of production resulting from the fact that for each hour a producer works at his machine another producer must work in the Army to protect the first one and his machine, so that the labour time is doubled. As at the same time competition is virtually suspended, the producer can fully cover that rise in cost by putting up price, and society must pay for it in high prices or, more truly, in short rations. Any real excess of price beyond this great increase in cost is due to the suspension of competition; and it should be clearly understood that without ordinary commercial competition our theory of prices does not completely hold good. But war conditions and limited competition are not normal, and under normal circumstances the shortage of gold would prevent any such putting up of prices above the cost of production level.

As such broad generalisations about the probable results of war conditions and hypothetical rises of price are much too complicated and problematical to be really enlightening or convincing evidence, it is desirable to return to more specific cases of the movement of 
wages from actual figures; and as gold has been shown to be the controlling factor in money values we may best begin our examination by noticing the result of fluctuations in the wages of gold miners. Unfortunately the record of such wages is short and incomplete; in fact, there seems to be no record at all for a great part of the world's gold production, so that we may congratulate ourselves that the Transvaal returns are available for a short period. Unfortunately, too, that period does not cover any times of great price variations, and the data is wanting altogether for some of the years during the period. The following table of wages and production in the Transvaal gold mines (Table 55) is drawn up in seven

TABLE 55.-TRANSVAAL GOLD MINES, WAGES AND PRODUCTION.

\begin{tabular}{|c|c|c|c|c|c|c|c|}
\hline & \multirow[b]{2}{*}{$\begin{array}{c}\text { I } \\
\text { Wages } \\
\text { and } \\
\text { salaries. }\end{array}$} & \multirow[b]{2}{*}{$\begin{array}{c}2 \\
\text { Dividend. }\end{array}$} & \multirow[b]{2}{*}{$\begin{array}{c}3 \\
\text { Production. }\end{array}$} & \multirow[b]{2}{*}{$\begin{array}{c}4 \\
\text { Persons. }\end{array}$} & \multicolumn{2}{|c|}{ Per person. } & \multirow[b]{2}{*}{$\begin{array}{l}\text { Per } \\
\text { centage } \\
\text { of } \\
\text { produc- } \\
\text { tion. }\end{array}$} \\
\hline & & & & & $\begin{array}{c}5 \\
\text { Wages } \\
\text { and } \\
\text { salaries. }\end{array}$ & $\begin{array}{c}6 \\
\text { Produc } \\
\text { tion. }\end{array}$ & \\
\hline 1902 & $\underset{3,1 \stackrel{£}{5^{6}, 997}}{f_{3}}$ & $\underset{2,127,725}{\ell}$ & $\underset{5,284,723}{f}$ & 53,863 & ${ }_{58 \cdot 6}^{t}$ & $\underset{98 \cdot I}{E}$ & $58 \cdot 4$ \\
\hline I904 & $6,495,627$ & $3,938,802$ & I0,434, 429 & I0 3,952 & $62 \cdot 5$ & I00.3 & $62 \cdot 2$ \\
\hline I906 & $7,698,629$ & $5,74 \mathrm{I}, 76 \mathrm{I}$ & $\mathrm{I} 3,440,390$ & I $63,7 \mathrm{I} 2$ & $47 \cdot 0$ & $82 \cdot I$ & $58 \cdot 0$ \\
\hline $\begin{array}{l}1907 \\
\text { I908 }\end{array}$ & $10,483,118$ & $\begin{array}{l}7,098,212 \\
8,757,882\end{array}$ & $\mathrm{I} 7,58 \mathrm{I}, 330$ & I 82,355 & $57 \cdot 7$ & $96 \cdot 4$ & $59^{\circ} 6$ \\
\hline I909 & II $, 6 \mathrm{I} 4,324$ & $9,523,518$ & $21,137,842$ & $20 I, I 3 I$ & $57 \cdot 7$ & $105 \cdot I$ & $55^{\circ} 0$ \\
\hline I9Io & $13,402,232$ & 9, г $30,95^{8}$ & 22,533 , I9o & 220,308 & $60 \cdot 8$ & $102 \cdot 3$ & 59.5 \\
\hline IgII & $14,272,867$ & $8,066,437$ & $22,339,304$ & 226,730 & $63 \cdot 0$ & $98 \cdot 5$ & 63.4 \\
\hline I9I 2 & $\mathrm{I}_{4}, \mathrm{I}_{54,27 \mathrm{I}}$ & $7,960,394$ & $22, \mathrm{I} 14,665$ & $229,2 \mathrm{I} 2$ & $6 r \cdot 8$ & $98 \cdot I$ & $64 \cdot 0$ \\
\hline I9I3 & I3,476,300 & 8,205, I99 & $2 I, 68 I, 499$ & 219,629 & $6 I \cdot 4$ & $98 \cdot 7$ & $62^{\circ} 0$ \\
\hline IgI4 & I2,499,354 & $8,073,436$ & $20,572,790$ & $20 I, I 62$ & $62 \cdot I$ & I02.3 & $60 \cdot 8$ \\
\hline I9I 5 & I $3,593,483$ & $7,619,4 \mathrm{I} 6$ & $21,212,899$ & 228,049 & $59 \cdot 6$ & $93 \cdot 0$ & $64 \cdot I$ \\
\hline I9I6 & $14,301,522$ & $7,271,589$ & 22,573 , III & 236,434 & $60 \cdot 5$ & $95 \cdot 5$ & $63 \cdot 3$ \\
\hline I9I7 & I 4, I 39,878 & $6,7 \times 8604$ & $20,858,482$ & 214,927 & 65.8 & 97.0 & $67 \cdot 8$ \\
\hline I9I8 & $\mathrm{I} 4,452,9 \mathrm{I} 3$ & $5,273,633$ & I9,726,546 & 210,035 & 68.8 & $93 \cdot 9$ & $73 \cdot 3$ \\
\hline
\end{tabular}

columns; the first is the wages and salaries which for our purpose may be taken together as wages distinguished from profits, which latter are included under dividends in the second column. These two factors are added together to give the total value produced per year, which is the total net production represented in the third column. We estimate the production in this way because it gives the best approximation to the net value produced, the published gross production figures being of no use to indicate the proportion of the wages to the production. The fourth column gives the number of persons employed; the fifth! wages per person; sixth, value produced per person; and seventh, the percentage of the value per person that is paid as wages. The first four columns are the published data, and the last three the result of the simple calculation 
that shows the relation of the gold miner's wages to the gold he produces.

These Transvaal figures show in the fifth column that the miners" wages do vary from year to year as in other industries, and as in them the value that is sold (column 6) usually rises at the same time as the wages. But as in normal times the price of gold cannot vary, always being about $£ 317 s$. $6 d$. per ounce, the value of the output in this commodity at any rate does not vary because the wages have gone up. They have made no difference to the price nor to the cost either, for we see by the table that in 1906, when wages were at their lowest point, the cost of gold was very high. The cost obviously' depends on the amount of labour necessary to get the gold; if only a small quantity is got per person it has cost much labour, and column 6 shows that it was only $£ 82 \cdot 1$ per person in 1906 . In that year the average result for all persons employed in the mines was only $21 \cdot 186$ ounces of gold per person, the gold miner only getting f $82 \cdot 1$ for his year's output per man, whereas in 1914 , when wages were high, each miner produced 26.40 ounces, or a return of $£ 102.3$ per man employed; that is, a saving to the community of $£ 20 \cdot 2$ per man in the cost compared with 1906 , in spite of the fact that wages had gone up 32 per cent. Obviously, as the price of the gold does not alter, wages could not go up by nearly a third, and dividends (column 2) by $4 \mathrm{I}$ per cent., unless the production of gold per person had increased. But why should wages go up with the increased production so as to be always about 64 per cent. of the total ? Such rise of wages can only be necessary because commodity prices generally have gone up, and that the increased profit therefrom has made a greater demand for labour. That prices are thus high, trade good, and wages going up whenever more gold is produced per person greatly favours our theory (Chapter VII.) that the level of prices depends upon the production per person in gold.

These examples of gold miners' wages clearly support our point of view that wages do not enter into cost of production or alter the price of commodities. For the fact that the price of gold was.not raised in I9I4 by the increase in wages is not simply due to the circumstance that gold produced is actually the cash obtained for the production. The increased production is not, as it may perhaps be thought, equivalent to a rise in its price. The value of gold did not go up " in effect "- was not made more. Gold did not go up in relative value, but came down in I9I4 relatively to other goods which were rapidly going up.

It is easily seen that in the production of gold it is not the rise of wages that alters the cost to the consumer, or price. But that on the contrary the improved production making the output larger and more profitable leads to the increased demand for labour in the mines, and that results in better wages being offered. But in the 
case of other commodities where the cash price does vary it is not quite so easy to ascertain whether wages can force up the price or not. It should, however, be clearly appreciated that in other industries the relation of the wages to the productivity and to the employers' interests is exactly the same in all respects as it is in gold mining, and that the share of the production alloted to wages certainly need not affect the total value that it is allotted from, or alter the price. Further, it has been shown that if commodity prices were put up by an organised effort to compensate for a rise of wages while the price of gold could not be so raised, the result would be a shortage of gold, and the monetary standard would have to be altered or prices would have to come down, which, as far as experience shows, they always do when the supply of gold is below what is required. So that gold supply is not only an example of how wages do not enter into cost to the community, but seems to be the cause why other prices cannot be raised to compensate for a rise of wages.

So obsessed are we with the consciousness that in all practical business estimates of manufacturing costs wages form an important item that it is difficult to keep thoroughly in mind that this factor of wages, which is so important a part of his costs to the individual manufacturer, is really of no importance to the purchasing public, who are alone concerned with the gross price they must pay for his goods. All through our inquiry it is the price to the community and the cost to the community that we are concerned with, not the cost to any particular person who, whether he is producing a book or a turnip, may, of course, be mistaken in his calculations, and so never obtain a price that will cover his costs, or who, in fortunate circumstances, may sometimes obtain a price far above his costs. For the effect of competition upon such producers with their various costs is that the average of their results is the cost which determines the mean price of the commodity.

Although when turning our attention to economic questions it is difficult to keep cost to the producer and cost to the community distinct from each other in the mind, business men are really under no delusions about it in their business. They are very keen to keep the wages costs down in their own business, because they know full well that if their wages are too high they cannot put their prices up without great danger of losing part of their sales; they know the trade price of their goods is fixed by something that will not alter because they have paid unduly high wages. It is this unaltering determining factor of labour cost to the community that we are concerned with, and the greater or less share of the product that may go to the wages or to the profits of a particular producer does not affect that product's gross cost to the community.

There are no doubt local cases where the price is definitely raised because the producer's wages bill has gone up, but even then it does 
not follow that the rise of wages was the ultimate cause of the rise of price. It must be asked in such a case how it comes about that the producer can raise his price? Obviously his competitors must have done the same, so that the rise must be a general one, and in that case it is necessary to show that there is no natural rise of prices due to a change in the gold production before it can be proved to be initially due to a rise of wages. The most common cause of this apparent rise of price due to increased wages is found in the smaller manufacturing industries, when labour is being tempted out of them into the larger manufacturing and raw material industries, and when prices are naturally on the rise. In which case the manufacturers have to put up prices nominally to be able to keep their workers by raising wages, but actually because they are following the raw material trades in a general rise of prices. And it is just in the production of some raw materials and the larger and more essential industries that labour has the least chance of raising prices by demands for more wages, because as the labour is not so highly specialised cheaper labour is easily brought into it, which makes it more difficult for labour to organise to force an increase of wages. Even in coal mining, where much of the labour is of a skilled nature, it does not appear that labour can force up prices to compensate for higher wages. For in some districts wages are fixed on a sliding scale in accordance with the selling price of coal; and why should wages not be supposed to rise without the price of coal having gone up? If the wages can add to the cost and raise the price, why should they not do so at any time, and without fixing any scale? And why should they ever come down again? In the case of falling prices it is not so usual to suppose that the fall is caused by wages going down. It is obvious from this sliding scale arrangement of wages that both miners and coal owners recognise that the price is fixed by something beyond the control of their particular organisations, and that wages must depend upon the price, and not the price upon the wages.

In agriculture it is difficult to see how wages could affect the market price when we remember the vast variety of wages which are paid at the various geographical points that send supplies to a common market. And that even locally the wages paid to each farm labourer must be calculated by the farmer as part of the cost of so many commodities, such as meat, wool, wheat, straw, hay, etc., and therefore it would be very uncertain how much of such wages must go to the price of each. Yet this would have to be ascertained if the market price of each of these things was to be altered by the wages. If, on the other hand, our contention that the price must move first is the correct one, it is evident that if a general rise of prices affecting more or less all these agricultural products is taking place, it must be making farming just that much more profitable. The extra profit 
will make farmers more anxious to increase the production of these profitable commodities by increasing their acreage, and that will mean a demand for more labour. This increased demand will lessen the amount of unemployment and reduce the competition for work among the wage-earners, which will at once tend to raise wages. A more exact explanation of how the share of production that goes to the wage-earners is controlled will be given in the two following chapters, in which also will appear the true significance of this contention that wages are not properly regarded as part of the cost of production. Here it remains only to show how it affects our general conception of wages as an economic phenomenon, and how it is supported by the experienced movements of wages.

If, as we claim, wages are only a portion allotted from the total value of production as the share of the wage-earner, variations in wages must tend to follow very closely the variations in the price of commodities, unless there is supposed to be a very large or unlimited margin between cost and market price, which our examination of prices has conclusively shown cannot be the case. That being so, any record of wages over a period of years should show similar fluctuations to those of commodity prices. There is very little exact data as to actual wages paid in industry in this country. Most statistical figures for wages being those for average rates of wages they do not, of course, show the increase or decrease in the money earned by the working for longer or shorter days, which variations are just the important point at times of trade fluctuations and changes of the price level. To know whether wages have really varied simultaneously with the value produced by labour we should know the total value produced by a given amount of persons and exactly what those persons received in wages. Merely the rate of wages is not sufficient, for at a given rate the total earnings may obviously vary very much in accordance with the number of days actually worked by each of those persons, to say nothing of cases where the rate does not really cover all the labour employed in the industry for which the returns are made. This difficulty of the absence of actual wages figures is, however, not so serious while in the present chapter we are simply comparing the general movement of wages with that of prices as it is in the following chapter when considering the exact proportion of wages to the total value at changing price levels.

The best figures we have found are the cash wages paid for a series of years in ro selected trades returned to the Labour Gazette of the Board of Trade. These returns start in 1905 when prices were beginning to rise from the low point in I904, and show that the wages paid in those trades rose just IIs. a year for the first two years. In I908, when prices fell and the total value produced in nearly all trades was less, wages fell by $£^{2} 2 \mathrm{~s}$.; then up to I9I3 
wages follow prices in a steady rise till they are $6616 \mathrm{~s}$. per year more than in 1908 . From 1914 wages began to be affected by war conditions resulting in a fall that year and then a big rise.

TABLE 36.-AVERAGE WAGES PAID IN CERTAIN SELECTED TKADES.

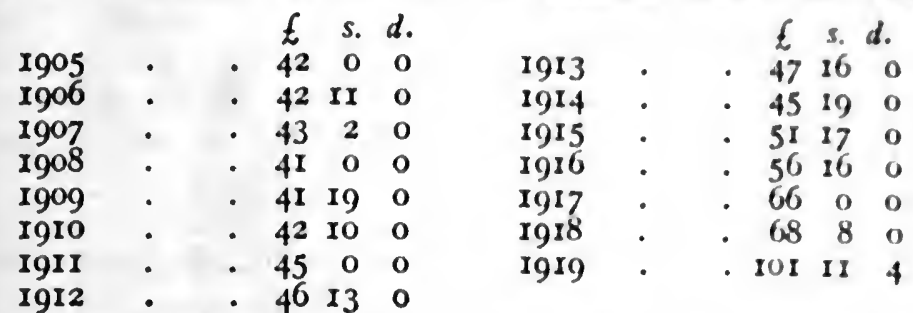

This is the only official return for actual wages paid that we can find for this country, but in this record at any rate it may be seen that wages closely follow the movement of normal prices or the value produced per person. Another example from a semi-official source may be found in the wages paid by the Industrial Co-operative

$$
\text { Diagram 57.-WAGES. }
$$

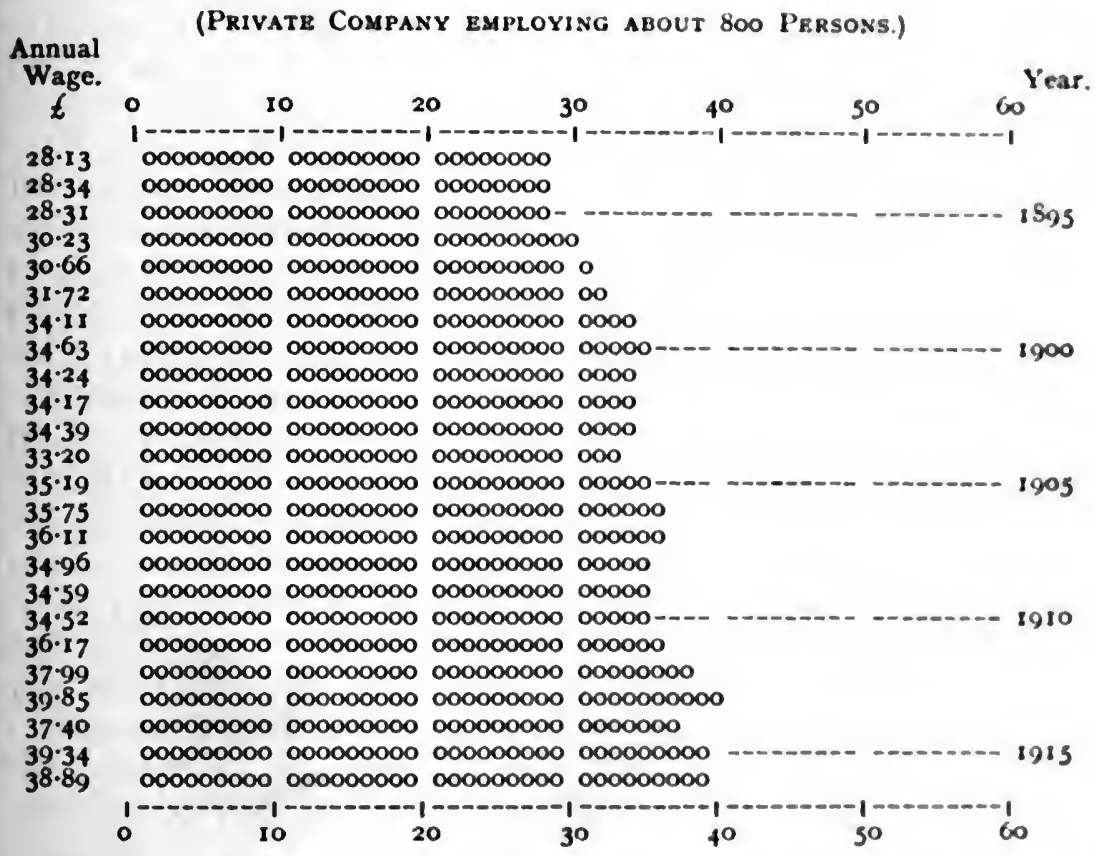

Society, wholesale and distributive; in the fourth column of Table 9 may be seen the annual wage per person paid by this Society since 1898. This concern has been increasing so rapidly during the period, and its conditions of business also considerably modify the conflicting interests of employer and employed, that these facts together somewhat alter the incidence of trade competition. So 
the periodical fluctuations in the proportion of the wages to the production, or the fluctuations of the value produced either, are not so strongly marked as in the last example; but considering these rather special conditions, it is remarkable that the general similarity of movement is so obvious. The high point in wages is reached in

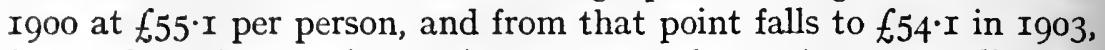
from when they begin to rise, rather before prices generally had reached the bottom in I904, and continued to rise with the general level of prices for the rest of the period.

The only other example is the wages paid by a private company since I893, which are given on Diagram 57. That diagram shows the usual rise up to the year I900, and the fall till I904, also the boom in trade which made a rise in wages for $1906-7$, as in other commodity values that we have noticed in many cases in our chapter on prices. This boom was followed by a slump in wages and prices in 1908-9, from which year both rise together till Igr3.

Much the longest record of wages movement that we can compare with the price fluctuations are those for coal miners in France and steel founders at Krupp's works in Germany. It will be seen by Diagram 58 that wages have moved up or down very much in accordance with prices as indicated by the curve AA. They will be noticed to fall below the curve when prices are high and above it when prices fall. This characteristic lag of wages in following price movement will be shown to be of great importance in the next chapter, but here it is only necessary to notice that the fluctuations are very much in the same direction and at the same time as those of the price curve. Diagram 59 may be taken as fairly typical of German wages, and although it shows a greater and rather more continuous rise of wages in the time covered by the diagram, this, as we have explained in relation to the coal production, is due to the backward social condition of the workers and low valuation of their productivity at the beginning of the period covered by the data. Notwithstanding the different appearance of the wages curve, the high and low points will be found to come at very much the same time as on the French Diagram 58 , which shows that the wages fluctuate with the level of prices. The following Diagrams, Nos. 60 to 65 , illustrate such wages rates as we can find data for in the records of other countries. Most of them show the rise and fall about the year 190o, and all of them agree in a distinct and considerable rise in recent years.

From these various records of wages paid in different years it appears that wages do vary as the value of the total production or normal price varies, and as we have seen the normal price varies only with variation in gold production per person, it seems that wages also depend on and must follow the wages obtained by gold miners. Further, as we have seen, it is not possible to put up the 
DLGRAM 58.-WAGES OF COAL MINERS IN FRANCE

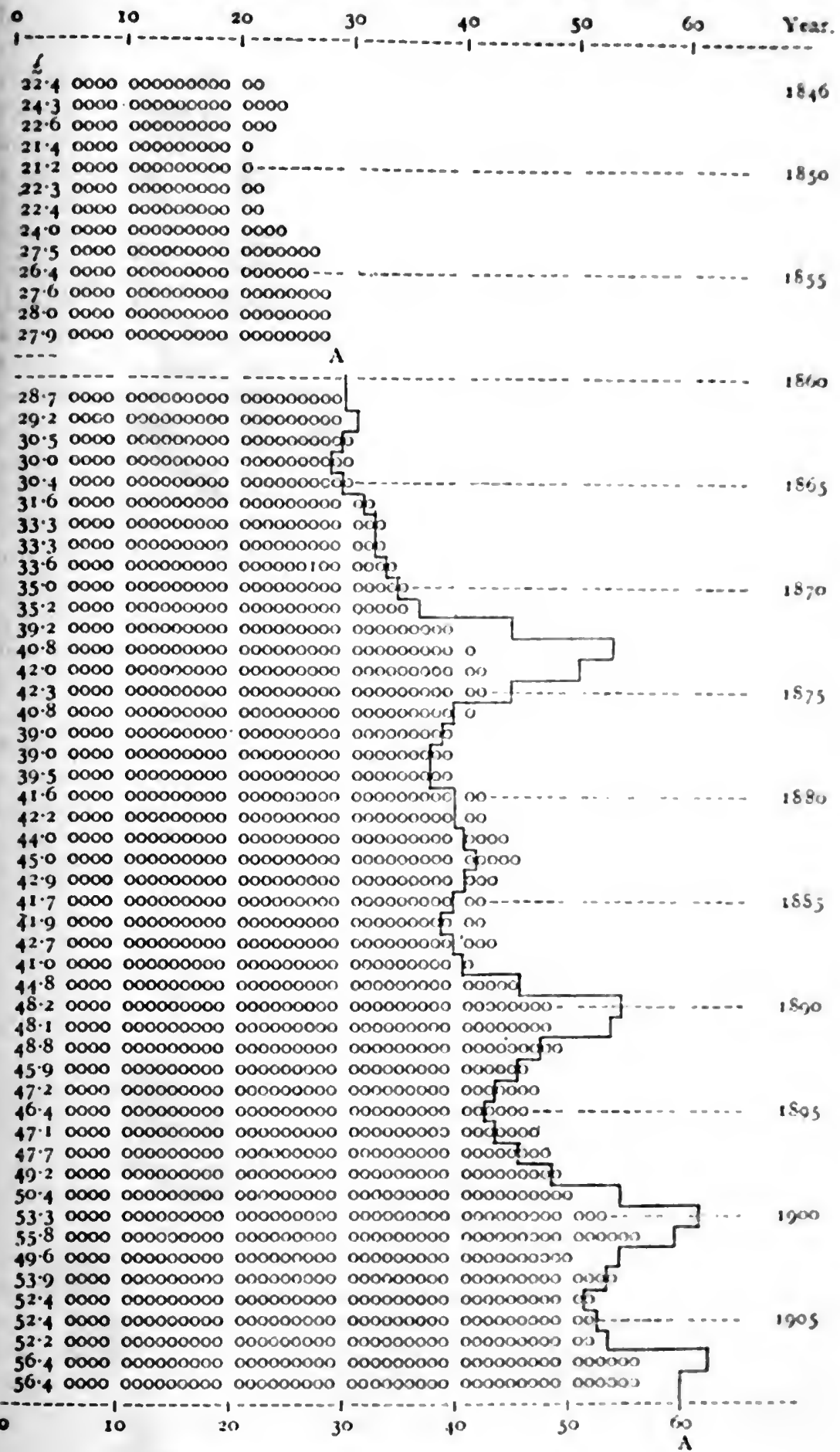


price of gold to compensate for higher wages paid, the fact that normal prices of commodities vary with the normal value produced in gold mines seems conclusive evidence that normal commodity prices cannot be put up to cover extra wages either. So that the evidence from actual wages returns does, so far as it goes, support our theoretical contention that wages do not enter into the cost of commodities or affect their price under the normal conditions of a fixed standard of value.

The contention that wages are a fairly fixed proportion of the production is supported by the conclusion arrived at in Chapter III. that wages are always about 52 per cent. of the total value produced, and it is naturally more probable that wages should be a constant proportion because the supply of labour is a very constant factor in the competition which determines the proportion of its remuneration. Labour supply is not made variable by any greater or less difficulty or cost of production as the values of commodities are, and by thus being a constant competitive force tends to get a constant proportion of its production. It is therefore quite probable that average wages follow the fluctuations in the production of gold more closely than commodity values do; for the latter, as we have seen often vary above and below the line through local variations or uncertainty in their cost. Wages closely follow these variations, but moving more slowly tend to fall behind the extreme movements of values and remain nearer the mean. We have in the case of American prices and to some extent in other cases taken the wages movement as the best evidence of the variation in gold production when direct data is wanting. And altogether the rate of wages seems the best evidence of the general level of prices for more remote years where the data either for gold production or commodity values is not complete or satisfactory.

The only long record of wages for Great Britain that we have been able to find is the wages of farmer's horse-men (horse-keepers) in Scotland, Diagram 24. This record shows that since $185^{\circ}$ wages have risen from $£$ r9 per year to $£ 43.3$; that is to say, this class of labour gets two and a quarter times more money (gold) for the same labour-time. That must mean the cost of getting gold has fallen I27 per cent., allowing normal commodity prices to rise a like amount. For these increased wages could not have been paid out of that normal price of 1850 unless any one has the hardihood to suggest that the farmers of 1850 were making I27 per cent. more profit than their successors are to-day. The record of wages paid in Krupp's Steel Foundry, Essen (Diagram 59), shows a still more remarkable rise in the same period, but the difference in the two amounts of increase is probably due, as we have before mentioned, to the fact that it was customary to put a lower social value upon the labour employed in Germany at the time the record starts. 


\section{Diagrax 59.-WAGES (GERMAN EMPIRE:)}

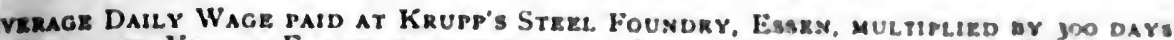

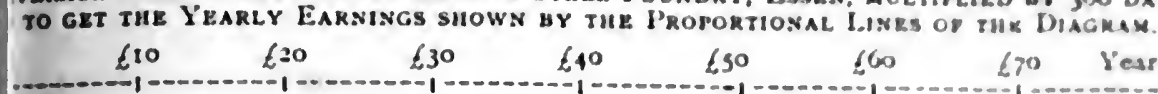

1/3: 000000000000

i/s 000000000000 o

iss

0000000000000000

i/ii, 000000000000000000000

i) II 000000000000000000000

i/11 0000000000000000000000

\% of 0000000000000000000000

0000000000000000000000

$\infty 00000000000000000000$

$\infty 0000000000000000000000$

$\infty 000000000000000000000000000$

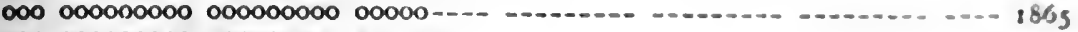

$\infty 000000000000000000000000$

00000000000000000000000000000

0000000000000000000000000000000

00000000000000000000000000000000

$00000000000000000000000000000000000 \ldots \ldots \ldots$

00000000000000000000000000000000000

0000000000000000000000000000000000000000

100 000000000 000000000 000000000 000000000 00000

0000000000000000000000000000000000000000000000

$00000000000000000000000000000000000000000000000+\ldots \ldots \ldots$

000000000000000000000000000000000000000000

0000000000000000000000000000000000000000

0000000000000000000000000000000000000

00000000000000000000000000000000000

$0000000000000000000000000000000000000 \ldots \ldots$

000000000000000000000000000000000000000 o

000000000000000000000000000000000000000000

000000000000000000000000000000000000000000

000000000000000000000000000000000000000000

$0000000000000000000000000000000000000000000 \ldots \ldots$

00000000000000000000000000000000000000000000

00000000000000000000000000000000000000000000

00000000000000000000000000000000000000000000

000000000000000000000000000000000000000000000

$00000000000000000000000000000000000000000000000 \ldots \ldots$

0000000000000000000000000000000000000000000000000

0000000000000000000000000000000000000000000000000

0000000000000000000000000000000000000000000000000

0000000000000000000000000000000000000000000000000

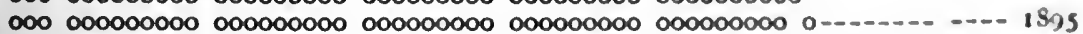

00000000000000000000000000000000000000000000000000

000000000000000000000000000000000000000000000000000000

100 00000000000000000000000000000000000000000000000000000

0000000000000000000000000000000000000000000000000000000000

000000000000000000000000000000000000000000000000000000000 0... 1900

000000000000000000000000000000000000000000000000000000000

000000000000000000000000000000000000000000000000000000

000000000000,0000000000000000000000000000000000000000000

100 00000000000000000000000000000000000000000000000000000000

000000000000000000000000000000000000000000000000000000000000001905 000000000000000000000000000000000000000000000000000000000000000000

000,00000000000000000000000000000000000000000000000000000000000000 100 000000000 000000000 000000000 000000000 000000000 000000000000000000 0000000000000000000000000000000000000000000000000000000000000000000

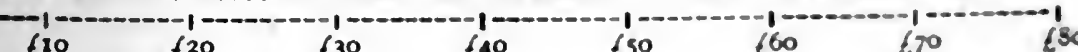

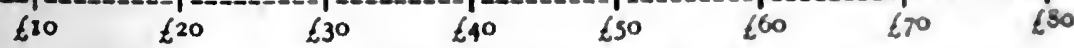

This complication, due to various classes of labour, will be discussed before this chapter closes, when will be made more apparent the importance of remembering that a rise of wages as well as a rise of 
normal prices, depends primarily upon a fall in the cost, or greater productivity per person of gold.

It is due to this cheaper gold that wages the world over have gone up I27 per cent. at least, but this is, of course, only saying that the labourer gets so much more gold for the same time worked, and it is conceivable that the prices of commodities he has to spend his wages upon might have gone up a like amount, in which case

\section{DiAgram 60.-W WAGES OF HIGHWAY LABOURERS (NORWAY).}

Average Annual Wage calculated on the (Summer and Winter) Daily
Wage For Piece Work. AT 300 Days PER Year.

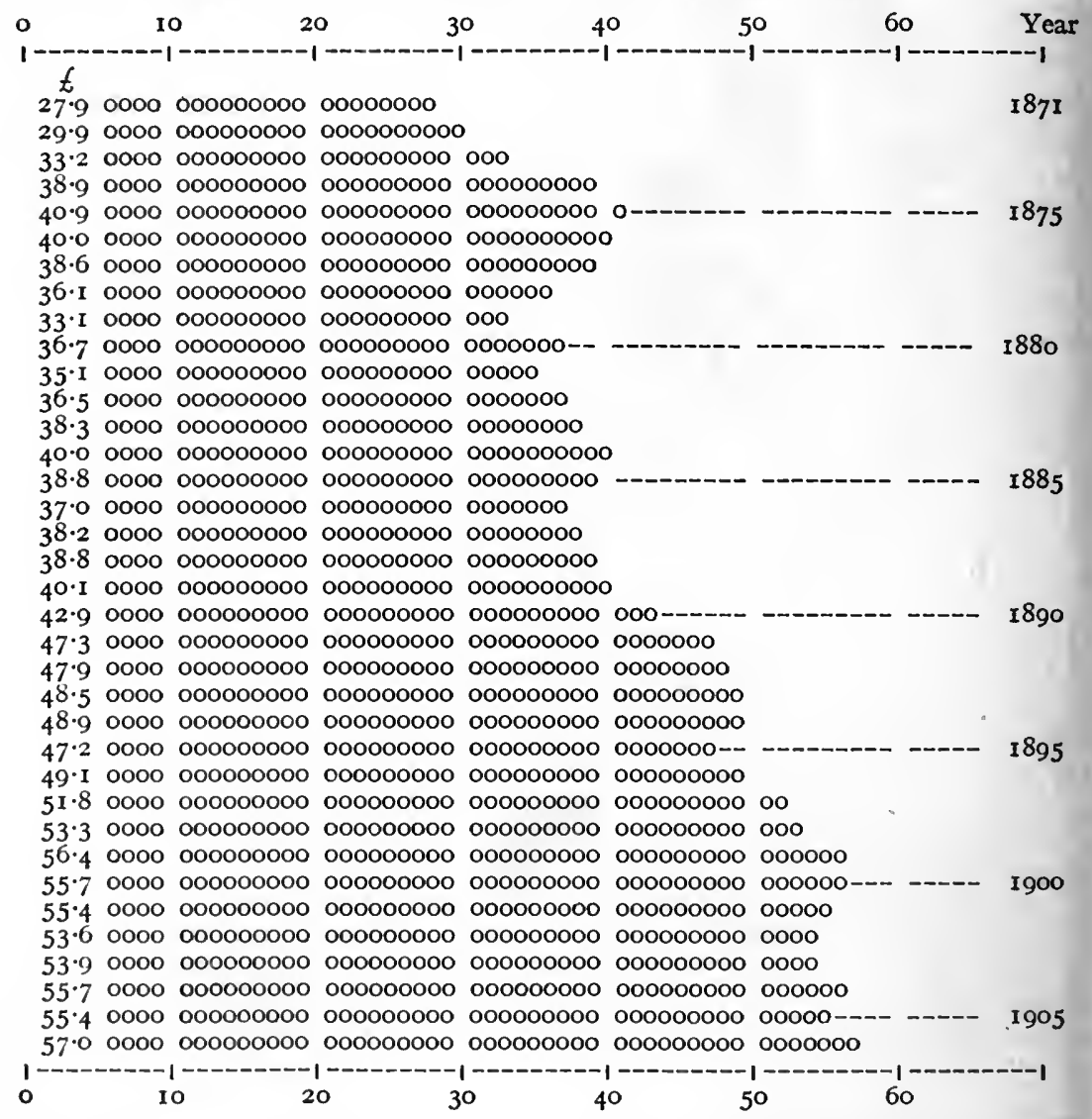

his real wages, or commodity wages, would not have altered. Possibly we may even have given the impression that this is the case by our repeated statements that normal prices have gone up. But as such impression would be incorrect, we must remind ourselves that normal price is the total price the community pays the producer for the commodity he produces in a given time (his labour-time), regardless of its quantity or price per unit, or of the shares of wages or profit into which it may be divided. 
Normal price is the market price or price per unit, multiplied by the quantity produced; and that total value may have gone up while the price per unit has gone down. If, for instance, owing to cheaper production of gold bread has gone up from ifd. to $6 d$. per loaf, the normal price which the producers get has risen 50 per cent. and if wages have gone up as much, the labourer would have $6 d$.

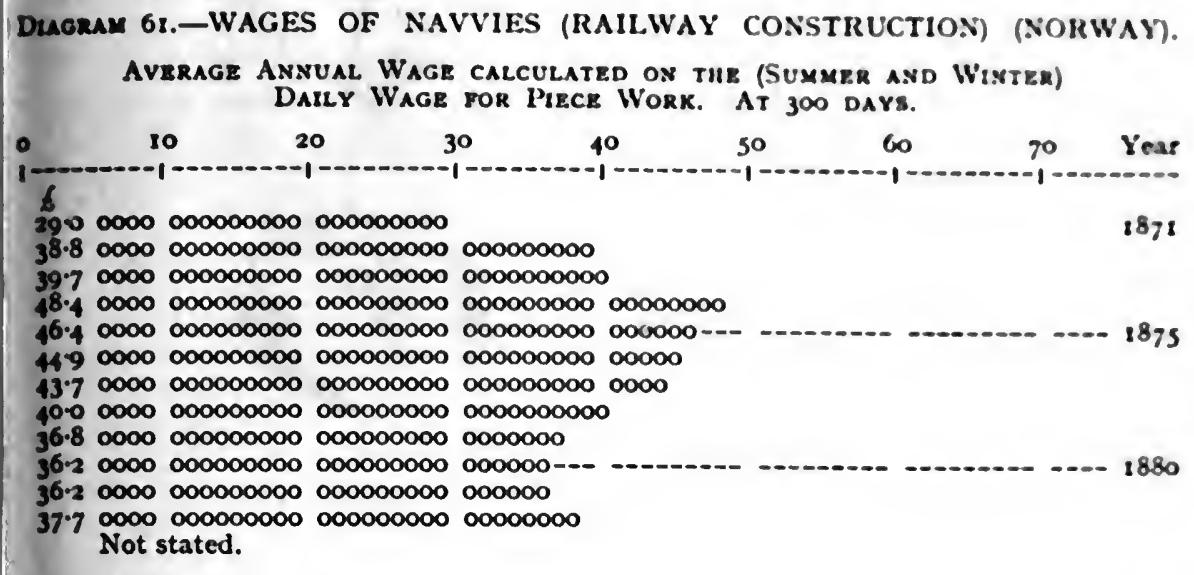

$52 \cdot 50000000000000000000000000000000000000000000$

$54 \cdot 5000000000000000000000000000000000000000000000$

56. $40000000000000000000000000000000000000000000000 \ldots \ldots \ldots . . . . . . . . . . .1895$

$\$ 9.500000000000000000000000000000000000000000000000000$

6I. 400000000000000000000000000000000000000000000000000

63.900000000000000000000000000000000000000000000000000000

65.0000000000000000000000000000000000000000000000000000000

6920000000000000000000000000000000000000000000000000000000000 -..- 8900

71.000000000000000000000000000000000000000000000000000000000000

71.7 000000000000000000000000000000000000000000000000000000000000

$69 \cdot 10000000000000000000000000000000000000000000000000000000000$

$72 \cdot 500000000000000000000000000000000000000000000000000000000000$

$73.40000000000000000000000000000000000000000000000000000000000000-1905$ 76.90000000000000000000000000000000000000000000000000000000000000000

1 $\begin{array}{lllllll}1 & 10 & 20 & 30 & 40 & 50 & 60\end{array}$

instead of $4 d$., and his real wages in goods would be unchanged. But if at the same time, owing to improved methods of production, two loaves were produced in the time that one was before, the normal price would still be $6 d$. instead of $4 d$. or 50 per cent. up, yet the price of a loaf would be $3 d$., the price would have fallen 25 per cent., and the consumer would get twice as much bread. The cost of living would have gone down 50 per cent. so far as bread was concerned. or since the wage-earner can now live (so far as bread is concerned) 
on half his earnings, he has as much again to spend on other things so is roo per cent. better off.

The classical index numbers quoted in an earlier chapter were based, of course, on these prices per unit of commodity, and in a case like the above would only show that the cost of living (bread) had fallen 25 per cent., whereas it was actually 50 per cent. cheaper in labour-time being twice as much real income in goods for the same

\section{DiAgRaM 62.-WAGES OF SEAMEN (GERMAN EMPIRE).}

Average Monthly Wages Rates of Money Wages (Food being provided).

\begin{tabular}{|c|c|c|c|c|c|c|c|c|}
\hline & & 0 & 0 & 4 & & 6 & & 70 \\
\hline $58 / 5$ & 000 & 000000000 & 000000000 & 000000000 & 000000000 & 00000000 & & 187 \\
\hline $55 / 5$ & 000 & 000000000 & 000000000 & 000000000 & 000000000 & 00000 & & \\
\hline $56 \%$ & 000 & óoooooooo & 000000000 & 000000000 & 0000 & 0000 & & \\
\hline $55 /$ II & ooo & 000000000 & 000000000 & 000000000 & 0000 & 000000 & & \\
\hline $50 / 5$ & OOO & 000000000 & 000000000 & 000000000 & 0000000000 & & & \\
\hline $42 /$ I I & 000 & 000000000 & 000000000 & 000000000 & 000 & & & \\
\hline $42 / 3$ & 000 & 000000000 & 000000000 & 000000000 & OO----- & & & \\
\hline $42 / 5$ & 000 & 000000000 & 000000000 & 000000000 & oo & & & \\
\hline $44 / 5$ & 000 & 000000000 & 000000000 & 000000000 & 0000 & & & \\
\hline $46 / 11$ & 000 & 000000000 & 000000000 & 000000000 & 0000000 & & & \\
\hline $46 / 9$ & OOo & 000000000 & 000000000 & 000000000 & 000 & & & \\
\hline $45 / 11$ & 000 & 000000000 & 000000000 & 0000 & 000000--- & & & \\
\hline $44 / 3$ & 000 & 000000000 & 000000000 & 000000000 & 0000 & & & \\
\hline $43 / 7$ & 000 & 000000000 & 0000 & 20000 & ooo & & & \\
\hline $45 / 9$ & 000 & 000000000 & 000000000 & 000000000 & 000 & & & \\
\hline $52 / 11$ & 000 & 000000000 & 000000000 & 000000000 & 000000000 & 000 & & \\
\hline $55 / 7$ & OOO & 000000000 & 000000000 & 000000000 & 000000000 & 00000 & & \\
\hline $55 /$ I I & OOO & 000000000 & 000000000 & OOOOOOOOOO & 0000 & 000 & & \\
\hline $54 / 7$ & 000 & O00000000 & 000000000 & OOOOOOOOO & DOOOO & OOOOC & & \\
\hline $2 / 9$ & 000 & 000000000 & 000000000 & 000000000 & 000 & 000 & & \\
\hline $50 / 4$ & 000 & 000000000 & 000 & 000 & 000 & & & \\
\hline $50 / 8$ & 000 & 000000000 & 0000 & 0000 & 000 & $0----$ & & \\
\hline $50 / 11$ & 000 & 0000 & 000 & 000 & 200 & o & & \\
\hline $53 / \mathbf{I}$ & 000 & 0000 & 000 & 000 & 200 & 000 & & \\
\hline $55 / 7$ & OOO & ooooc & 000 & OOO & Doo & 00000 & & \\
\hline $56 / 8$ & 000 & 000000000 & 0000 & 000000000 & 0000 & 0000 & & \\
\hline $61 / 0$ & 000 & 000000000 & 000000000 & 000000000 & 000000000 & 000000000 & & \\
\hline $61 / 11$ & OOO & 000000000 & 000000000 & 000000000 & 000000000 & 000000000 & O० & \\
\hline $61 / 0$ & 000 & 000000000 & 000000000 & 000000000 & 000000000 & 000000000 & 0 & \\
\hline $60 / 9$ & 000 & 000000000 & 000000000 & 000000000 & 000000000 & 000000000 & 0 & \\
\hline $60 / 9$ & 000 & 000000000 & 000000000 & 000000000 & 000000000 & 000000000 & o & \\
\hline $0 / 11$ & 000 & 000000000 & 000000000 & 000000000 & 000000000 & 000000000 & & \\
\hline $2 / 9$ & 000 & 000000000 & 000000000 & 000000000 & 000000000 & 000000000 & 000 & \\
\hline $66 / 1$ & 000 & 000000000 & 000000000 & 000000000 & 0000 & 000000000 & 000000 & \\
\hline & 000 & 000000000 & 000000000 & 000000000 & 000000000 & 000000000 & 000000 & \\
\hline & (c) & & & & 5 & 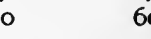 & & \\
\hline
\end{tabular}

From 1899 the term " able seamen" is used in a more restricted sense ; so as to exclude carpenters, boatswains, etc., who were formerly in some measure included.

labour. But even at this lower estimate the index numbers show that the cost of living has fallen more than Ioo per cent., and that society must be vastly better off than it was Ioo years ago. Investigations upon these lines of comparing wages with prices, or the cost of living with wages has been undertaken by many writers and carried out in an exhaustive manner, but it seems very doubtful whether any investigations on such lines have led to any conclusions which are helpful in meeting the industrial difficulties with which 
legislative and philanthropic reformers are confronted. The question is, Do such investigations really explain the problem we want to understand or show us what we have to do? The only result of such study seems to be a complaisant reassurance that society has progressed wonderfully in social and industrial evolu. tion, and that an era of complete progress and satisfaction is close at hand, after which hope the investigation usually closes with a number of well-stated reasons why any further progress involves very complex questions, which leaves the result of all current political or social efforts clouded by uncertainty without pretending to point out any exact line that must be the right one for future effort.

While it is undoubtedly true that the capitalistic method of

DUCRAY 64-AVERAGE YEARLY WAGE OF MALE WORKPEOP'.F (OTHEK THAN APPRENTICES) IN THE WORKSHOPS OF THE STATE KAII.WAYS IX WURTEMBURG, $1894^{-1908 .}$

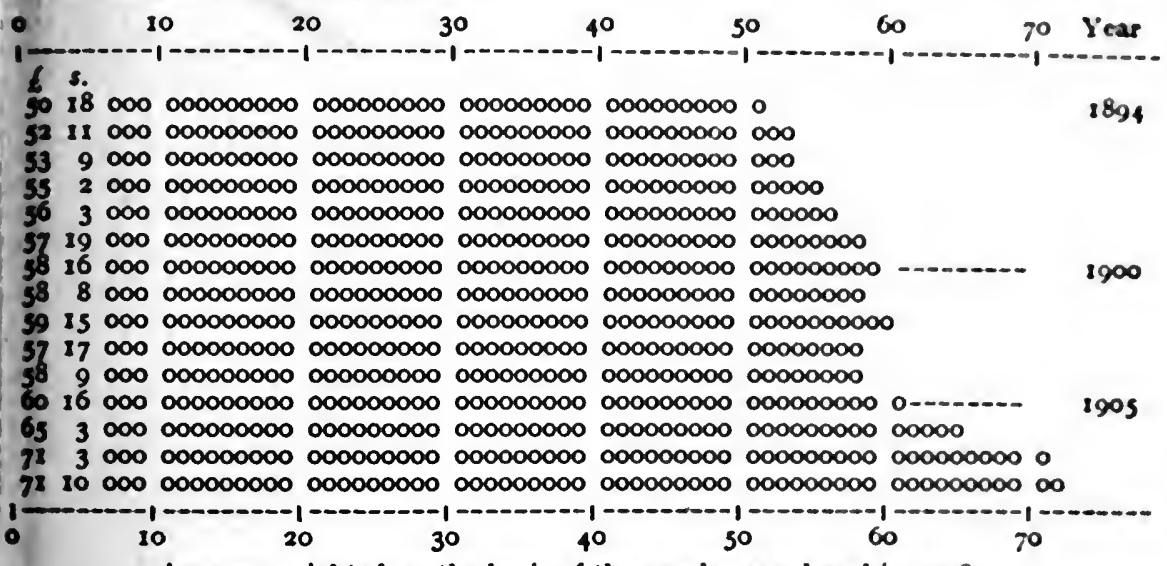

Average weighted on the basis of the number employed in 1908.

production has achieved marvellous success, and rapidly raised the standard of living and general well-being of the world as no other force can be shown to have done, it still remains a fact that we are faced with serious social problems that show no sign of being overcome. There is want and suffering that is none the less acute because we are told that things were worse roo years ago, industrial unrest and disorder that is none the less threatening because economists can prove it is based on economic misconception. Unless economic science can afford practical guidance in these current difficulties of social administration it has fallen short of its aim. and while we by no means wish to give the absurd impression that a scientific inquiry is not good and useful simply because it has not been able to carry its labours to fruition in the goal of complete knowledge, we believe there is a test to which a sound method of research must answer. Failing to attain absolute knowledge as all 
human methods must, it should be able to definitely demonstrate the point at which the evidence breaks down or is wanting, and clearly indicate what it is we want to know next, and, if possible, show how we can get to know.

It would seem that the line of investigating economic problems by comparing rates of wages with index numbers that represent market prices and the cost of living, fails when it comes to practical industrial questions in not being able to show exactly what we want to know next, and we believe our theory of wages helps us to find that next link in the argument. What we require to know is not whether wages in relation to the cost of living are better or

DIAGRAM 65.-AVERAGE RATES OF WAGES PER MONTH, WITHOUT BOARD, FOR FARM LABOURERS IN THE UNITED STATES, 1866-I9I4.

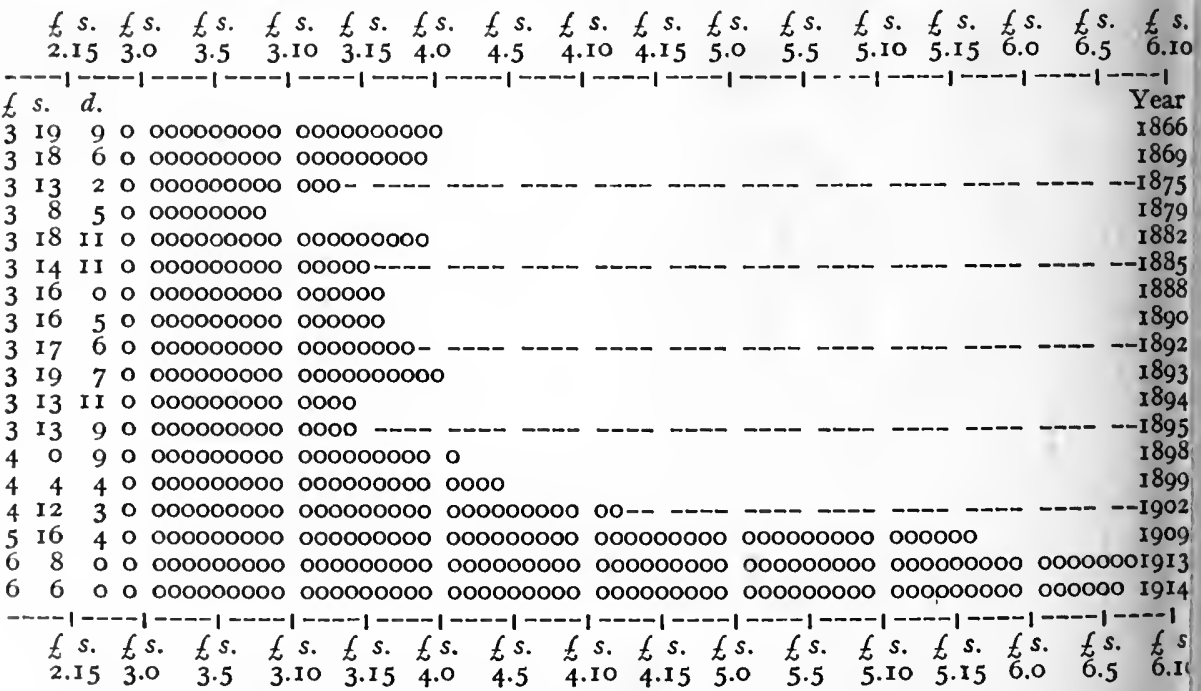

From Fourth Abstracts of Labour Statistics, 1866-1902, and U.S.A. Farmers' Bulletin, March, I9I4 (I909-I9I4).

worse than they were 50 years ago, but whether they are as good to-day as they possibly can be, and the first step towards that knowledge must be to find out what it is that the level of wages depends on-how the amount of wages to be paid is actually determined. We have seen that wages are the price paid for an undetermined share of the value produced; then we obviously want to know how the approximate value of that share is arrived at, and how the actual amount paid is determined? Because it is the fixing of that share and its distribution amongst the wage-earners that is the cause of all industrial problems and labbour trouble.

All the evidence given in our diagrams of normat prices and wages shows that they have moved together, and that wages must have always been about the same proportion of the production per person. 
By Diagram 66, illustrating the movement of wages in the United States, it will be seen that in the year 18.49 the wages were $\$ 247$ per person, against $\$ 579$ to-day. So that from the cost of living stand. point wages were 135 per cent. more in 1914 , even if the prices of commodity were the same, and many of them must have been much higher in 1849 , so that the real or commodity wages would be at least 200 per cent. more. But although from this point of view wages in the United States have improved so much, it was shown by the figures given in Chapter III. on the division of the national income (Tables 4,5 and 6 ) that the proportion of wages to the

Diagray 66.-AVERAGE WAGES, UNITED STATIS CENSUS OF PRODUCTION

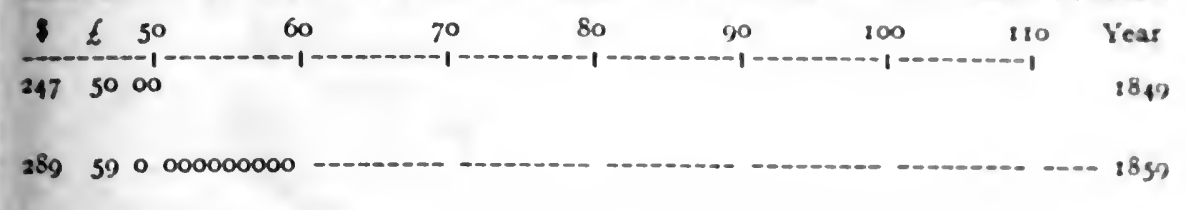

$30262000000000000-186$,

34771000000000000000000000.01879

$449100000000000000000000000000000000000000 .-185$,

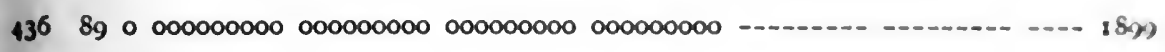

48910000000000000000000000000000000000000000000000000

$518105000000000000000000000000000000000000000000000000000 \ldots-\ldots$ ig:

579118000000000000000000000000000000000000000000000000000000000000000

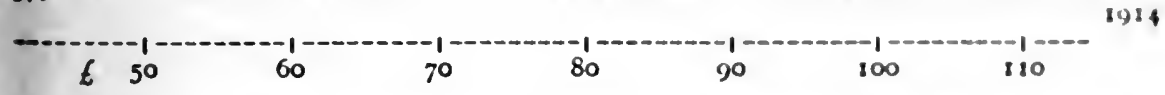

production of the labour in America is unchanged, the wages share of the production having averaged about 53 per cent. all the time.

In Chapter III. it is also shown that salaries seem to be about II per cent. of the production, and, although in that chapter we separated wages from salaries, because there were no published figures for salaries paid, and they were not included in the wages returns, there is no economic difference between salaries and wages, and they should both be included under the head of wages, and we shall so include them in the rest of our inquiry. So if salaries are added to the above United States wages figures, the average share of production that is paid as wages will be 64 per cent. This is perhaps rather high, and it was pointed out in that chapter on the division of the income that this percentage was not claimed as an exact figure; the data are not nearly exact enough to give anything but a fair approximation to the true percentage. But the tables 
given of English wages in such trades as were available (Table 8) show wages as 56.7 per cent. of the average production, which percentage was shown by Table 5 to be equivalent to 53 per cent. of the total product. That plus II per cent. for salaries is 64 per cent. of the product. Also French coal miners' wages (Diagram Io) are $5^{6}$ per cent., which, in the same way, equals 64 per cent. of total production. These and Table 9, showing the Co-operative Society's wages as 62 per cent., seem to us good evidence that at all times and places there has been a point between 60 per cent. and 64 per cent. of the production which marks the share due to wages. The percentage of wages in Australia from the only figures we can get is very low, being apparently only $55^{\circ} 9$ per cent. for wages and salaries together, but in this case there is certainly a large error in the available data. The total value produced is the gross value, and the deduction made for expenses by the Census is quite inadequate, only including light and fuel, we believe. It should also be remembered that as we claim that this value paid for in wages is an undetermined amount its determination by means of an average requires that the figures used in such average shall cover a considerable period, or shall be only for strictly normal years. Otherwise the average may be much distorted by abnormal local conditions, and some of these examples, especially the last one, are far too short a period to compensate for the rough data on which they are based. The more reliable examples, however, point to the fact that there seems to be an average point at which the wages share is fixed, and that it is somewhere between 60 and 64 per cent. of the total production. So that, though in any particular case the value paid for in wages is an undetermined quantity, the fact that average wages are kept so persistently near to 64 per cent. indicates that there must be some very practical law that settles what this undetermined quantity shall approximate to.

We hope in the next chapter to be able to explain this law, which determines the proportion of the production which goes as the wageearner's share, but there are one or two other points about this share of wages that require to be considered in this chapter. We have seen from the weighty evidence afforded by the numerous censuses of production taken in the United States, supplemented by such further evidence as other countries afford, that wages appear to be definitely about 63 or 64 per cent. of the production. But we have also seen that the value of that production expressed in money depends upon the amount of gold produced by a like amount of labour, so that the value of any commodity produced per person in a given time will be the same as the value of gold produced per person in the same time. Therefore, if wages are the same percentage in both cases, the wages of commodity producers will be the same, and fluctuate with those of gold miners, and the average wages 
in every industry will be the same as the wages of gold miners. As evidence of the truth of this conclusion it is interesting to find from Table 55 that even in the Transvaal mines, where black labour is employed, the average wages come so very near to the United States percentage of production. The period covered by these Transvaal figures is too short to give a very reliable average, but the wages percentage for the whole period is $6 \mathrm{I}$ per cent., and if the carly part, that is doubtless disturbed by the after-war conditions, is left out, and the later six regular years taken, the wages are 63 per cent. of the production. This is no doubt due partly to the fact that the production by this inferior labour is somewhat less than that of the highly efficient American labour, and that, therefore, the wages can be less without being a less proportion of that production. But it is also due to the fact that the low wages of the black labour necessitate higher wages for the white supervision and skilled labour in the Transvaal mines.

This brings us to the question of various rates of wages paid to the different classes of labour. We see from the production per person in different goldfields (Table 44) that both the production and wages vary, but the proportion of production that goes as wages seems to remain the same. Evidently different qualities of work in a gold mine are regarded by the management as producing, and no doubt do produce, different quantities of gold per person. An expert miner or even a white foreman, who uses no tools himself, evidently increases the output by more gold than a nigger would, or he would not be employed at higher wages. An organiser by his greater ingenuity obviously does produce more gold in the time he is at work than a coolie would do in the same time, or he not only would not earn more, but could not earn more. He cannot be paid out of any supposed inflation of the price, that does not vary; the extra gold raised by his organisation is the only extra value from which he can be paid. It may be seen by Table 44, of the Old World gold production, what a difference there is between the production of coolies in India and the miners of Australia, and as wages in these places are evidently about the same proportion of the output, it is evident the wages of a certain quality of labour depend upon the quantity of gold that quality of labour can produce. It is just as obvious that in the production of commodities generally there are the same differences in the quality of the labour, and what any particular grade of labour will earn depends upon what amount of the commodity it produces. But as the value of that amount of commodity depends upon the amount of gold produced per person. and the amount of that gold produced depends on the quality of the labour producing it, it follows that the value of the portion of commodity produced by a given grade of labour depends upon the quantity of gold produced by a like grade of labour in the same time 
So the average wages of any grade of labour will be the same as those paid to a similar grade of labour in a gold mine.

It is most important to thoroughly grasp the significance of this hypothesis, that the value or price of commodity produced in a given period of labour-time depends upon the amount of gold that particular labour or a like quality of labour would produce in the same time. Otherwise this theory of wages not entering into cost of production cannot be understood. For there are many cases, as, for instance, that of the production of coal in India, where the wages are so low that coal is sold for $4 s$. per ton at the pit head, which looks as if in other countries what increased the cost and made the price so much higher was the higher wages and not the greater labourtime, as we claim it to be. The Indian coolie certainly works as much time and more, but does he really work as much or as well ? The fact is, he does not, he is of less working capacity, his production is very small, and he can only get cheaply such coal as is very easily mined. The gold value of his share in the production is not up to the average gold standard, but only up to the value of gold produced by a like coolie washing gold from alluvial in a basket, and not earning any more than he could by growing rice or anything else. It must be remembered that the labcur cost or value is not the cost to a particular individual, but the cost to the community, and some qualities of labour being of less productive value to the community than others, a given time of this inferior labour is less valuable to the community. It will produce less gold or less of anything else that society wants, so a day of such labour is regarded by the community as less than a day's labour; it is only half a day's work. The average productivity per day is the standard of value per day to the community, so the value of a day's work of a producer of average capacity is equal to the gold produced by a miner of average capacity, and the values of higher or lower grades of labour are equal to the values produced by higher or lower grades of gold miners.

So it comes about that when society is determining what the wages of a certain worker shall be, it grades him by unconsciously judging that he would if working in a gold mine produce more or less than the average production of gold per person. The general law which we think governs the various grades of wages is that a worker of a given grade of capacity will be able to get the same remuneration that he or another worker of like capacity would have got if he had worked in a gold mine. But, although this appears to be the law that would actually obtain throughout industry if the distribution of labour and organisation was perfectly fluid, and could be regrouped without difficulty or friction, it is quite evident that friction does exist, and that in local cases the wages of a grade of labour might hang behind or rise much ahead of the level which it appears they should have attained to. This obvious possibility naturally 
leads to the impression that there are many glaring cases where wages in particular industries diverge very far from the level imposed by this law, and that in some trades where wages are very low it is obvious that the workers' average capacity is as good as in many trades where wages are higher. But although it may be easy to find a case of under-paid labour and assert that those labourers are as capable as some that are paid more, it is by no means so ceasy to prove this asserted capacity or to fully appreciate what actually constitutes capacity.

It is probably just this difficulty of actually grading the capacity of a worker or of a class of labour that gives rise to these abnormal cases of low wages or exaggeratedly high salaries. Obviously a class of labour cannot have its productive powers tested by being put to work in a gold mine, nor as a matter of fact can its members be subjected to any experimental test of their powers in any industry. The individual worker can only be tested by the ordinary competitive method, because the discovering of his full latent ability takes far too long to be done as an experiment before fixing his rate of wages. His whole life of work and earnings is an experiment to discover that undetermined value of the production which is his share. The result is that the wages at which a labourer starts work have no relation to his ultimate capacity, and often very little to his immediate productivity, but depend very much on custom, until by competitive experiment his true productive value is discovered. It may quite well happen in some cases that such experiment is so imperfectly worked and takes so long that each worker's life is over before the experimental stage is complete, and in that case the wages of his grade of labour depend upon custom and may do so for an unlimited period. This was probably the case with the often quoted chain. makers of Cradley Heath, a whole population of expert blacksmiths. both male and female, who for generations worked for a miserably low rate of wages, and one that was far below the general wage level of the country.

Custom had relegated this whole class of chain-makers to a grade of productive value below what appears to have been their actual capacity. That is to say, chains were worth more gold to the community than the makers got for them, and these workers had the capacity to get more gold if they had been in a gold mine than they got by making chains. Why, then, did they not go into gold mining or at any rate into some trade that paid as well as gold mining? Surely the rising generation among them could have done so? It is important to notice that they did not do so to an adequate extent because it means they acquiesced in the custom that fixed their wages; they had fixed their own wages by their custom of taking it for granted that they could not get more gold than they had always done before, either in a gold mine or anywhere else. So long as they 
so value themselves the employer cannot raise the standard of wages unless he can at once employ the whole population of chainmakers, because those whom he did not employ would work at the old wage for some one else who would be able to undersell him. So it came about that the workers in this industry were undervalued and underpaid until by Trade Union organisation they were able to prove their higher productive capacity. When as a class they made this claim society was obliged to recognise that the labour cost of chains was greater than had been supposed, and either pay more for chains or find some improved way of making them with less labour. Which of these methods was actually pursued we are not quite certain, but it may perhaps have been the former, for, as there was no labour willing or able to make chains at the old wages, all the employers might have raised their wages and put up their prices for chain without much fear of competition for the moment. It is unlikely in this case that the margin of profits was ever very large, and it certainly would not be reduced when wages were being raised by special organisation. If this was the case, and the normal price of chain was put up to compensate for the rise of wages, it looks like an exception to the law that wages, only being a share of the production, do not enter into cost or price. Nevertheless, we believe the law holds good, and that a case like this, if it ever actually occurs, is only a local distortion of the law due to assignable causes. The law is only absolutely true of the average wages in gold mining and the average wages in the rest of commodity production as a whole. Any grade of labour that is above or below the average might under suitable circumstances alter the standard of its wages and of its prices so long as it did not alter the general level of prices relatively to gold.

It is, however, difficult to see how a rise of wages and prices like the above could occur without altering the average value of commodity produced relatively to the gold production. Theoretically it could not unless gold, wages, and production were moving in the same direction. This is why it is so desirable to clearly recognise the general law in spite of its local modifications; it is only because cases like the above are so insignificant compared with industry as a whole that they can occur without perceptibly affecting the average level of prices ; their results are lost in the maze of social productivity. As their effects are so lost sight of and obscure, they afford very uncertain and inconclusive data for economic purposes, and should not be allowed to obscure the more general laws. If instead of this obscure industry it had been 25 per cent. of the working world who had tried to raise their wages and prices it is obvious that the high prices of commodities would make gold production relatively so unprofitable that its production would be greatly reduced, and then prices would have to come down and wages follow them. In a comparatively small industry like chain-making the fact that the law of payment 
by productivity is not completely operative is no doubt due to the friction in the industrial adjustment of labour and capital, but the facts are so complicated that without special knowledge of the case it is not possible to be quite certain of either the cause or the ultimate effect. We think that in this particular case the organised raising of wages and prices that is generally supposed to have taken place was only made possible by the backward condition of the industry. It seems, like many Birmingham trades, to have depended largely upon the personal skill of the workers, who were trained craftsmen and craftswomen in forging iron. That being the case, it would be possible for any small group or family of such craftspeople to produce completed chains ready for the market practically without any business organisation or management at all. The result would be that such groups could compete in the market against the somewhat larger manufacturer, and by working for practically no profit beyond their own wages keep the price of chain below the level of general prices. This would discourage better business enterprise from starting more up-to-date engineering methods of producing chain in up-to-date workshops such as would train the rising generation to enter other trades and flow easily out of this congested industry. On the contrary, these groups of back street producers trained their rising generation to follow the customary craft and accept the customary wages as the natural remuneration of their grade of ability, with the result that they became incapable of competing with the members of society outside their own craft and obtaining their rightful share of production. In this stagnant centre of craft industry the working of the natural law of wages would be retarded and fall behind in its adjustments, and the sudden organised raising of wages and prices which appears to be an exception to the general law was simply that law asserting itself after a period of retardation and bringing the chain-makers' wages and prices up to the general level. The organisation had roused into activity the latent competition, and it is upon effective competition that the very existence of the law depends.

Although we recognise that the law of prices may be retarded in its action by such customs as the above in fixing the productive value of a particular class of labour,we by no means admit that such cases are so numerous or so effective as to invalidate the argument for the existence of the laws of price or wages. No doubt custom does cause local deviations from the law in the case of wages in certain industries, but that it does so to the extent of any very great or permanent effect on the price is very doubtful. In the above case it was assumed that the average price of chain was too low and did go up as the result of trade union organisation, but there are many questions to be asked before this can be accepted as an unquestion. able fact. Are the better wages now paid to all and every person 
or their true representatives that were making chains at the time of the alteration, or are there certain persons, women blacksmiths for instance, who can no longer get their living by that craft? Are there actually as many men and women employed in the trade now as there would have been if the wages had been unaltered, and does the total output per person actually sell for more than it did, or is it simply that certain kinds of chain cost more, but that cheaper machine-made kinds are more largely used ?

These questions are important, because if less persons are employed for the same output their productivity has improved and they are worth more wages. And if only the cost of certain kinds of chain has gone up and machine-made or partly machine-made chain is being substituted for costly hand-made classes so that the total output does not realise a higher price than it would have done, the normal price has not really gone up. The productive methods may have changed, so that, although the wages of those who are now employed in the trade are better, the profits may be the same percentage as before, and the average price of the chains now made remain the same as it would have been for the kind of chains that they used to make. If this was the case it quite alters the position, for it means that the chain-makers by their custom of craft production were actually wasting labour in producing a class of work that the public did not need and only used because it was cheaper by custom. The chainmakers' productive capacity was not undervalued, it was a low capacity, because, though skilled as blacksmiths, they were incapable of finding out how to make the chain the public wanted in a cheap way, or of organising themselves so as to encourage inventive ability.

To really discover what actually did happen in this case of the chain-makers would require very exact data and minute investigation, and we only make the above suggestions to illustrate how difficult it is to show that any special case of abnormal wages and prices does or does not conform to the general economic law, and that it is therefore much more scientific to base our conclusions upon the broader evidence derived from average records that cover long enough periods to allow the various deviations from the law due to custom and other local retardation of its working to cancel each other and leave only the mean effect of such deviations to represent the movement that is due to and coincides with the law.

From such broader evidence as we have examined it appears that the records of wages paid over a considerable period of years show the share taken as wages tends to be a very definite proportion of the total production, and this could hardly be the case if custom in determining wages had at all permanently affected the total wages earned in many industries. For, as we have seen, the lower or higher total wages paid must be supposed to affect the price in the same direction if the wages are to remain the same proportion of the price. 
And if the price or value produced in any particular trade is thus permanently fixed by custom in wages this value should not vary periodically as the standard of prices varies. If it does so fluctuate with other prices, while still remaining on its own lower average level, it must be susceptible to the ordinary competitive forces that regulate such fluctuations, and why, then, do these forces not bring the wages and prices in that particular trade up to the general level ? If any trade does permanently fall below the average return per person it must either be because the labour is of an inferior class or that the ordinary competitive forces do not affect it, and in that latter case it would not follow the fluctuations in gold or general prices. So far as we have seen, no trades of any importance fail to follow such fluctuations, nor do the wages, as shown by the tables and diagrams in this chapter. That being so, it is very doubtful whether custom alone can appreciably affect wages and prices, unless it is the custom on the part of the workers of being inefficient. We have admitted the possibility that in isolated cases a price may be so affected, but think that many of the cases that naturally occur to the mind, such as the low wages of women compared with men's in similar employments, or the wages of farm labourers, are more apparent than real, the high or low normal price and wages being due to better or worse quality of the labour employed.

But while we think the varying grades of capacity account for most exceptional cases of high or low wages within any particular country, any country or large community that is to any extent geographically isolated may quite possibly have established a customary level of prices and wages of its own. The necessary conditions for such independent level would seem to be that a country should be self-contained and capable of producing nearly everything it requires as income. Just as America seems to have a high level of prices because it is self-contained and produces the gold it wants easily, so Germany might have a low level of prices and wages because it was self-contained and could only obtain the gold it wanted at a comparatively high cost (low prices). A country like Germany would naturally tend to keep prices low to obtain the gold that was considered necessary for its commercial stability and its extension of international trade. And it should be remembered that as all prices would be equally low and the production of the country practically self-satisfying, the members of the community might be as well off in goods income as in a country where the money value of a similar income was higher. As the individual workers might be as well off as they would be with higher money wages in a high price country, they would have no special temptation to emigrate and decrease the supply of labour in their own country and thereby send prices up to the highest point the gold supply would admit. But as the cash transactions of such country would still require a definite 
though smaller amount of gold for currency, the level of prices would still vary with the varying cost of that supply. And as the lower price coupled with efficiency of production would greatly encourage foreign trade, the spread of international commerce and enterprise abroad would lead to the country becoming much less self-contained, and with conditions that would ultimately bring a rise of prices to about the average international position, as they seem to have done in Germany as seen by the wages (Diagram 59).

Thus an efficient or inefficient self-contained country may maintain its own customary level of prices for a long time while international competition is not complete. But a single trade or class of producers in a country would not long continue to produce at low prices while they had to purchase at high prices all the things they wanted to consume, unless they were in some way inefficient as producers. Yet a glance at Diagram $I$, which shows the production per person in various industries that produce the national income, will show that there are very considerable differences between the production per worker in different trades. Even when allowance is made for the use of gross figures in those estimates there must be considerable difference in the value produced, and it may sometimes seem questionable whether the whole of this difference is due to the fact that some of these industries can be worked with an inferior class of labour which does not produce as much in a day as the more skilled labour does. It might be argued that if a skilled mechanic was put into a weaving shed to do a mill-girl's work he would not produce any more cloth than she does, but this would be a very crude conception of the position, the question could not be tested in this way. At one time men did do the weaving, and did not produce anything like what the mill-girl now produces, but the men were not content to work in that way, and by their mechanical ability made, or cooperated in the making of, various machines by which vastly more cloth can be woven than could have been previously made by either men or women. We claim that the mechanic to-day is in effect weaving more cloth per hour than the girl at the loom. The cloth produced is not by any means the work of the girl alone, but the joint product of the mill-girl and the mechanic, and it is a question as to which of them does most of the work in each yard of cloth produced. The only test would be to put the girl in the engineer's shop and the mechanic at the loom and see whether the ultimate output of cloth was more or less. That men have to a great extent gone out of the weaving into the production of machinery to increase the production of cloth and other things while women have remained in the sheds is presumptive evidence that men have more capacity for increasing their production by mechanical contrivance and are thereby producing more cloth than the women.

It is probable that the women's incapacity in the direction of 
improving the means of production is chiefly due to their custom of getting married and going out of industry at an age before they have acquired any great experience of industrial necessity and practice, so that custom may still be claimed as the reason for their relatively low wages, but in that case it should be noticed that the custom does itself constitute a defect in the women's productive capacity, they have not acquired the same experience and capability that men who have spent their whole working life in the shops have acquired. As we mentioned above, it is not always easy to say exactly what constitutes productive capacity, and it will usually be found that where the custom of a class of workers leads them to suffer low wages that custom is itself some form of incapacity. It may be a want of judgment or of executive ability which does actually reduce their productive value and would make them produce less cloth in a mill or less gold in a mine if left to their own resources. When such persons become more executive and better organise their labour it nearly always means a greater production per person, in which case the amount of their wages may increase without putting up the price or decreasing the profits. If in the case of the above chain-makers there were many small factors or other go-between persons who made no actual profit beyond the wages which their work was worth under the craft system of production, and owing to the improved organisation of the workers such persons' work was no longer needed, and they were crowded out of the trade, there would have been a saving of labour. The remaining workers would be able to get more wages without affecting the price or profit ; they would have become a little more executive and thus have improved in productive capacity. As these unnecessary factors, or other unrecognised workers who have been crowded out, would not come within the trade union organisation, it would be claimed that the whole wages of the trade had been put up. And as in that case the price would not be raised to compensate for the rise of wages, it would appear as if the share of production going to wages had increased without reducing the share of profit, but in reality the total wages would be no more, as there had been a saving of labour.

It is obvious that in attempting to account for the industrial adjustments that are observed to take place in particular trades it is possible to speculate upon an almost infinite number of probable causes and effects, while it is equally impossible with the existing data to demonstrate the certainty of any of these speculations. It is not uncommon in certain classes of economic writing, and very common indeed in political propaganda, to find such special industrial phenomena very elaborately exploited in support of some particular hypothesis. But in all such arguments we think it will be found that in the present state of the statistical data such complicated examples of industrial interaction are hopelessly inconclusive. 
While it is most desirable that the evidence necessary to elucidate such phenomena should be brought into existence, it is best until that can be done to confine our speculations to the broader line of investigation by evidence which can be drawn from the existing statistical records. Such evidence as shown in our many diagrams seems to show that :-

The value of the output of any commodity is determined by and is the same as the value of gold produced by a similar grade of labour in the same length of time.

That wages in the production both of gold and commodity are the same proportion of the total value produced and are approximately 64 per cent. of that value.

That if the percentage of production paid as wages is altered it must alter inversely the proportion taken as profits if the value of gold produced per person has not altered.

That as the value of gold produced per person may vary above or below the average in accordance with the productive capacity of the miner, so may the value of a particular commodity vary in accordance with the average capacity of those engaged in producing it.

That, wages being an approximately fixed proportion of the value produced, they will vary above or below the average as that value varies.

That the productive capacity of any group of producers, and consequently their wages and the value of their produce, may possibly in certain cases be fixed by custom above or below its true value, in which case the laws of value and wages are modified or retarded in their action to that extent. But it is very doubtful whether any such case can at present be established by convincing evidence, save in geographically distinct countries the productive requirements of which are largely self-contained.

That it is important to recognise that though the value of productive capacity might by custom be estimated as being too much above or below the average in a few cases, the average value of capacity cannot be so misvalued. If it were so it would react upon gold production and alter the standard of value till equilibrium in value was re-established.

That though under very limited circumstances where productive capacity has been graded too low by custom prices might be raised to cover the readjustment of wages, this could not be done if the amount of alteration was enough to have any appreciable effect upon the average value of commodities produced per person, as in that case again it would react upon the production of gold; so that again it is doubtful whether any actual case of such a raising of prices can be substantiated by any conclusive evidence.

So far we have concluded that wages are a definite share of the value produced per person engaged in the production, but before 
we proceed to investigate the laws that determine what proportion of the value produced shall be so allotted it will be well to glance at the chief theories that economists have advocated to account for the recognised phenomena of industrial wages. We have already discussed the "Wages Fund" theory under capital (Chapter IV.). and there practically dismissed it on the ground that so far as we could discover there is no such fund, wages being paid from the current production of the workers. Wages being thus paid from the result of the labourer's own work, this supply or fund can be indefinitely increased so long as there are persons to work and natural resources to work upon, and it hardly seems useful to postulate labour as a fund from which wages are paid to labour. As the produce made by this labour is invariably consumed by labour as fast as it is produced, that also cannot usefully be called a fund. It is often supposed that the whole of this produce of labour is not consumed, but is saved as capital that may be withdrawn from the wages fund. But, as we have shown in the chapter on capital, such savings described as capital are in reality always invested in some form of industry. and are therefore being consumed as wages by some one who is working for wages though not perhaps working for the person who saved.

But although the wages fund theory is now much discredited as a means of explaining the phenomena of wages, it should be recognised that its eminent authors were led into this method of postulating the relationship of the factors in production by the obvious fact that although the organisation of industry that can pay wages may be indefinitely increased by work, it is for some reason or another not so increased, and labour in some cases is left idle. But it does not help us much to say, as this theory seems to say, that there is no fund to pay a man's wages from because he has not been at work to make that fund. The question remains, Why has he not been at work? He surely is not idle because the result of his labour is not in his possession before he has made it ? There seem to be only two possible reasons for his position: either that there is an actual shortage of capital to keep him alive while he does his work, which is obviously not the case in a society where there is endless capital ready and anxious to be invested in any profitable undertaking, or for some reason there is a shortage of profitable undertakings, so that the owner of the capital organisation or improved resource will not allow this particular group of workers to use it. But seeing these workers only demand two-thirds of the result of their labour with that capital, why is it at any time an unprofitable undertaking to employ them in producing what they are short of ?

It is obvious that one reason why the owners of capital decline to employ all the available labour might be that they desired to keep some unemployed labour to compete for work with those who are 
employed and thereby keep down wages, which otherwise might rise above the average two-thirds of the production. But if that were so, why should the owner of capital always be content with one-third profit ? Why should he not keep more labour out of work and cut down wages below the two-thirds share? This introduces us to another famous theory of wages known as the "Iron Law," a name that was given to it by German socialists who regarded it as the fundamental law of wages under the capitalistic system of industry. The theory was originally held by the classical school who argued that the competition of the workers must always tend to bring wages down to the level of the barest subsistence that the workers would consent to live and work upon. Experience has proved that in civilised communities the workers' wages have risen far above the starvation point, a fact that has made it necessary for those who still believe in the iron law to qualify their idea of subsistence, postulating an ideal standard of living below which any particular grade of workers will not consent to be reduced, and above which they cannot rise. But as this recognised standard of living does not prevent, and is not claimed to prevent, the competition of the unemployed from reducing wages, it is not obvious how this idea of what are necessities of life can prevent the competition reducing wages below the possibility of maintaining that or any other standard. And if in some way a recognised ideal could maintain its standard of living, why should that standard not rise indefinitely and the workers' conditions of life improve without limit? These very contradictory possibilities show that the supposed law is quite useless as an explanation of the phenomena it is intended to represent. We have seen that the average wages of labour have risen greatly in 50 years, and no doubt the standard of living has kept pace with them ; but it remains to be shown what law has determined that throughout the whole of that period the proportion of the wages to the total value produced should remain about 64 per cent.

The theory of wages which perhaps comes nearest to our own view of the question is the one known as the "productivity theory." The economists of this school recognise that the general level of wages has risen greatly during the period in which the productivity of the community has been greatly increasing, and regard it as evident that labour tends to get the increase which its growing productivity has produced. It cannot be denied that labour has got part of that increase in its production, but there seems to be very little reason for supposing that it has got, or tends to get, the whole of what is the result of its own effort; yet that seems to be the view taken by some of the chief supporters of this productivity hypothesis. Such opinion seems to be based on the assumption that labour when organised in any industrial establishment naturally falls into theoretical groups or departments, in each of which there is employed 
labour of a certain grade of capacity. The capacity of that grade is represented by the latest addition or the least able man employed in it who will be set to work on any old machine, and being inexperienced, will produce nothing more than he gets as wages. The reason he is supposed to get all he produces is that if he did not he would go somewhere to work where he could do so, or work for himself without an employer. The other workers in the grade appear to get a pecuniary advantage of some kind not quite explained because their acquired skill has fitted them to be trusted with better machines; but all the wages they can demand or their value to the employer will be limited by the productive ability of this least capable man, because if any worker trying to get higher wages leaves the group the others can all move up one on the machines to fill his place, and the last comer, or marginal man as he is called, having moved up one, it is only necessary for the employer to find another marginal man. It seems to be claimed by this school of economists that, as the marginal man gets all he produces, and the others get just what they are worth more than the marginal one, they all get the share of the product that they actually produce. But as those of them that have been at work longer are using better and better machines or other capital instruments of production, they are producing more than the marginal man, and more than is necessary to pay their wages. This surplus being solely due to the use of the capital, is produced by that capital and not by the man that uses it, and is therefore claimed to be the portion of the product produced by the work of the capitalist to whom the machine belongs. and consequently to be his rightful share of the total production.

In this way it is supposed that labour gets the whole of what it actually produces itself, because if it did not it would work for itself without the aid of the capitalist. But while it may be true that labour consents to work for wages and an employer because it could not do so well for itself by working without tools in a wilderness, it by no means follows that when it works with machinery under capitalist organisation it necessarily gets the whole of what it then produces by its own actual work. The theory seems to suppose that any individual whose remuneration is limited by the marginal earnings of the grade he is in can always step into a higher grade if he has the capacity of the lowest or marginal man in that superior grade. But if, as seems inevitable, the converse of this is true, all that the highest man in the top grade of a business produces above the production of the top man in the next grade below is the result solely of the capital instruments he uses, his wage value to his employer is fixed by the marginal production in the grade below him. And in the same way the second grade's wages value is fixed by the one below, and so on to the bottom. So that the wages value of the highest paid person seems to be determined by the capacity of the 
actual marginal man at the bottom, and all that is earned above that lowest wage is made by the capital instruments and should be the capitalist's share.

Obviously the above does not agree with industrial experience; an individual cannot always step into the productive grade that will insure that his wages shall be the whole of what he actually produces. In fact, the whole supposition that labour in industry can either in theory or practice be so graded as to insure that every one shall get all that his ability makes seems a preposterous travesty of what actually takes place in any industrial establishment. It is one of the first aims of good management to get hold of a capable man who, not quite knowing his own worth, will do good work for low wages, and to keep such a man on low wages so long as possible. The new hand in a works is not paid all that he earns, or anything like it, and the object of a great deal of the best machinery is to enable young and inexperienced hands to do good work, and to render any great capacity unnecessary, so that it is often the marginal man who produces the best profit in a well-managed shop. The usual method of calculating costs results in getting an equal profit on all the labour employed, and the whole theory of the marginal man seems to be quite foreign to actual business experience.

This seems to have been more or less felt by other economists of the productivity school, and we find a modern work by Professor H. I. Moore the object of which seems to be an attempt to show that there is some substantial connection between certain general conclusions of pure economics and the concrete facts of industry. The author makes use of the data provided by the records of coal production in France, which he analyses by elaborate mathematical formulæ. By this method he shows not only that the trend of wages is upwards with the increased value of the production per person, which increase is only what might be expected from all records of industrial wages, but he shows what is much more important, that there has been a slight increase in the relative share of the product taken as wages by the labourers. This trend of increase in labour's share of the product he shows to be related to the increase in the capital with which labour works, and to increase more or less as the capital (machinery with which it works) increases more or less. Although such a connection may be recognised, it seems difficult to see that it has a connection with any general law. If the increase in labour's share of the product is due to the capital it works with, it would seem that the increase is the product of the capital, and should not according to the productivity theory go to increase labour's share. The fact that it does go to labour suggests that there is some margin between the actual value produced by the co-operating parties and the share allotted to each, and that their relative productive capacity does not completely 
determine that allotment. The law or cause determining the amount of the share seems undiscovered.

It is highly probable that in an undertaking that is well capitalised and organised there is a tendency for wages to be a little better than in less well managed concerns. Partly because a better class of labour will gravitate to a well-managed place, and secondly because a better grade of labour will be more likely to well organise itself to keep up the rate of wages without further increasing its own productivity. But such circumstances do not constitute a law which determines that either capital or labour shall get all that it produces.

We think the failure of the productivity theory to discover any general law that determines the division of the value that is produced in industry is due to failure to appreciate the true cause and nature of the value which it supposes the industry to have produced. If capital and labour are each supposed to get only that which is the result of their own work in the mutual production, the total value they divide must be solely the result of their mutual labour. In the above example the quantity of coal produced is the result of the co-operation of the capital and labour, but it cannot be said that the value of the coal was produced by them. Surely the value which society puts upon the coal cannot vary directly with the productivity of the miners? So when Professor Moore demonstrates that the wages vary directly with the value of the labour's production he shows that they vary directly in accordance with something that is not produced by the labour. It should be shown that the miners' wages vary directly with the tons of coal they produce if their wages are to be shown to be determined by their productivity. If wages are compared with the miners' actual production of coal, a very different result may be obtained, as shown by Diagram 67 of the production and wages of French coal miners.

In Diagram 67 the course of French coal miners' wages from $186 \mathrm{r}$ to 1908 is shown by the continuous line which gives the yearly average wages as percentages of the wages paid for the year 1900 : that is, the wages for any year are shown as so many hundredths above or below those of rgoo. The tons of coal produced per man are also shown as percentages of the production in 1900 , and the rise or fall of that production is shown by the broken line on the diagram, so that it can be seen at a glance to what extent wages have followed the variations in production. It will be scen that in the earlier years, while the production remained low, wages went up very considerably. and when production fell very low in $1875^{-6}$, wages went the highest they had been up to that time. From that date till I 889 the production went up very greatly, but the wages hardly went up at all. Then again, as the production falls, wages rise till again the lines cross each other in the year 1900 ; and wages have continued to rise and production to fall ever since. When in 1889 the production was 
8 per cent. above that of I900, wages were I6 per cent. below those of I900. And in I908, when production was 8 per cent. below that of Igoo, wages were 6 per cent. above. That hardly looks like wages

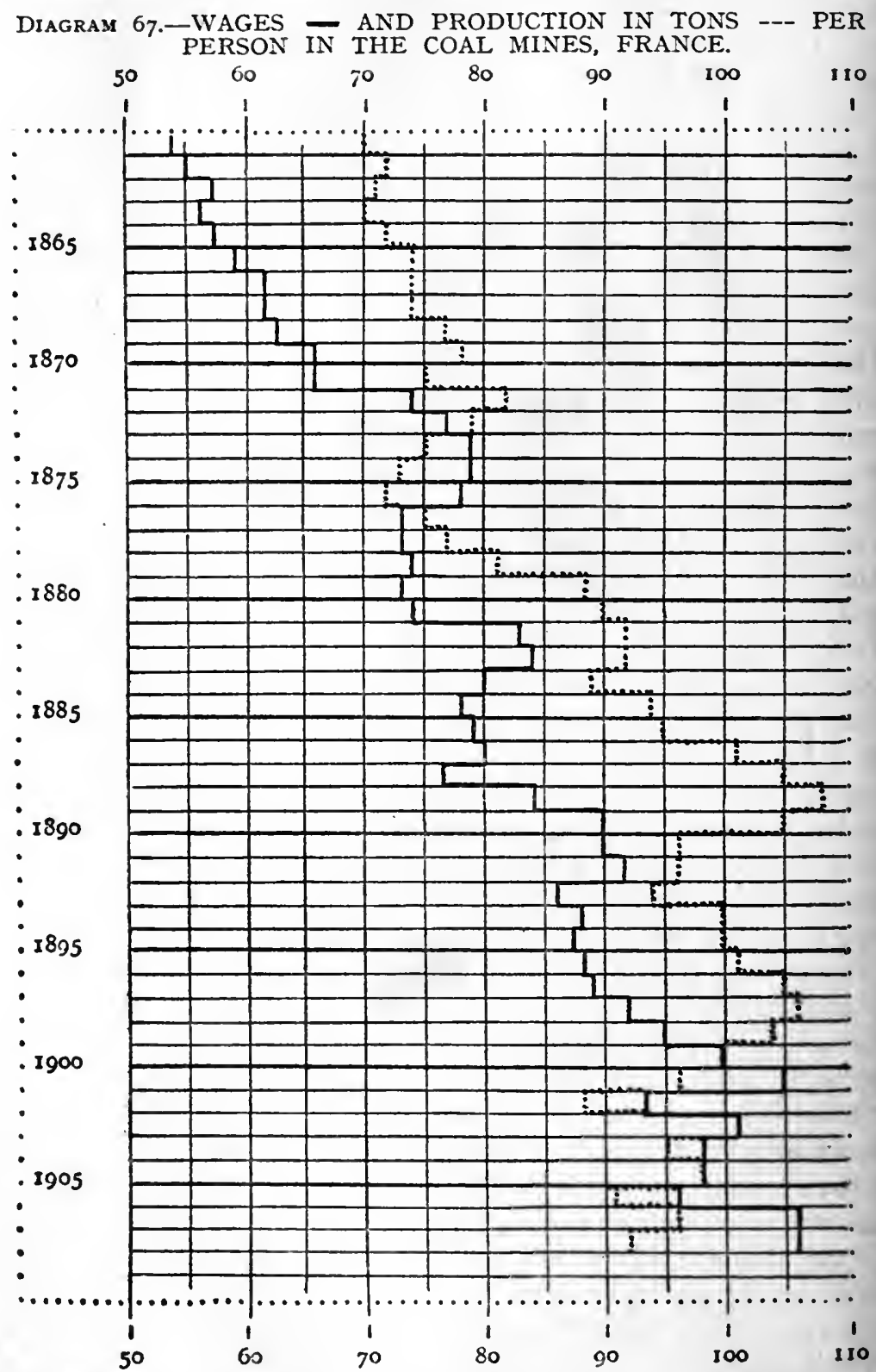

depending upon productivity, and there is good reason to think that if a similar diagram were made for English coal production and wages the contrast would be still greater, for the production has fallen more continuously ; but, unfortunately, we have no record of 
the actual wages paid to English miners. The lessening production and higher price is no doubt due to less easily worked seams of coal having to be mined; but why should the wages go up if they are determined by the falling productivity? It looks much more likely that they went up because the price went up and increased the value of the product of which they were a share. In fact, as the labour of getting coal becomes greater, the value and the wages go up to the point determined by the value produced by a like class of labour in gold mining, because gold is the concrete standard of value in which all prices and wages are measured.

If, as the productivity school contends, prices in the long run are determined by cost of the marginal or most costly increment to the production, why should the employer who produces this most costly part of the supply on some obsolete marginal instrument of produc. tion worked by a marginal man pay the whole of such value produced to that man as wages? Why should he not put a price on that most costly portion of work that would afford him his usual profit ? Other like producers would not be likely to undersell him to get from him that part of his business that did not produce any profit ; and if better-equipped businesses could do so, and make a profit by it, that means that his particular marginal increment of that commodity was not required, and the marginal man must go back to the land or consent to work for a wage that is not quite all he produces. It seems most probable that a man of the lowest ability that could possibly keep himself alive on rent-free land-for be it noticed that he must have some distinct capacity to do that in most parts of the world-would, if he went into a boot factory, produce 50 pairs of boots in the time it would have taken him to make or earn one pair on the land; and does it then seem likely the owner of that factory will give him the whole value of the 50 or more pairs of boots? Of course the supporters of the productivity hypothesis would suppose this marginal man would produce much less than the value of $5^{\circ}$ pairs of boots, but we should think that a very doubtful opinion; be would not, we think, be employed at all on any machine if he did not. In our experience employers do not pay their marginal men the whole value that they produce; we do not think there is any real evidence to show that the worst quality of labour is usually set to work on old machinery or is employed unprofitably at all. It seems a rather strange coincidence that this school of economic theorists should come chiefly from America, where the modern industrial creed demands the scrapping of every bit of machinery or plant that will not yield the maximum profit, and that no one shall be employed who is not efficient in his production-a country where it would seem that the backward and obsolete business would be the last in the world to determine the price or value of commodity. Such backward businesses simply do not make a profit above that which goes 
to make up any over-high salaries, but though in such case the wageearners as a whole get all they produce, they surely cannot all be marginal men or have any special correlation to their marginal men ? It will be found that the wages that have to be paid by that firm will depend upon what is being paid by better firms, not only in their own industry, but in industry generally ; in fact, the average industrial wages for that grade of capacity. And the price, too, of their unprofitable goods will obviously not depend on their high costs but upon the average costs of all producers of that commodity. There is no evidence to show that it is the greatest cost incurred in producing the final increment of supply that fixes the price or cost of the whole supply. If the marginal shoemaker spoiled one pair of marginal boots and had to make another pair in their place that final increment of boots would have cost him double; but it would be absurd to say that the price of boots to the community would be doubled by that extra cost of the final increment of supply. Yet if any large proportion of the country's supply of boots were spoiled in the making the price of boots would undoubtedly go up in accordance with that extra cost. It is evident that it is the proportion which the extra cost margin bears to the lower cost bulk of the production that determines how far that marginal cost will affect the general price, which is simply a roundabout way of saying the price depends upon the average cost of production.

Moreover, it does not appear that the marginal productivity theory can quite account for the division of the product between labour and capital even theoretically. For if the marginal man in industry produces a value of 5 s., and receives the same in wages, and the man in the grade above him who produces the value of Ios. receives $7 s$. $6 d$., the extra $2 s .6 d$. is supposed to represent the second man's ability over the marginal man. But why should he consent to that valuation? If he went back to the rent-free land to work on his own, 'his superior ability over the marginal man should make him able to produce $7 s$. $6 d$. where the other only produced $5 s$. If the employer needs him, he must pay him rather more than he gets on the land, say $8 s$., or he will leave his job. But if $8 s$., why should the man not demand the whole Ios. value that he produces, just as the marginal man gets all he produces? The marginal man cannot compete for the second man's job, because he is not able enough to produce the Ios. value. If, on the other hand, it is not the second man's ability but the quality of the machine he works upon that makes the production of Ios. value, the marginal man can with that machine produce as much as the other, and his competition for the job will enable the employer to cut down the wages for that work to about 5 s., and send the second man back to the land to cultivate with his superior ability. But in that case the marginal man, although he gets as much as he could get on the land, only gets half 
what he produces in the mill, and he might as well be back on the land also. Obviously, if the mill-owner wants either or both these men he must pay them more than they get on the land and less than they produce in the mill, less than their ability in the mill. There must be some other competing labour force which this theory does not show that determines the point between 5s. and 10s. where these men's wages will be fixed. It is the failure to explain this competition and how it determines the two-thirds of production point at which average wages are fixed that makes this theory so inconclusive and leaves it very doubtful whether the contributing factors in production do each get the actual share they produce.

Before it is possible to form a satisfactory theory of wages it is necessary to show first exactly how the price or value of the divisible production is determined, and secondly to show the exact nature and limits of the competition that determines the relative shares of that product. We believe that in the foregoing chapters we have given a satisfactory theory of how the value of production is determined, and we think that any one who has appreciated the confirmatory support given to that theory by the experiments in price forecasting described in the last chapter will also appreciate the practical advantage of our theory over the marginal theory of value. For by the marginal utility theory, if it were wished to forecast a cotton price, it would be necessary to discover the cost to the community or the marginal value of the most hopelessly costly pound of cotton grown on the worst bit of rent-free land in the world. How its cost to society could be known even when the particular pound was discovered we have no idea. In fact, the very notion of finding any price that way is absolutely hopeless. By contrast, at any rate, our theory looks reasonable, and the next step is to show the nature of the competing forces that determine the division of the value produced into the shares of wages and profits. 


\section{CHAPTER XI}

\section{PROFIT AND UNEMPLOYMENT}

In the last chapter we tried to show that wages were a share of the product of industry paid by the employer to the wage-earners as the value of that part of the product which was the specific result of the wage-earners' work, and it was left to be inferred that the remaining share kept as profits was the specific production of the employer. This share and the nature of the employer's claim to it remains to be discussed further in the present chapter, for it was pointed out that the actual value produced by the efforts of each of these two co-operating agents in an industry was so difficult to determine that the value paid for each of them was practically undeterminable. Yet experience has shown that in practice the share allotted to wages has always been about 64 per cent. of the whole, so that there appears to be some law that virtually determines wages shall be that average proportion. The nature of that law has been a fruitful theme of discussion amongst economists, who, up to the present, do not appear to have conclusively shown how the competition of the conflicting interests in industry can determine the point at which profits must be limited. The difficulty seems to be that it is not easily seen why, on the one hand, the labourer, according to his productive ability, should not claim the whole of what he produces and leave nothing for profit, unless the employers prevent it by withholding their capital, or more correctly, by withholding from labour the right to use the improved resources which they as capitalists possess. Or, on the other hand, if the employers can so withhold the right of access to these improved resources, why should they not do so until the wages share of the lowest grade of labour they require is reduced to that level of subsistence that could be obtained by cultivating no-rent land-in fact, the starvation level ? There is evidently some reason why the employer's desire for a larger share of the production stops long before it has reduced wages to starvation point; and no theory of wages can be said to be satisfactory that does not show a definite reason why such other point is determined by the competing forces. For it is just the legitimacy of this point of division between the shares of profit and wages that is the source of all economic dispute and of most political rivalry, and it should be the aim of any rational system of political economy to find some scientific basis for sound arbitrament upon this point.

The employer of labour must be a capitalist or represent such 
person who has been fortunate enough not to have been obliged to consume the whole of his share of the social production. and who. therefore, has a claim on the social capital, which share he can, if he so wishes, take in the form of instruments of production or organised industry. Such capital instruments and organisation having become their property, the capitalists have the right to with. hold their use from the wage-earners unless they receive what they think to be a fair share of the value produced by the use of their capital. As they own the capital, it would seem reasonable that they should have the sole right to say at what price it shall be used. but before that claim can be finally admitted it may fairly be asked whether the means by which they come to own the capital are strictly justifiable from the economic standpoint? Practically in no case has the capitalist actually made the instruments of production which he owns; they have come to him as his share of the production of organised labour, and only if that share was justifiable is his possession of capital justified. This means that any question as to the justice or desirability of the share of production that is taken as profits involves also a doubt as to the fair ownership of the capital acquired as that share. It is obvious, then, that before any conclusions as to the rightness or justification of the capitalist position can be come to it is absolutely necessary to understand exactly what is the social mechanism by which this share of the product is determined.

The justification of the share of production which can be taken as profits is thought by the productivity school of economists to be assured by the free competition of the capitalists. As we have pointed out in Chapter IV., capital is of no use and really ceases to exist as capital or even resources unless it is employed by labour, so that the withholding of capital from labour is a very serious loss to its owner, and the result is that the competition of employers to use their capital will bring down profits to the lowest possible point at which any one will consent to let his capital be used. But if that is so why should it be possible to make any profit at all ? It is recognised that there are industrial concerns in nearly all branches of commerce where at times no profit, properly so called, is made. Why should not the competition of such firms reduce profits to nothing? As the ability of the most capable wage-earners certainly reaches and overlaps the ability of the salaried manager, and the ability of the more capable salaried managers again overlaps that of the average employers, why should not the competition of these quite able producers lead to their employing the capital they are always producing in a business for themselves on a method that paid no profit above wages and salaries of ability? It seems that it would inevitably be so if it were not for the counter-competition between the workers to secure employment, which competition tends to reduce 
the wages and consequently increase the share that goes to profits. But although this competition is recognised by all economists it does not seem, if we may judge by the productivity school's representation of it, that its real nature and effect has been quite appreciated. If all the labour was employed either in industry or on rent-free land it does not appear that their mutual competition would tend to reduce wages. Th: man on the land would not compete for a wage-earner's job if in doing so he brought those wages down to as little as he could earn on the land. Nor would any worker compete to get a better job if in getting it he brought the wages for that job down to where he was before. There might be emulation and effort to improve in ability for the sake of getting a better post, but only in anticipation of the post continuing to bring a higher wage than the aspirant had been earning ; people do not usually strive to do more or better work unless it offers a better remuneration of some kind. Such a competition would not reduce wages or increase profits, which latter would undoubtedly be brought down to the point of extinction by the competition of the salaried employers. To give the kind of competition that will prevent this it is essential that the wage of the marginal man in industry shall be so much higher than what the man on the rent-free land can obtain, that when the latter has supplanted the former in his job at a reduced wage, that wage is still better than either of them can get on the land, otherwise he will not compete. But if that is so it appears that neither of them is on the rent-free land at his own wish, but that for some reason he cannot get into industry where he wishes to be; he is in fact one of the unemployed.

That profits are not brought down to the vanishing point is evidence that there is an effective competition between the wageearners, and to get such competition it is absolutely necessary that there shall be two men of equal productive ability (so far as the work required is concerned) and that one of them only shall be fully employed while the other is partly or wholly unemployed. It is now generally recognised by writers upon the wages question that it is the unemployed, or more correctly the partly employed, workers whose competition reduces the rate of wages for those who are at work. It is sometimes rashly stated by partisan controversialists that there is no one unemployed who is willing and able to work, but in the light of present day statistics such opinions can hardly be taken seriously. The fact that trades unions publish records of the number of their members who are out of work really puts the fact of unemployment beyond all question; a man who was too idle to work would not pay to be a member of a union, and it is certain his union would not long continue to allow him out-of-work pay if he was habitually idle. There is also another class of unemployed who, unfortunately, do not get represented on the unemployment returns but are 
nevertheless unquestionably forced by industrial conditions to be partly idle; these are persons who are in employment but only working short time. The fact that such persons are retained at their job proves they are willing and able to work the required hours, and their not being permitted to do so for the full day also proves that they are to that extent unemployed owing to industrial conditions. If a factory is only working three-quarter time the hands are unemployed a quarter of their time, which is equal to one wholly uncrnployed person to every three in full employment.

We have seen in the foregoing chapters that the average price of commodities is a definite value, determined by the labour cost of their production relatively to the labour cost of the gold in which their price is measured. Therefore the total average value produced by the persons employed in any industry is at any one time a definitely determined amount, and the sum of the shares into which that product may be divided must amount to exactly that value, so that if the share allotted to wages is more that to profits must be less, and vice versá. To understand how the average rate of profit is determined it is in the first place necessary to see exactly how unemployment of labour affects wages and thereby alters the rate of profits.

Unemployment affects wages in two distinct ways. The first is the very obvious one that a shortening of the hours of labour while the same rate of wages obtains will reduce the total amount of wages earned in any given period of time, such as a year, although the rate of wages is not changed. For instance, if the rate of wages is $\$ 2$ per week the total earnings for a normal year of 50 working weeks would be $£$ roo, and the loss of one week by unemployment would reduce the actual wages earned to $£ 98$; or at the other extreme, if the labour was unemployed for 49 weeks the actual wages earned in the year would be $£ 2$ only, although the rate of wages had not changed. This direct reduction by unemployment in the actual wages earned, from 6100 per year to nothing when no time is worked, is illustrated on Diagram 68 by the diagonal line running from o unemployed at the top to roo unemployed at the bottom. This reduction is so obvious that the figures for the alteration of the wages by this cause alone are not set out on the diagram, which is intended to illustrate the more complex effects resulting from this loss of employment.

This reduction in wages is the direct result of working less time at the same rate, without reference to the effect on the rate of wages due to the competition for work which is caused by the increase in the number of unemployed persons. It is sometimes contended that the partial unemployment of persons who are working short time does not tend to cut down the rate of wages, because these partly employed people are not competing for jobs, and therefore they should not be looked upon as an addition to the competing force of the unemployed. We think that this impression is due to a 
failure to quite appreciate the exact nature of the competing process, which when closely examined seems to chiefly depend upon the action taken by such workers who are working, or who are afraid they will have to work, short time. If a labourer is permanently out of work he obviously does not compete to reduce wages, and it can hardly be possible for a man to live in such condition unless he has private means. It is only when an unemployed person comes into work again that he becomes an active competitor for wages, and then the extent of the reduction he will submit to depends upon the difficulty he finds in getting into a job. If an industry in which an unemployed person is trying to get work is employing all its hands full time it means that business is fairly good and the unemployed person will not have great difficulty in getting work in it, and consequently he will not submit to any great reduction in his rate of wages. But if that industry is on short time the unemployed person will find he has to submit to a much greater reduction in his rate of wages if he is to get work.

This is largely due to the fact that those persons who are at work part of their time will be more anxious not to be thrown out of work altogether at such time of short employment, and rather than risk being replaced by the unemployed person they are likely to agree to some reduction in their wages, especially if they hope it may lead to more full employment. Employers who find themselves obliged to go on short time do not usually advertise for or try to find a complete staff of employed persons who will supplant their existing labour staff at reduced wages. They commonly call their leading hands together, or through their trade union officials express to them their regret that it will be necessary to further reduce the hours worked unless the employees can assist them in cutting down the cost of their goods by submitting to some reduction in wages, or by acquiescing in the introduction of labour-saving machinery or processes that will mean a temporary reduction of earnings at any rate. Negotiations made with trade unions are far more likely to be successful from the employer's point of view when many workers are on short time, showing that it is the competition of the partly employed to keep what they have that tends to reduce wages quite as much as the efforts of the quite unemployed to get a share. The power of labour organisations to keep up wages is always greatly reduced when much short time is being worked, and strikes then become almost hopeless. At such times there are many industrial expedients by which wages can be cut down, but it is hardly necessary to prolong this digression with a discussion of them, for it must be evident to any one who reflects on the possibilities of reducing wages under pressure of a shortage of work that the partly employed are a very effective competing force and form a very practical part of the unemployed.

Unquestionably the competition of labour to obtain work is a very 
powerful factor in reducing the rate of wages, a fact that is recognised by all economists and writers upon economic questions, so that in illustrating the effect of unemployment upon wages the direct loss of wages by short time worked or by complete unemployment, which loss is indicated on Diagram 68 by the diagonal line, must be added to by the amount that the rate of wages is lowered at the same time by the increased competition due to that increased unemployment. This means that if 25 per cent. of workers were unemployed or 25 per cent. of time was lost the lowering effect on the wages would not be simply a loss of 25 per cent. in wages as shown by the diagonal line, but the lowering of the rate would result in an additional loss in wages equal to a further loss of 25 per cent. of time, or some such amount, for. as we shall point out, the exact effect of this competition has still to be ascertained. But as this competition undoubtedly does have the same effect in reducing wages as an extra loss of time would have, it must be represented on any diagram that is to illustrate the effect of unemployment on wages. As it is not possible to show on the same diagonal line that 25 per cent. of unemployment is in effect 50 per cent., we have projected a parabolic curve on the diagram to indicate the joint effect of the percentage of unemployment and its ancillary competition which reduces the rate of wages. Unfortunately, there are practically no data to prove exactly what the competing force of any particular percentage of unemployment is, because, although we have some little evidence as to how much wages have changed for better or worse, we have hardly any data as to how much short time was worked. In addition to a little evidence relating to wages paid, we have a return made to the Board of Trade by certain trade unions as to the percentage of persons unemployed, that is, persons out of work. But this is only part of the competing force, which is in all probability more than doubled by the extra competition for work on the part of the large number of persons who have not been allowed to work the full hours that they are willing to do, and are therefore less able to resist and much more likely to accept reductions in the rate of wages.

It was pointed out in the last chapter that the evidence from records of wages over long periods shows that the average share of the product so allotted is about 64 per cent., and the diagonal line on Diagram 68 shows that to bring wages to this point by direct loss of time 36 per cent. of workers must be unemployed. This would obviously be a great exaggeration of the average unemployment, due to leaving out the reduction in the rate of wages caused by competition for work. If we can show that when wages are 64 per cent. the average unemployment is less than 36 per cent.. the difference between that less percentage and 36 per cent. would be the effect on the rate of wages due to competition, which is the factor we require to know as the basis for projecting the curve on our diagram. 
Wages averaging 64 per cent. of the product, we require to know the average unemployment, and, as we have said, the data for this are very inadequate, the only figures being the returns by various trade unions as to the number of their members who are out of work. Such returns only cover a very small portion of the working community, so can only be taken as suggesting the average number of persons who are unemployed. And this defect gets worse as we follow the data farther back in time, because the unions who made returns were fewer and therefore less representative. From these official returns, published in the " I4th Abstract of Labour Statistics," we find that from $\mathrm{I} 875^{-19 I 4}$ the average unemployment was 4.83 per cent., that is, about 5 per cent. of the workers (see Diagram 79). But this does not include persons working short time, and on that point the data are still worse. The only fragment of evidence we can find is from the "Abstracts of Labour Statistics," and shows the days worked by coal miners. From this record it appears that miners make about $7 \cdot 8$ per cent. short time (see Diagram 82 ), which, added to the 5 per cent. unemployed, would make the total unemployment about I 2 per cent., and from I 2 to I 3 per cent. would seem a probable amount for the average industrial unemployment.

This evidence is admittedly very scanty and unsatisfactory, and can only be taken as suggesting the probable total of unemployment. The evidence afforded by the unemployment returns from various other countries is very conflicting and suggests great want of accuracy in collecting the data. American returns for unemployment show an average of 16 per cent. of the workers unemployed, or as much as 22 per cent. including sickness, which seems as much too high as the 2 per cent. returned for Germany seems too low. This extreme difference is probably to some extent due to the fact that little or no short time is worked in America, the workers being fully employed or totally out of work, whereas in Germany they seem to systematically restrict total unemployment by working short time. As in neither case have we any record of the short time made, it leaves it very doubtful how much actual unemployment is covered by the " out of work " figures returned. It is quite possible that more data might have been obtained from German statistics had it not been for the outbreak of war. Table 69 gives the " out of work " returns for various countries, which returns seem in all cases to be made by trade unions and will therefore very poorly represent the unemployment in the many trades where labour is not organised by unions. From these conflicting figures we conclude that 12.5 per cent. would be a reasonable average amount to allow for short time and unemployment together as the average total unemployment.

If 12.5 per cent. be taken as the probable amount of unemployment the difference between 12.5 per cent. and 36 per cent. $=23.5$ per cent. is the amount by which competition for work reduces wages 
when 12.5 per cent. are unemployed. To show this on the diagram a vertical line must be drawn at 12.5 per cent. unemployment, and a horizontal line from 64 per cent. wages to 36 per cent. profit, and where these lines intersect is one of the points through which must be drawn the curve which is to show the effect of unemployment on wages. Obviously the curve must start like the diagonal line at the point where all are employed, and end like it where all are unemployed, so we thus get three points through which to draw the curve. As in practice wages never sink to any of the extreme points below about 20 per cent. unemployment, the actual course of the curve below this point is quite hypothetical and not of any importance. We have chosen a parabola as the curve most suitable to fit the few

TABLE 69.-PERCENTAGE OF UNEMPLOYMENT.

\begin{tabular}{|c|c|c|c|c|c|c|c|}
\hline & France. & Germany. & Belgium. & U.S.A. & Norway. & Denmark. & Australua \\
\hline $\begin{array}{l}\text { I899 } \\
1900\end{array}$ & $\begin{array}{l}8 \cdot 3 \\
8 \cdot 0\end{array}$ & & & & & & \\
\hline I90I & $9 \cdot 9$ & & & & & & \\
\hline I902 & II·3 & & & & & & \\
\hline 1903 & IO.I & $2 \cdot 7$ & $3 \cdot 4$ & & & & \\
\hline 1904 & I0.8 & $2 \cdot I$ & $3^{\circ} \mathrm{O}$ & I $2 \cdot 1$ & $4^{\circ} 0$ & & \\
\hline 1905 & $9 \cdot 9$ & $I \cdot 6$ & $2 \cdot I$ & $8 \cdot 5$ & 4.4 & $13 \cdot 25$ & \\
\hline I906 & $8 \cdot 4$ & $I \cdot I$ & $I \cdot 8$ & $6 \cdot 8$ & $3 \cdot 2$ & $6 \cdot 12$ & \\
\hline 1907 & $7 \cdot 5$ & $\mathrm{I} \cdot 6$ & $2 \cdot 0$ & $13 \cdot 6$ & $2 \cdot 5$ & 6.79 & 5.7 \\
\hline I908 & $9 \cdot 5$ & $2 \cdot 9$ & $5 \cdot 9$ & $28 \cdot 0$ & $3 \cdot 6$ & 10.96 & 6.0 \\
\hline 1909 & $8 \cdot 1$ & $2 \cdot 8$ & 3.4 & 14.9 & $5 \cdot 0$ & $13 \cdot 32$ & 5.8 \\
\hline I9I0 & 6.4 & $I \cdot 9$ & $2 \cdot 0$ & 15.6 & $\begin{array}{l}3.3 \\
.8\end{array}$ & 10.5 & 50 \\
\hline I9II & $\begin{array}{l}6 \cdot 3 \\
6 \cdot 0\end{array}$ & $1 \cdot 9$ & I.9 & $18 \cdot 6$ & $\begin{array}{r}1.8 \\
1.6\end{array}$ & $9^{\circ} 2$ & $\begin{array}{l}4.7 \\
5.5\end{array}$ \\
\hline I9I2 & $\begin{array}{l}0.0 \\
5.2\end{array}$ & $2 \cdot 0$ & $1 \cdot 3$ & 15.2 & $\begin{array}{r}1 \cdot 6 \\
1 \cdot 0\end{array}$ & $7^{\circ} \cdot 2$ & 5.5 \\
\hline $\begin{array}{l}1913 \\
1014\end{array}$ & $5 \cdot 3$ & $2 \cdot 9$ & 2.0 & $20 \cdot 8$ & 1.9 & $\begin{array}{l}0.9 \\
0.7\end{array}$ & $\begin{array}{r}3.3 \\
I I \cdot 0\end{array}$ \\
\hline 1914 & - & 72 & 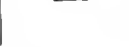 & 275 & & & \\
\hline
\end{tabular}

items of data available for our purpose, but that curve is not claimed as essential, nor need it be a smooth curve at all.

The first point that may strike any one in looking at the curve of wages on Diagram 68 is the fact that it shows the competition for work has a greater proportional effect in lowering wages when only a few per cent. are unemployed than when a greater percentage are so, whereas it would seem that as the number of unemployed grew competition should become more acute and lower wages faster. Probably neither view is quite correct, but it may well be supposed that the average wage-reducing effect of each unit or percentage of unemployed persons would be the same whatever the number of units. Of course 5 per cent. of unemployed persons getting back into work while the value of their production is unchanged would reduce wages five times as much as $\mathrm{x}$ per cent. getting back; but the 
last per cent. of the five would not make a greater or less proportion of alteration than the first per cent. that got back. If this were so, it would appear that the curve on the diagram does not correctly illustrate the amount of change in wages due to each percentage of unemployment, and that the displacement of the wages rate due to competition should be represented by another straight line running from o unemployment to the 64 per cent. wages and 12 per cent. unemployed, which would show an even competing force of 2 per cent. reduction of wages for each per cent. out of employment. But if such line was produced towards the bottom of the diagram it would point to the absurd conclusion that after 33.3 persons were unemployed, who reduced wages $66 \cdot 6$ per cent. by competition and 33.3 per cent. by lost time, which together is 99.9 per cent., there would remain 66 per cent. of workers in employment but getting no wages at all.

It therefore seems evident that the competing value of each percentage of unemployed persons cannot be regarded as the same for all amounts of unemployment, but that it must obviously be a diminishing force as unemployment gets greater, and that we are therefore justified in representing it by a curve that will pass through the three required points. But there is no evidence to show exactly at what percentage of unemployment the competition increases or diminishes, and it may not be regular in its action; therefore the only useful postulate is a diminishing progression throughout, as illustrated by a parabolic curve. The very rapid effect of the last one or two percentages on the rate of wages may not be quite correct, but as unemployment seldom reaches these points the error does not much affect the question. The effect of these few percentages may be rather too great to represent the average correctly on this diagram, which represents the effect of increasing or decreasing unemployment on wages only so long as the roo per cent. of full employment represents $£$ IOO or other value that remains constant, but they have some compensating advantage when compared with an actual rising movement of wages. When wages move the normal price or too per cent. total value never is stationary ; the employment only varies because the value of the production has varied. But if the $£$ roo production, which on the diagram is taken as roo per cent., should become $£$ IIo, then the average share going as wages when I2.5 per cent. are unemployed would come to 70.4 per cent. of the original $£$ roo total, but it would still only be 64 per cent. of the new value of $£ I I O$, so that a second diagram made when the total value had altered would if expressed in per cent. only be a copy of the first and show no difference; the diagram illustrates a static condition only. But the exaggerated effect on wages by the first few per cent. of unemployment is probably the result of the dynamic changes which must occur if the price or total value changes, and in 
view of the importance of these dynamic forces in our theory of trade fluctuations it is here desirable to understand how a change of the percentage of wages comes about.

It is important to keep in mind that the rise or fall of wages that we are discussing is an increase or decrease in the proportion of the produced value that is allotted to the wage-earners at the expense of profits. Because as there is good evidence that over long periods those shares have averaged one-third and two-thirds respectively. it would seem that the long established forces of competition by which this point of division is maintained would have become so completely organised on either side that absolute equilibrium would have been established, and that the shares of wages and profits would never alter unless there was some outside force that could definitely disturb that equilibrium. Such a cause of disturbance is found in changing prices caused by alterations in the production of gold. When prices rise or fall the money value of the production of labour becomes greater or less, and it is obvious that then the shares both of profits and wages might be greater or less without altering the proportion of either. But experience shows that at times of changing prices the proportion of wages to profits is apt to vary. In fact, it is only at times of varying prices that the proportion of wages can alter, for if prices are high or low and remain stationary at either position, equilibrium of competition will be established at the normal position between wages and profits. But while the price is moving in either direction the dynamic adjustments of the various forces, retarded in their action to different degrees by the industrial environment, may lead to displacement of the equilibrium point as one set of agencies is slower in adjustment than the others.

Thus when prices are rising and the money value of the product of labour is therefore getting greater, the first adjustment is an increased profit to the employer, because that is the direct and unopposed result of higher prices. There would be no reason why wages should rise if it were not that as profits have become large the employers naturally want to increase their businesses, and in doing so employ more labour. That means they work fuller time, which reduction of "short time unemployment " is an increase of actual wages, which again leads to a reduction of the competition for work. and the "rate of wages" begins to rise. But as the workers have no exact knowledge of the amount to which competition is reduced, they are not immediately in a position to demand higher rates of pay, and they commonly do not find out that they can do so until the increased cost of living due to high prices gives them a reason for an organised demand. So it comes about that while prices are actually rising wages drag behind and only rise slowly. so that the employer gets rather more than one-third of the production and เ.พ. 
labour rather less than two-thirds. Further, it should be noticed that when labour does demand increased wages there is not likely to be any great resistance to it on the part of the employers, so long as prices are believed to be going up; and thus it is that when times are good and the percentage of unemployment is small each reduction in that small percentage sends wages up faster.

As wages tend thus to lag behind during a continuous rise of prices the conditions of our curve for rising prices are never quite realised, and wages though rising fall just short of the points they should attain according to the wages curve on the diagram. But when the rise of prices slackens or stops the effect of the small percentage of unemployment quickly tells, and wages rise rapidly and the share of the product going to profits is reduced in favour of wages as indicated by the diagram. Employers do not at once realise that prices have reached the top, they are slow to start reducing their business, and it is then their side of the dynamic balance that is slow in its adjustment, and as the rise of wages is in full swing it is carried on and the condition of our wages curve for increasing wages is fully realised.

But when, on the other hand, prices begin to fall and profits are directly diminished by the amount of that fall, with the result that some employers put their works on short time or dismiss some of their hands, the consequent reduction of wages that should result from the increased unemployment is met with a stout resistance on the part of the wage-earners. After a time of good wages and full employment short hours come at first as somewhat of a relief to labour and are not then regarded as an unmixed evil, so that the competition for fuller employment is not very keen, and workers for a time will not consent to any reduction in rate of wages to obtain fuller employment. It is only as the percentage of unemployment gets high and short time work is long continued that the competition for work gets acute and wages begin to fall rapidly. This is just the reverse of what takes place in a period of rising prices. When towards the end of a period of rising prices wages begin to gain upon and overtake the increase in profits the employer's resistance to the rise of wages is at first slight, only stiffening as the loss in profits becomes obvious and certain ; and during the interval wages increase rapidly with each percentage less unemployed. When, on the other hand, at the beginning of a fall of prices unemployment begins to reduce wages, the resistance of the workers is very strong, only submitting to a rapid reduction of the wages rate as the competition for work becomes obvious and certain; and during the interval wages diminish but slowly with each percentage more unemployment. This reversal of speed in the movement of wages under different circumstances means that the upper part of our wages curve is only about correct for periods of rising prices, but this would only affect 
the first few percentages to any great extent. When starting from o unemployment, the third and fourth percentages of unemployment might have a greater effect in reducing wages than the first and second per cent. had; but the fourth might still have a less propor. tional effect than the third, and each subsequent percentage have a diminishing effect as indicated by the present curve. This effect might be indicated by a supplementary curve for falling wages, but the data for such periods do not seem sufficiently good to enable us to draw any useful line; so one curve is all we can at present make use of:

Having thus postulated a curve to represent the combined effect on wages by unemployment and competition for work, it remains to examine the few other bits of evidence that statistics afford and see how far they support the conclusions expressed by the curve. The evidence from variations of actual wages is very small, the only public records of wages for this country being those quoted in the last chapter. The use we require to make of such records is to find the average wages actually paid for a series of years, and see how far they rise or fall with the rise and fall of unemployment. In the first place we have only settled upon the average amount of 12.5 per cent. for total unemployment over the whole period covered by our data, and not an average for each year of a series. But we have the yearly average of the unemployed as it is returned to the labour statistics, and, as we have seen that lost time seems to be one and a half times as much again, we may add that amount to the official returns for unemployment to get the total effective unemployment for any year; this, at any rate, will be near enough to indicate with which employment point on Diagram 68 any year must be compared.

The Board of Trade figures for wages paid to a recorded number of persons in 15 selected trades (Table 70) covers a short period of years and shows the variation in the wages received. As it is the actual sum paid to that number of persons it of course represents any loss to those persons through short time that they may have had to work. But there are always some persons so much unemployed that their lost time amounts to a percentage of persons unemployed for the whole year. For example, if Io persons worked at a factory during a year of 50 weeks on three-quarter time as follows :-

8 work 50 weeks, $t$ short time $=121$ weeks each $=100$ lost.

\begin{tabular}{|c|c|c|c|c|c|}
\hline 1 works & $\begin{array}{l}\left\{\begin{array}{l}25 \text { weeks, } t \text { short time } \\
\text { and is unemployed }\end{array}\right. \\
\left\{\begin{array}{l}25 \text { weeks, \& short time } \\
\text { and is unemployed }\end{array}\right.\end{array}$ & $\begin{array}{l}=6 t \\
=25 \\
=6 t \\
25\end{array}$ & 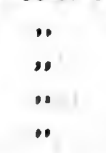 & $\begin{array}{l}= \\
= \\
=\end{array}$ & $\begin{array}{l}6 t \\
25 \\
25\end{array}$ \\
\hline & - & Tuta: & $k s$ lost & & $162 \mid$ \\
\hline
\end{tabular}


In the official returns this would be stated as showing that the factory employed an average of nine persons for the year working three-quarter time, thus :-

9 work 50 weeks, $\frac{1}{4}$ short time $=I 2 \frac{1}{2}$ weeks each $=I I 2 \frac{1}{2}$ lost.

To which we must add an average of one person

$\begin{gathered}\text { not at work }=\mathrm{I} \text { unemployed } 50 \text { weeks } \\ \text { Total weeks lost }\end{gathered}=\frac{50}{\mathrm{I62 \frac {1 } { 2 }}} "$

In such a case as this there would be Io per cent. of the workers totally unemployed although all of them worked part of their time. Of course, persons in this position are not regarded as totally un. employed, but they average xo per cent. unemployed, and the wages paid in the 15 trades would be Io per cent. less than they should be, in addition to the loss by the quarter of time not worked. But as these unemployed persons are part of the working community, and must as a matter of fact compete for and at times obtain wages, their lost time must be included as part of the wages lost to the community. It is the whole loss to the whole working community that we require to know if we want to see how much wages of the community vary from year to year. To find the real average paid per cent. of the working community represented by the $I_{5}$ trades the actual wages paid to the part of them returned as employed must be divided between the whole roo who might have been employed. Thus, if the official figures for any year that is being considered shows 95 per cent. of workers to be employed, that average would be fairly taken as applying to the 15 typical trades; so the average wage per person paid in those trades must be multiplied by 95 , the percentage at work, and divided by Ioo, the percentage that could be at work.

In Table 70 the wages are in the above manner reduced to the average for the community. The first column gives the actual wage per person at work, and the second column the average wage for the whole working community represented by the 15 trades. Thus the first year the average wage per person for the 95 per cent. employed was $£ 42$ Ios., which $\times 95 \div$ Ioo gives $£ 40$ as the real wages per person of the community. The third column gives the official percentage of persons in work, and the fourth column gives the reciprocal percentage of unemployment and short time together, in accordance with which the wages in the second column should, as we contend, vary from year to year.

Before examining this data it will perhaps be well to try and state exactly what we are aiming to do by the use of these figures and what may seem our rather involved manipulation of them. In the first place, the fact that we are comparing the variations in wages paid during a period of years with a curve on Diagram 68 must not lead to the impression that such curve represents the course of wages 
during a period of varying wages or prices; it has nothing to do with any period of time. The diagram is intended to show what at any given time the variation in the share of production going to wages would be for a given variation in the percentage of unemployment. other things being equal. The difficulty of comparing actua! variations of wages with such curve is that other things never are equal ; the actual changes must cover a period of time, and during that time the value of the product of which wages are a share will have changed owing to a change in prices. When prices go up, for instance, wages do not necessarily rise, certainly would not rise if

TABLE 7O-D WAGES RETURNED TO LABOUR GAZETTE. THE PER. CENTAGE CHANGE OF ACTUAL WAGES COMPARED WITH CHANGE SHOWN BY UNEMPLOYMENT DIAGRAM 68.

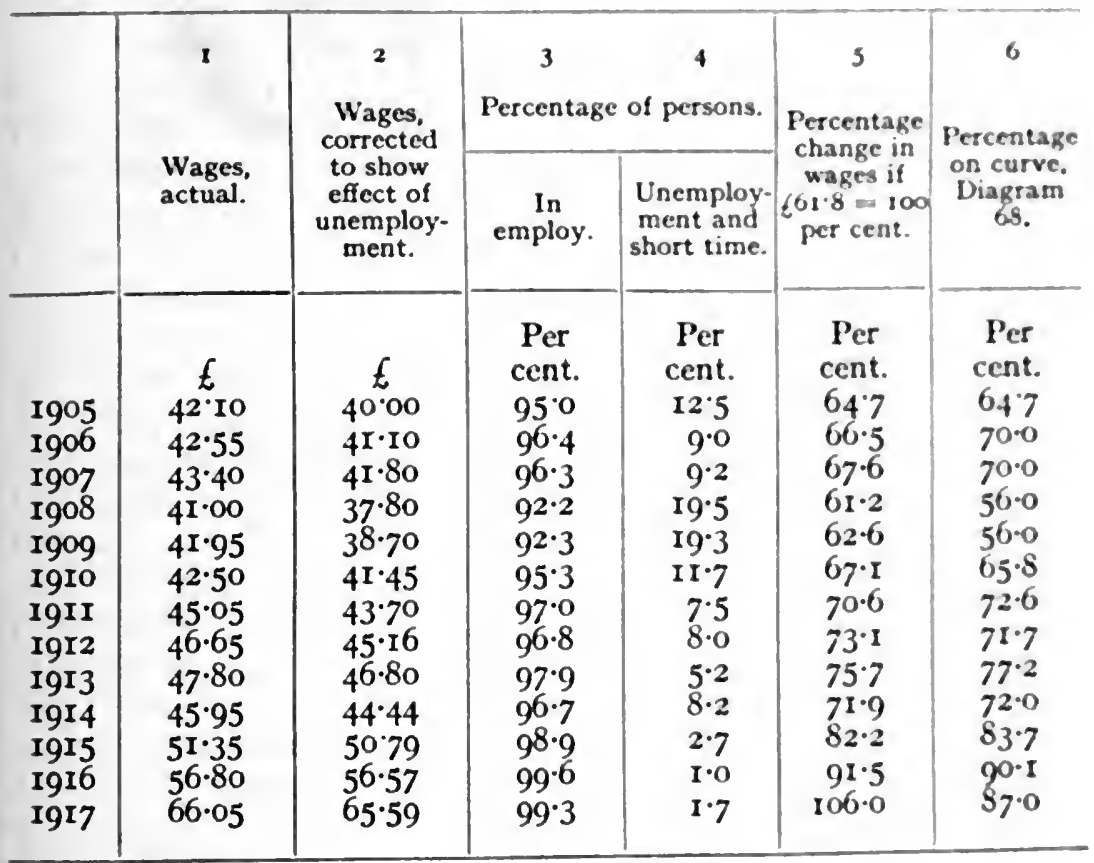

there was no more demand for labour. There must be an increased demand for labour and its reciprocal less competition for work to cause wages to rise; and this percentage of increased employment necessary to produce a given increase in the percentage of production going to the share of wages is theoretically indicated by the curve on Diagram 68. But although this increase in the percentage going to wages may have taken place duly in accord with the percentage of unemployment in a certain year, it may not be visible. If the rising price has increased the total product's value more than increased employment has raised wages, the wages, though an increased share of what the product was at the old price value, may be a less share 
at the increased price value of the product. So that when we compare the actual variation of wages with its respective point on our curve, the share of wages may be a less percentage of the present total value, although a greater percentage of the total value upon which the share of wages was previously based. Conversely, if prices have fallen greatly, wages may actually be lower than they were and yet a greater percentage of the total production.

We therefore require to take some year as a base from which to measure the change in the proportion of wages during subsequent years. But even then we cannot compare with that base the actual percentage of production which wages are in any particular year, even if we knew what that percentage was, which we do not because we do not know what the production was in the $I_{5}$ trades. But even if we did know what the percentage was it would not be comparable, because, as we have just pointed out, the percentage for a subsequent year would vary in accordance with the alteration of the value of the product due to variation in prices, and that element of variation would have to be eliminated before comparison could be made. The only thing we know about the wages in column 2 of Table 70 is that they vary from year to year owing, as we contend, solely to variation in competition due to variation in percentage of unemployment. They are actual wages simply, not a percentage of the production, so that their variation is not affected by price variation but only by competition. In support of this contended effect of unemployment we want to compare these variations in real wages with the variations in the theoretical percentages of the production indicated by the curve on Diagram 68, to see whether the amount of change in real wages from year to year corresponds to any extent with the theoretical changes in the percentage of wages due to a like, variation in the amount of unemployment as shown by the curve on the diagram. For this purpose the wages in column 2 must be reduced to percentages of a common base year, so that the variation in these percentages can be compared with the percentages on the diagram.

To get such suitable base the first year on Table 70 is taken for that purpose. The official figure for unemployed persons that year was 5 per cent., which multiplied by two and a half, as we have suggested to get the full effect of unemployment and short time, together would represent 12.5 per cent. on Diagram 68 . At I2.5 per cent. unemployment line the curve shows wages to be 64.7 per cent. of the total production, and if this is taken as hypothetically correct, the $£ 40$ (Table 70 ) wages for that year being 64.7 per cent., it follows that Ioo per cent. would be $£ 6 r \cdot 8$ wages per person, which is therefore regarded as the possible maximum wage for the labour represented in the 15 trades if the labour got all that is produced at the prices ruling in 1905 . What they did get, being $£ 40$, it was 64.7 per cent. of the maximum $£ 6 x \cdot 8$. The real wages from column 2 for each 
following year are likewise shown in column 5 as various percentagm of that maximum $£ 6 r \cdot 8$, so that the percentage of change frotn year to year can be seen throughout the series. As this $66 \mathrm{~g} .8$ base is calculated from a theoretical point on Diagram 68 it is, of course. quite hypothetical and only used as a probable and therefore convenient maximum wage from which to estimate the percentage of change in wages for each following year. It is not necessary that the wage thus taken as a base should be actually correct : if it was made rather more or less the following percentages would also be rather less or more ; but the proportional change from one year's percentage to the next throughout the series would be virtually unaltered, and it is only this percentage of change that we are concerned witl.

The percentages given in column 6 represent the percentage of the production that should go to the share of wages when unemploy:ment stands at the point indicated by the figure for the same year given in column 4. These figures in column 6 are the theoretical percentage that wages should be according to Diagram 68. Some of these figures can be found down the right-hand margin of that diagram, with the percentage of unemployment just under them. The others may be found by noting where the vertical line for the required amount of unemployment crosses the curve, and drawing therefrom a horizontal line to the margin, where its percentual value may be calculated from the figures that there appear above or below it, the small divisions on the diagram each representing I per cent. To facilitate such calculation we append Table $7 \mathrm{I}$, giving the theoretical percentage of the production that wages should be for every I per cent. of unemployment throughout the whole curve of wages.

When the percentages of actual variation in wages given in column 5 are compared with these theoretical percentages in column 6 or with the wages figures found from the curve on the diagram, it will be found that although the change shown in the two columns does not correspond very closely year by year, there is a tendency for the error of one year to be corrected by an opposite error in the next, so that they do nowhere diverge very greatly during the rising price periods. The change from 1905 to 1907 was roughly 3 per cent. actual, against 5.5 per cent. theoretical; the fall in 1908 was just over 6 per cent. actual, against 44 per cent. theoretical, which is a very big divergence. As we have said, our curve probably needs some allowance for periods of fall, but such a fall of prices as the present affords no sound data for such allowance or other curve. It was not a true period of falling prices, as we have mentioned before, but a short slump after over-speculative prices, and all trades were not equally depressed. The out-of-work figures for the shipbuilding and engineering trades went up to 13 per cent., which, multiplied by 21 . would be 32 per cent. Neither of these trades is included in our 15 trades, and their unemployment figures no doubt make the average 
TABLE 71.-EFFECT OF COMPETITION ON WAGES FOR EVERY I PER CENT. INCREASE OF UNEMPLOYMENT SHOWN ON THE CURVE OF INCREASING WAGES IN DIAGRAM 68.

\begin{tabular}{|c|c|c|c|c|c|c|c|c|c|}
\hline \multirow{2}{*}{$\begin{array}{c}\text { Short time and } \\
\text { unemployment } \\
\text { - persons per } \\
\text { cent. }\end{array}$} & \multicolumn{2}{|c|}{ Casb. } & \multicolumn{2}{|c|}{ Goods. } & \multirow{2}{*}{$\begin{array}{c}\text { Short time and } \\
\text { unemployment } \\
\text { - persons per } \\
\text { cent. }\end{array}$} & \multicolumn{2}{|c|}{ Cash. } & \multicolumn{2}{|c|}{ Goods. } \\
\hline & Profit. & Wages. & Profit. & Wages. & & Profit. & Wages. & Profit. & Wages. \\
\hline & Per & Per & Per & Per & & Per & Per & Per & Per \\
\hline I & $\begin{array}{r}\text { cent. } \\
9.9\end{array}$ & $\begin{array}{l}\text { cent. } \\
90 \cdot I\end{array}$ & $\begin{array}{r}\text { cent. } \\
9.8\end{array}$ & $\begin{array}{l}\text { cent. } \\
89 \cdot 2\end{array}$ & $5^{\mathrm{I}}$ & $\begin{array}{c}\text { cent. } \\
7 I \cdot 4\end{array}$ & $\begin{array}{l}\text { cent. } \\
28.6\end{array}$ & $\begin{array}{c}\text { cent. } \\
35^{\circ} \circ\end{array}$ & $\begin{array}{l}\text { cent. } \\
\mathrm{I}_{4} \mathrm{O}^{\circ}\end{array}$ \\
\hline 2 & $14 \cdot \mathbf{I}$ & 85.9 & 13.8 & $84 \cdot 2$ & 52 & $72 \cdot 1$ & 27.9 & $34 \cdot 6$ & I 3.4 \\
\hline 3 & $17 \cdot 3$ & $82 \cdot 7$ & 16.8 & $80 \cdot 2$ & 53 & $72 \cdot 8$ & $27 \cdot 2$ & $34^{\circ} 2$ & $12 \cdot 8$ \\
\hline 4 & 20.0 & $80 \cdot 0$ & $19 \cdot 2$ & $76 \cdot 8$ & 54 & 73.5 & 26.5 & $33 \cdot 8$ & I $2 \cdot 2$ \\
\hline 5 & $22 \cdot 4$ & $77 \cdot 6$ & $2 I \cdot 3$ & 73.7 & 55 & $74 \cdot 2$ & $25 \cdot 8$ & $33 \cdot 3$ & I I.7 \\
\hline 6 & 24.5 & $75 \cdot 5$ & 23.0 & $7 \mathrm{I} \cdot 0$ & 56 & $74 \cdot 8$ & $25 \cdot 2$ & $32 \cdot 9$ & II'I \\
\hline 7 & $26 \cdot 5$ & 73.5 & $24^{\circ} 6$ & $68 \cdot 3$ & 57 & 75.4 & $24 \cdot 6$ & $32 \cdot 4$ & $10 \cdot 6$ \\
\hline & $28 \cdot 3$ & $71 \cdot 7$ & $26 \cdot 0$ & $66 \cdot 0$ & $5^{8}$ & $76 \cdot 1$ & $23 \cdot 9$ & $32 \cdot 0$ & $10 \cdot 0$ \\
\hline 9 & $30 \cdot 0$ & $70 \cdot 0$ & $27 \cdot 3$ & $63 \cdot 7$ & 59 & $76 \cdot 7$ & $23 \cdot 3$ & $3 I \cdot 5$ & $9 \cdot 5$ \\
\hline IO & $31 \cdot 6$ & $68 \cdot 4$ & $28 \cdot 4$ & $6 I \cdot 6$ & 60 & $77 \cdot 5$ & $22 \cdot 5$ & $3 I \cdot O$ & $9 \cdot 0$ \\
\hline I I & $33^{\prime} I$ & $66 \cdot 9$ & 29.5 & 59.5 & $6 I$ & $78 \cdot I$ & $2 I \cdot 9$ & $30 \cdot 5$ & $8 \cdot 5$ \\
\hline 12 & $34 \cdot 6$ & 65.4 & 30.5 & $57 \cdot 6$ & 62 & $7^{8 \cdot 7}$ & $2 I \cdot 2$ & $29 \cdot 9$ & $8 \cdot I$ \\
\hline I3 & $36 \cdot 0$ & $64 \cdot 0$ & $3^{x} \cdot 3$ & $55^{\circ} 7$ & 63 & $79 \cdot 4$ & $20 \cdot 6$ & $29 \cdot 4$ & $7 \cdot 6$ \\
\hline 14 & $37 \cdot 4$ & $62 \cdot 6$ & $32 \cdot 2$ & $53 \cdot 8$ & 64 & 80.0 & $20 \cdot 0$ & $28 \cdot 8$ & $7 \cdot 2$ \\
\hline I 5 & $3^{8 \cdot 7}$ & $6 I \cdot 3$ & $32 \cdot 9$ & $52 \cdot I$ & 65 & $80 \cdot 6$ & 19.4 & $28 \cdot 2$ & 6.8 \\
\hline I6 & $40 \cdot 0$ & $60 \cdot 0$ & $33 \cdot 6$ & $50 \cdot 4$ & 66 & $8 I \cdot 2$ & 18.8 & $27 \cdot 6$ & $6 \cdot 4$ \\
\hline I 7 & $4 I \cdot 2$ & 58.8 & $34 \cdot 2$ & $48 \cdot 8$ & 67 & $8 \mathrm{I} \cdot 8$ & $18 \cdot 2$ & $27 \cdot 0$ & $6 \cdot 0$ \\
\hline 18 & $42 \cdot 4$ & $57 \cdot 6$ & $34 \cdot 8$ & $47 \cdot 2$ & 68 & $82 \cdot 4$ & $17 \cdot 6$ & 26.4 & $5 \cdot 6$ \\
\hline I9 & 43.5 & $56 \cdot 5$ & $35 \cdot 2$ & $45 \cdot 8$ & 69 & $83 \cdot 0$ & $17 \cdot 0$ & $25 \cdot 7$ & $5 \cdot 3$ \\
\hline 20 & 44.7 & $55 \cdot 3$ & $35 \cdot 8$ & $44^{\cdot 2}$ & 70 & 83.7 & $16 \cdot 3$ & $25 \cdot I$ & $4^{\circ} 9$ \\
\hline $2 I$ & $45^{\circ} 9$ & $54^{\circ} \mathrm{I}$ & $36 \cdot 3$ & $42 \cdot 7$ & 71 & $84 \cdot 3$ & I 5.7 & 24.4 & $4 \cdot 6$ \\
\hline 22 & $4^{6 \cdot 9}$ & $53 \cdot I$ & $36 \cdot 6$ & $4 I \cdot 4$ & 72 & $84 \cdot 9$ & I $5 \cdot$ I & $23 \cdot 8$ & $4 \cdot 2$ \\
\hline 23 & $47^{\circ} 9$ & $5^{2 \cdot I}$ & $36 \cdot 9$ & $40 \cdot I$ & 73 & 85.5 & I 4.5 & $23 \cdot I$ & 3.9 \\
\hline 24 & $4^{8 \cdot 9}$ & $5 \mathrm{I} \cdot \mathrm{I}$ & $37 \cdot 2$ & $38 \cdot 8$ & 74 & $86 \cdot I$ & I 3.9 & $22 \cdot 4$ & $3 \cdot 6$ \\
\hline 25 & $50 \cdot 0$ & $50 \cdot 0$ & $37 \cdot 5$ & 37.5 & 75 & $86 \cdot 7$ & I $3 \cdot 3$ & $2 I \cdot 6$ & 3.4 \\
\hline 26 & $50 \cdot 9$ & $49 \cdot I$ & $37 \cdot 7$ & $36 \cdot 3$ & 76 & $87 \cdot 3$ & $12 \cdot 7$ & $2 I \cdot 0$ & 3.0 \\
\hline 27 & $5 I \cdot 9$ & $48 \cdot I$ & $37 \cdot 9$ & $35^{\circ} I$ & 77 & $87 \cdot 9$ & $12 \cdot I$ & $20 \cdot 2$ & $2 \cdot 8$ \\
\hline 28 & $52 \cdot 9$ & $47 \cdot 1$ & $38 \cdot I$ & 33.9 & 78 & $88 \cdot 4$ & II 6 & 19.4 & $2 \cdot 6$ \\
\hline 29 & $53 \cdot 8$ & $46 \cdot I$ & $3^{8 \cdot 2}$ & $3^{2} \cdot 8$ & 79 & $88 \cdot 9$ & $I I \cdot I$ & I $8 \cdot 7$ & $2 \cdot 3$ \\
\hline 30 & $54 \cdot 8$ & $45 \cdot I$ & $38 \cdot 3$ & $3 I \cdot 7$ & 80 & $89 \cdot 4$ & $10 \cdot 6$ & 17.9 & $2 \cdot I$ \\
\hline $3 I$ & $55^{\circ} 6$ & 44.4 & $38 \cdot 4$ & $30 \cdot 6$ & $8 I$ & $90 \cdot 0$ & $10 \cdot 0$ & $17 \cdot I$ & $I \cdot 9$ \\
\hline 32 & $56 \cdot 5$ & 43.5 & $3^{8 \cdot 4}$ & $29 \cdot 6$ & 82 & $90 \cdot 6$ & $9 \cdot 4$ & $16 \cdot 3$ & $I \cdot 7$ \\
\hline 33 & $57 \cdot 4$ & $42 \cdot 6$ & 38.4 & $28 \cdot 6$ & 83 & $9 I \cdot 2$ & $8 \cdot 8$ & 15.5 & I. 5 \\
\hline 34 & $5^{8 \cdot 3}$ & $4 \mathrm{I} \cdot 7$ & $38 \cdot 4$ & $27 \cdot 6$ & 84 & $9 I \cdot 8$ & $8 \cdot 2$ & 14.7 & I. 3 \\
\hline 35 & 59.2 & $40 \cdot 8$ & $3^{8 \cdot} \cdot 4$ & $26 \cdot 6$ & 85 & $92 \cdot 4$ & $7 \cdot 6$ & $13 \cdot 8$ & $I \cdot 2$ \\
\hline 36 & $60 \cdot 0$ & $40 \cdot 0$ & $38 \cdot 4$ & $25 \cdot 6$ & 86 & $92 \cdot 9$ & $7 \cdot 1$ & I $3 \cdot 0$ & $I \cdot O$ \\
\hline 37 & $60 \cdot 8$ & $39 \cdot 2$ & $38 \cdot 3$ & 24.7 & 87 & 93.4 & $6 \cdot 6$ & I 2.I & ${ }^{\circ} 9$ \\
\hline $3^{8}$ & $6 \mathrm{I} \cdot 6$ & $3^{8 \cdot 4}$ & $3^{8 \cdot 2}$ & $23 \cdot 8$ & 88 & 93.9 & $6 \cdot I$ & II 3 & 7 \\
\hline 39 & $62 \cdot 4$ & $37^{\circ} 6$ & $3^{8 \cdot 1}$ & $22 \cdot 9$ & 89 & 94.4 & $5 \cdot 6$ & 10.4 & $\cdot 6$ \\
\hline 40 & $63 \cdot 2$ & $36 \cdot 7$ & $37 \cdot 9$ & $22 \cdot I$ & 90 & $94^{\circ} 9$ & $5 \cdot I$ & $9 \cdot 5$ & 5 \\
\hline 4 I & 64.0 & $36 \cdot 0$ & $37^{\circ} 8$ & $2 I \cdot 2$ & $9 I$ & 95.4 & $4 \cdot 6$ & $8 \cdot 6$ & 4 \\
\hline 42 & $64 \cdot 8$ & $35 \cdot 2$ & $37 \cdot 6$ & $20 \cdot 4$ & 92 & $95^{\circ} 9$ & $4^{\cdot} \cdot I$ & 79 & 3 \\
\hline 43 & $65 \cdot 6$ & 34.4 & $37 \cdot 4$ & $19 \cdot 6$ & 93 & $96 \cdot 4$ & $3 \cdot 6$ & $6 \cdot 8$ & $\cdot 2$ \\
\hline 44 & $66 \cdot 4$ & $33 \cdot 6$ & $37 \cdot 2$ & I $8 \cdot 8$ & 94 & $96 \cdot 9$ & $3 \cdot I$ & $5 \cdot 8$ & $\cdot 2$ \\
\hline 45 & $67 \cdot I$ & $32 \cdot 9$ & $36 \cdot 9$ & I $8 \cdot I$ & 95 & $97 \cdot 4$ & $2 \cdot 6$ & $4^{\circ} 9$ & ·I \\
\hline $4^{6}$ & $67 \cdot 8$ & $32 \cdot 2$ & $36 \cdot 6$ & I $7 \cdot 4$ & 96 & $97 \cdot 9$ & $2 \cdot I$ & $3 \cdot 9$ & - I \\
\hline 47 & $68 \cdot 5$ & $31 \cdot 5$ & $36 \cdot 3$ & $16 \cdot 7$ & 97 & 98.4 & $I \cdot 6$ & $3 \cdot 0$ & \\
\hline $4^{8}$ & $69 \cdot 3$ & $30 \cdot 7$ & $36 \cdot 0$ & 16.0 & 98 & $99^{\circ} 0$ & $I \cdot 0$ & $2 \cdot 0$ & \\
\hline 49 & $70 \cdot 0$ & $30 \cdot 0$ & $35^{\circ} 7$ & I $5 \cdot 3$ & 99 & $99^{\circ} 9$ & $\cdot 5$ & $1 \cdot 0$ & \\
\hline 50 & $70 \cdot 7$ & 29.3 & $35 \cdot 3$ & I4.7 & & & & & \\
\hline
\end{tabular}

for the year too high for trade generally; if the average was about I 6 per cent. instead of I9 per cent., our column 6 would have shown 60 per cent. in place of 56 per cent., which would not be far out. The 
figures are within $\mathrm{r} \cdot 3$ per cent. of each other for 1910 , and from 10 ) 10 to 1912 the change in both is about 6 per cent. : the next two years are rather irregular, but the change from 1914 to 1915 was about 18 per cent. in both columns, and the period from 1912 to 1916 shows a change of 18 per cent. in both columns also. The irregularity in 1917 is caused by the acute war conditions, the control of prices rendering competition almost abortive, and the partial suspension of the gold standard added to that has rendered it impossible for any economic theory based upon normal pre-war condition to hold completely gooxl.

It is, we think, legitimate to appreciate the tendency to agreement between these figures over groups of years rather than the frequent disagreements year by year, because any disturbance like a strike or large increase of unemployment late on in the year for which it is recorded may not produce its effect on wages till the following year. There are many industrial variations the effect of which carries over into the subsequent years, the calendar year being but an arbitrary landmark in industrial affairs. Compared in this manner, the above figures show a distinct correspondence in trend between the actual variation of wages and the variation in the share of production found by our curve to be the amount that should go to wages as determined by the amount of unemployment. To show such correspondence in trend is all we can expect to do when we remember the very rough nature of the data, especially with regard to the amount of unemployment.

Unfortunately the data represented by Table 70 are only for a very limited portion of the working community, and covers too short a period to show more than that the proportion of wages to profits does approximately coincide with the proportion of unemployment. To a little extend the time covered by the evidence, in fault of anything better, we add the further evidence afforded by the variations in wages paid by a private firm over a period of years. Such evidence is far from satisfactory, as any individual undertaking is apt to exhibit considerable variations due to business exigency, management and so forth, which are strictly local disturbances that would be obliterated if the data were on a broader basis that covered a number of industrial undertakings.

The figures for the wages paid by a private firm are given on Table 72 and arranged as in the last example. Although in this case again the actual percentages of variation in wages given in column 5 do not absolutely agree with those in column 6 , they will still be found to afford considerable support to the probable correctness of our curve on Diagram 68 and its use in illustrating the effect of unemployment upon wages. In the first year, i 893 , the percentage of unemployment, I8.7 per cent., is so high as to indicate that the year was probably the last of a series of decreasing wages, and as we have no previous data to form a basis of comparison for that period, we 
cannot say what percentage the wages of that year were of such base. So they only stand at the head of this table to indicate that 1894 represents the first year of rising employment and wages.

As in the last table, the wage for I894, which is seen in the second column of this table to be $£ 26 \cdot 38$, is taken as 58.6 per cent. of the

TABLE 72.-RETURN BY PRIVATE COMPANY. THE PERCENTAGE CHANGE OF ACTUAL WAGES COMPARED WITH CHANGE SHOWN. BY UNEMPLOYMENT DIAGRAM 68.

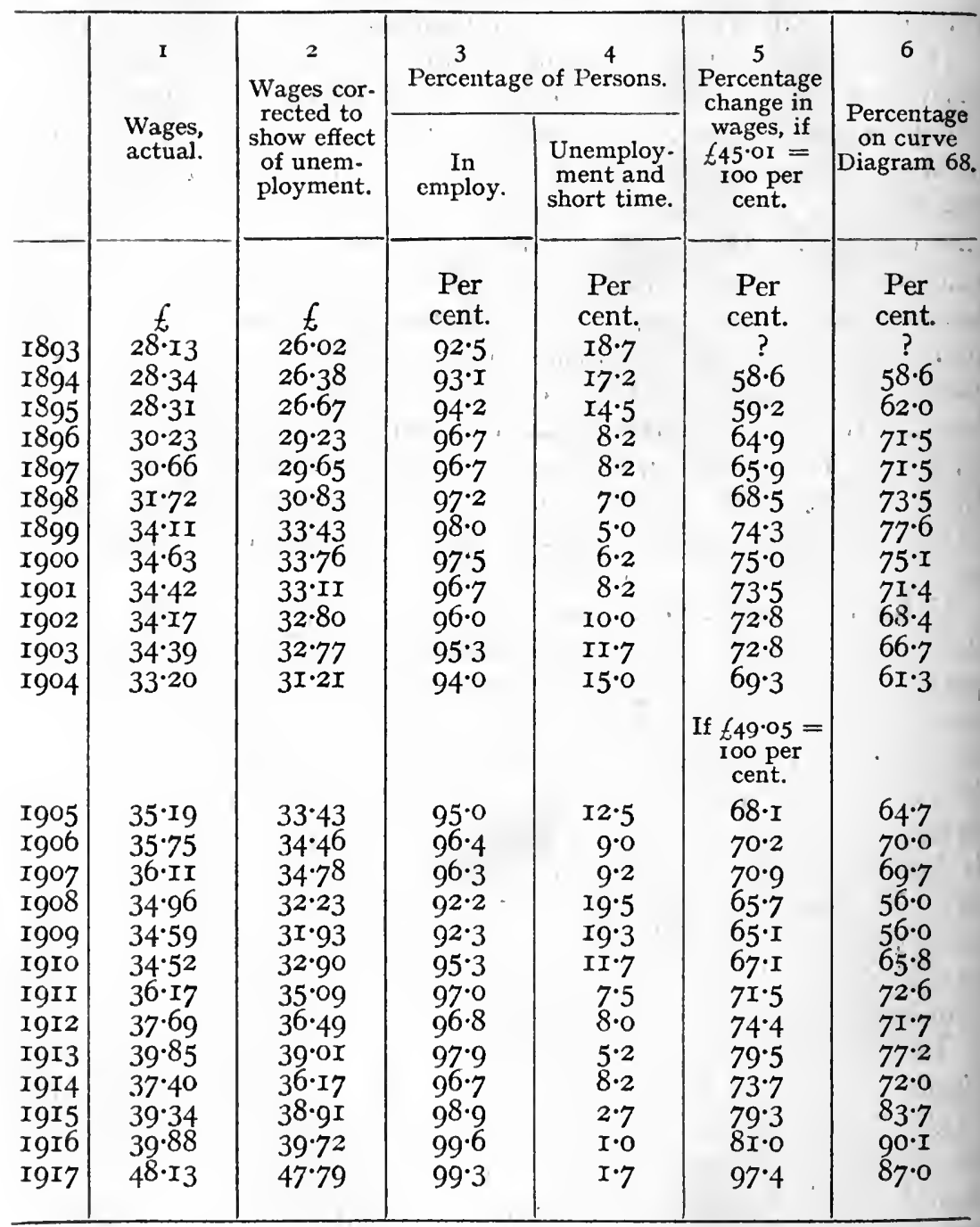

" possible maximum," which it should theoretically be according to the curve of wages when the unemployment is $17 \cdot 2$ per cent. This 58.6 per cent. will serve as a basis from which to compare the wages variations for the period of rising prices from I 894 to I900, in the early part of the latter year of which period the highest point in 
employment of labour was reached. In this period unemployment diminished from 17.2 per cent. to 5 per cent.. so that owing to the lessening of competition for work the wages should in accordance with column 6 , which represents the unemployment points on the curve, increase in the proportion of 58.6 per cent. to $77.6 \mathrm{per}$ cent. The actual increase in wages was in the proportion of 586 per cent. to 75 per cent. only, and this was no doubt due to the fact that the lowest point in unemployment did not coincide with the calendar year, but covered the end of $1 \$ 99$ and the beginning of 1900 . In the last three months of 1900 unemployment considerably increased owing to the falling off of trade brought about by the stopping of the Transvaal gold mines, and this increased competition for work depressed the average wage for the year somewhat below the theoretical point. If, however, we could have the annual data calculated for the twelve months covering part of these two years and ending before the fall in employment began it is probable the highest point of wages early in 1900 would average about the required 77.6 per cent., so that the actual variation of wages for the period is not very far from the theoretical movement indicated by our curve and the figures in column 6. It is often necessary to make a little allowance for overlap of maximum or minimum effects upon the yearly averages that we have to accept, for it is not to be expected that economic adjust. ments should correspond exactly to the calendar year's average. The above figures indicate that in this particular business the wages movement inclines to be rather slower than the general average. to the extent perhaps of being about six months behind. Such retardation seems to be indicated throughout the series, the wages for r89.5 being 3 per cent. behind the theoretical shown in column 6 : for 1896,6 per cent. behind ; $1897,4.5$ per cent. : 1898,5 per cent. : and $1899,3.3$ per cent. behind. Owing to the fall in employment starting before the end of 1900 the theoretical wage according to curve falls a little, allowing the actual figures to catch up and become level for that year.

It is important to notice as evidence of the effect of competition on the rate of wages that the rise in wages for the above period is greater than the direct rise due to working longer time. The decrease in unemployment from 1894 to the end of 1899 is 12 per cent. ; that is, 12 per cent. increase of wages earned, as indicated by the diagonal line on Diagram 68 ; but column 6 shows wages have actually gone up 16 per cent. in that time, and most probably more if the average was taken for a twelvemonth, including parts of the years I899-1900, and ending with the highest point in employment, which is the natural end of the period.

The next period, from I 900 to 1904 , being for falling prices and employment, our curve, as we have said, may not correctly show the effect of competition for work when wages are falling. If we had 
data from which to draw a curve of falling prices, it might show the figures in column 6 to be a few percentages higher, but hardly enough at $5_{5}$ per cent. unemployment to make the private firm's figures in column 5 agree with the theoretical. The actual fall in the firm's wages in the four years was about 4 per cent. against Io per cent. theoretical. Some of this 6 per cent. error may be due to the wrong curve, but probably the greater part of it is due to the depression in wages of this firm not being so great as the depression in wages generally. The wage per person figures of a particular firm may be distorted by conditions peculiar to that firm at any time, and that there was some error in this case is indicated by the fact that the change of wage shown in column 5 is less than the inevitable loss that must result from 7 per cent. less time that was worked as shown by column 4. This evidence, based on the experience of a single firm, is evidently not quite representative of average conditions of trade generally, and it is to be much regretted that we have no more comprehensive data for this interesting period.

Owing to the fact that a considerable rise of prices has taken place since the last base year of 1894 , it becomes necessary, or at any rate convenient, to take a fresh "possible maximum" base, otherwise the percentages of change in wages from the old base shown in column 5 will become so large as not to be easily compared with those in column 6. This is due to the fact that the advance in wages during rising price periods is progressive from year to year, whereas the percentage of unemployment is an independent estimate for each year, and it is important to realise how this progressive advance in wages takes place. It is obvious that if prices were continuously rising through improved gold production, and the whole of labour was employed, wages would keep pace and continue to rise with the rising price, there being no competition for work to prevent their doing so. The shares both of wages and profits can continue to get larger just so long as prices keep on going up, and may remain at about two-thirds of that high production as long as it is stationary. On the other hand, when prices fall through retarded gold production, the fall of wages due to increased unemployment only continues till a point is reached where wages are about two-thirds of the production, when employers will start increasing output again whatever the price may be ; or perhaps until an improvement in gold production again starts prices rising. So it by no means follows that wages will be reduced to the point that they stood at five or six years back, even though the percentage of unemployment may happen to be the same as it was then; that depends upon whether the gold production has gone back to the same point. Thus over a period of years wages (i.e., the percentage of total production) may have advanced more than they have gone back, but the position they will attain at the price level of any one of these years will depend and will 
always have depended upon the percentage of unemployment at the time.

To ret urn to the figures on Table 72 , the next period from 1905 to 1917 is really one of rising prices throughout, but it is interrupted by the boom of 1907 having outrun the gold basis of prices, which brought the boom to a sudden end in the autumn of that year, and caused a short commercial depression in 1908-9. The wages for the first year, 1905, will be seen to be 3.4 per cent. above the theoretical position. due probably to the too small reduction in the period just mentioned above; the rise therefore in the first three years up to 1907 is somewhat too small, being 2.8 per cent. actual against 5 per cent. by the curve. The depression of 1908-9. like the same depression on Diagram 70, shows as too small reduction of wages, an appearance probably due, as explained in that case, to too high unemployment figures (see p. 343).

From Igro to 1917 wages follow very closely the movement indicated by our wages curve, but at a slightly slower rate as in the first period. The slight discrepancy in 1912 is due to an evident error in the data collected by the Board of Trade, for the decrease in employment from 97 per cent. the year before to 96.8 per cent. implies a falling off in trade, whereas trade was improving, prices rising, and undoubtedly employment rising too, so that the actual rise shown by wages in columns 2 and 5 is probably more correct than the theoretical figure founded upon the imperfect data. With this exception the actual and theoretical percentages of change agree fairly well for the period, the highest point of $90 \cdot 1$ per cent. theoretical probably being reached by the actual in the period between 1916 and 1917 if the returns could be made up to the natural end of the high employment point instead of to the calendar year's end. The further rise of wages to 97.4 per cent. in 1917 is the result of war conditions, unlimitedly high prices, and the percentage of unemployment having fallen to practically nothing. But it is interesting to notice that when practically every one was employed the proportion of product going to wages rose to nearly the full roo per cent., being 97.4 per cent. in this case, and in that of the 15 trades 106 per cent. of the " possible maximum " calculated for 1905. This would have absorbed the whole production, leaving no profit whatever, if prices had been prevented from rising by the gold check which was in existence when the "possible maximum " of Ig05 was the limit. The alteration of the currency and suspension of much competition has rendered that base inappropriate, and it would now be necessary to calculate a fresh "possible maximum " for the War period if we had any possible data : but none is as yet forthcoming, the gold standard having failed us.

It seems from the above tables that our curve on Diagram 69 . representing the rise or fall in the share of production which goes to wages as the result of a rise or fall in unemployment is fairly well 
supported by the little evidence we have. It is not to be expected that the actual percentages should agree exactly with those of the curve ; no such exactness can ever be attained from use of data from any limited section of industry, save by the remotest chance. Correct returns both for wages and unemployment from virtually the whole field of industry would alone afford an exact demonstration of the curve that divides the share of wages and profits.

TABLE 73.-CHANGES IN RATES OF WAGES OF LABOUR.

(Labour Gazette.)

\begin{tabular}{|c|c|c|c|c|c|}
\hline & & & $\begin{array}{c}\text { Increase per } \\
\text { week. }\end{array}$ & $\begin{array}{l}\text { Decrease } \\
\text { per week. }\end{array}$ & Unemployment. \\
\hline & & & 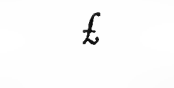 & $£$ & $\begin{array}{l}\text { Per } \\
\text { cent. }\end{array}$ \\
\hline 1895 & . & & - & 28,437 & $5 \cdot 8$ \\
\hline 1896 & . & . & $26,15^{2}$ & - & 3.4 \\
\hline 1897 & - & . & 30,494 & - & $3 \cdot 5$ \\
\hline 1898 & . & & 80,674 & - & $3 \cdot 0$ \\
\hline I899 & . & . & 90,407 & - & $2 \cdot 4$ \\
\hline 1900 & . & . & 207,555 & $-\bar{c}$ & $2 \cdot 6$ \\
\hline rgor & . & - & - & 78,658 & $3 \cdot 3$ \\
\hline 1902 & - & & 一 & $72,97 \mathrm{I}$ & $\begin{array}{l}4 \cdot 0 \\
4 \cdot 7\end{array}$ \\
\hline $\begin{array}{l}1903 \\
1904\end{array}$ & . & : & E & $\begin{array}{l}38,557 \\
39,1177\end{array}$ & $\begin{array}{l}4 \cdot 7 \\
6 \cdot 0\end{array}$ \\
\hline I905 & . & & - & $\begin{array}{r}4,087 \\
\end{array}$ & $5 \cdot 0$ \\
\hline I906 & 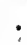 & . & 55,546 & - & $3 \cdot 6$ \\
\hline 1907 & : & . & 200,820 & $=-$ & $3 \cdot 7$ \\
\hline I908 & . & . & $\div$ & $6 x, 683$ & $7 \cdot 8$ \\
\hline I909 & . & . & - & 69,120 & $7 \cdot 7$ \\
\hline I9Io & . & - & $I 4,335$ & - & $4 \cdot 7$ \\
\hline IgII & . & . & 32,433 & 一 & $3 \cdot 0$ \\
\hline r9I2 & . & . & I3I,6II & - & $3 \cdot 2$ \\
\hline 1913 & . & & $\mathrm{I} 78,7 \mathrm{II}$ & - & $2 \cdot I$ \\
\hline $19 I 4$ & . & . & 5,062 & - & $3 \cdot 3$ \\
\hline I9I5 & . & . & 677,700 & - & $-\mathrm{Wa}$ \\
\hline I9I6 & & - & 595,000 & - & 0.4 \\
\hline
\end{tabular}

A little additional evidence may be gathered from Table. 73, showing changes in the rate of wages during 20 years. The figures are from the Labour Gazette, showing the total alteration in the amount of wages due per week to certain trades caused by alterations in the rate of wages in those trades. These figures cannot be examined in the same way as the above examples, because the number of persons to whom these wages were paid is not known, nor is it certain that the whole amount was paid, because if any short time was made the actual wage would come to less, although the rate was not changed. But as the amounts here given are what the varying rates should bring total wages to if full time was worked, they 
represent exactly what the change in rate was, and we can see how far the rate rises or falls with the corresponding variation in unent. ployment. The first column of the table is the alteration in the total wages per week due to increased rates year by year; the second column, the total weekly wages due to decreasing rates, and the third column is the official percentage of unemployed persons as in the other tables.

The increase in the rate of wages from 1895 to 1900 is very marked and corresponds to the decrease in unemployment shown in column 3 . The figures also show that the rate advanced in an increasing ratio to the amount of employment as the percentage of unemployment gets very small towards 1900 , in the early part of which year it fell as low as 2.I per cent. The next period, from 1900 to 1904 , is one of falling prices, and the rate is seen to fall very fast with the increase of unemployment, but in a diminishing proportion as the percentage of unemployment gets higher. The fall of wages rates carries over a little into 1905, when unemployment was getting less, and this illustrates the lag of rising wages rates behind the improvement in profits and employment when prices are going up, and this point should be noticed as it is an important factor in making changes from good to bad trade. The next two years' wages rates go up again rapidly with the decrease in unemployment, and as we have pointed out in the examination of Table 72 and also frequently when considering prices, this improvement in wages and trade generally should, in accordance with the gold basis, continue uninterruptedly from 1905 to 1917 . But the speculative and too rapid rise of prices in 1907 caused a crisis and trade set-back in 1908-9. This disturbance is very clearly seen in the change in unemployment and wages for these two years. The first year of the War also shows the panic effect in increasing unemployment and depressing wages, but it was soon - followed by full employment and continuance of the rise of wages.

The recorded changes in the rates of wages as set forth on Table 73 obviously support our contention that wages vary inversely as the amount of labour unemployed, but do not afford any evidence as to the percentage of change correlated to any particular percentage of unemployment, which is the evidence we require to confirm the exact position indicated by the trend of our curve on Diagram 68 . Actually the strongest piece of evidence for one point in such curve, as we have before mentioned, is afforded by the tendency of all wages to average over long periods a similar percentage of the net production. As was pointed out in the tables to the chapter on "Division of the National Income," the Census returns for the United States, France, Germany, South Africa, and the United Kingdom show that wages, including salaries, average 64 per cent. of the production of labour. As this conclusion is based on broad industrial evidence it must be regarded as one sound factor in determining the trend of the wages curve. But, unfortunately, none of the above Censuses 
give us the percentage of unemployment correlated to this average wage, and that is the other factor that is absolutely necessary for the locating of an exact point on the curve. As we have also pointed out, the data for this factor of unemployment are very conflicting and unsatisfactory, so that we were driven to the somewhat hypothetical conclusion that the average unemployment and short time together amount to about I2.5 per cent., which would then be the unemployment corresponding to wages at 64 per cent. of production.

Although this exact percentage is hypothetical it is obvious that competition for work must be maintained approximately at such a point, because, as we have seen, the price of the production is determined by the gold production and cannot be raised above that basis, and if all the labour is employed wages will inevitably rise to Ioo per cent. and leave no profit beyond the wages of management. Therefore, to make the wages 64 per cent. 36 per cent. of workers would have to be out of work or 36 per cent. of time would have to be lost in some way so as to save that amount of wages, as shown by the diagonal line on the diagram. As there is certainly no such proportion of unemployment as 36 per cent. we have to postulate a less amount, and as the average amount for England and the United States together is about ro per cent., our I2.5 per cent., the reasons for which have been previously stated, would seem a probable amount. Having projected our curve through this point of 12.5 per cent. unemployment and 36 per cent. profits, we proceeded to examine the evidence from records of actual wages, and found that evidence as set forth in the three Tables 70,72 , and 73 correspond very fairly well with the theoretical movement of wages as indicated by Diagram 68. So far as the few facts at our disposal go it seems reasonable to conclude that our diagram represents with approximate correctness how the variations of wages follow the variation of unemployment, and that the proportion of the net production that goes as the share of wages or of profits is actually determined by the amount of unemployment at the time.

We are now able to a certain extent to see the nature of the industrial mechanism by which the share of production going to the employer as profits is obtained. To get the average 36 per cent. of profit, which term as used by us includes rent and interest, employers must so control the instruments of production owned by them as to keep I2.5 per cent. of the labour of the community unemployed and competing for work. As shown by the curve of wages on Diagram 68, this competition resulting from I2.5 per cent. of unemployment is equal in effect to the direct loss shown by the diagonal line to be 36 per cent. lost time and 36 per cent. less wages. But while that loss of wages is self evident it may not at first sight be obvious that a change from full employment to 36 per cent. lost time, or its equivalent in competition caused by 12.5 per cent. unemployment, would raise profits from nothing to 36 per cent. of the total production, as 
the diagram shows. It might quite well be thought that as profits and wages are only shares of the total value produced a reduction of that total value by working shorter time would inevitably reduce the shares of both profit and wages. But is the total value reduced by working short time? It is necessary here to recall the conclusions come to in our long investigation of prices and the gold standard, the great importance of which conclusions will now become apparent. We have seen that the exchange value or price of a thing is a ratio naturally and inevitably fixed by the difficulty or labour cost of producing commodity relatively to the difficulty or labour of getting the gold in which alone the value is measured. If the employers withhold the instruments of production from some of the workers it does not alter the relative difficulty of producing goods or gold. In such case the commodities are still produced at the same labour cost per person employed in their production, so the value of their output or normal price per person per annum is unchanged, although the number of articles or quantity of commodity is less. This is the essential point brought out by our study of prices, that whether the persons employed and the quantity of commodity they produce is great or small its value or normal price per person will be the same while the production of gold per person is the same. This is inevitable if price is an equation between the labour cost of gold and that of commodity; these factors being unchanged there is nothing else in the equation to alter the price.

Of course, when the quantity of commodity produced is made less by the workers being put on short time the price per unit or price per quantity of commodity will go up to make the smaller quantity realise the same normal price as the greater. From our investigation of prices and gold production it seems conclusively shown that the normal price or total money value of the production of labour in commodity production is equal to a sum represented by the amount of gold which the same labour would be able to produce if it worked for the same time in gold mines of equal productivity to those actually in work.

The inevitable converse of this conclusion is that the total goods value of the gold actually produced is equal to a sum of goods representing the amount of goods the same miners would have been able to produce if they had worked for the same time in the production of goods. That is to say, the goods value of the gold produced depends upon the quantity of goods that have been produced in the same time that the miners have worked to get the gold. If the goods produced per person are less the gold will only buy less goods. Or conversely the less quantity of goods will fetch the same amount of gold as the greater quantity of goods did when more were made in the time; they have gone up in price per unit, and so kept the normal price unchanged. 
It is of the greatest importance to realise this fact, that the total money value per person, or per cent. of persons employed, or what we have called the " normal price" of the product, will be the same whether the quantity produced by that labour is greater or less, so long as the quantity of gold produced per person in mining remains unaltered. Although it may at first appear a preposterous theory that if half the working community was kept idle their resulting production would still be of the same money value as when they were on full time, a little thought bestowed on the foregoing argument will show its evident truth. Nor is this simply a theoretical conclusion but quite in accordance with the commonly recognised commercial facts. As was frequently pointed out with regard to the normal prices of crops it might confidently be expected that if the crop was small the price per bushel would go up till the average price obtained for the crop was as much as if the crop had been a large one. In manufacturing industry absolutely the same thing obtains as the production per person of goods becomes less through short time worked while gold miners are working full time with an unaltered output; the price per unit of such goods will rise till the total money value of the production is the same as when the number of units was more and the price less. A striking example of this in actual practice was seen in Diagram 28, showing the normal price and the price per ton of coal produced in this country.

From this, then, it appears that the employers by withholding employment and reducing the quantity of goods made while the total selling value of those goods remains the same can either, because the hours worked are less or the competition for work greater, pay less wages and still get as much for the reduced output as if it had been larger, thus securing a profit over and above the wages and salaries paid. But if this is so why do not the employers reduce the time worked and restrict the output of commodities till wages are reduced to the least amount that will keep the workers alive and able to do this smaller amount of work ?

If the average lost time of the community is taken to be $12 \frac{1}{2}$ per cent., its production in goods will only be 87 per cent. of what it would be if all were at work, and seeing that the total selling price of this smaller output will, as we have seen, be the same as if it had been the large one, the price per article or per unit of production must be raised. But in that case it is obvious that when the 36 per cent. profits comes to be expended in purchasing goods it will only be possible to purchase 36 per cent. of the 87 per cent. of goods produced, not 36 per cent. of the roo per cent. that would have been produced if all were at work; or, as it is shown on Diagram 68, 36 per cent. cash profits would only purchase $3 r \cdot 3$ per cent. of the goods that would have been produced if full time had been worked. If unemployment had been further increased to 25 per cent., so that 
only 75 per cent. were at work, the profits would only purchase 50 per cent. of 75 per cent., or 37.5 per cent. of the goods that could be produced if all were at work, and when the unemployment had reached 37 per cent., as may be seen from Table $7 x$, the profits in goods would begin to be a diminishing amount, at 45 per cent. unemployment "goods profits" being only" 36.9 per cent. of what could have been produced. At that point, as also may be seen from Table 7I, wages only purchase I8.I per cent. of what could be produced, instead of $98 \cdot 2$ per cent. when only one person per cent. was unemployed. The proportion of the total possible production that can be purchased by profits or wages at the different levels of unemployment is shown by the dark lines on Diagram 68, and they form the curves of "goods profits " at the top and "goods wages" at the bottom of the sheet. It should be recognised that these curves represent the real value of the income which these two classes of society would obtain as the result of the various possible amounts of employment. On Table $7 \mathrm{I}$ these proportional shares of production going to profits or to wages are set out in figures both for cash and goods for every I per cent. variation in employment.

It will be seen on the diagram that the curve of "goods wages" falls very rapidly as unemployment increases, and cash wages fall. but that the rate of fall diminishes as it nears the bottom. On the other hand, the curve of "goods profits " shows a very rapid rise at first, gradually becoming slower as it approaches 36 per cent., becoming stationary at 38.4 per cent. and starting to actually diminish with 38.3 per cent. as 37 per cent. of unemployment is reached, after which point it begins to diminish rapidly. It appears, therefore, that there is actually a point beyond which an increase of profits by means of a reduction of employment ceases to be an advantage from the point of view of increased wealth to the employer. The curve of "goods profits " shows the point of 31 per cent. unemployment is the very best position for making real profits. But seeing that at the same time the "goods wages" or actual income of the workers would have fallen to 30.6 per cent. instead of the average 64 per cent., the poverty of the community would be such as to much discount the little addition to profits by the last I5 per cent. extra unemployment and to render the conditions of business very unstable and difficult, so that it is not surprising that the ordinary desire to increase profits stops before any such difficult position has been reached. Such extreme state of unemployment being seldom if ever realised it is more important to us to discover exactly why profit increasing should stop short at about 12.5 per cent. unemployment, while the gain by another percentage or two out of work would be visible and actual. But it is desirable to notice in passing what effect increasing profits actually have upon the wealth of the community. In Diagram 68, it can be 
seen that while at any point of unemployment "cash profits" and wages added together equal roo per cent., "goods profits" and wages do not together equal roo, but fall off very rapidly as less time is worked, showing that society is getting poorer in real income.

Seeing that beyond the usual point of profits at 26 per cent. of the production an increased profit can be made without reducing the cash turnover of the business, it is not probable that employers will sacrifice this opportunity simply because they find their incomes do not go quite so far as they used to do. They will not regard the very high price of the things they consume as a reason for sacrificing any of their own profits, especially as in spite of such prices their " goods income " would be a little better, if only by a $\frac{1}{2}$ per cent. or so. Such considerations hardly enter into the calculations of business men; it is with them a question whether it is better at any time to raise the price for more profit and less work, or to keep the price and profit down to increase the volume of their business. It is therefore necessary to look at the question more from the commercial point of view if we wish to see the probable course that will be taken. Diagram 68 or Table 71 shows that when profits are 36 per cent. of the production an additional I per cent. of unemployment will allow the profits to go up I.4 per cent. without diminishing the money turnover, and it looks as if employers would always take advantage of such an increase. But as a matter of fact, this is not quite how the position appears to an employer, and it is important to realise that profit or interest is not regarded as a percentage of production at all by business men, but as a percentage of the capital employed by them in their undertaking. Such capital besides the gross turnover of the business usually includes interest on money borrowed or originally invested as the cost of the plant, etc., which investment constitutes a claim to a share of the 36 per cent. of production which the business makes beyond the cost of its labour. The amount of capital in two businesses pursuing the same industry may vary greatly and pay very different rates of interest, yet the price of their production must be the same or they could not sell in the same market, and the share of production going to profits will be the same if the two businesses are equally well managed; the difference in the capital makes no difference to the amount of profit but only to the number of persons who may share it. As the estimates of capital in different undertakings may vary so much, it is best for purposes of general economic comparison to speak of variations in amount of profits, only as percentages of the total production which is nearly alike in all businesses. But it is quite natural that the business man should contrast his varying profits with the capital claim which he or other persons have upon the business, and to appreciate his view of profit making we must view it from his standpoint 
To help us to take a commercial view of the case, we give in Table 74 a series of suppositionary trading accounts, arranged in order to show the variation in profits at different states of unemployment. The two first accounts are set out fully, and are supposed

TAMLE 74-TRADING ACCOUNTS AT VARYING STATES OF VMIMY. ME.NT

IV ALL FEPLOYED.

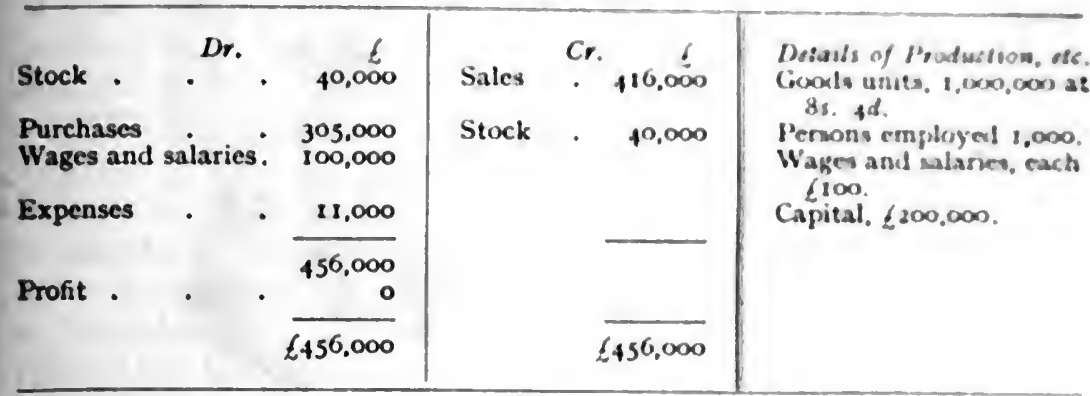

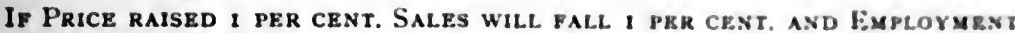
I PER CENT.

\begin{tabular}{|c|c|c|c|c|c|}
\hline Stock . & Dr. & - $\quad \frac{b}{40,000}$ & Sales & Cr. $\underset{+16,000}{\delta}$ & $\begin{array}{l}\text { Details of Production, ete. } \\
\text { Goods units, yo,000 at }\end{array}$ \\
\hline $\begin{array}{l}\text { Purchases } \\
\text { Wages, etc. } \\
\text { Expenses }\end{array}$ & $\dot{.}$ & $\begin{array}{r}305,000 \\
: \quad 90,100 \\
: \quad 11,000\end{array}$ & Stock & 40,000 & $\begin{array}{l}\text { Persons employed, ypo. } \\
\text { Persons unemployed. } 10 . \\
\text { Capital. }(200,000 .\end{array}$ \\
\hline Profit & - & $\begin{array}{r}446,100 \\
\quad 9.900\end{array}$ & & & Wages, etc., each, Eo1 - \\
\hline & & 456,000 & & 456.000 & \\
\hline
\end{tabular}

The items in the Trading Account are all the same under varying amounts of employment, except Wages and Profits.

\begin{tabular}{|c|c|c|c|c|c|c|c|c|}
\hline \multicolumn{2}{|c|}{ Persons. } & \multicolumn{2}{|c|}{ Wages and Salaries. } & \multicolumn{2}{|c|}{ Prote. } & \multirow{2}{*}{$\begin{array}{l}\text { Goods } \\
\text { units } \\
\text { produced. }\end{array}$} & \multicolumn{2}{|c|}{ Prike. } \\
\hline Employed. & $\begin{array}{l}\text { Unem. } \\
\text { ployed. }\end{array}$ & Total. & Each. & Tolal. & Per cent. & & Tet ualt. & $\begin{array}{l}\text { Rove poet } \\
\text { conte }\end{array}$ \\
\hline 980 & 20 & 85,900 & $87 \cdot 65$ & 14,100 & 7.0 & 980,000 & s. 1. & $=$ \\
\hline 970 & 30 & 82,700 & $85 \cdot 26$ & 17.300 & \$.6 & 970,000 & 87 & 3 \\
\hline 960 & 40 & 80,000 & 83.33 & 20,000 & 100 & 960,000 & 8 & + \\
\hline 950 & 50 & 77.600 & $81 \cdot 68$ & 22,400 & $18 \cdot 2$ & 950,000 & 89 & 5 \\
\hline 940 & 60 & 75.500 & $80 \cdot 32$ & 24.500 & $12 \cdot 2$ & 940,000 & 810 & 6 \\
\hline 930 & $7^{\circ}$ & 73,500 & $79 \cdot 03$ & 26,500 & $13 \cdot 2$ & 930,000 & 811 & 7 \\
\hline 920 & 80 & 71,700 & $77 \bullet 93$ & 28.300 & $14 \cdot 1$ & 920,000 & 91 & 9 \\
\hline 910 & 90 & 70,000 & $76 \cdot 92$ & 30,000 & 15.0 & 910,000 & 9 & 10 \\
\hline 900 & 100 & 68,400 & $76 \cdot 00$ & 31,600 & $15 \cdot 8$ & 900,000 & 9 & 11 \\
\hline 890 & 110 & 66,900 & $75 \cdot 17$ & 33.100 & 16.5 & 800,000 & 9 & 12 \\
\hline 880 & 120 & 65,400 & $74 \cdot 32$ & 34.600 & $17 \cdot 3$ & $\$ 80,000$ & 9 & 14 \\
\hline 870 & 130 & 64,000 & 73.56 & 36,000 & 18.0 & $8,0,000$ & $y$ & is \\
\hline 860 & 140 & 62,600 & $72 \cdot 79$ & 37.400 & $18 \cdot 7$ & 860,000 & 99 & 13 \\
\hline 850 & 150 & 61,300 & $72 \cdot 32$ & 38,700 & $19 \cdot 3$ & 850,000 & 910 & 13 \\
\hline 840 & 160 & 60,000 & $78 \cdot 43$ & 40,000 & $20 \cdot 0$ & 840,000 & 911 & 19 \\
\hline 830 & 170 & 58,800 & 70.84 & 41,200 & $20 \cdot 6$ & 830,000 & 100 & 20 \\
\hline
\end{tabular}


to be typical of the trade of the community. The variations in profits is made in agreement with our curve in Diagram 68, but the amount of profit so found is stated in these accounts as the percentage that it would be of the capital represented in the accounts. The bottom part of the table is a continuation of the series of accounts for various percentages of employment, but in an abbreviated form.

The first account represents the position of an employer who starts business when all the available labour of the community is employed. With a capital of $£ 200,000$ he employs $I, 000$ persons, paying them in salaries and wages an average of $£$ Ioo each; and these persons produce one million articles at $8 s .4 d$. each. The balanced trading account shows that no profit was made in the first case, although he sold all the goods he produced. But it should be noticed that the wages of these $\mathrm{I}, 000$ persons will purchase the whole net value they produce, and as the business is typical of the trade of the community, the other persons who produced the $£ 316,700$ worth of "Purchases" and "Expenses" paid for by this firm will also have taken the whole of that amount in wages and salaries, and so will be able to buy the rest of the million articles produced, thus consuming the gross output between them.

But as the employer has made no profit on the sale of all his produce he will naturally raise his price. Which he is supposed to have done by I per cent. in the second trading account, with the result that he gets a profit of $£ 9,900$, which is 4.9 per cent. on his capital. But it should be noticed he now pays less wages. If he had continued to employ the same number of persons so as to produce the same number of articles as before, and the rest of the community had done the same, no unemployment would have been created and wages would have gone up I per cent. like the price. Then the wages in this second account would have come to $£$ ro4,000, and owing to the rise of prices the "Purchases" and "Expenses" of the firm would also have gone up to $£ 316,000$, and the second account would then have balanced at $£ 460,500$, again without any profit. The wages and salaries of the community would still have purchased the whole production at the new price of $8 s .5 d$. per article.

This looks as if the employers might raise the price any number of times without producing any profit, and as a matter of fact, this is what ultimately happens if employers persist in raising the price as well as keeping up the production, thus making fictitious normal prices. It may seem that as the employer can after paying the wages raise the price of what has been produced, he can make a profit on that production before the wages catch up with the price. And when the wages do catch up he could raise the price again, thus making his profit however much wages went up.

But there would be one section of the community that could not participate in this comfortable distribution of profits. The gold 
miners cannot put up the price of their gold so long as it is the standard of value, and prices being so high, the gold obtained will not pay the high rate of miners' wages in some mines, to say nothing of profits. So there would at once be unemployment amongst the miners and a shortage of gold. The miners might be absorbed in the other industries that were putting up prices without limit, but could the high-priced production all be purchased by those who produced it? Obviously the total wages and profits of the community must be the same value as the total value (production) of which they are the sole constituents; what part the wages cannot purchase the profits can.

There is, however, in actual practice an essential difference in the purchasing potentiality of the shares of wages and that of profits. Wages and salaries are a determined amount actually realised by the recipients, whereas profits are an undetermined share that may be more or less when realised, or may never be realised at all. In the case of the above trading accounts when the price was put up to cover the rise in wages, due to everybody being employed, that price makes the total value greater than can be paid by the total salaries and wages. Theoretically the sliare going as profits completes the purchasing power, making it equal to the total value to be purchased. But the profits are not paid week by week with the wages, or even so regularly as the salaries. After such wages are paid the employer is left in possession of the stock produced by the labour that has been paid, and as we pointed out in Chapter IV., that stock is not purchasing power. It has to be sold before it can be realised as spending capacity.

Many such products have to go through several manufacturing processes before they are actually converted into purchasing power. The cotton crop on which wages have been paid for planting may be I8 months or two years before it is sold to the retail customer. Iron ore may be years before it is actually converted into or used up in making the consumable things that are the realisation. of purchasing power. Until the iron ore or the cotton is actually sold to the ultimate consumer, its value has not been completely reproduced as payment-it is not paid for. Each producer in the chain of processes will nominally have been paid for his work, but that only after a month or two, and then only in the form of credit. Each producer is credited at his bank with having received payment, but no concrete value of any kind has been transferred by the payment. Although this seems to be actually the case, it should always be remembered that theoretically a deposit of gold lying at the bank has been transferred to the possession of the person who is paid.

This system of payment by credit is for the purpose of distributing as much of the purchasing power as is realisable at the moment equally between all the contributors to the current production who 
are waiting for the final payment from the consumer. Otherwise the cotton planter might wait two years for payment while the retail draper got paid for his part of the work within a few weeks of its performance. But however this burden of stock may be distributed, it remains a fact that it must be borne by the employers of labour for a period that must at least average six months before such stock can be realised as purchasing power.

If while this purchasing power or profit has been deferred wages have gone up, a good part of that profit will have been absorbed by the wage-earning classes. If for the purpose of Table 74, we suppose wages to have gone up 36 per cent. in the six months of waiting, the wage-earners could purchase the entire stock they had produced. The employer in that case could purchase nothing as the result of his work in that time, except by an extension of credit. He would have made no realisable profit on the six months' work, except that he would have the new stock produced; and owing to the increased price its value would be enhanced by the amount of the unrealised profit. His capital in stock would be increased by the larger nominal profit, but as it would take another six months to realise it the wages would again go up and the profit again be deferred.

If in actual commercial practice prices are thus going up to cover the rise in wages caused by everybody being employed, there will be an increased tendency to inflated stock values and little or no increase of realisable profits. There will be what is called a shortage of money, and bankers will find themselves continually called upon to advance money on the security of these inflated stocks. As this will make the bankers increasingly liable to demands for gold by those persons who have large deposits of nominal gold transferred to their accounts in payment for some of this inflated stock, they will become anxious to increase their gold reserves; and that they will not be able to do, because gold will not be produced in any increasing quantity while commodity prices are so high. To make themselves secure they will in addition to putting up the bank rate of interest be less willing to lend money to persons in industry, which will increase the want of ready money and put some firms in difficulty.

This want of money will make producers less willing to give long credit, which will make the financial position acute for firms who have been spending money borrowed on the security of their unrealised profits, and they may have to realise by selling those stocks at a lower price and sacrifice their unrealised profit altogether. Also bankers may sell securities to obtain the required gold, causing a drop in the price of stocks and shares which will lead to a further contraction of credit. This contraction of credit is actually a fall in the price of certain securities and goods; and this fall in the value of their credit will cause some unsound firms to fail and un- 
employment will result. The unemployment will reduce wages. and firms that were reducing their production on account of the falling price will find they can save in wages and produce more clicaply. So prices can continue to fall till the gold standard of price is again found and the bankers can get gold.

This process of lowering prices to get gold will be discussed further in Chapter XIII. (see p. 395). But for the purpose of Table 74 it is only necessary to point out that profit made by putting up prices to cover rising wages when price is above the gold limit results in nothing but inflated stock values that cannot be realised as profit so long as all are employed and wages rising. Thus the gold check creates a financial difficulty which soon prevents $\mathrm{em}$ ployers from putting up price to cover wages. They are then obliged to produce less commodity and cause unemployment, which reduces wages and gives a profit without putting up the price.

In this way unemployment comes when profits are too low. The employer does not, of course, discharge a percentage of his workers to get a profit thereby, but by raising the price per unit of goods he reduces his production, which inevitably brings about the necessary unemployment. Having done so in the case of our second trading account, the employer gets 4.9 per cent. profit, which not being enough, he further increases his price. Another I per cent. rise of price produces another I per cent. unemployment, which in accordance with our curve on Diagram 68 reduces wages and the number of articles as shown in the first line of the abbreviated accounts, and raises the profit to 7 per cent. on the capital. In this way the scries of accounts shows the profits to increase with each percentage of additional unemployment, and they might go on indefinitely, as we have said. But it should be noticed that as the unemployment approaches 12 per cent., that is, 120 persons unemployed, the increase in profit falls off rapidly, being less than I per cent. on the capital for each per cent. less people at work, so that the employer may well begin to ask himself whether it is worth while to kecp on losing his hands for so small an increase to his profits when they are already good, at $I 7$ per cent. on his capital.

An employer in this position will reason that his profits are good and that he would be doing remarkably well if he could get a little more business, but he is not extending as he should be, his working staff had gone down 12 per cent. and he has plant enough standing idle to employ 120 more hands ; he will say. "It is time I cut prices a little or started to push some new line of goods." He cuts the price of his new line a little just to get it introduced, and thereby lowers the average price of his productions and his profit. But he makes his works busy again and increases the number of articles turned out, which it will be seen from column 9 in the trading accounts had fallen ${ }_{4}$ per cent. 
Of course, if the whole trading community, as we have been supposing, acted as this employer did his cash turnover would be no greater when his works were on full time than when I2 per cent. of his hands were idle; and in that case employers might be tempted to raise prices a little more and increase unemployment by more than I2 per cent. But not much more because they cannot insure that some of the wage-earners and salaried persons shall not in that case start in competition and be satisfied with a profit less than I7 per cent. Such new firm might successfully start that new line of goods, when both the profit and turnover of the old employers may be badly reduced. The reason why such new firms do not always come into competition and reduce profits to zero is because it is actually very difficult to start a business successfully when profits are small and wages high. But if profits were high and wages down below 60 per cent. of the production with I3 or I4 per cent. of unemployment it would be an ideal time to get into business, so ideal in fact that it never occurs in practical experience.

So it comes about that there is a point where employers' profits are so good that it is not safe to risk increased competition and loss of business for the sake of a relatively small additional percentage of profit, and the evidence from commercial statistics shows this point to be somewhere about I2.5 per cent. unemployment, with profits and wages at 36 per cent. and 64 per cent. of the net production respectively. This fact may be stated as a simple economic law to the effect that when the gold basis of price is stationary or moving more slowly relatively to the movement of the percentage of employment, as profits fall below 36 per cent. of the production and unemployment decreases it becomes increasingly difficult for new industrial enterprise to come into competition; but as profits rise above 36 per cent. of production and unemployment increases it becomes increasingly easy for new industrial enterprise to come into competition and cut down profits.

It does not require very much evidence to convince the mind that there is a limit to the percentage of profit that can be made, and that the limit will be at a point where it is becoming easy for new employers to come into industry. With such a limit granted it seems a most feasible hypothesis that until such point is reached employers will raise their prices and increase unemployment to obtain the profit which constitutes their payment for the management and organisation they have undertaken. Such profit is broadly speaking a just remuneration so long as the present capitalistic system of production is deemed necessary, because it is roughly payment by results. Whether the continuance of that system is necessary or desirable, and what abuses it may lead to, are other questions; but it should not be overlooked that it has been a very successful system, vastly increasing the social wealth both of employer and employed. 
From the above illustration of profit-making it should not be supposed that the employer obtains an unearned share of production simply by keeping a certain proportion of workers unemployed. It rests with him at the risk of his income to discover what profit it is possible to get in his particular trade, and how much of his production there may be an effective demand for. It must not be thoughe that the employer can always safely demand 36 per cent. of his production and that competition only springs into existence at that point; there is always a lively competition, and it is only well managed businesses that can contend with it up to the $12 \frac{1}{2}$ per cent. unemployment point. An exceptionally clever employer may get a profit somewhat above the average because competitors cannot imitate his excellent organisation without sacrificing most of their profits, whereas an employer who manages his business badly must be content with a profit below the average, or competitors who can easily attain to his scale of management will soon undersell him. So that while the average profit depends upon the average difficulty of starting new competition, the particular employer's profit depends very largely upon his particular capacity for resisting new competition. Nevertheless, the possibility of a profit of any kind depends upon keeping wages down below the value of what is produced, and this can only be done by causing a competition for work by persons who are to some extent unemployed. That there are persons unemployed, that they do tend by competition for work to lower wages, that there are great trade organisations to try and prevent that result, and that employers do decide whether it is or is not profitable to employ more or less persons, are such well recognised facts that it would seem to be self evident that it is this unemployment that makes profits possible. But this does not seem to have ever been definitely recognised by economists. Although Cobden's famous remark that " wages rose whenever there were two employers running after one worker, and fell whenever there were two workers running after one employer," is regarded as a very simple and correct statement of the facts, it does not seem to have been quite realised that the pecuniary advantage of either of those persons depends entirely upon how far he can make the other one do the "running after." and that if one does all the running the other gets all the profit.

It is somewhat difficult to quite discover what theory is implied by economists to be the alternative of this hypothesis that profits depend upon competition for work engendered by unemployment. Their considerations of the question usually consist of tentative suggestions and illustrations of special complications, which hardly seem to be carried to any logical conclusion. One such consideration seems to be that a large portion of what is generally included as profits is a species of rent, a composite quasi-rent of ability and of instruments of production and the general business advantages of 
the individual firm that can make large profits. But as will be further discussed in the next chapter, this rent nature of profit, while it may afford some moral justification does not seem to explain why that surplus should not all go to the wage-earners, unless the employer declines in some way to employ all the labour that could compete for employment in that industry. Perhaps the most common reason or not recognising the dependence of profits upon unemployment is a somewhat vague idea that there would be no unemployment if the workers were willing to work for wages that would leave a fair profit to remunerate employers. As such an arrangement would be fixing wages by agreement and not by competition it remains to be explained how what was fair wages and a fair price would be arrived at. But without stopping to investigate such details it is very commonly assumed that the workers' efforts to raise wages by organising strikes or short hours of work are mistaken, and that by forcing up wages above their fair amount they oblige the employers to put their prices up against their wish, and with disastrous though not very clearly explained results to trade.

But it must be remembered that, as we have previously pointed out, employers cannot really raise their prices to cover a rise of wages; and as the above hypothetical trading accounts may have given a misimpression upon this point it is necessary to recall what was represented there. The price that the employer can and does put up when wages trench upon his profits is the price per unit or per article, but that need not increase the price of his whole output or total production if the number of units is reduced. Our previous investigations have shown that the price of the whole produce " normal price" is determined by the cost of production to the community measured in the labour cost of gold, and that it can only vary as that labour cost or its own labour cost alters. We have also shown that wages do not enter into cost of production, being a variable share of the value that is produced. Therefore the gold standard of value being unchanged and the labour-time cost unchanged, the employer can only cover a rise of wages by increasing the price per unit of the article he produces, which, as we have seen in the above trading accounts, must reduce the number of articles made and the number of persons required to produce them. Thus unemployment is always the inevitable result of an attempt on the part of employers to raise prices and the only means by which profits can be maintained. When on the other hand the " normal price " rises as the result of improved gold production it does not cause unemployment; employment is always increasing as normal prices rise, but as the consequent rise of wages tends through slower adjustment to lag behind the rise in price profits can increase also. When, however, the gold standard stops rising and prices reach that limit, wages begin to catch up and then profits can only be kept at the normal rate by putting up the 
unit price of the commodities and increasing unemployment to the normal $12 \frac{1}{2}$ per cent. or thereabouts.

The above paragraph practically sums up our conclusions as to the industrial mechanism that produces value and determines its division between the two principal classes contributing to its production, and the importance of our investigations in the earlicr chap. ters should now be obvious. It is only when the inevitably determined nature of prices is understood that we can realise that while gold is the standard of value, the quantity of that metal that can be produced by a given amount of labour determines the total value of all the commoditics produced by a like quantity and quality of labour. And that being the limit of value that such labour can produce, it must also represent the limit of the purchasing power of that labour, so that any raising of the price (per unit) above that limit results in an inflated normal value of production, which allows wages to rise indefinitely at the expense of profit that is indefinitely deferred and becomes largely unrealisable. The consequent shortage of money and greatly over-priced stocks of goods gives the common impression of over-production and leads to a reduction of the number of units produced and unemployment.

While it is admitted that the evidence in support of some of these conclusions is meagre and unsatisfactory owing to the incompleteness of the available data, especially those relating to gold production, unemployment and wages, it still should be recognised that the probability of a theory does not rest solely upon the completeness of the data but to a considerable extent upon the power of the theory itself to give a comprehensive and connected explanation of the principles that underly industrial phenomena. If a theory can show that the special phenomena claimed by it as industrial laws or principles are all united by their dependence on some common natural cause, as parts of one whole system, the theory succeeds in distinguishing them as essential principles as contrasted with the confused mass of commercial details that always obscure our view of what is economically essential. And that success renders it highly probable that the theory is approximately correct.

We believe our theory of value affords such a fundamental prin. ciple, and will be found to give a common explanation of all the essential industrial phenomena, and that the explanation it gives is more connected and simple than any previously suggested. And further, that it has the unique advantage that it is of practical applicability to commercial estimates and price forecasts, and to some considerable extent to the estimating of movements of wages, and might be much more useful if a reasonable amount of statistical data respecting unemployment was forthcoming. So far as the available evidence goes it is strongly in favour of this theory of value, wages, and profits, and although the data are far too scanty to constitute 
anything like proof, they are, we believe, more than can be brought in support of any other general economic theory; so that the present contention cannot be dismissed simply on the score of insufficient data. The least that can be granted us is that we have shown reason why better statistical evidence regarding wages and unemployment should be demanded by all who take an intelligent interest in the industrial and social welfare of the community. 


\section{CHAPTER XII}

\section{RENT AND INTEREST}

It will have been remarked that nowhere in the foregoing pages have we specifically discussed the classical theory of rent: the reason we have not done so is simply because it has not seemed essential to the development of our own economic views either to invoke or to controvert that ingenious hypothesis which has so long been considered essential to a clear conception of the distribution of wealth. As the chief purposes of the theory of rent as expounded by Ricardo, seems to be the showing that rent does not enter into cost of production of commodities it does not present any difficulty to our view that it may be considered a share of profits, seeing that we hold that profits also do not enter into cost of production to the community.

As is well known, the theory of rent starts with the assumption that the cost of produce from land depends upon the cost of producing the final portion of the supply that the community finds it necessary to obtain from remote or barren land on the margin of cultivation; that is, the part of the supply that costs the most labour to get and bring to market sets the price of the whole supply. Therefore all land that is more productive or from which the produce can be got to market at less cost than the marginal lands produce can. must produce a surplus value over and above the cost of labour of all kinds and employer's profits, a value that is not produced by the labour upon that superior land at all, but is a free gift of nature or circumstances to the person or society owning that land. As this unearned increment costs society no labour it does not raise the value of the whole supply of the production or enter into cost of production, that cost being determined by the labour necessary to obtain the final increment of supply from the costly margin of cultivation.

If this contention applied only to the actual fertility of the land as it was applied by Ricardo and as it is still stated by economic writers when they wish to make the argument seem self evident, it might perhaps be accepted as a reasonable hypothesis. But in that case we are naturally driven to ask where this most unproductive margin of land actually is at the present time? For it is not obvious that we are getting our increasing supply of agricultural produce from worse and worse land. If this were so we ought to find that as the 
agricultural area increased year by year the return per average acre grew less as the less productive land had to be brought under cultivation. But on the contrary a reference to the diagrams of normal prices of wheat, maize, cotton, etc., grown in the United States shows that the return per acre gets greater rather than less as the area extends, which on the face of it makes the existence of a costly margin of cultivation look very doubtful. If it is sought to account for this increased return by intensive cultivation which would be equal to cultivating worse land, such an assumption would make it necessary that the yield from the old rent-paying land should have increased fabulously to maintain its superior productivity over the everincreasing margin of relatively worse land, and so far as we know there is no such remarkable rise in the productivity of ordinary farm land. It would appear that the new marginal land is the more naturally productive and that it is to the old rent-paying land that intensive culture must be applied, so that it is actually the land which is suffering from a marginal dose of capital that has to pay rent while the rich virgin land is rent free.

To meet this difficulty in the theory it is contended that distance from the market, involving cost of transport to and from the place of production, and other such extra cost due to remoteness, are equivalent to less productivity in the land. But this explanation is open to much the same objection as the other, for it is not really obvious that in this country we pay more for wheat because we are obliged to grow it in distant parts of the earth. On the contrary, we are under the impression that we get wheat from overseas because we get it more cheaply than we could grow as good a quality at home. Nor is it clear that any great part of our wheat supply comes from marginal land that affords no rent, most wheat supplying land pays a rent or some equivalent. Even in America, where much wheat is grown and little rent paid, it should be noticed that according to Diagrams 24 and 65, wages are 28 per cent. more than in England (I902); and undoubtedly the total value produced per person, including profits, is more also, so that if no rent is paid it is not because the land is not producing the value to pay it. Again, if the "Far West" does represent the margin of cultivation, it would certainly seem that rent of agricultural land near to the market in this country should have increased enormously since the American corn-growing country has been opened up ; whereas, on the contrary, rent from land in this country has fallen very considerably. There does not, at any rate, appear to be any progressive increase in rent of land due to this ever-extending margin of cultivation, so that all things considered it seems somewhat doubtful whether this hypothetical margin has any tangible existence.

But there is another consideration which more directly concerns our particular view of the matter. If a margin of cultivation is 
supposed, in what way does the surplus that pays rent differ from the surplus that pays the farmer's profits? If one farmer produces a crop which when brought to market affords a surplus for rent, and another farmer on more remote land produces a like crop, but finds his rent surplus swallowed up by the extra cost of working that remote land, why does the latter's surplus spent in extra costs enter into the value of the produce while the former's surplus spent in extra rent does not enter into the value of that produce to the community? Obviously because the extra cost was extra work performed by the community in getting the crop, whereas the extra rent was wealth enjoyed by the landowner as a gift of nature without any extra work on the part of the community. But on that margin of cultivation there will doubtless be still another farmer upon still more remote land producing a like crop who finds his extra labour swallows up not only his surplus for rent but also his surplus for profit, leaving him only his salary of management. The other farmers have done no more work than he has, but they have got an unswallowed-up surplus for profits, extra wealth enjoyed by them without any extra work on the part of the community. Why then should these profits be supposed to enter into the value of the crop to the community any more than the rent does. We contend that they do not, but that both profit and rent are a share of the result of labour, and not part of the labour or cost of production which cost must always be labour if it is really cost at all.

This is partially recognised by modern economists in so far as some forms of profit are seen to be in the nature of rent, and are variously described as differential or quasi-rent ; but it seems to us that all profit is exactly like rent, in so far as it does not enter into cost of production. And the above illustration might be carried further to the case of the super-marginal farmer cultivating such bad land that he did not even get wages, but could only keep himself alive by eating all he produced; he would do as much work as the other farmers, and being one of the community, his labour would represent the final cost of that product to the community. So it appears that the surplus value that goes as rent, profit, and all wages above this miserable subsistence, is the free gift of the soil without extra labour, and does not enter into the value of the product. Nor does it, as we contend; wages, profits, and rent are the result, not the cost that produces the result.

But while we agree with the classical economists that rent does not enter cost of production, and add that profit and wages do not either, we do not agree that the various shares of rent, profit, and wages are the result of a surplus value created by the high cost of the final increment of the supply that has to be obtained from the margin of cultivation. In addition to the difficulty of discovering the actual existence of this supposed margin we do not see that the n.w. 
totalivalue of the supply or its price will depend upon the cost of the marginal increment. This we have already pointed out in the chapter on wages, and we may here restate the same conclusions. It seems to be supposed that a marginal contribution to the necessary supply, however small, will determine the market price at the point fixed by the cost of that final increment. But if a million bushels of wheat cost $4 \mathrm{~s}$. per bushel, and one extra bushel to complete the market supply cost 5 s., there is no reason whatever why the price of wheat in that market should go up to 5s. per bushel. Even if the rest of the market happened to know of the existence of this one 5 s. bushel, they would not venture to hold out for that price for fear some one else should turn up with some wheat at $3 s$. $9 d$. They would sell at $4 s$., and if the producer of the odd bushel was lucky enough to get his 5 s., it would only raise the average price of wheat by one-millionth of Is. per bushel. The effect of the final costly addition to the supply is only to add to the total value of the whole supply by the actual extra cost of that final portion. If the rest of the supply really did go up just because the final addition cost more, the owner of that marginal land where the final increment was produced could demand a price that would afford him a good rent and profit. That he obviously cannot do so proves that the producers on good land compete to keep the price down to that no rent at the margin level, and do not necessarily put their price up to his level.

As before pointed out, the academic formula that there can only be one price at one time in the same market if all the buyers and sellers know what that price is, is a misleading and useless truism, because it neither correctly describes nor is in any way applicable to any existing commercial phenomena. None of the buyers and sellers ever do know what the actual price should be, and they never carry out their transactions at one and the same time. The market price on the great exchanges may vary several times in one minute, so there is no reason whatever why the marginal producer should sell his costly produce at the same price as that produced more cheaply on the more convenient land. He will hold on for a better price, and if the price happens to go up high while he is at market he may sometimes make a better profit than the man who, having produced cheaply, sells before the rise of price takes place because he is afraid it may not rise but fall. It is this want of certain knowledge regarding the price that enables each producer to sell his produce nearly on the basis of his own cost of production. And the result of the whole transactions in a commodity gives an average price that approximates very closely to the average cost of production, including of course the labour cost of management and direction.

These considerations still leave it possible that the producers from convenient land whose costs were below the average would have a 
pecuniary advantage over those on the margin of cultivation whose costs were above the average. But this in itself does not quite account for any great surplus, for it must be remembered that if all the agricultural labour was fully employed wages would nse to the whole amount of the average value produced, so that only those whose productive advantages were above the average would get any profit, in which case the surplus for rent would be a vanishing quantity, while those producers whose productive advantages were below the average would be getting less than the average wages. It is quite possible that a margin of this kind does at times exist, and consists of unemployed agricultural labour working on allotments or other marginal land for less than the average wages of full cinploy. ment, and that this labour constitutes the competing force that cuts down wages and makes profit and rent possible for the average agriculturist.

So it appears that rent like profits really depends upon unemployment, which we think is a much more probable cause for its existence than an increased use of land of inferior productive quality. For, as we have above shown, the amount of such unproductive land would have to be large to greatly increase the average cost of production. Under the present conditions of easy transit and easy distribution of population, good land and good markets are so accessible that average farming land is always to be found, and there is no actual evidence of any margin of cultivation, unless by that margin we mean the unemployed or those who are partly employed producing less than average wages.

It appears, then, that rent has no essential peculiarity that distinguishes it from profit, and it may clearly be regarded as the share of the profits of industry taken by the landlord in payment for the use of his land. The fact that more rent will be paid for good or convenient land than for bad needs no special theory for its explanation, as it is universally recognised that more can be paid for a good instrument or good article of any kind because it is more useful, either in business or pleasure. The payment both of rent and interest obviously depends upon whether the business that is responsible for them is carried on profitably enough to afford a surplus over wages and expenses out of which these liabilities can be met. Profits. interest and rent are all shares payable out of the surplus made by an industrial undertaking, to the various classes of employers who control that undertaking, the share taken by the direct employer or entrepreneur, being called profit, while the shares called rent or interest are those going to the indirect employers, who employ the entrepreneur and the labour he manages to use their land and capital. And it should be noticed in passing that an employer who has made himself responsible for rent or interest may be very much in the position of a manager for the landlord or capitalist who pays 
him by results, almost as a manager or agent might be paid by commission on results. Seeing that farmers' profits are for the purposes of the revenue estimated to be equal to only one-third of the rent value of their land - that is, one-quarter of the surplus, whereas rent is three-quarters, it looks as if the landlord really took the profit, and that in many cases the farmers' share was no more than the salary of management. These various forms of income derived from the result of industry being obviously shares of that result it is no longer useful to inquire how they respectively enter into cost, as they evidently do not enter but result from the cost. But it still remains a question whether the ownership of land does enable a proprietor to obtain a rent and profit which together are greater than the share of production that usually goes as profits of industry.

There is very little satisfactory evidence obtainable in regard to the actual production of farms in any country. We have for England the Census of Production from which we obtained the rough estimate of the production per person given in the chapter on the national income, and illustrated on Diagram 2. The total production from agriculture was there given as $£ 142,000,000$, and if the profits on this do not exceed the usual 36 per cent. of the production they would amount to $£ 5 I, 400,000$, whereas the evidence from the Income Tax returns suggest that a larger profit is made.

Table 75 gives the returns under Schedules A and B of the Income Tax for the Census year I907, and the total will be seen to be considerably larger than this 36 per cent. of the production estimated from the Census.

But in the average 36 per cent. profits we do not include salaries, which are regarded by us as wages, so that in addition to this profit over and above wages there is another II per cent. of surplus that is usually absorbed by salaries in industrial concerns. Unless a farm is worked by the bailiff of a landowner there is very seldom anything in farmers' wages in the nature of salaries, and as we have pointed out, it is probable that the farmer's income really represents those salaries. When the land is occupied by the landlord it is almost certain that the profit he returns under Schedule B is all salaries, and in the case of small tenant farmers the landlord probably takes all the actual profit, the occupier only retaining what is equal to a superior wage or salary. So to compare the surplus made as profits of agriculture with other industrial profits we must deduct from the above taxable income of $£ 69,336,000$ a sum representing the share of production that is usually taken as salaries. In the chapter on the division of the "national income," we estimated salaries as II per cent. of the production, and in this case II per cent. of the $£ \mathrm{r} 42,000,000$ would be $£$ I $5,620,000$, which, when deducted as below, leaves the income from rent and profits at $£ 53,7 \mathrm{I} 6,000$, which is only $£ 2,000,000$ 
higher than the $3^{6}$ per cent. of the production as estimated frotn the Census returns.

TAIILE 79.

Schedule A.-Land

Schedule B.-Farming profits

Less Ir per cent. of $£ \mathrm{r}_{4} 2,000,000$

36 per cent. of $€ \mathbf{1} 42,000,000$ production .

\section{Or about}

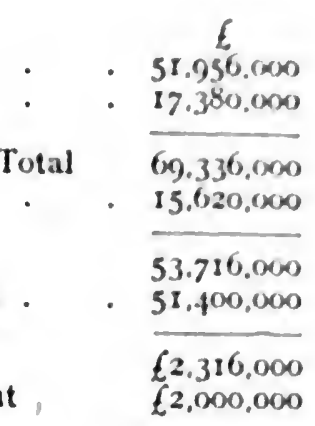

So if the returns to the Agricultural Census are correct the figures from the Income Tax returns suggest that agriculture is a little more profitable than other forms of industry, and that the landlords might get the benefit of that circumstance. But we think this conclusion very doubtful and that the data is not exact enough to be conclusive within a million or two.

A more likely explanation of the surplus is that the estimate of the total production from agriculture obtained from the Census is too low. It is doubtless very difficult to obtain the absolute total result of the business of farming, and the balance of two millions. when compared with the whole agricultural output, is only small and might quite well be the result of error. If the estimated output of $£ \mathbf{1 4 2 , 0 0 0 , 0 0 0}$ was increased by six millions or about $£ 3$ per person per annum, this surplus would disappear; so that we cannot put too much faith in it. There also may be room for considerable error in taking the total income as it is represented by the Schedules of the Income Tax returns. They probably do not show the very considerable reductions that have to be made for the various estate expenses incurred in getting income from land. Such things as Income Tax, Estate Duties and Rates are payment to Government for work done by Government employees, who add largely to the value produced by the land through making it accessible by roads, etc., and secure from unlawful spoliation. Also there is the cost of rent collecting and legal or other professional charges which represent work done to increase agricultural security and efficiency. Although all this work is deemed a necessary part of our agricultural system, it is performed by persons whose work is not included in the agricultural output, so that the sum of such expenses should be deducted from the incomes derived from rent as the landowner's costs of producing rent, thus reducing his gross returns to the net result. It is desirable to recognise this fact, as such expenses, and especially the taxes, are sometimes regarded as a kind of penalty 
paid out of income, for owning property, or a returned share for the community; whereas it is payment for work done by the community for the landowner, and part of the expenses of his business.

So that on the whole we are inclined to think that the profit from the owning and use of land is no greater than that from other industries. But if this share of the agricultural production that goes to pay profits and rent together is no larger than the shares so allotted in other industries, it may seem rather astonishing that the landowner can take so much of it, leaving the average profit to the farmer so small. It appears from the method by which farmers' incomes are estimated for the purpose of the Revenue authorities, that they only retain one-quarter of the total profit made, which seems very little for the employer's share in any industry. But it is questionable whether a farmer can be regarded strictly as the sole employer; he may be in the position of a joint employer with the landlord. It is obviously possible for the landowner to farm his own lands with the help of a salaried manager or bailiff. Even when his estates are extensive he will not be likely to let them to farmers, unless he can get a rent that on the whole will pay him better than keeping a staff of bailiffs to conduct his farming operations. So that, as we have pointed out, the position of the average farmer is often more like that of a bailiff paid wholly by results than that of the employer in other industries. The financial status of the individual farmer varies very greatly, and some, no doubt, are in as good a commercial position as many employers in other industries. But farmers in this country seldom, if ever, attain the wealth and financial influence of the princes of industry. Many of them never get more than a good farm bailiff might be paid, while there are small farmers whose position is little better than that of a superior farm labourer. The result of the competition of these various grades of farmers to obtain agricultural land keeps the average profit on farming down to very near the II per cent. of production that usually goes as salaries in other branches of industry.

Rent, like other forms of profit, seems to be simply a share of the production of industry taken by the employer who is the legal owner of that production under our accepted industrial system. This share, as we have seen, would be wholly absorbed in wages and salaries unless the owner so raised the price per unit of his production that the total value (normal price) was more than the purchasing power of the community determined by the gold supply. The result of such inflation of price would bring about financial difficulties, and over-priced stocks of produce that would soon force a fall of prices. Employers would then regard themselves as over-producing and reduce the output and cause unemployment. Agriculture is among the first to feel this fall of price, because of competition from foreign countries which produce at a less labour-time cost. So 
farming will not be extended and the percentage of unemployment will increase, with the result that the increased competition for work brings down wages and salaries and leaves a margin of profit. This process undoubtedly goes on in agriculture to produce profit and the rent that is the greater part of that profit, but the restriction of production is not quite so obvious in farming as in the industrial factories because a farmer cannot definitely put his land on threequarter time. Neither is it very obvious that any amount of land goes out of cultivation in times of bad trade: so far as this country is concerned, at any rate, it is not very likely either that a farmer who has rent to pay, or owner who has land from which he expects a good income, will leave that land altogether uncultivated, even if prices are low. But less labour is employed and pieces of land do get neglected when agriculture is depressed ; rents of land have been falling for many years, and there is no doubt that farms must have been neglected and deteriorating in amount produced, or the landowners would not have lowered the rents or undertaken the cultivation themselves. The reduction of output no doubt takes the form of neglected and understocked land and the corresponding unemployment of labour, rather than a systematic reduction of the cultivated area. The reduction of output also is obscured or rendered relative only by the great increase in labour-saving machines and methods which has enabled farmers to employ less labour without reducing the area cultivated.

As rent is a form of profit it should tend to reduction when trade is bad and prices falling, but the evidence of this is again obscured by the fact that rents have been falling during most of the recorded period, and the alteration in the terms of farm tenure is too slow to be clearly correlated with good and bad trade periods. The brunt of depression no doubt falls chiefly upon the tenant farmers, as the landlord can always fall back upon cultivating the land himself. This should result in the landlords farming more of their own land in bad times, but any figures for such lessening of the acreage let are obscured by the above-mentioned reduction of rents, and also by the increase in the population and general productivity of the country, which latter circumstance leads to a continuous increase in the demand for agricultural produce and a steady increase in the number of farms let to tenants. Yet in the period from $1 \mathrm{SOS}^{2}$ to 1912 the increase in the number of farms let does rise and fall roughly with the general variation of prices. Starting with a few thousand extra acres let each year, the number rises to 80 thousand acres between 1900 and 1901, marking the high price period. and the annual increase in acres let gradually falls from that point till it is only 3 I thousand extra in 1905. With the boom years of 1906 and 1907 it goes up again to So thousand, after which it again falls to a few odd thousand acres per year and recovers rapidly with 
the rise of prices, being 9I thousand in I9II and 303 thousand extra acres in I9I2.

Although agricultural statistics are too general in character and wanting in detail to afford any exact numerical data as to restriction of output, there can hardly be any question as to the very effective agricultural unemployment that keeps down wages. The wellknown winter unemployment that is such a trying feature of rural life is alone enough to explain why a farm labourer will accept a constant job at almost any wage, which means that the competition for such employment is very keen. This unemployment may be realised when we reflect that in spite of the increasing population the number of persons employed in agriculture has considerably decreased since I88I, as shown by the Censuses of Occupations of the People, a few figures from which are here given :-

PERSONS EMPLOYED IN AGRICULTURE.

England and Wales.

$\begin{array}{rrrr}\text { I88I } & \cdot & \cdot & I, I 28,300 \\ \text { I89I } & \cdot & \cdot & I, 049,000 \\ \text { I9OI } & \cdot & \cdot & 923,600 \\ \text { I9II } & \cdot & \cdot & 97 I, 700\end{array}$

Scotland.

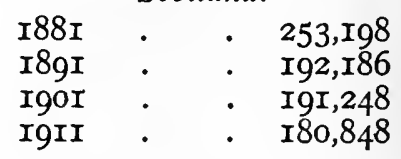

This means that while in agricultural districts there is a rapidly increasing population coming into existence that would naturally to a large extent tend to become farm labour, it does not remain there because there is actually a reduction of the opportunity of its being absorbed in that industry. This reduction of persons plus the natural increase of persons wanting employment would in the first of the above decades amount to about 2 per cent. in England and 4 per cent. in Scotland of persons permanently unemployed who are obliged to seek employment in other forms of industry. It may be supposed that as these persons leave the rural districts to find occupations in the towns they do not compete to reduce farm wages. But this, we think, is not the case ; it is exceedingly difficult for a boy of I4 to go from his home and keep himself in a town, and it usually means that he must live in his village and walk many miles a day in addition to his work. The result is that boys are brought up on the land, and it is not till they are about grown up that they find that ros. $6 d$. per week is not enough to live on and are then driven to leave agricultural work; but not before they have competed very effectively to keep farm wages down to their very low level.

But it is the short time worked that is the chief factor in reducing agricultural wages-the seasons and the weather are a constant excuse for keeping farm hands wholly or partly unemployed, and farmers are continually having to find odd jobs for young men at an absurdly low pay just to help them to stay in the district. This they could hardly succeed in doing were it not for the other village 
trades such as wheelwright, carpenter, builder, smith, baker, etc., most of whom employ some of the labour at times when the farmers do not want it : and by so doing enable men to stay in the district and compete to keep down wages. So that part time unemployment in agriculture is probably a good deal more than two and a half times the percentage of completely unemployed.

The result of this constant competition for alternative or more permanent jobs is the well-known flow of labour from the nural districts into the towns, a phenomenon that has called forth many fanciful explanations although the low agricultural wages are its all too obvious cause. There is no evidence whatever for the notion that people prefer to live in towns, and we think it is almost certain that if the opportunities for getting a living were as good in the country as in towns the flow of population would be the other way : there would be a flow out of factories into agriculture or whatsocver might be profitably done in rural districts. The unemployed of our towns is largely the result of the flow out of agriculture, and its existence helps to retard the flow and keep down agricultural wages as well as industrial, because it makes it more difficult for new comers from the rural districts to find work in the towns. It should not be supposed that there must be a separate unemployed for each industry; a general surplus of labour in the community will affect all wages, and especially in those occupations where much technical training is not required.

Perhaps enough has been said to justify our view that agricultural profits and rent are no exception to the method by which all industrial profits are made, but that agriculture may rather be regarded as the starting point of industrial exploitation of the unemployed. The essence of modern industry lies in the fact that the improvements in the art of production have enabled an ever larger proportion of the population to be liberated from the production of food and other primitive necessaries of existence for the production of the more luxuriant amenities of life.

It seems quite possible that the ordinary rent of agricultural land is covered by the usual 36 per cent. profit of industrial organisation. But the well-known fact that land comes to pay a considerably higher rent when it is in the vicinity of any large centre of population is often supposed to require some special theory of rent for its explanation. The fact that land near towns lets or sells at a high price naturally leads to the conclusion that in some way the growth of the town round that land has produced a value in it, and that as the value is not the result of labour upon the land its owner can appropriate such value without sharing any of it with labour. But it is probable that any such extra value only exists as latent value. and can only become actual wealth, either as capital or income, by employing labour upon the land. If such land has been idlc, or only 
been used for agricultural purposes, no value or only the ordinary return has been obtained from it, so that the owner must be supposed to have obtained his living from that or other source by labour or the organisation of labour at the usual 36 per cent. of production without any special advantage. We are not concerned here with the right or the desirability of his owning land, but only to discover exactly where any value he may get from land actually comes from. It is necessary that land should be owned by some person or community on some definite understanding of the obligations and duties of such owners, or labour upon it would have no security for the fruit of its efforts. And these duties do entail some labour or cost of labour. The owner of an acre of land in a growing town may claim to have performed these duties and not to have obtained any more than the ordinary profit of doing so; but when some speculator offers him $£ 5,000$ for his acre of land, it seems as if it had acquired a value out of all proportion to the work the owner had put into it. But where or how does any such value exist? Streets with drains and water pipes, etc., have been made round that land, to the cost of which the owner must have contributed; so that unless he has produced more than the average agricultural return from his land he has been a loser by those improvements. The railway and Post Office may have come close to his land, and many houses and shops, but he can obtain no service from them without paying for it, and they pay him nothing whatever either directly or through his land unless he makes an increased use of it. And when he comes to sell the land there is no increased value upon the land or produced by it that can be taken by the seller or claimed from society. The value that is offered for it is the property of the purchaser, and must have been obtained in the usual way as the ordinary 36 per cent. gained by the organisation of industry and exploitation of the unemployed, quite regardless of the existence of this acre of land or the surrounding city; the purchaser's wealth is neither more nor less because that land is near the town. The value is only latent in the improved resources that make up the surrounding town, and may not exist at all in his acre of land.

The fact that $£ 5,000$ is offered for that acre of land does not necessarily mean that such value has come into the land, the value need not be in it at all. If it had possessed any such value it certainly would have been used or sold that the owner might enjoy the income. The offer now made only means that some one has concluded that the time has arrived when that land will begin to produce a value. It may have been too small and isolated to be of any great agricultural value; too far from the industrial centre for cottage property; too near for villa residences, and not enough in the town for a hotel ; in fact, was not required by society for any purpose that would pay more profit than had been got from it before. But owing to the 
increase of the town the time had come when a hotel was likely so do well in that position, so the offer is made in view of the prompective value that it is thought can be earned upon land in that ponition.

Possibly the landowner has not enough capital to build the hotel himself, and the speculator does not see his way to pay for the land as well as building, so that the latter borrows the value of the land from the owner, giving him a mortgage on the hotel. And if that is the case we find that this very valuable acre has not enough value to pay for itself at the time of the bargain. Having come to such arrangements the hotel is built and proceeds to carn a profit of 36 per cent. of the value of the services produced by its staff of workers and the manager pays a share of that profit to the late landowner as interest upon his $£ 5,000$. Or the same proportion of the product might be paid as rent if the landowner had not sold but continued to own the land. Such value however it is paid is the production of the work performed in the hotel, and the surplus value produced by the hotel does not vary in any way with either the size or value of the land; it varies only with the amount that the hotel's wages bill can be kept below its net output. If instead of one highly valuable acre the landowner had a r,000 acres of remote agricultural land, and sold it at $£ 5$ per acre, or let it to an enterprising agricultural speculator, they would as before have started by farming it. to produce a profit of 36 per cent. of the production, and the same value would be produced and divided as was that from the above singie acre. The only difference is that one industry requires much land. and the other can produce the same value on a very small area, so can afford to pay a high price for the position of that land, which is the essential necessity of the hotel industry. The rent paid makes no difference to the cost to the community: if the hotel manager had bought his land for $f 5$ only it would mean that he would get the rent value instead of the other landlord. Society wants the hotel. wants it in the town and wants all the town advantages crowded into a small space thereby causing much value to be produced in that space. Society gets what it wants, and what the wage-earning part of society gets depends entirely upon the percentage of unemployment and its competition for wages.

The latent value of land near populous centres may not be the result of work done by the owner of any particular piece of ground the value of which is under consideration, nor may it appear as any visible improvement in that piece of land. Yet it is none the less the result of labour which affects the using of the land, and such labour has usually been organised by the owners of land in general, upon the usual industrial lines; when town rates are collected to improve the business and residential qualities of the neighbourhood. they are not used to produce a profit for the local administrators. but as they are expended in labour that is subject to competition of 
the unemployed in the usual commercial way, there no doubt arises a profit on the work they do, which goes as improved latent value to the property owners of the town. The resulting street with its light and water supply, etc., which adjoins a man's land greatly increases the usefulness of that land, and when he sells that land to be built upon he sells the purchaser the right to go to and from his house and get water and light, etc., by that street, which the purchaser could not do unless he bought that land. The increased price of the land is to cover the labour cost of the capital sunk in these improved resources of the town. And the purchaser of the land with the increased latent value gives the increased price, not because he gets increased value out of the land or from any person, but because he can employ more persons on the land than he could before the streets, etc., were made. He can organise more workers, or indirectly employ more, and acquire 36 per cent. of the production of each, or a share of that 36 per cent. if he only employs them indirectly.

But if at the end of the said street there is a theatre which is not the outcome of the rates, it is not quite so easy to see that the value of the land is in part due to the theatre, and that paying for the land is to cover part of the cost of the theatre. The price paid for a seat at the theatre is naturally supposed to cover the costs of the place, but such payment for admission only covers the cost of the current labour employed in the theatre, with a very small contribution towards returning the capital invested in the building. The repayment of the capital depends upon the number of tickets sold. If, instead of buying a house in the street, a man lives on cheap land eight miles away, where there is no public means of conveyance to the theatre, it will cost him a good deal beside the price of admission to get there. When he buys a house in the street the cost includes cheap theatre going. But as he gets to the theatre more cheaply he goes more often and helps repay the capital cost of that resource of the town. But he has had to share his advantage with the landowner by paying his higher price or rent, and has thus enabled that landlord to go to the theatre more often and contribute to its cost also.

The same thing is true and much more important of the railway station in this supposed street, especially if instead of a dwellinghouse we are speaking of business premises. It is essential to the success of a railway that labour should congregate in town centres along its course where industry can take advantage of its facilities for transit. It is not enough that a railway company shall make a line, etc., by which they can move great weights easily and get a large profit by moving them. They must share that advantage with the persons who want the weights moving, or those persons will still move them without the assistance of the railway. A railway does give a very great advantage to such persons who want goods 
moving or who require to travel; but if such persons are to fully avail themselves of the advantage they must have mills, warehouses and residences near the stations of the railway. To get this poxition they must share their advantage with those who own the land near stations and who must get their share of the advantages as an increase in the usefulness or value of their land.

A railway company sinks a vast amount of capital labour in giving an increased latent value to land and property where they open railway communications. To convert this latent usefulness into any great actual advantage the landowners must proxluce more goods ready for distribution by rail than ordinary agricultural land will produce. To do this they must allow industrial producers, merchants, etc., to use their land at a price, thus sharing their advantage with them. Industry by making the greatest possible use of the railway repays the capital invested in it. And as the increase of industry necessitates residential accommodation the increased cost of such land and houses is also part of the distribution of the advantage gained by improved resources amongst all contributors to the making of an industrial centre. The vast capital invested in labour to produce the roads, railways, waterworks and all the improved resources that go to make up a town has given the area of land a greatly increased latent value, or more correctly a greater usefulness, because more labour.can be employed upon it. That usefulness cannot become value at all until labour is employed upon it, but when it is so employed the usefulness of the labour is greatly increased by the improved resources of the land, because it can produce a greater number of useful things. The value produced by that labour, however, is not greater, the value produced per person depends solely on the value produced per person in gold mines; no extra value or unearned increment arises in any way from the use of the land with improved resources. But more persons can work upon that land and this concentration of the labour makes it possible to better organise the work and produce more by its increased division and specialisation. This concentration also affords the opportunity for the director of industry to organise and control a greater number of workers and so obtain 36 per cent. of the production of this greater number of persons, thus greatly increasing the total income he obtains in profits. For which great advantage he is willing to share that total profit with the persons who have allowed him to use these improved resources, which have been added to their property by their own organisation or that of other persons who had a pecuniary interest in making that property more useful.

This will explain why some persons owning land in certain situations that have become populous centres may get a share of profit in the form of site rent in excess of 36 per cent. of the work literally performed upon their land. But as a matter of fact the 
value out of which that excess site rent is paid is produced by means of the land. If a big industry is to be started at a certain place it is absolutely necessary that there should be dwelling-houses on the land adjoining that place, and if the adjoining landowners do not provide such houses, the organisers of the business must do so, and in either case it must be on that adjacent land, so that as the cooperation of the owner of that land is essential to the organisation of the industry at that place he can demand a share of the profit made by that business, just as the person can who has lent capital to the business, which is really exactly the same thing as lending a site.

But it should be particularly noticed that there is no extra or unearned value developed by this concentration of labour in a populous centre. All the value produced is the result of labour employed upon the land of such populous centre, or is the result of work assisted by the use of the land and the improved resources thereon. The value per person produced by that labour is not more, and the share taken as profit and rent is not more; the rent and interest, however extortionate, is all paid out of the 36 per cent. of production that goes as profit. No one is able to take a greater percentage of the production they organise because they have an advantageous position in a populous centre, but that concentration gives certain capitalists and landowners the opportunity to organise a greater proportion of the labour and get a greater share of the total profits at the expense of other would-be capitalists or landowners. But again it should be noticed that this advantage in the share of profit or rent is only on condition that the said landowner or capitalist can organise better or provide a better business site than other such capitalists and landowners. This proviso is an important one because it means that a landowner's site rent is not a permanent source of unlimited wealth; the changes in concentration and success of industries may render a site undesirable and much reduce the rent obtainable from it, so that it is found that a landed estate must be administered with a good deal of discretion and be organised to be of advantage to society if society is to pay a rent for it.

We have seen that so far as land is concerned it is probable that the value obtained in rent is never much more than the 36 per cent. of production commonly forthcoming in other industries. And as rent of industrial property is paid out of ordinary profit it must always be considerably less than that percentage. Although the site rent of some residential property may be very high compared with the area of the land, which is a circumstance of no importance, that rent is also paid out of ordinary profits so must be much less than 36 per cent. of the production that pays it. That is to say, no extra value has to come out of industry to pay these rents.

But site rent is in reality an unimportant detail compared with the mass of industrial production, and the consideration of the rent of 
property is a question of the rent paid as the remuneration of thone who organise the production of business premises and houses. This is a commercial industry like any other and produces a value out of which wages and profits are paid. If the production of such business is a house, for instance, when the builder sells the house he will realise about the usual 36 per cent. of the net value as his profit. But if the continues to own the house, the rent he gets is the deferrerl profit or interest on his money and should still only amount to $3^{6}$ per cent. of the original net value. But in case of house and other such property paying rent for many years after all the work upon its erection has long been completed, it is not so easy to see that the rent does not amount to far more than 36 per cent. of the production of the labour involved and that there is not much extra value as a high rent for the site. We are a little apt to regard property as a static condition of wealth and think of new property as simply an addition to an ever increasing and permanent source of income. But the experience of the ordinary owner of house property does not indicate that it has any great advantage in profits over other forms of business, and when we examine such data as can be obtained with regard to this subject we find that the ownership of property is by no means a static form of wealth. The demands upon income from rents are very considerable through the necessity of much new construction to meet the requirements of an increasing population and the adaptation of existing property to the changing requirements of the population. And as these demands vary very greatly in different cases it renders any examination of particular cases very complicated and useless. The only useful line of examining the question seems to be the endeavour to find the result of property owning as a whole, and subject to the whole of the dynamic forces of the changing community.

House and other property differs somewhat from land in that while the acquired value of land is seldom lost, the value of the property upon the land always deteriorates with age, and may do so to a great extent and in a short time from changes in the development of the neighbourhood where it is situated. This means that rent of property is not so nearly all profit as the rent of land is, but is part profit and part repayment of capital and payment for wear and tear. It is obvious that in addition to keeping his property in good repair. the owner must recover the capital invested in that property before it becomes so unsuited to its position and requirements as to be practically unletable. But it is not so obvious that property owners must devote a portion of their income from rents to the providing of houses and other forms of property for the use of the increasing population. It is plain, however, that the community must tind houses for its members, and if the existing owners do not provide enough house room while they are taking high rents as income new owners will spring up to do so, or even the State may enter upon 
housing schemes. Whoever undertakes the ownership of this increased property, the fact that it is new and more suitably situated will quickly render old property less valuable and lower its rentearning capacity long before it is worn out or dilapidated, so that an owner must be prepared to make new property or his old will soon bring him less rent. This means that though a house might exist for Ioo or 200 years its efficient rent-earning capacity might not last nearly that time without so much alteration and adaptation that it had virtually been rebuilt. In addition to the ordinary cost of keeping property in repair, there are from time to time costly alterations necessary to adapt premises to altered requirements, such as changed ownership and use and changes in the development of the neighbourhood. As we have said, properties vary so much in the amount and frequency of such alterations, and appreciate or depreciate from development of localities so differently that it would be altogether impossible to estimate the average profitableness of property from typical examples even if we had any data for such individual cases.

The only way to estimate from public statistics the average returns from ownership of house property is to discover as nearly as may be what society pays for houses during the period that an average house may be supposed to last, and taking that as the total cost of house property, see whether the usual cost of building and keeping up an average house, plus the ordinary rate of profit, comes to anything like the same total amount.

First we have to estimate the average rent-earning life of a house and the number of houses existing in that period, then that number multiplied by the average rent paid will give the cost paid by the community for houses in that period. The decennial Censuses of population state the number of houses building at the time of the Census, and these figures suggest that the yearly increase has been about 2 per cent. of the houses in existence. As the number of houses has doubled in the last roo years this yearly increase would amount to I per cent. for increase of population and I per cent. for renewals, which suggests that roo years is about the life of an average house. But when we come to the rent paid by the houses during that roo years it is quite obvious that owing to the yearly increase and renewals the houses in existence at the end of it have been paying rent for very different lengths of time. We, therefore, cannot simply multiply the average rent of the existing houses by roo to get the cost in rent of those houses, because some of them have only been in existence a year or two, and very few of them have been built roo years. From the above-mentioned Census figures it is possible to find the age of the houses returned to the Census of IgIr; and in Table 76 these Census figures since I8Ir are given in the left-hand column. Opposite each date is the number of dwelling-houses then 
existing, and each succeeding Census these houses will have been standing another ten years. So multiplying the Census figures by ten as in the right hand column gives the uniter ages of all the houses existing each Census, or the house years they have completed.

The figures between the dates are the number of houses added each decade, but as this total of additional houses is not complete till the last year of the decade, the average length of time they have

TABLE 76.-THE AVERAGF LIFE OF DWELLING.HOUSES.

If the average life of a house is roo years, all the houses returned in the Census of 1811 will have been replaced by new ones before the Census of Igrr. So, owing to the lowering of the average by the annual increase in house property, the average life of the houses returned to the Census of IgI I will be as below :-

\section{Census for England and Wales.}

Inhabited houses.

I8r - r,797,000

291,000 for increase at five years

I82I - $2,088,000$

393,000
$I 831 \quad 2,481,000$

463,000

I84I - $2,944,000$

334,000

1851 - $3,278,000$

46r,000

I86I - $3,739,000$

520,000

$187 I$ - $4,259,000$

572,000

I88I - 4,83I,000

620,000

I89I - $5,451,000$

8 I0,000

Igor - 6,26r,000

$88 \mathrm{I}, 000$

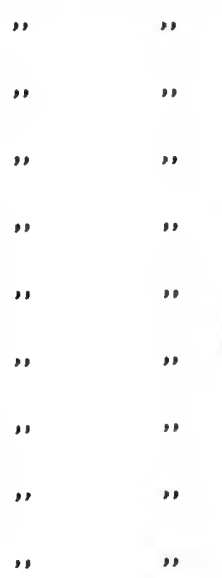

,
House years completed at nex: Census.

I7.970,000

I. 455,000

$20,580,000$

$1,065,000$

$24,810,000$

$2,315.000$

29. $4 \$ 0,000$

I, 670,000

$32,780,000$

$2,305,000$

$37.390,000$

2,600,000

$42,590,000$

$2,860,000$

$48,310,000$

3.100,000

$54.510,000$

4,050,000

$62,610,000$

- $4.405,000$

$7,142,000=$ average life of house returned at Census, $1911 \cdot 55$ years

stood at the end of that decade will be five years, so that multiplying the decennial increase by five gives the house years that those additional houses have completed. The table covers 100 years: and the total house years given at the bottom of the right hand column, if divided by the total houses existing in I9II, gives the average age of house years completed to that date as 55 . We thus get the number of years that the existing houses have been in use. but as a house is not earning rent at such times as it may be unoccu. pied we have to deduct 6 per cent. of the time to cover such loss from unoccupied houses, this percentage being calculated from the 
numbers returned as unoccupied to the Censuses of Igor and IgIr. So the rent-paying life of the existing houses only averages $5 \mathrm{r} \cdot 5$ years, which is taken as the rent-earning period in the following calculations.

In Table 77 the total lifetime rent of an average house is based on the above calculations, and will be seen to come to $£ \mathrm{I}, 030$. To this must be added a sum for rates which are payments for the labour on streets, drainage, light and water, etc., which are part of the value created by the labour in the providing of satisfactory houses for the public to live in. And, as we have previously pointed out, it is probable that the property owners get the greater part of

\section{TABLE 77.-ESTIMATED PROFIT AND LABOUR COST OF HOUSES.}

Life of House 55 Years, less Time Unoccupied.

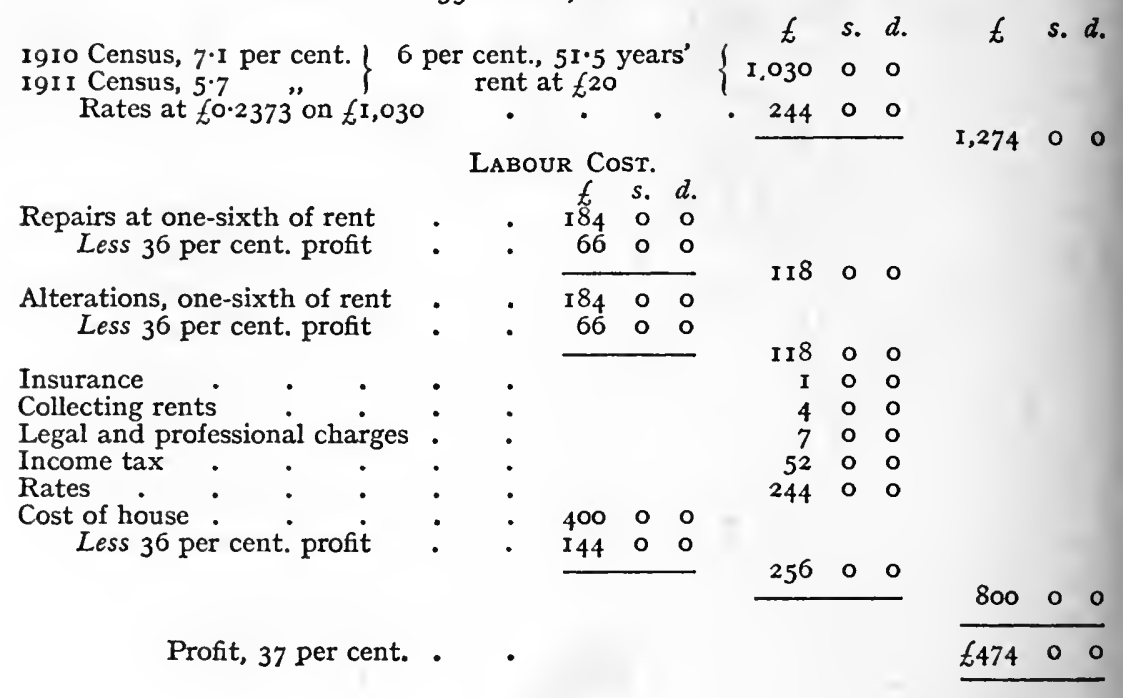

the profit upon this labour that is accessory to the direct labour upon the house and land. The total cost paid in rent, including rates, for the whole life of the house is $£ I, 274$. Against this total is contrasted the labour cost of the house, and in the bottom half of the table will be found in addition to the cost of building the house the various costs of keeping it up and administering the estate.

The repairs to the house are taken to cost a sum equal to one-sixth of the rent, which seems to be the proportion usually estimated and which is probably about correct, but the item for alterations, which often mean a good deal of rebuilding, is more difficult to estimate. Many of the houses and shops that have been built over fifty years have been altered almost out of recognition, and most houses of that age have had structural alterations of one sort or another made to them. As there are no data as to the probable average cost of altera- 
tions of this kind, we estimate it at a similar amount to repains. From these items and the building of the house the ordinary profit has been deducted so as to leave only the labour cost, so that the total profit for all employers and owners concerned shall appear in the final figures. The cost of rates is also included, as from what we have said above we consider they represent work done to make the house more valuable and probably afford the property owner a profit on the labour employed on improving the position of his property. The amount for rates is taken at the average rate paid on property generally, which includes property other than dwelling-houses, so may not apply absolutely to a house of this kind, but will not be very far out. The total labour cost of the house comes to $\$ 500$, which subtracted from the rent cost estimated above, leaves a profit of $£ 474$, which is 37 per cent. of the total rent value.

The profit shown from the above estimate and given in Table 77 is a little above the ordinary rate of 36 per cent., but this difference is probably due to the roughness of the data and might disappear if the true average cost of alterations and repairs, and also the correct rates for this class of property, were known. The calculation is admittedly rough, but it seems clearly to suggest that the profit from the building and letting of houses affords about the same average rate of profit as other forms of industry. It should be noticed that the 37 per cent. is all the surplus there is over and above wages and salaries to divide between the builders, repairers and owners in cases where the owner is not himself the builder. The relation of the house builders to the owners is probably very similar to that of the farmer to the landowner, and the builder often gets no more than the II per cent. of the production that usually goes as salaries. No doubt the shares of profit taken by the owner and the contractor may vary greatly in different cases, as may also the total profit on any particular properties, but our calculation given in the table probably indicates very nearly the average profit from house property.

To check this calculation and to a little confirm the probable correctness of the conclusions therefrom an attempt is made in Table 78 to compare the total national income from rents paid in a year with the annual cost to the nation of providing houses and other building, as returned to the 1907 Census of Production. The annual rent of the community is taken from Schedule $A$ of the Income Tax returns, plus, as in the last table, the rates for local govern. ment, less the part of those total rates that is the probable portion paid for agricultural land. The annual cost of buildings in the table is the net production as shown in the Census tables-that is, the total value added by the building trades above the cost of their materiak. etc., purchased; and from this net production the usual profit is deducted. These building constructions returned to the Census 
include all alterations and repairs carried out by the larger building and contracting firms, but a great amount of repairs and some alterations to property are done by small tradesmen such as house decorators, ironmongers, plumbers, jobbing carpenters, small builders, etc., who make no returns to the Census of Production. So that a further sum is added to the costs on the table to cover such work to property, and the item has been estimated at a sum which, together with the repairs, etc., returned to the Census, comes to equal one-

\section{TABLE 78.-NATIONAL INCOME FROM RENT OF HOUSES AND NATIONAL COST OF PROVIDING THEM.}

Gross Income brought under Review of the Income Tax, I907-8.

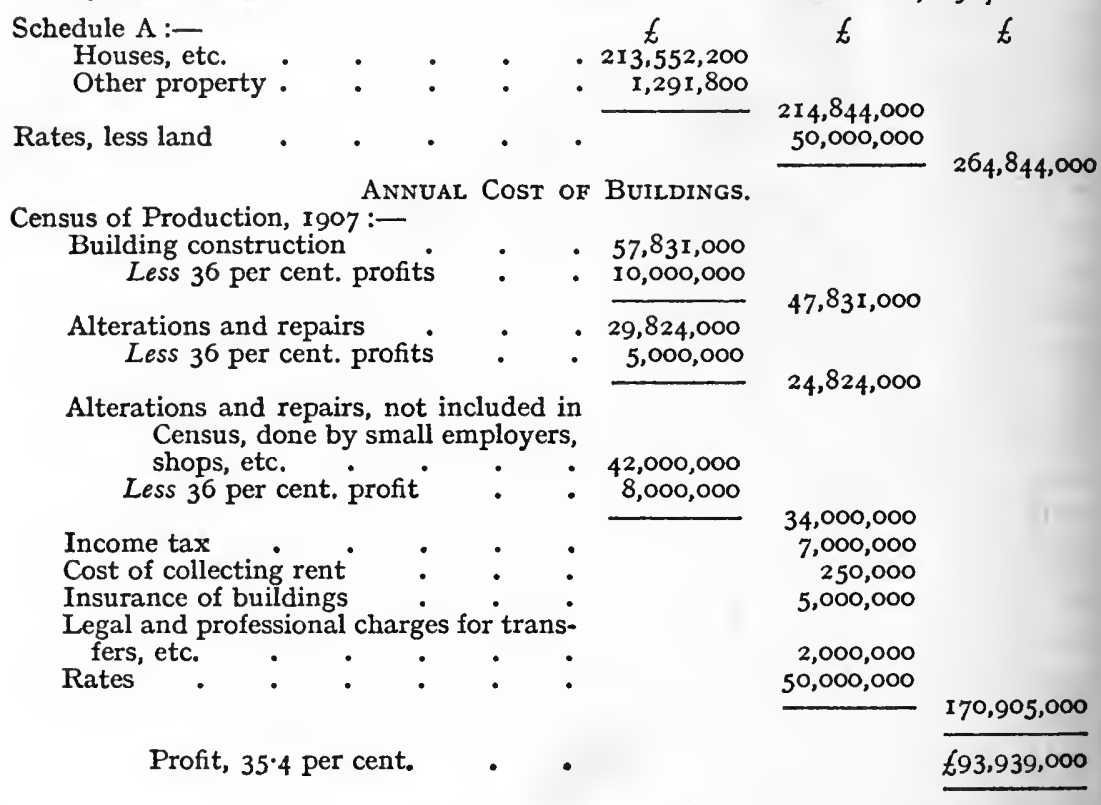

sixth of the rent for repairs and another sixth for alterations. The other items are the same as in the last table.

The total national profit on a year's building construction as shown by the difference between wages cost and rent cost comes out at $35^{\circ} 4$ per cent. of the production, which is nearer to the general average of profits than that shown by the previous calculation for a single house. The evidence of these examinations of property, rents and expenses indicates very clearly that the total profit from such undertakings does not much exceed those from other industries. But as the returns thus indicated include both builders' and owners' profit, these tables do not show how that profit is shared between those co-operating parties. The calculations suggest that the property owners may get some little advantage from the work done by local government servants who improve the usefulness of their 
property after the building construction is completed. The wages of local government employees being regulated by ordinary business usage, and the result of their work being valued by ordinary com. petitive business standards, there is probably a profit on such work. which, not being taken by the local authorities who employ that labour, goes to the community, which means the property owners get it as increased site rents. But the activities of local administration may detract from the value of some properties as much as they add to others, and the actual value of the property to the owners depends upon the work done upon their property to adapt it to the local conditions and requirements; also, the profit on such work depends on the ordinary division of the produced value between the labour and its employer.

The whole evidence of our examination of rents goes to show that there is no mysterious development of value which has not cost the community extra labour to create. The increased value of property near centres of population is all the result of labour, and as far as it affects idle estates is absolutely a latent usefulness that cannot be realised in any way till work is done upon such estate. And when work is done on such property the resulting profit, interest and rent depends entirely on the extent to which competition for work keeps wages below the total value of what is produced. So that rent of houses or interest on money invested in land or other property is no exception to the general law that profit is a share of production, the amount of which apparently depends upon the existence of unemployed labour competing for work and reducing the share of production that goes to wages.

It is, we think, most necessary in all economic considerations to realise that all values arising from property as rent, profit, or interest must in every case come wholly through the employment of labour as approximately 36 per cent. of the production of that labour. Even if a house with a view across a park to the sea beyond pays a site rent of four times that of a similar house that has no such view the extra value does not arise from the view or result from a natural advantage in position. If such house stood on a piece of barren land by the sea, eight or ten miles from a station or anywhere, the view would probably not give the house as much value as that of the house in the town without a view. The fact that some one is willing to pay the high rent for such a view from his house in a good town does not produce the value that enables him to pay that rent. But because a working population is concentrated at that place the tenant can organise much labour there and get 36 per cent. of the production of that labour, and so is willing and able to pay the landowner much rent for his view. It is a case such as we described in Chapter V., p. 106, of a one-sided equation of price: the view having much usefulness in giving pleasure, but no value, its price 
depends solely on the value of the thing given for it. And that value given is a part of the 36 per cent. produced by the labour organised by the person who pays the rent, and it in no way alters the value or price of what that organiser produces or the share of the production he can pay to the labour employed. It is simply a matter of sharing the profits afforded by the competition for employment in that centre of industry. 


\section{CHAPTER XIII}

\section{TRADE FLUCTUATIONS}

FROM our analysis of the various data obtainable with regard to prices and the value of the production of labour it appears that the value of commodities depends entirely on the relative amount of labour involved in their production; and the market value or price of a commodity will vary with its labour-time cost. But it should be clearly understood that by a commodity we mean a unit or stated quantity of commodity, whether it takes ro minutes or 10 years to produce. And a question may arise: If all the producers of commodities declare that the labour cost of their commodities has advanced, because all the things they require for their business cost more - as they commonly do when trade is good and prices risinghow can we say how much more labour time each commodity really requires or whether there is really any extra labour involved? Common experience suggests that there is no extra labour cost when trade is good, but that everything goes up in price because everything else is more expensive, which may be common experience. but is not very enlightening. In Chapter $\mathrm{V}$. we saw that to determine any actual movement of value we must have some fixed point to measure from, such as is afforded by our " normal prices " or value produced per person in a given time. This normal price does not vary with variation of labour time in the production of commodity, because if a thing takes longer to produce and the producer gets more for it he produces just that much less in his time, so his remuneration per period of time is unchanged-the normal price of his work is the same as before.

So long as gold is the standard measure of value the normal or labour-time price of commodity will change only with change in the labour cost of gold, however much the market price per unit of the commodity may vary. That being so, it seems that the average normal price of commodities is definitely determined by the natural difficulty or ease with which gold is produced, the value of a day's work of any sort being simply equivalent to what quantity of gold that grade of labour could have produced in the gold mining industry. The total value of the production in any industry being thus naturally determined by the contemporary productivity of labour in gold production, it follows that no alteration in the shares of that value which happen to go either as wages, profits, interest, or rent will make any difference to the total value so divided. The evidence examined in 
the last three chapters with regard to these divisions of production has shown that so far as the limited data go they appear to support this theory of prices and do not reveal any extraneous source of value or wealth.

The weak points in the evidence for this theory are the short and broken records of gold production per person and the scanty evidence as to unemployment and short time or wages actually paid. But, as before pointed out, complete proof is not to be expected in the discussing of any scientific theory; its usefulness depends rather on its power of finding a common cause and explanation of the phenomena under investigation, and of affording a sound basis for experiment, or prediction of result. Our long discussion and diagrams of price variation gave evidence of a common cause for such variations, and the production of gold was seen to follow the common movement so far as data were available. And that this general movement is actually connected with and dependent upon the gold movement was supported by the fact that the theory based upon that assumption afforded the basis for successful experiments in price forecasting.

It remains in the present chapter to show that this theory of prices, with its correlated theory of wages and unemployment, is able to give a complete explanation of yet another group of economic problems which have long been a field of much discussion. Fluctuations in business prosperity are universally recognised, and those periods of good and bad trade have given rise to much economic controversy, and have led to many and sometimes curious theories of their explanation. For instance, Mr. Jevons' remarkable attempt to trace them to the periodic appearance of sun-spots, which effort only tends to show how difficult economists found it to explain the variation of the price level by the accepted theories of price.

These fluctuations are noticeably periodic, and seem to be cycles of commercial activity, in which after a few years of rising prices and general business prosperity a highest point is reached, from which there commences a general fall of prices and a growing depression of trade till a lowest point is reached and the cycle begins to repeat. It sometimes very naturally happens that when trade has been increasingly good for some years business speculators are tempted to enter upon over-bold ventures, and the general optimism may carry prices too high when the summit of a good period is reached, so that when the depression starts some adventurous persons may find themselves in difficulties and something in the nature of a business crisis may mark the turning point of the trade cycle. As such rash business men are notoriously apt to make a great outcry and attribute their losses to anything and everything except their own want of judgment, their voice predominating gives the impression that a consensus of business opinion regards the depression as due to something not only beyond their control, but somewhat in 
the nature of an outrage upon society. The blame is usually charged to the Government, the foreigner or the financiers, the bankers generally coming in for a good share of it. This ordinary com. mercial outcry has, we think, led some economists to give too much weight to the financial element in the phenomena, and to exaggerate the cataclysmic aspect, at the expense of the more normal and progressive change in the price level.

Perhaps the most generally known exponent of the financial reasons for trade fluctuations is Professor Irving Fisher, who, under the general title of Purchasing Power of Money, apparently attributes fluctuations of prices chiefly to variations in the quantity of bank deposits. As we have before stated, we do not regard bank deposits as currency distinct from goods, such deposits being only an account of goods that have been passed on into the social capital and acknowledged by cheques paid into banks. These deposits, which, as we understand Professor Fisher, are the balances of all bank accounts subject to cheque, represent work done by the community but not consumed, so that these bank deposits may be regarded as the balance standing to the community's credit. Any increase in this balance means an increase in the total goods and services to the credit of the community, but does not raise the price of those goods or services in any way. At times of good trade and high prices no doubt the optimism of the market may run prices up above their natural position, but this is not due to the amount of currency. In our review of prices we saw many examples of too high prices, and how such errors were very promptly corrected by increased production and a quick fall to compensate for the undue rise. We cannot admit for a moment that optimistic buying can keep general prices up for any length of time, and although such rash speculation may at times produce a financial crisis which comes heavily on unsound business concerns, it does not explain the rise and fall of prices over a period of eight or ten years, or the bad and good trade experienced by substantial business houses.

In addition to our fundamental disagreement with Professor Fisher's equation of exchange, we are not quite able to understand why, if opening bank accounts can raise prices, he should suppose that prices will fall for some years after the bank rate has been put up sufficiently high to discourage business extension on borrowed money. When the bank rate of interest had risen enough to make borrowing unprofitable, no doubt business people would be less disposed to make speculative increases in their production : but why should they reduce either their prices or their bank deposits? If, as Professor Fisher quotes Professor Marshall to prove, these borrowers have been enriching themselves at the expense of the public, why should they be unable to continue their bank deposits without borrowing more money? Certainly a number of risky firms might 
have to go under if they had borrowed too much and failed to produce what was wanted, but why every one else should go on reducing their prices and bank deposits for two or three years afterwards is quite unaccountable. While Professor Fisher may correctly describe the phenomena of a crisis, the weak point in his argument is that it does not show how the general rise of prices starts or why when it stops a fall should take place. There is really no evidence of any shortage of currency at any time. Between Igor and I904 prices were falling and trade was bad, yet the amount cleared at the London Clearing House rose each year, and was $£ \mathrm{I}, 000,000$, 000 more in I904 than in I90I. This must have meant a great increase in bank deposits in that period, and it is to us inconceivable that there ever could be any falling off or shortage of this kind of currency. And if there was, cash would only have to circulate faster, increase in velocity, as Professor Fisher tells us it may, and all would be well. Nor, we think, would the quantity of actual gold have any effect on prices if the marginal competition in mining it was normally efficient and the labour cost of getting it remained unchanged-the supply would then always be just the quantity required.

We think a much simpler and more probable explanation of trade fluctuations can be found in our theory of profits and unemployment. Professor Fisher's views seem to have been influenced a good deal by the crisis of 1907 , and in the table he gives to illustrate the culmination of that credit cycle we find, rather unfortunately for his contention, that the bank deposits did not decrease that year or the next, so that the fall of prices could not be attributed to a reduction in the quantity of that kind of currency. And the table also shows that bank reserves greatly increased in I908, which means that gold had to be obtained to insure the stability of the banks. Bankers cannot increase their supply of gold by offering more than $£ 4$ (in gold) for four sovereigns' worth of gold; as we have seen, the only way to increase the supply of gold is to reduce commodity prices till gold mining pays as well as, or a little better than, other industries. This is what had to be done, and in the chapter on gold we gave quotations from American mining reports for I906-7, showing that in 1906 prices of commodities (metals other than gold) were so high that gold did not pay, and the output fell off. In Chapter XI. again we pointed out in connection with the illustration by supposed trading accounts that when gold is short or prices have gone above the gold limit, those people who must have gold have to sell their goods cheaper to get it. It is obvious that an increased supply of gold, however necessary, cannot be obtained without lowering commodity prices sufficiently to let gold mining pay. But it is not so obvious why a supply of gold should be so necessary, or who it is who will actually be willing to lower their prices to get the gold. 
It is quite understandable that as every cheque paid into the bank represents the transfer of a deposit of gold to the credit of the person named as being paid by the cheque, and as the bankers are alway liable to be called upon to supply gold money to the extent of any balance due to their customers, they are anxious to keep a reserve of gold large enough to meet any demands that ase at all likely to be made. But bankers have no goods to reduce in price, and it is not quite easy to see why persons engaged in production of commotities should reduce their prices so that their bankers may get gold. That the bankers put up the rate of interest seems a reason why producers should raise their prices rather than reduce them.

But is it not a fact that commodity producers do want gold, and as things now are managed, must have gold to satisfy their requirements, even though they do not know they are short of it, or that they have any difficulty to get it? One of the chief desires of the prudent commercial man is to save money. His reason for working to get a large income is not simply that he wants to spend it in luxuriant living, but to make certain of future wealth by saving part of such income. As we have before pointed out, there are very few things that can be saved at all without great loss by depreciation, and gold is pre-eminently the best thing to save : it is almost the only thing that cannot depreciate badly, and it is gold only that can actually be saved at the bank or anywhere else for any length of time. In these days of an elaborate banking system it is perhaps natural to suppose that although the hoarding of gold was the original form of saving, it is now quite possible to save money without a store of gold, but it is questionable whether that is actually so under present commercial conditions. The bank may so far as it thinks fit, and at its own risk, employ the gold deposited by its customers in financing industry and earning interest ; but what they are actually responsible to their depositors for is a hoard of gold, which must be delivered as such to their depositors if demanded. As pointed out above, a cheque accepted by the bank simply means that a hoard of gold has been transferred from one depositor to another. and it cannot be too insistently pointed out that nothing else of value is transferred by a cheque. If the customer cannot draw gold from his deposit at the bank he most certainly cannot draw it in goods of any kind. Although the depositor who is saving money is not conscious that he must save in gold, he wants the banker to have the requisite gold to insure the stability of the bank: and the interest he would expect to get for the gold he is supposed to have deposited depends, as we shall see, very much upon the gold being obtained.

The fact that bankers do not hoard gold to the full amount of their indebtedness to their depositors, and commonly issuc and accept negotiable paper in place of actual gold, leads to the conclusion that gold is not actually necessary to saving. If there is a short supply 
of gold, it seems that the use of fiduciary money, cheques and what is loosely called "credit," might be indefinitely extended, and that the depositor would be content to save without gold if he is credited when he requires it with purchasing power to the extent of what he has deposited and the interest thereon, because that credit will enable him to purchase what he wants. But we think it is quite open to question whether he will be able to purchase actually what he wants unless the bankers enforce the gold limit of prices by insisting upon getting a continual supply of gold.

The term " credit" used to indicate a form of currency is a very vague and uninformative one. Credit actually means trust or confidence in the fulfilment of a financial obligation, a deferred payment on the understanding that there is a legal claim upon the goods and property of the person trusted with such goods in advance of the payment. But when a banker accepts a cheque it marks the end of a financial transaction, and neither the banker nor his depositor, who has been paid by the cheque, has any further claim upon the goods sold or the property of the person who paid the cheque. There is no further obligation to be fulfilled; no one is trusted with anything, nor has the banker or his depositor a claim of any sort upon any concrete value whatever. As pointed out in Chapter IV., the banker does not in his deposit business give any one credit, or trust any person to fulfil any contract, but has confidence that the law of prices will inevitably bring about a financial position which insures that his depositor shall have power to purchase from the social capital all the value he has contributed to it, as shown by his bank balance.

This confidence lies in the fact that certain goods have been produced and passed on to the social capital, as witnessed by a cheque paid for them, and that the now legal owner of those goods must have passed on other goods to the same value before he could get a purchasing power to draw the cheque. Which means that he relinquished his purchasing power over his own production when he paid the cheque for these new goods. And as, further, any one who purchases either of these goods must relinquish the purchasing power over what he has previously produced, it follows that the unused balance of purchasing power over these goods will remain with the producer, who has retained a balance at his bank. Society credits this person with having added so much to the social capital, and debits the others with having consumed so much, and the bankers keep account of such debits and credits. This seems to be what is meant by credit in currency, but as the extent of such credit depends strictly upon the value of goods passed on to the social capital, it is not obvious that bankers can extend or contract such credit or inflate the currency by an increase of deposits. They cannot make the goods produced more or less, but if they extend the use of negotiable paper at the risk of their gold reserves running short, commodity 
prices may for a time rise above the gold production limit and the value of current deposits of such negotiable paper be exafferated by the high price of the goods they represent. But under ordinary circumstances the adverse rate of exchange and other resules to be discussed below soon result in a fall of prices below the natural position and an increase of gold reserve. Otherwise bankes could not continue to supply gold in exchange for the purchasing powes transferred to them by a cheque.

It must here be pointed out very definitely that the validity of this theory of the bankers' confidence in the inevitably permanent reten. tion of purchasing power by those who do not consume their income rests solely upon the assumption that the $f_{d}$ t transferred by cheque or other negotiable paper is of the same value as the sovereign in gold-that the value produced at a future time will, save for the slight alteration in the cost of gold, be virtually the same as at the time when a saving or deposit is made. It is recognised that if, while a deposit is lying at the bank, there is any considerable rise of prices, the depositor may find when he wishes to spend or invest his savings in some form of industrial production that he can actually purchase less goods than he originally passed on to the social capital to get his purchasing power to save. But as he would draw the full money value plus such interest as the bank might be paying, he would still be under the impression that he had saved money but had happened on a bad time to invest it.

As according to our theory a natural rise of normal prices can only result from a less labour cost of gold, such price movements are gradual and limited in extent by productivity of mines and improvements in the methods of mining. But if, owing to commercial prosperity and confidence, or to indiscretions of the national exchequer, there is at any time allowed an extension of paper currency at the expense of the "hoard " or gold reserve, prices and wages may go up very rapidly. And under those circumstances a person saving by means of a bank deposit might find in a year or two that his savings would not purchase half the actual goods he had produced to acquire the purchasing power. In such case it could hardly be said he had saved anything, and it is recognised as poor business to let money lie at the bank when trade is good and prices, wages, and profits going up. At such time stocks and shares such as are suitable for permanent investments do usually fall in price, and people who save by safe investments find themselves relatively poorer. Bankers are large holders of such securities, and find that as well as their gold reserves their reserves of stocks are falling in value, and they naturally become anxious to stop the inflation of prices and impose the gold check.

It will seem, however, that persons investing their savings in industrial concerns, in which the prices and profits are going up 
without the limit of the gold check, will find ample and profitable opportunities to save. That is, in industry they can employ labour and obtain 36 per cent. of the production or a prearranged share of that 36 per cent. as interest for their money. The bankers whose permanent investments have diminished in value owing to the rise in the industrial stocks and shares will have to increase their revenue by investment in industrial businesses in the form of loans and overdrafts at increased interest. But it is important to notice that savings thus invested cease to be purchasing power to those who saved, except for the 5 or Io per cent. interest. The rest is consumed, and becomes human energy, "productivity" or some other form of capital or improved resource. Society now only credits the investor with having added to the social capital the amount of that interest (if he does not consume it), and debits him with having consumed, or allowed others to consume the rest.

As all purchasing power thus invested is at once consumed by those who work with it, it is obvious that, whatever security may have been offered, the only source from which payment of the interest can come is the profit made by the employer of labour who has borrowed the money. Such profit depends on the fact that there is a certain percentage of unemployment to keep down wages, or when all are employed upon the fact that prices can go up to afford a profit above the wages paid. But, as we pointed out in Chapter XI. (see pp. 358-6r), if when all are employed the profit is not realised till long after the wages have been paid, the further rise of wages in the meantime may have swallowed up the greater part of the profit. The wage-earners having got their increased purchasing power in advance of the full rise of prices, they can purchase more one year and the employers less than they have each produced by their share of the work. The employer's purchasing power being therefore reserved, he could purchase more the next year, and the workers could purchase less if their wages remained the same; and the division of the production would then come to the normal proportion for each. But if in the second year everybody is still fully employed, the wage-earners again get the purchasing power and the profit is again deferred. These deferred profits are theoretically made, because the rising price makes each new stock produced so much more valuable in money. The stock and financial assets of employers and bankers increase prodigiously, and great nominal profits are made, yet little or no more profit is actually realised than when prices were at the gold standard level. As the cost of living will have gone up tremendously, every one will desire to realise some of their great increase of capital wealth as income or actual spending power. As a matter of fact, they will find they have to realise to the full extent possible, and that they are increasingly apt to be short of ready money at the bank. 
It is chiefly this tendency to be short of cash and to be increasingly indebted to the bankers that makes commercial people uneasy' as to the financial position when prices get exaggeratedly high in times of trade boom. At such times people in industry begin to feel that their deferred profits accumulating as capital in their own businesess ought to be realised and saved in permanent investments; and that is just what they cannot do. What has happened is that owing to full employment wages have really absorbed the whole purchassng power and all that is produced. The wages and actual salaries of management (i.e., what the employers actually spend as current expenses) together absorb the whole purchasing power: there is no concrete value left as profit properly so called. Producers are not really saving anything at all, but the fact is disguised by the inflated price of their stocks which show as a great nominal increase in their money assets. Members of the community are no longer able to save, because the community has for the time being abandoned the gold test of the value of a day's work, gold having become an ordinary commodity with a price that can vary. And as in that case there is for the moment no recognised standard of value either for labour or its production, nominal money prices can rise to cover wages without limit.

The phenomena may be stated as a law of variation of the fiducial standard of value. Gold, which necessarily cmbodies an actual labour-time cost, is the original and only recognised means of transferring purchasing power, fiduciary paper only witnessing the transfer of a supposed deposit of gold. Every time commercial organisation extends its use of fiduciary purchasing power in place of gold, or without increasing the gold reserve in proportion, gold ceases for the time to be the standard of value and becomes an ordinary commodity until the supply of, and demand for, it brings prices to the gold standard level. While gold is a commodity variable in price, commodity prices may rise indefinitely to the disadvantage of capitalists, who have to defer the realisation of their profits while paying wages at a continually rising rate. The shortage of realisable spending power caused by the absorption of profits by wages and stock leads to financial pressure, contraction of credit, and lessening of business enterprise with its consequent unemployment, which brings down wages, and prices can fall and allow the gold limit of prices to be re-established.

Seeing that an extension of current account business done by bankers when trade is good, even without the extension of bank loans common at such times, will constitute an extension of fiduciary purchasing power, and will unless gold reserves are proportionately increased also constitute a departure from the gold standard of value, inflation of normal prices from such cause has probably been of common occurrence in financial experience. When trade is good, 
owing to increased productivity in gold or other cause, and business confidence high, the bankers' business greatly increases. But the high level of commodity prices will reduce the marginal production of gold, and less of it will be deposited at the banks; reserves will not increase, and prices will tend to get inflated. Such inflations are usually short-lived, and reaction follows quickly; but they may at times be more protracted, and especially so if the financial equilibrium of a country has been disturbed by some big upheaval such as a war. We have repeatedly pointed out the high price periods associated with wars, and it is probable that in most of these cases there has been an inflation of prices above the gold standard in addition to any natural rise that was due to increased gold production at the time. Even without the use of unconvertible papermoney, which has led to the unprecedented inflation after the recent great War, there would always be a considerably increased use of fiduciary purchasing power.

While a country is at war there is, owing to shortage of labour and waste, a great falling behind in the production of improved resources, such as roads, railways, shipping, manufacturing plant, stocks of goods in process of manufacture, etc. As labour becomes plentiful after the war, and these resources have to be made good, there is plenty of profitable business to be done, and investment in productive industry is easy and lucrative. Prices are high, so that gold gets relatively short, but prosperity and confidence encourages an extension of credit and fiduciary purchasing power. At first there are large actual profits made, and there is much capital invested in industry. But as the whole of labour gets into employment wages begin to rise rapidly, and, as we have seen above, the consequent rise of price to secure a profit is always too late to prevent wages from absorbing a large part of such profit before it is realised, leaving the employer with a nominal profit in the inflated value of his stock and business assets.

This failure to realise profits will come on gradually after a time of great prosperity, and will be at first disguised by the fact that a diminution of ready money will be attributed to the necessary extension of businesses. Every one will be content to let the large nominal profits they have made go into increased stock and other assets of their business. But as the shortage of spending power and indebtedness to the banks becomes more evident, and the cost of living makes people desirous to realise some of their big profits, it is not difficult to see how a crisis might arise in which many unsound firms who had borrowed too much at the bank or invested in mistaken enterprises might fail and cause a certain amount of unemployment. But it is not quite so obvious why those firms who were sound and making a realisable profit on their production as large, at any rate, as before the inflation of prices should suppose they could realise more profit 
by reducing their prices. Such capable organisers could employ all the labour that might have been thrown out of work, without reducing their prices, for a community can always purchase and consume all it produces. And in that case, as all would still be fully employed, wages and prices would continue to rise: it seems that nothing could prevent such rise of normal prices, and that an inflation that had once got all the labour employed would never be able to stop or again return to a gold basis of price and wages.

But it must be remembered that although in times of trade brom all may be employed and business still be easy and profitable, there still remains the difference in productive ability that makes the difference between successful and unsuccessful controllers of industry. There would still be the different grades of productive power in the labourers of the community, and also in the countries with which they carried on their foreign trade. When there is increased commercial confidence from a natural rise in the level of prices, or in a marked degree when after-war conditions make prices high. there is a much increased demand for goods the supply of which has fallen behind the demand. And if at the same time there is a good supply of labour coming back from the wars into industry, the control of such industry becomes very easy and inferior management can make a profit, and also inferior labour can get a price for its share of production almost as great as the share taken by the highest grade; owing to incompetent management when inflation makes business easy, an inferior class of labour may get a greater share of its product than a higher grade of labour gets from what it actually produces. In fact it is probably this failure to correctly graduate the remuneration of the different grades of labour that is the actual cause of the inflation; gold production is the only industry where the price or wage depends directly and unalterably upon what is produced: when the competitive interaction between labour-time value in gold and that in commodities is suspended by the use of fiduciary purchasing power, the relative value of different grades of labour-time become distorted and often much exaggerated in value.

It should here be noticed that if labour could simply by organisation actually put up wages, there is no reason why the demands of any particular grade of labour should stop when they have absorbed all the profits. The least paid class of workers in any trade could put up their wages at the expense of the managers and the superior grades of workers, in fact, till every one was paid alike, whether they could work well or badly, produce little or much. Even if the remuneration of the recognised grades of labour is kept somewhere near the correct relative proportions, the inferior producers in each grade get an advantage at the expense of the superior. And further. the wages of the whole being too high relatively to that in other competing countries, forcign trade is curtailed and the advantage r.w. 
of cheap imports is replaced by costly production by very overpaid labour under emergency management of an incompetent character, which management can make a profit as well as the best so long as there is an actual shortage of produce, and a price that can go up indefinitely.

But during a period of easy profit-making there will have been a great difference in the management and organisation of different commercial undertakings, and a great difference in the wisdom and success of the various investments in industry. When all labour is employed it is very difficult to make a sound investment; it is not then possible simply to find capital to employ more labour-it is all employed. It is only possible to invest in an improvement in the means of production-plant or organisation that will increase the output of the same amount of labour. The only possibility of extending a business would be to get such improved method of production. During an inflation of prices everybody will be investing their profits in such extensions of capital, and the success of such extensions will vary greatly; some will be a real advantage, and many simply a mistake or of very little utility. In the early part of a trade boom during or soon after a war any kind of stock or increased resource will be an advantage, but as the depleted industrial resources get back to something like normal completeness it will begin to be found which are and which are not actual improvements in productive methods. Some such investments will turn out to be waste, and will cause a loss of purchasing power, because the community has produced things it cannot consume; and this loss of purchasing power will help the supply of goods to overtake the demand.

Firms that have been really well managed, and whose really improved resources have got the full value from the labour employed, will by their larger output have accumulated actual stock in goods produced more cheaply than other manufacturers have been able to do, but, like theirs, greatly inflated in value. As we have above seen, it would have become difficult for producers to realise their big profits as the inflation increased, and the firms with an actual stock might well reduce their prices a little to realise some of their profits by selling more quickly and getting their spending power before wages had gone up so much. And they would hope, no doubt, to extend their business by thus cutting the price. This drop in price brings pressure upon badly-managed businesses, and failures take place that cause some unemployment and reduce the social purchasing power by loss. The well-managed firms can then get more labour, and their stocks will again increase, which will enable them to resist the rise of wages to some extent. They may contest a point with the trade unions, and during a strike find the opportunity to clear their stocks in a rising market and thus realise some of the deferred profit that was not realised while all were employed. It 
does not matter whether they win their point with the trade union or not so long as they save wages for a week or two and clear their stock. After which improvement of their financial position they can again reduce prices on the strength of extending the total outpust of their business.

When the labour thrown out of work by the stoppage of the less fortunate employers comes to be employed at better-managed establishments, it would be found that though no doubt these firms could employ all the available labour if they wished to, they would not do so. Much of this labour would have been getting higher wages under bad management than its production was actually worth in a well-managed shop, and some workers would have to submit to a reduction of wage before they could find work. As this would be a question of justice between different grades of labour in the same union or between two unions the solidarity of the labour organisation would be weakened and strikes be liable to break down. The labour opposition is also weakened by the fact that as the cost of living would be falling about as fast as the wages, no one would be actually worse off by the reduction of the fictitious price and wages that ruled during the inflation.

The lower grades of labour that had suffered a reduction of wages would, when well organised with improved instruments of production, compete in prices with those employers who were still employing the pick of the labour. And this competition would tend to cut down prices and wages still further. So in this way is set in motion the machinery of falling prices. And the fall will continue until, by a process of competition to get labour on the one hand, and to get organising ability on the other, a point is found at which the greatest amount of actual and realisable profit is obtainable from each grade of labour. As one essential of obtaining the greatest profit is to produce at the lowest cost, it is necessary to import raw materials and any foreign goods that may be produced more advantageously in other parts of the world. Therefore the value of any class of labour must fall till it is equal to that of the same class of labour in other parts of the world, or as near to that value as the customary valuation of productive worth in that part of the world demands.

Such productive value point is indicated by the rate of foreign exchange, so that the fall of prices will continue until there is established a favourable rate of exchange for the country where prices are falling, or at any rate a condition of foreign exchanges which that country usually considers satisfactory. As gold is a commodity imported by most of the European countries, a satisfactory rate of exchange will probably mean that prices have fallen sufficiently to allow the required gold to be imported from gold producing countries. So that it is probable prices would fall to the gold production level 
even though the gold currency was not reinstated. But if that standard was to be again enforced, as probably it must always be, for the convenient transaction of foreign business, prices must fall till it pays to produce gold; and we think the above sketch of the inflation phenomena will illustrate the way in which such a fall of prices comes about. The inflation means that easy business conditions, due to a boom of trade and extension of fiduciary purchasing power, encourages inferior business organisation to pay over high wages to inferior labour in return for a nominally high profit which cannot be realised. The shortage of spending power caused by not realising their profits causes the inferior management that has produced wastefully to break down as trade becomes more normal and difficult, and the unemployment so caused brings wages to their normal level and prices down to the gold production level.

This is what, no doubt, happened in America in the latter part of I907, and in 1908 prices fell, gold mining revived, and bank reserves increased. At that time there must have been a considerable proportion of risky firms and speculative buyers working on borrowed money, and their failure to realise sufficiently upon their over-priced stock led them, and in some cases their bankers, into a financial crisis. But such crises, though common at such times, are not actually necessary to a turn of prices after a rise. In fact, the crisis of 1907 was not the culmination of a credit cycle or trade cycle at all; there was no natural increase in the difficulty of getting gold-the supply was increasing and prices rising, and they have continued to rise. The boom in 1907 was solely the result of market optimism and an increase of fiduciary purchasing power and the set-back in I908, the inevitable result of prices having been pushed above the gold limit in the previous year. A crisis does not appear to depend upon a trade cycle, nor does a cycle depend on a crisis.

The more important point for economists to explain is why for some years after a turn of prices from their highest point sound commercial houses and producers of every sort should find it necessary to keep reducing their prices at the expense of their profits and experience bad trade long after the bank rate and rate of exchange are normal. In a true trade depression prices are falling owing to the increased cost of gold; but it should be understood that falling prices alone do not constitute the commercial inconvenience or the actual hardship that marks many periods of bad trade. If a tailor has been selling a pair of breeches for $£ I$ Ios. and giving $£ I$ Ios. for a pair of boots, he is neither better nor worse off, because he only gets $£ I$ for his breeches and has to give $\ell^{I}$ for his boots. If prices fall, that is, gold becoming harder to get, society is no worse off, save for the infinitesimal amount of extra labour expended in getting the required gold. Nothing else costs more or less labour, and if all prices fell virtually the same amount there would be no perceptible 
shortage of anything. How, then, does the fall of prices bring about the loss, unemployment and want experienced in a period of bad trade? The symptoms of bad trade are reduced profsts, business difficulties, and failures resulting in increased unemployment, and finally a reduced rate of wages. As we have just seen, no one need be worse off because the total production has fallen in price: if the shares of that production going as profits and wages are both reduced in the same proportion their recipients will be as well off as before, the loss being purely nominal. What really constitutes the evil in bad trade is the unemployment and consequent reduction in the quantity of goods produced and consumed by the community. So the question is, why should society be so perturbed by a fall in the nominal money value of its production that it goes on short time and produces less of everything it wants and suffers a period of bad trade and want?

If prices remained always at one level it seems pretty certain that wages and profits would also preserve a constant ratio to the value produced. Competition would naturally tend to bring the division of the production to the point fixed by the supply of labour on the one hand and that of employers or organisers on the other, and keep it there so effectually that organised attempts to alter the proportions of such division would become obviously futile. But if the price, and therefore the total value of commodities produced, is frequently changing, any relative difference in the speed of adjustment of the competing forces on either side may make a difference in the resulting division, which will be prejudicial to either the employer or the employed as the case may be. If, owing to increased production of gold per person employed, prices are rising as they did from I895 to I 900 (see curve AA on Diagrams 26 to 28 ), each year there must be a continued adjustment of the very complicated dynamic forces which make up what we so glibly call competition : and upon the changing balance of these forces the division of the increasing value will depend. As may be seen by the curve on Diagram 43 (which it should be remembered is one year previous to commodity price movements, reading $1 \$ 95$ gold for 1896 prices), the standard of value raised prices from $£ 88$ in $x 895-6$ to $\delta 92$ in $1896-7$. If this simply meant 45 per cent. rise in the price of goods without any change in wages, profits would have risen 4.5 per cent. As we pointed out in Chapter XI., there is no reason why wages should rise with the rising price unless there is an increased demand for labour, so wages in 1896 would tend to remain at 64 per cent. of the $f 88$ value produced in 1895 , although the 1896 value had risen to E92. Such an increase in the profits would make every employer anxious to take advantage of it by employing more labour, which means a reduction of the percentage of unemployment. As shown by the diagonal line on Diagram 68, this reduction of unemployment 
means an increase in wages, even if there was no advance in the rate of wages. But as this increase is not necessarily an increased proportion of the product so long as prices are rising, the profits may still be nearly 4.5 per cent. above the average; and this will tempt new employers into the field, who to get the labour they want must offer higher rates of wages. This with the fuller employment gradually brings wages up to 64 per cent. of $£ 92$ value produced, which would be the correct average share were it not for the fact that while this has been going on prices have still further risen, till when $1897-8$ comes in the value produced is $£ 99$ while the wages have only got to 64 per cent. of $£ 92$ value, or very little more. They still lag behind, and the same set of competing forces continue to bring them steadily up, following prices each year up to I899-I900, but allowing them all the time to lag. This lagging movement of wages is clearly seen in Table ro in the chapter on division of the national income, which gives French coal miners wages in percentage of their production. (It should be noticed in this table that the figures show the percentage that average wage is of the average production per person, and that 56 per cent. was there shown to be equivalent to about 53 per cent. of the total production, which, therefore, requires II per cent. adding to make the usual 64 per cent. for salaries and wages together.) See also pp. 338, 35x, Chapter XI., and Diagram 73. This rise of prices with wages lagging behind constitutes a period of good trade from 1895 to I900, because owing to the lag there is a slightly higher margin of profit all the time. Production increases, business being comparatively easy, new competitors come into trade, unemployment sinks to a minimum, and wages are actually rising, though a less percentage of the whole value produced.

But when in Igoo (= I899 gold) prices begin to fall owing to the disturbance of the gold production, the opposite set of dynamic forces come into play. In Chapter XI. we showed that when prices are falling the worker's resistance to a reduction of the rate of wages actually made a larger proportion of unemployment necessary to bring about a reduction than the proportion necessary to prevent a rise when prices are rising. This resistance or slow adjustment causes wages again to lag behind in the downward movement. In r899-I900, when production was $£$ r24, wages would have only got to 64 per cent. of $£$ IIro or thereabouts, and only got to nearly 64 per cent. of $£_{\mathrm{I} 24}$ in Igor, when, owing to the fall of prices, the actual value produced was only $£$ I 20 . They would only fall to 64 per cent. of $f_{120}$ in I902, and so on down to I904, when they were about 64 per cent. of $£$ ro8, when the value produced was really $£$ I04. This lagging of wages is again well shown by French coal miners' wages (Table Io), where it may be seen that all through the period of falling prices the percentage of wages was rising, and at the lowest point of 
the depression was for three years above the average proportion of 56 per cent. (i.c., equals 53 per cent. wages only. without salaries). Also in Diagram 58 it may be seen how, when prices are shown to be high by the curve A $\mathrm{A}$, wages tend to fall below the curve, and when prices are low they tend to be above it. This lag of wages in a fall of prices makes a period of bad trade, because wages being alrove the average share of the production, the percentage of profit is reduced, business becomes increasingly difficult, slaaky furms tail, and all producers reduce their production: unemployment rapidly increases, and wages are actually less though a higher percentage of the smaller production. Thus a trade depression is the result of a natural fall of prices and the difficulty of sufficiently reducing wages. which difficulty by reducing profits leads to unemployment and decreased production of commodities. A rise of prices. on the other hand, has exactly the opposite effect, so that it seems that it is the variation of prices due to the varying labour cost of getting gold which causes good or bad periods of trade, not some subtle malady in trade or production that causes prices to vary.

Trade fluctuations are in a general way recognised as occurring periodically in all countries, and when they happen to be depressions are loudly commented upon by commercial men and the trade papers. Some economists also have laid great stress upon these periods of depression and inflation of commercial prosperity, making thern the special subject of their inquiry, while other important writers seem to quite ignore them or grant them a very superficial mention. Altogether there seems to be some little vagueness about these fluctuations of trade, either as to time of occurrence or the nature of the phenomena constituting a trade depression, leaving it a little uncertain which phase of the trade cycle brings the boon or the affliction. Some economists seem at one time to associate commercial disaster with high prices and commercial mania, resulting in a crisis, and at another time with low prices and commercial stagnation and failure, resulting in unemployment and want. Mr. W. H. Beveridge, in a modern work on unemployment, calls attention to this vagueness by pointing out that a trade depression should be clearly distinguished from a crisis or panic; and he further shows that periods of depression are marked by a high percentage of unemployment. This latter conclusion seems to us a sound association of the essential circumstances, and much more important than discovering some approximate period of years in which a cycle of trade from good through bad to good again may be found to take place.

Any one who has had at all an extended commercial experience, will remember periods of prosperity and good trade, and years when times were bad and business slow and difficult. But memory is vague, and a much more reliable guide to the periods of actual trade depression would be a true record of the percentage of unem- 
ployment from year to year. For obviously if labour is not employed it indicates that employers do not find they are getting a sufficient percentage of profit by employing it, or employed it certainly would be. This failure of the employment of labour to yield the average profit of 36 per cent. of the production is what we understand by a period of trade depression, and we have shown before why it may at its commencement sometimes be associated with a crisis, although it is not essential that the circumstances should be sufficiently pronounced to be actually recognised as such. We have above fully explained what we regard as the true reason why some periods of industry are comparatively unprofitable and why they result in the unemployment of labour. As it was seen, it appears to be the difficulty of adjusting wages to the alterations in the standard of value, which alteration is again due to variation of the value of gold produced per person in the gold mines. We believe that variation in the level of prices from this cause is the only thing that can cause a true cyclical depression of trade. Such periods of real trade depression are clearly recognised by writers like Mr. W. H. Beveridge, who have given special attention to the subject of unemployment, and this writer clearly shows their relation to unemployment, and to some extent to low prices. But it will be noticed if his table of the "Pulse of the Nation" is referred to, that the index number for price level does not bring out this latter relationship so well as our normal price indexes. The index numbers of Mr. Beveridge's table show the relation of unemployment to prices fairly well for the few years on each side of the base year Igoo, but become very unsatisfactory for years prior to 1894 . We think it will be found that our curve of normal price fluctuations agrees much more consistently with fluctuations of unemployment.

This curve AA which has been seen on our price diagrams is now applied as nearly as can be to the following diagrams, showing good and bad trade periods. It cannot be drawn specially for these diagrams, in proportion to the average value expressed by them, because as a matter of fact they do not express any value, and have no proportion in common with the price diagrams. So the curve on these trade diagrams is literally the average normal price curve of French, German and English coal. This being so, the fact that in Diagram 79 the curve AA is seen to recede from the unemployment curve in the early years and encroach upon it in the recent ones has no significance whatever. The advance of prices, which causes the average trend of AA to be upwards, is due to the progressive nature of the improvements in the methods of gold production, a cumulative increase of value from year to year, while the variation of unemployment is not cumulative in either direction, but simply a variation of percentage on either side of a fixed average of about 5 per cent. Nor has the actual percentage of unemploy- 
ment (length of line on the diagrain) any direct connection with the extent of the price fluctuations from ligh to low. The essential

DiAGRAs 79.-UNLMPLOJMIXT, SHOWING IVIKIOUS OF COOD AND BAD TKADI:

Uncmployed.

Per cont.

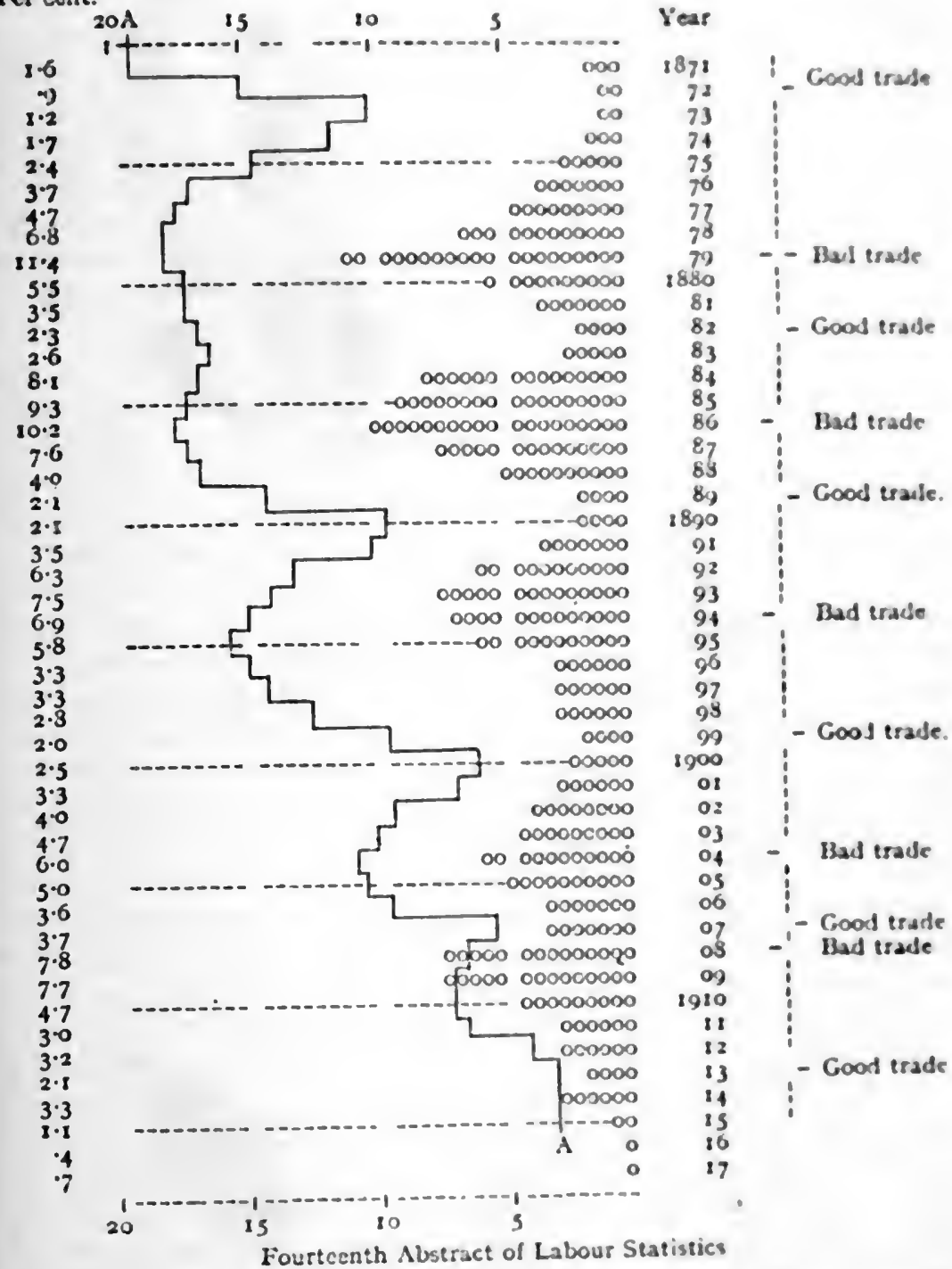

point is the agreement of the periods of high and low employment with those of high and low prices.

It will be seen that all down the period covered by Diagram 79 the maximum of employment agrees very well with the periods of high normal prices, and the maximum of unemployment with those 
of low normal prices. The chief exception is the maximum of unemployment falling in 1893 , which was two years before the lowest point of prices in 1895 . The highest point of unemployment falling in that year is probably due to the proportion of unemployment being exaggerated by its being specially high in the particular industries that make returns. It will be remembered that it was the year of the great coal strike mentioned under English coal prices (p. I35), and as this trade disturbance lasted about three months it will quite account for unemployment appearing too high that year. This irregularity in the exact years of high unemployment corresponding with those of most depression in trade does not really impair the evidence as to the period of the depression from 1890 to I895. That depression still shows a high percentage of unemployment, and the strike and unemployment of 1893 illustrates very well the opposition to the reduction of wages at the beginning of a period of falling prices, which, as we have seen, is the chief cause of bad trade.

To further show that the above fluctuations actually denote good and bad trade, Diagram 80 has been drawn up to illustrate how much the incomes coming under review of the Income Tax Department were increased or decreased year by year. It should be understood that the diagram does not represent actual increase and decrease of the national income subject to tax; with but few exceptions the total is more each year, and the general movement throughout is a steady increase. This increase is the inevitable result of the growing population which must always be increasing the national income, so that the only way we can see the state of the public prosperity reflected in these returns of income tax assessment is to notice how much more or less the annual increase is in the good or bad trade years. The amount of increase or decrease is given in million pounds in the first column of the diagram, and the proportional lines illustrate graphically the relative amount of these alterations. It will be seen that the increases in assessable incomes was distinctly greater in the years of improving trade and relatively less in those of the depressed periods; in fact, in some of the worst years there was an actual decrease in the amount of taxable incomes from that of the previous year. These fluctuations of the increase in incomes may be seen to accord very well with the curve AA, save for the one exception of the early period culminating in the trade boom of $1864-5$. There is no doubt that our curve of normal prices should show some rise in place of the depression we show at this point, but we have no English normal price data going back to this period, or, of course, any record of the gold produced per person. The boom, no doubt, was caused by the American Civil War, which sent many prices up very much and induced a great boom of commercial speculation in this country, but does not seem to have extended very much to 
Diagray 8O-ASSFSSMENT TO INCOME TAX.

(THE Iscrkase vol YeAx to Yew.)

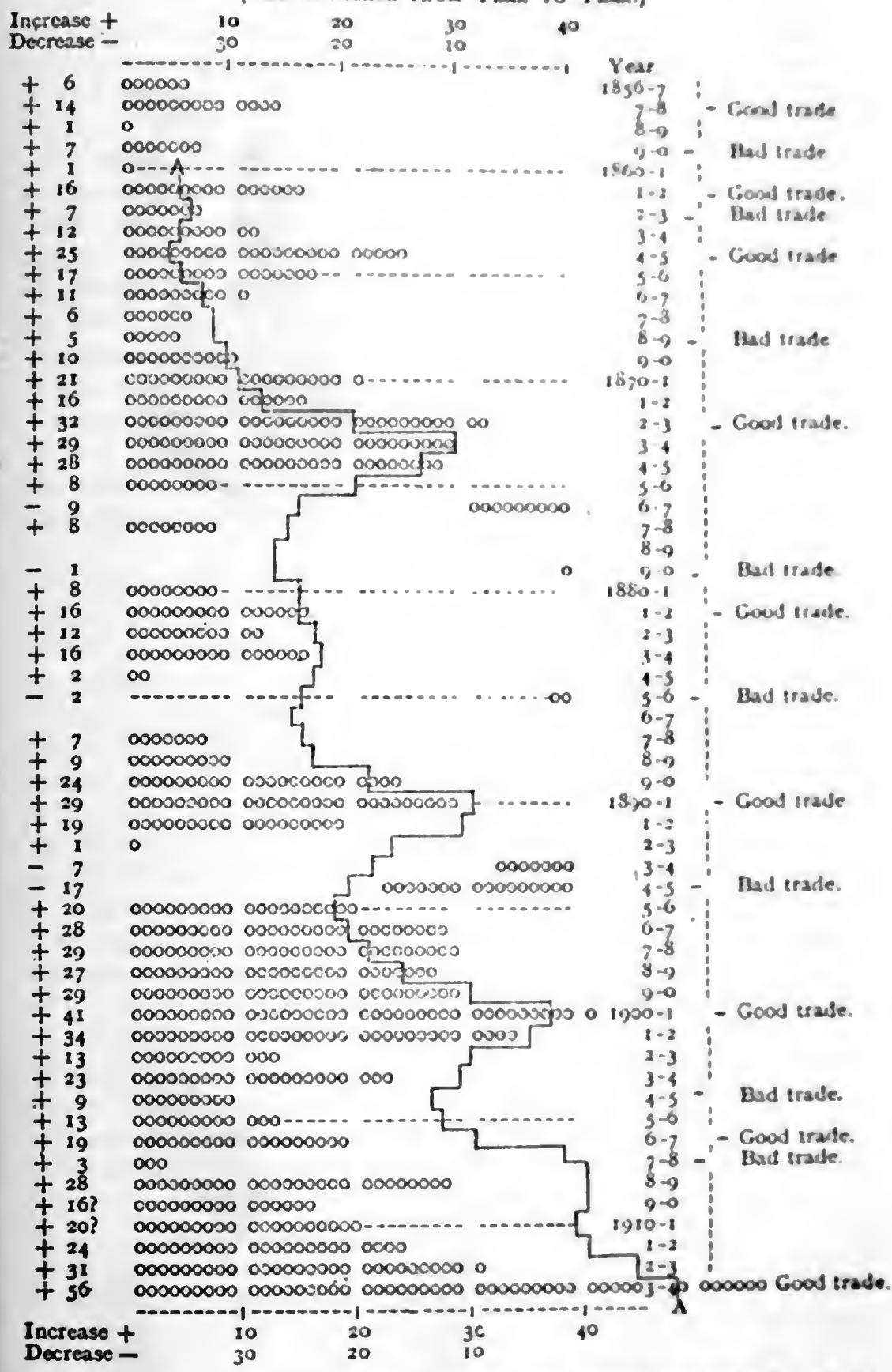

France and Germany. At any rate, the normal price of casl in these countries does not seem to have been affected by the war, and 
as, not having any data for English coal at that period, our curve of normal coal prices is based solely on French and German data, it does not show the inflation of price which, no doubt, occurred in this country at that time. As we have explained, such a rise of prices is due to increased cost, and probably would not show much rise of normal price if we had the correct net figures for the value produced and the number of persons employed in the production of the commodities the market price of which has gone up. As, however, it was the year of the cotton famine and there probably was a large percentage of unemployment, notwithstanding the fact that the few trades unions that made returns at that time show a high percentage of employment (given as 98.05 per cent. for I864), wages would be kept low and profits in many trades would be good from the employers' point of view. But the prosperity was of an uncertain and speculative nature, and the financial difficulties of the time are well reflected in the writings of contemporary economists like Mr. Jevons. By the diagram it may be seen that the prosperity was short-lived, and at the end of the next season in I 866 there was a financial crisis in London.

The still earlier period of good trade in 1857 was, no doubt, a similar boom caused by the Crimean War, but we have no normal price data whatever for that time, so cannot produce the curve AA for any good purpose. But for the part of the diagram where we have the data it will be seen that the rise or fall in the amount of annual increase of tax-bearing incomes testifies eloquently to the fact that these fluctuations of prices, unemployment, and bank rate represent periods of greater or less prosperity.

Table $8 \mathrm{I}$, not being in the diagram form with proportional lines, cannot have the curve AA marked on it, but as the points of good or bad trade are marked as in other trade diagrams, they can be compared with the profit and loss columns, and with the other diagrams also. The third column shows the number of companies whose business is included in the yearly totals of profit or loss. The table which gives the profit or loss made by about roo firms in cotton spinning is introduced as direct evidence of the rise and fall of profits in good and bad trade periods. Although in the examination of the commercial fluctuations of any particular industry it is usually necessary to make some allowance for the special circumstances of a particular trade, it will be seen that the fluctuations of profit correspond very well with those of the other diagrams. As in Diagram 79 the depression of I894-5 finds its lowest point in I893, which is too early to agree with the curve AA exactly. The coal strike may have had something to do with this, but the chief cause is the rather special method which the trade adopts in taking stock. It appears that when prices are falling it is the spinners' custom in taking stock to value their stock at the lowest possible figure, so as 
to insure against further loss from the expected continuation of the fall. This rather pessimistic view of the position has the effect of making the loss of profit appear great in the early part of the depres. sion, and may result in a somewhat early recovery from the lowert point so far as published trading figures are concerned. The recovery

TABLE 81,-PROITI AND LOSS, COTTON SPINNING COMBASIPS.

(Wm. Tattersall's Annual Cotton Ciscular.)

\begin{tabular}{|c|c|c|c|c|}
\hline Profit. & Loss. & Companies. & Year. & \\
\hline 125,000 & $-\overline{2,750}$ & $\begin{array}{l}60 \\
87\end{array}$ & 1884 & : Rat toado \\
\hline 二 & $\begin{array}{r}2,750 \\
61.718\end{array}$ & 87 & 1885 & - Bad trade \\
\hline$\overline{86,8}$ го & $\begin{array}{c}61,718 \\
-\end{array}$ & $\begin{array}{l}90 \\
88\end{array}$ & 1886 & i \\
\hline $\begin{array}{r}86,810 \\
250,932\end{array}$ & - & $\begin{array}{l}88 \\
85\end{array}$ & $\begin{array}{l}1887 \\
1888\end{array}$ & : \\
\hline $\begin{array}{l}250,932 \\
220,5^{8} 7\end{array}$ & 一 & $\begin{array}{l}85 \\
86\end{array}$ & $\begin{array}{l}1888 \\
1880\end{array}$ & $!$ \\
\hline $\begin{array}{l}220,5^{87} \\
3^{8} 4,050\end{array}$ & 一 & $\begin{array}{l}86 \\
9 I\end{array}$ & $\begin{array}{l}1809 \\
1890\end{array}$ & - Good trade. \\
\hline $\begin{array}{r}384.05^{0} \\
3^{8}, 75^{8}\end{array}$ & - & $\begin{array}{r}91 \\
\text { 10I }\end{array}$ & 1891 & : \\
\hline - & 94.770 & 99 & 1892 & : \\
\hline- & 60,790 & 99 & 1893 & Bad trade. \\
\hline $4,49 \mathrm{I}$ & - & 94 & 1894 & ; \\
\hline 63,167 & 一 & 94 & 1895 & i \\
\hline $49,63 I$ & 一 & 94 & 1896 & ! \\
\hline I $57.57^{\circ}$ & 一 & 94 & 1897 & : \\
\hline 271,804 & 一 & 90 & 1898 & 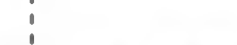 \\
\hline $38 r, 176$ & 一 & 86 & I 899 & is cond end \\
\hline 344.548 & - & 80 & 1900 & - Good trade \\
\hline 279.345 & - & 80 & rgor & : \\
\hline 一 & I,436 & 85 & 1902 & : \\
\hline 一 & 45,322 & 90 & 1903 & Bad tade \\
\hline 31,729 & - & 90 & I904 & Bad made \\
\hline 693,070 & 一 & 90 & $\begin{array}{l}1905 \\
1906\end{array}$ & i \\
\hline 590,002 & 一 & $\begin{array}{r}90 \\
100\end{array}$ & 1907 & - Good trade. \\
\hline $1,321,157$ & - & $\begin{array}{l}100 \\
100\end{array}$ & 1903 & i \\
\hline 500,511 & 272,072 & 100 & 1909 & Bad trade. \\
\hline- & 368,006 & 100 & 1910 & i \\
\hline - & - & 一 & I9II & : \\
\hline $55^{8}, 45^{\circ}$ & - & 100 & 1912 & $i$ \\
\hline 539,880 & 一 & 100 & 1913 & - Good trade. \\
\hline 53,183 & - & 100 & 1914 & Rad inde \\
\hline - & I 5,020 & 100 & 1915 & Bad trade \\
\hline 400,470 & 一 & 100 & 1916 & ! \\
\hline 20,2 & 一 & 100 & 1917 & 1 \\
\hline
\end{tabular}

in profits, however, was only slight until I 895 , so that this period is not much displaced from the general position for this depression, and the other fluctuations are very nearly correct. On the whole, this piece of direct evidence of fluctuating profits well supports the contention of good or bad trade agreeing with the variation of prices, and it is to be regretted that there is not more of such direct data published as statistics. 
Diagram 82 gives the only scrap of evidence we have of short time worked as distinct from unemployment, and it will be seen that it corresponds very well with AA so far as it goes. There is, no doubt, a great want of statistical data for the important question of time lost by persons who are supposed to be at work in various industries.

Diagram 83 shows that the bank rate of interest follows the same fluctuations as incomes and unemployment. In this case as in the other diagrams it should not be supposed that the rise and fall of the rate must be to the same extent as that of prices indicated by AA. The amount of interest has nothing to do with the amount of the price, but only indicates that trade is good or bad, and moneyearning a good or bad interest, and we are pointing out that it is

\section{DIAGRAM 82.-SHORT TIME. SHOWING PERIODS OF GOOD AND BAD TRADE.}

(The INCREASE From Year to Year.)

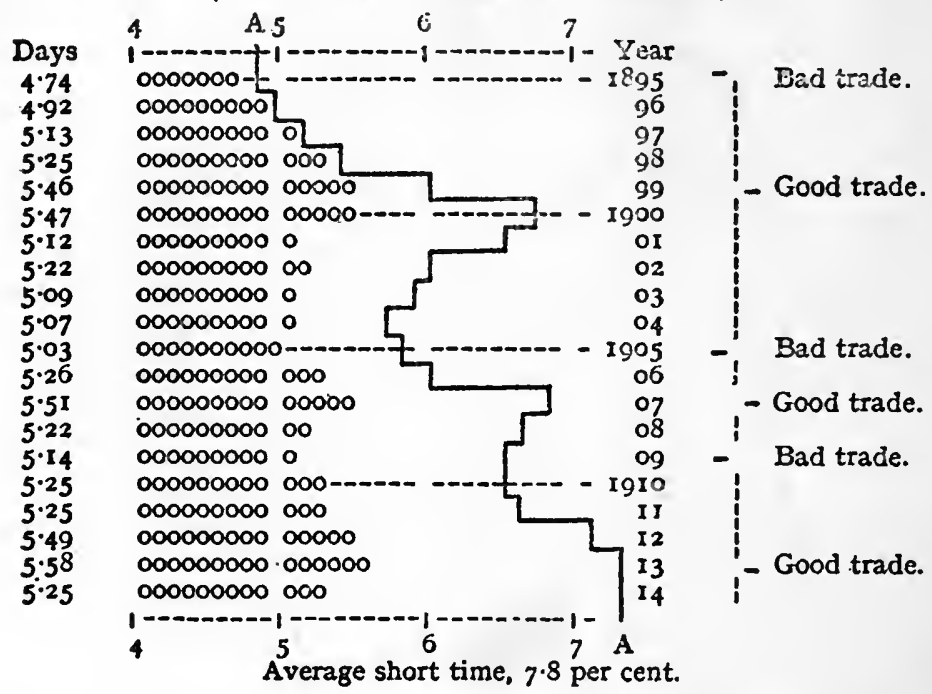

always good when prices are high or bad when prices are falling. It is, therefore, the agreement of the rise and fall of bank rate and price in time of occurrence that must be noticed, not the extent of the movement. It will be noticed also that the bank rate, like income tax, was high in the two early periods of 1857 and I864. This was again due to war prices and business optimism, and, as we have explained, is not represented by our curve because we have not the necessary normal price data for English production. If we had, no doubt our curve would show high price periods due to war prices as it does in 1873 (after-effect of Franco-German War), and I900 (South African War).

As these war rises of price seem an exception to the rule that improved gold production alone can cause a rise of normal prices, it is perhaps desirable at the risk of some repetition to explain 
DIAGRAM 83.-BANK RATIS OF DISCOUNT. SHOWING PERIODS OF GOOD AND HAD TRADE.

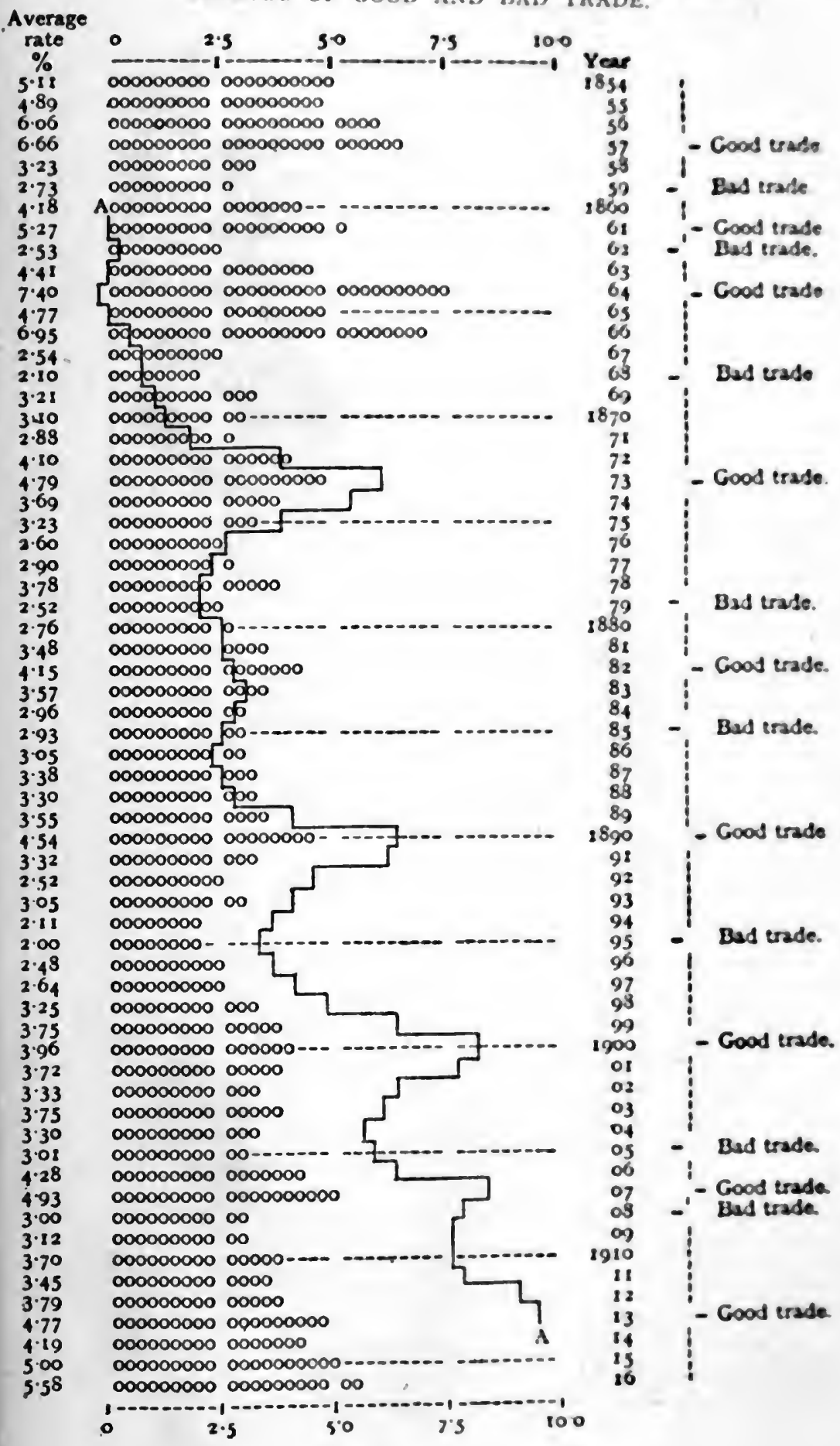


fully the phenomenon of war prices. In Chapter II. we recognised that cost of national defence and other Government expenses are paid through taxation and add to the cost of producing all commodities; it raises their price, and so is paid for by the consumer of those commodities. This means that all persons employed by Government, including soldiers and sailors, are taking part in the production of commodities, and their labour adds to the production of commodities, and their labour adds to the cost of those commodities. In war-time, of course, this part of the labour cost greatly increases, many more persons being employed on Government and defence, either as soldiers or persons engaged in making the extra munitions and supplies. After the war also this may continue for some time as the work upon the nation's improved resources has always fallen behind from neglect or shortage of labour. The large number of extra persons required to do rebuilding, road and railway making, and many other like things, as well as those engaged in bringing ships and guns for national defence up to the standard set by the late war experience, means a large portion of the national labour is engaged upon these extra national resources. As such work is not sold and consumed as soon as finished it is really an extra cost, paid for gradually as an addition to the cost of the things the nation is consuming. The market prices, therefore, go up though the normal prices theoretically remain unaltered, because gold production has not increased.

All our price indexes, however, show a great rise of normal prices in war time, but this is due to the gross figures being very defective data as to persons employed. All persons employed as soldiers or working upon armaments or other national resources should be included as persons producing the things which have gone up in price and are being consumed. A war is really paid for absolutely week by week as it proceeds, and the work of national restoration that follows is also paid for as it is done. Financial jugglery does much to disguise this fact, but the high cost of living testifies eloquently to the fact that it is taking two persons to produce the articles consumed in living where it previously required but one. If the market price has doubled, the total value of goods produced will have doubled; but if the persons producing it have also doubled, when it is divided by that number of persons the resulting normal price would remain as it was before. As, however, no statistical returns ever show the increased number of persons employed in the various industries owing to war, we have no data to get the true normal price at such times and, therefore, have to represent it as going up with the market price. Obviously it would be far from easy, where men are employed as soldiers or in rebuilding blown-up bridges, to show even approximately how far their labour enters into the cost of producing bread or boots by any record of 
the time they worked, the amount they did, of the use of the soldering or building to the baker or the bootmaker. But beyond doubt the price of the boots and bread records this extra cost very faithfully, and the difficulty of finding the correct nutnies of persons would be quite overcome if we had the true nes figuses for output.

In addition to this cause of high prices it commonly happens that the gold reserve check on prices is more or less relaxed by use of paper currency in time of war, which relaxation permits of indefusitely high market prices and a fictitious normal price far above its real value. These high prices make the production in belligerent countries too high in price for the foreign market, and foreign trade can only be done by means of a very adverse rate of excluange, which sends the price of imports up to the same level as home produce. But as this method robs foreign trade of most of its virtues, and the community is short of everything while the rising prices make trode and profit very good, the inflation will become difficult to stop. because the easy trade conditions will lead countries to produce at home, and at a higher cost, things that should come more cheaply from abroad: and the countries they used to export to have to do the same. This rearrangement of the production required in each country is at tirst certain to be attended with higher labour cost owing to want of experience, unsuitable locality, etc., so that the market prices rise in all trading countries whether at war or not; they must do so, or trade between the country at war and other countries would come to an end almost at once. In the case of our coal indexes on which the curve $\mathbf{A A}$ is based, the value produced was so affected whether this country was in the war or not. The extra cost of transit, price of machinery and supplies, and extra taxation, all of which represent more persons at work but not included in the returns as coal miners. increase the cost of coal, send up market prices and, apparently, the normal price. If we had the correct net figures for the total production, after these extra expenses were deducted. the total would probably be considerably less, and the output per person or normal price would not go up anything like so much as it does from the use of our nearly gross figures, especially in the case of the early high price periods. But there would, no doubt, be a considerable inflation by use of fiduciary purchasing power, and the subsequent reaction to get gold.

This error in the normal price curve in the case of war prices, and due to the lack of net production figures for such times, has to be kept in mind when we regard the curve $A A$ as representing the actual gold basis fluctuations of prices. We hase seen from the above diagrams that the periods of good and bad trade do agree with those of rising and falling prices, and in the previous chapters we have shown, as we think, good reason for thinking the movep.w. 
ment of normal prices is due solely to the varying production of gold per person. So that, allowing a little for the above error in war prices, the curve AA may be taken to fairly represent the fluctuations in gold production which are the ultimate cause of good and bad trade.

The records of income tax and bank rates, which so graphically illustrate the commercial life of the country, carry us back to a period for which we have no normal price or gold data, but it seems almost certain that the interesting trade fluctuations of that time were governed by the same common cause as those of more recent years. Although the recorded total production of gold in that period does not show any great variation in amount, and seems to have been very small, it does not follow that the output per person or cost of gold did not vary and so bring about natural variations of prices. Upon such variations there were certainly superimposed variations due to wars, so that prices undoubtedly varied very much and, as we have seen, would quite account for the fluctuations of trade at that time.

As we have said, it is not necessary that the rise of true normal price should be anything like in the same proportion as the rise of bank rate, or even in proportion to increases of income tax, provided wages were kept low by competition of a large percentage of unemployment. So that a relatively small fluctuation in the labour cost of gold with the superimposed high war prices might account for these trade booms and crises. It then remains most probable that from the very beginning these trade fluctuation diagrams demonstrate that throughout the record good and bad trade has always resulted from a change in normal prices, due to altered cost of production in gold. The record of income tax and bank rate in other European countries has not been examined so fully, but bank rates seem to have moved similarly in most countries, and incomes subject to tax have followed the same fluctuations in the French records. So that, although there is no record of the most important factor of unemployment in that country, these fluctuations, agreeing with our record of good and bad trade, make it almost certain they vary from the same cause. Such general fluctuations as these records show must be due to some cause that is common to trade as a whole, and it could hardly be anything else than altered labour cost affecting market prices, or alteration in the cost of the standard by which the labour cost is measured affecting normal prices.

The period for which there are any data whereby to estimate the labour cost of gold is certainly very short and broken by the special conditions caused by wars. Therefore the corresponding fluctuations can only be subjected to a strict comparison over this very short time. But while this time is too short to render the evidence afforded by the synchronising fluctuations quite con- 
clusive, they do so far as they go very forcibly suggest a direct and simple explanation of trade fluctuations, and one that is much more in accordance with the common commercial experience than any suggested explanation that we know of. Many of the oldes attempts to suggest a cause for such fluctuations seem to be unsup. ported by any evidence whatever beyond the fact that they occur periodically. They are vaguely connected with dernand for special kinds of goods, with bad and good harvest, and variations in supply and demand, but without much statistical evidence. The only" obvious connection between trade variations and supply and demand is that when trade is bad both supply and demand fall off, and when trade is good they both increase. In fact, as we have pointed out. supply and demand are only phases of the same economic conditions. and it is hardly conccivable that they can ever be anything but equal. All the common examples of over-supply are found when analysed to be cases of over-high price of supply.

Indeed, modern writers, after giving a somewhat perfunctory assent to the claims of supply and demand usually, seem to proceed without much support from that classic theory to explain how trade fluctuations are due to some phenomenal condition of currency or finance, which explanation is to a limited extent an approach to our present view of the phenomena. But while it is true that, gold being the standard or measure of value, any change in its cost of production must change the level of prices and bring about conditions that must result in the fluctuation of trade, it must not be supposed that the greater or less quantity of gold or other currency in circulation has any such effect, or even that a high or low level of prices of itself constitutes good or bad trade. If any such conditions of currency or prices were permanent for any considerable time the various competing interests would find their equilibrium about such fixed point, and a static condition of commercial prosperity would be arrived at. It is only the changing in price movements that bring about trade fluctuations. The effect of altered labour cost of gold acting directly upon prices, an increase or decrease of profit on the production of goods is almost an immediate result of the altered gold cost. Whereas the adjustment of the share of the value produced that shall go to the wage-earners takes time and necessitates a change in the amount of labour employed. While such changes are in progress profits must necessarily be increasing or decreasing, as the case may be, and trade is either stimulated or depressed as the result.

The fact that our theory of prices affords a natural and, we think. complete explanation of trade fluctuations seems strong presumptive evidence of its general correctness. It not only explains variations of price, fluctuations in percentage of profit and wages, and the amount of unemployment, but shows how these phenomena are 
integral parts of our commercial system, which could not exist in its present form if any of them were permanently absent. We question whether any other economic theory has ever so united all the chief industrial phenomena into one explanatory theory where each of them is a necessary part, and all are interdependent factors in explaining the present industrial system.

Note.-Our scattered remarks on the rates of foreign exchange having been simply descriptive of the phenomena that commonly attend trading transactions in a country that has a depreciated currency and inflated price level, they may have led to the impression that the rate of premium or discount at which foreign exchanges take place is determined by the relative price levels of the trading countries, which would hardly be a correct view of the matter. So far as the exchanges concern the nominal value of the currencies of two trading countries the above impression would be correct. If the paper sovereign, mark, or silver rupee have a nominal value that differs from their international gold value, the rates of discount or premium at which they will exchange will (other things being equal) represent the extent to which their respective nominal value differs from their actual or gold value, or the difference between the nominal price levels of their respective countries and the gold level.

But when the currency is about as much depreciated in one country as the other, or normally when their currencies are at their average gold standard value, there are still varying rates of exchange which do not then depend upon price level. High price level in a country might limit the possibility of foreign trade, but would have no tendency to make the imports permanently greater than the exports, or to make a constantly high demand for bills of exchange drawn against exports. Such adverse condition of exchange can only arise from the indebtedness of the country at the time to the country to which it is exporting, and means that its creditors are to some extent deferring their claim to settlement in view of a premium on the sale of their bills, which is virtually interest on the money which is for the time borrowed. It would therefore appear that normal rate of exchange is interest paid for borrowed money or for the risk and expense of negotiating the exchanges, and may virtually represent a rise of bank rate when the rate is nominally restricted to a low figure.

Both the above causes may affect a country's foreign exchanges in different degrees; our present adverse exchange with America may be all due to our indebtedness, while Germany's adverse rate may be due to its currency being depreciated by the undue rise of prices permitted by the suspension of the gold standard. 


\section{CHAPTER XIV}

\section{concluston}

IN drawing our conclusions from the evidence and arguments we have examined it is not our intention to formulate any claborate economic scheme that shall constitute a panacea for man's economic ills. But we believe we have shown good reason for recognising certain essential ideas which will be found to have a practical bearing upon political economics. Such facts as that the value of man's wealth is determined beyond any possibility of alteration by the apparently insignificant circumstances that determine how much he can produce of the commodity in which that value is measured, and that man's real wealth depends solely upon the useful. ness of his work and the quantity of the useful things he can produce, quite regardless of the value of those things measured in gold. Facts that if actually grasped by any considerable number of thoughtful persons would, we think, make a considerable difference to the economic and political outlook. We quite recognise that such change of outlook, however illuminating, will not constitute a solu. tion of all the social difficulties of the times; but if there is anything that can be regarded as a golden rule for economic guidance it is to seek the right outlook and insist on really understanding exactly and certainly why things are as they are before demanding their alteration. Our sketchy suggestions for a political aim are intended simply to point out the possible usefulness of a sound economic theory and, therefore, the necessity of completing the imperfect data wanted as evidence, and not as a working method of reform. It would be out of place here to discuss political practice, but as we have somewhat boldly claimed practical utility for some of our methods we feel it necessary a little further to point out their connection with some of the more practical economic questions.

Our claim of practical usefulness was chiefly for our theory of prices, and we believe that the principal difficulties of social cconomics centre round the question of the price or value of the produce of labour. However much we may have succeeded in realising that the usefulness of man's production is the test of his real wealth, the system of organisation and division of labour by which alone that wealth can be increased necessitates the continual estimating of that wealth's value in money or price. It seems difficult to see how, for instance, a boot and shoe operative could realise how many boots as such he must make in exchange for the goods and services 
required to provide him with a seaside holiday without an idea of price. The mind instinctively asks what value his share of the boots is, and how much he thinks of spending on his holiday? If the holiday is to cost $£$ ro, and he gets half-a-crown for his operation on a pair of boots, he will have to make 80 pairs to pay for his holiday.

We do not seem able to think of relative value at all without a specified price or money value of the goods or services that we are to compare, yet ultimately it will be found that it is the labour cost of the things that we really want to know. The shoe operative, having found what a holiday will cost, again quite naturally turns from the consideration of the relative price to the still more essential consideration of how long it will take him to make the boots-what will be their labour-time cost to him ? But when, having found how quickly he can make the boots, he is deciding whether he will with $f^{\prime}$ o be able to afford a week or ten days at the sea, he does not at all connect the railway fare, board and lodging, etc., with their labour cost-that is to him simply a matter of value or price.

In his own industry an operative having realised the labour cost of his own operation may easily extend his appreciation of the labour cost to other operations that are directly part of the making of a pair of boots, and so form a labour-time conception of the cost of boots. But such conception will, as a rule, be very defective, because as the operation becomes more remote from his, or is an accessory one, such as packing or warehousing, its price seems to him less connected with labour-time, and seems more a question of what the employer thinks he can afford to pay. When it comes to a question of the cost of organising and managing, it is not at all recognised that the manager's work in deciding what pattern shall be made or what new machine used, or a traveller's work in having a drink with a possible customer, or even the cost of transit, is actually labour-time cost of supplying boots to the community.

The persons who render these various services that do not involve any manipulation of the concrete substance produced or worked upon do not as a rule themselves recognise that their remuneration depends upon the labour-time cost of what they produce. They regard it as a value only, and as one that must be proportionate to the value of the things that are necessary for a subsistence such as they deem necessary for themselves. Commercial and financial estimates of costs are almost entirely comparisons of values that are only remotely associated with labour cost, which leads to the impression that there is a wealth in values which is considerably in excess of the actual labour cost. Such values are vaguely supposed to arise from the social requirement for things, and economists have certainly encouraged this view that there is a value of quite undefined dimensions that arises from social circumstances and is, or may be, quite independent of cost of production. 
This imaginary value is frequently requisitioned to yield indefi. nitely increased prosperity to the toiling community, not only by the workers whose knowledge of financial operations is limited, and by innumerable social reformers whose confidence in their own knowledge is unlimited, but by financiers and statesnen who often make extravagant demands upon this fund of unearned wealth as suggestions for financing social reforms or national expenditure. Experience has taught society to feel no surprise when these plausible schemes very naturally fail to mature ; but it should be recogniserd that such unfruitful and ill-considered schemes are exceedingly wasteful of human time and energy, and a pernicious source of social unrest. We feel sure that if our theory of value could once be realised to be the actual facts of the case it would at least put an end to this vague idea of a fund of unearned wealth of indefinite capacity.

The source of this error undoubtedly lies in the fact that no one person ever has a practical appreciation of the total labour time that goes to make up the value of a unit of commodity, as witnessed by the great amount of most necessary productive work that is permanently ignored by all Censuses of Production: and, on the other hand, there is the same incapacity to realise what has become of all the value produced by the labour that has been expended, as, for example, the case of the barrow-load of iron ore pictured in our introduction to prices. If it is realised that, whether the labour on a commodity is great or small, it will have produced in a given time neither more nor less value than is produced by a like quality of labour in gold mines in the same time, and that the average quality of labour is not likely to be superior in productive ability to that of the average miner, it becomes evident the average value produced per person cannot ever be more than the value of gold produced per person in the same time. The gross value of gold produced per person in 1907, as shown by the gold index, Diagram 43 . was $f^{14} \mathrm{I}$ per person, which is a good deal more than the average nes production in commodities estimated from the Census of Production Blue Books and illustrated on our Diagram 2, Chapter II. The only net gold production we can get is for the Transvaal mines alone, but as their gross production is a little above the average, we may take it that their net output closely represents the world's net production of gold. This production, as explained under Table 55. is $£ 96.4$ per person for 1907 , which is very close to the $\$ 100$ value produced per person, as shown by Diagram 2 and our investigation of the National Income.

It cannot be too insistently repeated that this $£ 100$ per year, or a total of about $£ 2,000,000,000$ for 1907 , was the total wealth produced. This includes, besides the wages of all persons whatever working in the industries of this country, the profits of all capitalists, wages 
of Members of Parliament and Government, and the ground rents and other income of the millionaires. Further, when it is remembered that this average income of $£$ roo must cover all expenditure or cost of living, including the living of the said capitalists and millionaires, it is fairly obvious that there will not be much surplus value saved at the end of the year. As was pointed out in Chapter II., there appears to be hardly any increase beyond the production by the increasing population; but there is at times a little increase in the form of improved resources for the increasing population to use.

Although it is inconceivable that value should arise except as the result of labour in one or other or both of the things exchanged, and therefore that labour must be the sole origin of wealth, ordinary business language leads to a vague impression that, some of the wealth so produced having become capital, it produces more wealth, or grows into more wealth which is an addition to that produced and consumed by the labour. In Chapter II. we showed how fleeting and intangible this capital is, being only the part of improved resources used up in producing income, and which is replaced as fast as it is used. A sewing machine, for instance, is an improved resource, and only the part of it used-its depreciation in I2 months -is actually capital for that year. But it must not be thought that the sewing machine manufacturer is engaged solely in making improved resources which are not wealth; the greatest part of his output is simply to replace the machines used up in producing income in the form of clothing, etc. He does not increase the capital, that is as it was; he has really been part of the person producing the clothing. If he had not kept up the supply of machines, clothing would have had to be made by hand-there would be less clothing. But if this machine-maker has been solely engaged in producing clothing by means of sewing machines, there is no other fund of wealth resulting from his work and capital except the clothing. There is no other wealth that is real or usable in any way, nothing that can be taxed or added to the national income or converted to any purpose whatever, except as wages and profits arising solely from clothingno wealth or income of any kind arises from the machines.

But owing to the necessarily permanent nature of most machinery and constructional instruments of production, it is not possible to make an addition or improvement to capital instruments or plant without making something that cannot be used up in producing income in anything like so short a time as it took to make that instrument. A sewing machine cannot be used up in the time it takes to make a new one, so that when a producer sets up a machine he has got an instrument that cannot be used up in reproducing its own value in the time that it took to make or earn it. While such a machine is being used up to reproduce its value in an extra output of clothing it is usually spoken of as capital, and is what we call an 
"improved resource." In this way there arises a great quantity of these improved resources as instruments used in production, and as they belong very definitely to the persons who use capital, they naturally come to be regarded as the wealth of such perwons, whereas they are only wealth to a person provided he can organise taleum upon them to more advantage than some one else can, or find sotne one who can so organise the use of his improved resources and be willing to divide the profit with him.

In the latter case of the capitalist not organising the us of his capital himself, it should be noticed that it is the actual organiser or entrepreneur who pays a dividend to the sleeping partner or share. holder, or a rent to the landowner out of his profit. The share of the production from that capital that goes to the rest of the labour as salary and wages is neither more nor less by that arrangement with the original organiser who has ceased to act but still draws part of the profits. The essential point is that the organiser must conduct his business, so well that the production of that business shall be above the average production in the industry sufficiently 10 afford a profit that will pay the interest and rent in addition to the ordinary wages and profits. As pointed out in Chapter IV., p. So, the simple acquisition of capital by what is called saving will not give its owner the power to control industry or take a profit from the use of his capital unless the person consuming that capital in organisation of industry can make and maintain an improvement in the means of production; that improved organisation alone can be the source of any wealth.

The concrete instruments of production that are usually owned by capitalists and are commonly estimated as wealth are not really wealth at all. Whether we call such instruments improved resources or fixed capital, it is most important to realise that, whether they belong to the capitalist or the nation, they are not wealth and cannot be converted into wealth now or at any future time. Although they will eventually be used in the production of wealth, they will also be renewed at the expense of that wealth ; any increase of wealth from them will depend solely upon their usefulness and the skill and wisdom with which they are used. And the division of that extra wealth between the worker and the capitalist will depend solely on the equation between the competition for labour and for organisation respectively.

Although the prosperity of a country may be increased by the wise construction and administration of improved resources, they are still only resources and not wealth. Nor is the wealth produced by the community necessarily greater by use of such resousces or capital. nor in any fixed proportion to such capital, as was shown by Table 15. giving the proportion of capital to the production in the United States. In the year I850 the capital was only about three-tenths 
greater than the production arising from its use, whereas in 1915 the capital was nearly three times greater than the production-that is, the wealth has not increased anything like so much as the capital. So not only is capital not wealth that can contribute to taxation or other financial requirements of the community, but the income arising from its use cannot be relied upon to yield any tax or income in proportion to the nominal value of that capital. And that being so, the acquisition of capital instruments by the State may be a doubtful experiment, and society might find it was paying more out of its annual production for such capital than the extra it was able to earn by the control of that capital.

While the popular suggestions for nationalisation of the instruments of production, distribution, and exchange appeal to our sense of what is fair play in the distribution of national advantages and the wealth that arises from the common labour of the community, it is doubtful whether it is generally known what exactly constitutes these advantages, or how they could be actually more national property than they now are. We are too apt to regard these advantageous productive instruments as wealth which, if nationalised, would directly enrich the community, and this, as we have above shown, would not be the case. It does seem, however, that the share of profit that goes to the shareholder, sleeping partner, or owner of land or private property would under a system of national ownership go to the State. This doubtless would enrich the State, provided it managed the production in these nationalised industries well enough to produce the same profit as was produced under private ownership; but would this really enrich the community? The increase of national wealth might simply go to pay increased salaries to Members of Parliament or the Government, or those of the permanent officials who rule the Government, or, as is more probable, to pay the high salaries of a multitude of industrial experts and advisers of the Ministry of Industry, who would undoubtedly arise to rule the permanent officials. And in such case might it not be found that the profit on industry and the use of natural resources was only going back as salaries to the same class of persons who got it under private ownership?

It is not easy to quite know what is to be understood by nationalisation, but it seems that it must ultimately mean a central bureaucracy to arbitrate upon and finally control industrial production and wages. It may, perhaps, be generally supposed that municipal undertakings like Water, Light, Trams, etc., and the national Post Office, are examples of nationalised production. And there have been recently made suggestions, more or less practical in character, for the control of some other industries in the same way. But in the chapter on rent we pointed out the probability that such undertakings are making a profit over and above the wages paid, just 
like any other business that pays its labour at competutive rates of wages. The fact that the profit from such undertakings is dis. tributed " in kind " to a very large number of sharcholden - that is. ratepayers-does not in any way alter the face that it is eskentially in the nature of profit. And we pointed out in Chaptes XII. alwo that probably some of that municipal production came as increased rent of town property to the landlords and owners as a very practical profit on their investments in rates. Moreover, the experience of the employees of municipal bodies suggests that there is no otrious advantage in working under socialised conditions of industry: they have to organise and strike work to get their fair share of the production just as in other industries.

Perhaps the most practical criticism of the idea that such institutions as the municipal undertakings realise the requirements of nationalisation is to ask why the Industrial Co-operative Society does not realise the nationalisation principle. It would seem that it is quite open to every person in the country to become a member of the Co-operative Society and to take an active part in the management, so far as any one individual can take a part in any nationalised concern. If the people of the community joined the co-operative movement and exercised their administrative duties with the ability that is ascribed to them by the social reformers, they could by being both the producers and consumers speedily monopolise the whole industry of the country, thus actually nationalising every industry without an Act of Parliament, and almost without altering a bye-law of the Co-operative Society. Why is this not done? Why is it not an accomplished fact by this time?

Instead of any attempt to nationalise industry through co-operation, the nationalisation advocate frequently points to the co-operative movement as the last word in capitalistic meanuess. But the only reason for such views seems to be that the co-operative movement is an institution "producing for profit and not for use." But obviously other industries that it is proposed to nationalise have the same fault; and this somewhat sententious accusation is no real reason for not approaching social ownership of capital through an institution that is already working on lines of social co-operation. If the Co-operative Societies are not conducted on right social lines. it is because society has not so conducted them, and if society is not capable of rightly directing its own institution it certainly is not capable of conducting other industries.

If the making of a profit is to be regarded as fatal to any scheme of nationalisation we must take it that separate trades or groups of producers under nationalisation must not be able to enrich themselves in any way by making a profit. Every member of the community will have a definite wage determined and only alterable by a central authority, a department or bureau of industrial control appointed 
by Parliament. But if such a bureau fixed the rate of wages, they must also determine the price of the production out of which the wages are to be paid. The price at which a commodity leaves an industrial group includes a good deal more than the wages of those particular workers. There are, of course, the material and expenses of machinery, etc., not forgetting the rates and taxes to pay for the services of the bureau, amongst other things. As these expenses consist almost entirely of wages paid in other branches of industry, it means that the bureau have to fix and continually adjust the prices and wages of every conceivable detail of production, from an Atlantic liner to a pennyworth of bird seed. To perform this herculean task there must be a whole army of experts in connection with the bureau, representing nearly every kind of industry; and even then how can they possibly fix a price of any kind? They may add the wages paid for each process to the wages represented by the cost of previous processes in material, etc., plus the taxes, and say the total cost is the price. But that is assuming that the right wages have been settled upon, which would not be the case by any means; the bureau have got to find both the fair wage and the fair price. From our study of prices it should be clear that there is no such thing as a fair wage and price-there is no such thing as abstract value. One person's wage or price can only be fair or unfair when contrasted with another man's price-one day's work with another. Without this contrast by competition of one producer with another there could be no price at all; if such price were fixed, regardless of reason or consequence, it would be fixed by the competition of opinions based upon what people thought they could produce, and would alter as one competitor or the other altered his opinion.

Inevitably the bureau would have to fix the standard of price and wages by competition, whatever their views on the subject might be, and it may serve our purpose to try and realise how it would probably be accomplished. As every one would naturally consider himself underpaid, prices and wages would tend to go up indefinitely, and commodities produced in the country would be high in price compared with those of foreign countries. This would completely prevent the high-priced country from thriving upon foreign trade, and throw it largely upon its own resources. Each froo worth of cotton imported by the cotton trade might be exported again at the same price, but to get a living they must add to its value by work upon it. If they add $f_{\mathrm{I}} 25$ to its value by making it into cloth at their high rate of wages, so that it is worth $£ 225$, when they come to export it would only be worth say $£ 200$, because their wages were 25 per cent. too high for the foreign market. As they would then have actually paid $£$ I25 in wages, they would only have $£ 75$ left to pay for the $f$ roo worth of cotton imported. Obviously foreign trade could not be done on that method, and the country would only 
import what it was obliged to for use in home consumption. If for home use the importers of $f 100$ worth of cotton make a value of $£^{225}$ in cloth, and sell it for that amount. they will have got thesr wages of $£ 125$ and $f$ roo to pay for the cotton.

But here will arise a fresh difficulty: how are they to convey the balance of $f$ roo, which is to their credit, over to the foreigner who sold them the cotton? They cannot send him Treasury notes or a cheque, for they are not money in a foreign country. When the debt is due, it is necessary to remit gold or groods that the foreigner will accept to the same amount. If prices are 25 per cent. above the gold standard, the cotton cloth manufacturers, whether they pay in gold, cotton cloth, or other home-made goods, will find that $6: 23$ worth of such goods is only worth froo to the foreigner, and will only be accepted at that value. The roo sovereigns will cost them $£ 125$ in their paper money, or that value in goods: for goods, as we have said, will only export at a reduction in price of 25 per cent. To get over this, of course the importers will, as soon as they get the cotton, put its value up to the level of prices in their home market : the $f$ roo worth will become $£$ r25. and the value of the cloth will be $£ 250$, which, after the wages are paid, will leave £125 to pay for the gold or goods that are exported to pay for the cotton. This means that the imported goods are 25 per cent. higher in price than they are in the country of origin, and the public might become suspicious that a profit was being made by some one. If wheat was 25 per cint. more at the home port than in the country it came from, home-grown wheat would be at about the same price, and the producers might begin to think that their wages were not a fair share of the high price. If the bureau put agricultural wages up 25 per cent. they would be accused of keeping up wheat prices for the advantage of agriculture, and if they did not they would be suspected of making a profit themselves.

And would there not be some profit made? If a group of cotton cloth makers improved their methods of working or got some monopoly of position or expert management, they might find that by the improved quality or quantity of their work they could sell cloth at the value of $£ 250$ that had only cost them $£ \mathrm{Ir}_{5}$ in wages, etc., which would leave them $£ 125$ to purchase goods to pay for the imported cotton and $£$ ro as profit. A ro per cent. profit, well deserved, we should contend, that might be divided amongst the workers and the management as they might agree. But they might not agree, and. anyway, it is a profit and not permissible in a "production for use" community. The only way to prevent such groups improving theis production and getting a profit to their own advantage is to make it the duty of the central control or bureau to fix such prices at the rate determined by Parliament. Their expert inspector would discover that a group of cotton cloth producers made cloth to the value of 
$£ 250$, while other producers only made $£ 240$ for the same amount paid in wages and expenses. The bureau would commend the group for their superior ability, perhaps give them some public notice or diploma, and take over the Io per cent. profit for the benefit of the State, or rule that the cloth should be sold at ro per cent. less for the benefit of the community.

In fact, the only obvious method of working such production would be for the groups of workers to simply be the workpeople and the works managers for the bureau, and the bureau would be the business managers and financial directors, who would pay the wages, direct the distribution or sale of the produce and administer the profit if any was made. Only so could the production be solely " for use" as distinguished from "for profit" of the organisers. It is hardly conceivable that the groups should be more than employees, because if the bureau or State took all their profits, or greatly limited the profit they might make, it would so hamper the financial position of such groups as capitalists that they would almost certainly find that at times of difficulty they had not made their expenses, in which case the bureau that had taken the profit would certainly in common reason have to make good any deficit. With such paternal oversight the groups would inevitably become wholly dependent upon the bureau. In fact, if they could not materially affect the rate of their wages by ably administering their own capital and profit, what purpose could there be in their taking any financial responsibility at all ?

This being the case, it is clear that separate industrial groups could hardly conduct foreign trade by being themselves the importers and exporters; such sales and purchases would be made through the central bureau. If the conditions of foreign exchange were as simple as they may seem from our above illustrations in a supposed import of $£$ Ioo worth of cotton, an industrial group might be able to import and to arrange its prices to cover the cost of purchasing gold to send in payment for the cotton. But it is notorious that foreign exchange is not a simple matter at all. If every importer just purchased gold and sent it abroad whenever he had to make a payment, the amount of gold required for currency would soon send its value far above its standard position; far more goods would have to be given for it. A country that does not produce gold must pay for gold and all other imports in goods that it can produce. And if such country is not to be permanently poor it must supply those goods only at the best price the foreigner will give for them, and only make for foreign trade goods that it can produce at the greatest advantage. If the importers of cotton had to purchase goods of every description to export in payment for the cotton they would have to be experts in buying all the kinds of goods produced in the country. Moreover, as sending goods in payment means selling 
them, these importers would have to have representatives in every country of the world to find customers who would buy these goxals at the right price. And further, as the shipment of goods takes considerable time, the value of goods either imported or exported might alter considerably between the time of ordering and delivering of the exports sent in exchange, so that the value sent in exclange might be a good deal too much or too little. These difficulties are. to a great extent, overcome at the present time by making the pay. ments in gold through the agency of bankers. The bankers with the help of the Clearing House can arrange to balance the debts they have undertaken to pay against the credits they have undertaken to receive from their various customers, and only then require to send the balance owing to any foreign country in actual gold. But if home prices were commonly 25 per cent. above those of a particular country, such balance would have to be sent. And as bankers can only get gold by purchasing high-priced home production and selling it for 25 per cent. less than it cost, and further do not directly carry out such mercantile transactions, they will (ignoring the many other complications that affect the exchanges) be obliged to pay a premium of about 25 per cent. for the credits due from forcign countries to home exporters, and charge a discount of 25 per cent. for discharging the debts of their customers who have to pay for imports.

As bankers, brokers and financiers generally are considered quite incompatible with an industrial system of production for use and not profit, these branches of industry would certainly be nationalised and become a branch or part of the central bureau and general management of the finance of the community. And that arrangement would seem to be the only natural course, especially as we have seen that the bureau would apparently have to do the foreign trade of the country. Thus there would come to be a gigantic body of officials and departments, a vast bureaucracy controlling the whole financial operations of the community, and also arbitrating in the disputes of the industrial groups with respect to the merest detail of both production and wages. They would be the only body in the community with any liquid assets or credit capital-that is to say, a reserve of purchasing power that could enable them to direcs or concentrate in producing improved resources or new industrial enterprises. There would grow up within this complex organisation a vast number of more or less permanent officials, whose monopoly of financial experience would give them great political advantage over the more representative elements in the bureaucracy. And. although the whole of them were nominally responsible to and dependent upon the electors for support in their positions, any interference with or demand upon the industrial control of the bureau would be a matter of party politics, and there fairly arises the question whether this bureaucracy would be as efficient and ccoan- 
mical in their control of the national capital as the plutocracy of the present time. It seems quite questionable whether an unlimited number of officials of various ranks, all dependent upon public favour and support, and none of them a final appeal on any industrial matter, could adequately conduct the production of the community. It would be an endless matter to discuss all the possible difficulties that might arise, and quite beyond the scope of the present work, but it may be well to briefly point to one or two as illustrations.

It may naturally be supposed that a properly constituted department could determine the standard of wages and prices, including the prices of imports, and arrange means of remitting payments for such imports, just as well as the same persons can do it under a system of private enterprise ; but that is not necessarily so. Under a competitive system of production the rising or inflated price will encourage rash speculation in production, and large and varying differences in the rate of foreign exchanges will further increase financial speculation and risk, the result of which is usually an increased number of individual failures which cause unemployment and allow the competition of the successful producers to cut down prices. We saw in the last chapter that an inflation of prices above the level at which gold and other foreign productions will exchange for a like value of home production made the profits that could be realised on industry less in proportion to the rising wages, a condition of trade that leads to unsound business and failures, or to prolonged strikes, which again increase the percentage of unemployment. Thus under ordinary competition there comes to be an average price for all commodities at about the gold production basis. And the variation of a particular commodity's price above or below that point will indicate an excess or shortage in the supply of that commodity, and the directors of production may thus know what is really wanted and may profitably be produced.

But under a system of production for use, where there was no competition to make profits, there would be no such natural price determined. If the industrial bureau wanted to encourage the production of some commodity of which society was short they would have to put up the wages and prices of that commodity to obtain the necessary labour to produce it. And as there would be no competition to bring the price down again, prices would tend to always rise and get far above the gold production basis. As we have seen, the country could still import and export what it required by putting up the price of the cheap imports to the high level of prices at home and reducing the costly exports to the low price abroad. But the doing of this might much embarrass the bureau politically.

If the bureau find that their imports are a million pounds or so in excess of their exports, and that they will be required to remit that 
balance at a certain date, they must at once sell exportable goods at a price low enough to find a demand in the countries to which they are indebted. They will thus make a considerable loss on the traneaction to cover which they should on sound financial principles resluce the average wage of the community so that the exports can be proxluced at an exportable price. But this there would be very great difficulty in doing - even a very small reduction would meet with great resistance from the workers unless the bureau kept a percentage of them regularly out of employment; and such resistance would lxe much greater if the reduction of wages was not fairly distribuserd, and it would almost certainly not be a quite fair distribution of the lons. If the bureau wanted exports, say machinery; made quickly in extra quantities, they could not at the same time ask the engincers to take less wages-they would have to pay them a little more, as a matter of fact, if they wanted the goods. The more obrious way for the bureau would be to restrict the demand for imports by putting up the price of imported goods. But if the chief import at the time was wheat, for instance, and the price of bread kept going up, the public might well think that they were being taxed to pay undue wages to the engineers or other manufacturers of exports.

Politicians would contend that the Government was scandalously mismanaging the country's trade, buying imports at most outrageous prices, paying too much for goods and selling them in the wrong market, taxing the people to cover their bad management, and paying themselves much higher salaries than they were worth. And it is probable that there would be much truth in these complaints. and the country would be paying a very high price for very bad management. It may here again be erroneously supposed that the departments could buy and sell at good prices, just as well as private speculators would do; but it is almost certain that they could do nothing of the sort. The bankers and bill brokers under present conditions are not required to know the right price for every commodity or the best price to be obtained in the markets of the world. The actual buying and selling of goods is left to the private enterprise of those who are experienced in their own business. Such persons or firms are prepared to take the risk of experiment and speculation on future opportunities, and must pursue such opportunities in every direction if they are to succeed in business. This insures that every possible means of discovering cheap supply shall be tried and every possible market exploited. The success or failure of these enterprises depends upon whether the judgment exercised was good or bad, and whether the labour in production was worth its price or not.

The best possible markets being thus found, an adverse rate of exchange simply indicates that the labour of the exporting country has been judged by competition to be over estimated in value, and has to be discounted by increased cost of what the Labour consumes r.r. 
as income. But the important thing to notice is that before this judgment is passed upon labour of the community the persons responsible for the prosperity of foreign trade have paid the penalty of their errors, or reaped the benefit of success. The failures and losses of the unsuccessful producers automatically set in motion the loss of confidence and other financial machinery which finds out the unsound and inefficient producers, and by causing unemployment, enables prices to fall to a level at which the foreign exchanges are at par, or at which gold can be imported.

Under a non-competitive production for use system a bureau might conduct foreign trade and find the right markets by employing the same persons who would have done the same business independently under competitive conditions. But it should if possible be realised what a vast army of officials this would mean, and what an intricate system of departmental formality and routine it would involve. However upright and willing this army of official buyers and sellers might be they could not risk the prompt speculation or bold enterprise which is so conspicuous a feature of smart business and success. The means to carry out such venture would have to come through the department and be sanctioned by higher officials, and the opportunity would have vanished long before the routine of the bureau could be set in motion. This red tape of Government departments would effectually discourage any enterprise in the conduct of business, or the finding out of productive possibilities. And again it is important to notice that the adverse condition of the foreign exchanges which puts up cost of living by restricting the imports of cheap produce does not, as before, fall in any special degree directly upon those individuals who have been inefficient in directing business, or set in motion any automatic process to reduce the inflated level of prices. Nominal prices and wages could go up indefinitely, and any reduction of them must come, if at all, in a "production for use community" by agreement, or by authority of the majority in Government. And it is not to be expected that the rank and file of the workers would be unanimous in support of such authority. It is just this political dictatorship in industry that is the most impossible form of society, and the industrial possibilities of this unwieldly bureaucracy would be stultified to extinction by its being in a chronic condition of general election.

It is desirable to try and picture to the mind the hopeless inadequacy of such a bureaucratic control. There is nothing so inaccessible to appeal for reform or justice as a powerful hidebound officialism. A strong central clique of capable permanent officials surrounded by a broad padding of elected representatives of the community, who would be of every shade of official incapacity, can become a Government impervious to any constitutional attack, because, as the more representative members of the bureau were dependent upon the 
officials for the security of their emoluments, and for the carrying out of any reforms they might be entrusted with by their electors, the officials might seriously compromise the reputation of any mernles by exposing his inexperience in finance or routine or by adroitly opposing the conflicting aims and interests of such representatives. Held together by its common interests, such a burcaucracy would come to wield despotic powers by virtue of its monopoly of experience and freedom from competition. It would derive great power from the fact that it could always increase everybody's wages and salarie simply by acquiescing in a rise of prices, while it could throw all responsibility for that increase in the cost of living upon the electon of the representative body. Such a bureaucracy managing all the capital resources of the country and paying high salaries to its officials would soon come to be looked upon with great suspicion by the public, and the worker would inevitably be driven to seck the aid of private capital and organisation to escape from the monopolist rule of the industrial bureaucracy, and, if necessary, might take unconstitutional means to set up private capital.

It is probable that no advocate of production for use has really contemplated the setting up of such a bureaucracy as the above, but it seems the only logical result of a non-competitive system of production or of any complete State ownership of capital. The advo cates of nationalisation seem to have some vague conception of groups of workers owning their own capital instruments of production and working upon the ordinary commercial lines to produce goods for sale at competitive prices in the open market, making only such profit as was necessary to insure them against times of industrial difficulty, as a reserve fund for extension, or to afford a suitable bonus in addition to wages as a stimulus to good work, organisation and enterprise. But it is difficult to see what or who is to determine what the profit should amount to, what should be the fair wage or the reasonable bonus. It, for instance, the labour in a mining dis. trict had the control of a specially good coal mine or two, would they not put up wages and salaries till they absorbed the whole value they produced from their monopoly, just as the capitalists would do? What would then be the advantage to other less fortunate miners, the community, or the State? How is the community going to insure that it gets any share of the profits that accrue to these co-operative societies of miners?

It is impossible to see how society would safeguard its interests as consumer without a central control that would become a bureaucracy. for the difficulties of a system of industry by powerful groups of co-operative capitalists are almost without number. It is not our intention to discuss these difficulties exhaustively at all, but one or two may be mentioned. In the first place, if industry was simply in the hands of such co-operative groups, it is not obvious how it would 
differ from the present competitive conditions, unless it is supposed that such groups would voluntarily reduce profits so much that no one could accumulate capital out of their income. If this was so, an industrial group putting up its prices and wages as it might quite reasonably think right to do, and getting them a little above the average, would certainly induce a flow of labour into that industry, and its output would increase until it was too great for the demand at the price. It would soon be found that instead ot a profit the group was short of funds, and that it had a stock of goods that could not be realised as income. Would these producers then see that they must reduce their prices and wages so that more of their goods might sell ? or would they not go on short time? - which would not only be taking less wages, but holding up the supply of their goods to the public loss. And would they not decline to employ any more applicants for work in their trade until the workers were reduced in number and the price and profit maintained ? If they do, they will constitute a monopolist corporation getting a profit by causing others to be out of work, and it is most important to notice that there is no safeguard against unemployment by the increase of co-operative societies. Under private capitalism such a monopoly would break down before it got fairly started, because of the flow of capital into the industry where prices were high. But without private capital, unemployed labour could not find the capital to start an opposition, however profitable it might be.

If, on the other hand, it is supposed that members of these working societies could accumulate capital and start competing groups in the industry, it is obvious that private companies and individuals could do the same, and the conditions of industrial society would be exactly as it is now and profit made in the same way. The worker would simply have the advantage of being able to work for a cooperative society as a member sharing the profit, which advantage he can have at the present time if he cares to avail himself of it. But the difficulty of co-operation is that the possession of capital by a large number of small shareholders does not give the individual holder any appreciable control of industry or directive power over their own conditions of work. It is not the amount or nominal value of his capital that gives an individual his control of production, but the size of his income. An excess of spending power gives an individual the power to decide himself what form of production that purchasing power shall be expended in, or very considerable influence with other persons desirous of investing their spending power. But a thousand individuals collectively holding the same amount of spending power would get no directive power either individually or collectively. Individually they have no weight, and collectively they can come to no decision owing to their conflicting opinions and interests ; and most of them having no directive 
wisdom at all are an incubus to the few more executive ones who must co-operate with them. The result is that collective industry comes to be controlled by the few and rich persons, and the control of the co-operative society is not really dernocratic, nor is there any reason to suppose the nationalised industries of the country would be.

While this fact seems to be recognised by all those who look to nationalisation as a panacea for industrial ills, there seerns to be a vague impression that if all the capital was taken over by the community its control would in some way become democratic. This curious fallacy is probably due to an impression that the individual would become better off simply by becoming the owner of a share of the capital wealth. That, in fact, the individual would then be in the controlling position that is held by the capitalist now. But we have seen in Chapter IV. capital is not wealth, and in a previous chapter that the income from the whole wealth of the country, if evenly divided amongst all its producers, would not amount to more than $£$ roo per person (pre-war value). So the average increase of individual spending power and influence in control of industry would not be conspicuously great, or likely to satisfy the many people whose vision of what is socially desirable is greater than their productive ability or willingness to work long enough to satisfy those ambitions. Such persons would undoubtedly demand an increase of Government control to enforce the people's rights to live a full life, and the inevitable bureaucracy would arise and almost certainly take a larger share of the $\{$ roo per person than the capitalists have done.

Even if the bureau only partially controlled industry. and did not assume the colossal proportions that we think it would, it would certainly be called upon to fix prices and hinder the competition of the productive groups. The control of a price would. as ever. stop the production of the controlled article by the competitive groups, and the bureau would have itself to produce it or raise the price and wages to get the labour to make it. Thus, as we have above seen, there would start an inflation and unlimited rise of prices. and as production would be largely in the hands of private or group capitalists the inflation would much encourage the growth of such capital and profits. It is to be feared that any form of central control would be actually harmful to the social prosperity. But the chief fact seems to be that the disturbance and possible disorganisation of industry would only result in a rather aggravated form of the present capitalist method of production. That, in fact, no escape from the capitalist system, or even from its evils, is likely to come from state ownership or central control of capital, or from collective ownership, which seems to simply come to the same thing.

The manifest difficulties in changing the social order and the 
persistency with which the capitalist control reasserts itself suggests that it alone meets some actual necessity, and experience seems to show that it is the only means of insuring a sufficient competition between producers to improve the methods of production. It is often contended that competition should not be the motive for work, and that the best work comes from the desire to serve, which may be a very proper sentiment, but our experience suggests the more prosaic conclusion that people usually work to get what they want. If producers were working to directly produce the things they actually want to use themselves they would not need competition to make them produce it as quickly as they could. But it should be remembered that such producers may go on for generations, even thousands of years, without finding out what is the quickest way to produce the things they want. In a society where, to secure that quick production, every one is solely engaged in producing what he thinks some one else wants, and expects some one else to pay them for it, there must be competition to insure that they produce a fair supply, and that they get paid a fair supply of what they want in return for it. As a matter of fact, it is impossible for any man, however well intended he may be, to know whether he is or is not producing the best possible value for the community except by being subjected to competition with other producers and other methods of work.

Competition being granted necessary, it seems that success in competition can only be measured by the successful producer getting a profit or increased income from his work. Otherwise his success would not cause any competition to oblige others to improve their methods or to convince him that any further improvement might be possible. He might reason that he could now produce more for society in a given time, and therefore might work less time, and without competition there is nothing to prove whether that was a right and reasonable conclusion or not. Allowing such producer the increased reward of his ability and service, the capital he accumulates from his increased income might certainly be taken over by a bureau or government; but if that bureau was well advised would it not select that able producer to have the working control of that capital to further improve the social production? In which case the capable producer would still administer the capital he had made and control industry as a capitalist; and it is not obvious that there would have been established any safeguard whatever against the abuses of the capitalist system. To confiscate a capitalist's rights and as capital or decreased taxation give it back to him or to other capitalists does not seem to insure any improvement in the distribution of wealth.

The above considerations raise the question as to whether the nationalising of the capital is what we want to accomplish at all. whether it is not rather that the community needs to complete the 
competitive system by competing itself. To compete for the purpone of insuring that the competition is to produce the greatest amount of wealth, not simply the greatest percentage of profit, of in $\mathrm{ket}$ work at the expense of some one else, without any thought or intes. tion of producing more for society by doing so. Our investigation of capital showed that the production passed on to the community was the "Social Capital," which, although nominally belonging (o) individual capitalists, could not be used or consumed by them with. out surrendering two-thirds of it to the workers. So that the only practical question is whether the workers can obtain any further share of the remaining third of the production. That share is determined by the competition to get work, not by virtue of any capital owned. So it seems that it does not matter who nominally owns the instruments of production so long as the communty knows what those owners must be made to do to render those instruments most useful to society, and sees to it that they do so use them. If the community as a whole does not know what is essential to an equitable method of production and distribution of wealth they cannot possibly control or organise such method, nationalised or otherwise. However long it may take to learn, society has got to understand exactly what the economic requirements of a right distribution of wealth are before such equitable system can be inaugurated. Before it is possible even to think cogently about the requirements of a better system of production, it is necessary to see exactly what is wrong with the present method, and it has been the sole purpose of our inquiry into the cause of value and its division into profits and wages to discover what it is that wants altéring in our present industrial organisation.

We have before had occasion to point out that whatever may be the defects of the capitalist system, it has certainly been an immense success in vastly raising the material well-being of the people. As pointed out in Chapter V., we can even by the dim light of the inadequate index number see that in the last roo years the material position of the people has greatly improved. In I 809 commodity prices were 175 per cent. higher than in 1902 , while wages were not half what they were in the latter year. It was seen by Diagram 24 and other wages tables that they have gone up at least r 20 per cent., and as prices were 175 per cent. higher in 1809 it may be stated that in I 902 a member of the community got twice as much wages as in 1809, and could purchase three times as much goods for the same money. So it appears that we get six times as much income in goods; in fact, the workers and all the members of society are probably 500 per cent. better off than in $x 809$ as the result of capitalist organisation of industry.

This evidence from market prices per unit of commodity as used for index numbers probably somewhat exaggerates the increase 
in wealth shown by those particular commodities, owing to the fact that in 1809 there was an after-war level of prices, whereas the price level was normal in I902. But against this exaggeration we have to set the great increase in the many social luxuries and personal means of enjoyment that have come into existence, or, at any rate, common use, since I809, and with which there was nothing at that time to compare in price with them. Watches, bicycles, motors, books, the novel that has come down from 30s. to a shilling or two, cinemas, railway and steamship travel, street lighting, draining and water supply, etc., are things that cannot be compared in a list of prices with those of I809, but mean a vast increase in wealth and comfort to all classes of the community. If we make allowance for the incalculable number of new forms of wealth that have come into existence, the 500 per cent. probably only feebly represents the real increase in the wealth of the people. There is really no data to actually measure the increase in figures, and those here suggested are only to indicate that it must be exceedingly great.

It is sometimes assumed, and especially so by those who are to any extent propagandists for social reform, that the great increase in wealth has not been adequately shared by the wage-earners, and that it has chiefly gone to increase the wealth of the capitalist classes. Of course, there may reasonably be some question as to what is an adequate share; but we find no evidence that the capitalist's share has increased, on the contrary it seems to have always been about the same proportion. Such wages data as can be found, and also the evidence afforded by our theory of prices, go to show that the share of the whole production going to wages and salaries has always been just about 64 per cent. So that wages must have kept pace with the share going to profits, and have increased 500 per cent. or more since I809.

When we realise how great a success the capitalist organisation has been, and how many real difficulties there are in the various ideas of social ownership of the instruments of production, it would seem very unwise to demand that capitalism be completely superseded by something indefinitely different simply on the belief that a new system would develop and naturally be better than the old. Such improvements will not develop while those who develop them fail to understand the cause or reason of their difficulties, and it is futile to demand a change without knowledge of what is wanted.

But it does not follow that the capitalistic system is perfect, or that its past success justifies its continuing any method that is an injustice to any section of the community, and it must be admitted that whatever the virtues of the present system may be, it has failed to convince society that it is the best that can be done, or that no injustice exists. The most obvious failure of the capitalist system is that some individuals of the community are much of their time 
unemployed and reduced to perpetual risk of destitution, while some others that do no work at all are very rich. There might seem to be a little difficulty in the way of making good the first part of the failure because there are some individuals whose powen of proxluction are so low that they form a drag on society, and are thenselves poor by nature. But the real failure is that these persons ase constantly forced into unemployment and prevented from doing the best work they are capable of. The fact that they can work is proved by their being employed in times of good trade when all are at work within $I$ or 2 per cent., and also by the fact that trade unions object to their being employed lest they should actually do the work at a lower rate of wages. They cannot earn the minimum wage, so that the employers will not find them work at that wage and the workers' unions will not let them work for less. The recognition of this principle of letting some labour go idle when it does not happen to be wanted has the inevitable result that more capable workers also find at times they are subject to periods of short time or unemployment. And the workers' organisations seem to think that this is necessary; sometimes even themselves organising for short time. So there is not the least reason to suppose that employ. ment would be any better if the workers were the owners of the nationalised capital.

This attitude of the workers with regard to short time and unemployment is the result of the utterly mistaken notion that low prices and wages are the result of some kind of over-production, and that a reduction of output per person would increase the number of persons employed and raise wages. So long as the workers are unable to see the absurdity of this over-production argument, the idle rich will continue to be able to get great incomes at the workers expense. The so-called over-production is in reality only orer-highpriced production, which reduces the demand and the quantity produced, and causes unemployment ; but, as also shown in Chapter XI., this high price keeps the total value of the output the same, although the quantity is less, so that as the wages paid out of that value are less when the workers are on short time, it leaves an increased profit for the employer.

This is the one essential fact that we deduce from our inquiry into economic theory, that all profits rightly so-called depend absolutely upon competition for work by the wage-arnen, and that there would be no such competition if there were no unemployment. Unemployment is the real defect of the system. and is absolutely unjustifiable in any kind of way. However incapable individuals may be, if they can work at all their labour will add a little to the commonwealth, and it is a crime to present them from doing that work, and it is a failure of industrial organisations not to help and encourage them to perform that work in the best way 
they are capable of. The capitalist system has failed badly in that it has always allowed an average of $\mathrm{I} 2$ or $\mathrm{I} 3$ per cent. of the labour power of the community to stand idle, thus probably.lessening the total wealth of the community by that I2 per cent. For there is no guarantee that this unemployed shall consist of the incapable class of workers, in fact, it is often to prevent them from lowering the rate of wages by doing the work equally well for less wages that organised labour causes stoppages of work, which stoppages it should be noticed are a form of unemployment that helps to keep the price up and afford a profit to the employers.

The only possible excuse for this unemployment of I2 per cent. of the workers of the community would be that it was inevitable, and that the directors of industry cannot help it. But it would be extremely difficult to make that excuse convincing in the face of the fact that a large number of persons who do no actual work are getting large incomes from money invested in the productive work of the community. If the directors of industry who do the necessary work of management and organisation can, after getting a remuneration that is sufficient to induce them to do the work of organisation, pay rent and interest to persons who do not work, they might equally well pay that sum in wages to employ the remaining I2 per cent. of workers, and that without reducing their own salaries or diminishing the efficiency of the management. But as they get this surplus remuneration in profit by causing unemployment, it means in plain English that the idle persons who live on rent and interest, or partly do so, are actually living at the expense of the workers whose wages are cut down by the competition of the unemployed for work in the industry of the community.

The most essential fact in nearly all problems of political economy is that to make a profit upon labour it is necessary to have some uncmployed labour to keep wages down by competing for work. This is really the only difficulty that organised labour has to overcome, and the overcoming of it is the only thing that will in the least improve the present commercial system; all other so-called reforms are utterly abortive while unemployment remains. Any attempt, for instance, to restrict profits by controlling the price will throw out of work the marginal producers who normally make little or no profit, and the unemployment that is increased thereby will bring down wages till the rate of profit is the same again ; in fact, it will never have altered to any extent appreciable by society. If again the wages were kept up by law of some kind, it might ruin the organisers of the marginal production; but as they would not then continue to organise labour and unemployment would greatly increase, the power of the labour government or organisation might be broken, because the unemployed would find they had a grievance against the labour organisation rather than against capitalism. It is notorious 
that this inability to satisfy the unemploged greatly dereaw the strength of trade unions when prices are falling. making the organisa. tion weakest at the time it reguires the most strength

At such times of stress labour organisations recognive the incon. venience of the unemployment problem, but quite fall 10 sns its essential importance, if we may judge by their helpless suesestion for its removal. For instance, to demand protection to encuurape the consumption of home-made goods, quite forgetting that such duty will raise the market price of the commodity, and that therefose less of it will be wanted, and less persons wanted to produce $1 t .0$. again, there is the futile demand that the unemployed shall tre main. tained while out of work, quite regardless of the fact that it is the rest of the workers who always must maintain them; no one clse can. So that organised labour actually wants to maintain a percentage of unemployed labour to compete for work and kcep down wages. These mistaken notions are probably all based on the idea that some form of taxation could be instituted that would make the idle rich obliged to pay for the maintenance of the unemployed, the cost of protection or whatever it might be : and it is most important to realise the impossibility of any such thing so long as there is any unemployment.

If our theory of wages, profit, and unemployment is once understood, it is obvious that the relative percentage of profit to wages is determined by the competition to get work on one side and to get workers on the other. The proportion of wages to profits is fixed by the point where these two competing forces are in equilibrium, and as any advantage to the wages at the expense of profits decreases the demand for workers, the increased competition to get work will displace the point of equilibrium to the disadvantage of wages till they are reduced to the old position where the competing forces are equal on either side. So if home trade is protected, profits in such protected trades would go up, save for the fact that their in. crease would tempt extension of those industries, and the demand for labour would send the wages up till the share of profits was the same as before. The share both of profit and wages would be highes by exactly the amount of duty imposed, save again for the fact that the increase would tempt a flow both of capital and labour into the protected industries until their prices and wages were brought down to the common level of prices.

In the same way, if the capitalists are taxed to support the unemployed, they, being less well off, there is not quite so much capital seeking investment in industry, so there is a little more competition for work, and the capitalists find they can just put up the price to cover the tax, because the balance of competition has been displaced in their favour. The rise of market price causes less demand and less labour required, and wages go down to cover the tax, so that 
the workers, as a matter of fact, pay it. By no kind of financial jugglery can the idle rich be made to pay for anything-the balance of competition will automatically adjust itself to any pressure put on either side. But if the supply of employers wanting labour could be stopped, wages would go down to subsistence point, and if the supply of unemployed persons could be stopped, wages would go up to the total of the production.

The one aim of labour organisation, therefore, should be to compel the Government to inaugurate a scheme that should insure the full employment of every individual in the industries of the community. It must be actual employment in competitive production at competitive wages; no substitute will evade the economic balance of competition, and no alternative can ever help to settle the due share of the national income that should go to the wage-earners.

The actual method of insuring complete and useful employment for every member of the community is, like all industrial evolution, essentially a matter in which experiment and practical experience must be left to discover the most effective method of carrying out the details. It is not possible, therefore, to give any cut and dried suggestion for a working method of employing everybody; but as the only just and rational solution of our industrial difficulties is to be found in at once finding work for all who want it, it is necessary to face the more obvious difficulties and necessities of the proposal by a preliminary consideration of what may be expected to result from such an attempt. In the first place we have been speaking of the whole production of labour being absorbed as wages if there was no unemployed labour to compete for work. But it should be understood that we use the word wages in the broad sense in which we have used it throughout to include wages and salaries of management. It must not be forgotten that industry will still require intelligent management, and that unless that management is of a very high order of efficiency the necessary invention and improvement in industrial methods, that has in the past raised wages of the community by hundreds per cent., will not be forthcoming. And if from that reason improved resources that required some speculative risk and forethought were not made in advance of an actual shortage of such aids to production, the resources in use might come to an end and productive efficiency be considerably reduced. In which eventuality the increasing population might very speedily swallow up the 36 per cent. advantage of the new system of industrial organisation.

The mention of the above percentage raises the question whether there would be anything like 36 per cent. addition to the present wages and salaries of the community? In most industrial concerns there are persons of the higher management staff, owners and shareholders, etc., who do not take any salary or do not consider themselves adequately paid by their salary, and whose remuneration 
comes to them as profits. As under the full employment oystem of industry these persons can no longer get a profit, they will, $\infty$ tas as their management is genuine and reguired. have to be puid alasies out of the 36 per cent. that would have leen ther profne. This brings us to the important question of how much of elue profits would be left after the necessary management had been paud? It is by no means necessary that any of it should be, or that there should be any advantage to the present wage-earners at all. It mighs quite well happen that this share taken from profits was complotely absorbed as the salaries of management. Any advantage to the community in general or the watge-earners in particular woukd depend absolutely upon whether the industries were better or more cheaply managed or not.

As the unemployed became permanently absorber in industry. wages would undoubtedly rise and profits largely vanish, but as the employers would vanish also the workers would be left to manage themselves and fix their own wages. It is well known that a number of persons with their many conflicting interests are hopeleasly in. capable of directing their collective activities in the details of the moment. To direct as well as to do the work is in the first place to sacrifice the advantage of division of labour, and all experience shows that a head or director must be chosen to manage the whole and investigate and decide upon the order of work and the contlicting interests of the workers. Such directors would have to arise to take the place of those capitalists that at the present time do manage their own industrial establishments; and the question is whether these persons would demand so large salaries as to leave the wageearners no better off than they are now. Or would the wage-earners vote the salaries down so low that no man of any ability would undertake to direct industry? Or the groups of workers quarrel eternally as to which they should do, and keep a huge Government bureaucracy to settle every detail of difference between them and absarb the profit, while industrial methods degenerated and invention and enterprise became impossible.

Obviously there might arise all the difficulties we have discussed as inimical to nationalisation. But the supposition of employment for all does not necessitate that there shall be no profit made under any circumstances. A person or group of persons who could by invention or superior organising ability make a profit over and above the standard level of wages would be free to do so. It would simply be payment by result for the benefit they rendered to society by the improved production. And a benefit it would be, although such organisers were able to take most of the advantage themselves as profit, for if they wanted those profits to be a large amount they must do a big business and would want more labour. To get such labour they must give a little more in wages, or in improved con. 
ditions of work, than their competitors do, or they cannot depend on getting the labour required. And further, such advantage will at some time cease to be controlled by its inventors, and even though protected by patent for a period of years, will ultimately become public property.

Only by so encouraging private enterprise is it possible for us, with our many conflicting interests and various conceptions of what is necessary work, to realise what is actually the relative value of each other's services, and what is a fair division of the mutual production. By allowing private enterprise to run side by side with collective methods of production it is possible to insure actual payment by results, which is the most stimulating and much the most fair method of payment. The sole objection to the present method of profit making is that the director's profit is not necessarily the result of his superior ability, but may be partly or all due to the community's inability to organise work for all its members. If society makes good this defect, and all are employed, any profit that can be made will be the result solely of productive ability above the average, and the idle rich will virtually disappear.

The only thing necessary would be for the Government to insist that every worker was employed for the full time that he was anxious to work. If the private employer was not prepared to employ all applicants for work in his trade and keep them going on full time, such persons wanting more work or better organised work might requisition the Government to supply them a factory complete with up-to-date plant, and to allow the workers to conduct their own industry in that establishment. The only control the Government need exercise over such business is simply the accountant's work of seeing that the books were kept and that a proper sum was deducted from the annual production as depreciation of the capital or sinking fund paid to the Government to repay the capital cost of the works. As this payment of the loan from Government would have to come out of the earnings of the concern, as well as the costs of its management, it might be found that the average share of wages was less than could have been earned under the private capitalists in the same industry. Under those circumstances some of the labour might go back under the capitalist's management, proving that his directive ability was a benefit to society, and that his profit was a fair remuneration paid voluntarily by the wage-earners for the benefit of his service. It is more probable that the workers would not voluntarily do so, but regard their loss as an investment in experience of industrial control, and by improved management improve the share of wages they could take. But for this better management they would have to pay a fair price, or it would go over to the capitalist camp.

Thus it seems a system of industrial organisation might be estab- 
lished in which each grade of productive ability got the remuneration which, in the estimation of the consumers, it had earned by its particular service. The reason why the services of the directors of industry are at the present time overpaid is that these employers need only employ as many persons as suits their convenience, and that those persons left unemployed lave not the means (1) acejuse the instruments of production necessary for producing an aderjute income or competing with the methods of the employen. If as we suggest, the workers could demand to have such instruments of production as were necessary, the employers would recognix the danger of allowing groups of worken to start in competition with them, and would try to fully employ all the labour and organise to such public advantage that the workers could not earn more by working under their own organisation.

And it should be realised that this survival of the really capable capitalists might continue for some time : it is by no means certain that all labour could organise itself in industry to better advantage than it found under a capitalist employer. Business ability would still be able to earn either as profits or salary the full amount which it added to the production of the community by its work and skill. But as such managers of industry would not, under ordinary circumstances, be able to get any profit above what their ability was actually worth, they would no longer have to pay interest to any one for the right to organise industry, so that all interest would soon fall to the Government rate, and if the Government charged no interest, neither could any one else.

A true economic rent might continue to be obtainable for a time. If any person had a property, invention or natural advantage that could be used to produce commodity or service at a lower cost or a better selling price than the average cost or average price common to the industry, it would still be possible to charge a rent for that advantage to be paid out of his profit by the employer who chose to use it. Probably such rent-paying advantages would be found to be few and far between, and under a condition of complete employment, steadily diminish and become a vanishing quantity. But as they would in any case only be a share of profits, they would not increase the cost of anything and would be no burden to the com munity.

It is probable that the change in amount of income from invest. ments in municipal and Government property would be quite slow and allow of gradual adjustment without any greater hardship than those common to fluctuating fortunes at the present time. As was pointed out when discussing the production per person in Light, Water, and Electricity, these great capital expenses for future use are simply on account of their size undertakings in the nature of monopolies, and the rise in wages of the comparatively small working 
staff would not so greatly affect the actual profit as in more competitive industries. The community would, therefore, be quite well able to fulfil their obligations to existing stock owners until in course of time such debts were paid off. Moreover, as profits and interest diminished, money for public works would have to be raised by direct taxation of the community, and, as before pointed out, it is quite questionable whether the working community would appreciate the necessity of paying for all the more or less speculative work of improved resources for future use. The electors might not support the Government in such undertakings, and in that case private capitalists and financiers might, at their own risk, still invest in such undertakings and make profit and interest thereby. As in such case the community had deliberately handed over such enterprise to the private speculator, and was anxious to avail itself of such resources as offered by the speculators, the profit accruing to such capitalists would be a just price which the community thought right to pay for their services.

When we remember the vast amount of capital always employed in the carrying out of work for future use, and the great business intelligence necessary for its organisation and control, it seems likely that financial ability would find scope for remunerative work for a long time after the institution of full employment for all, and that that change in the financial relationships of the co-operating classes in industry would be gradual and carried out on normal commercial lines.

The facts that there need be no social upheaval, that the only additional work thrown upon the central Government would be that they must see that every member of the community is able to have work, and that private enterprise could be left to continue or not as it could or could not justify its existence by results, gives this suggestion for industrial reform a simplicity and reasonableness that, we think, should recommend it to public attention. There would, of course, be a vast amount of detail to be considered in the practical inauguration of this or any other reform of industry that we do not pretend to discuss here. Such details would be essentially a matter of experiment and careful investigation of each particular practical question. We have here only discussed the general outline of the more obvious problems involved with the purpose of pointing out the great possibilities of a reform so simple and obviously right and just as the making it possible for every one to be at work to the full of their ability.

Our object has not been to formulate a scheme of reform, but to discover what really is the defect in the present industrial system. It is hopeless to discuss reforms and revolutions while we do not understand the actual working of our present industrial organisation. The essential points that our investigations seem to make 
evident are that the normal price or total value per person of com. modity is a value naturally determined by the labour cost of obtainisg gold or other standard commodity in which value is measurod, and is a price common to every country of the world where such commolity is regarded as a standard or required for use. Any inflation of prices above that real standard is only nominal and does not represent any increase of labour or of the results of labour. Although dunng inflation the whole product may be purchased in the country at its nominal value the community cannot pay for it in gold, or carry out its purchases with the existing gold in circulation without an extension of credit or the use of fiduciary money or actually debased paper. This extension of credit simply means increased nominal value of the social capital held by the various capitalists. But as the price of those capital goods is based upon the cost when they were made, and a considerable time elapses before they are sold to the consumer, they tend to be sold at a value below that of the current production that takes their place. The workers, whose wages have risen in the meantime, are therefore able to purchase rather more than their normal share of the value at the old price, while the capitalist is left with rather less than his share of goods, but what he has are at the new and increased price. While such inflation continues the workers get. a little more than their average wage, and the employer a little less that he can realise as profit. He has an increasing capital wealth, but a relatively less income, and is apt to get short of ready money. This with the adverse rate of exchange and the ordinary commercial difficulties leads to failures or strikes. which reduce prices and make unemployment which enables employers to get the usual profit.

Thus prices are always brought back to the natural standard of value as determined by the labour cost of gold, and in normal times prices never depart far from that basis. The price being unaltesable, a profit strictly so called can only be obtained if there is a percentage of unemployed labour to cut down the price of labour's share of the production; and, therefore, the capitalists fail in their professed function of employing labour by actually keeping about I2 per cent. of the community out of work. This seems to be the essential defect in the present industrial system. and. although some of our evidence may be inadequate to the conclusions arrived at, the arguments they subtend afford so connected an explanation of the common phenomena of industrial experience that it is certainly the first duty of society to see that the statistical data are made complete, and to prove or disapprove this theory of profits. Otherwise, the enigma of unemployment remains in a very sinister light. 



\section{INDEX}

AA, curve of price level on diagrams, 132, 137-9: of crops, 354: as evi. dence of cost price variations, iso 242-3: representing cost of gold, 417-18

Acre, value per acre in place of value per person, 144

Acreage, changes of as evidence of normal price being the cost, 152-3. 242-3

Agriculture, low production not due to low wages, 36 : improved methods. their effect on normal price per acre, 155-6 : small profits of, 374: unemployment in, 376-7

Allotment garden and home work, as improved resources, 92

American, wages data, 49-51: gold, no data for production per person in, 205 ; normal price level, 233-4

Assuan dam, effect on cotton prices, 182

BAD trade, nature of, 404-7

Baker, C. W., monopolies, 192

Bank balances, not a fund of money, 69 : as purchasing power, $71-2$

Bank rate of interest and trade fluctuations, 414

Banks, as users of gold, 218-19; to get gold must cause prices to fall, 394-404

Barley, U.S.A., normal prices of, 251

Beet sugar, normal price of, 168

Beveridge, W. H., on trade depression, 407-8

Bowley, Arthur L., Sc.D., estimate of national production, 36 ; wages share of production, 54

Bureau, or department management compared with individual management, 432-5: cotton forecasts, 273

Butcher's meat industry, omission of, 33

CApItal, in public works, 23-5; in form of production, 27-9: becoming national income, $37-41$ : difference in estimates of capital wealeh, 59: amount per person in American in. dustry. 59-60; estimate for Great Britain, 60-1: vagueness as to what capital is, $6 \mathrm{I}-2$; as the value of products used to produce wealth, 62-3: all used up and reproduced, 64 : not a fund of money or real wages, 67 : as the security for purchasing power, go : inevitable law of undiminishable nature of, 70-1: undiminished by paying wages, illustration of, 73-8: consumers' good' as eaptal. \& $4 \rightarrow$ : wex the result of aving. :-o-s, not aveot. illustration of, 79: aving (wo callons)

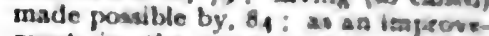
ment in the means of groductires. 84-6: result of improvervent in the amount of work ibme, illeveration of 80: no clase of workers kept by is while they do thes wuts. definition of. 22 : Lbour time irkagial as capital, 286, ox: value of dependent solely upon income trum, 4:3-5: not wealth or surplus value. $14-6$ capital goods not wealth. $24-6$ : collective capital wealth gives no control to workers, 436 -

Capitalist, the, $328-4$ : organisation successful. 439- to: organiation defective, $440-1$

Census of production $(1207)$. 16: defect of omissions in. 33: defert as to value per person, $34-6$

Central control of production, difficultire of, 287. See State Contrul.

Coal, normal prices of. Australts, ifo: Belgium. 136: France. 125-90: Ger: many, 131-3: Japan, 140: Spais. 137 : United Kingdom, $134^{-6}$ : United States, 141. 234-5: strike of isgl effect on normal prices, iss-e

Collective control of indusery, collective wealth does not give democratic control, 436-7. See State Contrul

Compensated or fixed unit of valee. 115-16. See Normal price.

Competition. of markinal production. 389-00: under State control, necessary to determine what shall the produced and its value, 132 : neceswary to knowledge of what is good individeal work. 437-8

Co-operative society, not thought to be democratic, 127; wages of. 3:-1 297-s

Copper prices, tyo

Copper, French syndicate, $89:$

Cost of growing whest and oats, s so-t

Cost of living, rise of prices, $18,1-1212$. probably a fall in cost of liviag. $1: 6-8$;

Cost of production. Latrour the only cont. 8 : price determinel by, as shown by cotton price forecarts. 2\%3. ast-5: estimate of cotton supily made froen. as compared with those trom matket reports, 273

Cost price, vagueness of term, 14 th-7

Cost value, no evidence of as davis. guished from price, $147^{-3}$ 
Cotton, American normal prices, 243-6 ; Egyptian normal prices, 175

Cotton price forecasts, difficulties of, 259; crop estimates, uncertainty of, 259; ginning report, 266; ginning report, calculation of price from, 272 ; forecast for crop season against calendar year, 265; " into sight movement," 259 ; bureau's estimates compared with labour-cost price estimates, 273

Cotton seed prices and "linters," 245-6

Credit, in industry, 359-60; as currency, 396

Crisis, nature of commercial, 394-404; of 1907, banks requiring gold, 394

Crop prices, acreage changes as evidence of price depending on cost, $152,242-3$

Currency, paper, 397-9

Curve AA on diagrams, 132, I37-9. See AA.

Custom in valuation of productive labour or prices, in Germany, 132 ; in beet sugar, I7I. See Wages, 311 .

DEMAND price, though high does not raise the price above cost, $I 77$

Description of phenomena mistaken for explanation of their cause, 6

Distribution of wealth, see Division, 47

Domestic service, production of, 22 ; share taken as earnings by, 56-7

EcoNomic science, neglect of, 2 ; backwardness of, 4 ; W. S. Jevons on want of data for, 5

Employment, full, and rent, 37I; of labour, not better under collective control, 44 I

Experimental method in economics, 255

Final utility theory not convincing, Professor Gide on, 104-5

Financial pressure, 399-404

Financier as a person employed in the production of commodities, 88

Fisher, Professor Irving, on trade fluctuations, 393

Flux, A. W., estimate of capital in Census of Production, 24

Forecasting prices, requirements for 257-8

Foreign exchanges, shipment of gold for, 215-16; and high prices, 4I7; under State control, $427-32$; rate of, 420

GIDE, Professor, price depending on quantity, IOI ; ordinary utility, I02; final utility, I04 ; cost of production, ro5: transient and chance nature of price, 107; measuring labour or effort of production, 124; experiment in economic science, $255^{-6}$

Ginning report, see cotton price forecasts, 266; cotton price calculation from, 272 : published calculation, 276

Gold, standard of value and normal price, 204; want of data for labour cost of, 205; price index of, 206-1 5 ; market price of not variable, 206; price level does not depend on quantity of, 208-10, 212 ; definite supply of wanted, $21 \%, 229$; production per person of, its effect on prices, 217 ; currency, origin of, 22I-2; flow of capital and labour into or out of gold production, 224-9; production and prices, U.S.A. geological survey, 224-6: small change in production per person has great effect on level of price, $226-7$; that labour time in gold production determines prices, general law of, 232 ; production of in America, 234 : failure to appreciate the position of prices determined by gold prodnction, 264 ; production and wages in, determine the value of production and wages in commodities, 298-302 ; check to putting up prices and wages, $358-$ 61 ; necessary to financial stability. 395-404; commercial mechanism to obtain, 394-404

Gold standard, when suspended, renders investment of capital difficult, $402-4$; encourages bad management and wrong production, 40I-4

Grades of productive value in labour, 310-17

Group control of industry, see State Control, 435-7

High prices and foreign exchange, 4I

House property, rent earning life of, 384-6

Hypothetical economics, 4 ; certain cases thought to be axioms that any theory must be made to fit, $8-9$

IMPORTS, a form of national production, $4 I$

Improved resources not capital, 66-7 ; become capital as they are used up in production of income, 91

Income, subject to tax, 56-7; real, in value of goods, 355

Index numbers, 108 ; questionable value of, 109; failure to recognise changes in cost of production, I I3-15; variations of compared with actual prices, II4-I7; require some standard of value that does not vary, II5; show great contradiction in movement of prices and wages, I I 8-19; method fails in the investigation of wages problem, 305-6

Individual failure check to price inflation wanting under State control, 433-4

Industrial reform, the only thing that can be done, $438-46$

Interest and rent, shares of profit, 37I ; payment for work done, not for providing money, 89-9I

Into sight movement, cotton, 259

Iron law of wages, 320

Iron, normal prices of pig, 185 
Jevons, W. S., utility and cost of pro. duction theories of price, $\mathrm{sO}_{4}$ : use of index numbers. 107 : gold given for is not the value of the commodity. 122; trade fluctuations. 392

Kleze, Professor G. A., wages fund theory, 67

LABOUR, low valuation of its produc. tivity by custom, 132, 311-17: has no cost of production, $289-90$ : regarded as capital, 280-90: difficult to know its value when gold standand is suspended, $401-4$

Labour cost, fixing the average price without knowledge of supply and demand: examples, wheat, 163-4: Egyptian cotton, 179, 183: price indeterminate without it, 202

Iabour-time, the intrinsic value by which alone values can be measured. 124. 221: though always the same innate value it may vary in price or value measured in gold, $200-1$ : note currency, 221: general law that labour time in producing gold deter. mines prices, 232

Labour unit of value, I 15-16; necessary to make a ratio of value possible. 123-4; per acre equivalent to unit per person approximately, 14t: or "normal price" seen in crops to be compensated and changing only with general standard of price, 198 $\rightarrow$ : theory of as the standard of price, $22 i$

Land, value of in towns, $377-82$ : latent value in towns, $378-9$ : value dependent upon unemployment, 379

Leiter corner, effect on oats prices. 158-9: on U.K. wheat prices, 165 : on U.S.A. wheat prices, $240-1$

Linters, cotton seed, $245-6$; in cotton price forecasts, $269,278-9$

Luxuries as productive capital, 66

MaIzE, normal prices of, 246-9

Marginal increment of supply does not determine the price, $369-70$

Marginal land, question of its existence, $367-8$

Marginal production competes to keep prices near to average cost (iron), $189-90$

Marginal supply (gold), 213-14

Marginal utility, theory of, 100

Market, academic formula for, 370

Market price, not the real price. 129: irregularity of in coal contrasted with normal prices, 142; vagaries of in oats, 154

Marshall, Prolessor Altred, final degree of utility, 102: extravagant scarcity prices, 105: difficulty of utility theory when applied to supply, 107

Martineau, figures for bonus on beetroot growing, 173
Marx. Kart. louble maniter of valep. ? hypothetical surplus ralue, $g$ - is

Money, not wralth bet cafital inotre meat to mesure valee, it-e; oboptaxe of, 350-(0, yy): quanssty iseory of 393-4: Law of iducial spapdang. yn

Monopolies, corner, ring. eymiticates. and trade troming. ellect on prikan. $165^{-6}$ : cxamples (copres). igs. (wheat). 2 40-1: (cotton). 215. cotton spinners, ahort timo policy, $2 b_{5}-1$

Mmore, Hroleswor II. J. protedectivtty theory of wagrs, 132

National income, 16: prosluction uons up in producing ibcome slow not make total production less, but remalas is value or price. 37 ; is it is conversed. $37-11$

Nationalisution, sec State Control, ise $3^{8}$ : would not give democratic control of industry. 436-7: of cajdes isstru. ments inevisably ixureacratic. is 35: Are not capital and indentry already nationalised as far as they can be? $43^{8-9}$

Natural price, 125-6, 120-200, 28s

Naval shipbuilding. depresioun of th 1008 distorts unemployment 6rases. 343

Net production, error of in Ceravs returns for coal, light and water, ete. 23: want of data (iron). 186

Normal prices, is 6 : example of. 124-5: the purpone in compariog them, 126: Clata for, 127 : isdex diagrams of, 127 $\rightarrow$ : per acre und as approximately equivalent to price per person. 14t: is the cost price, 146: diagrams is test for the exivsence of excessive profits, 1430?: per acse. crror due to improved method of cultivation, 155-6. 235: due to more costly methods. 181: similarity of movement in all commoditien is ev. dence that normal price is a nsturally determined value, 199-200: Ductus. tions of are about a mean level the fluctuations of which are common to all prices, $167-8$ : difterent levels of. 233: value is the same whether the amount produced per persoa is sreat or small, 353-4

OAts: normal price of U.K. iss-5: U.S.A.. 249-5i

Orwin, C. S. determination of farming costs (oats and wheat), i51

Output and wages in French coulcainer. 3ะ3.

PAPER currency: $327 \rightarrow$

Jotatoes, U.S.A. normal prices, is a

Price, nature of is chucl purt of this inquiry. 8 ; of things to masty deter. minable, as shown by practice of calculating capital valuea $12-13$ : reason for study of, t3: Why tave 
Price-continued.

different things definitely different prices? 94-5; necessity for a definite accessible standard to measure every price, $97-8$; cost of production theory of, Adam Smith and Ricardo on, 98; marginal utility theory of, Ioo; the fallacy that past labour fixes labour cost, but not price, I04; price of different commodities due to difference in labour cost, I44-5; of wheat and oats, I 50-I : no evidence of cost value as distinguished from price, 1 47-8; that wages do not enter as cost into price of commodities, 28996 : failure to understand labour cost results in surplus value fallacy, 422-3 ; forecasts as evidence of cost determination of price, $28 \mathrm{I}-5$; a naturally determined quality of things, I99200,285 ; price level data, late publication of for forecasts, $27 \mathrm{O}$

Price level, determined by labour-time cost, general law of, 232 ; rise of as evidence of gold basis of value, 242-3; average prices and wages in industry determined by average production in gold, 309-1o; put up to get what is wanted, 432-3

Prices and gold: Price level and gold production, 223-8; improved means of production with rising prices as evidence of gold per person determining price level, 230 ; wave of rise or fall in price started by change in gold production, 227; changed level of does not involve any great magnitude, 228 ; changed price level due to small flow of persons into or out of gold production, 226-7

Prices and trade: High price periods in Europe (French coal), I zo; AA curve as evidence of price level fluctuations, 180 ; fall of in $1900-0_{4}$ not a true example of high labour cost in gold, 213 ; economic use of variations above or below mean price, 286 ; difficulty of fixing value of labour or its produce without gold standard, 40I-4; fall of prices to get gold, 394-404; fall of prices, commercial process and mechanism of, 359-61, 394-404; inflation of prices, $397-404$; change of price level and its effect on profits and wages, 405-7; under State control competitive price necessary to determine what society shall produce, 432

Production for use. See State Control.

Production, net value of, r9; value per person, 20; total agrees with Dr. Bowley's estimate, 36 ; as capital, 27-9; remaining in capital stage becomes income in next year, 42 ; becoming imports, 41 ; per person, error in value (brewing, coke, food, etc.), 34-5

Production of national income: Agriculture, $3 I$; army and navy, 2I ; banks and commercial, 29 ; books, 22 ; coal, 22 ; coke, 26; domestic service, 22 ; fish, etc., 31 ; Government, 21 ; imports, 30 ; iron, steel, brass, etc. 26 ; professional, 21 ; railways, 26 ; sailors, 27 ; shops, 33 ; teachers, 21 ; textiles, 3I ; work of married women, 43

Productivity theory of wages, 320-3 ; Moore, H. J., 322

Professional earnings, share of production taken as, 56-7

Profit, share of production taken as, 55-8; compared with Income Tax returns, $57-8$; economists responsible for fallacy of wide difference between cost and price, I 45 ; excess of exposed by normal price diagrams, I49-50; division point between profit and wages, 328-52; profit and wages are divisions of a determined amount, 33 I

Profit obtaining, industrial mechanism of, $352-4$; real or goods profit, $354-5$; why employers do not increase unemployment to get more than the average profit, $354-62$; profit on capital recognised rather than profit on production, 356 ; gold check to profit when all are employed, 358-62 ; profit differs from wages in purchasing power, 359; only realisable as credit, 359-60; becomes capital value not realisable when prices are above the gold standard, $360 ; 36$ per cent. of production limit to profit, law of, 362 ; a reasonable payment of the employer by results, 362 ; profit depends ultimately upon a proportion of unemployment, 363-4; want of any alternative theory, $363-4$

Profit and trade fluctuations: Profit made by lag of wages movement behind price movement, 405-7; cotton spinners' profits, 4 I $2-13$

QUANTITy theory of money, 220, 222-3

RATE of foreign exchange, 420

Rent, agricultural: Is profit and rent a greater share than ordinary industrial profit, $372-7$; rent and full employment, 37I ; dependent upon unemployment, 379 ; rent and interest shares of profit, 371 ; farms let, variation in the annual increase as trade varies, 375 ; rent the greater part of agricultural profits, 374

Rent in populous centres, $377-82$; town land as such not more valuable than agricultural, 378-9; rent always a share of the 36 per cent. of production going as profits, $379-82$; of town land repayment for the organisation and making of that town, 379-82; site rent, $38 \mathrm{I}$

Rent of houses, $3^{8} 3-9$; rent-earning life of a house, $384-6$; rent and cost of producing an average house, 386-9

Rent, Ricardo's theory of, 367; how different from profit, 368-9; marginal increment of supply, $369-70$ 
Ricardo, theory of rent, 367 : price and labour cost. 98

Rye, normal price of Amarican, 25t

SAlarizs, share of production taken as.

Saving (so-callod), inevitable, 83: by bank accounts, 84 : nothing can bo saved, 84: does not produce capital or employ labour, but puts the control of labour into the bands of the person who saves, 95-6; gold necescary for. 395-9

Service, is production and all production is service, 20, 29: as capital, 64

Short-time employment, efiect of, 331-4 : in trade fluctuations, 414: policy of cotton spinners, $267-8$

Site rent. $38 \mathrm{I}$

Small industries not in Census of Pro. duction, 32

Smith, Adam, on price and labour cost. 98

Social capital, 72

Social reform, the only thing that can be done, 441-4

South African War, gold during, 212

State control of industry, 287, 426-38 society not able to conduct national industry as shown by undemocratic control in co-operative society. 427: inevitably bureaucratic 427-35: bureaucracy fatal to industrial freedom, 434-5: difficulty of foreign exchange, 427-32: political difficulty. 432-3: individual failure check to price inflation, wanting, 433-4: control by industrial groups difficulty. 435-7: what is wanted, 439 : does not offer employment for all, $44^{\prime}$

Sugar bounties, $169-70$

Sully corner in cotton, 181, 246

Supply and demand, that both depend on cost of production, 7.103 ; fallure of the theory of, 257

Surplus value. fallacy of, 147: wrong economic theory of price, responsible for, 422-3

TEA, normal prices of, 196-8

Trade fluctuations, nature of, 392 : Fisher Irving. 393: and depression. nature and cause of, 404-7i depression and unemployment. IV. $H$. Beveridge on, 407-8: shown by $\mathrm{AA}$ curve of normal prices, 408-10; and national income, 410-12: and profits of cotton spinners, $412-13$; and bank rate, 414: and short time, 414

Transvaal gold mines, 211-is: gold miners' wages in, 292-3: wages in as evidence that wages fluctuate with production of gold, 309

UNEARNED increment, $38 t-2$

Unemployed, competition of, 329-30

Unemployment, wages fund explanation of, 67. 86, 319: and short time, effect on rates of wakes, 351-6: in ectical. ture, 375-7: explaymens carve (tha

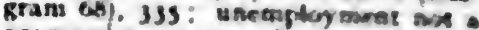
progresaivo cause of degerentura of wages which ase ultimately iforesuhes on production of gold. 31 : mrety ope employed. etece of in int? 14 : ovidence for the iz's pet cent. avrrace amount of, 352: why it is bue is. creaued above 12.3 per cent. in attopit higher protits. 394-ba: crids cheres in profits when all are empluyed, jethes: fimiting law of unemployment. under Sitate controt. is6: the cely industrial evil that can to altored $44^{2-4}$

VAlux. abortive theory of, s; Sefritiva of exchange value, 9: prouleced pot person, 20, 34: determined by poo. duction of fold per utsit of Latwur, 233 . 309-10: determined by fimal ixcre: ment of supply, fallacy of, 3as: total value or normal price of commodity the same whether the yuantity is ereat or sinall. 353-4

Wages, do not enter as cont into price of commodity, 2ky, 66 : not corretly the price of labour, is,-ep: are the price of labout's shase of value pro. duced. 290; pricer cannot be jet up to cover a rise of wiskes, ipo-s: paid out of capital. $73 \rightarrow 9$ : "ircon isw" of. 320: "marginal man" theory. 325 : rise of in Great Britain. Germany etc. 300 : index number method tails to investigate wages problem. yos-6: what we reyuire to know about wages. 306: always alout of per cest? of value produced, $30 \%-8$

Wages, actual : Few data, 206 : in trade that make returns to Board of Trade. 296-7: co-operative nociety's seturn. for, 297-8: private firm's returns loe. 398: of French cosl miners, 225: German steel founders, $295^{\circ}$

Wages, competition tor: linemploynd persons. 329: returns do not abow actual reduction of wages by wial unemployment. 3315-40: Hourd of Trade seturns for actual wages redaced to average for community includias the unemployed. 340 : Bowind of Truse wages figures compared wits wape curve, 340-5: private frmis wages compared with curve, 345-90: chasger in rates of wages compuret with change in unemployment. 350-t

Wages curve. methol of cocaparias wages with the curve of useraglor. ment and wages, 340-3: houct wages and goods protst curves, ist-s

Wages, custom in: Ditfereat grades of quality in Labour, 300: charmakrs wages, 311-1g: Labour' own vales. tion of its productive value, Itt: value in different coustrien J15: Iaw of averago prodactive valee. $31 \mathrm{a}$ 
Wages fund theory, 67-9; of unemployment, 319; Kleen, G. A., 67

Wages and gold: Portion of value produced in gold mining that is taken as wages, 292 ; wages in gold mining do not affect the price, 293 ; that wages follow gold production more closely than prices do, 300; that wages level depends on the wages earned in gold production, 299-302; average value produced per person in gold is the standard of prices and wages, 309-ro; that wages of any grade of labour depend on the production of gold by a like grade of labour, 310; difficult to appreciate difference in grades of productive ability, 310-1 7

Wages lag behind price movement, 298, $337-8,405-7$

Wages, movement of, only due to variation in price level, 337,405

Wages, productivity theory of, 320 ; Moore, H. J., 322 ; productivity and wages in French coal mines, 323

Wages share of production, American data for, 49-5I; Board of Trade figures for, $5 \mathrm{x}-3$; co-operative society, 52-3; coal miners', France and Prussia, 53-4; Dr. A. L. Bowley on, 54

War, prices rising to cover wages during. 290-1 ; after war inflation of prices, 400-4; apparent rise of normal prices due to gross output data, 4I4-8

Wealth, nature of, 15 ; real, is; froo per person, 34 ; potential and mobile rather than concrete, 43; no wealth in money or credit beyond the national income produced by current labour, 44-6, 423-4; distribution of, see Division, 47

Wheat, normal price in United Kingdom, I60; America, 235; not paying in England and area being reduced, 162

Work for all the only possible social and industrial reform, 44I-4 ; difficulty of management, $444-5$; social result of, 446-8

WW curve as correction of curve of prices, 237 


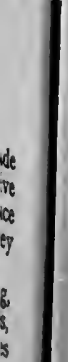





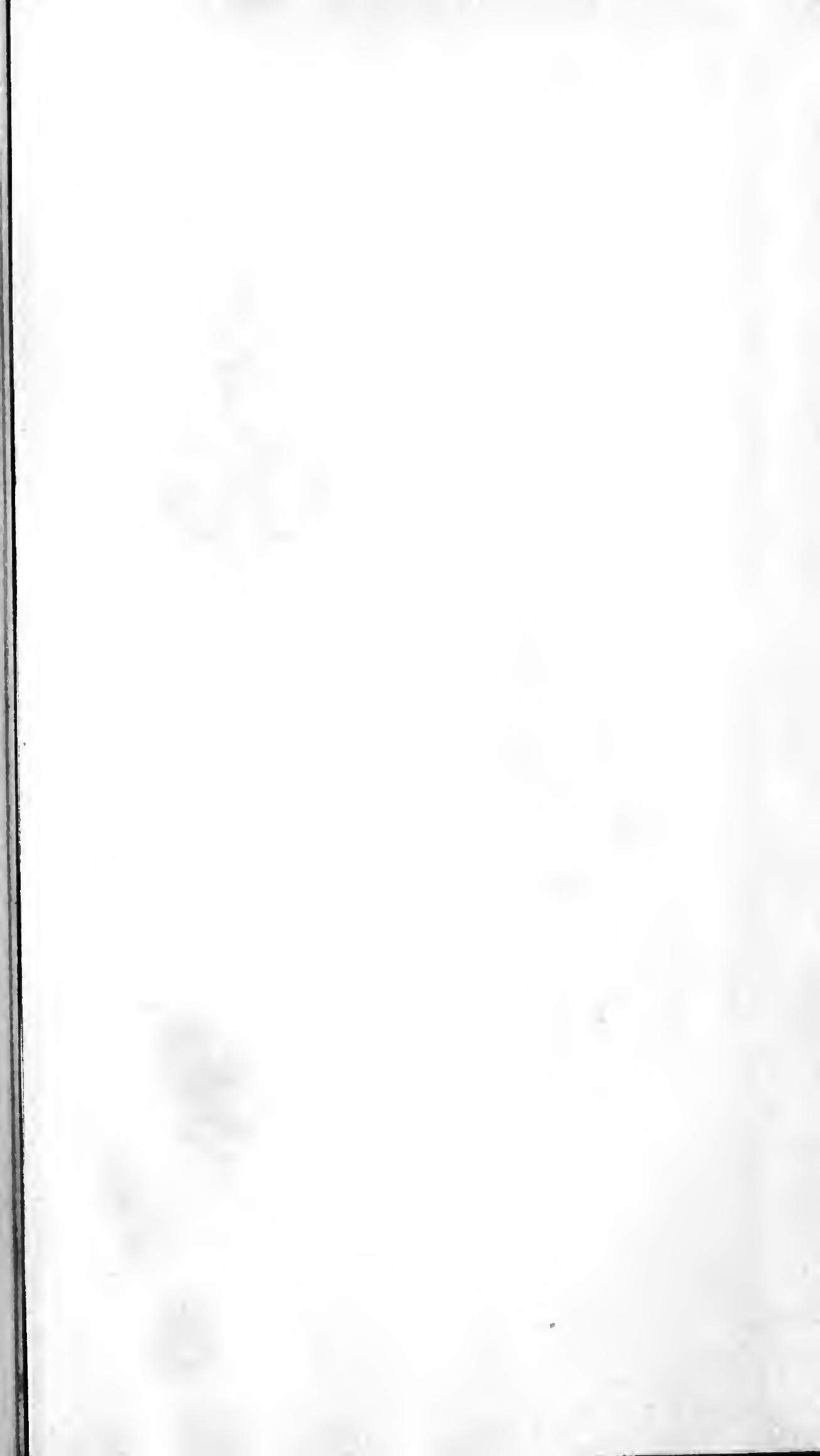



